\title{
Intervention or collaboration?
}

\author{
Citation for published version (APA):
}

Bon, A. (2020). Intervention or collaboration? redesigning information and communication technologies for development. [Doctoral Thesis, Maastricht University]. Pangea. https://doi.org/10.26481/dis.20201215ab

Document status and date:

Published: 01/01/2020

DOI:

10.26481/dis.20201215ab

Document Version:

Publisher's PDF, also known as Version of record

\section{Please check the document version of this publication:}

- A submitted manuscript is the version of the article upon submission and before peer-review. There can be important differences between the submitted version and the official published version of record.

People interested in the research are advised to contact the author for the final version of the publication, or visit the DOI to the publisher's website.

- The final author version and the galley proof are versions of the publication after peer review.

- The final published version features the final layout of the paper including the volume, issue and page numbers.

Link to publication

\footnotetext{
General rights rights.

- You may freely distribute the URL identifying the publication in the public portal. please follow below link for the End User Agreement:

www.umlib.nl/taverne-license

Take down policy

If you believe that this document breaches copyright please contact us at:

repository@maastrichtuniversity.nl

providing details and we will investigate your claim.
}

Copyright and moral rights for the publications made accessible in the public portal are retained by the authors and/or other copyright owners and it is a condition of accessing publications that users recognise and abide by the legal requirements associated with these

- Users may download and print one copy of any publication from the public portal for the purpose of private study or research.

- You may not further distribute the material or use it for any profit-making activity or commercial gain

If the publication is distributed under the terms of Article $25 \mathrm{fa}$ of the Dutch Copyright Act, indicated by the "Taverne" license above, 

Intervention or Collaboration? 

INTERVENTION OR COLLABORATION?

Redesigning Information and Communication Technologies for Development

\section{DISSERTATION}

to obtain the degree of Doctor at Maastricht University on the authority of the Rector Magnificus, Prof. Dr. Rianne M. Letschert in accordance with the decision of the Board of Deans to be defended in public on Tuesday 15 December 2020 at 13.00 hours

by

ANNA BON 
SUPERVISORS:

Prof. Dr. Sally Wyatt

Prof. Dr. Hans Akkermans (Vrije Universiteit Amsterdam)

ASSESSMENT COMMITTEE:

Prof. Dr. Wiebe E. Bijker (Chairman)

Prof. Dr. Cyrus C.M. Mody

Prof. Dr. Adele Botha (University of South Africa)

Prof. Dr. Roel Wieringa (University of Twente)

Graduate School of Arts \& Social Sciences

Faculty of Arts and Social Sciences

Maastricht University

SIKS Dissertation Series No. 2020-34

The research reported in this thesis has been carried out under the auspices of SIKS, the Dutch Research School for Information and Knowledge Systems.

\section{Maastricht University}

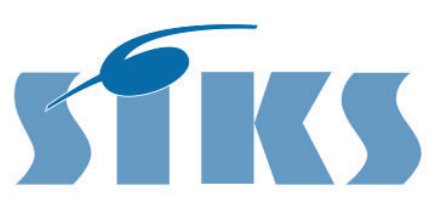


To Bruno, Paloma and Leeuw 
COLOPHON

Intervention or Collaboration?

Redesigning Information and Communication Technologies for Development

COPYRIGHT: (C) Anna Bon 2020

PUBLISHED BY:

Pangea, Amsterdam

December 2020, in the series of $\mathrm{W}_{4} \mathrm{RA}$ books

https://w4ra.org

COVER DESIGN:

Anna Bon

TYPOGRAPHY STYLE ADAPTED AFTER:

André Miede http://www. miede.de

ISBN PAPERBACK 978-90-78289-24-1

ISBN PDF-VERSION 978-90-78289-25-8

NUR 980

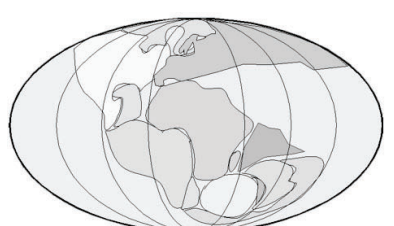

PANGEA 
How can we design and build digital technologies to support people in poor and lowresource environments to achieve their objectives? And how can we do this inclusively and ethically, while considering the complexity of their living and working environments? This is the central question in my research.

One of the grand challenges of international development cooperation is to make digital technologies available for social and economic development of poor regions of the world. To achieve this goal - often referred to as $\mathrm{ICT}_{4} \mathrm{D}$ - knowledge and technologies are transferred from wealthy countries to poor regions. Nevertheless, these efforts have often turned out unsuccessful and unsustainable, despite large budgets and numerous projects in prestigious international development programs.

Mismatch between the transferred technologies and the target environment is a recurrent problem of $\mathrm{ICT}_{4} \mathrm{D}$ projects. Improvement can be achieved, for example, by involving end-users in the design process. International development organizations are aware of this, and terms like "co-creation", "participation" and "user-oriented design" have nowadays become part of the international development discourse. However, real co-creation and user-centered design are incompatible with unidirectional transfer of technologies and knowledge (this is how $\mathrm{ICT}_{4} \mathrm{D}$ is commonly organized, in conventional international development). Moreover, the term participation becomes meaningless, in the light of externally formulated development goals.

One key question to ask is: what do the envisaged users want? Remarkably, many $\mathrm{ICT}_{4} \mathrm{D}$ projects, programs and policies do not really ask and (field) investigate this question, which can only be answered by extensive research on-the-ground.

This thesis describes the search for and the design of an alternative approach to $\mathrm{ICT}_{4} \mathrm{D}$. Ten years of field and action research with partners in Mali, Burkina Faso, and Ghana have led to a collaborative, iterative and adaptive approach, dubbed "ICT $4 \mathrm{D}$ 3.0". What is novel of this alternative approach and how does it answer the central question?

First of all, $\mathrm{ICT}_{4} \mathrm{D} 3.0$ is a practical approach for critical investigation and action. It consists of a reconfigurable framework that guides the design and development of information systems, bridging the knowledge gap between developers and users to unlock and integrate different domains of (global, local, indigenous, academic, nonacademic) knowledge. It targets complex, resource-constrained environments where many (for the ICT developers and researchers) unfamiliar conditions or obstacles may exist. It fosters innovative capacity and learning in action, bringing together people with different backgrounds and perspectives in trans-disciplinary and multicultural teams. It is socio-technical, result-oriented, focused on the objectives of the stakehold- 
ers and the requirements of their livelihoods. This approach has been validated in various different contexts, by users, ICT developers, practitioners and students.

Second, $\mathrm{ICT}_{4} \mathrm{D} 3.0$ contributes to a theoretical understanding of $\mathrm{ICT}_{4} \mathrm{D}$ as a process of networked innovation in complex (adaptive) systems. The underlying idea is that knowledge sharing and diffusion of innovations are complex (non-linear) dynamic processes that evolve and propagate through social networks in rather unpredictable ways, whereby innovation works out differently, depending on context, and whereby contextual (e.g. social, cultural, environmental, political) factors play an important role, and have to be considered. This theoretical framework explains the effectiveness of a collaborative, iterative, adaptative approach in $\mathrm{ICT}_{4} \mathrm{D}$.

Third, $\mathrm{ICT}_{4} \mathrm{D} 3.0$ is built on ethical principles. When reflecting on the meaning and purpose of digital development, it is clear that digital development is not only a question of technology and practice, and collaboration is more than a prerequisite for successful technological innovation and long-term sustainability: collaboration is a fundamental human, ethical value. Therefore, as a reflective practitioner, one has to ask oneself whose interests one is actually looking after, which goals one is trying to achieve, where they come from, how power and political issues play a role and which core values are at stake. This makes $\mathrm{ICT}_{4} \mathrm{D} 3.0$ into a democratic process of dialogue and deliberation, in which all voices are heard, in which the local context and complexity are central, and in which development goals are determined by the users themselves and not imposed from outside. In this light, the approach proposed in this thesis takes a value position and can be considered a decolonial approach, striving for democracy, emancipation, autonomy and social and economic betterment.

Field experience shows that $\mathrm{ICT}_{4} \mathrm{D}$ can be a meaningful, collaborative, networked process of knowledge sharing, driven by local initiatives, realizing change for the better, in a complex world. 


\section{CONTENTS}

i EXPLORING THE PROBLEM I

I INTERVENTION OR COLLABORATION? 3

1.I Be collaborative! 3

1.2 What do the "unconnected" want? 4

1.3 Brief history of this research 5

1.4 How this thesis is structured 9

1.5 Research design and methodology 14

1.6 Theoretical framework 19

1.7 Positioning this research in the academic landscape 20

1.8 Data collection 27

1.9 Validation of results 28

1.10 Selected publications 29

1.11 Summary 31

2 THE LOGIC OF INTERVENTIONISM 33

2.1 $\mathrm{ICT}_{4} \mathrm{D}$ policy and practice 33

2.2 $\mathrm{ICT}_{4} \mathrm{D}$ as linear innovation 34

2.3 Issues of context 38

2.4 How are goals constructed? 41

2.5 Theoretical framework: network complexity 43

2.6 Diffusion of innovations 50

2.7 Multiple paths to innovation 52

2.8 Summary 54

3 A TOOLBOX OF METHODS FOR ICT4D 57

3.1 Collaboration with users, adaptation to contexts 57

3.2 Participatory paradigms and value-driven research 61

3.3 Pragmatically adapting methods to novel context 63

3.4 Summary and outlook 64

ii CONSTRUCTING OPERATIONAL SOLUTIONS 67

4 UNDERSTANDING CONTEXT 69

4.1 First task: explore the context 69

4.2 First field visits to a rural region in the Sahel 70

4.3 Regional context: soil degradation in the Sahel 71

4.4 Context analysis at local and human scales: re-greening in Mali 79

4.5 Lessons learned from the context analysis 85

5 NEEds ASSESSMENT AND COLLABORATIVE gOAL CONSTRUCTION 89 
5.1 An iterative approach to goals and needs 89

5.2 First iteration: jointly exploring the problem space 90

5.3 Second iteration: jointly defining the solution space 96

5.4 Case: needs' assessment in Guabuliga, Ghana 96

5.5 Case: needs assessment with farmers in Mali 105

5.6 Case: meteo-services for farmers in Burkina Faso $\quad 113$

$5 \cdot 7$ Summary 122

6 USE CASE AND REQUIREMENTS ANALYSIS 123

6.1 Use cases and requirements in $\mathrm{ICT}_{4} \mathrm{D} \quad 123$

6.2 From unstructured ideas to use cases and requirements 124

6.3 The structured narrative method 128

6.4 Summary 140

7 ENGINEERING, DEPLOYING, EVALUATING I4I

7.1 The information systems engineering dimension in $\mathrm{ICT}_{4} \mathrm{D} \quad{ }_{14} \mathrm{I}$

7.2 Case: building systems for farmers in Mali 142

7.3 Context, needs, and user requirements 142

7.4 Engineering the system in a collaborative way 149

7.5 Field deployment 155

7.6 Collaborative impact evaluation 157

7.7 Summary 163

8 sustainability AND ICT4D 165

8.1 The business modeling dimension in $\mathrm{ICT}_{4} \mathrm{D} \quad{ }_{165}$

8.2 Economic sustainability as a requirement: a business case in rural Mali 166

8.3 A method to assess economic sustainability 166

8.4 Case: developing an ICT service in rural Mali 170

8.5 Evaluation of different possible business models $\quad 177$

8.6 Reflection 189

8.7 Summary 190

iii REFLECTIONS 191

9 SYNTHESIS: A CONSISTENTLY COLLABORATIVE FRAMEWORK FOR ICT4D 193

9.1 Considering the full information systems life cycle 193

9.2 Teams and partnerships 193

9.3 Composition of the full ICT research \& developing team 196

9.4 A configurable framework 197

9.5 How the framework addresses the concerns of the context 200

9.6 A process model for ICT4D service development 203

9.7 A consistently collaborative framework for ICT4D 205

IO VALIDATION OF THE RESEARCH OUTCOMES 207

10.1 Utility as external validation 207

10.2 Using the $\mathrm{ICT}_{4} \mathrm{D}$ framework in different contexts 207 
$10.3 \mathrm{ICT}_{4} \mathrm{D}_{3.0}$ and Community Service Learning 208

10.4 Evaluating $\mathrm{ICT}_{4} \mathrm{D}$ in the Field 216

10.5 Yet another context: $\mathrm{ICT}_{4} \mathrm{D}_{3} .0$ in Amsterdam 217

10.6 Evaluating the results 219

10.7 Other operational frameworks for $\mathrm{ICT}_{4} \mathrm{D} \quad 220$

10.8 Summary 221

11 ICT4D = INNOVATION COMPLEXITY $\neq$ INTERVENTION 223

11.1 The innovation dimension: iterative, adaptive, collaborative 223

11.2 Two-way communication: developers - users 232

11.3 Upstream - downstream 233

11.4 Innovation, knowledge, and social networks 235

11.5 Social learning 239

11.6 $\mathrm{ICT}_{4} \mathrm{D}$ as a knowledge-exchanging innovation network 240

11.7 Innovation, meaning and culture 244

11.8 Summary 246

12 THE VALUE OF COLLABORATION 247

12.1 The values and interests dimension in $\mathrm{ICT}_{4} \mathrm{D} \quad 247$

12.2 Alternative methods of knowledge production 248

12.3 Values and interests in $\mathrm{ICT}_{4} \mathrm{D}$ research 249

12.4 Collaborative $\mathrm{ICT}_{4} \mathrm{D}$ and policy frameworks 252

12.5 A positive and normative argument for collaboration 253

iv CONCLUSION 257

13 A TENTH PRINCIPLE FOR DIGITAL DEVELOPMENT: PUTTING THE LAST FIRST 259

13.1 Intervention or collaboration? 259

13.2 Innovation 260

13.3 The proposed framework: $\mathrm{ICT}_{4} \mathrm{D} 3.0 \quad 261$

13.4 Future perspectives for this research 263

13.5 The 1oth Principle for Digital Development: Putting the Last First 265

V APPENDIX 267

A IMPACT OF THis RESEARCH 269

A.1 Digital inequalities 269

A.2 Giving a voice to the unconnected 269

A.3 Impact of this research on education 272

A.4 Organizing the scientific and professional community 275

A.5 Social enterpreneurship and inclusive innovation 276

A.6 This research and the Sustainable Development Goals 277

B CHRONOLOGY OF FIELD TRIPS AND ROADSHOWS 2009-2020 279

B.I Data collection and field work 279 
в.2 List of activities, participants, materials 279

C LIST OF DATA 2009-2020 291

C.1 Trip reports 291

C.2 Folder structure of all data $2009-2020 \quad 291$

C.3 Data from field research 2009-2020 292

BIBLIOGRAPHY 3 II 


\section{LIST OF FIGURES}

Figure 1

Figure 2

Figure 3

Figure 4

Figure 5

Figure 6

Figure 7

Figure 8

Figure 9

Figure 10

Figure 11

Figure 12

Figure 13

Figure 14

Figure 15

Figure 16

Figure 17

Figure 18

Figure 19

Figure 20

Figure 21

Figure 22

Figure 23

Figure 24

Figure 25

Figure 26

Figure 27

Figure 28

Figure 29

Figure 30

Figure 31

Figure 32

Figure 33

Figure 34

Figure 35

Figure 36
Structure of this thesis. II

Structure of Part II of this thesis. $\quad 12$

Proposed praxis-oriented methodology for ICT4D research. $\quad 19$

Various literatures that have informed this thesis. 21

Stakeholders and their relationships in the $\mathrm{ICT}_{4} \mathrm{D}$ landscape. $\quad 35$

Linear innovation model. $\quad 37$

Waterfall model. $\quad 48$

Problem space and solution space. $\quad 52$

Complex interactions in the Sahel. 53

Field visit to Ranawa, Burkina Faso 71

Map of regreening in the Sahel. 75

Environmental change 1975-2003 in Niger. $\quad 77$

Regreening in the Sahel. $\quad 78$

Farmers in Mali and their mobile phones. $\quad 82$

Local farmer-innovator Yacouba Sawadogo. $\quad 84$

Needs assessment elicitation cycle. 90

A call flow diagram for a voice dialogue. 94

How to select and decide what to do. 95

Needs assessment in Guabulia, Ghana. 97

Interviewing a veterinary expert in Ghana. 101

Concept map of vet interview. 102

Prototype of the DigiVet system. 104

Workshop in Bamako, 2015. 105

Group work assessment. $\quad 107$

Start of problem elicitation. $\quad 107$

Field visit in Mali. $\quad 110$

Visit to a dairy cooperative. $\quad 112$

Paper-based data about milk. 113

Farmers and rain gauges. 114

Meteo workshop. 115

Rain data collection project. $\quad 116$

Result of needs' assessment on meteo-data services. 119

A mobile voice-based weather service. 121

Outcomes of selection of most promising workshops. $\quad 125$

Portfolio of key-ideas AOPP. $\quad 126$

Storyboard of Tabale system. $\quad 128$ 
Figure 37

Figure 38

Figure 39

Figure 40

Figure 41

Figure 42

Figure 43

Figure 44

Figure 45

Figure 46

Figure 47

Figure 48

Figure 49

Figure 50

Figure 51

Figure 52

Figure 53

Figure 54

Figure 55

Figure 56

Figure 57

Figure 58

Figure 59

Figure 60

Figure 61

Figure 62

Figure 63

Figure 64

Figure 65

Figure 66

Figure 67

Figure 68

Figure 69

Figure 70

Figure 71

Figure 72

Figure 73

Figure 74

Figure 75

Figure 76

Figure 77
The Tabale use case. 131

UML state diagram for Tabale. 132

Development view for Tabale. 133

Screenshot for Tabale. 133

User diagram for Tabale. 136

Deployment diagram for Tabale. 137

UML Activity diagram for Tabale. ${ }_{13} 8$

The voice server. $\quad 139$

Meeting farmers in Tominian, Mali. $\quad{ }^{142}$

The workflow of RadioMarché. 147

Mockups of the web interface. 148

Logo for the RadioMarché system. 150

Design of RadioMarché. $\quad 151$

Modeling the information concept of RadioMarché. $\quad 152$

Communiqué text in Bomu. 154

Two voice-platforms compared. $\quad{ }_{158}$

Increase of sales due to RadioMarché. 159

Monitoring sales trends. $\quad 160$

Plan for spreading and scaling-up. $\quad 162$

Causal loop diagram for RadioMarché. $\quad 164$

Radio platform design. $\quad 167$

An educational $e^{3}$ value model. $\quad 168$

The office of radio Moutian in Tominian, Mali. $\quad$ 171

Caller log. $\quad 172$

Foroba Blon team members. $\quad 173$

Radio journalist of Radio Moutian, Mali. $\quad 174$

Radio platform activity diagram. $\quad 176$

Foroba Blon web interface. $\quad 177$

Village reporter business model. $\quad 180$

Radio-based business model. 186

Citizen journalist business model. $\quad 188$

Workshop with farmers in Burkina Faso. $\quad 197$

Field visit in Mali. 199

$\mathrm{ICT}_{4} \mathrm{D}$ framework. 202

ICT4D intention-strategy model. 204

Field trip in Sarawak. 210

Logo of the app with children. 213

Testing an app with children. 215

Logo for the Dengaway student project in Sarawak. 215

Linear innovation model after Schumpeter. 224

Mobile recharger business. 228 
Figure 78

Figure 79

Figure 80

Figure 81

Figure 82

Figure 83

Figure 84

Figure 85

Figure 86
Mobile entrepreneurs Burkina Faso. 229

Hierarchical, hybrid, network organization. $\quad 238$

Nonaka's model of knowledge exchange. 239

Field visit near Gourcy, Burkina Faso. 241

From tacit to explicit knowledge. $\quad 242$

$\mathrm{ICT}_{4} \mathrm{D}$ course at VU, 2014. 244

$\mathrm{ICT}_{4} \mathrm{D}$ value chain, by Richard Heeks. 253

Looking at $\mathrm{ICT}_{4} \mathrm{D}$ from its applicability perspective. 254

$\mathrm{ICT}_{4} \mathrm{D}$ 3.o explained. $\quad 255$ 
LIST OF TABLES

Table 1

Table 2

Table 3

Table 4

Table 5

Table 6

Table 7

Table 8

Table 9

Table 10

Table 11
Six principles of action research. $\quad 17$

Four praxis-oriented methodologies compared. 18

Toolbox of inspiring methods for $\mathrm{ICT}_{4} \mathrm{D}$ research. $\quad 65$

Examples of topics of concern and information needs. 108

Users of the Tabale system. 134

Prices of products and services. 180

Number of customer needs. $\quad 182$

Number of actors in a market segment. $\quad 183$

Sustainability analysis using the $e^{3}$ value model. $\quad 183$

Seven frameworks for $\mathrm{ICT}_{4} \mathrm{D}$ design and development compared. 222

All use cases described in this thesis. 289 


\section{ABBREVIATIONS}

AOPP Association des organisations professionnelles paysannes

API Application Programming Interface

AR Action Research

CAS Complex Adaptive System

CEO Chief executive officer

CERN European Organization for Nuclear Research

DIM Diffusion of Innovation Model

DFID Department for International Development UK

DSR Design Science Research

DTMF Dual-Tone Multi-Frequency

EU European Union

FB Foroba Blon - voice-based service for citizen journalism in Mali

EU FP-7 Seventh Framework Programme of the European Union

fCFA West African currency (franc CFA)

FM Frequence Modulation

FMNR Farmer Managed Natural Regeneration

GO Governmental Organization

GSM Global System for Mobile Communication

HTML Hypertext Markup Language

HCI$_{4}$ D Human-Computer Interaction for Development

ICT Information and Communication Technology

ICTD Information and Communication Technologies and Development

ICT $_{4} \mathrm{D}$ Information and Communication Technologies for Development 
IP Internet Protocol

IS Information Science

LFA Logical Framework Approach

MARP Méthode action recherche participative

Mbps Megabit per second

MDG Millennium Development Goals

MIS Management Information Systems

MoSCoW Must have, should have, could have, would not have

MVP Millennium Villages Project

NGO Nongovernmental organization

OLPC One Laptop per Child

ORTM Office Radio Télé du Mali

PRA Participatory Rural Appraisal

PTD Participatory Technology Development

PTDA Post-2015 Development Agenda

RCT Random Control Trial

RQ Research Question

SDG Sustainable Development Goals

SMS Short Message System

SSM Soft Systems Methodology

STS Science and Technology Studies

TTS Text-to-Speech

UCC University of Cape Coast, Ghana

UDS University for Development Studies, Ghana

UML Unified Modeling Language

UN United Nations 
UNDP United Nations Development Programme

USAID United Stated Agency for International Development

VOICES Voice-based community-centric mobile services for social development

VU Vrije Universiteit Amsterdam

W4RA Web Alliance for Regreening in Africa

WSIS World Summit on the Information Society

www World Wide Web

XO OLPC's \$10o-laptop 

Part I

\section{EXPLORING THE PROBLEM}

[In which we explore one of the central problems of $\mathrm{ICT}_{4} \mathrm{D}$ : how to make information and communication technologies that serve the needs of people in resource-constrained environments] 



\section{INTERVENTION OR COLLABORATION?}

$I_{4} T_{4} D$ (Information and Communication Technologies for Development) refers to the efforts to "connect the unconnected" and make the benefits of digital technologies available to people in resource-constrained environments. Yet, despite numerous policies, projects, programs and significant budgets, the efforts have not been very successful in serving the poorest and least privileged people of the world. Whereas ICT4D is framed, at the international policy level, as a user-centered endeavor, implementation boils down to linear transfer of technology and knowledge from the Global North to developing regions. In search of approaches that serve people and communities in resource-constrained environments, one key question should be asked: what do the "unconnected" want? The search for an answer, which can only be obtained through dialogue and collaboration, is central to this thesis.

\subsection{BE COLLABORATIVE!}

"Design with the User", "Understand the Existing Eco-system", "Build for Sustainability" and "Collaborate" are slogans in International Development that mark a new trend towards more user-centered, innovation-oriented, agile approaches in $\mathrm{ICT}_{4} \mathrm{D}$ projects and practice. ${ }^{1}$ The new discourse is a reaction to the poor outcomes of donor-funded $\mathrm{ICT}_{4} \mathrm{D}$ projects in reaching and serving the needs of people deemed the least privileged [197, 417, 202, 263]. Whereas "being connected", in particular through the Internet and the Web, is seen as a crucial enabler of economic and social development and key to the global knowledge-sharing society, at the moment of writing, July 2020, almost three billion people ${ }^{2}$ are still digitally excluded, the majority of whom live in poor regions of the world.

Since the 199os national and international policies have been launched, to "connect the unconnected" and "bridge the Digital Divide". The World Bank Group alone invested up to 2.9 billion US dollars in the period 2003-2010, to support the ICT sector in connecting the poorest countries of the world [177]. In 2015 the United Nations, with support from its 193 member states launched the Sustainable Development Goals (SDGs) for the period 2015-2030. The SDGs include a target (SDG 9c)) to achieve "universal and affordable access to the Internet in least developed countries". ${ }^{3}$ Similar policies are echoed by international and national development organizations, includ-

\footnotetext{
I See: e.g. https://digitalprinciples.org/, (accessed o8-10-2020)

2 Source: https://www. internetworldstats. com/stats.htm, (accessed o8-10-2020)

3 See: https://sustainabledevelopment.un.org/sdg9, (accessed o8-10-2020)
} 
ing big development donors such as the EU4 ${ }^{4}$, DFID 5 , USAID and the World Bank (e.g. [403, 367, 179, 178]. Large budgets to bridge the so-called Digital Divide, have been spent worldwide. Yet, despite all of the policies, projects, programs and significant financial efforts to bridge the Digital Divide, $\mathrm{ICT}_{4} \mathrm{D}$, as shown in various studies, has not been very successful [263, 177, 271, 101, 100, 179].

Concerned about the low success rates of $\mathrm{ICT}_{4} \mathrm{D}$ projects, in 2012 a group of highly influential international development donors and multilateral organizations ${ }^{6}$ started conversations, to reconsider existing policies and practice and institutionalize lessons learned for $\mathrm{ICT}_{4} \mathrm{D}$ [417]. This led to a new direction and a renewed framing of $\mathrm{ICT}_{4} \mathrm{D}$. In 2015 a new set of nine Principles for Digital Development was formulated: "(i) Design with the user. (ii) Understand the existing eco-system. (iii) Design for scale. (iv) Build for sustainability. (v) Be data driven. (vi) Use open standards. (vii) Open data, open source, open innovation. (vii) Reuse and improve. (viii) Address privacy and security. (ix) Be collaborative".7

In 2015 and 2016 a series of round table conferences involving a broad community of international $\mathrm{ICT}_{4} \mathrm{D}$ practitioners ${ }^{8}$, discussing policy and trending topics in $\mathrm{ICT}_{4} \mathrm{D}$, revealed large barriers in putting these principles into practice [417]. Many obstacles and barriers were attributed to the international development system itself [417].

\subsection{WHAT DO THE "UNCONNECTED" WANT?}

In looking for alternative approaches to $\mathrm{ICT}_{4} \mathrm{D}$ practice that do serve people in poor, resource-constrained environments, one key question is: what do the "unconnected" want? This question can only be answered by extensive research on-the-ground. Remarkably, many $\mathrm{ICT}_{4} \mathrm{D}$ projects, programs and policies do not really ask and (field) investigate this question, while the answer may give efforts to "connect the unconnected" a very different direction. In this thesis I describe how an operational approach to $\mathrm{ICT}_{4} \mathrm{D}$ practice can be developed, in a way that is collaborative, iterative and adaptive. I have attempted to sketch the contours of such an $\mathrm{ICT}_{4} \mathrm{D}$ practice. I have exemplified this by many field-research based cases and studies.

The present study problematizes the idea of "connecting the unconnected" and especially the conventional development approach to it. In this thesis I argue that the mainstream approach to $\mathrm{ICT}_{4} \mathrm{D}$ policy and practice - which can be read as a contemporary framing of conventional (i.e. North Atlantic) development thinking [325, 326, 320, 130] - involves many (often tacit) assumptions that are generally accepted, but do not nec-

4 See: https://ec.europa.eu/international-partnerships/priorities/digital-partnerships_en, (accessed o8-10-2020)

5 DFID's Digital Strategy 2018-2020: https://tinyurl.com/dfid2018digital, (accessed o8-10-2020)

6 This includes the World Bank, UNESCO, USAID, DFID, SIDA and UNDP and other development organizations that invest in digitally-supported development projects.

7 See: https://digitalprinciples.org/, (accessed 08-10-2020)

8 The community of $\mathrm{ICT}_{4} \mathrm{D}$ and Digital Development practitioners has various platforms. One of the most active is ICTWorks. https://Www. ictworks.org/, (accessed o8-10-2020) 
essarily hold for every context, geography, culture or worldview. Alternatives that can work on-the-ground are needed and this is a major theme of this thesis.

\subsection{BRIEF HISTORY OF THIS RESEARCH}

This thesis is one of the outcomes of an interdisciplinary research program named $\mathrm{W}_{4} \mathrm{RA}$ or Web alliance for Regreening in Africa. For me this research adventure started in the summer of 2009, when Hans Akkermans, founder and director of the Network Institute at the Vrije Universiteit Amsterdam, asked me to help him organize a symposium titled the 'Web and Social Development', as a tribute to Sir Tim Berners-Lee, the founder of the World Wide Web [25], who would receive an honorary doctorate from the Computer Science Department at VU Amsterdam. At that moment Tim BernersLee was in the process of founding a charity organization, the Web Foundation, where "Web Access for Everyone" was the central goal. Hans, who was head of the Computer Science department, also asked me to brainstorm with him about a new, interdisciplinary research project on the same subject as the symposium.

I was working as an international project manager at VU's Centre for International Cooperation $^{9}$ (CIS) and managing several ICT-related development projects in Ghana. As an ICT professional I had closely followed, in several jobs, the emergence of the Web since the 1990s. With my Brazilian background I had been thrilled to see the Web expand to Latin America in the early 2000s. When I joined CIS in 2006, I became fascinated by the social and technological developments that were taking place in Africa, the least connected continent. I studied the problems related to the Digital Divide and wrote a few papers on this topic (e.g. [33, 34, 35, 52, 44]). In November 2008, I presented a paper about the Digital Divide between Europe and Africa at the International Conference "Rethinking Development Studies", which took place at the University of Cape Coast, in Ghana [269]. Yet, in my working environment at VU there was not much interest for the societal challenges of the Digital Divide.

In search of ideas for this new research project about the Web and social development, I talked with many people. One of them was my colleague Chris Reij, who is internationally recognized for his efforts to support African Regreening Initiatives. Chris told me that regreening is a farmer-led innovation movement of great impact on local communities in West Africa. Regreening improves local livelihoods and, if scaled up, it has the potential to feed millions of people. However, the (indigenous) knowledge how to do this, is diffusing very slowly in rural areas, due to a lack of communication channels. This is aggravated by the low levels of literacy and poor infrastructure in the rural regions.

Despite the lack of a clear link between regreening and ICTs or the Web, I proposed it as a project idea to Hans. Surprisingly this idea met the requirements of the envisaged research, i.e. knowledge sharing, local agency, innovation and its diffusion in a

9 See: https://www.vu.nl/cis, (accessed o8-10-2020) 
complex - for us unfamiliar - environment. These became the ingredients for a new, interdisciplinary sociotechnical action-research program.

\subsubsection{The start of a new research program}

In preparation of the new program, Chris, Hans and I made a trip to Burkina Faso, in September 2009. Chris introduced us to rural communities and we talked to innovative farmers in their fields. These were open, explorative conversations, sitting with the farmers under a tree, in front of their village. I was impressed by the openness of the farmers, to discuss with us topics that concern their livelihoods. One of the farmers-innovators was Yacouba Sawadogo, "The Man who Stopped the Desert". ${ }^{10}$ Yacouba Sawadogo, despite being an illiterate farmer in one of the poorest regions in the world, was one of the key persons in the diffusion of a widespread local innovation. ${ }^{11}$

The new research program, which was given the name W4RA - Web alliance for Regreening in Africa, was officially launched on 20 October 2009, in the presence of two iconic persons: Tim Berners-Lee, representing the Web and Yacouba Sawadogo, representing regreening as a local, indigenous innovation. Because of my efforts as a co-organizer of his event, I was invited to join the research team, initially as an international project manager. Since "action" and "research" in this project are closely intertwined, I started to participate in the actual research, as a requirements engineer, information analyst, workshop moderator, field trip reporter and in various other roles. In the initial period (2010-2013) I contributed to various publications of the team: [6, 105, 104, 184, 1, 181], and initiated and wrote a few articles myself [41, 42]. I also acted as (co-) editor and author of various technical documents from our field research in Mali. ${ }^{12}$ However, plans to write a PhD thesis came only in 2014.

\subsubsection{Links to Web Science research}

Because of its scientific background and clear connections with the Web, the $\mathrm{W}_{4} \mathrm{RA}$ was positioned, from its inception, as a Web Science research program ([6, 184]). Web Science is a young interdisciplinary academic field of which the research agenda has been designed by Tim Berners-Lee together with other Web pioneers [26, 201].

Web Science research consists in general of: (i) research of the Web as a technology in evolution, and (ii) research of the Web as an empirically observable sociotechnical phenomenon. With these two strands, the Web Science interdisciplinary research

10 Yacouba Sawadogo featured in a documentary with the same name, by Marc Dodd, 2009, https://www. youtube. com/watch?v=fPqVSagqB7I, (accessed o8-10-2020)

11 In 2018 Yacouba Sawadogo received the prestigious Right Livelihood Award: https://www. rightlivelihoodaward.org/laureates/yacouba-sawadogo/, (accessed 08-10-2020)

12 See project deliverables of the VOICES project: https://w4ra.org/publications/voices/, (accessed o810-2020) 
agenda has a dual knowledge focus: on episteme, the knowledge category that refers to analytical knowledge and universal truth [11, 152], and on techne: which refers to instrumental skills and technical know-how [208, 369]. These are two of Aristotle's well-known knowledge categories.

The $W_{4}$ RA research is concerned with problem solving in the real world. The scope of the $\mathrm{W}_{4} \mathrm{RA}$ is beyond the existing Web, at the fringes of the Web. It reaches out to Internetless regions where it encounters questions and problems of, for example, social inclusion or indigenous innovation. The $\mathrm{W}_{4} \mathrm{RA}$ program can be categorized as phronesis or practical wisdom ${ }^{13}$, one of the lesser-known intellectual virtues of Aristotle $[11,151,6,421,138,369]$. In phronetic research, the researcher has a concern with the stakeholders and tries to influence the research outcomes to their benefit. Research goals are defined by deliberation in a communicative space between researchers and users [224], in what is called the agora, or public debate in society [224, 5].

\subsubsection{Bringing this research into education}

In 2012, based on the knowledge acquired in the sociotechnical fieldwork of the $\mathrm{W}_{4} \mathrm{RA}$ research team in rural Africa, we made plans to introduce this knowledge in academic education. ${ }^{14}$ The envisaged course should focus on the practice of designing, building and engineering ICT systems and applications in programs and projects in a development context, while reflecting on contextual issues. We considered it an important component in the education of Computer Scientists to become familiar with grand societal challenges in International Development, the problematics of resource-constrained contexts and the concept of the Digital Divide. The ICT4 $\mathrm{D}$ course, which we started in April 2013 as an educational pilot, with only twelve master students, is nowadays one of the official elective courses in the master curriculum at the Vrije Universiteit Amsterdam for the tracks Computer Science, Information Science and Artificial Intelligence, with about fifty students every year. ${ }^{15}$

One of the discussions during the design of this course was how it should be labeled. Labeling of new, interdisciplinary education and research is also important to position it and create links with other academic communities. Conversely, a good label makes it possible to contribute, with new perspectives and alternative methodologies, to existing communities. Alternative labels we considered for the course were e.g. Web Science for Development, Development Informatics, Computer Science for Development or $\mathrm{ICT}_{4} \mathrm{D}$. Given the fact that $\mathrm{ICT}_{4} \mathrm{D}$ is a broad concept, which relates to the International Development agenda and to the practical implementation of ICTs in a

13 Phronesis is described by Flyvbjerg et al. as "practical wisdom on how to address and act on social problems in a particular context" [152].

14 The initiators and lecturers of the $\mathrm{ICT}_{4} \mathrm{D}$ course are Victor de Boer, Stefan Schlobach, Christophe Guéret, and myself. In 2017 André Baart and Francis Dittoh joined the lecturing team.

15 See: https://studiegids.vu.nl/en/Master/2018-2019/information-sciences/X_405101, (accessed o810-2020) 
development context [197], we decided to name our course: Information and Communication Technology for Development, ICT4D. ${ }^{16}$

It can be noted that "our" ICT 4 D course is different in content and set-up from other $\mathrm{ICT}_{4} \mathrm{D}$ courses. It includes - besides the social and political perspectives - the information systems engineering perspective, co-creation and user-centered design in practice. $\mathrm{ICT}_{4} \mathrm{D}$ education at other universities in the world ${ }^{17}$ is commonly part of curricula in Social Sciences, Policy Studies and Management Information Systems (MIS), that do not include a technical engineering component.

In 2018, together with my colleague lecturers Jaap Gordijn, Victor de Boer and Hans Akkermans, I initiated a second course at VU, in this same curriculum - this time with an extensive field-research component for the students, which they have to carry out as team work, according to community service learning principles, in a resourceconstrained environment in Asia or Africa. This project-based course, which has a focus at designing and engineering information systems in complex environments in a user-centered way, is titled "ICT 4 D in the Field". ${ }^{18}$

Because of the close relationship between the $\mathrm{W}_{4} \mathrm{RA}$ research program and the content and methods taught in these two $\mathrm{ICT}_{4} \mathrm{D}$ courses at $\mathrm{VU}$, we started to refer to the $\mathrm{W}_{4} \mathrm{RA}$ program as $\mathrm{ICT}_{4} \mathrm{D}$ research.

\subsubsection{A community of discourse}

As from the start, the W4RA's societal objective and orientation to complex, resourceconstrained contexts, requires interaction and close collaboration with practitioners and end-users. Therefore, $\mathrm{W}_{4} \mathrm{RA}$ is structured into a core team. I have participated in this team from its inception. The team is surrounded by a wider network of participants and interested partners, who are academics and non-academics from different backgrounds, cultures and knowledge domains, all committed to a common cause.

Gradually, W4RA has become an active international mini-community, with master students, frequent social events, guest lectures, publications, working papers, field research projects, longstanding partners in Africa (such as the Malian farmer organization AOPP), local organizations, a central website with all W4RA's related resources ${ }^{19}$ and since 2014, as part of our $\mathrm{ICT}_{4} \mathrm{D}$ course, an annual international symposium: Per-

16 Since 2018, the term ICT4D in International Development policy is gradually being replaced by "Digital Development", see e.g. https://www. ictworks.org/ict4d-digital-development/\#.Xm3noUtCdBx, (accessed o8-10-2020)

17 e.g. $\mathrm{ICT}_{4} \mathrm{D}$ at the University of Manchester, UK:

https://Www. manchester.ac.uk/study/masters/courses/list/06237/msc-icts-for-development/, and other http://groupspaces. com/ipid/pages/ict4d-courses, (accessed o8-10-2020)

18 See: https://studiegids.vu.nl/en/Master/2018-2019/information-sciences/XM_0008, (accessed o810-2020)

19 See: https://w4ra.org 
spectives on $\mathrm{ICT}_{4} \mathrm{D}^{20}$, with international guest speakers and up to 100 attendants each year.

During weekly meetings of the $\mathrm{W}_{4} \mathrm{RA}$, team members discuss and reflect the ongoing research topics. Students and invited guests, for example researchers and experts from other disciplines and backgrounds, often join these meetings - always with coffee, stroopwafels or speculaasmolens - to discuss the research and related topics, from different perspectives. The organization of these events and meetings, to keep this (trans-disciplinary, multicultural and international) community together is one of my self-imposed tasks.

For me the $\mathrm{W}_{4} \mathrm{RA}$ is a community of discourse. I see parallels with the late 18th century salons of Enlightenment, in Paris. Contrary to what is often thought and said, these salons, led by women, and frequented by men, were spaces of innovation and discourse about science and society, in the turbulent era of revolution and scientific innovation in 18th century Europe [168]. The W4RA bears some similarities with these salons. The difference is in its multicultural dimension and co-creation aspects.

Finally, in 2014, I started to think about writing a thesis. I wanted to capture the rich experiences and make explicit what had remained in our heads as tacit knowledge, obtained during years of field work and discussions. I also wanted to connect the myriad of ideas into an over-arching framework, as educational material for the $\mathrm{ICT}_{4} \mathrm{D}$ course. And I felt the need to share my personal reflections about the collaborative research program that I had helped to organize.

\subsection{HOW THIS THESIS IS STRUCTURED}

This thesis is one of the many outcomes of the $\mathrm{W}_{4} \mathrm{RA}$ research program. Its structure consists of three parts. In the first part I explore the problem and critically investigate contemporary policy and ensuing practices of $\mathrm{ICT}_{4} \mathrm{D}$ in International Development. This first part is my personal reflection on what I see as one of the problems of International Development, in which I have worked as a practitioner and project manager for many years. Part I presents an overarching theoretical model for my research.

In Part II of this thesis I describe use cases collected during many collaborative field research trips in which I have participated as member of the core team, from 2009 to the present day. Here I describe the work of many people, including my own, from my own perspective. I present the development of socio-technical systems, what could impossibly be the work of a single developer or researcher.

The presented use cases have been selected because they give the best illustration of how the framework was iteratively constructed. Each chapter in Part II describes a different aspect (or component) of what gradually emerged as the practical approach how to tackle complex situations in a user-centered, collaborative way, in resourceconstrained environments. But this is not all the data that contributed to the design of

20 See: https://perspectives-on-ict4d.org/ 
the proposed framework. I have done much more fieldwork in resource-constrained environments in Africa and Asia with the research team, as can be seen in the Appendix B. As this is too much to describe in one thesis, I have made a selection.

In Part III, I reflect on practice, theory and policy and discuss the need for critical and ethical considerations. Whereas Part I and III consist of my personal reflection this is unpublished work - the design and analysis of the use cases in Part II are team work. Some sections contain parts of previously published work, as mentioned in the footnotes, placed here in a broader context.

\subsubsection{Exploring the problem}

In Part I, to understand the problem, in Chapter 2, I investigate the assumptions underlying the main contemporary approach to $\mathrm{ICT}_{4} \mathrm{D}$ policy and practice. The main contribution here is in showing that a "linear" notion of, what I have framed as, "intervention" lies at the root of conventional $\mathrm{ICT}_{4} \mathrm{D}$. Change is thought to be (causally) brought about by an intervention, generally conceptualized as some measure (such as a new technology - say ICT, or Internet - or some other "improvement") that is introduced from outside, and as a result causes social change. This intervention thinking is not just one of the possible conceptions of development: it has been developed into a global standardized system, such that any development project, program, and policy must conform to this - witness, for example, the rigid requirements and demands widely imposed by donors and funding agencies upon program and project proposals (cf. logical framework, theory of change, detailed rigid planning, fixed budget lines).

There are problems with this view on development (e.g. [269, 75, 74, 331]). First, it ignores what is known about the subtle and contextual ("nonlinear") realities and how they ("nonlinearly") influence the processes of sociotechnical innovation and social change. Second, a prime characteristic of intervention thinking is that the people subject to development interventions, the so-called "beneficiaries", are in fact treated as an amorphous mass (often mentioned as the "poor and marginalized" e.g. [194, 361, 190]) who undergo the intervention as passive objects, instead of being treated as active subjects in their own right with their own specific interests, contexts, values etc. that consistently must be taken into careful consideration.

Phrased in ICT terms, in today's development thinking the "waterfall model" still reigns supremely, although this model in the literature is scientifically and technologically falsified in the 1980 os [61, 30]. In ICT science as well as practice, this model, which breaks down a project in linear sequential phases, where each phase depends on the deliverables, is now generally considered inadequate for managing complex projects in dynamic contexts with uncertainties and changing requirements. Policy makers and development practitioners have been slow in adapting to these new realities and insights. This leads to the formulation of questions for the present research: 


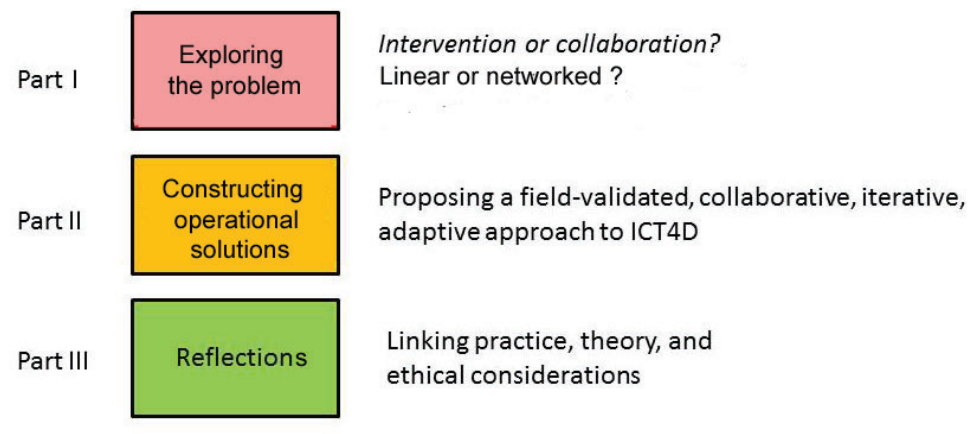

Figure 1: The structure of this thesis.

RQ-1 What are the underlying assumptions and ensuing limitations of the conventional (Global North) approach to today's ICT4D projects, programs and policies?

RQ-2 How can these limitations of $\mathrm{ICT}_{4} \mathrm{D}$ policy and practice be corrected, so as to come to a new approach that truly incorporates the diverse considerations from the Global South - which may significantly differ from those of the Global North?

Despite the dominance of the intervention model as the prevailing paradigm in development and $\mathrm{ICT}_{4} \mathrm{D}$ policy and practice, there are also counter-voices and alternatives. Alternative ideas that do justice to changing contexts and realities on-the-ground as well as to the perceptions, values, and interests of the people that directly matter - the intended beneficiaries - come from many sources, including the Global North.

In Chapter 3, I will review a variety of sources for alternative ideas - not necessarily from ICT or development practice - that avoid the linear views that characterize conventional $\mathrm{ICT}_{4} \mathrm{D}$ policy and development approaches. Some alternative ideas are inspired by modern ICT methodologies primarily developed in the Global North, including agile approaches and living labs, where the end user has been put at the center. Others come from critical and participatory development thinking (putting the last first [71], as authors such as Chambers have put it, polemically). As I will argue, there is a diversity of useful critical ideas and insights how to come to better development programs in general and $\mathrm{ICT}_{4} \mathrm{D}$ projects in particular.

The follow-on key question is how to make these alternative ideas practical and operational in a development context. Or, more specifically: what are the requirements [419, 132] for a new approach to $\mathrm{ICT}_{4} \mathrm{D}$ in practice? More specifically:

RQ-3 How can we design an operational approach to developing ICT systems and services, such that it (i) takes into consideration the complex realities of local context, and (ii) involves the envisaged users in decision-making and sociotechnical development? 


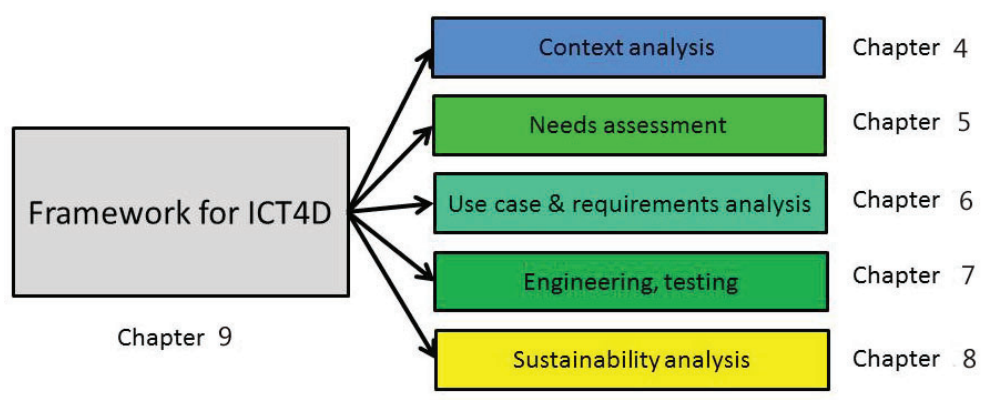

Figure 2: The structure of Part II of this thesis, presenting an operational approach for designing and building information systems and services in resource-constrained environments.

Whereas the first and second research questions are concerned with policy and practice in international development and will be discussed in this chapter, the third question is a design question, and concerned with practice. This takes place at the grassroots level. It is the subject of Part II.

\subsubsection{Constructing operational solutions in the field}

In Part II, I will present and discuss in five chapters, the tasks of an operational method how to develop ICT systems and services for people in resource-constrained environments, in a collaborative, iterative and adaptive way. The method is iterative: a task can be started if enough information is available from previous tasks. A previously started task may continue when the next task takes off. Special emphasis is put on (i) the composition of the interdisciplinary and multicultural team and (ii) the importance of the early upstream stages of ICT systems development. It emphasizes needs analysis in context 'sur le terrain'/'on the ground' - even before ICT technologies are necessarily being implied. The reason is that inherently sociotechnical systems such as $\mathrm{ICT}_{4} \mathrm{D}$ services have a heavily contextualized nature: the often "unknown unknown", that requires extensive field-based research.

First, Chapter 4 argues for in-depth local context analysis, apart from and even before any ICT or Information System solution is considered. Information System needs and solutions are heavily contextualized. The intervention model with its externally imposed one-size-fits-all ICT solution ideas (such as affordable Internet everywhere) misses the point here. Rigorous context analysis is one of the keys to success, and as I show in Chapter 4, corresponding bottom-up field research (in contrast to western desk research carried out at-a-distance) leads to quite different sets of priorities and portfolios of ICT solutions than the usual top-down and outside-in conventional approach. 
Next, in Chapter 5 I propose a method for "collaborative goal construction", as part of the needs assessment. The method consists of exploring the problem space, with the local users, making a portfolio of possible solutions and selecting the objectives for the $\mathrm{ICT}_{4} \mathrm{D}$ project, as formulated by the local users, while considering the limitations of the local context and the available resources. This method is novel in ICT4 $\mathrm{D}$ practice. It is part of an intrinsically collaborative decision-making process for $\mathrm{ICT}_{4} \mathrm{D}$ projects.

In Chapter 6 I present the "structured narrative method". This method enables to capture complex unstructured information and presents it in a structured format. It facilitates communication about requirements in a non-formal way, using narratives and storyboards, while capturing technical system specifications, and represents them through formal models, bridging the worlds between users and technical developers. Moreover, it also covers more than just the narrow technical system. It includes business requirements and information related to the local context - topics not commonly covered in mainstream use case and requirement analysis methods (see e.g. $[173,236,248,388])$.

Chapter 7 shows how engineering, deployment, testing and evaluating can be done in a non-interventionist, collaborative, adaptive, iterative way that accounts for the specific on-the-ground context, how real innovation works and how local users can influence the process and outcome of an $\mathrm{ICT}_{4} \mathrm{D}$ project. The pilot demonstrates the importance of extensive sociotechnical field research, of cultural aspects, of collaborating with end-users, of embedding an ICT system in the local context.

Chapter 8 examines the key issue of economic sustainability of ICT solutions in networked business ecosystems. These are systems in which stakeholders depend on each other for their survival and well-being. It is often (and correctly) complained that prospective development solutions commonly do not survive the pilot phase when the project ends. We argue, in Chapter 8, that economic sustainability analysis must and can be done much earlier in the systems development cycle, rather than being an $\mathrm{ICT}_{4} \mathrm{D}$ project afterthought as is often the case. To this end, I will present a novel and rigorous method, based on the $e^{3}$ value networked business modelling theory and methodology [170, 169], which is able to do so at an early stage, and I will illustrate this approach by practical sustainability studies from our own field research.

\subsubsection{Reflections}

In Part III I reflect on the meaning and generalizability of our empirical findings and field experience which is detailed in Chapters 4-8. In Chapter 9, a new framework for $\mathrm{ICT}_{4} \mathrm{D}$, which emerged from extended periods of field investigation, is presented as an intention-strategy process model, summarizing the main results of Part II. In Chapter 10, this framework is validated against several criteria: utility, adaptability to other contexts, generalizability. 
In Chapter 11 , the point is made that $\mathrm{ICT}_{4} \mathrm{D}$ fundamentally deals with innovation and has to be treated accordingly, both methodologically and theoretically. Relevant knowledge sharing and diffusion about technologies occurs through social networks, whereby many social and cultural factors come into play in rather unpredictable ways. In contrast, intervention models to development do not take the introduction of ICTs as innovation but as a regular, business-as-usual measure. Intervention models, with their ideas of mechanistic change, thus ignore that innovation and its diffusion is a complex nonlinear dynamic process that works out differently and adaptively in different parts of the world. Hence, an important critique of current $\mathrm{ICT}_{4} \mathrm{D}$ policies and programs is that they do not adequately take into account the nonlinear, adaptive lessons from innovation diffusion, complex systems and social network theory. The alternative approach to $\mathrm{ICT}_{4} \mathrm{D}$ practice proposed in this thesis does.

$\mathrm{ICT}_{4} \mathrm{D}$ and Development undertake to make the world a better place. At least, this is often said or suggested. To take such claims scientifically seriously in the international development debate, they must be critically scrutinized like any scientific claim to see whether they are really warranted. We do so in the reflective Chapter 12. So, the general issue is not just about better methodological approaches to $\mathrm{ICT}_{4} \mathrm{D}$ practice. Beyond this, one has to ask and investigate whose interests in the Global South (or North) one is representing, what goals one is trying to achieve, where these goals and policies are coming from or how they are constructed, how matters of power and politics play a role and what core values are implicated in this. Therefore, in Chapter 12, I argue that collaboration is not just a method, but a core value. It is, or should be, an intrinsic part of an inclusive democratic process of discussion and exchange of views where the stakeholder voices of the Global South are truly included, where one is able to deal with local context and complexity and goals are not imposed from the outside, but emerge from the true Global South stakeholders themselves. This work can be read as an attempt to move towards a more decolonial and de-imperializing paradigm for $\mathrm{ICT}_{4} \mathrm{D}$.

In Chapter 13 I revisit the research questions from this first chapter (in section 1.3) and reflect on the design question: how an operational approach to developing ICT systems and services should look like, while taking into consideration, in the design process, the complex realities of local context and involving the envisaged users in decision-making and development.

\subsection{RESEARCH DESIGN AND METHODOLOGY}

Central to my research is the design and construction of technologies as practical solutions to concerns of people in resource-constrained environments. To ensure sustainability of the proposed solutions, the produced knowledge must be applicable in broader or different contexts. This can be formulated as a dual research goal: (i) to solve 
real-world problems of people through socio-technical innovation, and (ii) learn from the process and generalize its outcomes. What are the central ideas of this research?

(i) Focus on technologies as well as people: knowledge of technology design/information system engineering, as well as knowledge of the local (social, environmental, business etc.) context must be available in the (trans-disciplinary) research team.

(ii) Scope of the research is on resource-constrained environments: environments with limited resources, for example rural Africa, are often new and unfamiliar to the researcher/developers team. This aspect requires special attention.

(iii) A reflective attitude, concerned with ethical aspects: concerned with people and their problems or situation, considering the intricate aspects related to issues of e.g. poverty, interests and power. Being respectful to local culture and local people/communities is essential.

This research combines design and knowledge production for the improvement of a real-world situation. Given the complexity and dynamics of resource-constrained contexts, it has a flexible research design, to cope with uncertainty, dynamic contexts and multiple perspectives. As it is concerned with people and real-world situations, in which knowledge, according to ethical human values, is not value-free, it needs an emancipatory, reflective and critical attitude, based on deliberation and dialogue. Moreover, as it is exploratory and based on field experimentation in an open environment, it must cater for a cyclic, learning-by-doing approach. These requirements lead us to the space of praxis-oriented research paradigms. These can be found in different disciplinary traditions, of which I will discuss and compare Design Science, Action Research, Soft Systems Methodology and the adapted methodology which I use for my research, see also Table 2.

\subsubsection{Design science research (DSR)}

The subject of design science research is an artefact in a real-world context [205, 419]. Design science plays a central role in the development of ICTs (e.g. [422, 382, 205, 204]). It guides technological innovation, Computer Science, Information Science, Artificial Intelligence, Information Systems Engineering, Requirements Engineering, HumanComputer Interaction, and many other creative disciplines [422, 205]. The goal of design science research (DSR) is to find a solution for a problem that improves something for stakeholders in a certain context [205]. Since the act of designing is a purposeful endeavor, it is essential to understand the stakeholders' (operational) goals, as well as to have knowledge of the context [419]. Context can be social, technological, cultural, environmental, political etc. 
Design science research produces artefacts as well as knowledge. An artefact can be a technology, a technique, an algorithm, but also a method or set of methods [419]. A design science project usually consists of several cycles in which an artefact is iteratively improved and adapted to the context in question [264, 418]. Two types of research questions pop up iteratively during the design process: knowledge questions and design questions, as a recursive set of nested problems [418]. Knowledge questions can be evaluative: what are the effects and impact of the artefact? or e.g. predictive: how will the artefact behave in other contexts? Answering these questions may yield new (technical, user etc.) requirements for the next cycle of design and construction [264]. This process is iterated until an optimum is reached. It is constrained by the time, budget and available knowledge/resources.

Prior knowledge is what we consider the expertise brought into the research [419], for example ICT knowledge, knowledge of methods, techniques and tools. This can be explicit, formal (e.g. from textbooks), or tacit knowledge, as a person's experience [295].

\subsubsection{Action research $(A R)$}

Action research is concerned with people and has a purposeful, emancipatory character $[136,333]$. Its goal is to generate new knowledge to improve a social, real-world situation and learn from it. [333, 348]. Action research started in the mid-1940s from the aspiration to make (social sciences) research more relevant and purpose-oriented [252, 136, 137] by incorporating a problem-solving element [18].

Action research is carried out in participative communities [333]. Essential is the concern, not only to explore, describe and explain, but also to facilitate action and help change or make improvements to a real-world situation [20]. This is done either indirectly, by e.g. influencing policy, or directly by improving practice [348]. Knowledge is acquired through action [58]. Action research consists of a cyclic process of learning and improving. The resulting knowledge is actionable, for example a policy framework or a new method how to bring about change in a given situation.

Action research applies principles of equity and democracy. It avoids the notion of researcher versus "subject", in favor of collaboration between academics and nonacademics, organized such that the people concerned have a say in the research strategy and decision-making. They often have a co-research, co-design and co-creation role [348]. Some decolonial authors [132, 53] refer to this methodology as "collective research and action". The view on action research that emerged from my/our W4RA field research over the course of ten years, and my reflections during the preparation of this thesis, have led to the formulation of six principles [38], which are summarized in Table 1.

Proponents of action research and real-world research include critical theorists as Jürgen Habermas, Herbert Marcuse [223, 128] but also participatory action researchers from the Latin American tradition, such as Orlando Fals Borda [136, 137] and Paulo 
Table 1: Six principles of action research [38].

\begin{tabular}{ll}
\hline $\mathrm{Nr}$ & Principle \\
\hline 1 & $\begin{array}{l}\text { Principle of Critical Investigation of Concrete Situations (field, professional, practice). } \\
2\end{array}$ \\
& $\begin{array}{l}\text { Principle of Value: Developing/Taking a Value Position (democracy, emancipation, } \\
\text { autonomy, social and economic betterment). }\end{array}$ \\
3 & $\begin{array}{l}\text { Principle of Stakeholder Collaboration (involving Co-Investigation, Co-Design, } \\
\text { Co-Creation, whereby goals and interests as seen by stakeholders themselves are central). }\end{array}$ \\
4 & $\begin{array}{l}\text { Principle of Dialogue (multiple actors and stakeholders to be involved). } \\
5\end{array}$ \\
6 & Principle of Action: Discovery and subsequent Realizing Change for the Better. \\
\hline
\end{tabular}

Freire $[154,153]$. This perspective of science makes it easier to link science to innovation and to work in the dynamic complexity of society.

\subsubsection{Soft systems methodology (SSM)}

Soft systems methodology is closely related to action research and relates to the tradition of real-world, problem-solving social sciences research [20,86]. Like DSR and AR, SSM uses an iterative approach to improve a situation through action [18]. SSM combines organizational process modeling and business process modeling, and offers methods for inquiry and social learning. SSM is useful to tackle complex, messy situations and open-ended problems, which are characteristic of complex, dynamic environments, in which there may even be divergent views on the definition of the research problem - the so-called wicked problems [86, 85].

Outcomes of a change process in SSM depend upon interrelated factors, e.g. (i) people (ii) perception of the situation (iii) methodology. Particular is the iteration between "thinking in the real world" with "thinking in an abstract, systems world" [18, 86]. Flexibility and adaptability are inherent to SSM [86]. SSM is used in business, health care, education, and management of organizational change. In international development cooperation SSM is not commonly used.

\subsubsection{Combining AR, DSR and SSM}

Various studies have shown the advantages of combining design science research, action research and also soft systems methodology (e.g. [19, 217, 375, 420]). This is possible because of a shared notion of generating knowledge by intentionally modifying a real-world situation and evaluating results of the actions, despite the very different methods and techniques to achieve this. Overall, DSR, AR and SSM differ largely from the linear approaches and methods that are commonly used in International Develop- 
Table 2: Four praxis-oriented methodologies compared, with respect to: research process, focus, domain and outcomes/results.

\begin{tabular}{llll}
\hline Design Science Research & Action Research & SSM & ICT4D \\
\hline Design \& evaluation & Action \& learning & Action \& learning & Design \& evaluation \\
Iterative & Iterative & Iterative & Iterative \\
Context-aware & Participatory & Systems thinking & Collaborative, context-aware \\
User-centered & People-centered & Organizational & Community-centered \\
Technical/engineering & Social/action & Social/organizational & Socio-technical \\
Artefact \& knowledge & Change \& knowledge & Change \& knowledge & Artefact \& knowledge \\
\hline
\end{tabular}

ment projects to implement change $[74,331]$. This point will be further elaborated in Chapter 2.

\subsubsection{A praxis-oriented methodology for ICT $4 D$}

As discussed in section 1.3, the present research is concerned with people and technology design. It aims to serve stakeholders' operational goals. It does so by (i) taking into consideration the complex realities of local context - resource-constrained environments - and (ii) involving the envisaged users in decision-making and sociotechnical development. This asks for a praxis-oriented methodology in which elements from design science, action research, and soft systems methodology can be combined 1.5. Table 2 lists the main charactistics with respect to research process, focus, domain, outcomes/results for a quick comparison between DSR, AR, SSM and the present methodology for $\mathrm{ICT}_{4} \mathrm{D}$.

The present research addresses real-world problems of communities in resourceconstrained environments, e.g. in Drylands of West Africa, by design and construction and deployment of innovative information systems. To do so, knowledge from different domains is required - not only ICT knowledge but also about the local context (e.g. sustainable land management, agro-forestry, pastoralism, animal health, local culture, language, environmental knowledge, indigenous knowledge). Knowledge generation in this project is a networked process $[333,224,294])$ in which users play a role as local experts and co-researchers. ${ }^{21}$ The research process is iterative, based on collaboration, deliberation and learning.

Praxis-oriented research starts with a framework of ideas [88]. For the present research elements were borrowed from various disciplines: technology innovation [415], software engineering [215], agile development methods [117], participatory action research [139, 137] and various livelihood approaches [71, 74, 76, 78, 373]. User-centeredness, collaboration and the ability to cope with complex real-world contexts are common characteristics. These methods are part of a toolbox of methods for $\mathrm{ICT}_{4} \mathrm{D}$, see Chapter 3 .

21 This shows also similarities with Mode 2 research: New ways of knowledge production [297, 298, 160]. 


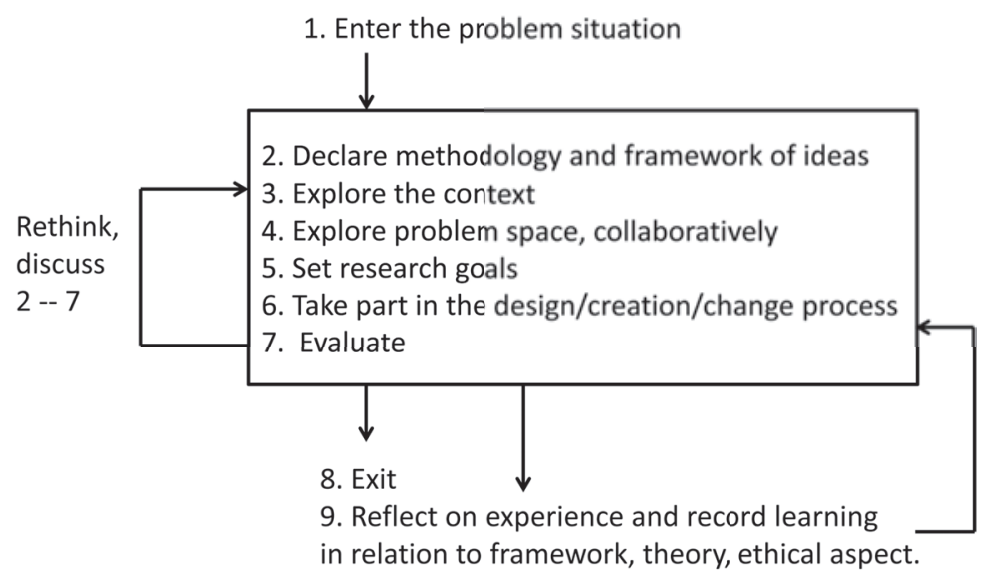

Figure 3: Process of the present $\mathrm{ICT}_{4} \mathrm{D}$ research, inspired by Peter Checkland's process for action research in Information Systems [88].

In Figure 3 the praxis-oriented methodology for $\mathrm{ICT}_{4} \mathrm{D}$ research is shown (inspired by Peter Checkland [88]). At the start, only a basic methodology and framework of ideas is available. After exploration of context and problem space, together with the envisaged users and stakeholders, the research goals are formulated and the design, creation and evaluation can take place. This process is re-iterated various times. Meanwhile the methods and actions are discussed and if necessary adapted. At the end, the produced artefact (framework and approach) and knowledge (theory, ethics, policy advise, emerged from practice) are presented and disseminated.

The $\mathrm{ICT}_{4} \mathrm{D}$ researcher must reflect and be aware of his or her role and responsibilities, as a professional and as a citizen. While the focus is on delivery of an effective result, it is equally important to consider and deliberate about the ethical aspects. To do so six principles for guidance and reflection are proposed [38], see Table 1.

\subsection{THEORETICAL FRAMEWORK}

Various $\mathrm{ICT}_{4} \mathrm{D}$ studies discuss how theory is to inform practice (e.g. [237, 253, 383, 103]), whereas the inverse directionality, of practice informing theory, is less present in ICT $4 \mathrm{D}$ research [167]. In this thesis I show, based on the empirical findings of our extensive field research, how $\mathrm{ICT}_{4} \mathrm{D}$ matches a process of socio-technical innovation and how this can be explained from the theoretical perspective of network complexity.

Network complexity provides a theoretical lens through which various patterns can be observed in the development context in which $\mathrm{ICT}_{4} \mathrm{D}$ is implemented. A networked approach means two-way knowledge sharing = collaboration between various stakeholders, including ICT developers and users. The empirical findings of our field research (discussed in (Chapters 4-9) link ICT design and engineering to a (broad) process of 
socially networked innovation that aims at a betterment of people's and communities' livelihoods. This occurs in knowledge networks [275, 95] or networks of innovation, in which knowledge is exchanged by interacting agents, driven by a common goal and purpose to solve a real-world problem [402].

Complexity theory explains the effectiveness of a process of socio-technical innovation which is adaptive (to fit the variety of contextual requirements), collaborative (to encompass as many viewpoints and knowledge domains - academic as well as nonacademic - as possible on the subject and context), and iterative (because of learning cycles). The various insights obtained from the field-based research support the choice of networked (iterative, multi-perspective, trans-disciplinary) methods/approaches in $\mathrm{ICT}_{4} \mathrm{D}$, which are more capable of coping with complexity in dynamic, evolutionary contexts, than linear and interventionist approaches. We therefore consider the practice of $\mathrm{ICT}_{4} \mathrm{D}$ to be a networked process of sociotechnical innovation.

According to complexity theory, a system/organization/artefact matches a given context, (and is therefore capable of solving a problem in this context), if the level of complexity of the system/organization/artefact is of the same order of magnitude as the complexity of that context [16]. This is an important insight to consider, in the design of artefacts, but also in the organization and implementation of projects in complex dynamic contexts.

Another insight from the field-based research is that change is not, in a linear, causal way, the effect of introduction of new technology. Based on the complexity framework, change can also be conceptualized as a networked process that is driven by local agency, and diffuses and evolves in complex development contexts. This has consequences also for the way how the observed and envisaged "change" is measured and evaluated and for the choice of methods and instruments to do this. These and other aspects of $\mathrm{ICT}_{4} \mathrm{D}$, from the theoretical perspective of network complexity, are discussed in Chapter 2.

Based on the above considerations, I will show that practical and critical, field-based $\mathrm{ICT}_{4} \mathrm{D}$ research can inform theory and provide a theoretical basis to understand many real-world phenomena that are constitutive of the intertwined social (local and global, communal, policy/political) as well as technical aspects [38]. The theoretical framework for the present research is further elaborated and discussed, with many examples, in Chapter 2 and Chapter 11.

\section{7}

POSITIONING THIS RESEARCH IN THE ACADEMIC LANDSCAPE

Various academic traditions have informed or influenced my research, e.g. Web Science, Information Systems Engineering, Innovation Research, Complexity Research and Critical Development Studies. Links exist also to other fields, for example ICT4D research and Science and Technology Studies (STS). STS is the interdisciplinary field concerned with theorizing and investigating the relationship between science, technology and 


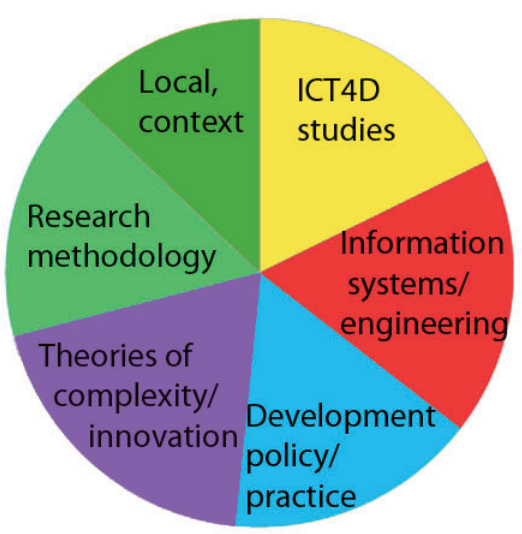

Figure 4: Various literatures and subjects that have informed this thesis are mapped as a pie chart according to the relative number of references in the bibliography (C.3.15).

society [384, 143]. STS investigates technology as a social process in society and is concerned with the material basis of knowledge production $[185,426]$. Two major strands can be observed in STS, one strand, more in the empirical, observational tradition, another more in the critical tradition, focused on society, reform and activism, in the name of e.g. equality, feminism, welfare or the environment [384, 141]. With its roots in North America and Western Europe in the 1960s, STS as an academic field has originally focused on science and technology in the western world. In recent years more and more investigations in STS are focusing on contexts in developing regions [225, 209]. Some of these studies include postcolonial and decolonial perspectives [392].

To show how my research relates to e.g. STS, ICT4 D research, decolonial studies and other academic fields, I will discuss similarities and differences for some aspects of my research. I hope my research can contribute to other fields of investigation with alternative methods and different perspectives. Figure 4 shows various literatures that have informed my thesis. These are grouped into six subjects, displayed as a pie chart.

\subsubsection{About critical studies of technology}

My research takes the position that the idea of "connecting the unconnected" and especially the conventional idea of "transfer of technologies" for social and economic development, is a western-centered, top-down approach, based on assumptions that need to be critically assessed. In this position my research has parallels with critical theory in STS on technological determinism (e.g. [142, 140, 425, 123, 141]). Critical STS studies show how technology is framed as an "agent of change" in language and policy, in which it becomes conceptually disconnected from users and their social world, leaving no space for human agency [425]. 
In recent years, an increasing number of studies have addressed problems and threats of technology and technological determinism for society [425, 144, 212, 279, 433]. Critical theory is commonly part of academic studies in the tradition of episteme or analytical knowledge. In some studies, an actionable approach is adopted, in the tradition of phronesis $[152,369,133,134]$. How technological determinism works out in societal programs to bridge the "Digital Divide" in western countries such as the USA or European countries is subject of various critical studies [428, 425, 135, 133, 314]. My research shares a critical position with these studies that show how technocratic solutions create new power structures and inequality for vulnerable groups.

My research has been inspired by various critical field-oriented, (action) research studies, from various disciplines and traditions (e.g. [79, 73, 372, 373, 137, 138, 154, 246, 56, 338, 339, 280, 99]). An example is Chambers' critical call in 1983, for putting the farmer first in rural development [71] up to his more recent studies [74, 77, 76]. This actionable, practically oriented approach shows the need for value-driven research, inclusiveness, reversed (grassroots, south-north) perspectives, and imagination. Chambers introduced the user-centered "people paradigm", in contrast to the, what he calls "things paradigm", which describes the interventionist approaches to rural development, based on transfer of (agro-) technologies, expert-based knowledge transfer, and outsiders' biases [74]. Chambers' work has had much influence in stirring up the Development Debate, and has influenced the Development discourse [372].

\subsubsection{About collaboration, participation, user-centered design}

Participatory action research, co-creation and user-centered design in ICT, sometimes called vernacular and mundane engineering [274] are central to my research. These approaches and methods are also common in some feminist studies of technology, e.g. $[133,134]$. Also, in $\mathrm{ICT}_{4} \mathrm{D}$ research, as it is carried out by several African universities, design science, co-creation and user-centered design, Living Labs and interdisciplinary field-oriented investigations are commonly used [29, 110, 203]. These field studies, of which many are from and in South Africa, have similarities with my research (e.g. $[68,315,182,409,54])$.

A special example of an interdisciplinary setting is "ICT4E": ICT for Education, in which learning technologies are designed and tested with users in rural community schools in South Africa [202]. Some of these practice-oriented studies have organized their findings as operational frameworks how to "do" ICT4D, as I have done in my research e.g. [29, 120, 145, 187]. This is further discussed in Chapter 10.

Another field where user-centered design and co-creation are common, is the subfield $\mathrm{HCI}_{4} \mathrm{D}$ : Human-Computer Interaction for Development. This field is known for its special attention to culture, context and usability (e.g. [400, 207, 316, 306, 109]). $\mathrm{HCI}_{4} \mathrm{D}$ provides interesting tools and methods that can enrich the framework for $\mathrm{ICT}_{4} \mathrm{D}$ presented in this thesis. Human Computer Interaction, focused on the system's 
interface with the user, has a narrower scope than my research, as e.g. business requirements or mechanisms of collaborative goal construction, as described in this thesis, are not within the scope of $\mathrm{HCI}_{4} \mathrm{D}$ [401, 115].

\subsubsection{About giving a voice to the "unconnected"}

Part of the academic $\mathrm{ICT}_{4} \mathrm{D}$ community, especially studies in the tradition of management information systems research (MIS), view critical realism as a foundational perspective on research (e.g. [253, 383, 237, 322, 103]). In these studies, it is common that theory informs practice. The inverse directionality, of practice informing theory, is less present here [38]. A consequence of this unidirectionality (from theory to practice) for $\mathrm{ICT}_{4} \mathrm{D}$ research, is that the perspective of the end-user and his or her context only accessible through research in the field - remain absent in the discourse. Especially when the study concerns problems in contexts unfamiliar to the researcher(s), the user's perspective is indispensable, as I argue in this thesis.

In 2014, I published the first version of the framework and theory that I present in this thesis, dubbed "ICT4 $\mathrm{I}_{3} .0^{\prime}$ [36]. I proposed this as an inclusive, field-based alternative to the linear (and quite techno-optimistic) framework named "ICT4D 2.0" [195]. ICT4 2.0 is a theory-driven policy model of $\mathrm{ICT}_{4} \mathrm{D}$, in which the end-user perspective and the operational aspects are not addressed [194]. As I argue in this thesis, the voice of the end-user must be heard, also at the policy level. This can only be achieved by allowing the end-user to participate in the ongoing development dialogue. In that sense, moving from the "ICT4 2 2.0" paradigm to " $\mathrm{ICT}_{4} \mathrm{D}_{3.0}$ " would mark the entrance of the "user" in the dialogue and decision making [36, 198].

\subsubsection{Context, indigenous knowledge and innovation}

Context is relevant for information systems development [5] and in $\mathrm{ICT}_{4} \mathrm{D}$ it needs even more attention, given the barriers that exist in resource-constrained environments. Involving users as local experts in their specific knowledge domain in co-creation and co-research - also when this knowledge is indigenous - is therefore one of the main aspects of my research. The Sahel in West Africa is the context of this research, and therefore many field visits have been made. This is further discussed in Chapter 4 .

On the subject of local farmer innovation in Africa and regreening initiatives, a large body of interesting literature exists, which has informed my research [339, 337, 423, 344, 186, 377]. However, local expertise consists often of indigenous knowledge, of which sometimes no written resources exist, and interviews with local domain experts can provide the insight necessary to build contextualized information systems.

Indigenous knowledge has often been ignored or even sometimes ridiculed by western scholars [338, 240]. Since recent years indigenous knowledge is becoming of interest in various studies (e.g. [59, 228]). Here also my research finds parallels in STS, where in- 
digenous knowledge is becoming a field of interest [261, 209], as reflected in studies of Transnational or even "Indigenous STS"22, while traditionally, this discipline was more focused on technology in society in western countries [262]. Studies of action-research in STS on local innovation in handloom weaving in India [261, 262] and e.g. on the adoption of biogas in rural India [405] have parallels with my research in West Africa, which is discussed in Part II of this thesis. One of the examples of changing (academic) attitude towards indigenous knowledge is the case of the Bali subaks [242, 244, 240], see also Chapter 11.

With respect to context, local knowledge and local agency, many interesting fieldbased studies exist on the innovative use of technology in developing regions, for example [161, 232, 311, 309]. These studies focus on re-use, adaptation and impact of new technologies on local livelihoods in developing countries, while my research focuses on co-design and engineering of new technologies with local stakeholders.

\subsubsection{Links to postcolonial and decolonial studies}

This research shares ideas and principles with postcolonial and decolonial studies from various academic communities, including Geography, Political Sciences, Anthropology, Educational Sciences and STS (e.g. [267, 59, 411, 314, 209, 392]). In recent years various academic communities widened the scope to include postcolonialism as a new perspective from developing countries [209].

Decolonial studies tend to be more radical than postcolonial studies, and they are often led by scholars in developing countries, especially from Latin America (e.g. [136, 153, 131, 53, 411]). Decolonial authors go in general a step further and question the obviousness in which colonial power structures, colonial thinking and even racism, tacitly permeate international policy, digital development and scientific research [272, 299]. Some of them criticize the term postcolonial, as this suggests that colonialism is a finished period, whereas they demonstrate in their studies how this is still a dominant paradigm in policy and science [299]. By criticizing interventionism in International Development policy, my research takes a critical, decolonial or de-imperializing stance in $\mathrm{ICT}_{4} \mathrm{D}$. This will be further discussed in Chapter 2.

\subsubsection{Information Systems Engineering}

Various aspects from Computer Science and Information Systems Engineering are present in my research. This (technical) literature from IS engineering (see Chapter 3 ) is not widely cited in the (social-science oriented) $\mathrm{ICT}_{4} \mathrm{D}$ research literature. For the preparation of this thesis a vast state-of-the-art body of knowledge from the Informat-

22 Transnational and Indigenous STS was the topic of the $2018{ }_{4}$ S (Society of Social Studies of Science) Annual Conference in Sydney, Australia. 
ics/Computer Science disciplines was used [24, 201] regarding Information Systems engineering $[87,421,424,215]$ (in particular from the subfields of requirements engineering $[5,247,172,129,236]$, software and service engineering, information systems modeling and specification $[145,49,419]$, and - to a lesser extent - knowledge engineering $[370,4]$ and management and e-business innovation, such as the $e^{3}$ value methodology [170, 169]). This contains many state-of-the art insights from ICT/IS engineering science that are of direct relevance to $\mathrm{ICT}_{4} \mathrm{D}$ (e.g. agile and living lab methodologies $[117,8,23]$, advanced and goal-oriented requirements engineering, distributed/networked forms of service and software development, and information modelling advances). Conversely, the notion of development context and resource-constrained environments can be a source of inspiration for Computer Science and information systems engineering, as many problems in low-resource contexts are still to be explored and solved. Such problems are underrepresented in Computer Sciences that sees itself having a "global" reach and significance.

\subsubsection{About case studies}

With a focus on situated knowledge and on case studies informing theory, my research has parallels with various disciplines including Ethnography and STS [2]. STS is considered a "Science of the Middle Range" [270, 427], which means that it does not claim a universal validity of produced knowledge (in contrast to disciplines like e.g. physics, chemistry, or astronomy, that do claim a universal scope). The importance of this premise becomes even more apparent, in studies that include knowledge from nonwestern contexts. This requires rethinking the benefits of envisaged "progress", which are so often proclaimed in International Development policy and practice [70]. Case study research - which is absent in various disciplines (as a result of e.g. positivist research paradigms) - as a source of qualitative data is used in my research, from which patterns are collected that lead to the collaborative construction of new knowledge [2]. This has parallels with the way case studies are used in Information Science, Requirements Engineering, Artificial Intelligence, Knowledge Engineering [370, 248, 422]. As action researcher I am also a participant in my case studies.

\subsubsection{International Development research, policy and practice}

In the book Rethinking Development Studies in Africa, John Victor Mensah, Stephen Kendie and other African scholars show how international development continues to be dominated by modernization theory (characterized by accumulation, individualism, liberalism and the free market), whereas local traditions and the voice of the people 
concerned are considered irrelevant [269]. ${ }^{23}$ They argue for more critical analysis, while rethinking scientific research and its relevance and meaning for the African context.

With respect to policy in International Development, my research takes the position that practice must also link to the macro-level and inform or critically assess policy, bringing the findings from field-based research (i.e. the operational, field-based micro-level, which includes the voices of the "unconnected" people) to the level of the international Development Debate. Regarding $\mathrm{ICT}_{4} \mathrm{D}$ policy, there is a range of policy documents relevant for $\mathrm{ICT}_{4} \mathrm{D}$ from major donors (World Bank, USAID and other donors e.g. $[403,367,179])$. Interesting is also a set of critical cases of $\mathrm{ICT}_{4} \mathrm{D}$ and studies that analyse the conventional methods of project management and evaluation in donorfunded development cooperation projects, concerning policy, evaluation, management information systems, sustainability frameworks and human computer interaction studies $[263,177,271,101,100,179,400]$. Literature on international development project management provides insight in management methods imposed on practitioners and projects by development donors (e.g. [331, 429, 354]).

\subsubsection{Complexity and innovation studies}

Innovation theory is relevant to understand information and communication technologies in developing countries [414, 415], especially from the perspective of complex adaptive dynamic systems [350, 351]. A novel point put forward in this thesis is the analysis that $\mathrm{ICT}_{4} \mathrm{D}$ efforts are to be interpreted (and managed) as inherently innovative - even if they comprise mainly established or "old" ICT technologies (i.e. not advanced in terms of today's western standards). The literature regarding complexity theory gives a theoretical background to explain why $\mathrm{ICT}_{4} \mathrm{D}$ projects are inherently complex, why they can easily fail, why simple recipes (such as linear intervention) cannot be expected to work in most cases (also not at the $\mathrm{ICT}_{4} \mathrm{D}$ policy level) and why alternative engineering and management methods (here dubbed: iterative, adaptive, collaborative) are needed that stand a better chance in dealing with the real-world $\mathrm{ICT}_{4} \mathrm{D}$ complexities in the field. Therefore, I consulted literature on innovation theory [350, 402], networks of innovation [275] and complexity research e.g. $[327,328,210,240,351,157,16]$. This is a contribution to the field of $\mathrm{ICT}_{4} \mathrm{D}$ research and practice, where these theoretical frameworks are not commonly used.

Regarding technology innovation and participatory approaches, a variety of sources for alternative ideas exist that avoid the linear views and technological determinism. Some come from modern ICT practices, initially developed in the Global North $[415,23$, $129,124,248,172]$. Others come from critical and participatory development thinking (e.g. $[71,341,65,136,138,338])$. These are discussed in Chapter 3 .

23 See: Proceedings of the Conference "Rethinking Development Studies in Africa", organized by the Institute for Development Studies of the University of Cape Coast, Ghana, 7-8 November 2008 [269]. 
The present research is based on a considerable amount of data. During the research period (2009 - 2020), a large base of research data was systematically collected and (digitally, safely and redundantly) stored. Permission was asked to the interviewees for filming, audio taping and the use of photos, as well as for publication of materials online. Part of the data (2011-2013) were collected in the framework of the EU-FP7 VOICES project and its work package "m-agro knowledge sharing pilot". ${ }^{24}$ The other data sources are listed in Appendix $C$ and are accessible on request.

The raw data include audio recordings of all meetings and interviews, video, field notes, sketches and photos. There is semi-processed information such as field trip reports, use case descriptions, portfolios, prototype descriptions, use case scenarios, conceptual models, technical specifications, of which I have produced a large part. There are materials such as short films, articles, blogs, lecture notes, and presentations. All field trips reports, use case descriptions, prototypes, and models are shared and reviewed by the research team. The data collected between September 2009 and June 2018 consists of 13,611 photos 4,268 video fragments and 672 audio files of a total of 200 hours of recordings of full workshops, focus group discussions, interviews and user tests. We did a total of 198 days of fieldwork in a period 2009-2020 in Mali, Burkina Faso, Ghana and Sarawak, Malaysia. In this period, I did 103 full days of co-creation workshops with local users, (together with the interdisciplinary team of researchers, professionals and students, over more than a decade).

In line with the team-based approach during the field sessions, all field data from all the researchers present in the workshops and field trips were stored in backups every day. As I was often the workshop moderator, my team members took pictures, operated the audio and video recorders, and who were not talking but observing, could take field notes. At the end of each day, all data sources were copied to all researchers (also for reasons of redundancy and data safety). After each trip a field trip report was made and shared in the team with key-users.

Through this systematic data collection method, extensive triangulation was done, with respect to data collection, method and theory [113, 114, 112, 255]. Since the field research was carried out with different communities, in multiple projects and different countries, there is furthermore extensive regional triangulation, supporting crosscontext generalization from diverse case materials.

One note should be made about FAIR ${ }^{25}$, the endeavor to make all research data Findable, Accessible, Inter-operationable and Re-usable. In our research, data consist of materials collected during co-creation workshops. Co-creation practices have consequences, also for data ownership. Whereas FAIR is based on the (tacit) assumption that the researcher owns the data, as soon as the consent papers are signed by the "subject",

24 All relevant materials are at https://w4ra.org/publications/voices/, (accessed o8-10-2020)

25 See: https://en.wikipedia.org/wiki/FAIR_data, (accessed o8-10-2020) 
the case of co-creation implies a shared ownership, also for data, which is part of a joint intellectual property. For this reason our research data are processed in line with the objectives of the end-users/interviewees/local partners, which implies that they are not fully shared online. In Table 11, in Appendix B, all use cases described and analyzed in this thesis are listed.

\subsection{VALIDATION OF RESULTS}

Knowledge claims in a process of scientific research, must be subject to critical scrutiny [319, 149, 88, 4]. In the following paragraphs I will set requirements for validity, utility and generalizability of the present research. In Chapter 1o this will be operationalized in a number of case studies.

\subsubsection{Validity criteria}

Knowledge claims are well founded if sufficient grounds are offered, which are connected to the claims by reliable, applicable warrants, which are capable of being justified by appeal to sufficient backing [399]. In sciences where knowledge claims are based on experiments, carried out under idealized conditions, validation can be done on basis of replicability of an experiment. In research carried out in the real world for example with people, open environments or dynamic contexts - the influencing factors are often interrelated and uncontrollable. Validation is based on a rational communicative argument, that is defended and made credible [5]. Below are criteria for validation of the present research, that obviously falls in the latter field-based category.

\subsubsection{Validation by peers}

A validation method, used in design science research, is to let peer researchers test the research outcome (artefact), by using it, for example in a similar project or different context. This is done before the artefact is implemented [419].

\subsubsection{Utility}

The utility criterion holds especially for praxis-oriented oriented research, such as action research and design research. Claims of utility must be evaluated and confirmed by its stakeholders. This is an indirect validation instrument, as it does not concern the research process itself. 


\subsubsection{Generalizability}

Generizability as a quality criterion, refers to the scope of knowledge claims. In the present research the knowledge and artefact(s) are based on case studies and experimental field pilots in various countries and regions, carried out under dynamic, realworld conditions. In Chapter 1o I will discuss to which extent the research outcomes can be generalized to different contexts.

\subsection{SELECTED PUBLICATIONS}

This thesis relates to a number of peer-reviewed publications and working papers from the period 2011-2020. ${ }^{26}$

1. Anna Bon and Hans Akkermans [2020]. "Digital (In)Equality, Digital Inclusion, Digital Humanism - Summary of the Web Science Workshop DigDivDigHum20." In: In 12th ACM Conference on Web Science (WebSci '20 Companion), July 6-10, 2020, Southampton, United Kingdom. ACM, New York, NY, USA, 3 pp. https://doi .org/10.1145/3394332.340289

2. Anna Bon, Jaap Gordijn, Cheah WaiShiang [2020]. "Digital inclusion requires a business model too." In: In 12th ACM Conference on Web Science (WebSci '20 Companion), July 6-10, 2020, Southampton, United Kingdom. ACM, New York, NY, USA, 7 pp.

https://doi.org/10.1145/3394332.3402832

3. Anna Bon and Hans Akkermans [2019]. "Digital Development: Elements of a Critical ICT4D Theory and Praxis". In: P. Nielsen and H. C. Kimaro (Eds.): Information and Communication Technologies for Development. Strengthening Southern-Driven Cooperation as a Catalyst for ICT4D, IFIP AICT 552, Chapter 3, Springer Nature Switzerland, Basel, Switzerland.

https : / /doi .org/10.1007/978-3-030-19115-3_3

4. Anna Bon, Jaap Gordijn, Hans Akkermans, Victor de Boer, André Baart, Cheah Wai Shiang, Sze San Nah [2019]. "Community-centered, Project-based ICT4D Education in the Field". In: P. Nielsen and H. C. Kimaro (Eds.): Information and Communication Technologies for Development. Strengthening Southern-Driven Cooperation as a Catalyst for ICT4D, IFIP AICT 552, Chapter 32, Springer Nature Switzerland Basel, Switzerland. https : //doi.org/10.1007/978-3-030-19115-3_32

5. Anna Bon, Hans Akkermans, and Jaap Gordijn [2016]. "Developing ICT services in a low-resource development context". In: Complex Systems Informatics and Modeling Quarterly, (9) pp 84-109. https://doi.org/10.7250/csimq.2016-9.05

26 Available at: https://w4ra.org/publications/, (accessed o8-10-2020) 
6. Anna Bon, Jaap Gordijn, and Hans Akkermans [2017]. "E-service Innovation in Rural Africa Through Value Co-creation". In: Handbook of Research on Strategic Alliances and Value Co-creation in the Service Industry, pp 355-373, IGI Global, 2017. https://doi .org/10.4018/978-1-5225-9273-0.ch043

7. Anna Bon, Victor de Boer, Nana Baah Gyan, Chris van Aart, Pieter De Leenheer, Wendelien Tuyp, Stéphane Boyera, Max Froumentin, Aman Grewal, Mary Allen, Amadou Tangara and Hans Akkermans [2013]. "Use Case and Requirements Analysis in a Remote Rural Context in Mali". In: J. Doerr and A.L. Opdahl (Eds): Requirements Engineering: Foundation for Software Quality. REFSQ 2013. Lecture Notes in Computer Science, vol 7830. Springer, Berlin, Heidelberg, pp 331-346. https : //doi.org/10.1007/978-3-642-37422-7_24

8. Anna Bon, Victor de Boer, Pieter De Leenheer, Chris van Aart, Nana Baah Gyan, Max Froumentin, Stéphane Boyera, Mary Allen, Hans Akkermans [2015]. "The Web of Radios, Introducing African Community Radio as an interface to the Web of Data". In: E. Simperl et al. (Eds) The Semantic Web: ESWC 2012 Satellite Events. ESWC 2012. Lecture Notes in Computer Science, vol 7540. Springer, Berlin, Heidelberg, pp 1-14. https://doi.org/10.1007/978-3-662-46641-4_16

9. Anna Bon, Victor de Boer, Christophe Guéret, Gayo Diallo, Jaap Gordijn (Eds). [2018] Proceedings of the 5th International Symposium Perspectives on $\mathrm{ICT}_{4} \mathrm{D}$, Co-located with 1oth ACM Web Science Conference (WebSci'18) Amsterdam, the Netherlands, May 27, 2018. http://ceur-ws .org/Vol-2120/

10. André Baart, Anna Bon, Victor de Boer, Wendelien Tuyp, Hans Akkermans [2018]. Ney Yibeogo - Hello World: A Voice Service Development Platform to Bridge the Web's Digital Divide. In: M. J. Escalona, F. Dominguez Mayo, T. Majchrzak, $\mathcal{E}$ $V$. Monfort (Eds.), WEBIST 2018: proceedings of the 14th International Conference on Web Information Systems and Technologies : Seville, Spain, 18-20 September, 2018 (Vol. 1, pp. 23-34). Setúbal: SciTePress.. https://doi.org/10.5220/0006893600230034

11. Francis Dittoh, Victor de Boer, Anna Bon, Wendelien Tuyp, André Baart [2020] "Mr. Meteo: Providing Climate Information for the Unconnected." In: In 12th ACM Conference on Web Science (WebSci '20 Companion), July 6-10, 2020, Southampton, United Kingdom. ACM, New York, NY, USA, 6 pp.

https://doi.org/10.1145/3394332.3402824

12. Nana Baah Gyan, Victor de Boer, Anna Bon, Chris van Aart, Hans Akkermans, Stéphane Boyera, Max Froumentin, Aman Grewal, Mary Allen [2013]. "Voicebased Web Access in Rural Africa". In: Proceedings of the 5th Annual ACM Web Science Conference, May 2013, Paris, France. pp 122-131. ${ }^{27}$ https://doi.org/10.1145/2464464.2464496

27 Nominated for best paper award at ACM WebSci'13 Conference, Paris, France. 
13. Victor de Boer, Nana Baah Gyan, Anna Bon, Wendelien Tuyp, Chris van Aart, Hans Akkermans [2015] "A Dialogue with Linked Data: Voice-based Access to Market Data in the Sahel". In: Semantic Web 6, IOS Press, pp $23-33$. https://doi.org/10.3233/SW- 130132

14. Chris van Aart, Anna Bon, Hans Akkermans, Victor de Boer, Stéphane Boyera, Wendelien Tuyp, Nana Baah Gyan [2011]. "The Web of Voices: How to connect 4.5 billion Internet-less people to the Web": In: Outrageous Ideas, International Semantic Web Conference. ${ }^{28}$

15. Victor de Boer, Pieter De Leenheer, Anna Bon, Nana Baah Gyan, Chris van Aart, Christophe Guéret, Wendelien Tuyp, Stéphane Boyera, Mary Allen, Hans Akkermans [2012]. "Radio Marché: Distributed Voice- en Web Interfaced Market Information System under Rural Conditions". In: Ralyté J., Franch X., Brinkkemper S., Wrycza S. (Eds) Advanced Information Systems Engineering. CAiSE 2012. Lecture Notes in Computer Science, vol 7328. Springer, Berlin, Heidelberg. https ://doi .org/10.1007/978-3-642-31095-9_34

16. Hans Akkermans, Nana Baah Gyan, Anna Bon, Wendelien Tuyp, Stéphane Boyera, Aman Grewal, Mary Allen [2011]. "Is (Web) Science ready for Empowerment?". In: Proceedings of the Third ACM Web Science Conference, Koblenz, Germany. https://doi.org/10.1145/2527031.2527041

17. Christophe Guéret, Stefan Schlobach, Victor De Boer, Anna Bon and Hans Akkermans [2011]. Is data sharing the privilege of a few? Bringing Linked Data to those without the Web. Outrageous Ideas, International Semantic Web Conference. ${ }^{29}$

\subsection{SUMMARY}

In this first chapter, I have briefly exposed the central problem, the research design and the requirements for the methodology. By incorporating elements from design science research, action research and soft systems methodology, this study is positioned in a praxis-oriented paradigm. In Chapter 2, I will further explore the problem, mentioned in RQ-1 1.4.I and introduce network complexity as the theoretical framework. 

In this chapter we take a closer look at the logic of the conventional approaches to $I_{C} T_{4} D$ in policy and practice, interrogating it through a set of critical questions. How are goals and objectives for ICT 4 D defined? What is the role of end-users and beneficiaries of ICT $4 D$ ? How are project evaluations done? Which project management methods are used? How does ICT 4 D cope with the complexity of real-world contexts? To answer these questions, I will discuss and assess several cases of high-profile ICT 4 D and development projects from the literature. An emergent pattern from the cases presented here, is an idea of top-down, externally defined "intervention", which lies at the heart of current development and ICT 4 D thinking, and contrasts with a usercentered, collaborative approach. Complexity theory offers a theoretical lens to explain why $I_{C} T_{4} D$ projects are inherently complex, why they easily fail, why simple recipes (such as linear intervention) do not work in most cases, and why alternative engineering and management methods are needed to deal with real-world contexts. I therefore introduce network complexity as a theoretical framework, in which ICT4D is conceptualized, not as a linear intervention, but as a networked process of sociotechnical innovation in a complex dynamic context.

\subsection{ICT4D POLICY AND PRACTICE}

Intervention - a deliberate action to bring about a particular change and achieve a preferred state of affairs - is a central concept in international development [325]. Interventions are designed according to international development policies. They aim to improve a situation or solve a real-world problem that affects people in poor parts of the world. Interventions are financed through national and international public and private funds. ${ }^{1}$ The word 'intervention' is derived from the Latin verb 'intervenire', which means 'to come in between', 'to interfere'.

Interventions in international development are organized through a hierarchical structure of stakeholders, each with different responsibilities. Stakeholders include policy-makers, funding agencies, project executers/implementors, and evaluators (e.g. $[226,429,10])$.

Policy-makers are responsible for development of policies at national and international levels. Donor agencies formulate programs according to these policies and fund the actions. Execution and management of development projects is done by practitioners from implementing agencies, who have been selected and contracted, through

I E.g. the Rockefeller Foundation and the Bill \& Melinda Gates Foundation, the "Nederlandse Postcodeloterij" and many others. 
an official procurement procedure. Evaluation of results is done by evaluators or researchers. ${ }^{2}$

$\mathrm{ICT}_{4} \mathrm{D}$, as part of international development programs ${ }^{3}$, is designed and formulated according to policies at the level of international organizations and institutions, including the United Nations, the European Commission and the World Bank. Interventions are organized according to a stepwise project lifecycle, using a "linear" project management approach, which consists of various phases. First there is programming in line with development policy and strategies. Second is the identification of needs, followed by a phase of formulation, in which design and preparation of project plan by experts takes place, followed by selection of an (independent) implementing agency. Next is the phase of project implementation. Evaluation and reporting of results and impacts to the donor are the final stages of the project cycle.

Goals and objectives for $\mathrm{ICT}_{4} \mathrm{D}$ interventions are formulated in line with international development policies, to achieve concrete results, outcomes and impacts. The results and outcomes of $\mathrm{ICT}_{4} \mathrm{D}$ interventions are evaluated against baselines. ${ }^{4}$

\subsection{ICT4D AS LINEAR INNOVATION}

$\mathrm{ICT}_{4} \mathrm{D}$ generally consists of a transfer of technologies, information or knowledge to developing regions. How this is done in a high-profile $\mathrm{ICT}_{4} \mathrm{D}$ project, that aims to improve primary education in developing countries, is discussed in this section. For this project, a group of scientists and developers in the Global North have invented and designed a technological concept, assuming that this will solve a problem in the developing world [177]. The technology is funded by national governments and development donors and rolled out at large-scale in developing countries.

\subsubsection{OLPC: laptops to transform primary education}

In January 2005, at the Economic Forum in Davos, Switzerland, researcher and inventor Nicholas Negroponte presented his \$10o laptop to the international community as a tool that would radically transform primary education in the developing world. This was the OLPC, the famous One Laptop per Child project. ${ }^{5}$

Negroponte convinced the policy makers of the potential of his proposed solution and in November 2005, Secretary-General of the United Nations, Mr. Kofi Annan, presented the first prototype of the so-called "XO laptop" at the World Summit for the

2 See e.g. USAID: ADS Chapter 201 - Program Cycle Operational Policy, Partial Revision Date: https: //www. usaid.gov/sites/default/files/documents/1870/201.pdf, (accessed o8-10-2020)

3 This is referred to in international policy as ODA: Official Development Assistance.

4 E.g. the Handbook of Project Cycle Management in Development Projects [394] gives a structured overview of the topic.

5 Source: https://tinyurl . com/OLPC-Davos-2005, (accessed o8-10-2020) 


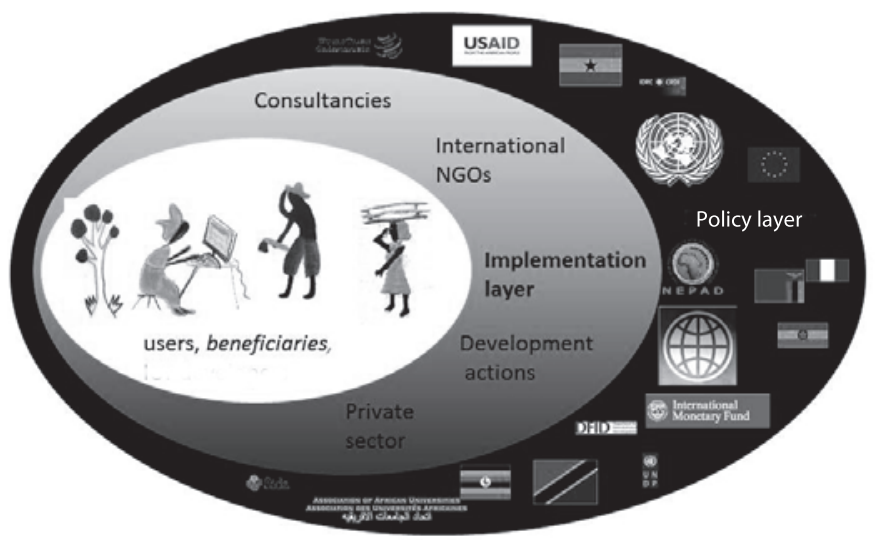

Figure 5: Onion model of stakeholder groups and their relationships in the $\mathrm{ICT}_{4} \mathrm{D}$ landscape.

Information Society in Tunis, to an audience of about 17,000 people, amongst whom there were heads of states, representatives of international organizations, academia, civil society and the private sector. ${ }^{6}$

Negroponte's invention had unique hardware. The XO laptop was equipped with novel features for power supply, display, networking, keyboard, and touchpad [286]. It had a screen that allows reading in bright sunlight. It was energy-efficient, using a solar battery. It was built to endure dust and heat. It was designed for use in a local area mesh network of only XO laptops, even without an Internet connection. ${ }^{7}$ The estimated lifetime of the XO laptop was about four years. ${ }^{8}$

OLPC presented itself as an educational project, not a "laptop project". 9 The XO laptop was designed and produced by the OLPC organization as a scientifically grounded self-learning tool, based on the constructionist theory of learning by doing [305, 312]. Its claim was that the access to a connected laptop would engage children into knowledge acquisition. ${ }^{10}$

The marketing strategy of OLPC persuaded many governments of developing countries to commission large-scale deployments of $\mathrm{XO}$ laptops for primary education. The largest deployment took place in Peru, where the national government spent 225 million US\$ on OLPC's XO laptops. ${ }^{11}$ In Uruguay 395.000 XO laptops were delivered to 2332 public primary schools, in 2009. ${ }^{12}$ OLPC wanted to deliver the XO laptop in bulk only, with a minimum of 1.000 .000 laptops per order, but this figure appeared too

\footnotetext{
6 Source: https : / / tinyurl . com/OLPC-WSIS-2005, (accessed o8-10-2020)

7 Source: https://www. itu.int/net/wsis/c2/docs/may-18/06.pdf, (accessed o8-10-2020)

8 Source: http://one. laptop.org/about/hardware, (accessed o8-10-2020)

9 Source: http://laptop.org, (accessed o8-10-2020)

1o Source: http://wiki. laptop.org/go/Education, (accessed o8-10-2020)

11 Source: http://www. economist. com/node/21552202, (accessed o8-10-2020)

12 Source: http://one. laptop.org/map/uruguay, (accessed o8-10-2020)
} 
optimistic. In April 2007, OLPC lowered the minimum order to $250.000 \mathrm{XO}$ laptops [63].

The XO was nicknamed the $\$ 100$ laptop, but its actual unit price was 160 US\$, not including deployment costs, maintenance and training of teachers [301]. Nicholas Negroponte estimated that, by the end of 2007, 150 millions of XO laptops would be shipped annually. ${ }^{13}$

After its hyped entrance into the international development stage [284, 63], various difficulties were reported for the OLPC project [301]. The evaluated pilots of OLPC deployments in Ethiopia, Haiti, Nepal, Rwanda and Uruguay reported difficulties in teacher-student relationships. Ethiopian and Haitian pilots reported that teachers encountered problems in using the constructionist teaching approach. The overall use of $\mathrm{XO}$ laptops in class remained limited, because of reluctance of schoolteachers to adopt the new teaching methods [301].

Evaluations of local XO deployments have been performed in various countries (e.g. $[301,416,284])$ to assess the various deployments and measure the impact of XO use on children's cognitive skills. Some studies indicated that marginalized students were less capable of exploiting the XO's potential than students with higher socioeconomic backgrounds, and pointed to the fact that the $\mathrm{XO}$ was exacerbating existing divides [416].

In 2012 an impact evaluation of the OLPC project was done by the Inter-American Development Bank in Peru [146]. A randomized control trial study was performed for test scores in math and language of children from 319 primary schools in Peru. The evaluation of the impact on children after 15 months of exposure to the XO showed only a slight increase in cognitive skills that could be attributed to the XO laptop. Obviously, the computer/student ratios in this evaluation study showed a considerable rise: from 0.12 to 1.18 [97].

After an evaluation study of OLPC between 2009 and 2013 at two schools in Ghana, investigators Leslie Steeves and Janet Kwame (2017) commented: "The history of OLPC illustrates how projects in the developing world commonly unfold. A small handful of powerful government and development leaders, usually men - in this case, Ghana's late Finance Minister Kwadwo Baah - Wiredo, former president John Kufuor, Nicolas Negroponte, and Jeffrey Sachs are taken with an idea and deploy the resources to carry it out, without broad consultation and certainly without engaging the agency or voice of recipients at the grassroots" [389].

According to various studies OLPC suffered from a lack of complementary infrastructure, skills development for teachers and students, and adaptation to local practices and constraints $[177,97,9]$.

13 Source: http://news.bbc.co.uk/2/hi/technology/4292854.stm, (accessed o8-10-2020) 


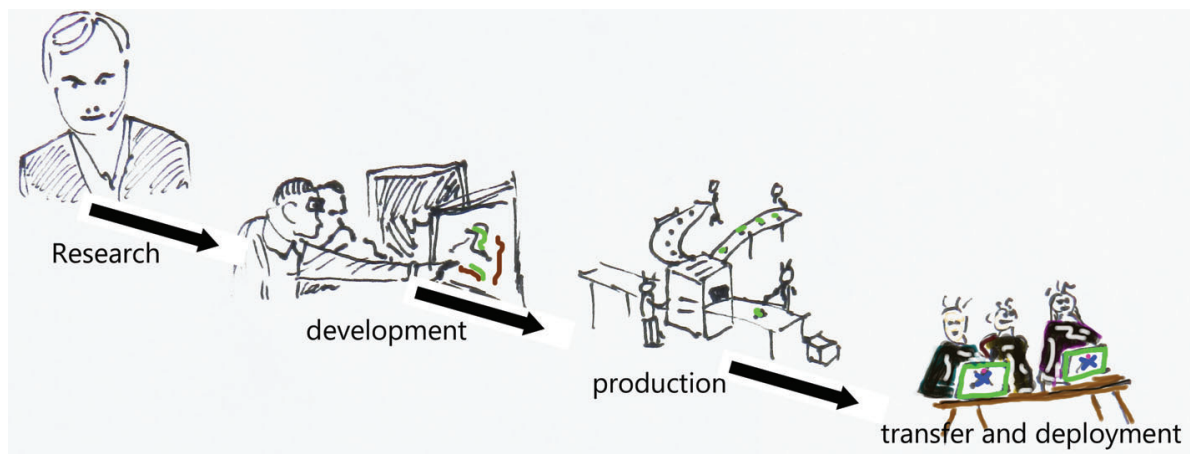

Figure 6: A conceptualization of the linear model of innovation, which was used in the development and roll out of the OLPC.

\subsubsection{OLPC and user participation}

Notwithstanding the claim of the OLPC organization that the XO laptop was developed to fit 'the developing context', with its rugged, robust hardware, its low energy consumption and its bright green colors to prevent it from theft, the whole idea including hardware, software and educational concept - had been developed in the Global North. The XO was invented, designed and produced at large-scale, and subsequently rolled out in developing regions.

The implementation of the OLPC project follows the "classical" linear model of innovation, which has been described by economists such as Schumpeter (1911), Ryan and Gross (1943,1950), Usher (1954) and Maclaurin [371, 359, 358, 404, 164]. According to this model innovation is a "linear", one-way process, consisting of several steps. First there is an idea by an inventor or expert. This is followed by a phase of research and development. Then comes production, deployment, marketing, and finally diffusion and adoption by users (see Figure 6).

This model of innovation is nowadays considered outdated [234, 235, 233, 163]. Many recent studies have presented alternative models, in which innovation consists of a nonlinear, networked process of social change, characterized by iterative cycles of communication, learning, and feedback [368, 150, 402, 415, 338, 280].

The OLPC's XO laptop was implemented as a large-scale transfer of technology without participation of real users in the formulation of goals and objectives and without user-centered requirements analysis. It was designed according to assumptions that were not validated by local users. The OLPC project is a typical example of a top-down, linear intervention. This example illustrates the tendency in development cooperation to scale up technological solutions without the notion of adaptation to specific contexts, or user-centered design and innovation. 


\subsection{ISSUES OF CONTEXT}

The introduction of computers and the Internet in poor regions is often thought to improve people's access to information. Yet, the following cases show a mismatch between the transferred technologies and the local context.

\subsubsection{Telecenter projects: rolling out ICTs in poor environments}

Rural poverty is commonly associated with a lack of information: e.g. on markets, customers and prices, agriculture practices, inputs, best practices and opportunities for microfinance. To improve information access for poor rural communities, $\mathrm{ICT}_{4} \mathrm{D}$ is often proposed (e.g. [194, 361, 197]).

To connect the rural poor, community telecenters have been rolled out in many developing regions, since the 1990s [194]. Examples of telecenter projects are e.g. Bario ${ }^{14}$ in Sarawak, OMAK ICTs for the empowerment of indigenous women in Bolivia ${ }^{15}$, Timbuktu Multi-Purpose Community Telecenter Mali ${ }^{16}$, and Gyandoot ${ }^{17}$ in India.

Telecenters are physical service centers that provide facilities such as email, web browsing, office applications and printing, to local communities. Telecenters are extensively described in development literature, as for example: "... a mechanism which uses ICT to support a community's economic, social and educational development, reduce isolation, bridging the digital divide, promoting health issue and empower women" [12]; or "[telecenters] give rural communities an opportunity to adapt to new technologies and use those technologies to suit their real needs." [93].

Telecenters are typically equipped with personal computers and Internet connectivity. Sometimes fax, radio, television and telephony are part of the equipment. Some telecenters provide training in the use of mainstream computer applications and computer use [189]. Telecenters are commonly financed or subsidized by governments, development donors or through private funds, in contrast to Internet cafes, which are commercial service centers, located in urban areas [12, 189, 161].

In Rwanda, the national government launched a program in 2005 to establish telecenters all over the country as an intervention to improve conditions in rural areas. Up to $90 \%$ of the population in Rwanda consists of rural dwellers, living from subsistence farming [381]. The estimated adult literacy rate in Rwanda is 65 percent. ${ }^{18}$ However, in rural regions literacy is estimated to be not more than $50 \%$ [300]. About $70-90 \%$ of the population speaks only Kinyarwanda language [362].

\footnotetext{
14 Source: http://WWw. ebario.org/ebario-telecentre.html, (accessed o8-10-2020)

15 Source: http://www.bridge.ids.ac.uk/global - resources/resource/A52945, (accessed o8-10-2020)

16 Source: https://tinyurl. com/k72r85q, (accessed o8-10-2020)

17 Source: http://www.dhar.nic.in/gyandoot.htm, (accessed o8-10-2020)

18 Source: http://Www. unicef.org/infobycountry/rwanda_statistics.html, (accessed o8-10-2020)
} 
The telecenter project was part of a technology-oriented policy by the government of Rwanda, in which one billion US dollar was invested in ICT and technological innovation for the reconstruction of society through rapid socio-economic development, in the aftermath of the war of 1994, in which one million people were killed and all basic infrastructure of the country was destroyed [64].

Between 2006 and 2012 thirty government rural telecenters were installed all over the country. An extensive research of the telecenters of Rwanda was done by Seth Buhigiro in 2012. He visited the rural regions and wrote a case study about community telecenters in rural regions of Rwanda, including the Gicumbi, Rulindo, Nyabihu, Kayonza, and Huye telecenters.

Seth Buhigiro reported positive findings from his evaluations, mentioning that telecenters provide Internet access to people who were previously deprived of ICTs. The major constraint to the use of telecenters is the widespread illiteracy of the rural population, and the variety of local languages spoken by the majority in rural areas. Also, the relatively high cost of telecenter services is a barrier for the poorest people [64]. This shows how the main barriers to information access have remained for those who were considered the actual target group of the intervention.

As one of the interviewees in the rural telecenter remarked:

"... yeah, users have challenges such as language problem, most of the people here speak Kinyarwanda and French language, and yet to use Internet and learn computer programs the user must have basic knowledge of English. Secondly adult people are not skilled with computers and they find it difficult in adopting to the use of ICTs such as Internet, and other administrative services such as word processing, excel, and powerpoint to assist them in their day to day activities. Thirdly, telecenter cost of charge to some services such as Internet, scanning, and fax is a challenge to some of the users especially those who are unemployed and local farmers..."[64].

A staff member of another rural telecenter in Rwanda expressed the following concern:

"... this is a rural area, most of people are not educated, they do not know how to read and write and using telecenter is a challenge to them. Language is another issue for those who cannot read and write; the majority speaks Kinyarwanda and some speak French and yet the content is in English. This has been the major challenge to the user point of view..."[64].

\subsubsection{Maji Matone: SMS text-messages to improve water quality}

Lack of understanding of the local context is an important risk factor for mismatches between proposed technology and context. One case has been reported from a threeyear project in Tanzania, the Maji Matone project ${ }^{19}$ which started in 2009. ${ }^{20}$ This project

19 Source: http: //www. daraja.org/our-work/rtwp, (accessed o8-10-2020)

20 Source: http://transparency.globalvoicesonline.org/project/maji-matone, (accessed o8-10-2020) 
aimed to improve the quality of water for the benefit of rural communities in Tanzania. In the course of this project, people from local communities were requested to send feedback to the project organization, on the state of drinking water. They should do this using SMS text-messages. These data would be processed and used to inform the local government about the water quality.

Although the project implementers expected that 3000 SMS text-messages would be sent out by the community members, only 53 were issued. Two reasons were identified for the lack of success. Firstly, the project designers had not considered the poor mobile coverage in the region. Secondly, water collection turned out to be a task of women and children, who did not own a mobile phone, and so could not report the requested information to the project data store. ${ }^{21}$

A proper needs assessment and context analysis before the start of the project might have revealed the mismatch at a much earlier stage. A flexible project structure or attitude might have led to adaptation of the planned activities during project execution. Involvement of local villagers in the project design would have led to a different project design, or even to alternative objectives, but would certainly have prevented the poor result.

Adaptation is a concept in software engineering [69]. This example shows that this concept is apparently uncommon in mainstream $\mathrm{ICT}_{4} \mathrm{D}$ approaches.

\subsubsection{Mismatch between technology, needs and context}

Mismatch between the assumptions made by the project design and actual local needs and context is a recurrent problem of ICT4D projects (e.g. [100, 27, 177, 400, 7, 263]). As illustrated by the case of telecenters in Rwanda and by the water project in Tanzania, user needs and requirements were probably not properly collected before deployment. This may have resulted in solutions that are not meaningful, deployed technologies that do not fit the local infrastructure, or systems that are useless because of issues related to language or illiteracy. The total cost of ownership of the technologies may be too high, making the project financially unfeasible after donor-funding ends [229]. Sometimes the introduction of technologies lead to unequal benefits, in which some stakeholders become disadvantaged as the result of the intervention [413].

Pressed by the urgency to scale up and achieve measurable results within the project period, development agencies and donors often favor "one-size fits all" solutions, not based on a proper context analysis and without adaptation to specific contextual conditions. This can be observed in e.g. the OLPC, Maji Matone and Rwanda telecenter projects.

Remarkably, many practitioners in development and $\mathrm{ICT}_{4} \mathrm{D}$ uncritically overlook this rather biased and narrow view on development which is expressed by the interventionist approach. A reason for this bias may be the fact that - at least for the

21 Source: http://tinyurl.com/vulnerability-poverty, (accessed o8-10-2020) 
implementing agency - the project donor represents the "customer", i.e. the organization that funds and sets the project objectives. "Customer satisfaction" in the case of donor-funded $\mathrm{ICT}_{4} \mathrm{D}$ equals "donor satisfaction". This makes the implementing agency less inclined to carefully listen to the end-users or try to satisfy their specific needs.

\subsection{HOW ARE GOALS CONSTRUCTED?}

The above cases show that ICT4 $\mathrm{D}$ projects do not involve users in the process of innovation, and do not take contextual variations into account. But what about the definition of project goals? Are end-users and beneficiaries involved in the formulation of objectives that concern and affect their livelihoods?

In the following section the Millennium Villages Project (MVP) is discussed and assessed. This is a high-profile, multi-country development project that aims to demonstrate that rural poverty in sub-Saharan Africa can be solved through financial investment and massive introduction of technologies from the Global North $[363,360]$.

\subsubsection{Millennium Villages Project: an intervention to eliminate rural poverty}

The Millennium Villages Project ${ }^{22}$ was set up in 2005 by the Earth Institute, Columbia University in New York, the UNDP 23 , and a non-profit organization called Millennium Promise. ${ }^{2425}$ In line with the United Nations Millennium Development Goals (MDGs) ${ }^{26}$ 27 the MVP was presented as an initiative to lift development country villages out of a 'poverty-trap'. Its target groups were mainly subsistence farmers in sub-Saharan Africa, with a daily income of 1 or 2 US dollar per day. This included communities in various regions, ranging from rainforest margins to pastoralism on arid lands [363, 360]. This high-profile project, which was the idea of development economist Jeffrey Sachs, aimed to achieve quantifiable results within ten years.

MVP started implementation in a small village named Sauri, in Kenya, soon followed by a village in Ethiopia, named Koraro, in February 2005. In 2006 the MVP was extended to Ghana, Kenya, Malawi, Mali, Nigeria, Rwanda, Senegal, Tanzania, and Uganda, covering seventy-eight villages, and targeting a population of 500.000 people [363]. These regions were selected for having a high percentage of underweight chil-

22 Source: http://millenniumvillages.org (accessed 11-11-2017)

23 United Nations Development Programme http://undp.org (accessed 11-11-2017)

24 Source: http://millenniumvillages.org/millenniumpromise/(accessed 11-11-2017)

25 The complete http://millenniumvillages.org website has been removed in the period of writing this thesis. I have chosen to leave the broken links, testifying this prestigious project's silent end.

26 The global intention, ratified by all UN member states in 2000 to cut poverty, hunger, disease, gender inequality, environmental degradation, lack of access to safe drinking water and sanitation in the period of fifteen years.

27 Source: http://www. un.org/millenniumgoals/ (accessed 11-11-2017) 
dren [329]. Baseline studies and household surveys were carried out in each village. The population was categorized according to classes of relative wealth $[363,360]$.

To increase local agricultural yields the MVP supplied 'scientifically proven western agro-technologies' such as modified hybrid seeds and artificial fertilizers [363]. The inputs were subsidized by the project, as a replacement for traditional indigenous species which are commonly used. Local farmers received training how to apply the new technologies. Meanwhile, roads and power infrastructure were built, mobile telephony and Internet were installed and free anti-mosquito bed nets were provided to households. Educational and health services were implemented. The MVP provided microfinance loans to selected households [363]. These interventions were carried out in each of the selected regions [363].

The estimated project budget for the MVP was 500 million US dollar, for a period of ten years. An average of 110 US dollar was spent per beneficiary person, per year [360].

The MVP applied commercial marketing strategies to present the project to the general public, e.g. using endorsements from celebrities including Bono, Brad Pitt and Angelina Jolie, by merchandising articles e.g. Millennium T-shirts from Tommy Hilfiger $^{28}$, and by continuous use of social media, Facebook, Twitter, blogs, podcasts and videos.

\subsubsection{Millennium Villages Project's construction of goals and objectives}

The MVP is an intervention that wanted to bring about a particular change in a state of affairs. The actual state of affairs is formulated in terms of deficiencies: e.g. lack of technical expertise, lack of investment, lack of infrastructure, lack of knowledge.

After the needs identification the intervention is designed and planned. The intervention consists of a transfer of knowledge from a technical expert to a beneficiary group - referred to as capacity building - or transfer of technologies, goods or capital. Construction of new infrastructure is also part of the intervention [363].

The MVP describes the situation in the intervention area in terms of 'hunger, disease, gender inequality, environmental degradation, lack of access to safe drinking water and sanitation'. A sense of urgency is evoked, using terms as 'extreme poverty', 'extremely low productivity' and 'insufficient core infrastructure', and even a 'crisis in telecommunication' [363].

Sanchez et al. describe the MVP as a research project, in which the central hypothesis [363] is that 'poverty' in Africa results from lack of 'productive capital'. In the MVP's rationale, the so-called 'poverty trap' can only be overcome through financial investments that augment the capital stock of households and communities in rural Africa. The MVP project wants to demonstrate that investments at the level of 110 US dollar

28 Source: http://millenniumvillages.org/field-notes/tommy-hilfiger-shirts-are-a-hit/ (accessed o8-10-2020) 
per capita per year, over the period of 5 to 10 years, will lead to an escape from the so-called 'poverty trap' [363].

But is this hypothesis-based research design of MVP flexible enough to allow adaptation of plans, in case new insights are obtained, during the project period? Suppose, for example, that the proposed investment-model proves to be harmful for certain groups of farmers? Suppose that zero-investment solutions would appear more successful for the farmers in the millennium villages, will the project give space for a communitybased decision to refuse the artificial fertilizers and hybrid seeds which are supplied by the MVP, in favor of a locally produced, inexpensive innovation? Will the MVP's research set up be revised and altered in this case?

The MVP claimed to be 'community-based', applying a 'participatory approach to planning, implementation and monitoring' that 'contextualizes the specific set of interventions for each village' [363]. However, its strategy was externally defined, as stated in MVP's main principles and strategy: "Where adverse cross-sector tradeoffs are possible, there must be guidelines, incentives, or disincentives to minimize them" [363] p.16776.

The design and approach ${ }^{29}$ of the Millennium Village Project reveal the assumptions that underlie this large-scale intervention: change is supposed to be brought about by an external entity (in casu an American development agency). It can be implemented in a limited time span (of ten years) and will yield a measurable difference. Actions can be applied anywhere, despite the different contexts.

Despite rhetoric about "participation", MVP did not consider local agency. As illustrated by its project design, the intervention and transfer of technology were determined and decided upon by outsiders. The beneficiaries, the subjects of the development interventions did not play an active role in the project life cycle. They were considered passive recipients, not included in the formulation of goals and objectives or in project design. This example shows the tendency in international development to rapidly scale up technological solutions without adaptation to context or user-involvement in decision-making.

\subsection{THEORETICAL FRAMEWORK: NETWORK COMPLEXITY}

The "linear" conceptualization of cause and effect - in contrast to a networked, systemic approach to change - as illustrated in the above examples of $\mathrm{ICT}_{4} \mathrm{D}$ projects is central to what I framed, in this thesis, as interventionist logic. This logic holds various assumptions, quoting Preston [325] "(i) the supposition that there is 'something' to be acted upon (ii) the expectation that 'it' will respond in a predictable fashion (iii) the idea that intervention can be accomplished, according to a clear set of expectations", i.e. not accidentally, but intentionally, according to externally defined goals. But, is it likely that 'it' - in a complex,

29 Bill \& Melinda Gates Foundation and Rockefeller Foundation also support this approach, see e.g. http: //tinyurl.com/GreenRevolution-Bill-Melinda (accessed 11-11-2017). 
real world context such as for example rural Africa - will respond in a controlled and predictable way?

\subsubsection{Linear methods in international development}

Interventionist logic is rooted in international development, as can be observed in the project management methods that are prescribed and used. An example is the logical framework approach (LFA), a widely used project management method in international development [214, 13]. The logical framework approach was developed in 1969 by American development agency USAID, as an instrument to design and evaluate development projects. It has strong influences from business and the military. Since 1997 the World Bank and many other organizations have adopted it as the standard tool for project appraisal [354]. Presently, all European Union assistance is planned through the LFA approach.

The logical framework approach is a cause and effect model, based on a set of interlocking concepts and hypotheses. It assumes that development projects are instruments of change, which have been selected by the donor agency as the best and most cost effective action to achieve a desired, beneficial result [354]. The framework allows the donor to control the project, by monitoring and evaluating it according to a stepwise, linear method [226]. The core of the logical framework is its 'temporal logic model' in a series of connected propositions [354]. These propositions are set in a table - the logframe - which summarizes a development project. ${ }^{30}$

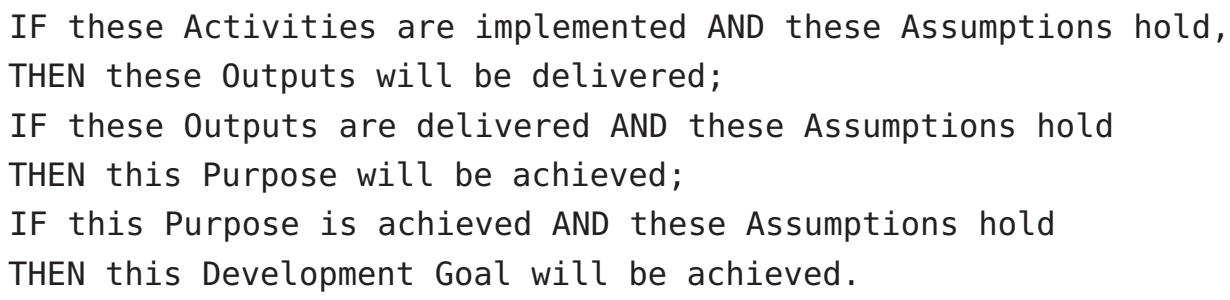

The framework breaks a project down into four levels of objectives: activities, outputs, purposes and goals. Activities of a project will result in outputs; several outputs are combined into achieving the project purpose; at a higher level, there is the goal. As such, the logical framework approach covers the entire project management lifecycle from design to project implementation and monitoring \& evaluation.

The specification of purposes to achieve the goal, is the task of the program manager, who operates at the donor agents' hierarchical level..$^{31}$ Specification of outputs to achieve purpose is normally done at the implementation level, by a project manager. 
The LFA focuses on clarity and detail. It is closely linked to a budgeting framework. This makes it attractive for development donors as a management tool for development projects and grant-making. ${ }^{32}$

Another project management framework with similarities with the LFA has been introduced in the 1990s in international development: the so-called "theory of change" (ToC) [159]. Similar to the logical framework approach, the theory of change describes a set of assumptions that explain the steps that lead (linearly) from problem to development goal. The ToC framework maps the connections between activities and outcomes, to a planned intervention [390]. The theory of change is a planning tool, which uses so-called "backwards mapping", a way of defining change as a long-term goal, and of identifying the intermediate and early-term changes which are required to cause this desired change. Through a paper-based (desktop) exercise a set of connected outcomes is created. This is known as the pathway of change. 33

The theory of change is increasingly used in international development project proposals, as prescribed by donors and development agencies [390]. It is also based on the linear ideas in which change is a direct, proportional, additive and predictable result of (development) interventions, following a cause - effect logic. Similarity between LFA and ToC is the emphasis on project management and impact evaluation (see also: $[13,10,226])$. Despite claims of flexibility, these frameworks confine and structure a project into a linear process, in which each step leads to a predictable outcome. Success or failure are determined by evaluating results against (externally defined) goals, with the use of preset performance indicators.

\subsubsection{Evaluating the effects of interventions}

Evaluations of international development projects follow the interventionist logic. Evaluations are carried out after (post-hoc) implementation, with respect to a "static" baseline, that pre-existed the intervention or action. Donor-funded development projects demand evaluations, in the first place, for accountability reasons, to assess whether an intervention is effective, how it contributes to change, and if not, what should be improved and what are the lessons learned. Moreover, evidence is required to make sure that project funds have been well spent.

As "change" is thought to be brought about by the intervention, evidence is demanded, to which degree the change can be attributed to the intervention. According to an evaluation expert at the World Bank, Paul Gertler: "focus on attribution is the hallmark of impact evaluation" [159].

32 Basic Introduction to Project Cycle Management Using the Logical Framework Approach: http://www. eeas. europa.eu/archives/delegations/ethiopia/documents/eu_ethiopia/ressources/ pcm_manual_en.pdf, (accessed o8-10-2020)

33 Source: http://www. theoryofchange.org/ (accessed o8-10-2020) 
Evaluation studies of $\mathrm{ICT}_{4} \mathrm{D}$ can be qualitative, quantitative or a mix of these two flavors [374, 349]. Qualitative and mixed evaluation studies are often field-based (e.g. $[238,271,285])$. There is a large body of ethnographic studies that assess the impact of new technologies on people and society in developing contexts (e.g. [107, 82, 232, 161]). Another category of evaluation studies consists of qualitative desk research studies that evaluate $\mathrm{ICT}_{4} \mathrm{D}$ at a high conceptual level. These desk studies extract general trends from $\mathrm{ICT}_{4} \mathrm{D}$ deployments and provide sustainability frameworks to inform policy makers (e.g. [194, 199, 196, 263, 167, 101]). In general, these desk studies do not provide relevant guidance for on-the-ground improvements of $\mathrm{ICT}_{4} \mathrm{D}$.

Quantitative studies, which produce "hard figures" are the preferred methods for evidence-based policy-making in international development [159]. They are considered more convincing to policy makers and the general public than results of qualitative studies [349]. Various quantitative impact evaluation methods including randomized control trials (RCT), regression discontinuity approach [408], propensity scores [353] and various other (quantitative) methods are used [159]. These quantitative evaluation methods focus on (linear) causal inferences by calculating which percentage of the observed change is due to the intervention in question. These evaluation methods, however, do not answer the question how the observed change occurred, and what can be learned from the process [92].

An example of a quantitative evaluation method which is frequently used in international development, is the randomized control trial (RCT) (see also [308, 331]). Randomized control trials to assess the effects of a treatment are common in medical sciences and experimental psychology (e.g. [220, 308]).

The idea of this evaluation method is as such: an intervention A on a given development situation $\mathrm{X}$ causes outcome $\mathrm{B}$. There are two control groups in situation $\mathrm{Y}$ and $\mathrm{Z}$, which are assumed to have identical or at least comparable conditions as situation $X$, but are not receiving treatment by intervention A. After intervention A is finished, the measured performance indicators from groups $\mathrm{X}, \mathrm{Y}$ and $\mathrm{Z}$ are quantitatively measured, and statistically evaluated. If the perceived differences between the indicators of $X, Y$, $Z$ are found to be significant, the difference is attributed to intervention A. Groups $X, Y$ and $\mathrm{Z}$ are "randomized", and kept separated, to avoid "contamination" of the data. This hypothesis-based approach to impact evaluation is based on the cause-effect logic. It is useful in trials in which the groups can be controlled. It requires full consent of the participating subjects, who are aware of being used in a trial.

In international development randomized control trials are questionable, for various reasons. Robert Chambers questions the use of randomized control trials (which he calls "reductionist rigor" [78]) in development experience and practice, where:

"... receiving environments are diverse, controls liable to contamination, measurements difficult, causality multiple or intertwined and problems messy, wicked and not amenable to obvious or straightforward solutions. In short, what is rigor for learning about complexity? [78]" 
A point against randomized control trials in "real world" evaluations is made by Ray Pawson. In his book Evidence-Based Policy (2006), Pawson points at the limitations of simple causal inferences in real world contexts, where many different, interdependent variables may be at play. Pawson shows how randomized control trials lack explanation power, on how interventions work in real situations. [308].

Colin Robson, in his book Small-scale evaluation (2017) [349], points at the ethical aspects of randomized control trials, e.g. by denying (prohibiting) a certain group of people (the so-called control group) the use of a promising technology or innovation, to avoid "contamination" of the study groups.

An ethical argument against the use of randomized control trials in international development assessments is that RTC aim, in the first place, at attributing the observed change to the given (externally induced) development intervention. This implies that activities (e.g. local agency) that may have contributed to the observed betterment are not considered in the evaluations (as shown in the example of the Millennium Villages Project).

In short, post-hoc evaluations are based on the idea that an intervention produces a predictable, observable change that can be attributed to the action. Quantitative methods are aimed at attributing the observed change to the intervention, but do not provide guidance to improve the project during its lifetime.

Qualitative, field-based evaluation methods such as case studies, (by some researchers labeled as "anecdotic" (e.g. [194, 92, 159]), process evaluation [349], mixed methods, participatory evaluation methods including adaptive iteration, triangulation, plural perspectives, field visits and many other eclectic methods (of inclusive rigor according to Chambers (2015) [78]) can give deeper insight in complexity of (interdependent) contextual factors, in the underlying mechanisms of the change processes, especially when performed during project execution, and not post-hoc [350, 78].

\subsubsection{Linear models in ICT in the Global North}

Interventionist methods are not restricted to international development. They are also known from e.g. healthcare, education, military warfare, organizational management and ICT [355, 16, 331].

In the 1960s and 1970s, a linear, top-down method, named the waterfall model with large similarities with the logical framework approach - was widely used in the ICT (business and industrial) sector in the Global North. The waterfall model was used in software development to centrally manage, plan and control large-scale ICT projects $[355,215]$. According to the waterfall model, software development consists of a series of sequential stages: (i) a plan is made, (ii) requirements are agreed upon, (iii) a design is created, and code is written accordingly; when coding (i.e. implementation) is finished, (iv) the software is tested and verified against the pre-set requirements and 


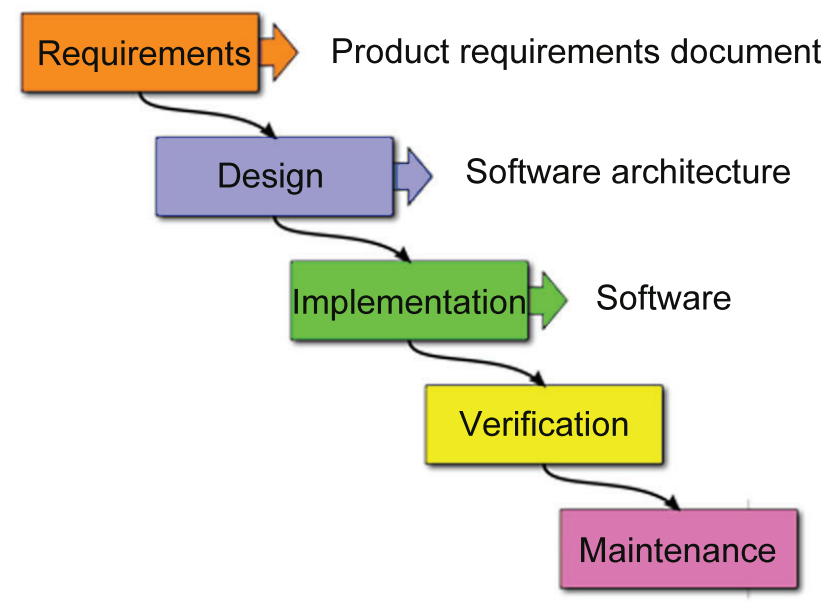

Figure 7: Conceptual diagram of the linear, waterfall model, consisting of five phases of software development. Adapted after a diagram by Peter Kemp and Paul Smith, source: https://en.wikipedia.org/wiki/Waterfall_model, (accessed o8-10-2020)

design, (v) the system is rolled out, and maintenance can start [247]. These steps can be visualized as a waterfall, see Figure 7 .

The waterfall model is orderly and looks logical and sound. It has shown to work well in the (special) case of standard, predictable software development projects, in which user needs and requirements are fully known at the start of the project [245]. As this condition (of full understanding of requirements) is seldom the case, certainly not in innovative projects, in complex contexts or in large software development projects where built-in flexibility and adaptability are required, the waterfall model turns out unsuccessful [310]. Flexibility and adaptability are fundamentally absent in linear models such as the waterfall model.

The waterfall model has been held responsible for high rates of failure in large ICT projects and software developments. Various studies showed that 80 to 85 percent of ICT project failures are due to incorrect or changing requirements or lack of user involvement $[248,254]$.

In $\mathrm{ICT}_{4} \mathrm{D}$ policy and programs "linear" (waterfall-type) approaches are still common (as illustrated by projects such as the OLPC and the MVP). Various ICT4D studies propose "linear" models. An example of a step-wise model for $\mathrm{ICT}_{4} \mathrm{D}$ that describes a linear path from strategy to implementation, to adoption/use/sustainability/scalability and impact, is the "ICT4D value chain", [194, 199, 197]. In this linear model, that aims to inform development policymakers, the "exogeneous factors" (what I would refer to as the contextual factors), are positioned (conceptually) in the latest stages of the chain, between the phases of outcomes and impact (see [199]). Since context analysis is not positioned in the design phase of this model, this model implies that the tech- 
nologies are invented elsewhere, without concerns for contextual complexities on the ground and then transferred to the developing region.

Nowadays, in various domains adaptive methods and strategies for coping with complexity, dynamic contexts and uncertainty, have been introduced. For example, in software engineering and technological innovation agile methods have emerged as a reaction to plan-based methods and rationalized, engineering-based approaches that were dominant, especially in the 1960s and 1970s in large-scale software development projects [124, 248]. Agile methods address the complexity and unpredictability of the real world. Whereas the linear approaches focus on purposive planning and action, "adaptive" or "interpretive" understandings such as agile methods recognize the need for continuous reconfiguration and realignment to ever changing environments [278].

\subsubsection{Linearity versus complexity}

The point that linear frameworks are inappropriate to deal with the complexity of "how the world works", is already made in various studies, although not specifically for ICT4D [331, 16, 242, 74]. For example, Robert Chambers (2010), in his book Paradigms, Poverty and Adaptive Pluralism [74] shows the inappropriateness of blueprints and planning, pre-set and closed goals, centralized decision making, reductionist analytical assumptions, and standardized universal methods and rules, which are commonly applied in rural development. Chambers attributes widespread failure in development projects to the dominance of the so-called 'things paradigm', a way of imposing standardized methods on uncontrollable and unpredictable conditions of real-world contexts and people. Chambers proposes to introduce system's thinking and a peoplecentered approach, and ensuing bottom-up processes and participatory actions, in international (rural) development [74].

Studies in complexity research, over the past decades, have focused on the structure and behavior of nonlinear systems as they are observed in social, biological, physical, chemical, ecological and other contexts ( e.g. [327, 158, 210, 273, 239, 241]). These are called complex systems or complex adaptive systems, in which "adaptive" refers to the fact that these systems are exposed to external influences, dynamic, and adaptive to change [211]. Complex systems do not follow blueprints, but evolve over time [327, 328]. Small changes in a complex system can result in disproportionately large effects $[327,16,210,251,250,240])$.

Complex (adaptive) systems exist at various scales of magnitude and are characterized by large numbers of interacting components or "agents": people, bacteria, ants, molecules, organisms, cells, etc. depending on which type of system. Agents interact and exchange information according to simple rules, but without a central controlling mechanism [210]. Agents display a form of organizational learning in which selection and re-invention lead to new rules and emerging characteristics [273, 239]. Self- 
organization, localized interactions of agents and feedback loops that create higherlevel emerging patterns are characteristic for complex systems [327, 328, 239, 211].

A complex adaptive system is able to adapt itself dynamically to changing environmental conditions [210]. Whereas cause \& effect relationships in linear systems are smooth and proportionate (which makes them measurable and predictable [227]), this is not the case in complex adaptive systems. Anticipating, designing and planning the behavior of these systems, have shown not to work [16]. This does not mean that complex adaptive systems are totally unpredictable and unmanageable. According to complexity researcher Bar-Yam there are no "best practices" to tackle complexity. Each situation requires a different solution. Distributed/networked organizations are best equipped to solve problems in complex adaptive systems [16].

Developing regions can be conceptualized as complex adaptive systems. They are dynamically governed by factors (variables) which interact at various scales: the global scale (e.g. climate, economy), the national scale (e.g. politics, legislation, economy), the local scale (the environment, social networks), the human scale (livelihoods, households, people) $[111,377,332]$.

Developing regions, for example in rural Mali, consist of interacting agents: people in their social networks, acting at various scales. There is a high level of heterogeneity in people's behaviour. A central coordination of human behavior is absent. The rural environment is dynamic, open and constantly changing and adapting to new conditions under internal and external influences. Emerging patterns, which result from the aggregated behavior at lower levels, can be observed in landscapes, agriculture, communities, urbanizations, culture, language, economy, politics, infrastructure, social networks etc. Development interventions that target one of the many factors or, more specifically an ICT deployment in such a complex context, need careful consideration to avoid unexpected and unintended side-effects.

\subsection{DIFFUSION OF INNOVATIONS}

As agents in a complex adaptive system, people interact, build relationships, exchange knowledge through strong or weak links [174], in social networks that evolve over time. The aggregation of all human agency leads to emerging patterns and larger-scale phenomena, which we can observe in the world around us [328, 211, 16, 275, 273].

One of the observable phenomena in social networks is diffusion of innovations. This is a process in which an innovation is communicated through certain channels over time among the members of a social system or network [350]. In recent studies large similarities have been observed between complex adaptive systems, social networks $[275,273]$ and diffusion of innovation models [351, 96].

The term "innovation" can mean various things: it may refer to a technology or artefact, but also to an idea or practice. Innovations are adapted, reinvented and adopted, while they propagate through the social networks. Diffusion of innovations occurs over 
time according to an S-shaped rate of adoption curve [350]. Diffusion of innovations is a general process, i.e. not bound by the type of innovation, who the adopters are, or by place or culture ([350], p. xvi). The rate of adoption changes over time, which classifies the adopter in the following adopter categories: innovators, early adopters, early majority, late majority, laggards [350]. The "critical mass", is the point in time, during diffusion, after which the process becomes autonomous and self-sustaining [350, 14].

Diffusion of innovations is a major discipline in the field of behavior research. Diffusion of innovation studies took off in the 1940s-1950s, first as a branch discipline of rural sociology. This was commissioned by the US government as to obtain more knowledge on the process of diffusion and adoption, to improve the (then highly centralized) national extension services for agriculture, that aimed to make farmers adopt newly invented agricultural practices and technologies [359, 358]. For decades the classical, linear model for diffusion of innovations was the dominant model amongst researchers, policy makers and change agencies ([350] p. 394). Studies were aimed at understanding how adoption works, and how this can be improved, scaled up and made more efficient. In the course of the years, new insights have emerged on the process of innovation and its diffusion. Innovation research has expanded to other domains including technology, public health, education, international development, business, media, entertainment. The similarities between the diffusion of innovations model as an open, evolutionary, nonlinear system, and complex adaptive systems have been identified [351].

A breakthrough in innovation research was marked by the advent of the World Wide Web in the early 1990s. Internet and Web have not only changed the nature of the diffusion process itself, but have also brought new insights in this field of research. Nowadays much is understood about the properties of decentralized innovation. This is the process in which innovations bubble up somewhere and spread horizontally via peer networks with a high degree of reinvention, as the technology or artefact is modified to fit the particular conditions of the users ([350], p. xviii).

Innovation research is relevant for $\mathrm{ICT}_{4} \mathrm{D}$, as it provides insight in the process of adoption, users, and information-sharing processes. In diffusion of innovation a number of variables are at play: the properties of the innovation or technology itself, the social networks where it is diffused, the characteristics of the adopter categories, and the way how information is spread and shared over the members of a social network [350]. This has to be taken into consideration, when developing, building, testing, evaluating technologies for users in low resource environments.

In the latest edition of his book Diffusion of Innovations (2003), the late innovation researcher Everett Rogers compared decentralized diffusion with highly centralized, top-down interventions. He perceived that decentralized systems are more likely to fit users' needs and problems, as users feel a sense of control when they participate in making key decisions, for example: which of the perceived problems most need attention, which innovations meet their needs, how to seek information and from which 


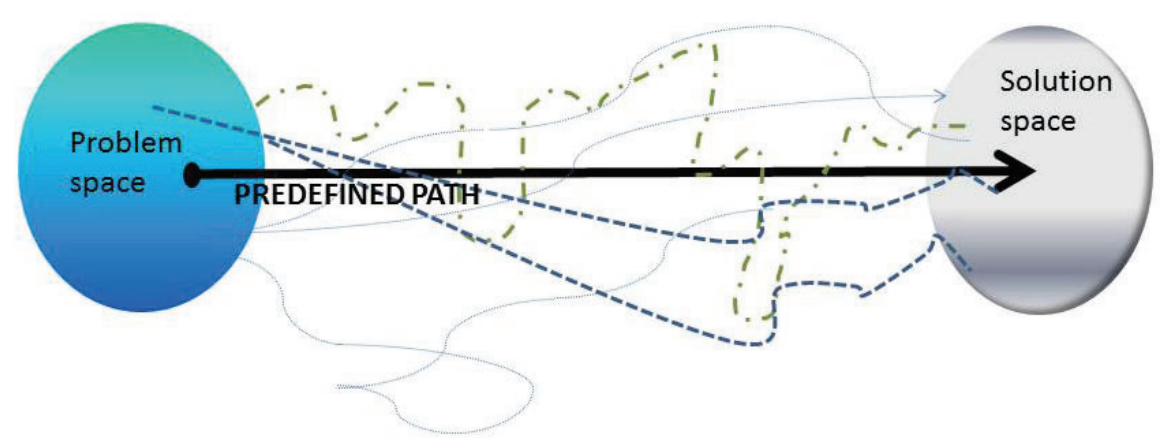

Figure 8: A conceptualization of many possible alternative paths between problem space and solution space.

sources, ([350], p. 398). These observations hold important lessons for $\mathrm{ICT}_{4} \mathrm{D}$ developers and policy makers, when developing information services to "connect the unconnected" people.

\subsection{MULTIPLE PATHS TO INNOVATION}

As shown in the previous sections, the logics of interventionism is built on a causeeffect model in which an intervention has a clear and measurable effect. The interventionist approach, the linear project management methods and the cause-effect evaluation models used in $\mathrm{ICT}_{4} \mathrm{D}$ all have in common that they confine the solution space to one single point, which must be reached, following a predefined path from problem to solution. This holds the (ungrounded) assumption that there is a complete understanding (by the implementers) of the end-users' problem, at the start of the action.

In contrast, adaptive approaches are based on a different world view. They can be conceptualized as follows: given a certain (real world) problem there is a solution space which can be explored. A large number of possible paths from a problem to an acceptable solution may exist. Since the outcome of an innovation is not known beforehand, its trajectory cannot be predicted. An innovation process typically consists of exploration, iterative loops of action, testing, adjustment and re-invention until finally an acceptable solution is found.

A simple problem-solution model is shown in Figure 8, showing multiple paths. The straight line represents the $\mathrm{ICT}_{4} \mathrm{D}$ action, predefined from start to end as described and prescribed by the logical framework approach, using predefined performance indicators to monitor, measure and evaluate result. This approach does not consider that the solution space may be wider, but not fully known at the start of the action. It also does not allow deviations from the path when new information becomes available and new knowledge is generated during the time frame of the action/project. The dot- 


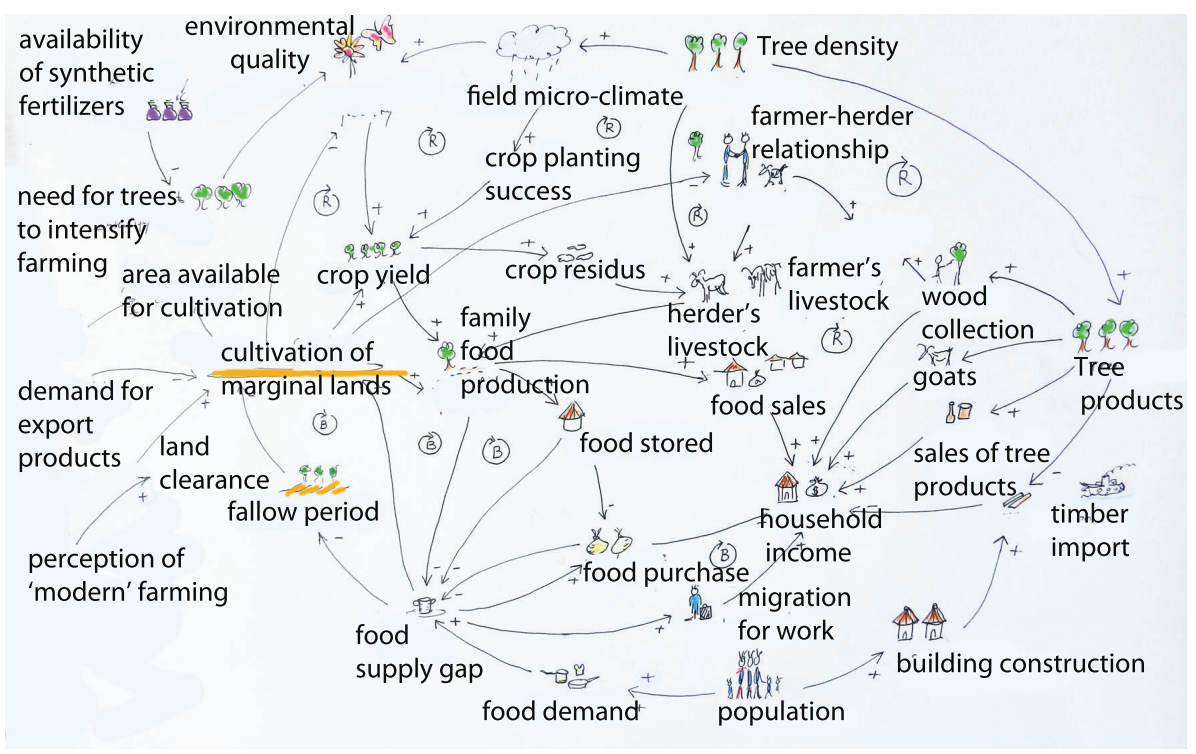

Figure 9: Conceptual model of complex interactions in the Sahel. Variables are influenced and influencing, which leads to complex feedback loops of interactions. If a causal loop sustains the direction of change it is labeled $\mathrm{R}$ (reinforcing). If it reverses the direction of change, it is labeled B (balancing). Adapted after a model by Sendzimir, Reij \& Magnuszewski (2011) "Rebuilding Resilience in the Sahel: Regreening in the Maradi and Zinder Regions of Niger" Ecology and Society 16 (3): 1, Fig. 6. [377].

ted, curved and curled lines represent iterations and alternative solutions which are based on iterative adjustment to new situations and progressive understanding, possible feedback loops or improved solutions. In contrast with linear models of innovation and transfer of technology, the adaptive model is built on the idea that innovation is an evolutionary path which is iteratively adapting to users' requirements and changing contexts. This reflection on linearity and complexity gives an idea about the limitations of interventionist projects.

Linear cause-effect models have been criticized for being inadequate in real world research, for example, by Orlando Fals Borda who did participatory action research with poor farmers in rural areas of Colombia [136].

An illustration of the shortcomings of linear cause-effect models in the complex context of rural West Africa is given in a study by Sendzimir et al. (2011) [377] on the root causes for change in land-use in the Sahel. ${ }^{34}$ For this study a system approach was used, based on data from different sources: long-term rainfall indices, trends on population growth, historical facts on droughts, famines, locust outbreaks, political trends since colonial times. Recent remote sensing data were compared with historical data to assess differences and trends in tree density [377]. This study demonstrates how many interconnected chains of causalities result in emerging webs of interactions [377]. A

34 The Sahel is the region where our $\mathrm{ICT}_{4} \mathrm{D}$ field research took place. 
causal-loop diagram in Figure 9 visualizes the multiple interacting factors. The conclusion of this interdisciplinary system analysis is that, in this context, interrelationships between ecological, economic and socio-political variables exist, which are both cause and effect, through complex (causal) feedback loops. In impact evaluation studies with a more limited scope, (e.g. evaluating one variable only) the observed change is explained as a single cause-effect chain, whereas, in the real world a whole network of variables is interacting and reinforcing or balancing effects.

This study by Sendzimir et al. shows that, even in a simplified model as Figure 9, with only a limited number of variables, many feedback loops are at work. In this networked configuration, a linear approach will not be adequate, as many unexpected effects may occur. To deal with the complexity of a development context such as, for example, the Sahel of West Africa, a systemic approach is needed, which is more capable to cope with the non-linear realities of the given context.

\subsection{SUMMARY}

In this chapter I have discussed a number of policy obstacles at the root of international development and $\mathrm{ICT}_{4} \mathrm{D}$ : the imposed operational frameworks for project and program management (linear waterfall model, logframe); the end-users or "beneficiaries", not treated as independent actors in their own right, with their own specific interests, contexts, values; a hegemonic discourse whereby interventions from outside are framed as the way of bringing about desirable change.

The term "intervention" is widely used in development circles, in policy, practice and research (e.g. [304, 83, 229]). Yet, the term evokes strong associations to medical curation, laboratory experimentation, and to imposing political or military power. This has deep implications for thinking about development. Intervention, therefore, is not an innocent concept. It is a fundamental concept that needs to be unpacked. In this chapter, I have shown some examples of $\mathrm{ICT}_{4} \mathrm{D}$ interventions.

Despite advances in complexity and innovation research, "linear" (waterfall-type) approaches are widely applied in international development projects. Linear, top-down project management methods, such as the logical framework approach (see section 2.5.1), which is prescribed to project implementers by donor agencies for reasons of transparency and control; methods for post-hoc evaluations used to compare the observed change with respect to a project baseline as to attribute the observed impact to the intervention in a linear cause-effect way without considering the unpredicted side effects: these are all characteristic of the interventionist approach. This critique applies to development in general, ergo, also to ICT in development. This is what I refer to as "conventional $\mathrm{ICT}_{4} \mathrm{D}$ ".

Complexity theory offers a theoretical lens to explain why $\mathrm{ICT}_{4} \mathrm{D}$ projects are inherently complex, why they easily fail, why simple recipes (such as linear intervention) do not work in most cases, and why alternative engineering and management methods 
are needed to deal with real-world contexts. I have introduced network complexity as a theoretical framework, in which $\mathrm{ICT}_{4} \mathrm{D}$ is conceptualized, not as a linear intervention, but as a networked process of sociotechnical innovation in complex dynamic contexts.

In contrast to the interventionist approach, a networked process of sociotechnical innovation, in which systems and services are developed according to goals and needs of users and their context, asks for a different approach than one based on a transfer of technologies and knowledge from the Global North. The approach must (i) be able to cope with dynamic contexts of high uncertainty and complexity, and (ii) be reflective and critical, based on deliberation, as to deal with social contexts in which knowledge is not value-free. In the next chapter a number of established methods and approaches are reviewed, from a variety of research traditions, which meet these two basic requirements. 

In this chapter I present a toolbox of existing methods, ideas and approaches, borrowed from various sources: some from ICT, software development or technology innovation, others from rural development practice and participatory action research. They are sources of inspiration for the present research, that seeks to design an operational approach to developing ICT systems and services, such that it (i) takes into consideration the complex realities of local context, and (ii) involves the envisaged users in decision-making and sociotechnical development. In Table 3 , at the end of this chapter, the methods are compared.

\subsection{COLLABORATION WITH USERS, ADAPTATION TO CONTEXTS}

In software development and technology innovation it is common practice to involve end-users in the process of developing technologies. End-user involvement has proven crucial for the generation of ideas and new solutions $[415,23]$. In e.g. the domains of industry, business, organizational management and ICT, many user-centered methods have been developed over the years. There are methods to structure and manage twoway information flows, or to bridge the gap between developers and users. There are methods that provide insight in local contexts [129]. In ICT4D programs and projects the creative capacity of end-users is still largely untapped. What can $\mathrm{ICT}_{4} \mathrm{D}$ learn from these methods, that are already widely used in (high-tech and low-tech) innovation? I will review a number of methods and approaches in the following sections.

\subsubsection{Living labs}

Living labs are spaces for technological innovation [23]. One of the definitions of living lab is "a user-centered research methodology for sensing, prototyping, validating and refining complex solutions in multiple and evolving real-life contexts" [129].

Initially, living labs were experimental environments, used to observe people (users) and their patterns of interactions, during the phases of design and evaluation of experimental, technology-rich homes and other smart real-life contexts [23]. ${ }^{1}$ Nowadays, living labs are spaces where the innovative capacity of end-users is used for co-creation of new products and services.

I The term living lab is used both for the methodology and for the environment where the experiment takes place [23]. 
Living labs are used in many different sectors, e.g. ICT-development, health care, rural development and industry. Each domain uses living labs in a specific way, adapted to the specific needs.

Firms and industries frequently use living labs in open innovation projects - often in consortia or communities of practice - including different types of stakeholders (e.g. industry, academics, government, civil society) [148]. The purpose of these collaborations is to learn from external ideas and increase the ability to innovate (e.g. [415, 23]).

Despite various types of implementation, the overarching characteristics of living labs are (i) engagement of users in innovation; (ii) methods to elicit and capture domain-based knowledge; (iii) elicitation of new meanings and understandings; (iv) methods for capturing tacit knowledge; (v) understanding of and validation of ecosystems [8]. All of these are relevant and useful for $\mathrm{ICT}_{4} \mathrm{D}$.

\subsubsection{Agile methods}

Adaptive methods and strategies for coping with complexity, dynamic contexts and uncertainty are used in various domains of (social and technical) innovation. In software development these are grouped under the umbrella of agile development methods. ${ }^{2}$

Agile methods have emerged as a reaction to plan-based methods and rationalized, engineering-based approaches that were dominant, especially in the 1960s and 1970s in large-scale software development projects [124, 248]. Agile methods, in contrast, address the complexity and unpredictability of the real world. Whereas the linear approaches focus on purposive planning and action, "adaptive" or "interpretive" understandings such as agile methods recognize the need for continuous reconfiguration and realignment to ever changing environments [278].

Agile methods - as the word agile suggests - are flexible, light-weight and adaptive. They avoid as much as possible bureaucracy and procedural tasks. As in other project management methods, social interaction, collaboration, co-ordination and communication are important elements. Communication in agile development is usually informal, face-to-face, predominantly verbal, and sometimes even tacit (e.g. observing users perform tasks, or giving demos) [379]. Agile methods recognize the value of people and their relationships [288].

Most characteristic for agile development methods are the short iterative cycles rapid building of prototypes and showing them to the envisaged users to collect their feedback for improvement. Solutions are designed, built and improved together with end-users [175, 343, 424]. Agile methods foster creativity and focus on quick responses to deal with dynamic environments and changing requirements [117].

Since agile methods have been applied in many different settings, no clear-cut definition can be given [117]. For some people "Agile" is a set of technical practices, for others a project management style, a philosophy, a set of collaboration practices that

2 See also: http://http://agilemanifesto.org/, (accessed o8-10-2020). 
cater for the needs of customers and end users, or even a set of principles and values of professional conduct. ${ }^{3}$ The following subsections give a few examples of agile-related methods.

\subsubsection{Non-hierarchical team work}

Agile software development is an inherently social endeavor in which team spirit and group work are important aspects. Teams are small (e.g. 5 - 10 people, depending on the type of task) and non-hierarchical. One practical method to organize teams such that they can tackle complex projects, according to agile principles, is the "scrum method" [346]. Scrum teams are self-organizing - not directed by managers or coordinators outside the team - and choose for themselves how they can accomplish the task. Scrum team members may have different/complementary skills, as to jointly accomplish a common task. Scrum teams are known for their flexibility, creativity and productivity. Tasks are carried out iteratively, in short feedback loops. Scrum was originally developed for software development projects, but is nowadays being used in different types of (complex) projects. ${ }^{4}$

\subsubsection{Prototyping}

Prototyping is a method used in information systems engineering, often in combination with agile development methods. It is a system development method that consists of construction and test of prototypes of systems, in collaboration with the prospective users [412]. Protopypes facilitate the elicitation of requirements, and are often used in the dialogue with the prospective users [127]. Prototyping involves designing and deploying artifacts for the purpose of learning about the artifact in its environment. Prototypes take different forms. The simplest is a mock-up prototype that shows the basic idea of an envisaged system [18]. The main function of a prototype is to exchange ideas about the design of an artefact with the users. Rapid prototyping is a form of prototyping in the presence of the user, in a workshop or hackathon. The advantage of rapid prototyping is to demonstrate to the users the flexibility of design and implementation, and the ability to improve a design based on user-feedback.

\subsubsection{Context analysis}

Context analysis is an inherent aspect of many methods of software development including agile software development and living labs [28]. Context knowledge about the end-users' environment is obtained e.g. by visiting the user in situ, e.g. by organizing so-called roadshows during which demos are given and prototypes of technologies are

3 From: Hakan Erdogmus' foreword in the book Agile Development Methods [117].

4 Source: https://www. scrum.org/resources/what-is-scrum (accessed o8-10-2020) 
shown. Roadshows may encourage brainstorming and improve elicitation of requirements and facilitate design. Roadshows often have a social aspect, in which developers and users, who often have different viewpoints or conflicting views on software's features and functionality [287] get to know each other and start to collaborate and exchange ideas in an informal way [379].

Despite the importance of context, the actual activity of doing a "context analysis" is not an explicit task in innovation methodologies (in contrast to e.g. use case and requirements analysis or user-centered design which are extensively described in software development and technology innovation literature (e.g. [23, 117, 248, 173, 172])). When developers and end-users do not share the same (cultural) background and are unfamiliar with each other's context, context analysis should be an explicit task.

\subsubsection{Use case and requirements analysis}

A "use case" is a formal description of the interaction between user and software system. Defining use cases and finding requirements is a central task in software development. Use case and requirements analysis is an inherently sociotechnical activity that requires collaboration between developers and users. This can be organized through co-creative workshops [259, 388].

Non-technical users find it often difficult to describe requirements for a technological solution. To overcome this problem, a variety of elicitation techniques have been developed, such as prototype demonstrations, story boards and non-formal modeling. These methods are used to encourage brainstorming, define requirements and validate the actual design together with the users $[248,173,172]$.

\subsubsection{The concept of "ba"}

From another domain of organizational management, the Japanese concept of $b a$ can be a useful framework for collaborative innovation projects. This concept, originally proposed by the Japanese philosopher Kitaro Nishida, [292, 293], can be translated as "place" or "space". It has been elaborated into a model for knowledge creation and knowledge management in organizations. According to this model, "knowledge" is embedded in a shared space, where relationships emerge. This space can be physical, virtual or mental. Nonaka and Konno describe ba as a "frame, made up by the borders of space and time, in which knowledge is activated as a resource for creativity". The inherent dynamics of knowledge as a social process is reflected in the idea that knowledge should be "nurtured, supported, enhanced and cared for" [293]. The concept of ba places emphasis on the social and communicative aspects of innovation and knowledge sharing, and on "meaning" in e.g. organizational culture. This could be a source of inspiration for a collaborative type of $\mathrm{ICT}_{4} \mathrm{D}$. 


\subsection{PARTICIPATORY PARADIGMS AND VALUE-DRIVEN RESEARCH}

If $\mathrm{ICT}_{4} \mathrm{D}$ wants to do justice to perceptions, values and interests of people who directly matter, i.e. the supposed beneficiaries, it must take a position in the debate about interests and values. There are various research methodologies which are reflective and value-driven, that can provide inspiration to shape an inclusive and truly participatory approach to $\mathrm{ICT}_{4} \mathrm{D}$. Given the interdisciplinary and goal-oriented nature of $\mathrm{ICT}_{4} \mathrm{D}, \mathrm{I}$ will review a number of value-driven methodologies and ideas in the following sections.

\subsubsection{Participatory approaches}

Dissatisfaction with the conventional methods in development projects (in which goals are set by external agents, and transfer-of-technology 5 is common practice) is not a recent phenomenon. In rural development this triggered critical practitioners and researchers to develop new, participatory approaches, long before $\mathrm{ICT}_{4} \mathrm{D}$ entered the stage (e.g. [71, 341, 65]).

In 1983, Robert Chambers published his book "Rural Development: Putting the Last First" [71], in which he polemically showed how "outsiders", i.e. development experts, NGO staff, researchers, donor agents and other stakeholders, unaware of grassroots perspectives, often overlook local needs and context.

Chambers called for a paradigm shift in development, towards a more people-centered approach. People-centered and grassroots alternatives, which are referred to as "livelihood approaches" [372, 373] and farmer innovation [338] gained momentum as a new "people paradigm" by putting people first in words and actions [74, 71]. As a practical implementation of this way of thinking, new participatory approaches were introduced.

\subsubsection{Participatory Rural Appraisal}

Participatory Rural Appraisal (PRA) comprises various decentralized, open decisionmaking systems' approaches and methods. PRA enables local people in poor rural environments to plan, act, and share knowledge about their own lives and conditions, in order to enhance their own livelihoods [72]. While formerly information was elicited and extracted by outsiders, e.g. through rigid, closed-question surveys, PRA uses focus group discussions and semi-structured interviews, mapping and modeling, transect walks, matrix scoring, seasonal calendars, trend and change analysis, well-being and wealth ranking and grouping, and analytical diagramming [72].

PRA is increasingly being used in various sectors of international development, including natural resources management, agriculture, poverty and social programs, and

5 In rural development these are for example improved seed, pesticides and fertilizers [338]. 
health and food security. Participatory evaluation, and assessment of self-perceived success by local communities $[336,338]$ have proven useful to assess the relevance of action during project execution, and to provide information to adjust project plans when needed. These methods are fundamentally different from the mainstream approaches that consist of "giving instructions to farmers" [72, 74].

\subsubsection{Participatory Technology Development}

Participatory Technology Development (PTD) stems from a similar tradition as PRA. PTD goes a step further, by, not only involving local beneficiaries in agenda-setting and evaluation, but also focusing on (local, indigenous) knowledge sharing and diffusion of local innovations [338].

PTD is a hands-on method, based on intense collaboration between farmers, development agents and researchers. PTD combines and merges skills and knowledge, in order to support local innovation. PTD fosters farmers' experimentation and seeks to try out new ideas while trying to adjust to changing conditions of the dynamic contexts. When linked to a wider network of (action-) researchers and development practitioners, PTD and local farmer innovation have the potential of reaching many people and providing adequate solutions to local problems [338].

\subsubsection{Farmer Innovation Methodology}

Farmer Innovation Methodology has been developed in the late 1990s in Africa, in the domains of soil and water conservation to fight desertification. Farmer innovation is still used, although it is not mainstreamed in rural development [99, 338, 335, 98, 280]. The idea of the farmer innovation methodology is to harness innovations and experiences from local farmers and disseminate them to a wider group or community. The methodology consists of various components: identifying and verifying farmer innovators, analyzing their innovations, organizing farmer-to-farmer exchange visits and local study tours, setting up farmer evaluation, stimulating joint experimentation, raising awareness and lobbying, and institutionalizing the farmer innovation approach [338].

An important aspect of this methodology is to educate the "outsiders" in the participatory way of working and thinking, quoting Chris Reij and Ann Waters-Bayer: "many scientists and extension agents have difficulties in communicating eye-to-eye with farmers. Their conventional training and vision of development through the transfer of modern 'improved' technologies have imbued them with a sense of superiority [...] most of them cannot imagine that they can also learn from (illiterate) farmers" [338]. 


\subsubsection{Positive Deviance to speed up innovation}

Another example of a community-centered approach to innovation and evaluation is a method to identify local successes, called "positive deviance". The principle is simple and consists of looking for outliers: people who succeed against all odds. Positive deviance is founded on the premise that innovators exist in any community or group. Working with the same resources as anyone else, the innovator has overcome a problem that still confounds others [307]. Quoting Pascale et al. "This individual is an outlier in the statistical sense - an exception, someone whose outcome deviates in a positive way from the norm. In most cases this person does not know he or she is doing anything unusual. Yet once the unique solution is discovered and understood, it can be adopted by the wider community and transform many lives" [307].

Positive Deviance was first used as a method in the 1970s, in health and malnutrition research in rural regions of Vietnam. It consisted of looking for exceptions and learning from innovative solutions in order to disseminate this knowledge and help others. For example: look for children who were less affected by malnutrition despite the widespread occurrence of malnutrition amongst children in this region, and learn how their mothers had succeeded in coping with the problem.

Quoting the initiators of Positive Deviance: "As a problem-solving process, this approach requires retraining ourselves to pay attention differently - awakening minds accustomed to overlooking outliers, and cultivating skepticism about the inevitable 'that's just the way it is' . Once the concept is grasped, attention to observable exceptions draws us naturally to the 'who', the 'what' and especially the 'how' " [307].

In contrast to the (cause-effect) impact evaluation approaches (that focus on attribution of the observed impacts to the donor-funded intervention, as discussed in Chapter 2), Positive Deviance tries to identify mechanisms for local successes: i.e. positive, observable exceptions, which are not the 'failing norm'. Looking at positive outliers is a way to obtain a better insight in local innovations [307].

\subsection{PRAgMATiCAlly adAPting methods to NOVEL CONTEXT}

From the methodologies in this chapter we can learn that - in whatever context, lowtech or high-tech - a key element of true innovation is the dialogue with the real users. Saa Dittoh, rural economist from the University for Development Studies in Ghana, explained this during a symposium on $\mathrm{ICT}_{4} \mathrm{D} .{ }^{6}$ Researchers and development agencies should take a modest role, not pursuing total control. They should blend with the rural communities and provide constructive interaction.

The methods listed in this chapter are not meant as blueprints for a new type of $\mathrm{ICT}_{4} \mathrm{D}$, but as a source of inspiration, or a framework of ideas. The methods can be

6 This was said during a keynote speech at the Third International Symposium Perspectives on ICT4D, 6 April 2016, at VU Amsterdam. 
re-used, re-invented, adjusted and re-applied. The most important success factors are collaboration between all participants - researchers, developers, users, local and nonlocal stakeholders - knowledge sharing, adaptation to context, and a flexible, open, learning-by-doing attitude. This is, as Saa Dittoh describes, the plug-in principle: applying adaptive management and collaboration to jointly improve a situation. Quoting Saa Dittoh:

"... scientific knowledge cannot replace indigenous knowledge. Thus, scientists are at best bettering agents, not change agents. In order to plug-in a certain technology or idea, the interventionist has to understand the existing situation thoroughly and respect the members and existing knowledge within the community. If you think you have a better solution, try first to understand the existing situation. Do not judge too fast. There is a reason why a situation is as it is. ${ }^{\prime \prime}$

\subsection{SUMMARY AND OUTLOOK}

This chapter has briefly reviewed the toolbox of methods and techniques for $\mathrm{ICT}_{4} \mathrm{D}$. They share a framework of ideas, that feeds the methodology of this research. In Table 3 the various methods and techniques are compared, looking at seven properties.

In the next part of this thesis a collaborative, adaptive, and iterative approach to $\mathrm{ICT}_{4} \mathrm{D}$ is discussed. The methods described in this chapter have pragmatically been adapted for this approach that covers the full lifecycle of software development, including (i) context analysis, (ii) needs assessment and collaborative goal construction, (iii) use case and (iv) (business \& technical) requirements analysis, sustainability analysis \& business modeling, (v) building, testing, deploying and evaluating. Each of the phases is described in a dedicated chapter, illustrated with examples and cases from the field.

7 Prof. Saa Dittoh has over 30 years of field experience working with African rural communities and the rural context, and also with development agencies and projects. 


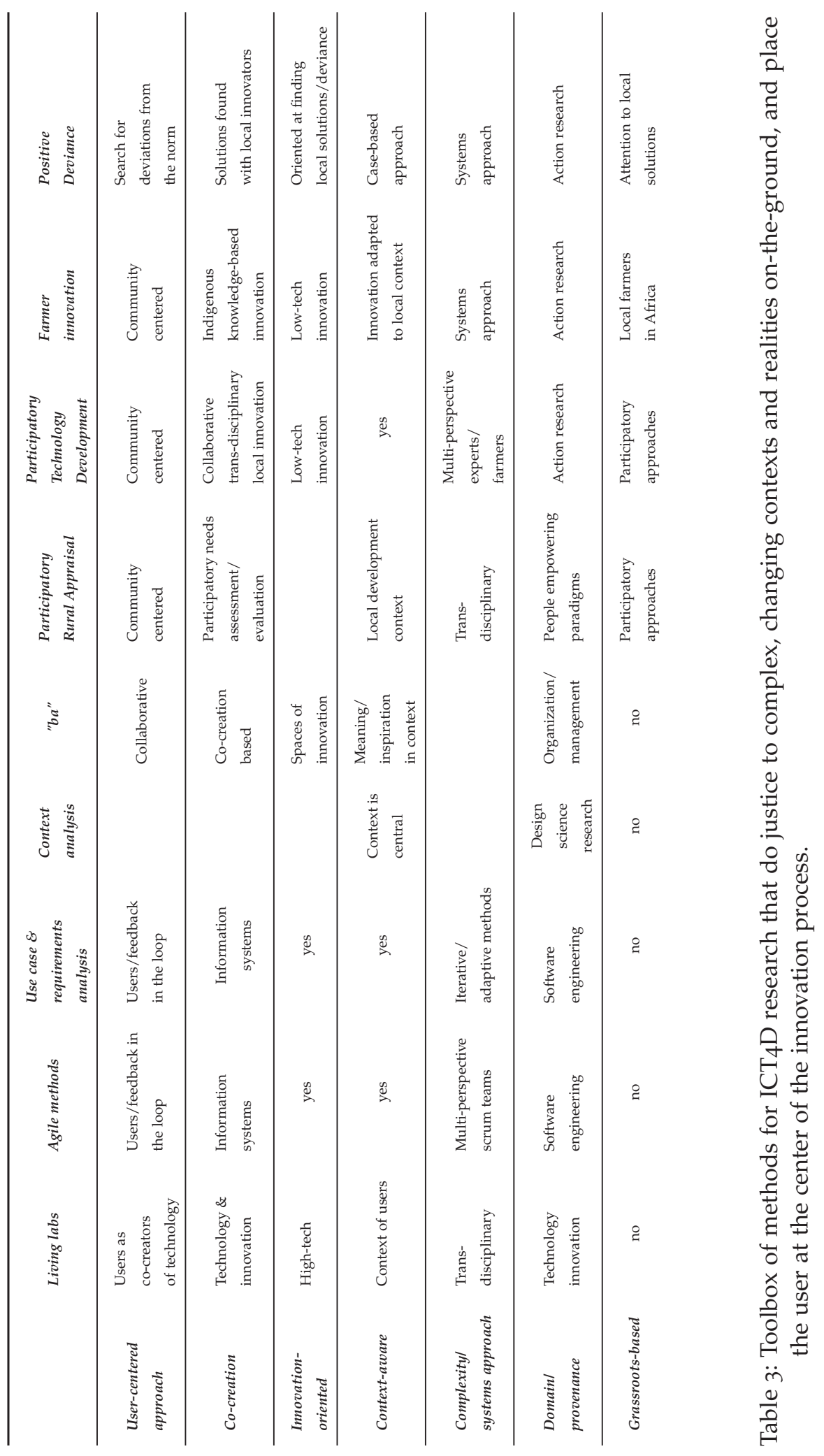





\section{Part II}

\section{CONSTRUCTING OPERATIONAL SOLUTIONS}

[In which a method/approach for $\mathrm{ICT}_{4} \mathrm{D}$ is iteratively constructed in five chapters: (i) context analysis (ii) needs assessment (iii) use case and requirements analysis (iv) engineering, deploying, evaluating (v) sustainability assessment. Each chapter covers one of the tasks in the lifecycle of information systems engineering, as adapted for low-resource environments.] 

When developing ICT services in a low resource environment, ICT developers will deal with situations where the context is largely unknown to them. Therefore, the team of developers should take considerable time to become familiar with the context where the envisaged endusers live. Context has various scales: the regional, the local, the human scale. By observing how factors at different levels (or scales) interact and influence each other, the ICT developers obtain (i) specific information that relates to the envisaged ICT development and (ii) a general insight in the complexity of this specific real-world context. This aligns well with the second Principle for Digital Development: Understand the Existing Eco-system. ${ }^{1}$

\subsection{FIRST TASK: EXPLORE THE CONTEXT}

A big gap between technologists (ICT developers, researchers etc.) and the world of the end-user is not uncommon in $\mathrm{ICT}_{4} \mathrm{D}$ projects. Therefore, this chapter stresses the need to start any $\mathrm{ICT}_{4} \mathrm{D}$ project with an extensive context analysis. "Context" in this chapter refers to the livelihood of rural communities, in the extended sense as described by Scoones [373]. I will describe how the $\mathrm{ICT}_{4} \mathrm{D}$ technologists become familiar with the local context, why this is important and what can be expected. The ICT developer wants to answer questions which are of concern for ICT (e.g. do people have electricity?) and for a more general understanding (e.g. what do people do for a living?)

This chapter describes the first context analysis on our research project, in a setting of regreening initiatives in the Sahel. It introduces a rural context in Africa and describes it at various scales. It does not claim to give a full historical account of the region, but gives patchy information, jumping freely from the regional scale to the local and human scales, back and forth. It gives meta-information and comments why this is relevant for $\mathrm{ICT}_{4} \mathrm{D}$. At the end of this chapter, in section 4.5.1, as a concrete outcome of the context analysis, a number of concerns is listed, which are relevant for $\mathrm{ICT}_{4} \mathrm{D}$ in low resource environments. This chapter provides background to the use cases of Chapters 5-8, in which regreening remained an important theme, over the course of almost a decade.

1 https://digitalprinciples.org/, (accessed o8-10-2020) 
In September 2009, in the framework of the interdisciplinary research program $W_{4} R A$, the "Web alliance for Regreening in Africa", our team of researchers started a field work program in the Sahel in West Africa to find out if, and how, ICTs - despite local constraints of a low-resource environment - can be made useful for local communities. The researchers' team was introduced by local organizations to rural communities in Mali, Burkina Faso and Ghana.

During the first visit the team had the opportunity to become familiar with the local (poor, rural) context. We asked local people if they would be interested in having ICTs (services); if people would like to improve knowledge sharing; we analysed the local conditions for deploying ICT services here; we tried to understand the major constraints. During the field trip in September 2009 the $\mathrm{W}_{4} \mathrm{RA}$ team visited several farmers in the field (See Figure 10). Ranawa, a rural community of 2300 inhabitants, in the Yatenga region of Burkina Faso was visited. This I wrote in my field report:

[Ranawa, 27 September 2009] There is no electricity in this village. People in Ranawa live from subsistence farming and produce millet, sorghum, sesame and have some livestock. The inhabitants of the village of Ranawa have been very successful in applying innovative regreening techniques on their fields, which has increased their crops. We started our visit by a walk through the fields, to see the crops in between the upcoming trees. Our team was introduced to the villagers of Ranawa by our local partner, Mathieu Ouedraogo (president of the local NGO Réseau MARP). We did a focus group with the chief and twelve villagers, while sitting under a tree, next to the village. Translations were made simultaneously by our local partner between the local language Moore and French. We learned that here in Ranawa up to 98 percent of households use mobile phones for social interaction and business, e.g. to ask for market prices in town, to negotiate with potential customers. We learned that about $1.000-5.000$ fCFA (about 2 - 10 euros) is spent on average per person per month on mobile airtime. Some people in the village earn money by selling airtime (telephone units) in small units. Since there is no electricity, phones are charged using a motor cycle battery (a phone charging business). The Ranawa community estimates mobile telephony essential. The villagers are open to innovations and curious about new systems of communication and access to relevant information. We noticed an interested attitude towards new technologies. Extra costs are said to be acceptable, but only if the new technologies bring real advantages.

This is an impression, from my first field visit to a small village in Burkina Faso. All following field trip reports and data (February 2010 - January 2020) are listed in Annex B. This field visit marked the start of the research program in $\mathrm{ICT}_{4} \mathrm{D}$. Context analysis is the first step of every $\mathrm{ICT}_{4} \mathrm{D}$ research, and is often repeated, during the whole process of information systems development, as will be shown in the next chapters. From this 


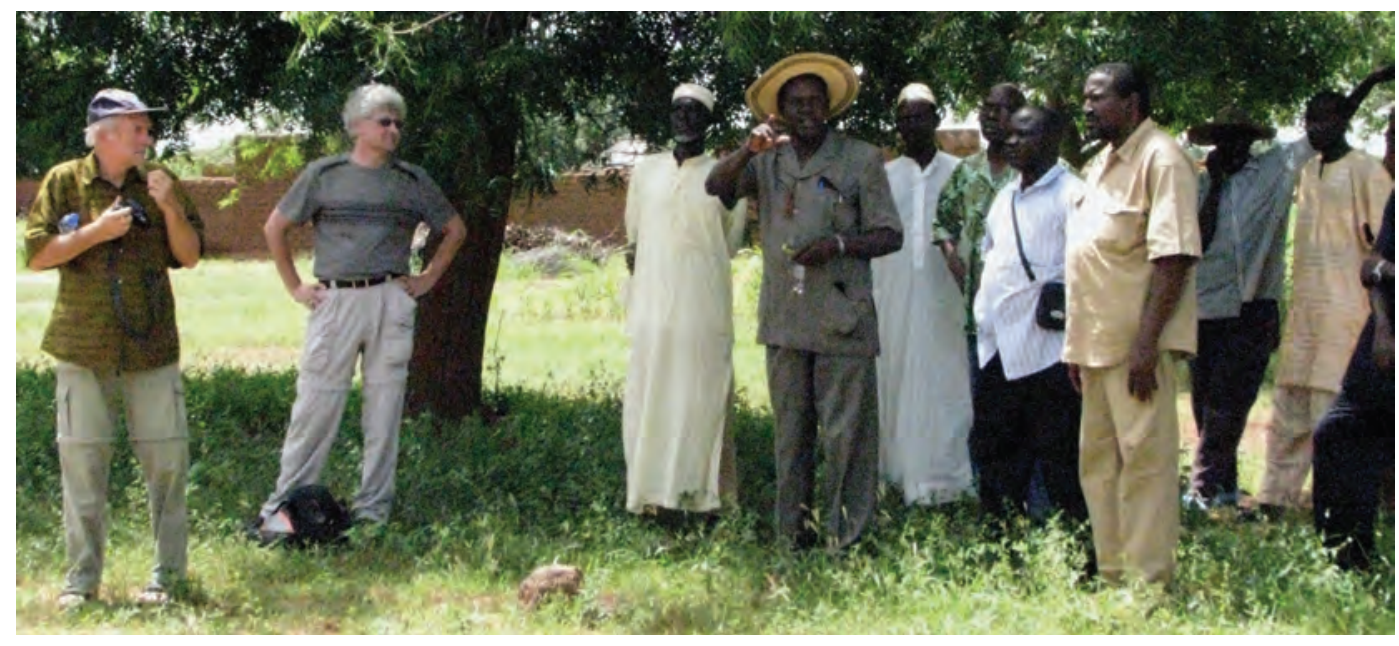

Figure 10: Our first context analysis visit to Ranawa village, Burkina Faso, September 2009. ${ }^{2}$

visit we collected a number of key concerns for $\mathrm{ICT}_{4} \mathrm{D}$ in low resource environments. These are listed in subsection 4.5.1.

\subsection{REgIONAL CONTEXT: SOIL DEGRADATION IN THE SAHEL}

This section discusses one of the important problems that affect food security in the Sahel. We learn about the development interventions that have taken place to improve environmental conditions and increase food security. We learn about bottom-up initiatives of local communities that have emerged as a reaction to failing interventions. We observe how regional patterns affect the human scale.

\subsubsection{Degrading landscapes in the Sahel of West Africa}

The Sahel is a climatic zone, rimming the southern part of the Sahara desert, stretching east-west across the African continent from the Atlantic Ocean to the Red Sea. With a population of nearly 50 million people the Sahel transects ten countries in sub-Sahara Africa, which are amongst the poorest in the world. ${ }^{3}$ The majority of people in the Sahel live from rain-fed, subsistence agriculture [98]. Average annual rainfall varies from 250 to $600 \mathrm{~mm}$ in the Sahel and is concentrated in a rainy season of 4 to 5 months [393].

The Sahel has recurrently been plagued by droughts and famines. The major droughts occurred in the periods 1910-1914, 1942-1949, 1968-1973 and 1982-1984 [337]. During these periods lack of rain has led to disappearance of livestock and to destruction of

3 Senegal, Mauretania, Mali, Burkina Faso, Niger, Nigeria, Chad, South Sudan, Ethiopia, Eritrea; source: World Bank Indicators 2015. 
cereal crops. This has threatened the livelihoods of millions of people. Currently, the local communities can cope with the environmental situation, but they are vulnerable for the effects of an unpredictable climate and for other natural and economic hazards (for example locust plagues, diseases, floods, price fluctuations of commodities).

In the Sahel of West Africa, soil degradation, progressive loss of vegetation, falling ground water levels and low cereal yields are factors of concern for the inhabitants $[397,337]$. Since the early twentieth century until present day, interventions have been undertaken for soil and water conservation in the Sahel. The approaches and the opinions how to do this have changed over the years, and are still being debated [191, 393, 335].

Since the early 2oth century 4 modernization of African agriculture has been promoted, to increase agricultural output and achieve self-sufficiency in terms of food production [281, 265]. Traditional African small-scale farming practices were gradually replaced by larger-scale, western-style agriculture [345, 377, 186]. African farmers were taught by agronomists and national extension services and development experts to clear their fields from vegetation, by periodic cutting and burning. Crops on clean fields were considered more productive than the traditional inter- and doublecropping, which was more labor intensive and looked "messy" [191]. National and regional research institutions were established who did research and focused on varietal improvement and fertilizer application [393]. Cash crops including cotton and cocoa, were promoted and introduced for export [191].

Soil degradation was often blamed by the authorities on overgrazing by pastoralist herds or tree cutting by local communities [191, 22]. To restrict the use of trees and land, forestry law was issued under French colonial administration. This remained in force for years after independence (1960), in Mali, Burkina Faso and Niger [22, 393]. In general, forestry law and policies to protect the natural environment turned out disadvantageous for rural dwellers. Pastoralists were allowed to graze their herds in designated areas only and farmers lost ownership over trees [377].

In Mali and Burkina Faso the Forestry Services who controlled exploitations of forest resources were organized along para-military lines [393]. NGOs, engaged in agroforestry projects, had collaborative relationships with governmental technical extension services and the Forestry Services who were responsible for protection of trees (from theft) [393]. In practice this was devastating for local communities, who received fines for e.g. cutting firewood for the production of charcoal, even on their own fields [22].

The change of land use from traditional to modern agriculture and the removal of the original vegetation caused increased erosion of top soils by wind and rainfall, causing soil degradation and loss of arable lands, over the years [281, 265, 345, 186]. In the 1980s, especially in the longer periods of drought, barren plains, infertile soils, dust storms, severe fodder shortages, and agricultural pest outbreaks were frequent in the Sahel $[337,377]$. Disappearance of vegetation led to conflicts between sedentary

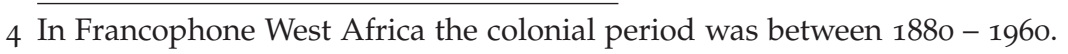


farmers and pastoralists [377]. Farmers had to expand farming to marginal lands to keep up production for a growing population. ${ }^{5}$

\subsubsection{Intervention or participation?}

In colonial and early post-colonial years (before the 1980s) rural development was focused on technical aspects of implementation [335]. Participation of local communities in decision making or in project implementation was not a common practice [281, 265].

In the 1960 and 1970, when droughts led to widespread food shortages, a wave of interventions was launched by development agencies and governmental agencies. The goal was to rehabilitate productive capacity of soils, through control of rainfall and runoff, improved soil fertility management and reforestation. In the Central Plateau of Burkina Faso, a region severely affected by drought, water harvesting structures such as stone bunds, dikes, and dams were built to prevent erosion by surface water run-off during the rainy seasons [335]. These projects were rolled out without participation in decision-making by local communities [281, 265]. (An illustration of the interventionist approach, see Chapter 2.) This was clearly a non-participatory, technology-driven intervention.

Over time it became clear that dikes, dams and stone-bunds were not being maintained by the local population. Lack of communication led to neglecting and sometimes even destruction of the artefacts by local communities [265, 281].

\subsubsection{Interventions that do not serve local goals}

In the 1960s, tree planting projects to fight soil degradation were executed by international NGOs. To "buy in" participation of local communities in tree planting projects, development agencies used paid labor or food-for-work as incentives for the local population [344]. ${ }^{6}$ A large tree planting project was implemented in this way by CARE International7 in the Maradi and Tillabery regions of Niger [393].

A case of excluding beneficiaries from decision-making is the story from the Majjia Valley project, rolled out in Niger, in 1967 [393, 67]. This development project aimed at massive tree planting to prevent crop failure from wind and water erosion [67]. The tree species used was Prosopis juliflora, an exotic tree that germinates easily and grows fast. The tree was selected by the development agency, despite being strongly disliked by local farmers [67].

Rebecca Butterfield studied this project in 1996, and reported from interviews with local communities: "Farmers reported to have a love-hate feeling towards the species

5 The Sahel region has a population growth of 2,7\% per year [336]. Over a period of decades this reinforced the trends of land degradation and desertification [337].

6 This was done to recruit local people and pay them in natura [98].

7 E.g. CARE did many agro-forestry projects in Niger in 1960-1990s [393]. 
[i.e. Prosopis juliflora], with the majority of people reporting a strong dislike. Translations of common names given to the tree explain why: 'viper', 'bastard thorn,' and 'dangerous thorn' (shejain kawa, mugun kawa in Hausa language). Thorn pricks are painful, causing hands and limbs to swell. One unfortunate farmer who stepped on a thorn, was said to have developed gangrene and died." [67].

In a working paper (1994) about rural development in Mali, the American agency USAID admits: 'By the late 1980s donors and increasingly the Malian Government recognized that block plantation woodlots in villages did not work. Much debate took place on how to increase participation of the population in forestry and natural resource programs' [147].

\subsubsection{Participation or still intervention?}

While participation in post-colonial times was common practice, in the late 1980 s 1990 a new development discourse emerged, in favor of participation and communitycentered approaches [335]. This was induced by several trends, debates and publications $^{8}$ which showed the effectiveness and necessity of participation in rural development (e.g. [430, 80, 335]). The top-down, interventionist attitude was blamed for frequent failure [393, 345, 22, 345].

A recent example of how a large-scale intervention fails, is the Great Green Wall. This recent continent-scale intervention aims to improve the environment in the Sahel, and fight soil degradation by massively planting of trees. ${ }^{9}$

In 2007 the Global Environment Facility (GEF) has commissioned the Great Green Wall program to fight desertification and land degradation in the Sahel. It plans to realize a $7700 \mathrm{~km}$ tree belt stretching the length of the Sahara Desert, in 11 countries (Senegal, Mauritania, Mali, Burkina Faso, Ghana, Togo, Benin, Niger, Chad, Sudan, Ethiopia). The program, with a budget of 2 billion US\$, is financed by the World Bank, the Global Environment Facility, the Least Development Countries Fund and the Spatial Climate Change Fund. ${ }^{10}$

Proposed by the African Union in 2007, the Great Green Wall aims to be the largest artefact on the planet and restore 50 million hectares of degraded land to provide food security to 20 million people, create 350.000 jobs and sequester 250 million tons of carbon. ${ }^{11}$ Tree planting has started in Senegal and uses soldiers and students as labor for planting activities.

In spite of high investments and expectations, survival rates of planted trees have been disappointing. Field studies of the Great Green Wall reported a $20 \%$ survival rate for planted trees within two months after planting. ${ }^{12}$ Concerns exist about sustain-

8 e.g. Robert Chambers' book "Rural Development: Putting the Last First" [71].

9 Source: United Nations Convention to Combat Desertification, https://www.unccd.int/actions/ great - green - wall - initiative, (accessed 08-10-2020)

10 Source: http://www.greatgreenwallinitiative (accessed o8-10-2020)

11 Source: http://edition.cnn. com/2016/09/22/africa/great-green-wall - sahara/ (accessed o8-10-2020)

12 Source: http://tinyurl.com/dead-baby-trees (accessed o8-10-2020) 


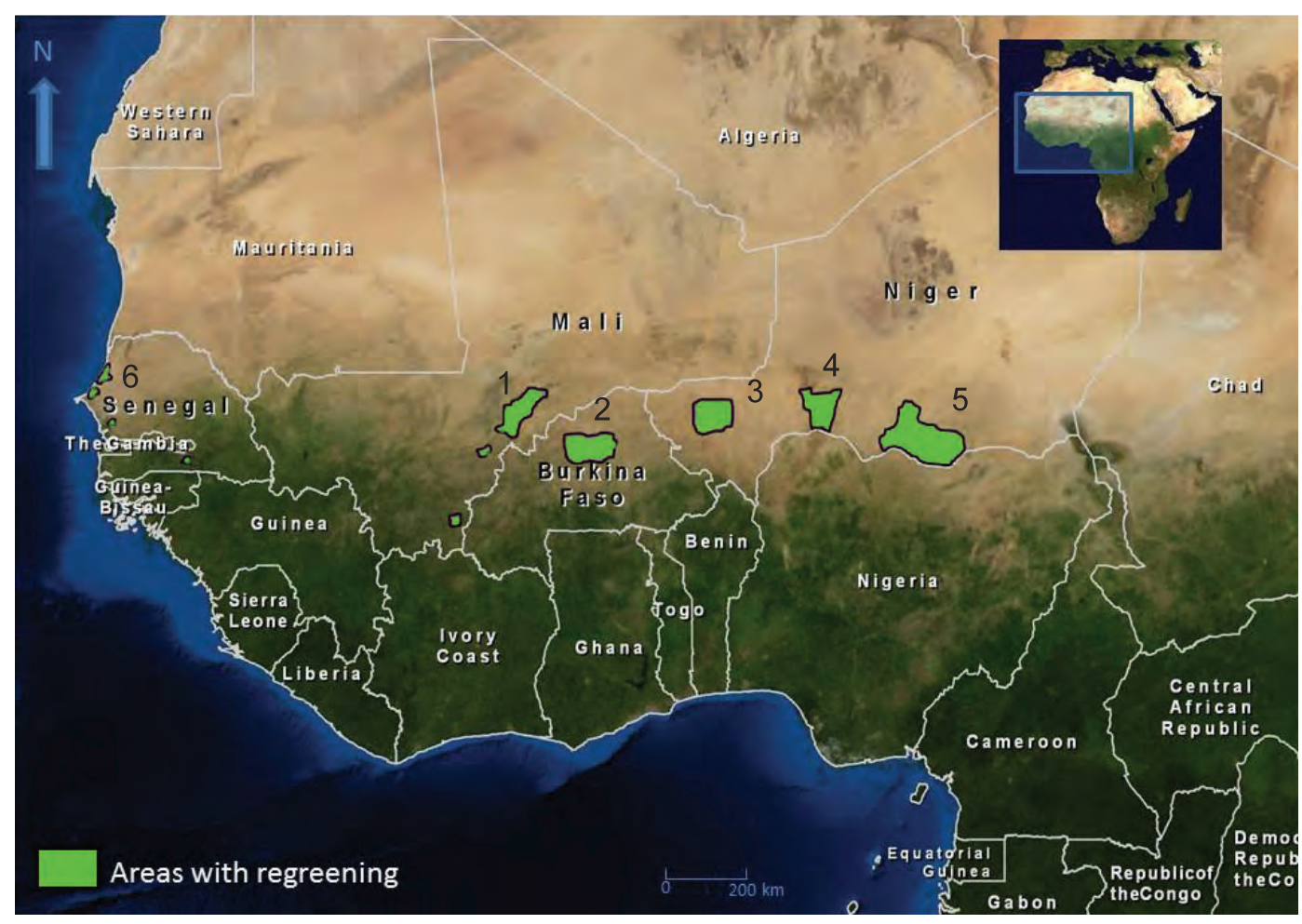

Figure 11: Map of West-Africa showing areas of emergent regreening: $1=$ Seno planes in Mali, $2=$ Central plateau in Burkina Faso, $3=$ North of Niamey, $4=$ Maradi, $5=$ Zinder, 6 $=$ Senegal. Courtesy of Chris Reij.

ability of the project and the maintenance of the trees after the project period. As local farmers do not own the trees, it is unclear who will care for protection of the trees. ${ }^{13}$

Notwithstanding a change in discourse and much rhetoric about participation, the tendency of the international community to pursue large-scale ambitions and centrally planned interventions has remained until present day in (rural) development.

\subsubsection{Strength of local initiatives}

Independent of the Development Debate about participation, a new, grassroots trend emerged in the early and mid-1980s that opened avenues for food security in (African) drylands. It was regreening, a large-scale phenomenon consisting of "many trees on farmland" $[338,339,423,377,336]$. A map with areas of regreening in the West African Sahel is shown in Figure 11. Regreening ${ }^{14}$ is the consequence of change in land-use by rural communities or local farmers-innovators who experiment, invent new agricul-

13 Pers. comm. Chris Reij, World Resources Institute, Washington, USA, 18-11-2016.

14 Regreening is often referred to as agro-forestry. 
tural practices and/or re-introduce traditional ones [339, 344]. One of these practices is 'farmer-managed natural regeneration' (FMNR), a set of inexpensive manual techniques that can help increase the number of trees on farmland [339].

Regreening occurs in regions with variable rainfall and frequent droughts and is particularly beneficial for rain-fed agriculture, in areas threatened by soil degradation [423]. Regreening is gradually spreading to drylands of Burkina Faso, Ethiopia, Mali, Niger, Malawi [338, 339, 98, 423]. Regreening improves resilience of local livelihoods through better crops and availability of tree products throughout the year $[339,98]$. According to various studies on soil and water conservation in rural Africa, (e.g. [338, $339,423]$ ) regreening is leading to a transformation of the environment, restoration of degraded soils and increased crop productivity. Regreening can be observed in landscapes as a large-scale emerging pattern from distributed actions by many farmers [339].

In February 2006, when Chris Reij and Gray Tappan, two agro-environmental researchers ${ }^{15}$ travelled through the countryside of Niger to study the local environment and the state of soil degradation and desertification, they observed a vast area of farm land with trees in the region between Zinder and Maradi, in the south-east of Niger. This is a zone of high population density, up to 100 inhabitants per $\mathrm{km}^{2}$. Remote sensing studies from the US Geological Survey revealed that 5.000.00o hectare of farm land had been regreened by the local population [340]. Tree density appeared to be 15 to 25 times larger in 2006 than tree densities recorded in 1975 in the same regions (see Figure 12), amounting to 200.000.000 trees [340, 337]. The scale and impact of regreening in Niger had remained unreported until 2005, despite many interventions and monitoring \& evaluation studies from the previous decades [340, 337].

These new agro-forestry systems impacted 1.250.000 rural households in the ZinderMaradi region. There was an average increase in crop yields of $100 \mathrm{~kg}$ per hectare [337]. The impact was an estimated total production of 500.000 tons of cereals per year, providing food for about 4.5 million people [337]. Trees, tree products, better crops and healthier livestock enabled farmers to produce for local markets and provide food for a growing population [219, 336]. Regreening in Niger is seen as one of the largest recent agro-environmental transformations in West Africa [337].

Regreening in Niger has been studied from various perspectives. Sendzimir et al. [377]) used conceptual modeling tools and a system approach to map interrelating factors that contribute to regreening in the rural context of the Sahel, as shown in Figure 13. This study combined different types of data: recent remote sensing data, historical data, trends in tree density [377]. Large-scale regreening has been observed in Niger and has been explained as an emerging pattern from many distributed actions and complex interactions [377]. This complexity shows the need to embed development

15 Pers com. Chris Reij (VU Amsterdam) and Gray Tappan (US Geological Survey); reported at the Program on the Global Environment Inaugural Conference, University of Chicago, May 2008. 

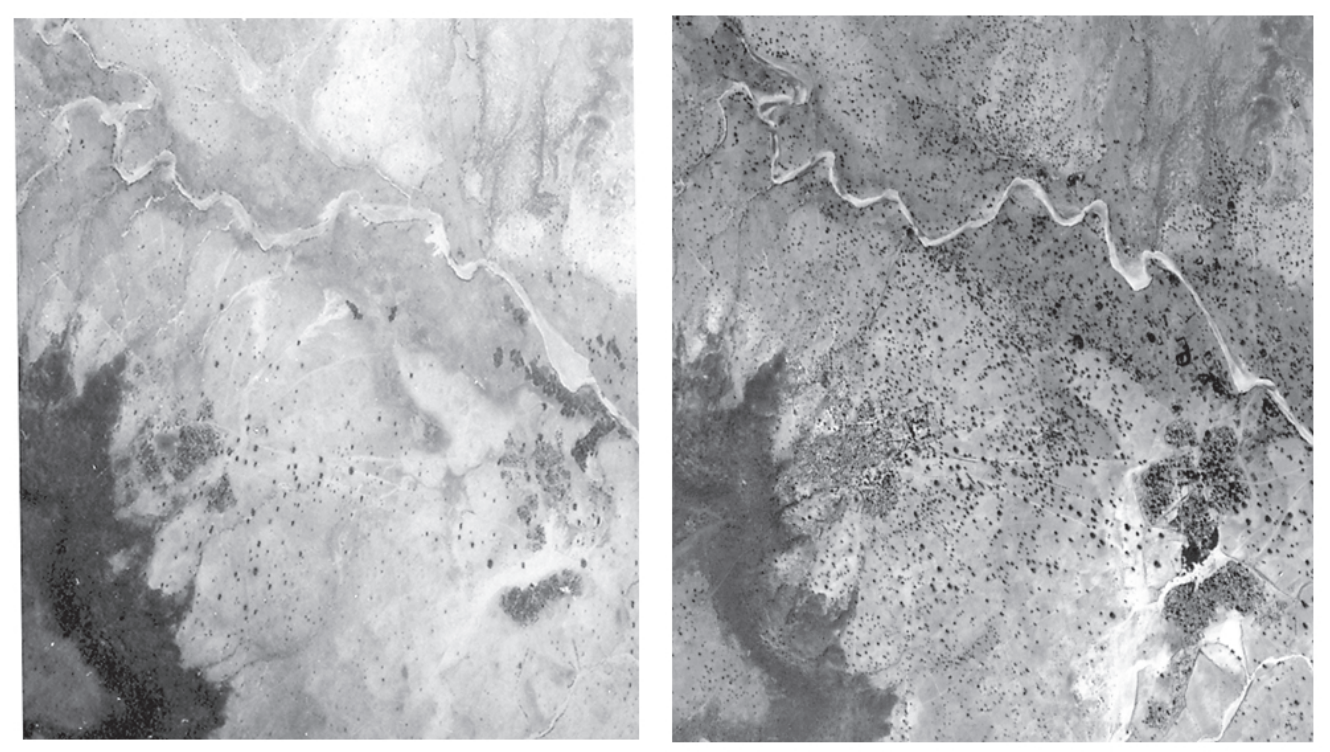

Figure 12: Environmental change in 28 years. Left image shows the village of Galma (Niger) in 1975. Right image shows the same village in 2003. Most of the black dots are mature trees. Satellite image: courtesy Gray Tappan, US Geological Survey, reprinted after Reij \& Winterbottom. Scaling up Regreening: Six Steps to Success. World Resources Institute, 2015 [339].

actions and technological innovation in existing processes at various scales (regional, local, human scale).

At about the same period, in the mid-2ooos the trend of large-scale regreening was observed in Mali. ${ }^{16}$ The widespread emergence of young trees could be attributed to various interrelated factors: change in land-use, adaptation to changing environmental and political contexts and improved collaboration between local communities and supporting practitioners (cf. [340, 337, 377]). In the next paragraphs, a recent history of regreening in Mali is described, as reconstructed from various sources: personal interviews, internal project reports and literature.

\subsubsection{The context of regreening in Mali}

After a coup d'état, in March 1991, the Malian president Moussa Traoré, in power since 1968, was overthrown. A transitional government started the process of policy change and decentralization. In line with international policies, the Malian government withdrew activities and subsidies in rural sectors [397], abolished subsidies for

16 The information in this section is based on internal reports of AOPP; interviews with Mary Allen Ballo, former secretaire-executive of Sahel Eco and the Sahel Eco Annual Report 2005. 


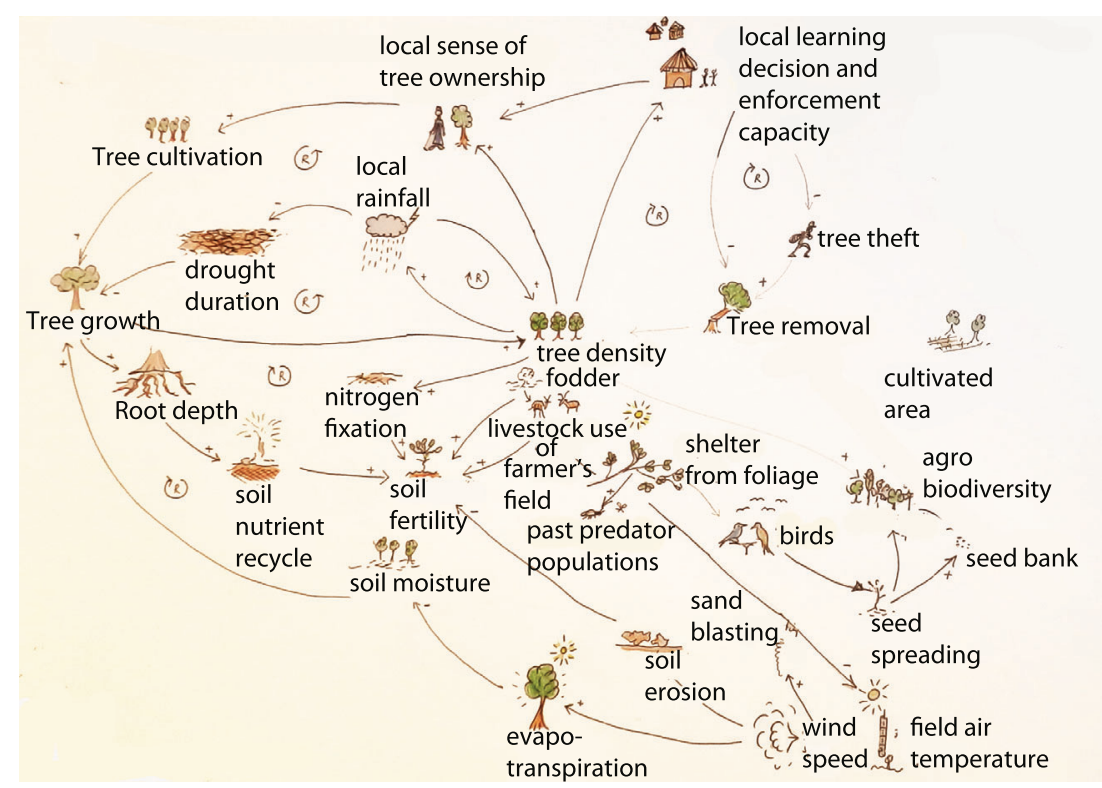

Figure 13: Conceptual model of the variety of interrelated variables that influence large-scale regreening in a complex setting. Adapted after a model by Sendzimir, Reij \& Magnuszewski (2011) "Rebuilding Resilience in the Sahel: Regreening in the Maradi and Zinder Regions of Niger" Ecology and Society 16 (3): 1, Fig. 5. [377].

e.g. fertilizers and seeds and stopped its support to local production and trade. This process of policy change had already been encouraged by international development organizations since the 1980s, through structural adjustment programs. ${ }^{17}$ The clauses attached to the loans required privatization and reduction of state interference [342].

The effects of decentralization, which have been widely criticized for their negative effects on the social sector [21, 22], were disconcerting for local farmer organizations, who were not prepared for the transition and lacked channels of communication and access to markets. Family farms were heavily affected. ${ }^{18}$

Unexpectedly, the policy-led decentralization in Mali also triggered new local initiatives in rural areas including revitalization of traditional village organizations and emergence of community organizations and village authorities [397]. Local organizations were compelled to reorganize themselves and take over the support of (smallscale) production and commercialization in agriculture, livestock and fishery. ${ }^{19}$

One of the policy changes after 1991, was the revision of ancient forest law in Mali, which was a legacy from colonial times. This law strongly prioritized environmental protection over local agency and farming activities [22]. Based on this law, policy had

17 Structural adjustment programs (SAPs) consist of loans provided by the International Monetary Fund (IMF) and the World Bank (WB) to countries in economic crises.

18 Source: http://tinyurl . com/W4RA-A0PP - rep- pdf (accessed o8-10-2020)

19 See also AOPP Forest Connect Internal Report 2014. 
granted national Forest Service absolute authority over trees. This condition had hampered many regreening activities. National Forest Service agents were authorized to give farmers fines for pruning trees, even on their own lands. The Forest Service had the authority to grant permits (e.g. to urban timber salesmen) to cut trees on farmers' fields. Farmers could not defend themselves against the intruders. The policy changes in 1994 restored the power balance.

The new situation empowered local communities to reclaim ownership of the trees on their fields. ${ }^{20}$ This made regreening and agro-forestry a new and feasible value activity for many small-scale farmers $[377,336]$, as local communities were given autonomy to manage trees and practice farmer-managed natural regeneration. ${ }^{21}$

The above description illustrates again how various levels/scales are interacting: the national policy is influencing indirectly local agency; the regional scale in turn interacts with the local scale.

Having obtained an idea of the issues at regional scale, we (as $\mathrm{ICT}_{4} \mathrm{D}$ developers) will now zoom into local and human scales. We assess project reports and meet local farmer organizations and national NGOs, and read case studies about the work of local innovators.

\subsubsection{Bottom-up initiatives in Mali}

In the 1990s new bottom-up initiatives, village structures and community organizations emerged, and old ones revitalized in rural Mali. Examples are the (traditional) Alamodiou association, and the new Barahogon association, in the region of Mopti, in the south-east of Mali. In 1995 AOPP (Association des organizations professionnelles paysannes), a local association of professional farmer organizations in Mali, was established as an initiative by local organizations of family farmers to jointly improve livelihoods of local farmers.

AOPP was aware of a decreasing resilience and vulnerability to food shortage among small producers, in the light of the monopolized market system in Mali. This situation was exacerbated by poor communication, wide-spread illiteracy and lack of organization at the village level. AOPP encouraged farmers to use, as an alternative source of income, non-timber forest products (products from trees, such as sheanuts, honey, baobab leaves and fruits), since tree products are available throughout the year, including the dry season when there is no harvest. Adding the benefits of trees to soil

20 Personal communication Mamadou Diatiké, 2016.

21 Personal communication with Mary Allen and Mamadou Diakité. 
and water management, regreening became a valuable new endeavor for many rural dwellers. ${ }^{22}$

The Barahogon association took the initiative to start regreening on the Seno-plains, an area that was covered by sand dunes as a result of soil degradation. Since the 1990s a long corridor on the Seno-plains had faced serious erosion, soil degradation and the formation of bare sand dunes. In search for solutions to soil degradation, the Barahogon association started to increase the number of trees in this region. This community organization requested local $\mathrm{NGOs}^{23}$ to train them in regreening techniques and farmer managed natural regeneration.

Regreening activities were set up and knowledge sharing sessions organized, how to prune trees and clear lands without destroying vegetation. Farmer-to-farmer visits, cross-learning and exchange of indigenous knowledge and practices were part of the collaborative approach by several local and non-local NGOs and the local communities. ${ }^{24}$ Bottom-up initiatives by local farmers, sometimes supported by development organizations, resulted in a regreened area of 450.000 hectares. ${ }^{25}$ on the Seno-plains in Mali $^{26}$

\subsubsection{The effectiveness of adaptive management}

Meanwhile, various local organizations started to set up project activities to make rural communities in Mali aware of their new rights on trees. The first step was to disseminate knowledge to farmers about new tree legislations and about simple affordable techniques how to manage trees. A second step was to create an added value from local non-timber forest products through local transformation and production, financial management and improved communication.

Local farmer organization $\mathrm{AOPP}^{27}$, promotor of family farming and local self-sufficiency in food production, defended the interests of its members at national level. ${ }^{28}$

Sahel Eco, a Malian NGO established in 2005, became involved in training and dissemination on regreening, applying a user-centered, context-sensitive, collaborative approach. Team-building activities were central to Sahel Eco's approach. Farmer-tofarmer visits were organized. Knowledge and experiences were exchanged between farmers.

\footnotetext{
22 Source: AOPP internal project report: Forest Connect.

23 In the late 1990 SOS Sahel UK, CARE, Oxfam, USAID and various other agencies were active in this region and collaborated with local communities.

24 Personal communication with Mary Allen and Mamadou Diakité.

25 Source: http://tinyurl . com/Seno-plain-atlas-USGS (accessed o8-10-2020)

26 Recent work by Gray Tappan, US Geological Survey.

27 In 2016 AOPP consisted of 250 local farmer organizations, with 40.000 members, who live from small-scale agro-forestry, livestock and fishery.

28 Source: AOPP internal project report: Forest Connect.
} 
To make regreening economically viable for farmers, Sahel Eco helped to set up new, so-called "agroforestry value-chains". The activities consisted of (i) training farmers to process/transform tree crops into consumables and (ii) improving local communication to support sales of tree products (commonly called "NTFP", non-timber forest products).

In interviews Sahel Eco staff members told me how they adapted and embedded actions in local culture. For example, there were daily broadcasts on local community radios to disseminate information about new forestry legislation, informing villagers (in their own local language) that tree cutting by intruders was not allowed.

The collaborative, user-centered approach and adaptive management of Sahel Eco matched well with our approach. Sahel Eco staff members taught us important lessons and provided many insights about the local context that were valuable for our ICT $4 \mathrm{D}$ research.

\subsubsection{Meaningful activities and collaborations}

Spread of regreening occurred at various scales: via social networks, personal contacts and mass media (radio was the only one available in rural Mali). The importance of personal communication, face-to-face encounters, testimonials and meaningful collaborations at the human scale was stressed by those involved in activities to support communities.

(Here again we make a leap from the general description to the human level of meaning and social interaction). An example of meaningful dissemination of knowledge about regreening, is the broadcasting of popular songs and poems in local languages on local radio, describing the usefulness of the Balanzan tree, a tree species (Faidherbia albida). This tree has many advantages for farming and soil conservation. These poems became famous as they were frequently broadcast in 1995 on community radios in the cercle of Bankass, by radio Seno. They made farmers aware of the benefits of regreening. ${ }^{29}$ In this poem, written originally in Bambara language by Mamadou Diakité ${ }^{\circ}$ the tree begs the farmer for protection:

\footnotetext{
'Paysan du Séno vient m'aider, soit un espoir pour moi, pour me sauver Paysan du Séno protège moi contre les dabas

Paysan du Séno protège moi contre les charrues

Paysan du Séno protège moi contre les coups des haches des éleveurs

Paysan du Séno protège moi contre les feux de brousse

Paysan du Séno me sauver n' est pas difficile, il suffit de gratter le sol autour de moi et matérialiser ma présence...'
}

29 Source: Interview with Mary Allen, February 2016.

30 The former coordinator of the SOS Sahel UK. 


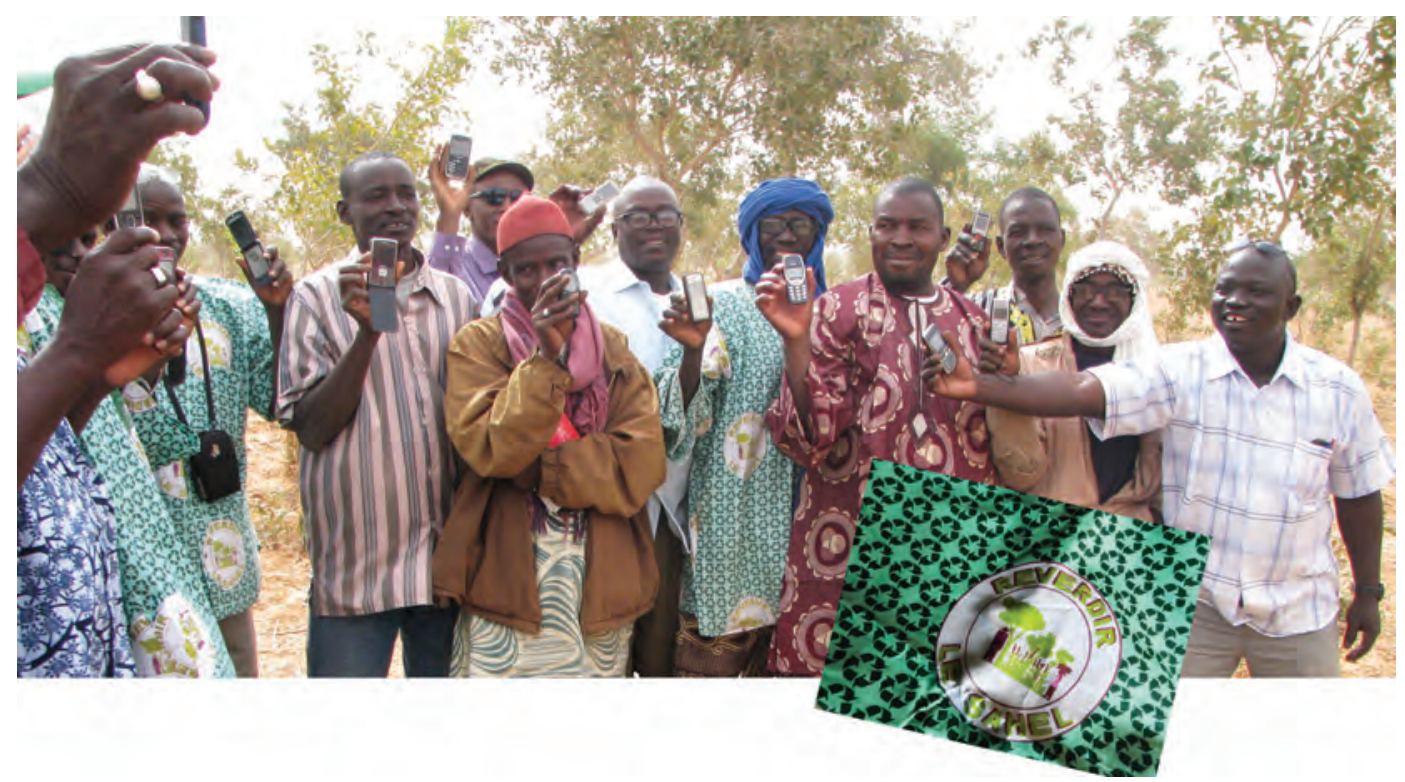

Figure 14: Mali, January 2011: Sahel Eco launched a regreening pagne, with the famous "Reverdir le Sahel" logo, as a meaningful and team building gift to those concerned with regreening. Photo: Bruno van Moerkerken.

A meaningful dissemination action by Sahel Eco is the green "regreening" pagne. This cloth (see farmers and NGO staff dressed in green on Figure 14) was awarded to farmers who were regreening champions. The regreening Sahel Eco cloth became famous in the region. Farmer Moussa Sangara was one of the champion farmers-innovators we met in his field, who started practicing regreening in the area of Bandiagara and disseminated this to others in the region of Mali.

Scaling-up and dissemination actions included advocacy films about agro-forestry and regreening. Salif Aly Guindo, President of the Barahogon Association from Ende wrote the following acknowledgement:

"Thanks to the production and diffusion of the film about our experience of farmer managed natural regeneration the Barahogon are known today both inside and outside Mali.' [...] 'Although this gives us great feelings of satisfaction we are also aware of the many challenges that we still face including reaching $100 \%$ adoption of FMNR ${ }^{31}$ in Barahogon member villages. ${ }^{22 "}$

Personal testimonials of local successes like the one from the president of Barahogon or the experiences of regreening champion Moussa Sangara are important for diffusion of innovations, through dissemination. AOPP collected a testimonial from Fanta Diamountene, a woman from the rural community of Farakala, in the district of Sikasso.

31 Farmer-managed natural regeneration.

32 Source:http://tinyurl.com/sahel - eco-Barahogon (accessed o8-10-2020) 
Aged 49, Fanta became producer of non-timber forest products. Formerly, she worked in farming, but due to food insecurity she became interested in tree products. In 2005 she started to collect neré seeds ${ }^{33}$ and sell them at the market of Farakala, as a source of income for her family. In 2006, after being trained by AOPP and after the establishment of a new women's union, she started to produce soumbala, a staple food transformation of the neré seeds. She managed to sell $50 \mathrm{~kg}$ of soumbala per month for $50.000 \mathrm{fCFA}$, earning 10.000 fCFA (about 15 euro) per month. In 2013 she increased her production to $150 \mathrm{~kg}$ per month. This has raised her year income to 450.000 fCFA (675 euro). This enabled her to pay the study fee for her daughter. Fanta is now the president of a local women organization. 34

\subsubsection{Late emerging impacts}

Until late 1990s - early 2000s, the impacts of regreening remained hidden for development experts and researchers despite joint activities to promote farmer-managed natural regeneration by farmer organizations and NGOs. Some projects were considered a failure, because no impact was noticed at the end of the project period. In 2005, almost ten years later, the effects of farmer managed natural regeneration - becoming visible only after quite some time - were observed, almost by coincidence, by researchers and development agents traveling through the countryside. 35 The area of regreening successes seemed to be expanding autonomously from community to community. In the same period (mid-200os) regreening successes from Niger and Burkina Faso were published [344, 334, 336] and connections were made between several stakeholders (farmers, researchers, NGOs) in these countries. ${ }^{36}$

\subsubsection{Case: farmer innovation in Burkina Faso}

In the mid-1980s regreening started in the Central Plateau of Burkina Faso [336]. This change in land-use was triggered by a period of crises in the 1970 and early 1980s, when the Sahel was struck by droughts [336, 337]. During these years, harvests failed, cattle died and food ran short [219]. Vegetation disappeared from the fields and wells fell dry. Trees were cut and sold as firewood - for many a last source of income $[219,336]$. Subsequent years of low rainfall had devastating consequences for the rural population. Famine made people - especially the male population - migrate to neighboring countries, in search for paid labor. Women, children and elderly people stayed behind [276].

33 Neré seed is a tree product.

34 Source: Mady Sidibe personal communication and AOPP internal project report http://tinyurl.com/ W4RA - A0PP - valorisation - pdf (accessed o8-10-2020)

35 Interviews with Mary Allen, former executive secretary of Sahel Eco.

36 Niger, Burkina Faso, Mali, but also northern Ghana. 

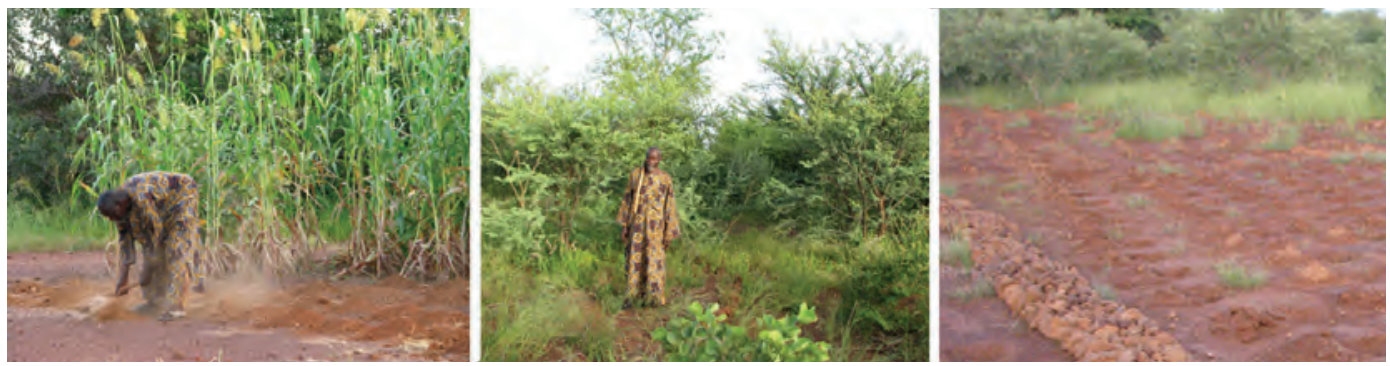

Figure 15: Left: Innovator Yacouba Sawadogo practicing zaï by hand, middle: Yacouba in his regreened field; right: a field recently elaborated with zaï and stone bunds. Field visit to Ouahigouya, September 2009.

Despite the lack of food, water and resources, a number of farmers in the Yatenga area in Burkina Faso decided to stay and struggle for change [219]. Yacouba Sawadogo, a farmer from the village Gourga, in the Yatenga province, was one of them. Yacouba Sawadogo experimented with zaii, a traditional practice of manually digging pits in the rock-hard barren soil and filling them with manure, to improve soil fertility and infiltration of rain water ${ }^{37}$ (see Figure 15). The method proved successful and Yacouba started to disseminate his knowledge to other farmers in the region. Yacouba Sawadogo became one of the key-innovators and established an association for the promotion of zaï and organized a so-called zaï forum every year, where farmers could share experiences and knowledge [219, 338].

Another farmer-innovator was Ousseini Zoromé, from Somyaga, a village near Ouahigouya, in the Yatenga province. Ousseini Zoromé also applied zaï and protected sprouts and bushes on his fields, so that they would become trees [219]. He laid stone bunds to improve water infiltration and prevent soil erosion. Ousseini Zoromé increased the number of trees on his land from 9 to 2000 in twenty years ${ }^{38}$. He also created a zaï school, and trained 1000 farmers to restore degraded lands [338, 219]. The knowledge exchange between farmers occurred mainly through face-to-face communication, because of the wide-spread illiteracy [336].

Various studies demonstrated the usefulness of simple and affordable techniques 39 for soil and water conservation, and showed how these practices were widely being implemented, often without external support or donor funding [340, 337, 116]. Farmermanaged natural regeneration (FMNG) was an example of innovation and re-invention of traditional knowledge by farmers.

37 Personal communication with Yacouba Sawadogo, January 2011.

38 Personal communication with Ousseini Zoromé , January and July 2014, February 2017.

39 E.g. planting pits called tassa or zaï and demi-lunes (semi-circular sand bunds to improve water harvesting) were introduced and disseminated. 
Farmer-led innovations spurred changes in land-use and intensified coopeation between farmers, herders, practitioners, researchers and government agencies, and NGOs ${ }^{40}$ [98, 338]. Farmers and pastoralists, who previously disputed land-use, managed to jointly set up combined agro-forestry systems, involving interaction of cattle, manure, soil fertility and trees. Local non-governmental organizations (NGOs) supported bottomup identification and dissemination of community innovations [377, 336]. Meanwhile other distributed actions contributed to the improvement of local livelihoods [377]. The discovery of ancient tree root systems in the soil, as a potential source for new trees, became of great benefit for local regreening initiatives [344, 339]. Regreening innovations spread accross vast areas. Two decades later, regreening had reached a scale of 200.000 hectares in the Yatenga and Zondoma regions of the Central Plateau of Burkina Faso $[337,339]$.

\subsection{LESSONS LEARNED FROM THE CONTEXT ANALYSIS}

The previous sections have introduced a complex rural context in West Africa at three different levels: (i) at the regional scale, briefly touching on historical backgrounds of soil degradation and food shortages; (ii) at the local scales of communities and farmer organizations; (iii) at the human scale. The last one requires field visits and face to face meetings. Especially when the ICT developers have a different (e.g. urban, western, technical) cultural background, and are insufficiently familiar with the circumstances of the end-users, as well as the limitations of the environment in which they live. Therefore, context analysis must be done in a systematic way, addressing the regional, local and human scales. This provides understanding that could not have been obtained by e.g. desk studies only.

As made clear in the context analysis in this chapter, the variety of interrelated factors and feed-back loops that exist in a complex context as e.g. the rural Sahel in West Africa (as illustrated in Figure 13) require a realistic and much more refined "theory of change" than the technology-driven, non-participatory and centrally planned interventions and evaluation approaches (e.g. logical framework approach, linear theory of change) that are often used in international development projects, as e.g. described in Chapter 2. I therefore propose context analysis as an explicit and integral part of the adaptive approach. (How context analysis fits into $\mathrm{ICT}_{4} \mathrm{D}$ research and practice is done is elaborated in Part III).

40 For example the OXFAM agroforestry project PAF, which introduced stone bunds in the Yatenga region, the Dutch PEDI project, the IFAD funded soil and water conservation project in the Sanmatenga, and the German-funded PATECORE project in the Bam region. 


\subsubsection{Concerns for $\mathrm{ICT}_{4} \mathrm{D}$}

Apart from insight in the context, this analysis also yielded information that is directly relevant for ICT4D. Based on field visits (e.g. [104, 42, 106, 41, 184, 183, 40]) a list of observations and concerns has been set up, related to (i) the specific local conditions, which can be encountered in low-resource environments, and (ii) methods to bridge the cultural gap between the ICT developers and users and their local context. Our most important observations are listed below.

INTEREST BY LOCAL PEOPLE IN ICTS The rural community we visited expressed their interest in new technologies that might help improve their information needs. They told us they would be prepared to pay a small (reasonable) amount for a service, if this would really improve something that they value. This interest of local users was confirmed in many other trips between 2010 and 2020, to various regions in West Africa.

LOCAL NEEDS UNKNOWN Information needs of inhabitants of low resource environments may be very different from customer needs in wealthy parts of the world. For example, a reliable weather service, although seen as trivial in an urban environment, would be of great added value to rural communities in the African drylands as it simply does not exist now in any usable and accessible form. Thus, an $\mathrm{ICT}_{4} \mathrm{D}$ project should explicitly focus on the real needs of the prospective beneficiaries or end-users, with an eye on developing ICT services that really matter to the users.

CONTEXT UNKNOWN Context analysis is not a one-off activity as I will discuss in the next chapters. It is a recurrent activity, in which understanding of the context is gradually increased. It is important to note that the context analysis should be independent of ICTs going to be deployed or not. The analysis' outcome might even be that no ICT solution is desirable, possible, or suitable..$^{41}$

SIGNIFICANT LEVELS OF LOW-LITERACY In rural regions of the Sahel, as in many developing regions in the world, low-literacy is still widespread, so this has a severe impact on ICT. It restricts the affordances of much available technology (for example, systems using SMS-text messages are out of the question). One of the ways to deal with this is to explicitly consider the preferred mode of interaction of users, e.g. using voice/speech, in local language.

(UN-) AVAIlability of CRUCiAl technology ANd INFRASTRUCTURe An important constraint is the problematic availability of important infrastructures and tech-

41 All too often we, as $\mathrm{ICT}_{4} \mathrm{D}$ researchers or technology developers, are inclined to think in terms of technology solutions, without an in-depth context or problem analysis. 
nologies. In rural regions an electricity network is commonly not present, while in urban areas outages are a regular phenomenon. As a consequence, internet connection is absent in rural regions, and suffers from high cost and less-than-desirable quality (e.g., needed bandwidth) and reliability in the urban areas. Communication technology, in particular mobile telephony (still mostly feature phones, not smartphones), is widely available, but expensive; in rural regions radio is a popular mass communication medium (more than TV, because of its electricity demands). Also, hosting of ICT services is not always possible or at least very costly. Therefore, during the design process, the developers should keep in mind that service deployment already in the purely technical sense is a real down-to-earth problem, and innovative solutions should be sought.

LOW PURCHASING POWER In developing regions, purchasing power of the intended end-users is relatively low. Therefore, many proposed ICT solutions, even if technically feasible, may not be financially feasible, simply due to customer cost considerations. Hence, $\mathrm{ICT}_{4} \mathrm{D}$ should support the evaluation of the prospective service, specifically with respect to the purchasing power of end-users.

LACKING UNDERSTANDING OF ICT POSSIBILITIES For many intended end-users, it is the first time that they are exposed to ICT technologies such as Internet and Web. This complicates the ICT requirements elicitation process, and before that, finding an adequate ICT-enabled service in the first place. Therefore, $\mathrm{ICT}_{4} \mathrm{D}$ should deal with ICT-agnostic end-users, for instance by demonstrating successful ICT services in a recognizable development context, show rapid prototypes and mock-ups, and demonstrations.

MISMATCH BETWEEN DONOR'S AND BENEFICIARIES' GOALS In practice, many $\mathrm{ICT}_{4} \mathrm{D}$ projects receive donor funding (e.g. from the EU, the World Bank, or large philanthropic funds such as the Bill \& Melinda Gates Foundation) to increase access to and use of ICT in developing countries. There is no convincing reason to assume that donor agency goals will match those of the supposed beneficiaries living in another part of the world.

CONCERNS RELATED to ECONOMic sustainability As explained above, $\mathrm{ICT}_{4} \mathrm{D}$ projects often receive donor funding. Such funding is essential to develop and initiate the service. However, many $\mathrm{ICT}_{4} \mathrm{D}$ services discontinue once donor funding comes to an end. In such cases, the service is not sustainable. During ICT4 $\mathrm{D}$ service development, a clear understanding should be created concerning financial sustainability. Typical questions that emerge are: What is the delivery and maintenance structure of the service after the piloting phase? Can the service survive in the longer run by end-user fees or other ways of cost recovering? 
ETHicAl CONSIDERATIONS OF OUR APPROACH When doing $\mathrm{ICT}_{4} \mathrm{D}$, the developer/researcher is often confronted with intricate aspects related to issues of e.g. poverty, interests and power. The wellbeing of the stakeholders is a first priority. Therefore, a reflective attitude, concerned with people and their problems/situation and being respectful to the local culture and local people and communities is essential. Ethical considerations have consequences for the way how project goals are defined, use case and requirements are analyzed, how data is collected processed and stored, how dissemination of materials is done. This has consequences for he ownership of the produced artefacts, which have, for example, not only the researchers' full ownership. Ethical aspects of the research and its intended and (possible) unintended consequences must be discussed in an open dialogue in the team and with all stakeholders.

\subsubsection{Context analysis is key for ICT4D}

Context analysis is not a one-off activity as I will show in the next chapters. It is a recurrent activity, in which understanding of the context is gradually increased. It is important to note that the context analysis should be independent of ICTs going to be deployed or not. The analysis' outcome might even be that no ICT solution is desirable, possible, or suitable..$^{2}$

This chapter has shown that context analysis is a key element of a collaborative, adaptive, iterative approach to $\mathrm{ICT}_{4} \mathrm{D}$. I argue that context analysis should be an explicit activity in any development action that aims to improve a complex, real-world situation. This is necessary because context analysis provides (i) understanding of an on-the-ground validated "theory of change" and its complexities in general; (ii) relatedly, it yields a set of key concerns that need to be addressed.

42 A mistake often made in $\mathrm{ICT}_{4} \mathrm{D}$ and technology development in general is to jump into conclusions about the need for technology, prior to an in-depth context and needs analysis. 


\section{NEEDS ASSESSMENT AND COLLABORATIVE GOAL CONSTRUCTION}

Needs assessment is a fundamental component of a collaborative approach to ICT $4 D$. It consists of two iterative steps. The first is getting to know what the envisaged users' operational goals are, which information they need to achieve these goals and what their current constraints are. This step can be considered as an introduction to the problem space. The second step is about exploring the solution space, setting priorities what can and should be done. The result of the first iteration is a list of needs and priorities, as expressed by the end-users. The second iteration yields a long-list of project ideas or a portfolio of key ideas for ICT4D. The process of needs' assessment involves extensive two-way knowledge sharing and collaborative decision making. This shows how the first Principle for Digital Development: Design with the User ${ }^{1}$ can be made operational.

\subsection{AN ITERATIVE APPROACH TO GOALS AND NEEDS}

This chapter describes a methodology for collaborative and iterative needs' assessment in $\mathrm{ICT}_{4} \mathrm{D}$. Firstly, it describes how the problem space is explored during face-to-face meetings with representative users. Secondly it shows how the solution space is explored and how this leads to a list of project ideas which can be elaborated (at a later stage) into ICT systems/services/solutions.

The first iteration is getting to know the users' own needs and objectives and making them explicit. It is not easy to distill one's information needs, especially when a user or user group does not know what ICTs or "information needs" are. Conversely, it is difficult for the $\mathrm{ICT}_{4} \mathrm{D}$ developer or researcher who is an outsider, to understand the users' operational goals, workflows and activities. To cope with these issues we developed a collaborative, iterative workshop approach, capable of tackling complex, unstructured information.

During the second iteration, after having collected a number of user stories, constraints, problems, possible solutions and business ideas, it is time for selection of key ideas: which ideas are most interesting for the users, balanced against technical and cost considerations. The developers' team must make sure that user expectations are realistic (what can be achieved and what will work), given the constraints of costs, time, feasibility and technical skills.

Needs assessment yields a portfolio of key ideas and user stories which can be analyzed and elaborated into real systems' design. The process can be jointly evaluated

1 See: https://digitalprinciples.org/, (accessed o8-10-2020) 


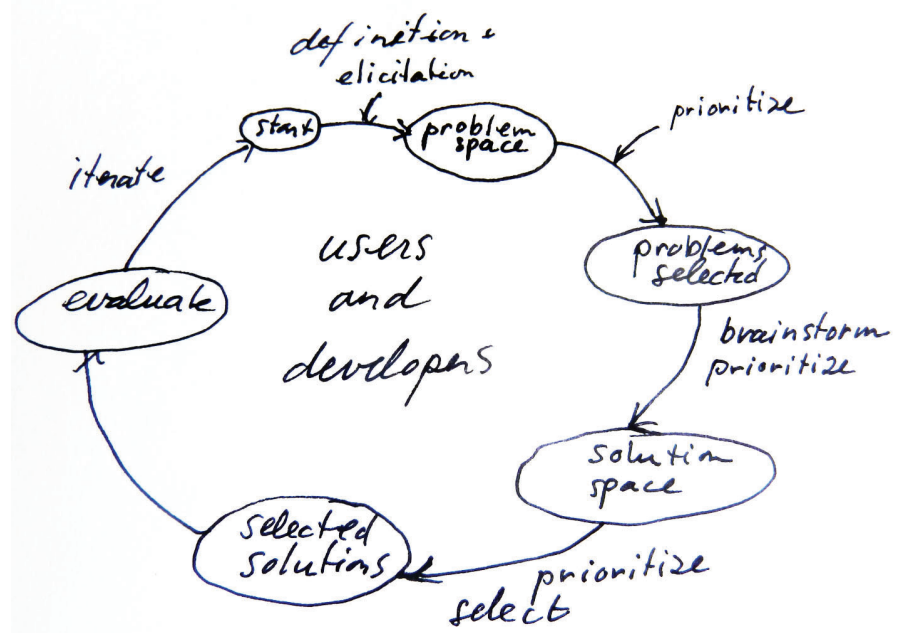

Figure 16: Our proposed model for a collaborative, iterative needs assessment: defining a problem space, a solution space, selecting and evaluating key ideas.

and re-iterated. Collaborative goal constructing and decision making by developers and users remain important, throughout needs' assessment. The iterative process is sketched in Figure 16.

The collaborative/iterative needs' assessment approach is illustrated in this chapter by examples from workshops by the $\mathrm{W}_{4} \mathrm{RA}^{2}$ research team and local partners, in rural Ghana, Mali and Burkina Faso, in the period $2010-2018$.

\subsection{FIRST ITERATION: JOINTLY EXPLORING THE PROBLEM SPACE}

To build useful technologies - in low-resource environments or anywhere else - it is important to bridge the (cultural, physical, language) distance between developers and users. Partnerships, dialogue and mutual trust are essential. Face-to-face meetings and collaborative workshops, preferably in the users' own environment, must be organized. Representative sites must be visited. Developers learn what users perceive as needs, problems and opportunities. To encourage creative thinking, technology demos or short videos are shown.

Needs assessment requires extensive information analysis. This is done with focus group discussions, group assignments, field visits, technology demos etc. We used from the Toolbox of Methods described in Chapter 3: living labs, which are innovation spaces where developers and users jointly innovate [23, 8]; soft systems methodology, for assessing and conceptually modeling users' needs [86]; the Japanese concept of 'ba' [293, 295], for establishing creative spaces of innovation and dialogue; various elements of participatory technology development (PTD) from African farmer innovation are

2 https://w4ra.org 
applied [338]. Appendix B lists the activities that have taken place (or are still ongoing) during our field research trips, in the period 2009 -2020 in Mali, Burkina Faso and Ghana.

ROADSHOWs Our research in West Africa involves roadshows to farmers in the field, living in small rural villages. Meetings with key users take place in open spaces, under a tree, in the users' own environment. Commonly, a field visit to a rural community takes 2-3 hours, starting with a courtesy visit to the village chief, followed by focus group discussions with a group of people. These meetings are chaired by a local contact-person (a local NGO or university staff member). The contact person makes the international team aware of local protocols.

TALKING WITH USERS To avoid communication gaps, it is important that developers talk with envisaged end-users themselves, not just with intermediaries (NGO people, local experts, governmental agents). Whereas these intermediaries may be sources of (contextual) information, they do not replace the dialogue with the real end-users. ICT developers may be tempted (for various reasons, e.g. to save costs or time) to talk with intermediaries only. However, this will not reveal the full picture of needs and requirements, and will not lead to a good (ICT) solution.

ROLE OF THE MODERATOR: The workshop moderator/requirement engineer mediates between users and developers and poses what if and how is this done questions:

- How does the actual process or workflow work?

- How do things work currently?

- Who are the stakeholders/responsible persons in the given process?

- What are the tasks of every stakeholder?

- What do the stakeholders want to achieve?

- Are there any problems related to lack of information and/or difficulties in communication?

- How do the users themselves perceive the problem(s)?

- What causes the problems?

- How could this be solved/done differently?

- Are there any alternatives?

- What if the actual constraints can be solved using innovative technologies? 
- For which reason would potential users value a certain (technological) solution?

- What would be improved by building a new ICT solution?

- What should or could be improved?

- What could possibly go wrong?

- What happens if the system is left unchanged?

- Why...?

An important task of the moderator is not to be satisfied with a simple answer. To understand the completer process and work flow, who is responsible for what, how is the communication, what are the goals of each stakeholder, the moderator has to ask many open questions "flink doorvragen!"

ROLE OF THE OBSERVERS The moderator is too busy to take notes. One or more observers are present during the workshop, to take notes, make photos, record audio, and observe the conversation. They can ask questions to help the moderator.

LOCAL ENVIRONMENT: Field visits are useful for the ICT developers - who are often unfamiliar with rural contexts - to observe and experience how things are done in practice. Users may not be used to describe how they perform tasks or work, so it is useful to observe them while performing. Talks during field visits trigger discussions between developers and users and lead to new questions and answers.

TESTIMONIALS OF OTHER USERS: Local users who have previously participated in a similar project, are invited to share their experiences. The explanation is better understood when told by peers.

EXPERT INTERVIEWS: Interviewing a (local) domain expert is a method for elicitation of specific domain knowledge and understand how local work flows are organized. In a complex new context, the interviewer must take an open attitude, and realize that she does not know what she does not know. She asks many "what if" and "how" questions. Interviews are semi-structured and preferably done with more than one interviewer, to capture as much information as possible. Sometimes a translator is needed, if the interviewee speaks only a local language. Interviews are recorded and filmed and written out in field notebooks. Photographs are made, (with consent from the users). Conceptual models or mind maps are used to visualize the structure of the interview, see e.g. Figure 21. 
BUSINESS IDEAS AND STAKEHOLDERS: Considering the future sustainability of possible ICT solutions, business ideas are assessed, which relate to the users' operational goals: their work or business. Participation of local (potential) business partners is an essential aspect of the needs' assessment, to understand the local eco-systems in which $\mathrm{ICT}_{4} \mathrm{D}$ services are supposed to be deployed. Business partners can be e.g. local radio stations, veterinarian services, local ICT business and other local interested stakeholders.

LEGACY SySTEMS: ICT development (in general) is easier to build and more sustainable when it starts from a 'legacy' system, i.e. an existing information or communication work flow that is already in place. The advantage of legacy systems is that, even if inefficient, they represent a useful and/or meaningful process in the local context. Legacy systems can be paper-based, manual or oral communication of information system, that have a clear work flow. During needs' assessment legacy systems and existing work flows are studied in detail by the developers, through interviews with different users of the system.

PROTOTYPES AND TECHNOLOGY DEMOS: ICT demonstrations such as mockups, prototypes, story boards and films show users what ICTs have to offer. In contrast to deploying an application at once, this method ensures that solutions are meaningful for local goals and context. These demos encourage group brainstorming about constraints and ideas for possible solutions.

Rapid prototyping, i.e. building a demo system according to users' ideas during the workshop, is a quick method to increase understanding of the users about ICTs and its development process and encourage brainstorming and evaluate usefulness of an idea. Users can evaluate the prototype immediately and give feedback. This requires the presence during the workshops of skilled technical $\mathrm{ICT}_{4} \mathrm{D}$ developers. A platform ${ }^{3}$ for rapid prototyping in rural conditions (no internet, mobile solutions, high temperature, no electricity) is essential.

Contextualization of demos and prototypes is important. As an example, a call flow diagram in Bambara, as shown in Figure 17, was used to explain users how a voicebased application works. ${ }^{4}$

FILMS AND PRESENTATIONS: Short (3-5 minute) clips of ICT systems, previously built for similar environments, are shown during workshops to make users aware of the possibilities of context-sensitive software solutions and to encourage brainstorming. Sometimes demonstration is not possible due to a lack of electricity. Ideas and requirements are collected on notes, audio tape and video. Brainstorming sessions are

3 For example the Kasadaka was developed for this purpose, see: http://kasadaka.com (accessed o8-102020)

4 The translation of this text to Bambara was done by one of our partners and key-users, Amadou Tangara. 


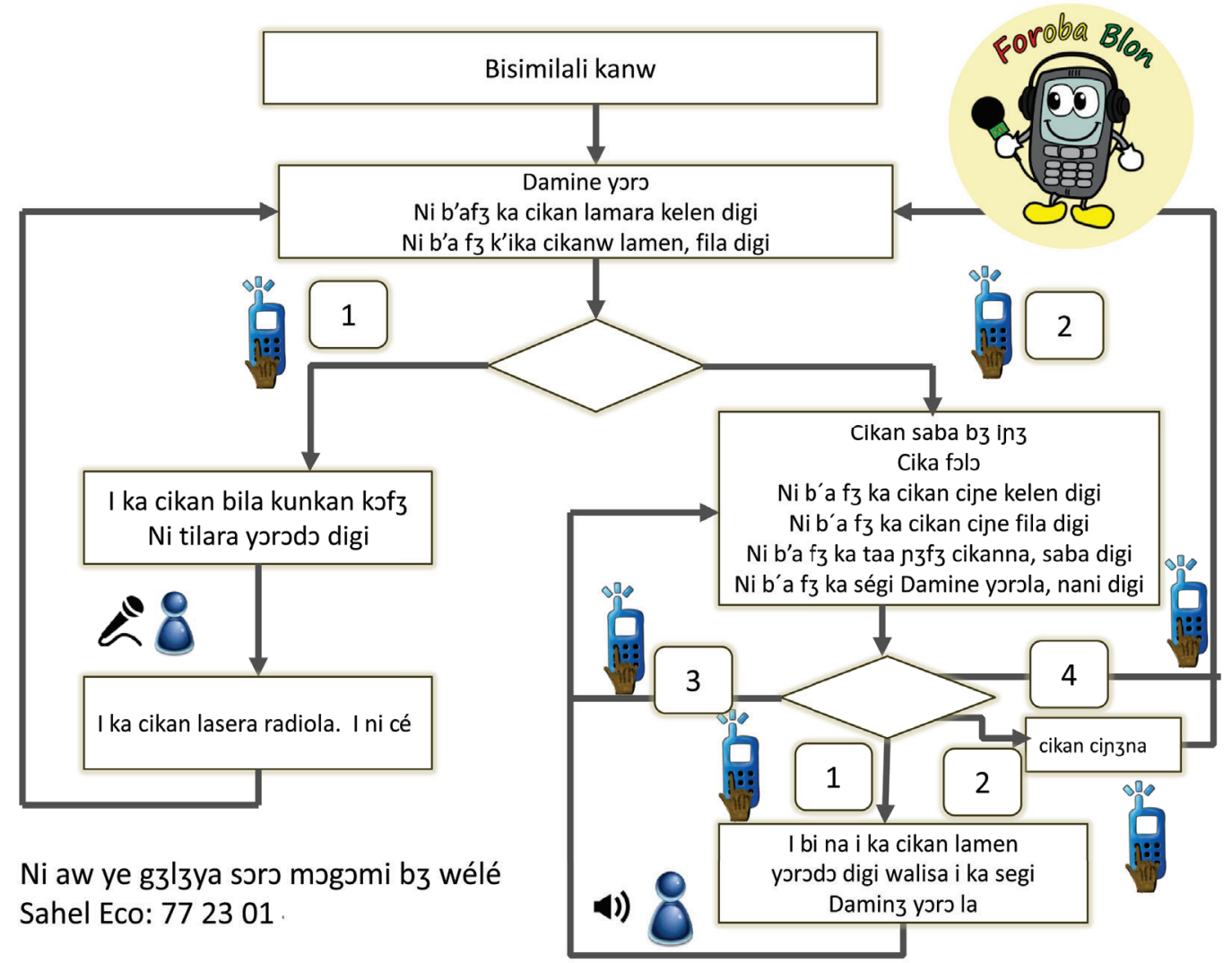

Figure 17: Example of a contextualized call flow model for a mobile voice-based dialogue in Bambara language. This model was used to communicate with end-users about the requirements for a voice-based system. Logo by Victor de Boer; call flow by Anna Bon and Stéphane Boyera; translation by Amadou Tangara. 


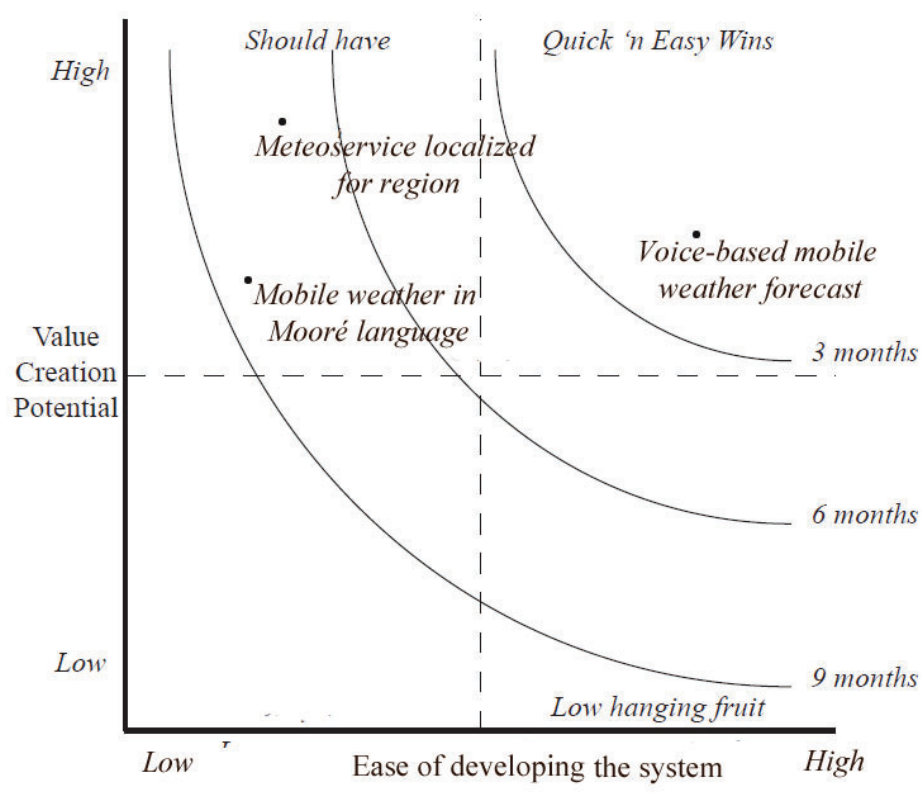

Figure 18: Prioritizing projects based on two criteria: relative value for local users, mapped against relative ease of technical development/deployment. In this diagram a number of project ideas for a meteo service are plotted, relative to the two criteria/axes. Adapted after Amir Hartman, John Sifonis and John Kador (2000) Net Ready: Strategies for Success in the E-conomy. NewYork: McGraw-Hill. Copyright: Hartman et al. 2000 [192]

audio-taped and filmed, (with prior consent of all participants). Comprehensive field trip reports are produced. 5

CUltural aspects: Field visits often have a ceremonial aspect. During context analysis and needs' assessment visit in January 2011 to the village of Tongo-Beo in northern Ghana, our team leader was offered a goat by the village chief, as a token of appreciation for the work in support of the community. During another visit in January 2011 to the village Yameriga, in Ghana, about 50 women welcomed us with a dance performance. After this ceremony and a village gathering with 150 people, we made a tour in the village and surrounding fields.

In the following sections, needs' assessments sessions are described, performed in Ghana, Burkina Faso and Mali. The W4RA team visited various sites in rural Africa to understand the user's objectives, needs and constraints, and collaboratively find out what could be done to improve information sharing and communication, given the (limited) available resources and local constraints.

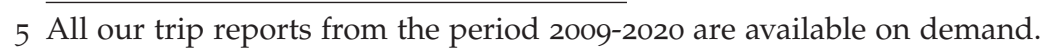


The result of the first iteration needs' assessment, described in the previous section, is a list of domains, problems, constraints, ideas. The next iteration is a joint exploration of the solution space. Selection of key ideas is based on relevance: which problem is considered most pressing by the users? For each of the selected problems a solution space is sought. From the range of solutions, a selection is made. This selection process is done collaboratively, during the workshops.

COllaborative goal constructing Prioritizing and selection of key ideas is based on two types of criteria, firstly: what would be the most advantageous solution for the users; secondly: what would be feasible, given constraining costs and complexity for its technical development added up to the given local constraints: e.g. available infrastructure - e.g. no electricity, no internet - local purchasing power of people with very low incomes, and cultural issues such as language and (il-) literacy. We can distinguish the following sub-criteria: (i) usefulness (i.e. increased efficiency of a certain task or improved communication), (ii) being fully adapted to the local context, (iii) feasibility in cost of use, (iv) simple in use, (v) generalizable and transferable to other regions, (vi) easy/inexpensive to develop and maintain, (vii) interesting in terms of local business or commercial service. The diagram in Figure 18 (from Hartman et al. [192]) can be used to map the different project ideas to see their relative priority according to these two criteria. This method is used by Cisco to prioritize ICT development projects in a high-tech environment, and has also proven useful for $\mathrm{ICT}_{4} \mathrm{D}$ needs' assessment and collaborative goal-construction. In this example in Figure 18, three different project ideas from farmers in Burkina Faso are mapped.

Each of the proposed solutions/key ideas is jointly evaluated against these criteria. This results in a portfolio of user stories, to be further elaborated, designed and built. Evaluation can lead to new ideas or solutions. The process can be re-iterated for improvement. This is conceptually visualized in Figure 16. A more extensive description of structured portfolio selection in $\mathrm{ICT}_{4} \mathrm{D}$ is given by $\mathrm{W}_{4} \mathrm{RA}$ team member/colleague Nana Baah Gyan (2016) [183].

The exercise of setting priorities results in a portfolio of use cases that can be further developed. The following sections illustrate how collaborative needs' assessment works in the field. The cases are from our field research in West Africa, For more understanding of the general context of Africa's drylands, where these use cases have been collected, we refer to Chapter 4 .

\subsection{CASE: NEEDS' ASSESSMENT IN GUABULIGA, GHANA}

Since 2009, in the framework of the research program W4RA - the Web Alliance for Regreening in Africa - our team has worked, together with a team of researchers 


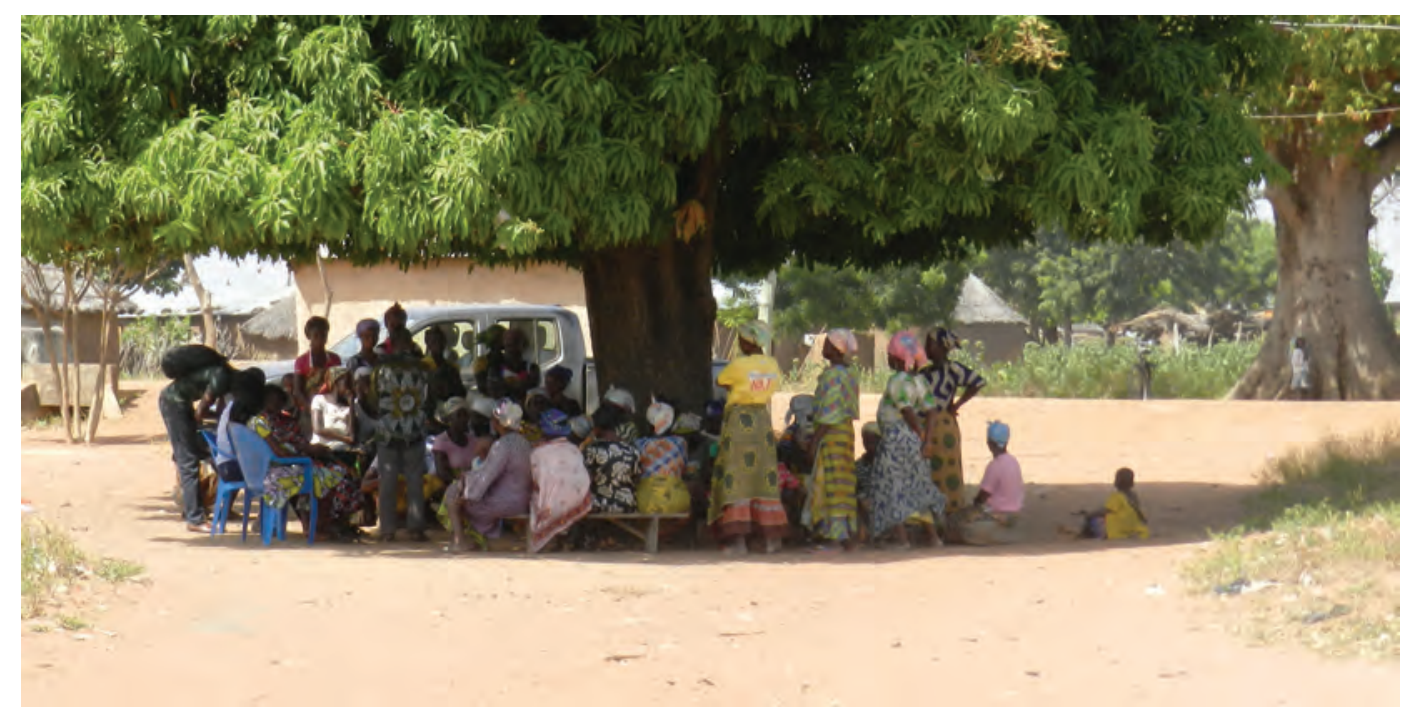

Figure 19: Needs assessment workshop with women of the rural community of Guabuliga, Ghana, December 2014. Photo by the author.

from the University for Development Studies (UDS) in Tamale, Ghana, to improve and facilitate knowledge sharing in rural communities in Africa. UDS, which is a public university in Ghana, has the goal to help improve living conditions of people in rural areas, through community-oriented education and research. ${ }^{6}$ This is operationalized through the Third Trimester Practical Field Programme in which each student at UDS has to do a community-based internship and work in a rural community during a certain period of his/her study.

In 2014 and 2015 we teamed up with researchers from UDS for a needs' assessment in the Guabuliga rural community in Northern Ghana.7 This village has about 2000 inhabitants who live from farming and livestock. Despite the fact that UDS does not have an $\mathrm{ICT}_{4} \mathrm{D}$ department or an $\mathrm{ICT}_{4} \mathrm{D}$ research program, the approach of UDS to do a needs' assessment with local communities is user-centered, and bears similarities to our collaborative $\mathrm{ICT}_{4} \mathrm{D}$ approach.

\subsubsection{Focus group discussions}

In December 2014, and April 2015, our UDS partners drove us to Guabuliga, near Walewale, in the Northern Region of Ghana. We did two needs' assessment workshops with a group of men and women of this community.

The visits to Guabuliga started with a courtesy visit to the village chief. We told the chief about our research and asked him permission to do this workshop. After the

6 http://www.uds.edu.gh (accessed o8-10-2020)

7 This workshop was funded by Dutch donor agency Nuffic, through the NFP-TMT program. 
visit, focus groups discussions took place at the village square. Four different groups of UDS and VU researchers worked with different members of the community in parallel. One of the group meetings took place in the shade of a mango tree (see Figure 19). In total 130 participants, of which 85 women, participated in the focus groups. Figure 19, and the following paragraph, give an impression of the focus groups. The questions are written in italics, the answers are a summary of all the reactions of the participating farmers, men and women. The whole session was translated simultaneously from local language Mamprusi to English and vice-versa, by researchers from UDS, who participated in the workshop.

This focus group started with seven women and five men, at the village square named Maasuyiri. After half an hour the numbers grew to about 30 people: 12 men and 18 women. The UDS/VUA team explained the purpose of the visit and the reason for the focus group. Amongst a few other topics, the following was discussed with the villagers: (i) land, water \& ecosystems (ii) weather and climate (iii) livestock. (These topics discussed with the community were not set by our team but came up naturally from the group discussions.)

LAND, WATER \& ENVIRONMENT AS ECOSYSTEMS: What have you seen changing in positive or negative sense, in the past 30, 20, 10, 5 years?

"We have seen loss of soil fertility. The land is increasingly exhausted and as a result, crop yields have significantly declined. This requires that farmers start the application of chemical fertilizer to crops such as maize, soya beans and millet. Moreover, over time the amount of rain has decreased significantly and this adversely affects crop yield and causes food shortages in most parts of the year. (e.g. shea trees are drying up, dawadawa is not fruiting this season and these could exacerbate the problem of food shortage). Most of the observed changes occurred between 6 to 20 years ago."

What are the crops, animals, and wildlife found here?

"There has been much change over the years. Food crops such as zamzam (sesame), adowa, naara (early millet) and sumpea are no longer cultivated. In the past, it was common to find rabbits, antelopes and other wildlife in the bush but today, most of these animals have become rare in the bush. There is literally no more wildlife in the area (they have significantly declined in numbers). Only hedgehogs and rats are still quite common. Bush burning may be the main reason for driving wildlife out of these lands."

What do you produce?

"In the past we cultivated crops like black-eyed peas (supea), zamzam (sesame), naara (early millet), adowa. Nowadays we produce maize, late millet, beans, sorghum, and groundnuts."

WEATHER AND CLIMATE: What do you see as the important challenges for farmers related to climate and weather? 
"The main challenges are erratic, unpredictable rainfalls, low soil fertility (tired soil) and excessive sunshine."

How do you try to address these problems?

"We leave crop residue on our farms and then plough them back into the soil during the farming season to improve the soil moisture. We use stone bunds to direct the flow of run-off water, and apply contour ploughing. We use manure and compost to improve soil fertility. We make sheds to minimize the consequences of excessive sunshine and rain water for vegetable nurseries, where we grow e.g. pepper and tomatoes."

What kind of weather information would be helpful to address this?

"Daily rainfall forecasts would be useful. Information on rainfall duration in the rainy season - to help farmers in making planning decisions which types of crops to sow/plant, where and when. Information on the severity of wind and its direction is highly needed to help farmers prepare in advance, e.g. reinforcing house roofings, planting trees to serve as windbreaks."

LIVEstock: How beneficial has livestock been to you, and in which ways?

"Livestock is used in Guabuliga as savings. Livestock can be sold whenever there is a need to diversify sources of income, when there is low food production. Sales of livestock is done to provide an income to buy food, pay school fees, health care insurance, house building, clothing. Other advantages of livestock are: manure on farms, payment of dowry. Cattle, especially bullocks are used to plough on farm land."

What are important problems you face related to livestock?

"Prevalence of animal diseases is increasing, and is currently a major cause of livestock mortality. Unpredictable patterns of disease outbreaks that lead to death are occurring. The known disease cycles/calendar are not applicable anymore. There is a perception that livestock imported from neighboring countries have diseases that infect local breeds. The symptoms are enlarged organs such as heart and lungs. This is a major cause of death of the cattle of Guabuliga. Other challenges in relation to livestock are: there are not enough water points or wells for animals to drink from. As herds have to walk large distances to find water, this increases the risk of livestock theft, especially amongst roaming grazing herds."

What are people doing to address these problems of the livestock?

"Veterinary officers (from Wulugu) are often contacted (via mobile phone) whenever there is an outbreak of disease that affect livestock in the community. Vets provide vaccination services and curative advice. In the past, community members dug ponds to collect and supply drinking water to their livestock. This has stopped because of low rainfall."

What kind of information would help to address these problems?

"Information related to the signs and symptoms of various animal diseases, categorized and sorted would be very helpful. This should include timely information on 
what to do when an animal shows signs and symptoms of diseases, and information on disease incubation period."

\subsubsection{Interviewing an animal health expert}

To obtain more background knowledge on animal health in rural Ghana, in December 2014 and May 2015, we were introduced by Francis Dittoh, researcher at UDS $^{8}$, for an interview to the local public veterinarian service in Tamale, from the Ministry of Agriculture $^{9}$, see Figure 20.

We wanted to know if an application to diagnose animal diseases would make sense. We wanted to have more knowledge on how animal health works in this rural context. The author interviewed the vets. The other colleagues took pictures and did the recordings. The interview was done in English. A questionnaire, prepared by students from VU, was the starting point for the interview, but it soon became a semi-structured interview. This interview with the local vet can be seen as a context analysis. This illustrates the iterative character of our approach. The interview was necessary after the need expressed by the Guabuliga community. A concept map of the structure of the information, obtained from the interview, is shown in Figure 21.

The veterinarians we met in Tamale, in the Northern District of Ghana, are traveling vets from a public service. They travel around and visit rural villages in the region around Tamale. We talked to Abubakari Zibuila, technical officer Tamale Veterinary Clinic, Dr. Amoro Nelson Agemga, from Tamale Metro Veterinary Clinic, and Senior Dr. Baba Issah, Zonal Officer in Tamale East, who actually gave most part of the interview. ${ }^{10}$ In our interview we focused our questions on the most important animals, cows, goats and sheep.

What is a veterinarian's working day like in Ghana?

"We attend cattle at the community, when a farmer approaches us if an animal is sick. It is too stressful to bring the animal, so we go there when they call us. Sometimes it happens when the animal gives birth. We work from Monday to Saturday, visiting the [rural] communities."

How many veterinarians does each region have on average?

"There are 14 vets in Tamale, working for the Metropolitan Agricultural Development Unit. There are eleven vets in the metropolitan area and three in the outside district."

Which types of animals are taken to the veterinarian?

8 Francis Dittoh is currently a PhD researcher and colleague in the W4RA team.

9 The meeting took place Thursday 17 December 2015 12:15 - 13.45h.

10 This interview is shortened and revised for readability. The original is available at request, both on tape and written out. 

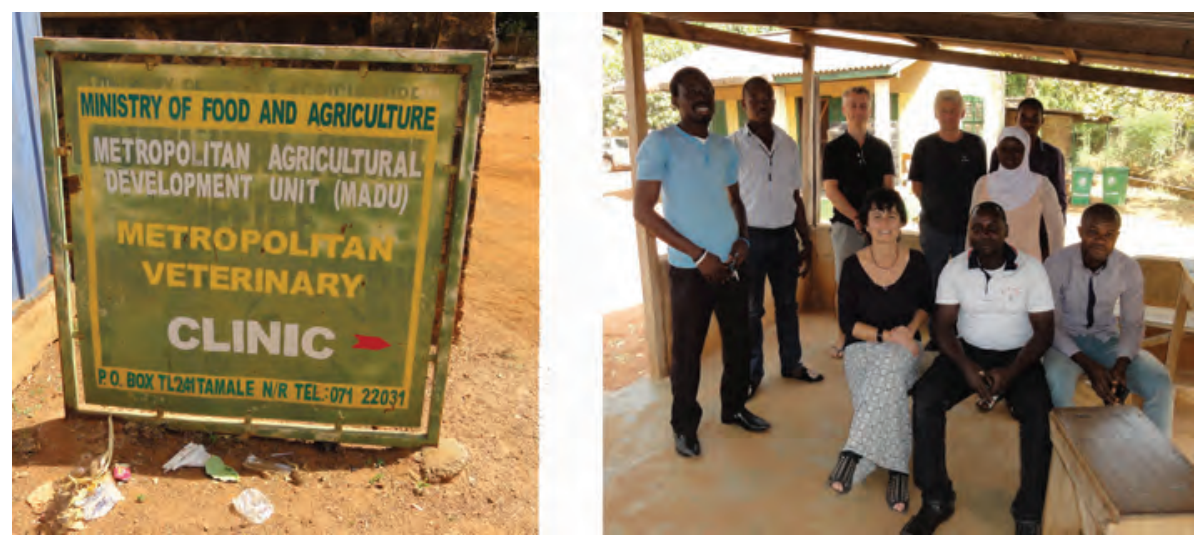

Figure 20: Visiting the veterinary service in Tamale, Ghana, 17 December 2015.

"Vets treat all kinds of animals: cows, goats, sheep, horses, donkeys, chicken, pigs, birds, fowls, and even dogs, cats and sometimes snakes. All the species you can think of."

What are the common diseases of animals brought to the vet?

"If we base on cattle we distinguish the following diseases often reported: Foot and Mouth Disease (FMD). Farmers here are married to poverty, so they do not vaccinate. Some treat with antibiotics. Some do not, by the second or third disease the cattle die. Sometimes it seems to heal by themselves. But then it can spread the disease. Black Leg or Black Water is a bacterial disease. It affects the arm or the high limb. It is acute. It can occur overnight. CBPP (Contagious Bovine Pleuropneumonia) is the third endemic disease here in Ghana. Anthrax is the last one. For now it has not occurred. We have taught the farmers about Anthrax. When they understand it, they agree a date to confine the animal on a certain date for vaccination. The last time we experienced Anthrax in Tamale was in 2001. In other regions Anthrax is endemic, and it occurs every year. Since we had a vaccination, every community has to vaccinate. They have to pay for this and we do the vaccination. Sometimes they do not confine [the animals]. You go to the community that has responded. Anthrax is a highly infectious and fatal disease of mammals and humans, is caused by a relatively large spore-forming rectangular shaped bacterium called Bacillus anthracis."

How much does a veterinary consult or surgery cost on average?

"The farmers are married to poverty. They may have 30 cattle but they do not want to pay for a vaccination, until the disaster suddenly occurs at their farm. They do not vaccinate because of the cost. They would like to have free vaccination. Formerly, the Ghanaian government paid for vaccinations, but due to economic motives, they now leave it to the owners. Only the farmers who see the importance, call us and pay for it. The cost of Anthrax [vaccination] is 3 Ghana Cedi ${ }^{11}$, for CBPP it is 4 Cedi; for Black

11 Cedi or GHS is the Ghanaian currency, 1 GHS is about 0,2 EUR 


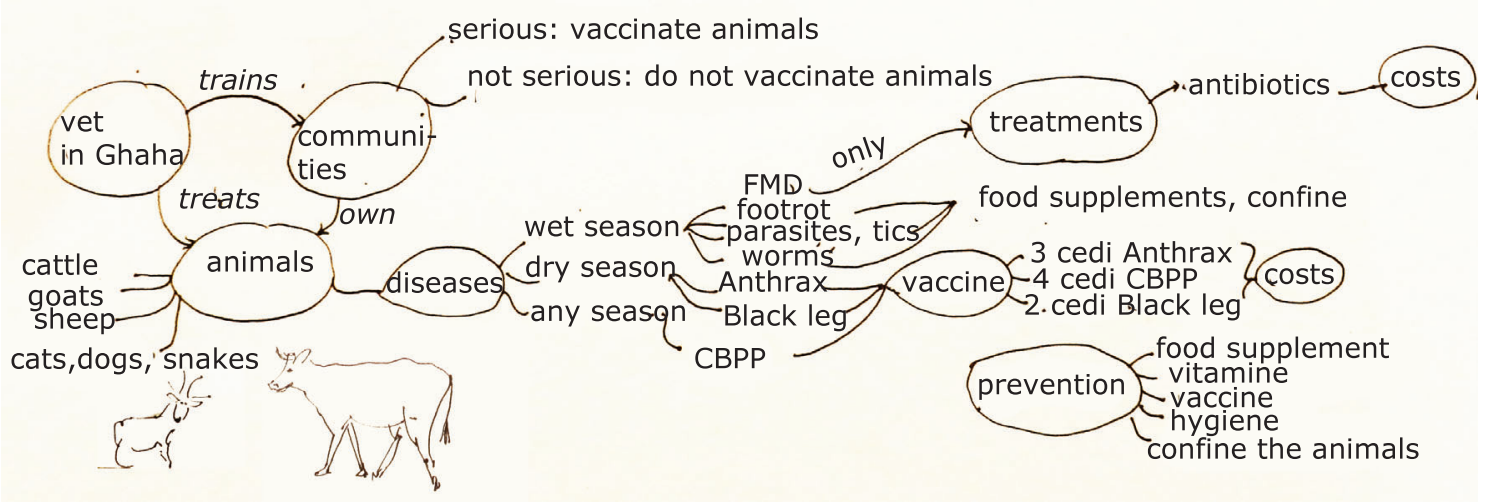

Figure 21: A (field-based) mindmap of the information obtained from the interview with the vet. It shows the important concepts and their relationships, by the author. This model was used to build DigiVet, a decision support system for animal health, by Gossa Lô.

Leg is 2 Cedi. The FMD does not have a vaccination; by contact it will spread; you collect the sample from an infected animal; in Ghana there is no vaccine. What we do is, we prevent the spread to other animals in two or three days. The treatment of FMD is with antibiotics, which can cure it. The cost of antibiotics is difficult to estimate, as it depends on the body size, on the condition of the cow and sometimes you also need other medicines. We can charge below 5 Cedi, but it can go up to 20 or 40 Cedi. "

What are the diseases that are characteristic of the rainy season/the dry season?

"During the wet season there is FMD, foot rot and parasites, tics on the grasses. Cattle grazes and the tics invade the system of the animal. Tic diseases can break the system. The most contagious of all diseases is FMD, as this can affect any four-legged animals (no birds). During the dry season, in the peak of the heat, Anthrax and Black Leg are the usual diseases. Animals are grazing closer to the ground. Anthrax can live in the ground $30-40$ years. They can also get Tetanus."

How are these diseases treated/prevented in general?

"All the diseases have vaccine, only the FMD does not have vaccine, only antibiotics."

Do you use ICTs, such as computers or cell phones, in order to complete your daily tasks?

"We use mobile to make a picture of a disease snapping with your phone to show the authorities. Our system is so poor, we do not have notebooks. Farmers do not use pictures, they are sometimes illiterate. They can only call you. An animal died so they call us. When they have a situation they want us to come within an hour."

Does the government provide some service or subsidy for vet services?

"Only for fertilizers, but not related to animal health."

Do you use the internet for consulting vet info?

"We do not use ICTs for professional use. Only for personal use." 
About goats and sheep: Do farmers vaccinate goats, what diseases do they get?

"Yes, goats are affected by similar diseases as cattle. They can get PPR ('Peste des Petits ruminants'), a sheep virus disease, to which we also vaccinate. Sheep and goats can get Black Leg, Foot Rot, Anthrax, basically the same diseases as cattle."

Can farmers easily recognize the diseases?

"We give workshops to farmers. Serious farmers are the ones who care for their cattle and say 'oh it is time to confine and vaccine the animals'. These are the serious farmers. A whole community can be a serious community. They have an interest. The rest of farmers do not do that."

Why do farmers keep cattle?

"For economic benefits. They cannot slaughter themselves. Use the donkeys for ploughing. They apply the manure for the land. Treatment and service is hard for them. The most important thing to teach to farmers is how to know when the animal is healthy or when it is diseased. Some conditions are not diseases, but only [due to] nutritional conditions. Some things can happen when they [the animals] do not get good food. E.g. in the rainy season you see when a calf has worms: it will walk in a wobbly way. So, you ask the farmer to confine the animal and de-worm it and give it supplementary food. When animals have Foot Rot you advise them to bring the animal out of a wet area in the rainy season and to take the animal to a dry place so the foot will heal."

"When its immunity goes down, the animal can get other diseases. You can do some prophylactic by boosting their immune system. We give them calcium or multi-vitamin. This is expensive to farmers. Our farmers are married to poverty. They may have 100 animals, but they will say 'I do not have money'. They will categorize it as difficult. We tell them not to plough with [sick] animals, but they refuse. When problems occur, they call us. When the rain has reduced they come. Rains start around June until October. We also give them advice about cropping. We say: go to other communities to learn from each other. We train them."

How often do you train the communities?

"Community training is done when you give a vaccination. We do that and we take the opportunity to talk and train."

\subsubsection{Evaluating ideas for $\mathrm{ICT}_{4} \mathrm{D}$}

We showed the vets a prototype of the system which is shown in Figure 22. What do you think of this DigiVet system? Would you use the system? Do you think the system would be used when implemented? Can you give us any tips or advice regarding the systems? Could you think of any additional things the system should be able to do? Would you be willing to answer some questions regarding this project in the future?

"Show the farmers the application and they will start using it. A veterinary officer can show it. If they know the condition and diagnose, you do not have to go there 

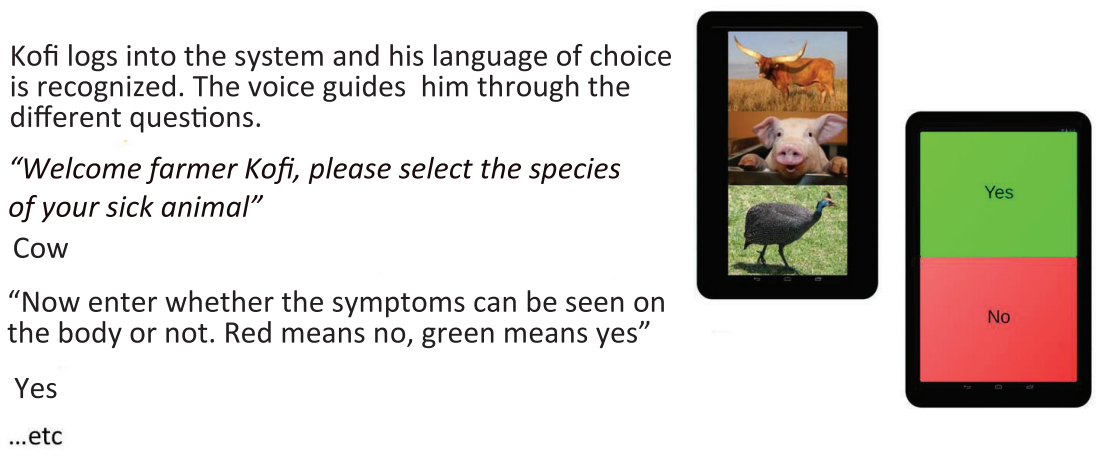

Figure 22: Example of the prototype for DigiVet, a system to diagnose animal health, designed and built by Gossa Lô and Romy Blankendaal.

anymore. So, it will help them, certainly in combination with the vet officer's visit. Sometimes it is difficult to diagnose Black Leg from a snake bite for them. Depending on the number of tablets, we want to do a test with two or three tablets to see if it works."

We will start building a prototype based on your input and show it to you again. It will not work the first time. It will take months or a year before it works.

\subsubsection{A prototype for animal health diagnosis}

Based on the (first) information collected from the Guabuliga community, and more needs' assessments (iteratively) by colleague researchers from the $W_{4} R A$ team, in the community of Zanlerigu ${ }^{12}$ in northern Ghana, animal health appeared to be one of the serious concerns in this region.

It was decided to build a simple prototype for a system for animal disease diagnosis. The idea was to enable farmers in rural Ghana to obtain veterinary information about animal diseases based on symptoms of various local diseases. The prototype would be shown to the farmers, in a next visit, to ask them if this would be a useful application. The idea was to make a mobile, voice-based system in the local language Mamprusi, but for demo-purposes a simple demo on a small touch screen (tablet) was used (see Figure 22).

A prototype named DigiVet was designed and built. This was demonstrated during several workshops, including in Mali for AOPP. To improve DigiVet, the students/junior researchers ${ }^{13}$ from the $\mathrm{W}_{4} \mathrm{RA}$ team ${ }^{14}$, built a knowledge representation model in $2016^{15}$.

12 Gossa Lô and Myrthe van de Wekken did their master research field work in this village.

13 Gossa Lô and Romy Blankendaal, supervised by Stefan Schlobach and Victor de Boer.

14 With a grant from the Network Institute@VU.

15 See http://w4ra.org/wp-content/uploads/2017/05/GossaRomy_Report.pdf (accessed o8-10-2020) 

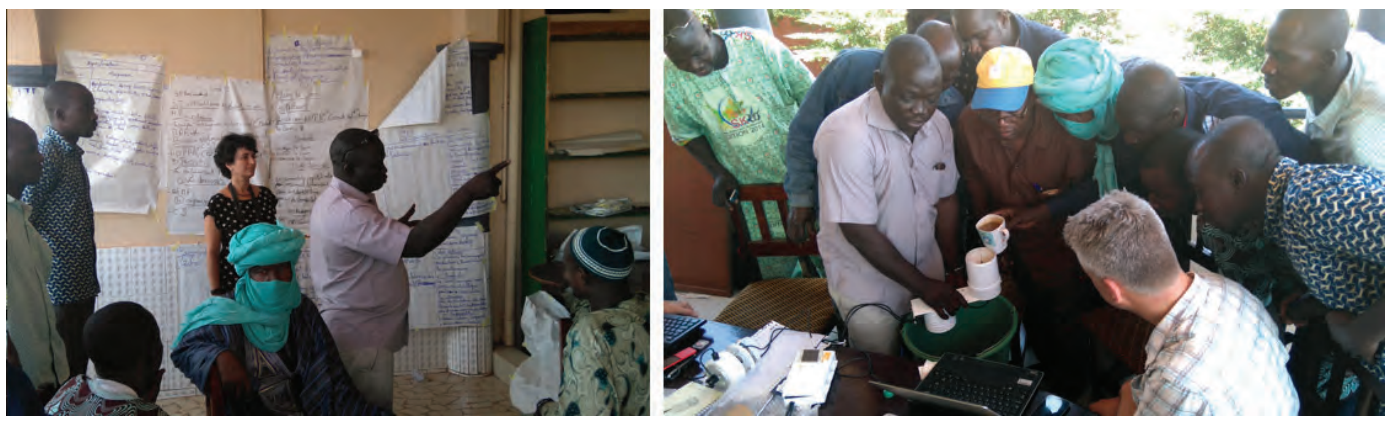

Figure 23: Left: plenary discussions after needs' assessment group work; right: demo of digital meteo-station by key-user Amadou Tangara, 11 October 2015.

This knowledge model was based on various sources of veterinary expert knowledge, including from the veterinary in Tamale. With the extended DigiVet system, farmers would be able to select from a menu the symptoms of a sick animal. The system provides the user with a possible diagnose, and advises whether or not to contact a veterinarian. In this way, DigiVet aims to help farmers to be able to diagnose their diseased animals. DigiVet is still being developed and improved, in $2017^{16}$.

\subsection{CASE: NEEDS ASSESSMENT WITH FARMERS IN MALI}

In 2014 the $\mathrm{W}_{4} \mathrm{RA}$ team started a collaboration ${ }^{17}$ with Malian farmer organization $\mathrm{AOPP}^{18}$, aimed at improving access to information and communication for smallholder farmers and pastoralists in Mali. AOPP is in fact an association of about 240 smaller farmer organizations with more than 40.000 members. AOPP's objective is to improve living conditions of farmers and achieve food self-sufficiency through peasant agriculture, family farming, multi-functional scaling methods, within the strategic framework of poverty reduction. AOPP has a presence in the whole of Mali. The members of AOPP are small scale farmers and pastoralists.

AOPP invited our team to discuss how to improve communication and access to information for smallholder farmers in Mali. At AOPP's request, our team organized a series of needs' assessment workshops in Bamako, with participation of a group of twenty farmers, all coordinators for AOPP in different regions in Mali. The methods, techniques and tools, used for the needs' assessment are described in the following sections.

In October 2015 the first needs' assessment workshop took place at the office of AOPP in Bamako. Eighteen farmers from different regions participated in the work-

16 A poster, by Gossa Lô about this system can be seen at https://w4ra.org/wp-content/uploads/2015/ 05/Poster_Gossa.jpg (accessed o8-10-2020)

17 The workshops with AOPP were facilitated by a grant from Nuffic within the NFP-TMT program.

18 AOPP is an acronym for Association des Organisations Professionnelles Paysannes. 
shop: Mopti, Tombouctou, Ségou, Sikasso, Bamako, Gao. The ICT developers team consisted of six people. Two potential, local service providers joined our team: an expert in rural development and community radios, and one ICT expert from a small Malian ICT-enterprise.

During the first of the four-day workshop presentations, demos, plenary discussions, interviews and work in smaller subgroups are done. The session is opened in Bambara language by the executive secretary of AOPP. This is followed by an introduction round. AOPP is introduced by its executive secretary. He summarizes the major constraints of smallholder farmers and pastoralists in rural Mali. Talks and discussions are in French. Simultaneous translations are made in Bambara and Dogon on the fly, for the participants who are not fluent in French. The president of AOPP does not speak French, only Bambara.

The first day is spent on introductions and demonstrations of (voice-based) mobile systems in African languages. Demonstrations are given of various examples of information systems. A demonstration is given of a local digital weather station, which can collect and diffuse information on local rainfall, and other meteorological data, see Figure 23. As the water supply was temporarily unavailable at AOPP's office (a recurrent problem in Bamako) Tangara, inventively, pours old coffee in the rain gauge, to demonstrate to the group how this digital meteo-data service works.

The farmers show interest in receiving information on actual amount of rainfall per day, during the rainy season. This information, if available as a voice message in local language, on a daily basis, is considered useful for taking seeding and harvesting calendar decisions.

After demonstrations three subgroups of five to six participants each, are requested to make an inventory of domains of concerns and related problems, in terms information needs. During the group presentations, the moderator tries to elicit the problems and describe them in terms of goals, stakeholders, relationships and opportunities.

After the working sessions of 1,5-hour, group results are presented in a plenary session. Key ideas, user stories and business ideas are discussed, grouped and summarized. This resulted in five domains: (i) agriculture, (ii) animal rearing, (iii) fishery, (iv) agro-forestry, (v) internal organization of AOPP. The groups make a longlist of general constraints, which are presented next. Some participants are unable to write. Each group appoints a scribe.

The following list in Figures 24 and 25 were produced based on the discussions about domains and related information needs. At first, the participants write down large challenges. As these are too complex, they are decomposed into different smaller problems which might be easier to tackle. The results are summmarized in Table 4.

In a further session they go into detail on concrete problems, related to information and communication. The moderator asks to be specific and add operational goals to each challenge. This is an iterative assignment which yields information on an in- 


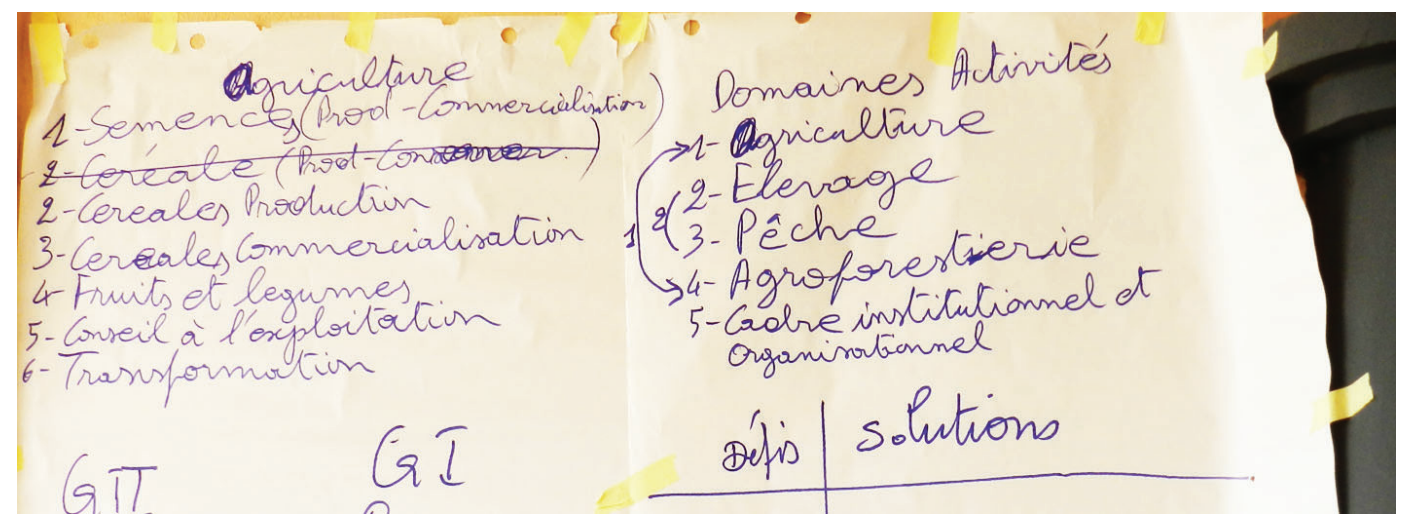

Figure 24: Result of needs' assessment workshop with farmers in Mali. First step: assessment of the different domains, 10 October 2015.

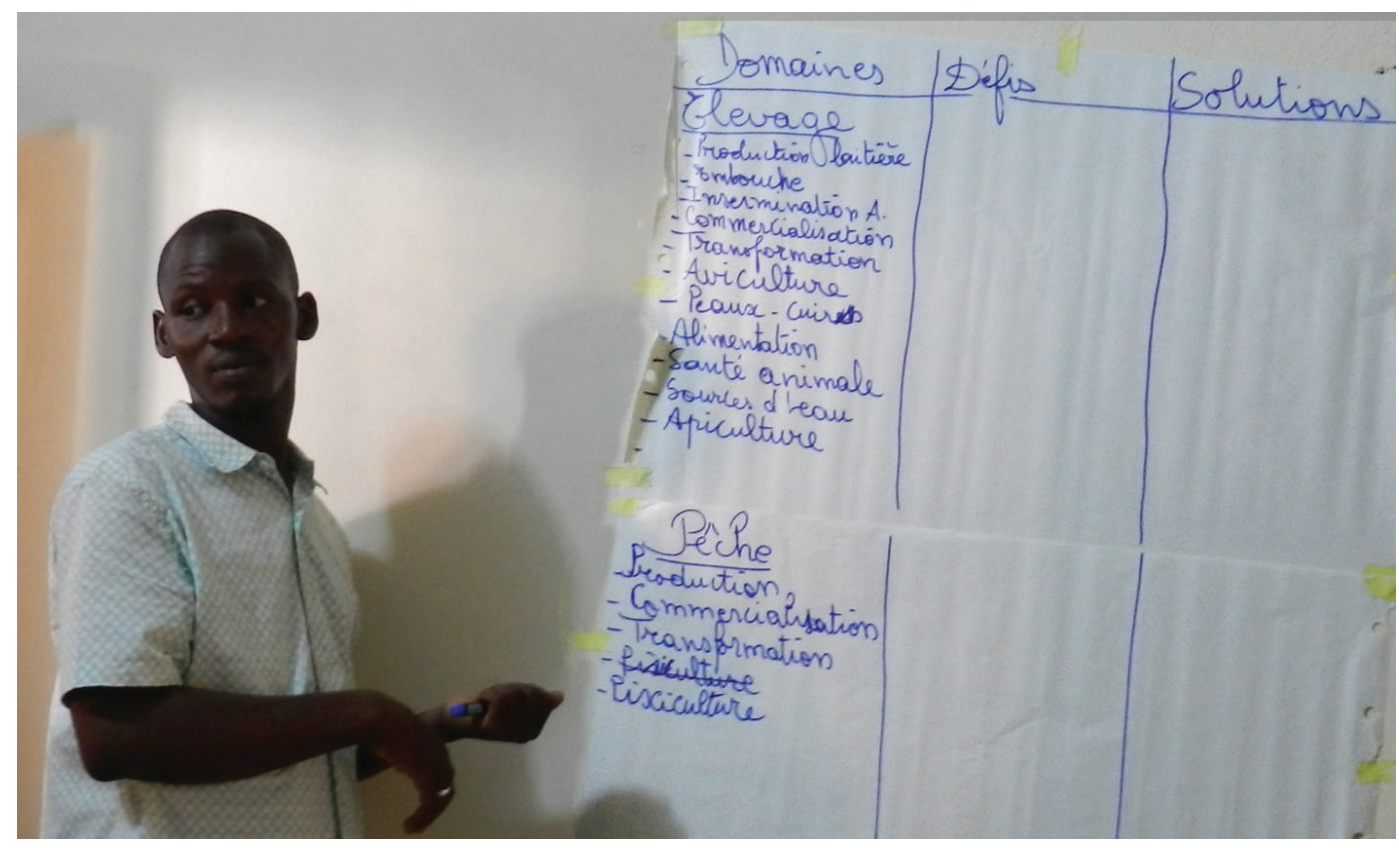

Figure 25: Second step: brainstorming about problem and solution spaces, related to information and communication needs. 


\begin{tabular}{|c|c|}
\hline DOMAINS & INFORMATION NEEDS \\
\hline agriculture & seeds, fertilizers, transporting services, trade \\
\hline regreening & agroforestry, production, trade, transformation techniques \\
\hline livestock & animal health, vaccination schemes, conservation of milk, trade \\
\hline fishery & fish conservation, transport, trade \\
\hline market information & broadcast offerings, access to customers, local markets \\
\hline soil \& water & water conservation, information on techniques, irrigation methods \\
\hline meteo & weather forecasts, indigenous knowledge, cropping calendars \\
\hline alert systems & alerts on floods, outbreaks of disease \\
\hline legislation & information about tree laws, in local language, easy access \\
\hline farmer organization & communication; monitoring system; diffusion of information \\
\hline
\end{tabular}

Table 4: Domains and topics and related information needs

creasingly higher level of detail and specificity. This is necessary to model and design information systems.

GROUP WORK RESULTS The constraints to information and communication which came out of the workshop are (i) lack of infrastructure in rural regions (no electricity, no Internet); (ii) common illiteracy; (iii) variety of languages; (iv) low income. (This is consistent with earlier workshops which we did in Mali and Burkina Faso.)

The existence of full coverage of community radio and the wide availability of (GSM, voice-based) mobile telephony in rural regions, are opportunities. Advanced ICTs (such as smartphones, computers, internet-dongles with mobile internet connections are only owned by local NGOs, rural radio stations and agro-extension workers, and some youngsters in the villages, who often travel to urban areas. When available, mobile internet is very expensive: prices are comparable to voice-based access, 100 fCFA per minute.

The following types of information needs are formulated: (i) information/knowledge retrieving, e.g. getting information on market prices, weather forecasts, animal diseases, seeds etc. (ii) communication/knowledge sharing, e.g. inform others about local rainfall, fire alerts, regreening techniques etc. (iii) information/knowledge dissemination and broadcasting, e.g. sending announcements to inform a large public e.g. advertisements, invitations for an event, weather alerts etc.

\subsubsection{Finding key ideas: seeds}

One of the interesting key ideas was to have a seeds information system. The AOPP staff suggested us, during the workshop, to co-create a seed information system for farmers in remote areas. The system must be accessible through mobile phone, in local languages. For the developers' team to obtain as much information about seeds, an 
interview with a seed expert was done, and a field visit took place, the next day. With this information, the $\mathrm{W}_{4} \mathrm{RA}$ team built a prototype, during the workshop.

USER STORY: SEEDS Henri, farmer and coordinator of farmer organizations in the Ségou region for AOPP, gave me this information in a short interview. ${ }^{19}$

Seeds in Mali are produced and provided to farmers by a national research institute. $^{20}$ These seeds are referred to as semences de base. Seed producing farmers can obtain these basic seeds for the large-scale production of second-generation seeds, referred to as certified " $R I^{\prime}$ " seeds, which are allowed to be sold on the market. The problem is that the sales of seeds is hampered by lack of communication, as farmers in rural villages are often illiterate and do not have computers or Internet. Therefore, a system or service should be useful, where farmers can offer seeds for sale or request seeds for purchase.

In southern Mali, various cereals are produced. Farmers must decide what they are going to produce next year, and which seeds to buy. AOPP collects information from all its members, from the whole country, and asks what they are producing, and which seeds they are requesting. Given the poor communication channels, this information is available centrally, i.e. at the AOPP headquarters in Bamako, but does not go back to the farmers at the start of the chain, i.e. in the unconnected rural areas.

FIELD VISIT WITH AOPP To better understand the context of seeds in Mali, in October 2015, we visited, with the group of twenty farmers from AOPP, a field where AOPP does field experiments with seed varieties and new cropping techniques. Figure 26 gives an impression of this field excursion.

RAPID PROTOTYPING AND EVALUATING IDEA FOR SEED SySTEM Based on this request, a first (rapid) voice-based prototype was built, and demonstrated during the workshop. For the sake of simplicity, the prototype was in French - not local language. It has a mobile voice-interface. Without bothering much about the exact content (seeds, names, exact workflow), this prototype, built overnight by our developers' team ${ }^{21}$ gives the farmers an idea how a voice-based mobile applications might look and feel.

For the developers it is good to know if the users know how to press the phone buttons (DTMF - dual tone multi frequency is pressing a key in answer to a voice dialogue). Is the voice menu structure clear enough? Below is an example of a demo dialogue (the original version was in French), built and shown during the workshop, for a possible seeds information system. Below is the phone of a prototype for a mo-

19 During the workshop at AOPP, 11 October 2015.

20 Division de la Recherche Agronomique de l'IER, la Section de Contrôle et de Diffusion des Semences Sélectionnées (SCDSS).

21 Victor de Boer and Wendelien Tuyp made this prototype in one evening. 


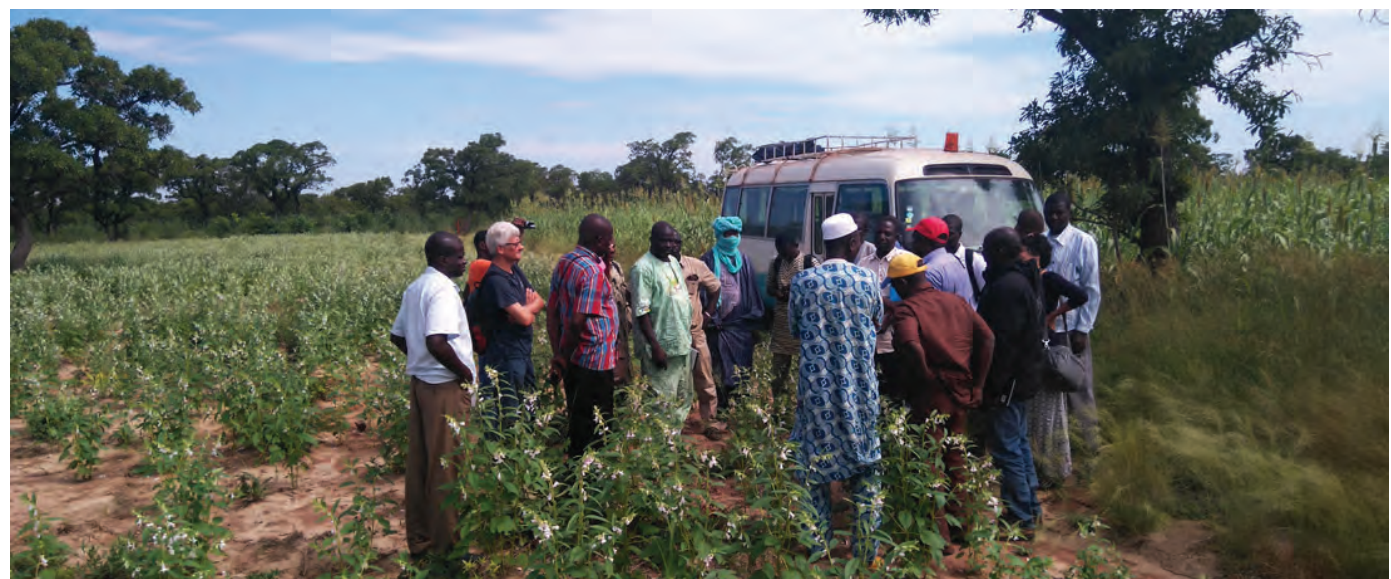

Figure 26: Field visit and context analysis with workshop participants: AOPP farmers and W4RA team (south of Bamako, 12 October 2015, Photo: Victor de Boer.)

bile/online seed market. Farmers can call to this system to place offerings of seeds and browse current offers of seeds of various quality levels, in a specific region.

* Welcome to the AOPP seed market place.

* If you have seeds to offer, press 1 .

* If you are looking to buy seeds, press 2 .

* If you want information about seeds, press 3.

* What type of seeds are you looking for?

* What type of seeds do you have to offer?

* For red rice seeds, press 1.

* For fonio seeds, press 2.

* For nere seeds, press 3.

* Select the quality of your seeds.

* For semence de base, press 1

* For R1, press 2

* For R2, press 3

* Press 9 to go back to the start menu

* What is your Cercle

* For Mopti, press 1

* For Tominian, press 2

$* \ldots$

* You are offering:

* red rice seeds in the Tominian cercle 


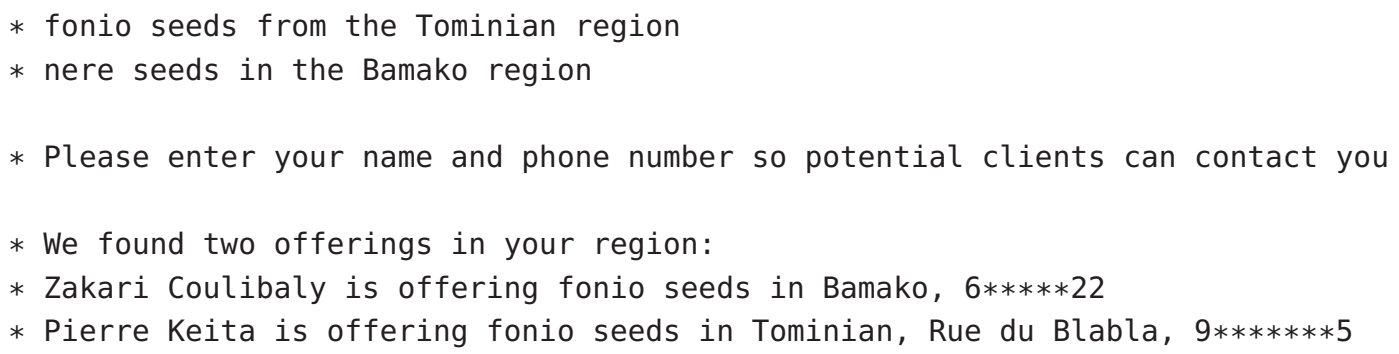

This prototype gives an idea (look and feel) to the envisaged users, how a possible seed information system might work. A mobile, voice-based seed information system is one of the key ideas and wishes of AOPP for its members (farmers in Mali). This will be further elaborated into a system, in the near future, e.g. in 2018.

\subsubsection{A milk information system}

Another key-idea that emerged from the discussions with the pastoralist members from AOPP was related to the value chain for milk in Mali. With more than 1o million cattle and 32.7 million sheep and goats, livestock rearing in rural Mali is an important source of food and livelihoods for nomadic and sedentary pastoralists and farmers [84]. It contributes to rural household production systems. ${ }^{22}$ Where milk was formerly sold by the producers standing with their products along the road, value chains for dairy are gradually improving due to improved local organizations. Rural pastoralist organizations and cooperatives strive to enhance the economic position of milk producers. ${ }^{23}$

FIELD Visit to A SMALl DAIRY COOPERATIVE In May 2016, the research team organizes a field excursion to a small dairy cooperative named "Cooperative de producteurs de lait Ouelessebougou", a member of the union of milk producing cooperations in Mali, see Figures 27 and 28. This (iterative) context analysis and needs' assessment was necessary to learn and help improve information exchange between milk producers and the cooperative.

Our partners from farmer organization AOPP introduce us to the coordinator of Ouelessebougou and a few other members, and help us by translating during the meeting between Bambara and French. The technical installations of the factory are visited first. After the tour we have a focus group discussion, to understand the context, the operational goals and the information needs of the milk producers. The focus group is done with a group of about 25 people, including the coordinator of the cooperative. It gives us a general idea of the context and a first idea about information needs.

22 Source: http://tinyurl.com/shareweb-pastoralism-mali (accessed o8-10-2020)

23 See e.g. https://www. theguardian.com/journalismcompetition/mali-milk-production (accessed o8-102020) 


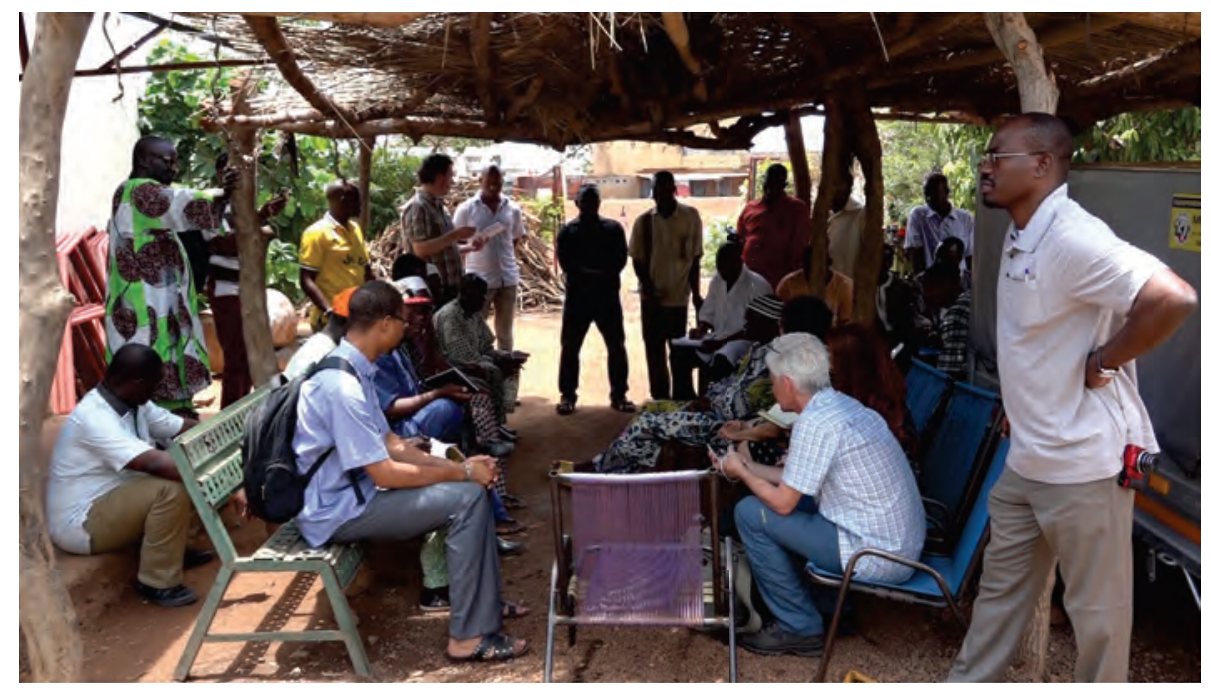

Figure 27: A field visit to dairy cooperative Ouelessebougou. Focus group discussion after the visit to the small factory, 8 May 2016. Photo: Leeuw van Moerkerken.

FOCUS GROUP WITH DAIRY COOPERATIVE This cooperative receives milk from 3 communes and 600 milk producers, who provide a total of 1500 liters per day. A Malian cow produces no more than two to seven liters a day. Commonly this milk is extracted by hand. A member of the cooperative fetches the milk in the villages and brings it to the dairy factory by motorcycle. Milk has to arrive here within 4 hours after extraction. The milk temperature has to be between 21 and 35 degrees Celsius during transport, and it has to be tested within that temperature range. Conservation of milk is a problem in Mali, with daily temperatures of up to 40 degrees Celsius. Milk can be kept fresh for four days after pasteurization (when refrigerated). Part of the milk is transformed into yoghurt, in this factory. The milk is tested, pasteurized and packed. It receives an official quality certification. The milk is sold here at 300 fCFA per liter. At the market in Bamako it costs 450 fCFA per liter.

The members of the cooperative tell us their concerns. The match between milk producers and buyers is difficult. Milk is a highly perishable product. Its production amount varies considerable between the rainy and the dry season, when there is not much to graze for the herds. In Bamako, milk is mixed with milk powder, and sold at a lower price. Our dairy cannot compete with these low prices. Communication with the producers is a problem. Radio and mobile phone are already used, but communication could be largely improved.

Another problem is the poor sales network and inadequate refrigeration facilities. This means that resellers can only obtain a limited quantity of milk. In Mali there is hardly a demand for yoghurt or cheese. There is still a long way to go, to improve the milk value chain. This cooperative holds a good administration, however, all administrative data are stored and processed on paper, on the wall, see Figure 28. 

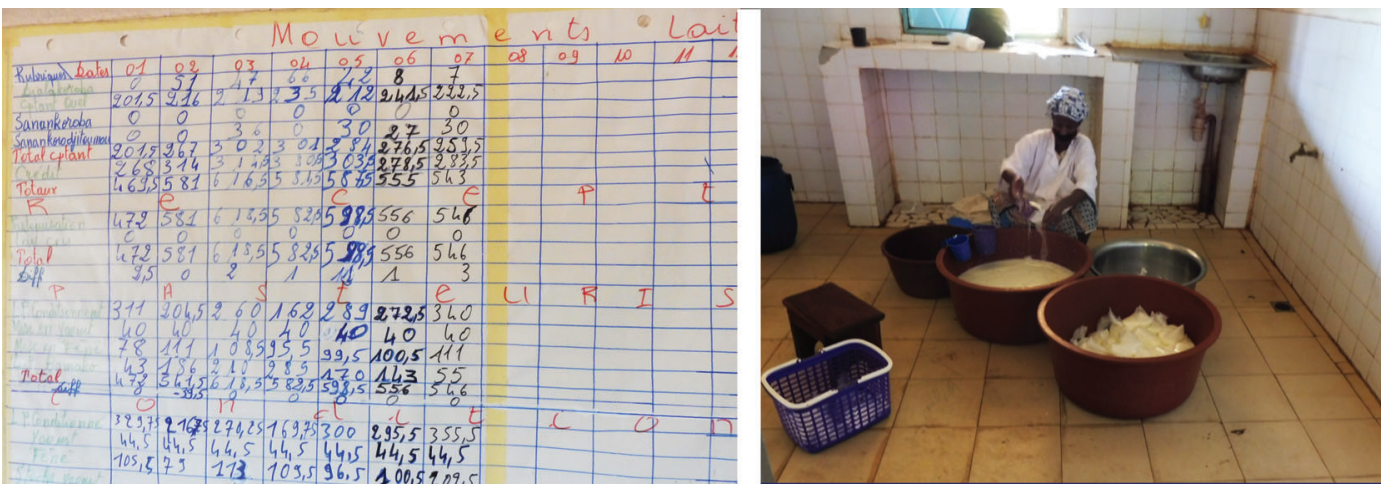

Figure 28: At the office of milk cooperative Ouelessebougou. All data about the milk is kept on paper. The fresh milk and yoghurt are sold in small plastic bags, 8 May 2016. Photos: Anna Bon and Leeuw van Moerkerken.

A PROTOTYPE MiLK INFORMATION SYSTEM Based on the discussions with AOPP farmers and their wish to improve information exchange for the milk sector, a preliminary idea is developed to improve the communication between the producer and the collector of milk. A simple prototype is built for a voice-based milk information system by developers/researchers ${ }^{24}$ from the $\mathrm{W}_{4} \mathrm{RA}$ team [347]. This prototype is presented to the farmers of AOPP in June 2016. It is currently still under construction ${ }^{25}$ in December 2017.

\subsection{CASE: METEO-SERVICES FOR FARMERS IN BURKINA FASO}

During various collaborative workshops ${ }^{26}$ with farmers in Burkina Faso, Mali and Ghana between 2010 and 2017, one of the information needs most often mentioned was information about weather, specifically rain forecasts. Farmers were interested in receiving timely and accurate information on the (cumulative ) amount of rainfall in their own region. During the rainy season this information is required every day.

Agriculture in West Africa is mainly rain-fed. In the Sahelian zone of Burkina Faso and Mali the rainy season extends from June to October. Cropping and harvesting are done during the rainy season. Meteorological information is of great importance for farmers. Daily information on fallen rain, is important to plan cropping calendars. Our project partner in Burkina Faso, the NGO Réseau MARP explains that in recent years (1991-2009) rains have become more erratic and less predictable, probably due to

24 Aske Robenhagen and Bart Aubers developed the "Mali Milk" application as part of the ICT4D course 2016 at VU.

25 A full report of the "Mali Milk" application by Aske Robenhagen can be downloaded at https://w4ra. org/wp - content/uploads/2016/07/Downscale2016_paper_2.pdf (accessed o8-10-2020)

26 These workshops were partially financed by a grant from Nuffic in the NFP-TMT program. 


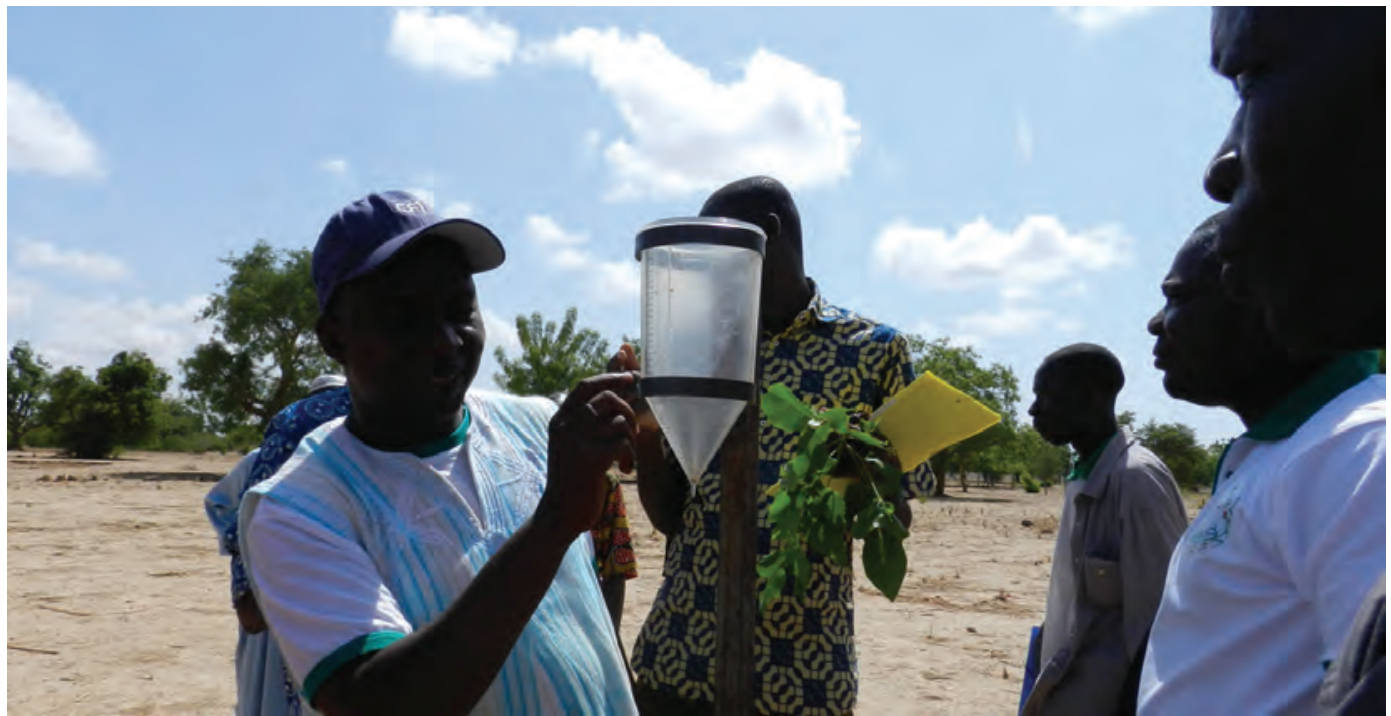

Figure 29: Farmers in Gourcy, Burkina Faso, discussing the manual rain gauge in the field. All data on rainfall, collected by farmer Oumar, is stored on paper, 23 June 2016.

climate change. Heavy rains and floods in various regions have caused casualties and soil erosion.

\subsubsection{Example of a series of collaborative workshops with farmers in Burkina Faso}

In January, April and July 2014 the $\mathrm{W}_{4} \mathrm{RA}$ team ${ }^{27}$ holds various focus group discussions with farmers-innovators from the Zondoma and Yatenga regions in Burkina Faso. We visit local radio stations: La voix du paysan, Radio Solidarité, Radio Notre Dame du Sahel in Ouahigouya, and Radio Savanne in Gourcy. The radios are already broadcasting information on rainfall for the local communities, on a daily basis during the rainy season. We visit the fields of several farmers - innovators. Many farmers are already collecting rainfall data on their fields, using rain gauges which they received from NGO Réseau MARP, including a short training how to use them. Rain information is still difficult to share with other farmers, due to absence of good communication channels.

The first goal is to find out the need and co-design possible solutions, related to weather information. Information on the Web is not accessible for the farmers in this region, who only speak Mooré, and do not have an Internet connection. Understanding what the farmers really want requires dialogues, group discussions and demos of possible solutions through prototypes. The feedback of the farmers will be used for

27 Wendelien Tuyp, Hans Akkermans, Chris van Aart, Victor de Boer, Mathieu Ouedraogo, Amadou Tangara and the author. 


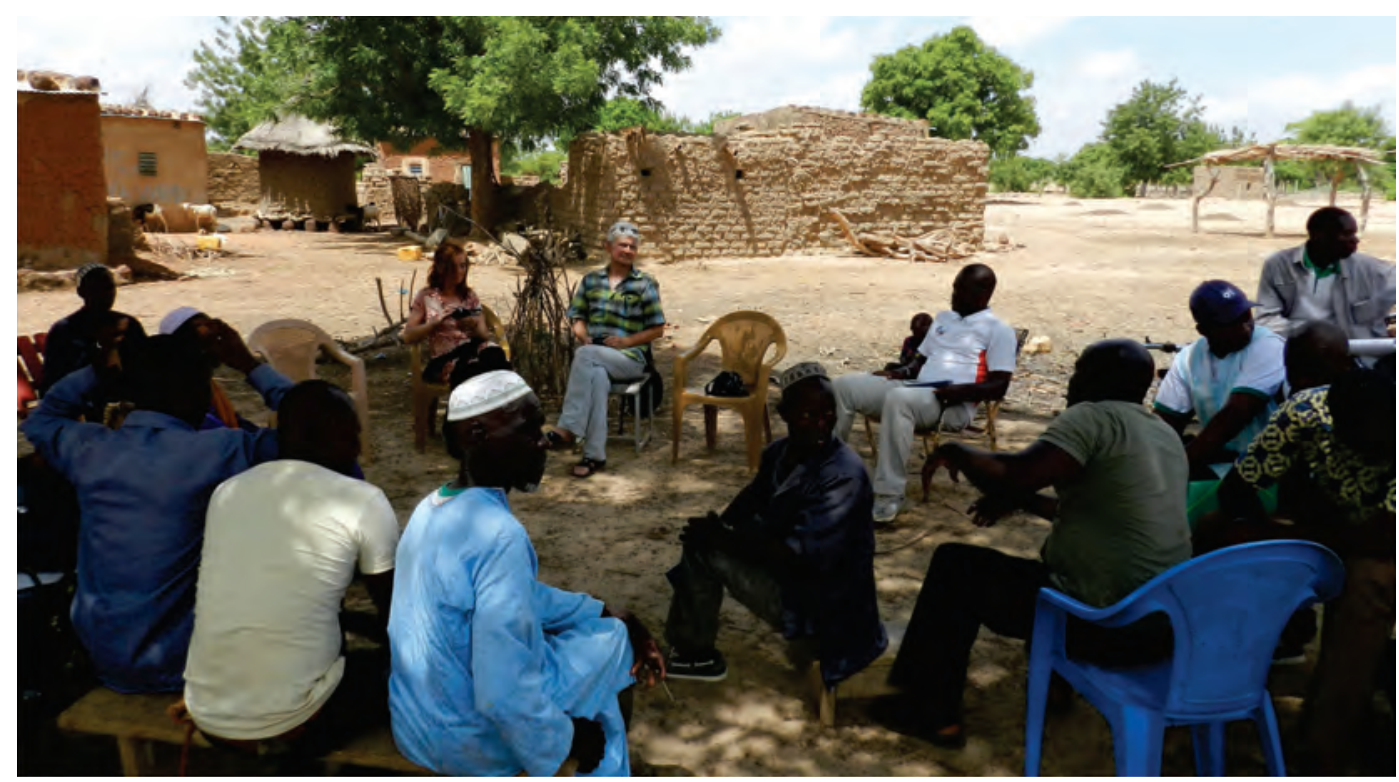

Figure 30: Workshop and field visit $\mathrm{W}_{4} \mathrm{RA}$ team and innovative farmers from the Yatenga and Zondoma regions, Burkina Faso, 23 June 2016.

further improvement of the systems. This takes several cycles and frequent face-to-face meetings.

After an interruption of this project in 2015 (due to temporary lack of project funds), in 2016 the needs' assessment is taken up again. Another field visit is done to the same locations in Gourcy, Zondoma region, in Burkina Faso, from 21 to 24 June 2016. ${ }^{28}$

This is a follow up of meetings in January, May and July 2014, with the same group of farmers-innovators and radio stations. This time, not only farmers, but also staff from the national meteorological service and staff members from a number of local radio stations participate in the needs' assessment workshop. In total 24 people including the moderators. An excursion to the fields of one of the participating farmers, is part of the workshop. We visit the field and see how farmers are currently collecting rain data, see Figure 29. We sit together with the farmers, to discuss the issues surrounding meteorological data, see Figure 30.

THE METEO-WORKSHOP - DAY I The first workshop day is spent reviewing the meteorological data collection projects, which are already going on in the region: one project with the Direction Générale Météorologique. The second day is for further elicitation of the farmers' information needs and to brainstorm about possible solutions and applications.

28 My team members were this time Wendelien Tuyp, Hans Akkermans and Francis Dittoh, in collaboration with the director and three staff members of Réseau MARP. 


\section{OpÉRATION TEST DE PRODUCTION ET DIFFUSION DE} L'INFORMATION CLIMATIQUE ET MÉTÉOROLOGIQUE

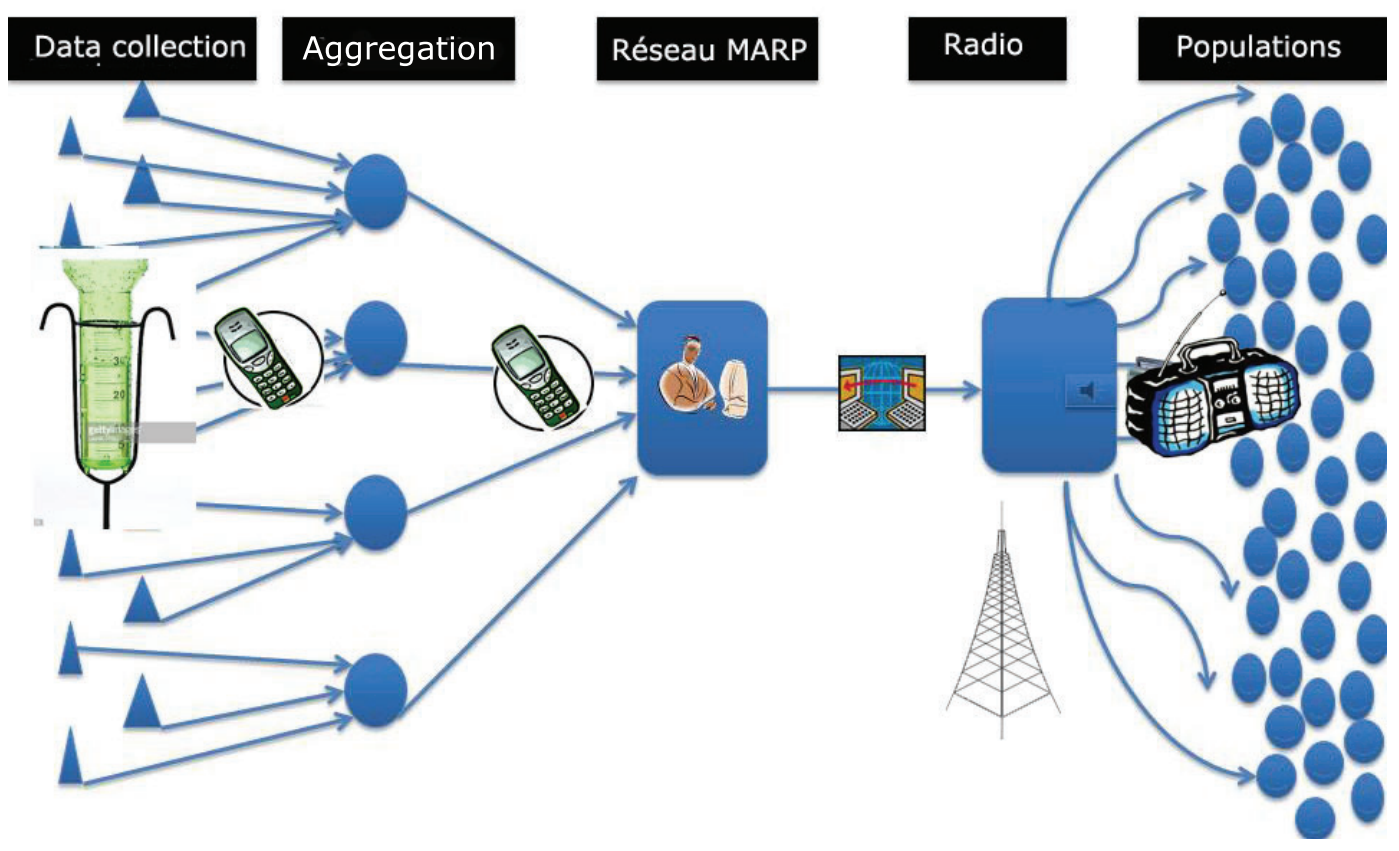

Figure 31: Conceptual model showing the collection of rain data, and its aggregation and broadcasting on the local radio stations. This model represents a key-idea for a voice-based mobile data service. It is based on an existing (legacy) system, which is running since 2014. Courtesy of Julien Ouedraogo, Réseau MARP.

We are told that the national meteo-service sends a bulletin by email to a number of recipients, with the actual weather forecasts. To inform the public, the regional radio stations from Ouahigouya, La Voix du Paysan broadcast a program with the current meteo-forecasts from the bulletin. This is broadcast twice a week, during the rainy season.

We discuss another meteo-project, which is coordinated by Réseau MARP. This meteo-project is about collecting local rain data and aggregating this to disseminate it to the communities (See Figure 31). This project fills the gap of local information needs, which the national meteo-services are not able to bridge.

This development project, managed by Réseau MARP, is done with a number of farmers, who receive a short training how to collect rainfall data in the field using a rain gauge. These data are written down on paper by the farmers (who have been selected for this pilot based on literacy). Farmers give this information by phone to a person, who aggregates all the rain data from the region concerned, and sends them to Réseau Marp. A staff member from Réseau MARP currently enters all data into an 
Excel sheet. This sheet is forwarded to the local radio for broadcasting. The project is effective and appreciated by the farmers, however, it is time consuming for the NGO and for the radio stations. ${ }^{29}$ Another problem is that the info is only broadcast at certain hours, so many farmers do not get the information, when they are working on the field.

After the plenary session, the group is divided in smaller groups of about five or six people each. The difficulties that are encountered related to meteorological data, are discussed and written down on a large piece of paper. This is presented by one member of each team in the plenary session. (Many of the participants in this workshop only speak Mooré. Group work allows them to discuss and brainstorm in their own language, and report the outcomes back in the plenary session.)

The difficulties encountered by Group 1 are (i) there are not enough rain gauges in the field to have sufficient rain info (ii) the phone network is often unavailable in the villages (iii) the internet connections are poor for those who have to use this e.g. the radio stations (iv) people do not have radio receivers at home (so many families cannot listen to radio) (v) currently, information is broadcast based on administrative regions. The farmers are used to other names, which they refer to as the "real" geographic names (vi) radios complain about the costs of making phone calls to send the information to the information gathering people.

There are solutions proposed in the various groups: (i) give farmers rain gauges and radios (ii) improve network connections; choose a better network operator (iii) make farmers aware of the administrative names of the regions (iv) revise tariff-cost structures for all kind of data services including phone and radio broadcasts.

WORKSHOP METEO DAY - 2 The second day is spent on further analysis of information needs and possible solutions. The group of innovative farmers express a wish to have weekly and daily weather forecasts in the rainy season, for example when it will start and end; want heavy-rain alerts, and want to have accumulated rain data per week (in $\mathrm{mm}, \mathrm{cm}$ ). They prefer to have this on mobile than on radio (as they do not carry the radio into their fields). They would like to receive the information on a daily and weekly basis. Why is this of interest to the farmers: forecast for season helps them to know which seeds to use on what locations and in what period; daily info allows to plan the daily operations. Which problems have they encountered: (i) the radio as well as meteorological services have a poor internet connection; (ii) not enough training in the meteo-domain for radio people; (iii) meteo-organization is understaffed; (iv) not all farmers have radios at home.

29 The needs' assessment yields the need to improve the existing workflow. This is what we refer to as a legacy system. 


\subsubsection{Summaries of (break-out) group findings}

The work in break-out groups provides concise information about the needs and concerns of the farmers. Each group has appointed a scribe (since not all people have literacy skills, or speak French). Groups are mixed and consist of seven to eight people: farmers, radio journalists and meteo people. A summary of two of the group results, which are communicated back to the plenary session, is given below.

SUMMARY OF GROUP II - DAY I The ongoing meteo-project, managed by Réseau MARP (RM) is discussed. The idea is that the actual daily rain data is collected in various villages, using rain gauges, and written down on paper. These pluviometry data are communicated by mobile phone and then aggregated centrally at the commune level. All the community data are then aggregated centrally to RM, then from there sent to Radio Savanne. This radio broadcasts this weekly, every Friday at 08.oo am. There is said to be feedback on these broadcasts from the population to Radio Savanne. The same info is sent also every ten days to the province level and the rain info from Gourcy and Tayo is also sent to the national meteo-service Direction Générale Météorologique (DGM);

Several meteo-stations also send their info to the national meteo-service. This service sends around an email bulletin to a mailing list (unspecified, but includes Radio Voix $\mathrm{du}$ Paysan) and do short radio and tv broadcasts. The difficulties discussed in this workshop are: (1) the telephone network is often weak (in rural regions); (2) there is poor coordination of all the information streams; (3) sustainability of this system is questionable on the longer run. Possible solutions are not yet discussed this day.

SUMMARY OF GROUP II - DAY 2 The break-out groups are given four questions about an envisaged meteo-information service to discuss. These are summaries on a flip-over. See for this group and day Figure 32. Which information is needed most? (1) rain forecast; (2) forecast of wind; (3) forecast of the sun intensity; (4) number of rains that have fallen;

Which channels are preferred? (1) mobile (2) radio.

What is the frequency of delivery of information? (1) weekly; (2) every 3 days; (3) every day (4) every month;

Why is this information relevant? (1) for cropping calendar; (2) for the choice of which variety of seeds (e.g. early or late ones); (3) to know about wind helps to avoid crop diseases; (4) sun intensity is a factor in crop growth; (5) accumulated rain data help forecast on productivity.

SUMMARY OF GROUP III - DAY I The actual rain data is collected in villages, then aggregated centrally at commune level, then sent by mobile phone to resource persons, then it goes to the radio by mobile (and apparently broadcast). The diffusion of infor- 


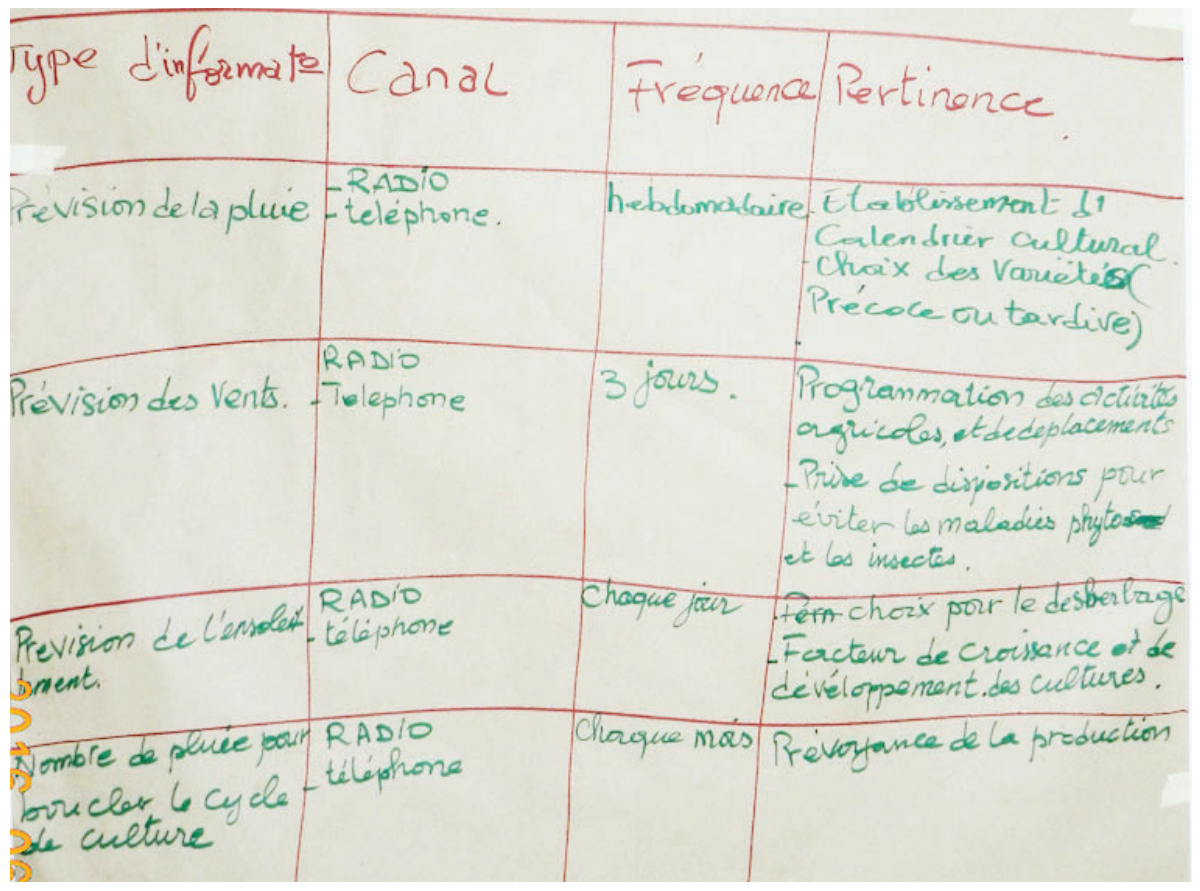

Figure 32: Results of brainstorm during the workshop in Gourcy, Burkina Faso, by farmers, meteo-experts and local radio journalists: discussing the solution space. This is the summary of ideas of Group II, Day 2 of the workshop.

mation gives an idea locally of the evolution of the rainy season; it allows farmers to take decisions e.g. on seeding; gives also flooding alerts. Farmers are already collecting rain data for 20 years; 33 rains is a good year; 4 rains or more in June is a trigger to start seeding and will give a good harvest. Difficulties encountered are: (1) poor mobile network; (2) farmers do not have rain gauges and do not know how to use them; (3) there is not a formal organized system in place to diffuse the info.

SUMMARY OF GROUP III - DAY 2 Which information is needed most?: (1) rain forecasts every 3 days; (2) rain fallen (in $\mathrm{mm}$ ); (3) alerts for strong winds.

Which channels are preferred? (1) mobile (2) radio [Note: costs of calling are a concern]. What is the frequency of delivery of information? Every 3 days.

Why is this information relevant? (1) It helps plan cropping calendar; (2) You can prepare yourself for strong winds.

What is missing in the current system? (1) The meteo-information is not available in the right language. 


\subsubsection{Collaborative decision making}

The last day of the workshop, after the field visit, the following to-do list is made by the group of participants. The following data which were provided by different parties, will be needed to build and deploy the system. The list is set up by all participants. This includes the workshop facilitators - ICT developers - and envisaged users.

- Global and local data integration service meteo Burkinabe DGM, INERA, Réseau Marp, et données au niveau des communes etc;

- Collaboration with VU-Réseau MARP for the recording of speech/dialogues in Mooré for the application;

- Developers at VU/2Coolmonkeys design/build a new prototype based on the requirements of this workshop;

- Key users: farmers, radios, for the evaluation of the systems during their development;

- Business/technical partners: local technical/ICT/radio people, entrepreneurs (radios, NGOs, entreprise TICs);

- Lobbying at national level to raise awareness of the need for accurate/localized/timely local rain data. This can be done by Réseau MARP.

\subsubsection{Jointly defining the solution space}

After various needs' assessment workshops with farmers in Burkina Faso, it is clear how important meteo (and specifically rainfall) data are for farming in rural Africa. A number of key ideas is collected, i.e. a solution space is defined.

Farmers expressed the need to have better access to weather data, and to be able to upload their own collected data, to share that with other farmers in the region. This can be summarized as three types of key ideas concerning meteo and weather.

The different key ideas for meteo are shown on Figure 33 as a concept map. The importance of having a technical Meteo Data Service Platform, to host the different data services (in the absence of a good Internet infrastructure in the region) is also an outcome of the needs' assessment workshops. The constraints due to lack of computers/illiteracy also lead to a number of choices. This concept map can be considered a portfolio of key ideas related to meteo-data services in rural Africa.

1. Daily weather forecast (amount of rain) for the next 1-2-3-4-5 days;

2. Alert in case of heavy winds/storm; 


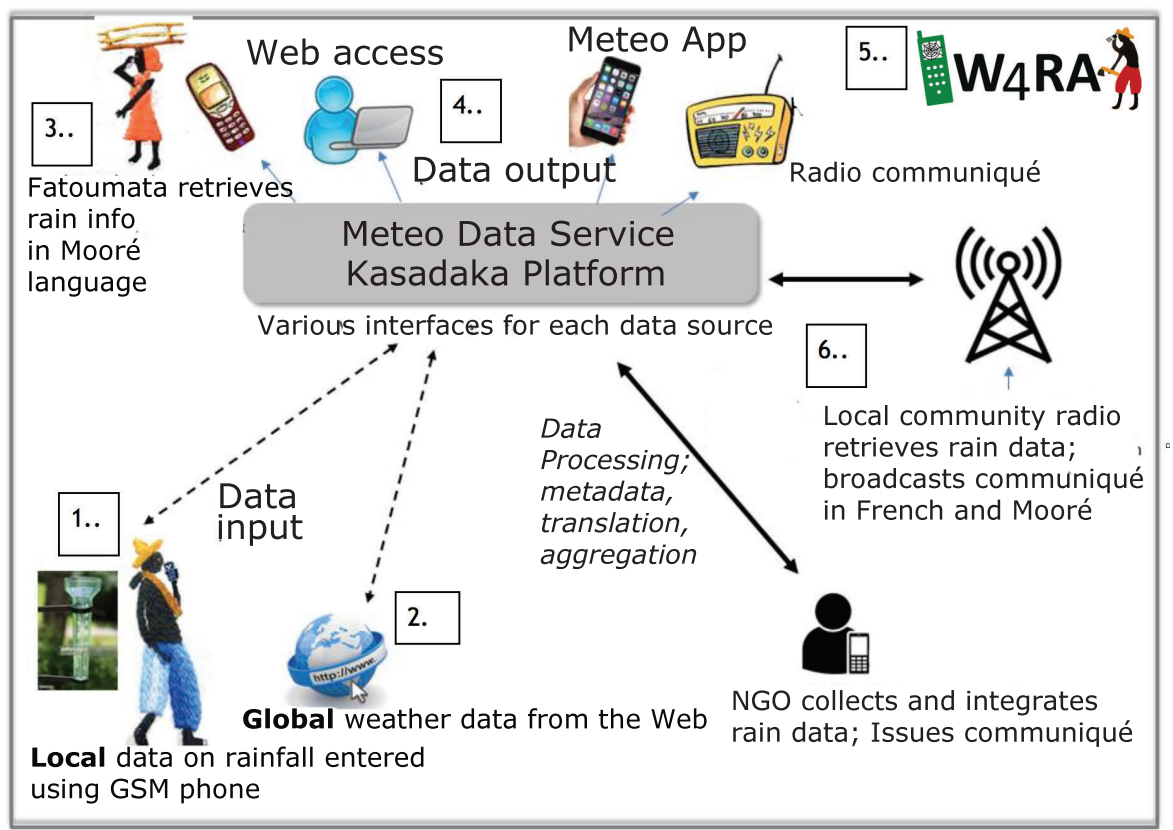

Figure 33: Conceptual model of a mobile/voice-based technical platform. This model also shows the portfolio of key ideas for meteo-data services for farmers in this region of Burkina Faso. Source: Anna Bon. (A description of the Kasadaka Platform is given in Chapter 7)

3. Amount of rain (in $\mathrm{mm}$ ) fallen overnight, locally or in the region.

The daily weather forecasts and storm alerts are currently already available on global online weather services on the Web. However, due to a lack of computers or smartphones and due to lack of literacy skills, farmers would like to have this info (points 1 and 2) accessible on their mobile phones in local languages.

The amount of rain collected in various regions, by farmers who measure rain data from the rain gauges in their fields, is not being diffused. Farmers would like to enter this data into a system and make this data available for the rural population. These ideas lead to various use cases which can be integrated into a suite of meteoapplications for rural West Africa, see Figure 33.

Based on one of the key ideas, researchers and students ${ }^{30}$ of the $\mathrm{W}_{4} \mathrm{RA}$ team built a prototype for a mobile voice-based information system in English and French. ${ }^{31} \mathrm{~A}$ prototype was tested in Gourcy by farmers, in June 2016. The farmers phoned a local phone number and interacted with the system, which gave them information on the latest weather forecast [51].

30 Jari Ferguson and Kim Bosman developed this in June 2016 during the ICT4D course at VU.

31 A voice-based weather information prototype in Mooré language is being developed for the farmers in West Africa by W4RA researchers André Baart and Francis Dittoh, and ICT4D master students in 2017. 
This development of meteo-data services for farmers in Africa is an ongoing project which will be continued in 2018, as part of the ongoing $W_{4} R A$ research program.

\section{$5 \cdot 7$ SUMMARY}

As illustrated in this chapter, the proposed method for needs' assessment is collaborative, and rooted in the local context. Methodologically, there are similarities with workshop methods used in agile methods and living labs. The main difference is the method for collaborative goal construction and joint decision making with end-users about the problem and solution spaces. This is based on assessment of what users and their communities have as operational goals. This links to their livelihoods and local value activities.

Having collected a long list of user needs, the next step in the process will be to describe/design use cases and collect user requirements for an envisaged solution. The process of use case and requirements analysis and conceptual modeling of the system is also done in collaboration with the users. This process is described in Chapter 6. 
In the process of collaborative ICT $4 D$ development, a list of project key ideas is collected during needs' assessment workshops and context analysis (described in the previous chapters). From this list of key ideas, a selection is made of the best and most promising project ideas. These will be further elaborated into an ICT 4 D system or service, through an iterative process in which we are "spiraling down" from a vague and often poorly specified idea through various iterations, towards a concrete design in which all requirements are defined, tested and formally specified. ${ }^{1}$ This process requires intense two-way knowledge exchange in order to transform the key idea into a technically specified model with the right requirements. To do this I propose a structured narrative method, which optimizes the (collaborative) process of use case and requirements elaboration. ${ }^{2}$ This is a way to bring the second Principle for Digital Development into practice: Design with the User. ${ }^{3}$

\subsection{USE CASES AND REQUIREMENTS IN ICT4D}

This chapter presents a method for use case and requirements analysis and elaboration, which can be used in software development projects in which: (i) the cultural background of users and developers is very different, so that communication deserves special attention; (ii) the context is complex and may be unfamiliar to the developers. As these conditions are often encountered in $\mathrm{ICT}_{4} \mathrm{D}$ projects, this method is specifically useful for software development in low resource environments.

To build ICT solutions it is necessary to find user requirements - i.e. what the users want the envisaged system to do. A requirement, in software development, is defined as a property, a functional behavior of a software system [55].

This process may be difficult when e.g. users are unfamiliar with ICT, when developers are unfamiliar with the local context, or when there are large differences between developers and users in e.g. language, educational or cultural background. (This in contrast to ICT/software development projects in the Global North, where developers and users are more likely to share the same language and culture.)

1 This has some similarities with the spiral model of famous software engineer Barry Boehm (1988) [31]

2 Parts of this chapter have been published previously as a project deliverable in the EU-FP7 VOICES research project: Anna Bon \& Hans Akkermans (Eds.) Deliverable No D1.1. VOICES Use Cases and Requirements (2011) https://w4ra.org/wp-content/uploads/2014/08/VOICES_D1.1-v1. 0 - VUA_FT-28Sep2011- final . pdf, (accessed o8-10-2020)

3 https://digitalprinciples.org/ (accessed o8-10-2020) 
To facilitate use case and requirements elaboration the "structured narrative method" was developed. This method structures the information collected during workshops and face-to-face meetings.

The method facilitates communication about requirements (i) with end-users in a non-formal way, using narratives and pictures, sketches, cartoons or storyboards; (ii) between technical developers in a formal way, structuring the information and capturing the technical system specifications. The method will be explained in the following sections.

\subsection{FROM UNSTRUCTURED IDEAS TO USE CASES AND REQUIREMENTS}

Having selected during the needs' assessment workshops a list of key ideas, the next step is to analyze and elaborate use cases and requirements. This is an iterative process that requires (again) good communication between developers and users.

During co-creation workshops software developers discuss requirements with key users, however, users - especially when they are not technical - find it difficult to formulate requirements. It is therefore the requirements engineer's task to facilitate requirements. This is done using various techniques.

The next step is to analyze, decompose and structure all information. We therefore use a "structured narrative method" that is understandable for end-users while providing a specification baseline for technical development, which can be gradually extended, by technical developers. Figure 34 shows the outcomes of a workshop which I moderated in May 2016 with farmers of AOPP in Bamako, Mali, in which key ideas were collected and use cases were analyzed together. The process of structuring ideas into use cases is a joint assignment that includes the moderator, the participants and the other $\mathrm{ICT}_{4} \mathrm{D}$ developers/ team members who are all present in the workshop.

\subsubsection{Co-creation workshops}

While the use case and requirement workshops can be similar to the needs' assessment workshops (all workshops are co-creative), the focus during use case and requirements analysis is more specific, and enters into deeper and more specific technical details. The aim is to bridge the gap between the (unstructured and rather vague) user story and a fully specified formal model for the envisaged ICT system.

To elicit requirements prototypes are (re-) built, and iteratively improved. Scenarios and storyboards are designed and discussed with the users. Business requirements are discussed, to assess the system's sustainability ex ante. 


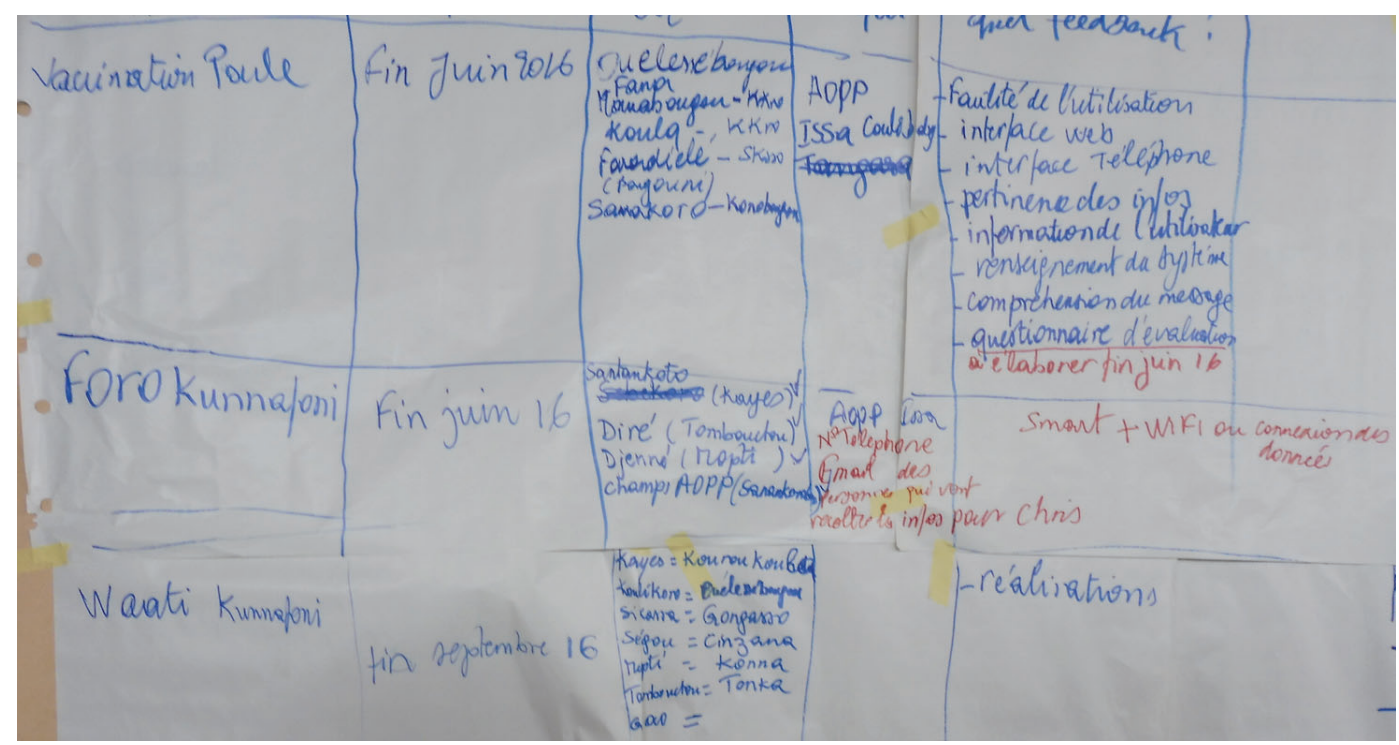

Figure 34: Example of outcomes of a selection workshop for key ideas/user stories collected with farmers of AOPP in Bamako Mali, May 2016. The selected key ideas are (i) mobile chicken vaccination alert service, (ii) a service to count cattle in the field, (iii) a weather information service, named Waati Kunnafoni.

\subsubsection{Techniques used during use case and requirements workshops}

During the use case and requirements workshops developers give technology demos; short films are shown. In the presence of users, prototypes are built. Users are given blank (A1-size) paper and marker pens in different colors to sketch and draw models during small group assignments.

To facilitate communication about the selected key ideas/use cases, a meaningful name is chosen for each key idea. These names must relate to the envisaged system and its goal/purpose. Names are preferably given by the users, in their local language. A meaningful logo is designed for each use case (by one of the creative workshop participants).

As an example, during various workshops with AOPP, (in October 2015 and May 2016.4) and farmers in Burkina Faso (April and June 2016, February 2017), we collected a number of key ideas. This included a mobile weather data service in local languages. This weather data service was coined in Bambara language Waati Kunnafoni. There was a mobile alert system for vaccination of chicken, a mobile system to count the number of cattle on a given terrain/area, named Foro N'afa; there was a milk information system and various other ideas, see the portfolio of key ideas on Figure 35. A logo was designed for each use case as shown in this portfolio Figure 35.

4 Public reports of our workshops are available from the monthly archives of https://w4ra.org Full trip reports and all data are archived can be provided at a request. 


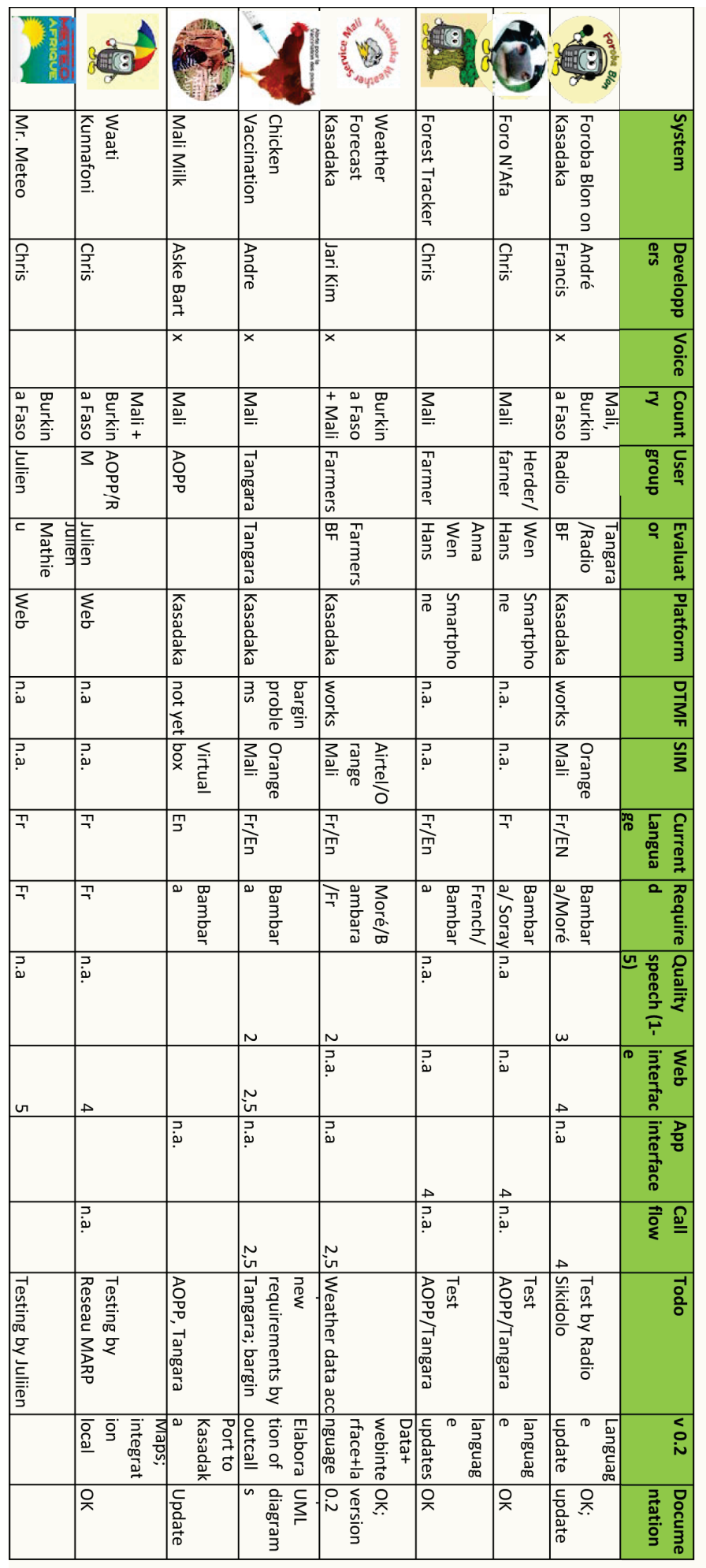

Figure 35: Example of a list of key ideas/user stories collected by the research team with farmers in Mali and Burkina Faso in 2016. 
During the co-creation workshops with farmers in Mali (members of the AOPP) and with a group of farmer-innovators from the Zondoma and Yatenga provinces in Burkina Faso, the following collaborative elicitation techniques were used.

RAPID PROTOTYPING: Development of ICT prototypes and demos during the workshop in the presence of the users, is a powerful technique for elicitation of requirements. This is part of agile development methods [117]. In contrast to deploying an end-application at once, this method ensures that solutions fit the local goals and context. Users can give information, feedback, and evaluate the prototype immediately. Ideas and requirements are collected on notes, audio tape and video. The main advantage of rapid prototyping is that the communication between developers and users is optimal and can be discussed at once, without losing any time and having a risk of miscommunication about requirements.

STORYBOARDS: A use case storyboard is a central storyline - just like in a movie, video clip storyboard, animation, or demo, showing the event-state chain of the actors' activities and interactions. The main scenario is given in a well-structured narrative, e.g. through 1 to 5 steps. This scenario is developed in an early stage, shortly after the workshop as it is an important communication tool between developers and end-users. It summarizes the idea of the system, and makes it easier to discuss the various user and technical requirements. The use case scenario can easily be adjusted, expanded or refined based on feedback from the users. A storyboard is shown in Figure 36.

CONCEPTUAL MODELING: Often used in requirements engineering to visualize aspects of the real-world problem, convey the key points and facilitate communication about the design. Informal models can be used such as brief sketches, cartoons, scenarios, short films. Often, more technical descriptions are used, using UML (Unified Modeling Language [356]). UML is a formal language with a graphical syntax. It can be used as a blueprint, providing detailed specification through different views on the system's architecture. In Figure 41 an example of a UML use case diagram is given. It shows two different user categories and their (inter)-actions with the system. These are, in this case, (i) NGO-staff and (ii) farmers. UML allows to model technical specifications needed for implementation of source code. In Figure 38 is an example: a UML state diagram specifying the different states of the system, the events and the variable names and types for each state of the system.

CONTEXTUALIZATION OF Demos AND models: Since users in a low resource environment/ $\mathrm{ICT}_{4} \mathrm{D}$ project may be unfamiliar with $\mathrm{ICT}$, communication about the system design can be facilitated by contextualization of the demos and models. As an example: we made a visual call flow diagram for a voice-based information system in local language Bambara, to explain the basic idea of the system, and the different menu 


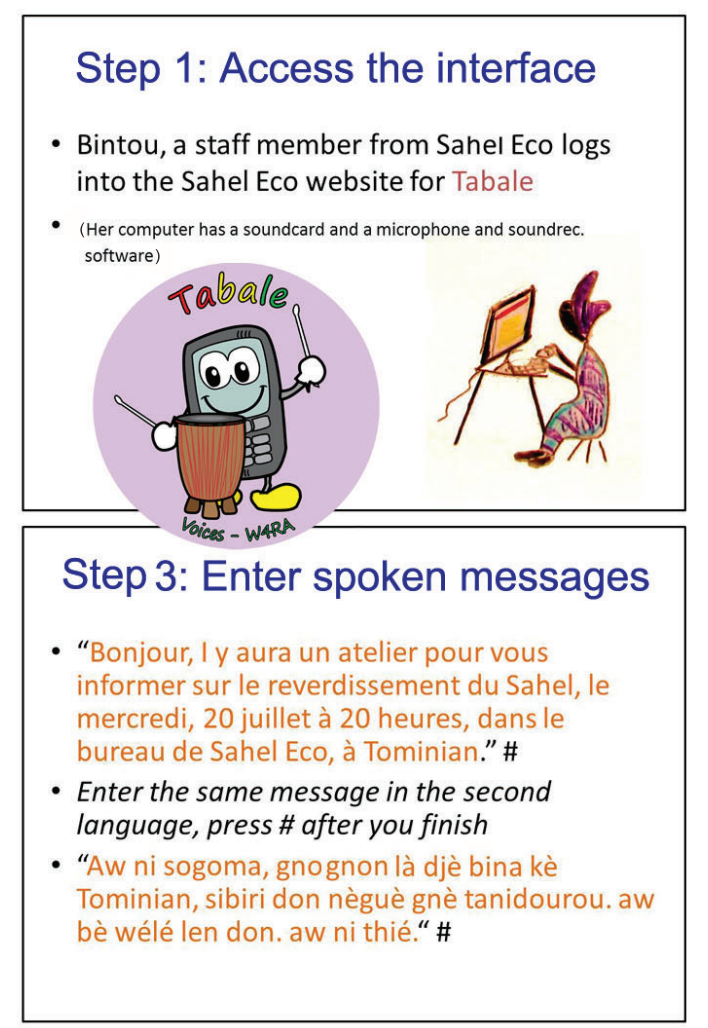

\section{Step 2: Enter user data}

- Moussa Ali Guindo, 23345565, Bambará

- Sidonie Tangara, 23268638, Bambará

Jean-Batiste Sangaré, 23566254, French

\#\#\#

- < How many languages do you want to enter?>>

- 2

- $<$ Now enter your voice message in the microphone of your computer $>$

\section{Step 4: Users receive messages}

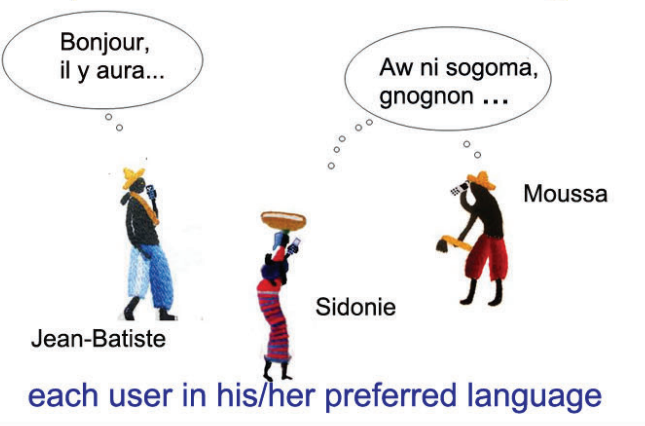

Figure 36: Storyboard showing a use case scenario for an envisaged mobile voice-based system in multiple languages. The use case was coined Tabale. The Tabale logo is designed by Victor de Boer.

options. It helps elicitation and validation of the system's requirements. The translation of the text in Bambara language was done by our local partner Amadou Tangara, see Figure 17 in Chapter 5.

STRUCTURING All COLlected DAta: The co-creative workshops yield much information that needs further elaboration. I therefore propose a structured narrative method and a uniform format to capture all information, and make sure no relevant information is left unelicited. This method is described in the following section.

\subsection{THE STRUCTURED NARRATIVE METHOD}

Co-creation use case and requirements workshops generate a large amount of rich, but unstructured information (listings, tables, pictures, recordings of interviews, focus groups, prototypes etc.). In order to structure all this (rather patchy and messy) information and transform it into a set of formalized ICT specifications and models we 
use a systematic method that facilitates (i) elaboration/formal technical specification of the use cases, (ii) communication about the requirements between developers and users and (iii) collaborative evaluation of design/requirements/technical specifications of the system's architecture. The method has been developed and used in 2011 during the VOICES project, and has been used ever since in various ICT4D courses from 2013 -2020.5 and has been validated during our use case and requirements workshops from $2011-2019$

The structured narrative method is simple to use and learn. It is compatible with standards, guidelines, and requirement for information system development and information architectures. The advantage of using this approach is to get a uniform description of the various ICT ideas, in which all information is elicited, especially when various people are doing interviews and collecting use cases simultaneously. Data collected during workshops must be elaborated by the requirements engineer, interviewer or $\mathrm{ICT}_{4} \mathrm{D}$ team members as soon as possible into this format, when memory is still fresh. The best results are obtained if the format is filled by various team members, to get various different viewpoints.

\subsubsection{The format explained}

The structured narrative method uses a structure format that provides a simple, but shared information basis and reference point for all participants (developers, users) in a uniform way. Its set-up in 14 questions (o to 13) is simple and compatible with software development guidelines, standards and methods which are used for information architectures [55]). The questions 0-3 are related to the value proposition of the key idea.

o. Describe the key idea - What is the key (business) idea? Why is it valuable or of interest for the user? (Make a summary of max. 200-300 words.)

1. Name and logo-give an understandable, meaningful and distinctive label to the use case scenario, preferably with a reference to the local context or language. If possible, make a meaningful logo.

2. Stakeholders - Who are the users of the envisaged system? What are their roles and responsibilities?

3. Make a table of the users and other stakeholders of the use case and their concerns/operational goals.

4. What is the context and scope of the use case?

a) Who are the (external) stakeholders (in the eco-system but not using the system) and what are their concerns and goals?

5 See also the technical documentation of VOICES: https://w4ra.org/wp-content/uploads/2014/08/ VOICES_D1.1-V1.0-VUA_FT-28Sep2011-final.pdf, (accessed o8-10-2020). 
b) What is the scope of the use case scenario? - especially: what is the system's boundary? what is outside it? what is not being considered?

c) What are important (pre-)conditions that must be or are assumed to be satisfied for the scenario? (context features, e.g. resources, infrastructure, technical support, characteristics of the environment)?

5. Design a use case scenario script - the central storyline (just like in a cartoon, a video clip storyboard, an animation or a demo; the script might e.g. be given in the form of a film or animation, showing the event-state chain of the actors' activities and interactions). The main scenario is given in a well-structured narrative, e.g. through 1 - 5 number of steps, for e.g. actor1, (inter)action, actor2.

6. What are success or performance measures for the scenario (especially in relation to what a pilot demonstration should be able to show)?

7. Information concepts (static data structures) - Further script information, e.g. in the form of a few UML class diagrams showing the meaning of important concepts. (This gives some info on static data structures.)

8. Interaction and communication (dynamic interaction structures) - Further script information, e.g. in the form of a few UML sequence, state or activity diagrams. (This gives some info about dynamics, interaction and control flows.)

9. Technology infrastructure - What actions with respect to infrastructure, technologies and technology components (Internet/Web, mobile, information, communication, voice services, both hardware and software) must be taken or made available in order for the scenario to work?

10. What is the layout or configuration of the (networked) interactions between the parties involved in the use case scenario?

11. Cost considerations - What are estimated associated costs (operational, investment, development, in/outsource) for these technology infrastructure and components? Who carries these costs?

12. Networked feasibility and economic sustainability of the envisaged system - The following checklist of questions needs answers:

a) What is the technical feasibility of the scenario (e.g. risk analysis, technical obstacles to overcome, system-level impacts, maintenance issues)?

b) What is the business and (socio-)economic feasibility and sustainability of the scenario?

c) What are possible goal conflicts and dependencies between the actors in the scenario? 


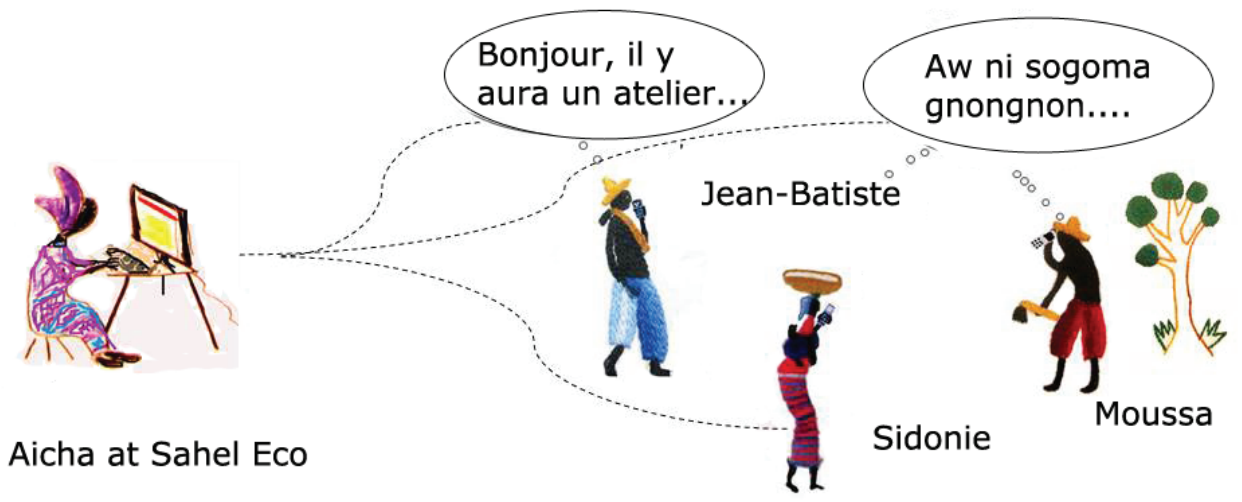

Figure 37: Informal sketch or model of the envisaged mobile event-organizer showing the scope of the system and its users. It shows the key idea of having a voice-based mobile system in multiple languages.

d) Are there preconditions for the scenario to work and is it sufficiently interoperable with the wider context in a business/technical sense?

13. Key requirements - So-called MoSCoW list of requirements [412] (Must have, Should have, Could have, Won't have), as a starting point for further architecture design, and system and component development.

In the next section the structured narrative method is elaborated for a key idea collected with users in rural Mali, cf. Figure 37. I have done this in the framework of a European ICT research project named VOICES ${ }^{6}$. First, the unstructured user story is collected during the workshop. Next, it is structured and modeled according to the proposed method.

\subsubsection{A key idea as an unstructured narrative}

Sahel Eco is a small local Malian NGO, concerned with and experienced in supporting smallholder farmers and their regreening activities, see also Chapter 4.

Sahel Eco has its main office in Bamako and branch offices in Tominian, Sevare and Mopti. In 20117, Sahel Eco had about 11 employees, of which two in Bamako and the others posted in the various regions, to have direct contact and be able to support the communities in the rural areas. Sahel Eco gives trainings and organizes farmer-tofarmer visits. Sahel Eco helps to disseminate and improve regreening initiatives, and trains farmers how to improve methods to make a living out of tree products. One of

6 See the the VOICES research project, funded by the EU in the FP-7 program. See also https://w4ra.org/ publications/voices/ (accessed 08-10-2020)

7 At the time of this research. 


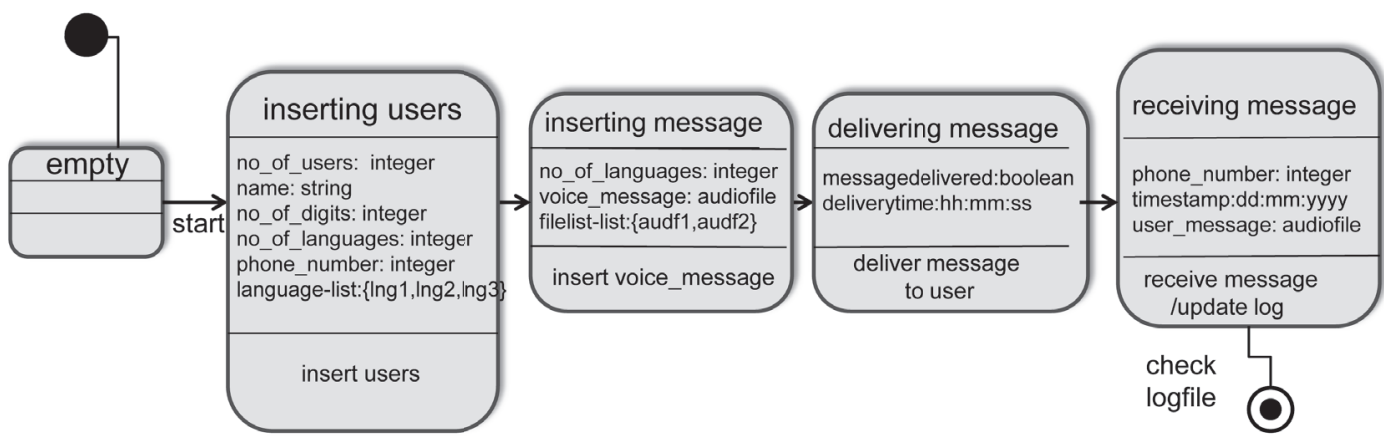

Figure 38: A formal model in UML: state diagram for the mobile event-organizer Tabale. This model shows the different states, state transitions, events and variables for each state of the system. These specifications are necessary for the technical development of the system. By Chris van Aart and the author.

the activities is their support to emerging agro-forestry value chains, which will help farmers to sell their tree products.

Presence in the field is an important asset of Sahel Eco. Sahel Eco's employees are Malian experts in agro-forestry and local farming, most of whom raised in a rural community. Amadou Tangara was the chef d'antenne, posted in Tominian. While Tangara did not have a background in ICT, he soon became a key-user, co-creator and co-designer of various ICT solutions.

At Amadou Tangara's request the following key-idea was elaborated. Amadou Tangara organizes events and workshops on a regular basis, where rural communities meet each other (in e.g. the Ségou and Mopti districts in Mali), to change ideas and raise awareness about regreening. The invitees are farmers who live in remote villages, and only have mobile phone. They do not use SMS. Some are illiterate. Moreover, the farmers speak different languages: some speak French, others only local languages such as Bambara or Bomu. To organize an event, Tangara has to make 25 different phone calls, which takes him too much time.

The idea to facilitate Tangara's work, is to build a system that sends automated phone messages to a group. The envisaged situation is that a registered number of farmers receive an automated spoken voice message on the phone, informing time and place of an event or meeting. Farmers are addressed in their own language. They can phone back and retrieve the voice message again at a later time. The message is (optionally) issued in several languages.

Tangara must first enter a spoken message (in several languages), using a webinterface on his computer. Upon pressing the send-button, the system automatically calls a number of selected users on their mobile phones, addressing them, each in his/her own language. An informal sketch of the use case is given in Figure 37. 


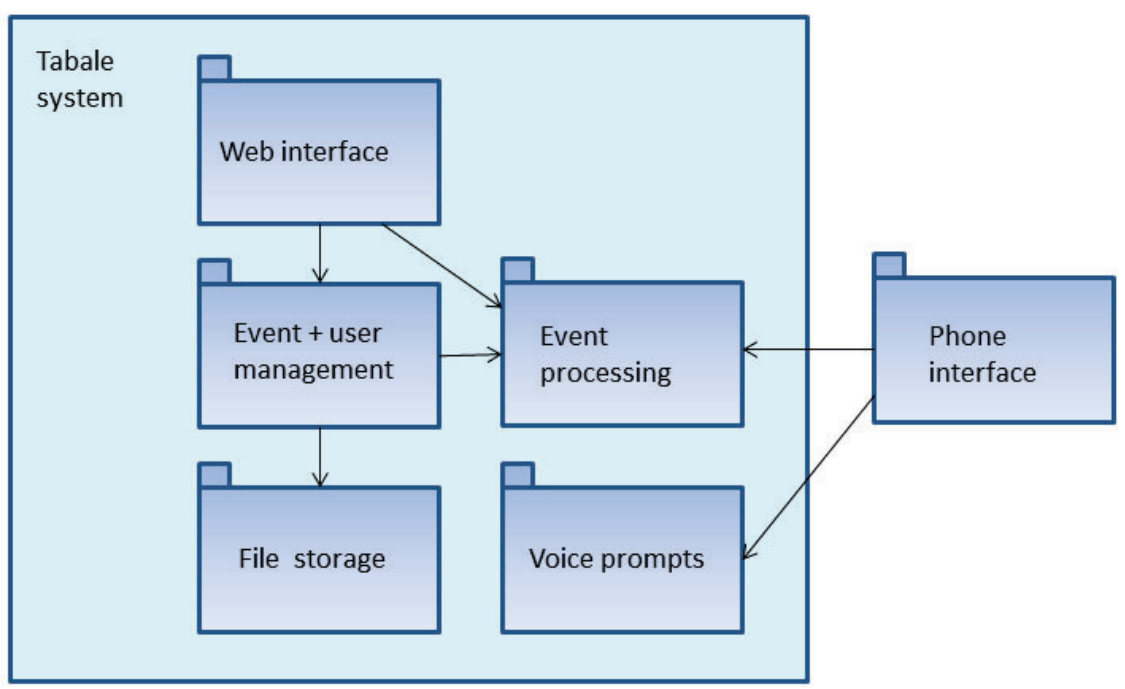

Figure 39: A view of the different modules and how they interact for the mobile eventorganizer. Anna Bon and Chris van Aart.

\begin{tabular}{|c|c|c|c|c|}
\hline Liste des événements & Contacts & Liste des appels & Ajouter un événement & Ajouter un contact \\
\hline
\end{tabular}

\section{Ajouter un événement}

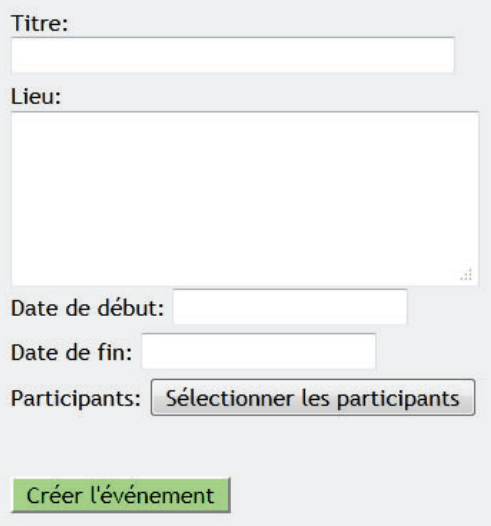

\section{Langues:}

Sélectionnez les langues utilisées pour l'événement, et enregistrez un message pour chacune d'entre elles.

$\begin{array}{cl}\square & \text { Anglais } \\ \square & \text { Français } \\ \square & \text { Bambara } \\ \square & \text { Bomu } \\ \square & \text { Dogon }\end{array}$

Figure 40: Screenshot of the prototype of Tabale, developed and built iteratively, Anna Bon, Victor de Boer, Nana Gyan, Chris van Aart, Max Froumentin. 
Table 5: Stakeholders and their concerns for the Tabale use case.

\begin{tabular}{|r|l|l|}
\hline ID & Actor & Description \\
\hline 1 & NGO & Manage users and user profiles (add new/update/delete users) \\
2 & NGO & Record audio in several languages (French, Bambara, Bomu) \\
3 & NGO & Create an event (add date, users, message) \\
4 & NGO & Manage events (add new; update; delete) \\
5 & NGO & Monitor incoming calls \\
6 & NGO & Launch event \\
7 & Farmer & Receive phone message communicating event \\
8 & Farmer & Respond pressing DTMF \\
9 & Farmer & Generate communique report \\
10 & Farmer & Call phone number to retrieve message \\
11 & Support & Monitor system; maintenance \\
\hline
\end{tabular}

\subsubsection{Structuring the key idea into the structured narrative format}

The user's narrative as illustrated above is elaborated using the structured narrative format.

o. Summary of key idea We want to build a system that sends automated phone messages to a group. The extension worker must enter a spoken message (in several languages), using a web-interface on his computer. Upon pressing the send-button, the system automatically calls a number of selected users on their mobile phones, each in his/her own language. An informal use-case story board for this use case is presented in Figure 36. A screenshot of the system's webinterface is shown in Figure 40.

1. Name and $\log o$ The name given to this use case is Tabale. This is a meaningful Malian word, in Bambara language, referring to the traditional village king's drum. When there is an emergency or an important event or meeting, the messenger goes around by horse and beats the drum, to gather people to the village square. A logo for this use case was designed, see Figure 36 for the Tabale use case.

2. Stakeholders and goals There are three stakeholders/actors, (i) an NGO webmaster; (ii) the farmer who will receive the message, gives a reaction (will attend meeting yes/no/does not know yet) and who can call back and retrieve the message at a later time; (iii) a person who provides technical support to the system. This information is summarized in Table 5 .

3. Make a list of actors and their roles in the system

4. Context and scope for the Tabale use case: 
a) Who are the (external) stakeholders and what are their concerns? Apart from the users (the message sender and the receiving users) there must be service providers to deliver this service, including a local phone (GSM) network.

b) What is the scope of the use case scenario - especially, what is the system's boundary? what is outside it? what is not being considered? The scope for the case under consideration is shown in Figure 37.

c) What are important (pre)conditions that must be or are assumed to be satisfied for the scenario (context features, e.g. needed resources or infrastructure or other characteristics of the environment)? The system should work in the absence of an Internet connection in the villages where the recipients live.

5. Use case scenario script - the central storyline (just like in a cartoon, a video clip storyboard, animation, or demo; the script might for example be given in the form of a film or animation, showing the event-state chain of the actors' activities and interactions). The main scenario is given in a well-structured narrative. For our case study this is shown in Figure 36.

6. What are success or performance measures for the scenario (especially in relation to what a pilot demonstration should be able to show)? The Tabale system is successful if the sender can issue a single message and multiple receivers can receive it by mobile phone, and are able to understand it, and reply to it.

7. Information concepts (static data structures) - Further script information e.g. in the form of a few UML class diagrams showing the meaning of important concepts that give some info on static data structures.

8. Interaction and communication (dynamic interaction structures) - further script information, e.g. in the form of a few UML sequence or activity diagrams. (This gives some info about dynamics, interaction and control flows.) This is shown in Figure 41: a UML use case diagram, a state diagram 38 and an activity diagram 43 .

9. Technology infrastructure: what are the consequences for technologies and technology components (Internet/Web, mobile, information, communication, voice services, both hardware and software) that must be made available in order for the scenario to work?

In this case the system should be able to connect a computer to the phone network and stream voice messages, and store incoming phone calls. The system should be able to work with an internet connection, but also without it, as this infrastructure is often lacking in rural Africa. A deployment diagram is given in Figure 42, showing the various interfaces and gateway. A simplified (non-formal) network diagram, sketched in Figure 44 gives a general idea of the set-up. A view of all development modules is given in Figure 39. 


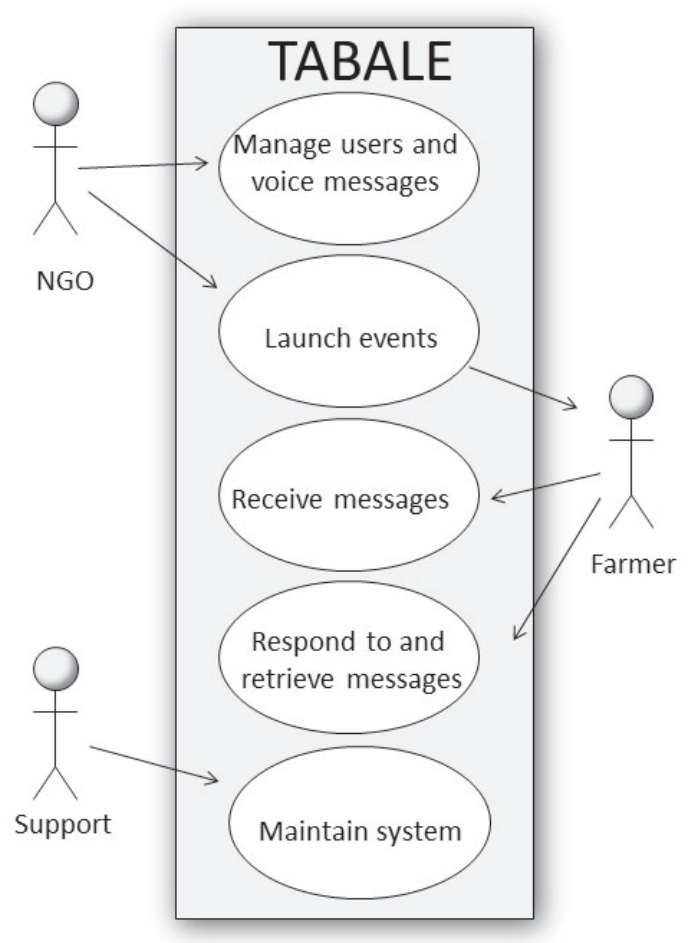

Figure 41: This user diagram for Tabale is for developers, but can also be explained to nontechnical users, as it is a simple model. It shows the three categories of system users and the different task they perform in this system. By Chris van Aart and the author. 


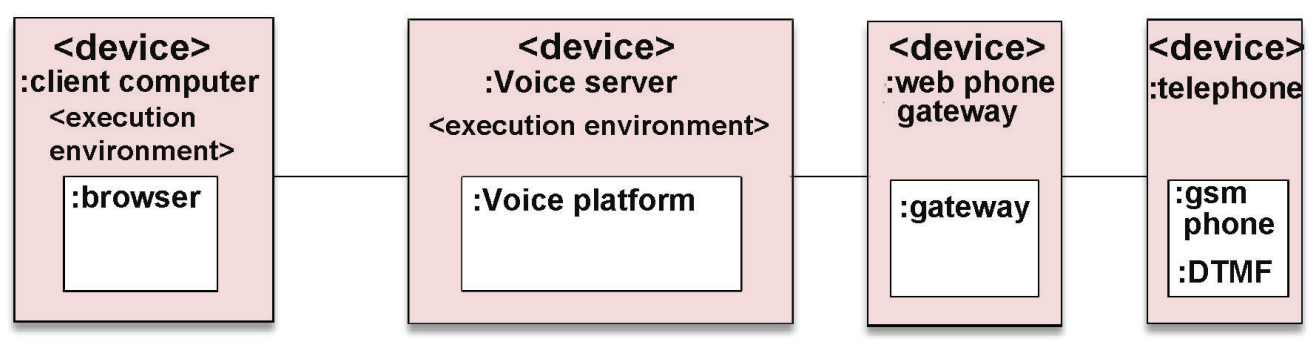

Figure 42: The requirements for the mobile event-organizer have consequences for the technical infrastructure. This is not trivial in the context of rural Mali. This model shows the deployment diagram for this system. Adapted after a sketch by Chris van Aart.

10. What is the layout or network configuration of the interactions between the parties involved in the scenario? To describe the context and scope for the scenario, we sketch a layout or network configuration of the interactions between the parties involved in the scenario and we make a sketch of user/system interaction for the Tabale system, see Figure 37. The physical network requires a system or platform that can generate and send voice messages to the phone network. This platform is displayed in Figure 44 .

11. Cost considerations: what are estimated associated costs (operational, investment, development, in/outsource) for the envisaged technology infrastructure and components? Who carries these costs?

The initial costs of the Tabale case are estimated as the costs of the platform and the initial installation. Recurrent costs are: the maintenance of the system, and phone costs for the NGO or extension worker. The initial development costs would be carried by the $\mathrm{ICT}_{4} \mathrm{D}$ project. The software would be made available as open source (free of license cost). The operational costs would in this case be carried by the NGO as part of their exploitation. (This section needs further elaboration, as will be discussed in Chapter 8.)

12. Feasibility and sustainability: The following checklist of questions needs answers:

a) What is the technical feasibility of the scenario (e.g. risk analysis, technical obstacles to overcome, system-level impacts)?

Technically the Tabale system would be simple and robust. The problem is the phone connection which has to be local (to allow local phone calls).

b) What is the business and (socio-)economic feasibility and sustainability of the scenario? 


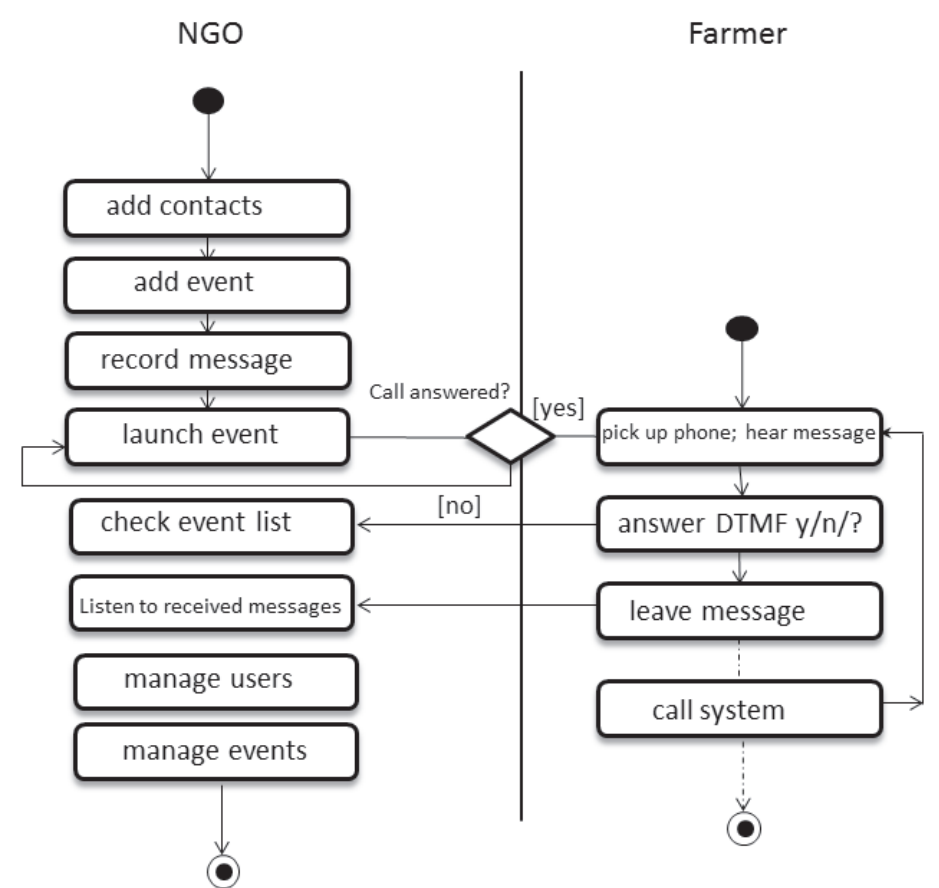

Figure 43: An example of a formal UML activity diagram for the mobile event organizer system. It shows the events and interactions in sequence, between the two user categories and the system. 


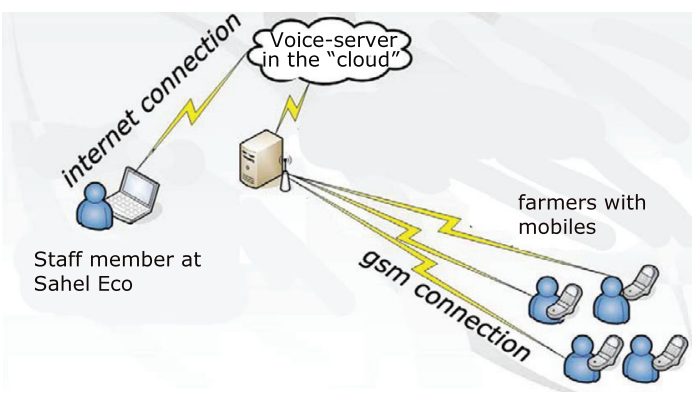

Figure 44: An informal model of the infrastructure needed for the mobile event organizer: a voice server connected to the Internet and to the mobile (gsm) network.

As a tool to communicate between an NGO and farmers, the feasibility and sustainability are well defined. The system saves time and is therefore useful and saves money.

c) What are possible goal conflicts and dependencies between the actors in the scenario?

There are no serious goal conflicts identified for this case.

d) Are there preconditions for the scenario to work, and is it sufficiently interoperable with the wider context in a business as well as technical sense?

The system runs on a platform that connects to a local phone network. This platform must therefore be available locally. The recipient users must have mobile phones.

13. Key requirements So-called MoSCoW list of requirements [91] (Must have, Should have, Could have, Won't have) as a starting point for further architecture design, and system and component development. ${ }^{8}$

For the mobile event-organizer, Tabale, it is an essential requirement (a must have) that it has a Web interface where user profiles can be entered, including their phone numbers and language preferences and that a voice message can be recorded in several languages. It must be able to send the message to a number of phones at one button push: see Figure 40.

Should have: the possibility for the user to reply and leave a message that is stored in the system and is accessible via the web interface. It could have an option where users could phone in. It will not have to rely on an Internet connection to reach the users, since there is no Internet in the villages. It will not use SMS to reach the users, because they are often illiterate.

8 See for a further discussion of the MoSCoW-method: [91] and RFC-2119 https://Www.ietf.org/rfc/ rfc2119.txt,(accessed o8-10-2020) 


\subsection{SUMMARY}

In this chapter I have presented a method for elaboration of use cases and requirements: the structured narrative method. This method captures and structures key ideas and user stories. It enables to capture complex unstructured information and presents it in a structured format. It facilitates communication about requirements in a non-formal way, using narratives and storyboards, but also captures technical system specifications and represents the information through formal models.

This method is appropriate for $\mathrm{ICT}_{4} \mathrm{D}$ software development projects as it bridges the worlds of users and technical developers. Moreover, it also covers more than just the narrow technical system. It includes business requirements and information related to the local context - topics not commonly covered in mainstream use case and requirement analysis methods (see e.g. [173, 236, 248, 388]).

The structured narrative method is useful for $\mathrm{ICT}_{4} \mathrm{D}$, but can also serve other software development projects, especially those situated in dynamic (complex) contexts or in projects in which communication between various stakeholders is cumbersome, due to e.g. large differences in backgrounds or world views. From 2015 we used this method in the master courses ICT $4 \mathrm{D}$ and $\mathrm{ICT}_{4} \mathrm{D}$ in the Field, at VU.9

9 Examples of $\mathrm{ICT}_{4} \mathrm{D}$ projects in 2018 in which the structured narrative format was used are: BipVote: Rural Mali voting system [206], Marcedi: a crop price information app for market participants in rural Ghana [125], Rain Forecasting Service for Ghana [171] and various other student projects. 
Developing a useful and valuable system for people in a low-resource context requires multiple iterations of building, testing, and evaluating. Given special conditions that may exist in lowresource contexts - e.g. poor infrastructure, language, cultural differences between developers and users - this involves a broad interdisciplinary team, collaborating closely over a period of time. This chapter describes the case of a field pilot of the development and deployment of a voicebased market information system in rural Mali, aimed to support farmers and their emerging value chains. It covers the full lifecycle of software development of an ICT4D project, starting with context analysis, needs assessment, use case and requirements analysis, engineering, testing, evaluating, deploying the system in a real-world production environment, and doing an impact assessment after some time. It shows how problem analysis is done iteratively, how the complexity of the local environment requires a non-linear approach to project management. This is the most complete and extensive case that describes the collaborative, iterative adaptive $I_{C} T_{4} D$ approach. The ICT 4 D information system was fully developed according to the goals of local farmers in Mali. The real-world outcomes of this action have been measured and the project had a lasting impact.

\subsection{THE INFORMATION SYSTEMS ENGINEERING DIMENSION IN ICT4D}

This chapter presents the story of an $\mathrm{ICT}_{4} \mathrm{D}$ project in rural Mali that followed the collaborative approach, as described in the previous chapters. It started with a context analysis and needs assessment with local farmers and radio stations. During deployment, several unexpected events occurred that required action, and deviation from the original project plans, to make things work. E.g. we had to build speech technologies in local African languages, which was not foreseen. The infrastructure provided by the telecom provider proved not to be sustainable after the end of the project, so other solutions were to be sought for long-term sustainability. User impact evaluation yielded both unexpected outcomes and positive impacts. There were several take-home lessons for $\mathrm{ICT}_{4} \mathrm{D}$ researchers and developers. This case shows how $\mathrm{ICT}_{4} \mathrm{D}$ development works in a complex context, and how collaboration with local users, many iterative cycles, flexibility of the team and adaptation to the local context are required and can be practically implemented. A large team contributed to this unique project. 


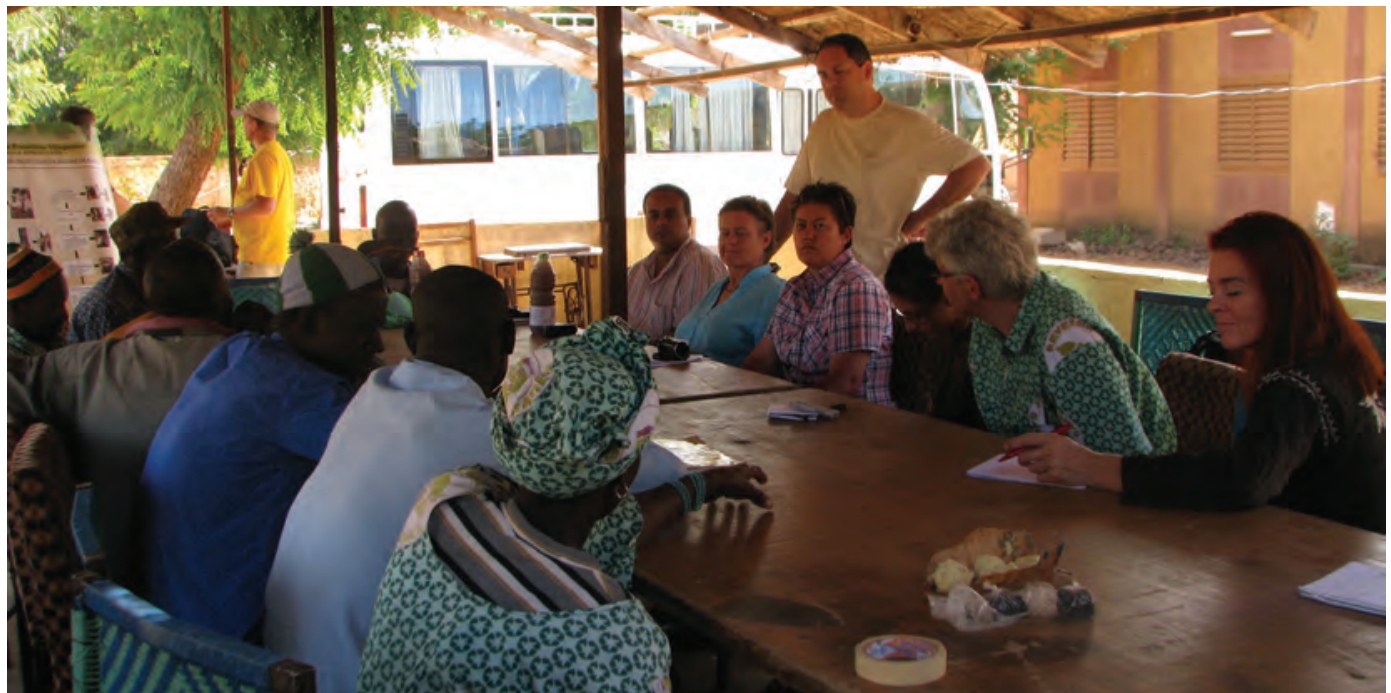

Figure 45: Needs assessment meeting between developers and farmers in Tominian, Mali, 17 November 2011. Photo: Bruno van Moerkerken.

\subsection{CASE: BUILDING SYSTEMS FOR FARMERS IN MALI}

In the framework of a European ICT research project named VOICES ${ }^{1}$ the $\mathrm{W}_{4} \mathrm{RA}$ team and partners did a 30-month field experiment, which led to deployment of a voicebased market information system in rural Mali. The interdisciplinary, multicultural team $^{2}$ in this project consisted of researchers and ICT developers: speech technologists, web developers, requirement engineers, information analysts, but also: regreening experts, key-users, business partners and local farmers. A full technical design of this system has previously been published $[184,183]$ and can be seen in various documentaries. $^{3}$ The requirements analysis and technical development of this system are more extensively described in the PhD thesis of $\mathrm{W}_{4}$ RA team member Nana Baah Gyan [183].

\subsection{CONTEXT, NEEDS, AND USER REQUIREMENTS}

A twelve-day roadshow through rural regions in West Africa (by bus through Mali, Burkina Faso and northern Ghana), marked the start of the VOICES project in January 2011. Our research team did field visits to farmers in the field, we held interviews and focus group discussions with farmers in small villages, see e.g. Figure 45 . We learned from these visits and meetings about the importance of forest products - which

1 This was done in the framework of the VOICES research project, funded by the EU in the FP-7 program. See also https://w4ra.org/publications/voices/ (accessed o8-10-2020)

2 From $\mathrm{SBC}_{4} \mathrm{D}$, VU Amsterdam, 2CoolMonkeys, Web Foundation, North West University, South Africa, Sahel Eco and other stakeholders.

3 e.g. http://w4ra.org/the_making_of_radiomarche (accessed o8-10-2020) 
result from large-scale regreening - for farmers in Mali. This chapter briefly describes the context, the needs assessment, the requirement analysis and iteratively building, testing and evaluating of a market information system that aimed to help farmers sell their forest products. This is what we learned about the emerging so-called agroforestry value chains in rural Mali:

In years of low rainfall, when normal crops (cereals, cotton, and vegetables) have low yields, farmers are vulnerable for food shortages. Tree products can be a valuable additional source of income, as the trees are more resistant to drought and their growth cycles are different from the cultivated crops. Tree products such as baobab leaves, honey, shea nuts, grains and fruits, are available at different times of the year.

For example, one of the forest products which is widely used by the rural communities in Mali4 is the nut from the shea tree (Vitellaria paradoxa). Collection of shea nuts and local production of sheabutter is done by women. Sheabutter is sold at the local markets, as a kitchen consumable, used for baking. Sales of sheabutter can increase the income of women and leave their households less vulnerable to crop loss and dry seasons. Another forest product, mainly collected by women, is neré. Firewood and other non-timber forest products, such as seeds, nuts, fruit and honey, are easy to harvest and manage on the long term. By processing these products (for example into sheabutter, soumbala, purified honey and charcoal) the farmers can improve their income.

To support farmers in Mali, local NGO Sahel Eco started a project to help improve the production and commercialization of tree products 5 . Farmer women who harvested the nuts of the shea tree, were trained in simple, affordable processing techniques to improve the quality of home-made shea butter. Bee keepers - usually men - were trained by Sahel Eco to increase quantity and quality of honey. However, selling tree products is difficult for the farmers who live remote from the markets; the local roads are in bad condition and transports are expensive.

FOCUS GROUP WITH FARMERS IN SÉGOU In November 2011 our research team, consisting of fifteen international and local participants, met eight farmers (three women, five men) who live in the Ségou district and produce tree products: honey, shea nuts \& butter, tamarind, and saban (a fruit). The meeting took place under a tree and was in the Bambara language, simultaneously translated to French and English by various participants.

Farmers told us that formerly, farming and trading was done individually, without success. Two-three years ago, these farmers joined forces and formed small farming \& trading cooperatives, called bemba. Together they started to improve the quality of the (tree) products: shea butter, shea soap and honey. There are now six bemba of ten farmers each, organized per product. This new organizational structure had greatly

\footnotetext{
4 And other countries in the Sahel.

5 Sponsored initially by TreeAid in the Tree4Change project.
} 
improved trade and their negotiating position. Formerly, women farmers, who are mostly illiterate, were often tricked by buyers.

We asked them about the use of mobile phones. They told us the phone is an important business instrument. Every farmer owns or has access to a mobile phone. Phones are personal - not shared by a group - but can be borrowed. Some women do not own a phone themselves, but use their husbands' phone. This is awkward because the men often travel and the wives stay at home. Expenditure on mobile calls is 2000 to 3000 fCFA per month ${ }^{6}$, mainly on commercial calls to customers.

Three women told us they used the phone for trading e.g. phoning buyers or NGO representatives. Beeping (ringing and quickly hanging up to avoid having costs) to potential customers is not usual. The typical phone usage is (i) to keep in touch with family and friends, (ii) using the calculator, (iii) using the built-in phone clock. SMS text messaging is not popular in this group. Young people are sometimes asked for help (although the farmers in this group know how to use SMS). A female participant said 'SMS is for people who can read and write'.

In terms of mobile network coverage, some of the villages e.g. Sibila, near Ségou, did not yet have a mobile network. Near the road the mobile network access was reasonable, but only at night. Farmers mentioned that bad network connection wasted their airtime, since many calls failed. Farmers knew how to top up their phone balance. ${ }^{7}$ Sometimes they asked the airtime reseller to assist with topping up. There was no electricity in the villages. Only 12-volt batteries and solar panels. Mobile phones are recharged in the local shop, for 100 fCFA.

The farmers expressed difficulties in finding customers. Still, they were not sure if they would pay for an ICT system that would broadcast their product offerings on the radio. Their production could be increased, as human labor is not the restricting factor. The problem is the access to customers, as well as the transportation of the goods. Individual production is too small for 'big' customers, such as international companies. The farmers thought that the local market would be the best place to find customers for their products.

Based on the information obtained in this focus group discussion, and in various other workshops and interviews ${ }^{8}$ during two road shows in Mali between January 2011 and November 2012, three use cases were selected. These three use cases were further elaborated. 9

RURAL COMMUNITY RADIOS AS RURAL INFORMATION HUBS In January and November 2011, we also visited a few radios. These are important information hubs

6 This is about 3 to 4.50 EUR per month. This may represent 5 to $10 \%$ of an average monthly income in this rural region of Mali.

7 This is done using the USSD channel of the mobile network.

8 A full descripton of these use cases and related data can be found in the VOICES project deliverables: https://w4ra.org/publications/voices/, (accessed o8-10-2020)

9 The other two use cases: Tabalé and Foroba Blon are discussed in resp. Chapters 6 and 8. 
in rural Africa, in the absence of the Internet and other media. Since radios could be potential business partners for the envisaged ICT deployments, we visited and interviewed the radio journalists. This is what we learned about rural radios in Mali:

Some of the community radios in rural Mali have computers and an Internet connection, some have computers and no access to the Internet and some have no computer facilities at all. ${ }^{10}$ These rural radios reach between 80.000 and 150.000 listeners, with a radius of 100 up to $200 \mathrm{~km}$. Rural radio stations create their own localized programs by broadcasting local and regional news, music, informative programs, round table programs and paid announcements. All radios we visited had mobile access. We met the following radios:

- Radio ORTM Ségou, a state-owned radio with only computers and a 2 Mbps fixed line (ADSL) Internet connection. Radio ORTM Ségou broadcasts programs in French and Bambara, the most widely spoken language in Mali.

- Radio Moutian, in Tominian, a private radio financed by paid announcements broadcasting and private gifts. Radio Moutian has a computer but no Internet. Programs are mainly in Bomu, a local language of the Tominian region.

- Radio Seno, Bankass, a private radio. There are no computers, no Internet. The radio has many listeners in the region. The main language is Dogon.

- Radio Sikidolo, Konobougou, a private radio with computers. They use a Dongle to access the Internet over mobile network (this is very expensive). The language is Bambara (although the journalist Adama Tessougué is from the Dogon region).

In 2011, these radio stations were still using old, analogue equipment, such as tape recorders. The information they broadcast was not stored or kept for access or reuse. The radios did not have ways to manage or reuse the spoken radio content. We brainstormed that combining mobile phone and radio would give opportunities for innovative data services. E.g. radio listeners phone to the radio station and leave voice messages that they want to have broadcasted, or react to popular radio programs leaving news, opinion, regional information etc.

USE CASE ANALYSis OF MARKET INFORMATION SYSTEM To help improve the sales of tree products for the farmers, a development project was set up by Sahel Eco in $2010^{11}$ in the Cercle de Tominian, south-east Mali. The project organized radio advertisements to improve sales of the farmers' forest products on the radio. For this pilot, they selected representatives from nineteen villages in the district of Tominian, from the cooperatives of Hirosin and Farakunna, who were requested to send weekly detailed offerings of the available forest products to Sahel Eco. The workflow is described in the following paragraph.

10 This can change over time, this particular information was collected in February 2012.

11 Part of a project named Village Tree Enterprise, financed by UK agency Tree Aid. 
ORIGINAL WORK FLOW OF USE CASE Amadou Tangara, the chef d'antenne for Sahel Eco in Tominian, aggregated product offerings of forest products from farmers of 19 villages on his laptop, and sent this information to four community radios, every week. The radio stations broadcast the offerings as paid advertisements. Broadcasts by the radio, cost $1000 \mathrm{fCFA}^{12}$ per minute airtime for non-commercial clients. This was paid by Sahel Eco during the pilot.

The offerings were entered in a table format (Excel sheet) on Tangara's laptop. He included the product names, amount available per product (in $\mathrm{kg}$ or liter), price per unity, quality of the products (e.g. filtered or unfiltered honey), contact name and phone number of each producer.

The idea of making the radio announcements was promising, but the workflow was time-consuming. Firstly, Tangara could not send group messages to the farmers to aggregate the offerings, because they (evidently) did not have Internet. So, he had to collect all the information individually and aggregate the 19 different offerings from 19 villages and send it to the radios. (These product offerings were sent to Tangara by SMS, for which the contact persons had received a small training by Tangara). An ICT solution was requested, to improve this workflow.

Based on the input, a semi-formal model of the workflow was sketched, to make sure the whole process was well understood. This was based on an informal sketch which I made hastily in my notebook, and proved later to be very useful to communicate and explain others (also non-technical people) about this process. This sketch is shown in Figure 46. It was decided that we would leave the 19 farmers outside the scope of the system, and concentrated on developing a system to facilitate the work of Tangara and the radios. The scope of the envisaged ICT system is marked by a grey box in Figure 46.

To understand the roles of radios in this pilot, we talked with ORTM Ségou's journalist Fousseyni Diarra, and Radio Moutian's journalists Gustave Diallo and Bakary Dembelé from Tominian and we visited Radio Seno in Bankass. At radio Moutian and at radio Seno one had to go to a local cyber café to download Tangara's product offerings spreadsheet, which he sent to them by email. The offerings - in this project they were referred to as communiqués - were read out by the radio journalists and broadcast in local languages. In Ségou the language was Bambara, in Tominian this was Bomu, in Bankass and Mopti, this was Dogon. The task was time consuming for the radio staff, who had to read this boring list of phone numbers, prices and products, and repeat this, for various broadcasts. It was also prone to errors.

We jointly decided, (after a process of needs assessment and use case elaboration, as previously described [183]), to design and build the above use case, because it was promising for the farmers and it would support regreening initiatives in Mali.

Speech technologies were chosen to generate spoken communiqués from the (textual) market offerings. This was useful for the radios, because now they could broad-

12 Local currency: 656 fCFA is 1 EUR. 


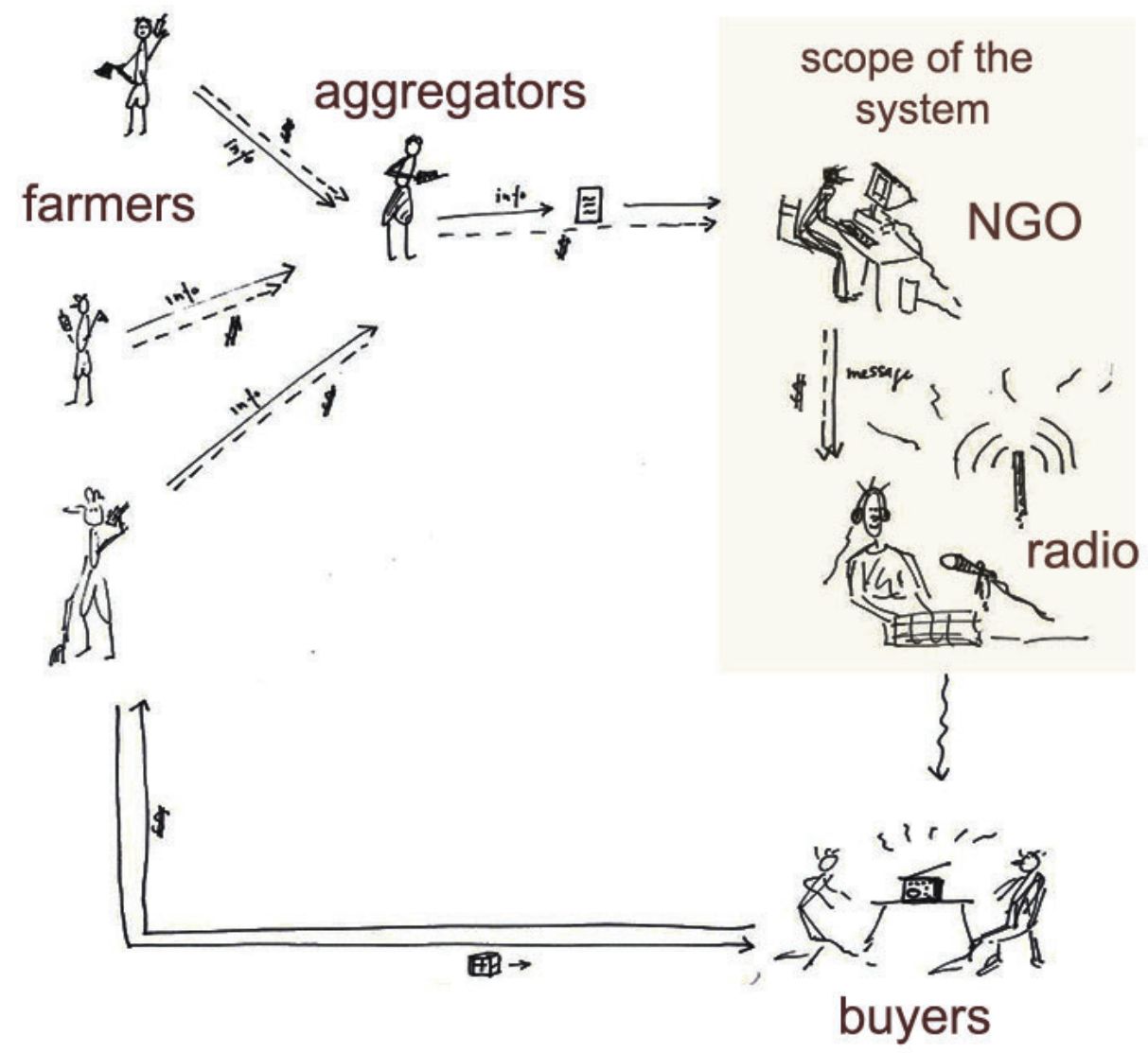

Figure 46: Sketch of the complete workflow for the market information system including the scope of the envisaged system (marked by the grey area). This sketch proved very useful in various occasions for understanding the total workflow, including the scope of the envisaged system. 


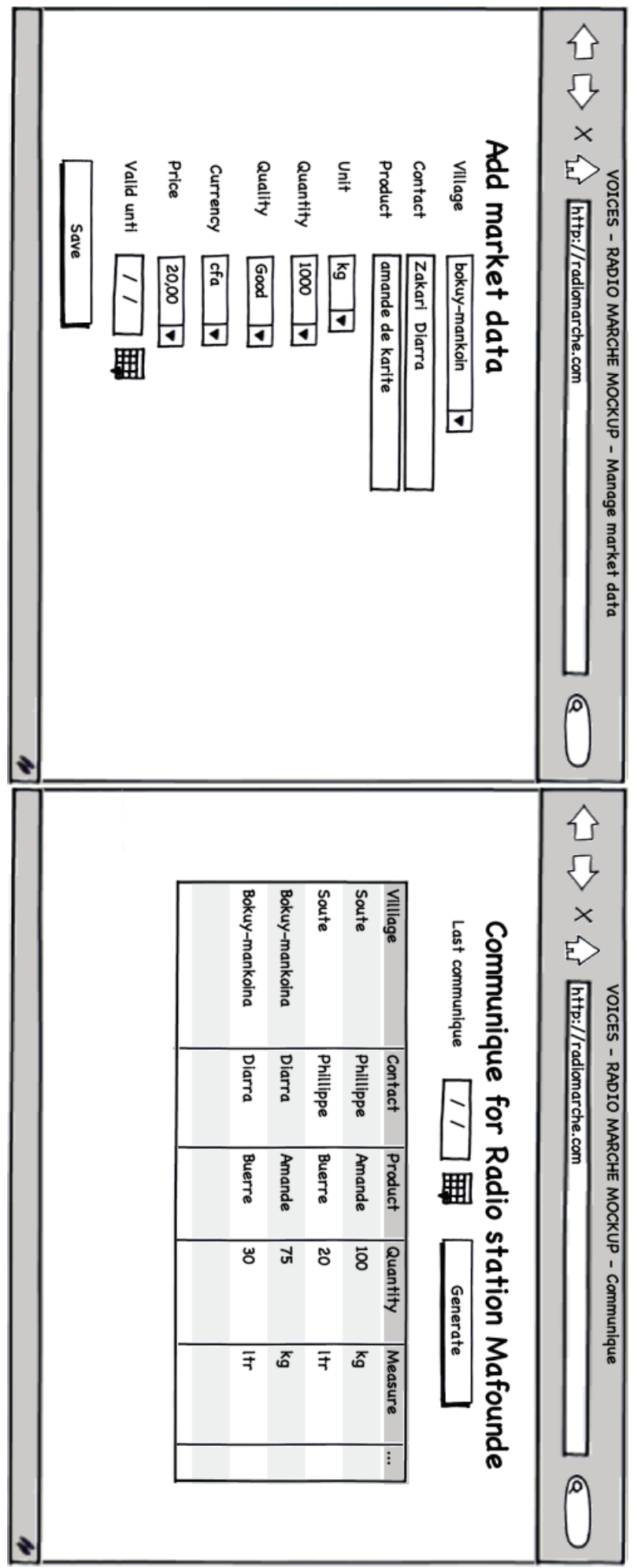

Figure 47: Mockup for RadioMarché, pictured by Chris van Aart and Nana Baah Gyan, to give users an idea of the envisaged web interface. 
cast the same automated voice messages several times. The automatically spoken communiqués with market offerings could only be accessed by mobile phone by the participating radios who did not have an Internet connection in their offices. So, this was an important requirement - a "must" in MoSCoW terms [91] (see Chapter 6).

A web-based interface with pull-down menus was designed, where Tangara could easily enter the project offerings he received from the farmers. A mockup for this interface was designed (by Chris van Aart and Nana Gyan) to show Tangara the look and feel of the web interface and to have his feedback (see Figure 47). For monitoring and evaluation purposes, a database was built, to organize and keep track of all offerings over time. (As previously, Tangara used to store the data in an excel sheet.) This made it possible to create aggregates and reports, and keep track of the sales and offerings.

An important requirement was that the automatically generated communiqué must be issued, through voice, in both French and Bambara language. Language support also for Bomu, i.e. the possibility to create voice messages in this language, was considered important for the region of Tominian but this was temporarily postponed.

Additional requirements were: the audio of the voice communique must be of a quality good enough for broadcasting on the radios. The voices used to generate the message must sound familiar (local accent) in this region. Given the fact that the radio journalists' voices were known and appreciated in the regions, the generated communiqué should be built using the journalist's own voice. Each of the four radios participating in the pilot should be able to access its own generated voice communiqué, by dialing a certain phone number.

The name given to the system was RadioMarché. The conceptual design of the system is shown in Figure 49. A logo was designed by Victor de Boer showing the three concepts of the system: market, radio, mobile phone. The national colors of Mali: yellow green and red were used. The little fellow is named Monsieur Mouriba. The name was given by Amadou Tangara. Figure 48 shows three members of the W4RA team, with RadioMarché T-shirts.

\subsection{ENGINEERING THE SYSTEM IN A COLLABORATIVE WAY}

Based on the requirements collected during the various meetings ${ }^{13}$ with the key-users, various UML models were designed, for example a UML class diagram see Figure 50 according to the format as described in Chapter 6.

When the first demos of RadioMarché, spoken in French, were presented to the users, we received feedback with respect to language: to have a real impact in rural areas of Mali, RadioMarché must be able to generate communiqués in local languages. This hard requirement was a complicating factor for the developers' team. No one had proficiency in these languages. But since this was a critical success factor for RadioMarché,

13 A case description of several of these needs assessment workshops with local farmers and the use case and requirement have been described in a PhD thesis from 2016 by Nana Baah Gyan [183]. 


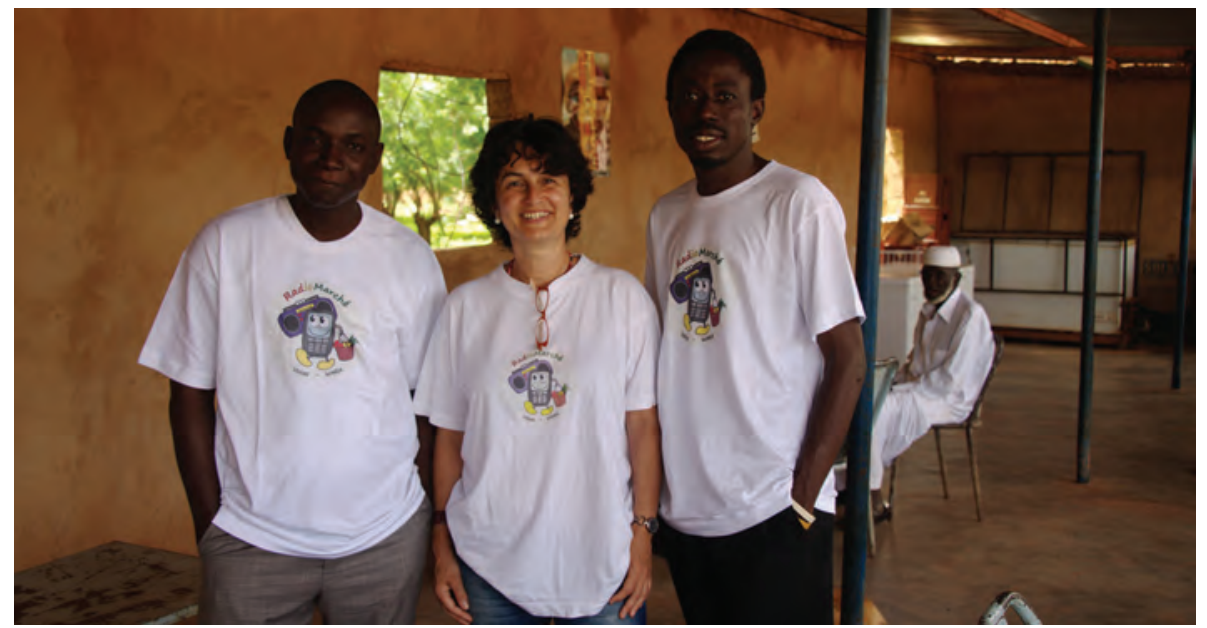

Figure 48: Three members of the W4RA team (RadioMarché logo on the T-shirts) in Burkina Faso for a co-creation workshop. Logo designed by Victor de Boer. The small cartoonfigure is named Monsieur Mouriba. Photo by Bruno van Moerkerken, July 2014.

we jointly decided to build language interfaces in Bambara and Bomu, two local languages in Mali. The voice applications were built with recordings, translations and help of local radio journalists and Sahel Eco staff members. ${ }^{14}$

\subsubsection{Building and testing the speech interface}

The RadioMarché TTS takes textual information as displayed in Figure 51 as input and produces an audio file that can be broadcast to radio listeners as output. The resulting communique is accessible by either (i) phoning the system, or (ii) downloading the audio-file from the website.

For widely-spoken languages such as English, French or Chinese, fully operational TTS systems already exist. These are available on the Web. However, this TTS system for Bambara, Bomu and Malian French, was specifically developed by speech technology expert Etienne Barnard and his team from North-West University in South Africa, together with Stéphane Boyera from $\mathrm{SBC}_{4} \mathrm{D}$. This was done at the request of the users in Mali, because of the need to contextualize the communiqués.

To do this, a Text-To-Speech (TTS) module was built for RadioMarché. ${ }^{15}$ This was done using so-called Slot \& Filler Text-To-Speech method. This method and system, which is developed specifically for under-resourced languages, uses a limited dictio-

14 For more information on speech technologies in this context $[17,54,230]$.

15 Parts of this section are from an internal report by Etienne Barnard, who built the TTS with Stéphane Boyera. 


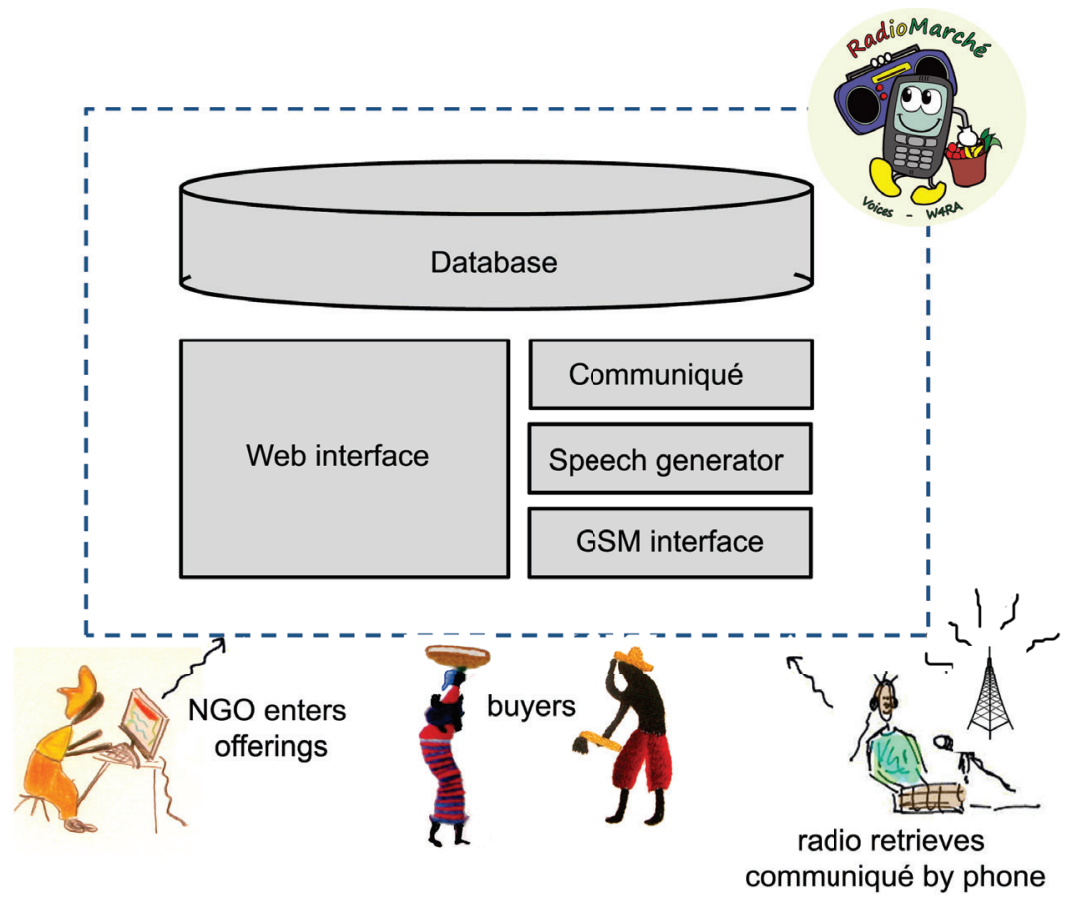

Figure 49: Conceptual design for RadioMarché, showing the components of the system; I made this model with Victor de Boer; the RadioMarché logo designed by Victor de Boer.

nary, with words from a specific domain only. ${ }^{16}$ A toolkit for text processing and speech segmentation enables rapid development of a TTS for new languages. ${ }^{17}$

The first version was only in the local French dialect. Similar systems in the Malian languages of Bamako and Bomu were developed, and evaluated in a later cycle.

According to the needs of the local stakeholders, we did not use standard French voices - which would have been easy, because automated voices are freely available on the Web, also in standard French. ${ }^{18}$ Instead, we had to record local utterances, spoken by radio journalists. Radio journalists Fousseyni, Gustave Diallo and our key-user Amadou Tangara translated the text, necessary to generate all possible communiqués, and recorded the messages in French, Bambara and Bomu. From their recordings the automatic speech generation was built. Evaluation of the speech generator took several cycles, which we did with the partners during our trip in Mali. I wrote the following notes in my trip report of November 2012:

16 See also the master thesis by Justyna Kleczar, VU Amsterdam, July 2017 http://tinyurl.com/ Kleczar-Slot-and-FillerTTS (accessed o8-10-2020)

17 Source: E. Barnard and F. C. Pinto. Proposal documents to standards committees. VOICES project deliverable D3.1, 2013.

18 We note that "Malian" French and "French" French are not fully the same. 


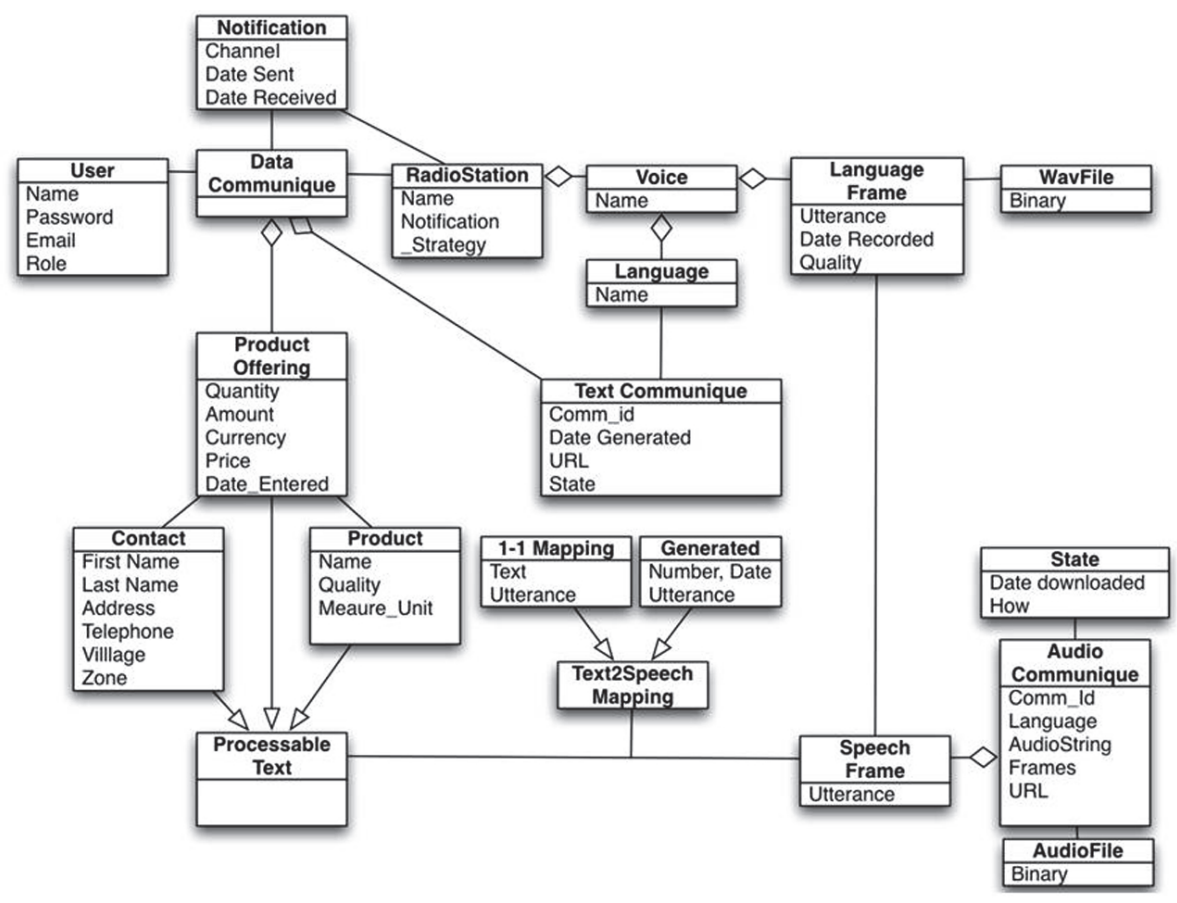

Figure 50: A (UML) class diagram for RadioMarché showing the classes, attributes, their relationships and dependencies, as technical specification for the developers. After a model by Stéphane Boyera and Nana Baah Gyan. 
"We evaluated the first version of the TTS for Bambara with two native speakers: Fousseyni Diarra and Amadou Tangara. The written text contains a few grammatical errors, which they corrected for us. The two evaluators found it possible to understand the spoken communiqué. However, this quality of speech is still not good enough for broadcasting. There were not sufficient pauses between words and sentences. The intonation sounded unnatural. The same was done for the Bomu language TTS. The written text contained grammatical errors. Native speaker Bakary Dembelé corrected this text for us. Five Bomu native speakers (farmers) commented on the TTS generated Bomu communiqué: They found it possible to understand it, however, the communique did not sound completely natural, 'it is like the speaker is not breathing between the sentences'. Still, the voice quality was found acceptable."

Feedback was processed and a new version was released and deployed for RadioMarché. Local users helped to improve the interfaces, by evaluating the quality of the automatically generated speech communiqués. In order to gain an improved understanding of the experimental Text-to-Speech (TTS) systems, early in the development process of RadioMarché, the first cycle of acceptance studies was performed in April 2012 in Mali, at the office of Sahel Eco. This is a summary of the technical evaluation of the VOICES project, by Etienne Barnard and Mary Allen:

During user acceptance studies the usability and desirability of speech technology was evaluated by the target populations. This first cycle evaluated the intelligibility and naturalness of our initial set of slot-and-filler text-to-speech (TTS) systems, which function in West African French. ${ }^{19}$

For the evaluation and user acceptance of the TTS voice system, ten people were invited at the office of Sahel Eco in Bamako. The respondents were asked to listen to audio files containing two versions of exactly the same bulletin. One version was the automatically generated communique and the other was a natural voice reading out the same text. Both naturalness and intelligibility were investigated. The users were requested to give their feedback on the speed of the speech, if it was understandable and if it sounded natural. Quoting Etienne Barnard. ${ }^{20}$

"The first version ('recorded speech') had been recorded by one of the radio journalists. The second ('generated speech') was created with our system (Slot-and-Filler TTS). Ten listeners from our intended target population (residents of Bamako who understand French) were invited by Sahel Eco to act as respondents in the usability test. These respondents (4 females and 6 males) were all adults with at least a basic level of literacy in French, but were not pre-screened in any other way. Each respondent listened to both the generated and the recorded versions of the bulletin (half the respondents hearing the generated version

19 Source: Internal project report VOICES D3.3, by Etienne Barnard, 2013.

20 Source: Internal project report and personal communication with Etienne Barnard for the VOICES project 2011-2013. 


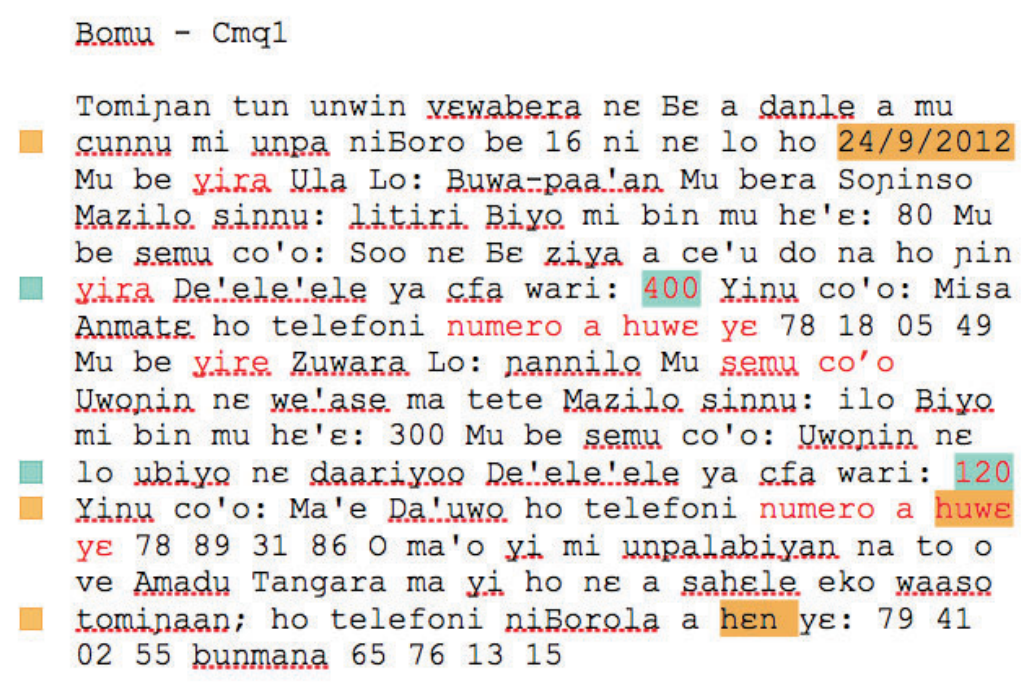

Figure 51: The text of the communiqué in Bomu, as broadcast by Radio Moutian, translated and reviewed by radio journalist Bakary Dembelé, from Radio Moutian.

\begin{abstract}
first, and the other half the recorded version). After listening to each bulletin, each respondent was asked to complete a questionnaire that was designed to assess the intelligibility and naturalness of the speech that had been presented. Upon completion of the second questionnaire, the respondents were also asked to compare the two systems, and to provide any additional feedback according to their own preferences. As expected, the users generally preferred the normal speech. However, all ten respondents found the TTS-generated speech either 'very easy' or 'somewhat easy' to understand. The respondents generally found the speech rates acceptable, for both recorded and generated speech. The respondents who were not perfectly happy with the speed were almost equally likely to prefer slower and faster delivery - thus suggesting that the current rates are the best compromise available."
\end{abstract}

Although the acceptance tests for the speech technologies were limited in scope, they provided credible answers if the respondents find the current TTS system intelligible or unnatural. The user study confirmed the viability of the basic approach to generate speech. Moreover, this result gave us the green light to proceed with this aspect of the project, as previously planned.

It was reassuring that this experimental approach seemed to elicit the information that we desired without any unexpected surprises. These conclusions allowed us to proceed with confidence in the development, deployment and assessment of additional S\&F TTS systems. A similar approach was used in a later stage to assess the Bambara speech-recognition system. 


\subsubsection{Users testing the mobile interface}

In November 2012, production prototypes for RadioMarché and Tabalé (see Chapter 6), were ready to be shown to prospective end-users: two NGO-staff members Amadou Tangara and Drissa Gana and five farmers from a small rural community near Tominian. The prototypes were improved according to their feedback. The farmers evaluated especially the Tabalé system (which is described in Chapter 4).

During the evaluation meeting we did a quick recapitulation of the original legacy workflow - what people used to do before Tabale - and then we explained what the designed system was envisaged to do. We tested the system, and evaluated its functionality, the user interface for different roles, and collected all feedback from the users. Not all users in the evaluation were French speakers, so there was some translation done between French and Bomu, the local language in the Tominian region. The use of $\mathrm{DTMF}^{21}$ on the mobile phones (e.g. press 1 for yes, 2 for no), the navigation of the voice-menu, and the quality of the pre-recorded voice messages were tested. The respondents gave feedback on several aspects of usability. All their feedback was collected and the system was improved and released based on their comments. After the users' evaluation of the first cycle, and having fixed the bugs and added new functionality, a new version was released.

\subsection{DEPLOYING A SYSTEM IN A LOW RESOURCE ENVIRONMENT}

It is challenging to deploy an ICT system successfully (and ensure its sustainability), when the local Internet infrastructure is unreliable, extremely expensive, or totally absent. As this is the case in many regions in rural West Africa, we had two possible options for the local deployment of RadioMarché: (i) to use a cloud solution, i.e. a server accessible through an Internet connection (while this may be unreachable or too expensive for local users); (ii) to build a local infrastructure based on small-scale hardware solutions (whereas the technical solutions may not yet be proven technology).

\subsubsection{Large-scale server in the cloud}

For our RadioMarché pilot, Orange Labs (one of our project partners in the $\mathrm{EU} \mathrm{FP}_{7}$ VOICES project ${ }^{22}$, developed an open source voice platform. The platform, which became operational in 2012, was named Emerginov ${ }^{23}$. The platform was available without costs for the users during the project period of VOICES. After the end of the VOICES project, Orange closed the Emerginov service. The consequence was that the

21 DTMF is a telecommunication signaling system using the voice-frequency band over telephone lines between phones and switching centers [119].

22 http://mvoices.eu (accessed o8-10-2020)

23 See: http://emerginov.org (accessed o8-10-2020) 
RadioMarché and Tabalé systems were no longer available for the local users. (This is a typical example of the unsustainability of donor-funded $\mathrm{ICT}_{4} \mathrm{D}$ projects, in combination with lack of interest in longer term results by some of the project partners.)

\subsubsection{A small-scale local server as an alternative}

Aware of the need for a telco-independent voice platform in rural Mali, (to be independent of the current platform offered temporarily by the telecom operator) and the wish of local users to continue the voice-based services after the project period, in 2012 the $\mathrm{W}_{4} \mathrm{RA}$ team started development of an alternative voice server for phone and Internet access in low-resource environments. We used small inexpensive hardware, in a research project which was named "Downscaling the Web"..24

After several iterations, in May 2015, a prototype voice server for rural development in Africa was released and given the name Kasadaka, a Ghanaian name which means "talking box". ${ }^{25}$ The first deployment of the Kasadaka system is a rapid prototyping platform. It allows quick and efficient needs' assessment and requirements elicitation during the workshops in Africa. Its hardware ${ }^{26}$ is small (the size of a credit card), and inexpensive (about 6o EUR). It can endure rural conditions: heat, dust, as it does not have spinning disks. It is a low-energy consumer and can be used with a small solar battery. It can (if available) be connected to the Internet using a WIFI or a fixed Internet connection. It can be used stand-alone. It has a dongle with a SIM card to allow access to the phone network through (GSM) phone. The server is powered by the free and open source framework Asterisk ${ }^{27}$, a software development framework to build (voicebased) communications applications.

The Kasadaka server offers API's for applications built in e.g. PHP, a server-side scripting language for making dynamic and interactive (including voice-based) Web pages and interactive voice dialogues, and for VoiceXML ${ }^{28}$.

The small-scale Kasadaka voice-platform is an ongoing research project by researchers and students ${ }^{29}$ from the $\mathrm{W}_{4}$ RA team at VU Amsterdam. Kasadaka aims to serve the needs of users in low-resource contexts. It supports development and deployment of speech-based mobile applications. A software development kit for Kasadaka (SDK), that facilitates development of voice applications (for people with limited program-

24 This was initiated by $\mathrm{W}_{4} \mathrm{RA}$ researcher and colleague Christophe Guéret, see https:// worlswidesemanticweb. org (accessed 08-10-2020)

25 A full technical description of the Kasadaka can be accessed at http://kasadaka.com (accessed o8-102020)

26 Raspberry Pi: https://tinyurl. com/y7kopfvd, (accessed o8-10-2020)

27 See Asterisk: https://Www. asterisk.org/ (accessed 08-10-2020)

28 VXML is an official $W_{3} C$ standard, see: https://WwW.w3.org/TR/voicexml30/, (accessed o8-10-2020). VXML is the standard markup language for voice browsers specifying interactive media and voice dialogues between humans and computers.

29 André Baart, Victor de Boer, Francis Dittoh and Christophe Guéret are the developers of Kasadaka. 
ming skills), will be further developed and tested under rural conditions in the coming period. ${ }^{30}$

\subsubsection{Which server should be used when?}

Figure 52 shows two possible infrastructure solutions: (i) one based on a large cloud server, connected through the Internet (ii) a local server infrastructure based on inexpensive hardware. Which one is best suitable depends on the scale of the deployment. The small hardware solution has only one or two available phone lines, so it can handle two concurrent incoming calls, thus limiting the size of the service.

The cloud server is an expensive solution, especially for users in rural Mali. The costs of hosting a server in a datacenter, in combination with a fixed-line connection to the local phone network are far beyond what a small ICT entrepreneur or radio station in Mali can afford (> 1500 EUR per month is an estimate of the hosting costs including a fixed phone line for 32 concurrent lines, in Bamako, Mali). In the stage of piloting and testing, the small hardware solution is an inexpensive and robust solution for the voice-platform. A more sustainable technical and business solution is currently being studied/developed. ${ }^{31}$

The outcomes of the RadioMarché deployment with respect to the underlying infrastructure and voice platform have given new insights on various problems of $\mathrm{ICT}_{4} \mathrm{D}$ which are widespread, highly relevant, but not yet solved. This leads to new research questions, for example with respect to (i) technical infrastructure (cf. the Kasadaka project), (ii) further development of speech and voice technologies and (iii) business/financial aspects of sustainability of $\mathrm{ICT}_{4} \mathrm{D}$. These topics are currently subject of ongoing research at VU Amsterdam, in the framework of the $\mathrm{W}_{4} \mathrm{RA}$ research program on "knowledge sharing for the rural poor".

\subsection{COLLABORATIVE IMPACT EVALUATION}

The RadioMarché system turned out to be a promising step forward and was highly valued by local users and beneficiaries. In October and November 2012 participatory impact evaluations were performed for RadioMarché ${ }^{32}$. Five radio stations ${ }^{33}$ were visited and feedback was collected with written questionnaires ${ }^{34}$. Farmers who partic-

30 See: Master thesis by André Baart, VU Amsterdam, December 2017, https://tinyurl.com/ kasadaka-sdk-a-baart, (accessed o8-10-2020)

31 By the W4RA team at VU Amsterdam, in close dialogue with Radio Sikidolo and other stakeholders in Mali.

32 For the evaluation report see: http://tinyurl . com/W4RA-Web-of-Voice-pdfs (accessed o8-10-2020)

33 Radio ORTM Ségou, Radio Sikidolo (that joined the project in 2012), Radio Koutiala, Radio Mopti, Radio Seno Bankass.

34 A full evaluation of the RadioMarché system, deployed in rural Mali, can be found in http://tinyurl. com/W4RA - Voices - D5 - 4p. 42 (accessed o8-10-2020) 


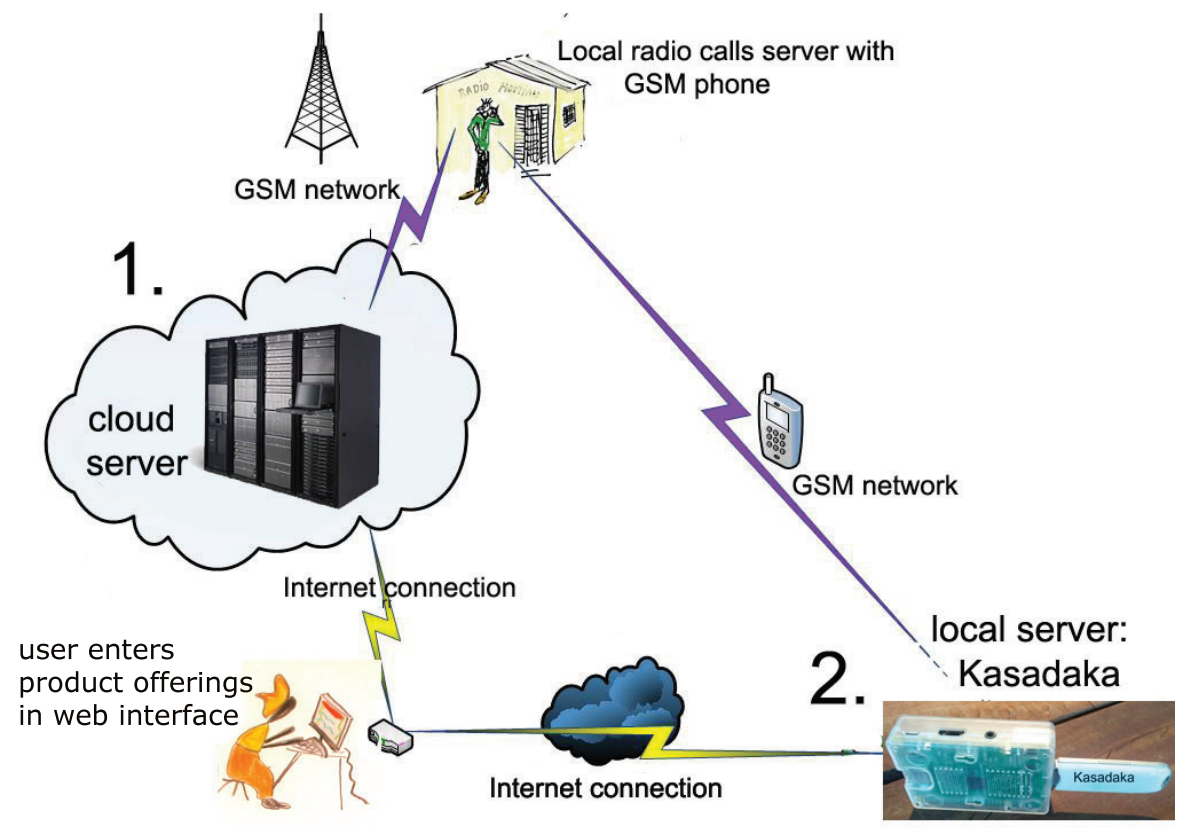

Figure 52: Two options for a voice-server under rural conditions: (1.) a "big server" in the cloud or (2.) develop a "downscaled", inexpensive solution/infrastructure, and deploy it locally. This is the "Kasadaka" project, which is currently (2019) still being developed by the team. 
Offerings per product

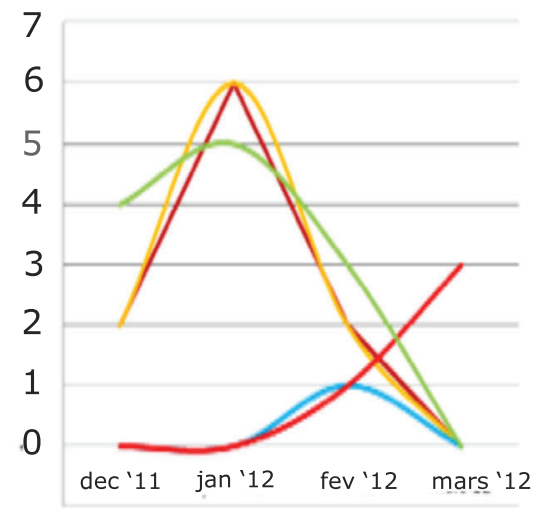

Improvement of sales (\%)

w.r.t. November 2011

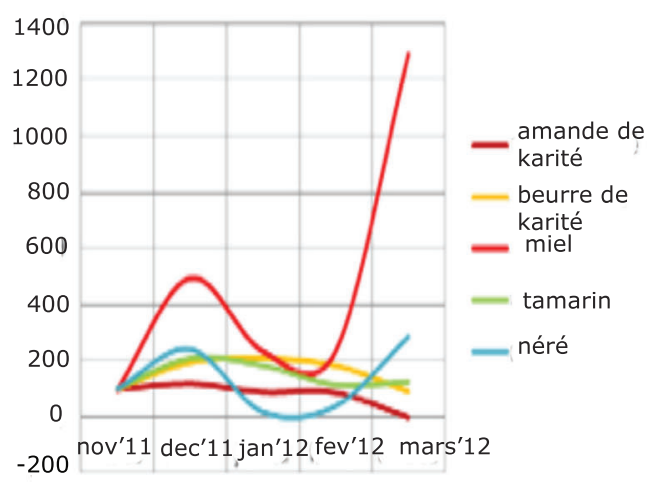

Figure 53: The number of product offerings, sent by the 19 farmers per product (left); the relative increase of sales in relation to November 2011 (right). By Amadou Tangara and colleagues. Courtesy of Sahel Eco.

ipated in the pilot and buyers, triggered by the RadioMarché announcements, were also interviewed. The impact evaluation had some unexpected outcomes, that could not have been planned in advance.

MONITORING THE PILOT During the RadioMarché pilot, monitoring activities were done by Sahel Eco to keep track of the evaluation of the sales in relation to the broadcasts (see Figure 53). They assessed the number of product offerings that were sent by the 19 contact persons from the villages, the number of products offered, the number of broadcasts made by the radio, and they evaluated the amount of sales effectuated (see Figure 54). This last indicator was assessed by interviewing the farmers regularly, through questionnaires to the radio stations on the usability of the system, and questionnaires to potential customers. ${ }^{35}$ Apart form that, a logging system to monitor the activities on the digital platform was available for this monitoring. In April 2013 I held a long interview with key-beneficiaries Zakary Diarra, producer and reseller of honey, and Naomi Dembelé, producer of shea butter. With their consent these interviews have been placed online. ${ }^{36}$

Unexpected outcomes The broadcasts of RadioMarché in 2011 and 2012 created a demand of honey that could not be met by the producers, according to the radio journalists ${ }^{37}$, so they requested Sahel Eco to stop the broadcasts of communiqués for honey, unless stock would be readily available. They suggested to create sales points

35 These scanned, paper-based data forms are available at a special request.

36 http: //tinyurl. com/W4RA- Naomi - interview- 2013 (accessed o8-10-2020)

37 In interviews with Fousseyni, Bakary and Tangara in November 2012. 


\begin{tabular}{|c|c|c|c|c|c|c|c|c|}
\hline \multirow{2}{*}{ Produits } & \multicolumn{5}{|c|}{ Quantités vendues } & \multirow{2}{*}{$\begin{array}{l}\text { Total } \\
\text { vendu }\end{array}$} & \multirow{2}{*}{\begin{tabular}{c|} 
Prix par \\
unité moyen
\end{tabular}} & \multirow{2}{*}{$\begin{array}{l}\text { Montant } \\
\text { (en fCFA) }\end{array}$} \\
\hline & $\begin{array}{r}\text { Nov. } \\
11\end{array}$ & Déc. 11 & Jan. 12 & Fév. 12 & Mar 12 & & & \\
\hline $\begin{array}{l}\text { Amande de } \\
\text { karité }(\mathrm{kg})\end{array}$ & 12000 & 14330 & 10845 & 10595 & 0 & 35770 & 160 & 5723200 \\
\hline $\begin{array}{l}\text { Beurre de } \\
\text { karité (kg) }\end{array}$ & 1040 & 2021 & 2171 & 1904 & 951 & 7047 & 1000 & 7047000 \\
\hline Miel (I) & 300 & 1491 & 706 & 709 & 3880 & 6786 & 2000 & 13572000 \\
\hline Tamarin $(\mathrm{kg})$ & 2100 & 4415 & 3865 & 2390 & 2610 & 13280 & 250 & 3320000 \\
\hline Néré $(\mathrm{kg})$ & 350 & 840 & 60 & 135 & 993 & 2028 & 450 & 912600 \\
\hline \multicolumn{8}{|c|}{ TOTAL GENERAL en francs CFA } & 30574800 \\
\hline
\end{tabular}

Figure 54: Monitoring of the sales of forest products was done during the RadioMarché pilot. Diagram: courtesy Sahel Eco, internal project report 2013. By Amadou Tangara.

for honey in Ségou and Tominian, to take the burden off the radio stations, who are called frequently by buyers interested in honey.

The broadcasts had a tremendous effect, according to the stakeholders. Sales of honey went up. Farmers, who had, through this system, started to collect and sell more honey, could not meet the increased demand for honey. More farmers started to produce honey in the villages. A sales point for honey was set up at the branch office of Sahel Eco in Tominian. $3^{8}$

Zakary Diarra was one of the honey producers, from the village Bokuy-Monkuina, in the Tominian district, who benefited from RadioMarché. In an interview he said: "I now sell 200 liters of honey. With RadioMarche, after the broadcast on the radio, I was able to sell all of my honey. I am now able to pay schooling for my four children and I could even buy a cart and a donkey, last year. People call me now So Zakary, which means Zakary of honey". 39

Naomi Dembelé, a women farmer from the village Sira, who produces shea butter, said in an interview to me: "Thanks to this system we, the women who produce shea butter, are known throughout the country, and whenever there is a demand for shea nuts people will come to me. I am proud that I am known across the country."

The demand for neré seeds was increased as well. However, demand for shea butter did not expand in the same way as honey. The packaging and transport of transformed products remained a difficult issue. According to Sahel Eco director Mary Allen, this pilot showed that agro-forestry value chains have potential, but need better organization, especially for certain products which have a lower local demand. In September

38 Les TICs dans les chaînes de valeur agro-forestières. W4RA Working Papers 2014-1 http: //tinyurl . com/ y7xszbkj (accessed o8-10-2020)

39 See: http://w4ra.org/interview-with-zakary-diarra-beekeeper-in-mali/ (accessed o8-10-2020) 
2013 Sahel Eco and farmer women started to engage transporters and to package shea butter in smaller quantities, to try to improve the local value chain for shea butter.

RadioMarché increased the sales of honey in 19 villages in the Circle of Tominian. It also brought new ideas how to set up local businesses in non-timber forest products. Farmers who benefited from the increased sales were very pleased with the system, and reported various benefits, some of which are difficult to quantify (however, not less important as a project outcome), such as "increased status in the village".

For the NGO the pilot made clear that various tree products in the region (e.g. sheabutter) need more elaboration, and more organization, to increase sales. In the case of the sales of honey, RadioMarché turned out highly valuable. For shea butter this was much less the case. This made clear to Sahel Eco that development of new value chains for sheabutter would need a different approach. They decided to take action and get a better understanding of issues related to transport, packaging of the product, choice of local market, marketing ${ }^{40}$ ).

RE-USING THE SYSTEM FOR A DIFFERENT PURPOSE Based on the increased demand of honey and other tree products, Amadou Tangara, in 2013 and 2014, (one year after the end of the formal pilot) started to re-use the Tabalé system ${ }^{41}$ to organize group sales for honey. Whenever a customer announced himself in Tominian at the Sahel Eco branch office or at the radio, with a large demand, Tangara used Tabalé to request farmers in the environment (whom he knew), to reply how much honey they could deliver. This was an unexpected use of the Tabalé system, and shows that it can have a useful applicability, for a different purpose than for which it was originally designed and built. This is an example of the general observation that adaptation of innovations by users is one of the characteristics of real innovation [350].

DisSEMINATION In 2014, farmers in the Yatenga region in Burkina Faso, after a presentation by Amadou Tangara, requested a version of RadioMarché. This should be revised, as the local language here is Mooré, and the products offered by the farmers are different. Five journalists from radio stations in the Yatenga and Zondoma region in Burkina Faso helped us to translate and record the new voice-dialogues in local Mooré language, in July 2014, for the local contextualization of RadioMarché. The name in Burkina Faso, according to the farmers, would be Raas Kibaya, market information in Mooré language. This project in Burkina Faso is still ongoing, in 2018.

TIME AND COSTs The RadioMarché project was sponsored during a limited period (36 months) ${ }^{42}$. During this period the farmers received the system without payments.

40 Personal communication with Mary Allen, Amadou Tangara, Madeleine Dembelé, in Bamako, Mali, September 2013

41 Described in Chapter 6.

42 It was an EU-funded project, VOICES, in the FP-7 program. 


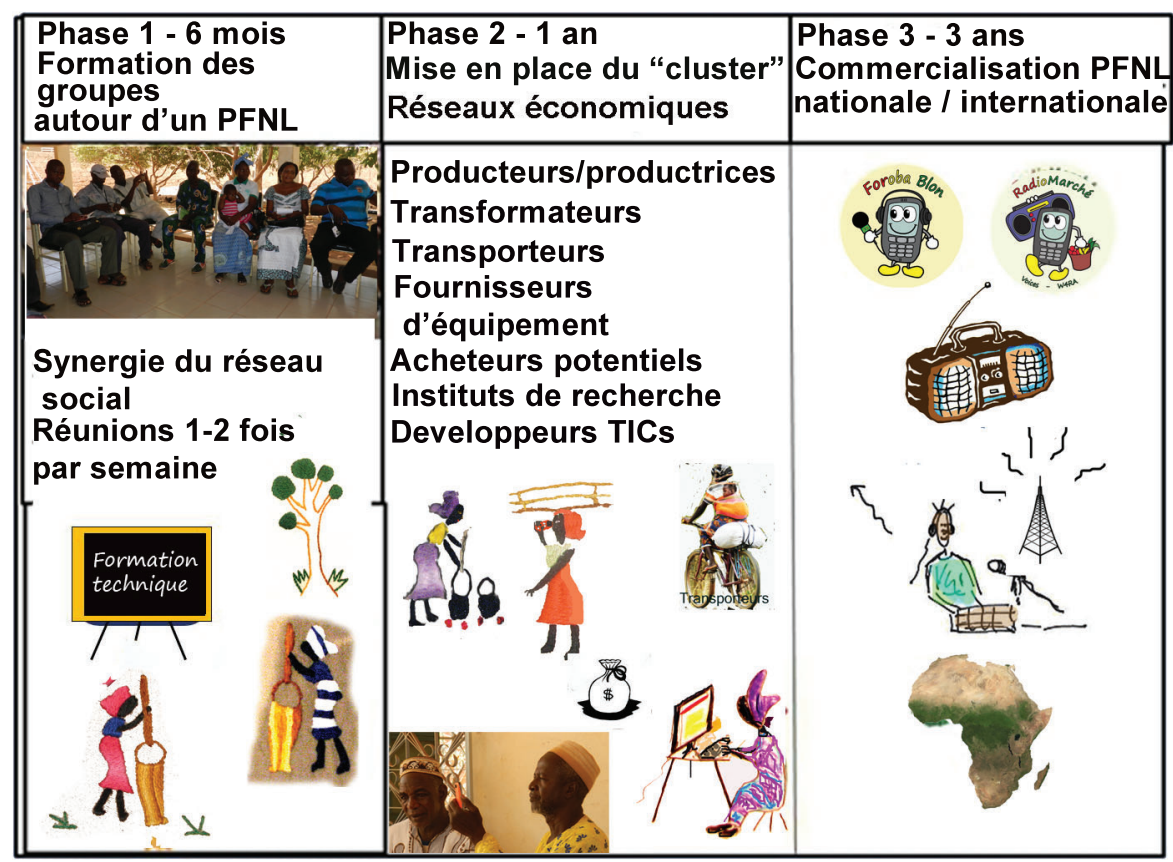

Figure 55: Plan by local users to scale-up the agro-forestry value chains, using ICT. Phase 1 : formation of groups and training; phase 2: bringing together stakeholders; phase 3: commercialization of the forest products using RadioMarché and Tabalé. (PFNL produits forestiers non-ligneux) By Amadou Tangara and the author.

The ICT systems were continued after the VOICES project 43 , because of the great interest expressed by the local stakeholders (farmers, NGO) to keep the systems up and running, and their willingness to pay a small fee to use it. Despite the interest expressed by local users, in 2014 project partner Orange, who was responsible for the (cloud-based) voice platform Emerginov, pulled the plug and discontinued the whole project. The users were not pleased with the discontinuation of the ICT services.

It is difficult to estimate the costs of the development of the systems RadioMarche and Tabalé, because this was not financed by one single source. The project was not only an $\mathrm{ICT}_{4} \mathrm{D}$ project, but a field research experiment, involving students and researchers and producing project deliverables and scientific papers. The (minimum) estimated input to build the two systems would be: a project manager, four ICT developers, a requirement engineer, four radio journalists, two NGO staff members, a speech technologist, 19 local farmers. The estimated cost is about 40 person-months ${ }^{44}$. In Chapter 8 this financial aspect will be further elaborated.

43 The VOICES project ended in July 2013.

44 This is a common method to calculate costs in projects. 
A system approach to evaluation The case of RadioMarché shows that impact evaluation of a complex $\mathrm{ICT}_{4} \mathrm{D}$ project needs a system approach. In this case the voice-based market information system RadioMarché increased the sales of treeproducts for farmers from nineteen villages in the Tominian region. The RadioMarché system helped the farmers to increase their access to local markets, through broadcasts on local radios, and increase sales of tree products. The improved sales led to improved household income for the farmers involved. This has a positive and reinforcing effect on the cultivation of trees on farmland. As such, it reinforces and supports regreening in Mali through more sales of tree products. It also has a positive effect on food security, through improved household income for farmers. The complex interacting variables are visualized in a concept map in Figure 56, showing a number of local variables, and how RadioMarché interacts in this complex context. This concept map is also a representation of an alternative "theory of change", but one grounded in empirical data and extensive field research (in contrast to the linear, deskresearch-based theory-of-change, often used in development projects [390]).

LOCAL PLANS TO SUPPORT EMERGing VALUE CHAins Based on the experiences with RadioMarché, Amadou Tangara with feedback from farmers in the Mopti region, developed a 36-month scaling up plan for value chains of non-timber forest products (NTFP) in rural Mali. The technical plan was formulated by Tangara and reported and published as a $\mathrm{W}_{4} \mathrm{RA}$ working paper by the Network Institute. 45

The plan consists of three phases. The first phase (of six months) is to train groups of farmers during six months in the transformation of forest products, e.g. how to produce (homemade) sheabutter, and filtered honey. Farmers will also receive training in financial management. The second phase (of one year) is spent organizing/improving the local value chain for the specific product, bringing together groups of farmers, producers, local transporters, potential customers, microfinance organizations, research institutes and ICT developers, to create the social environment for the value chains. The third phase (of up to three years) will be devoted to commercialization of the products across regions and to other countries. This requires ICT services, similar in setup and having mobile voice interface like the ones in RadioMarché and Tabalé. This plan, as designed by Amadou Tangara, is conceptually visualized as a diagram in Figure 55.

\section{$7 \cdot 7$ SUMMARY}

This chapter has shown that engineering, deploying and evaluating can be done in a non-interventionist, collaborative, adaptive, iterative way that accounts for the specific on-the-ground context. The case of RadioMarché is an example how real innovation works and how local users can influence the process and outcome of an $\mathrm{ICT}_{4} \mathrm{D}$ project.

45 See: http://w4ra.org/wp-content/uploads/2014/08/Web-of-Voices-Working-paper_v0.11.pdf (accessed 08-10-2020) 


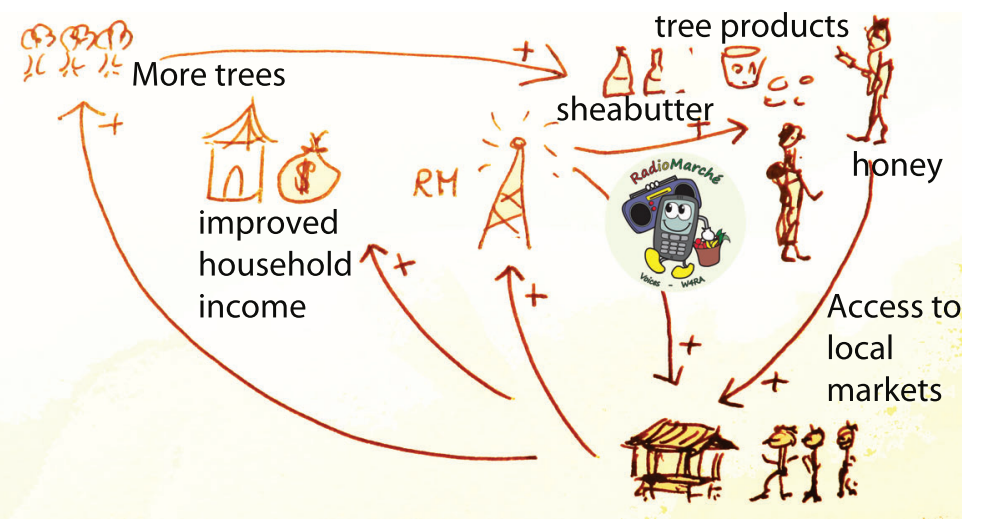

Figure 56: This causal loop scenario shows how the innovative technology RadioMarché is embedded and interacts with various variables in a complex context. This model represents a "theory of change", but one grounded on empirical field data and experience.

The pilot demonstrates the importance of extensive sociotechnical field research, of cultural aspects, of collaborating with end-users, of embedding an ICT system in the local context. The RadioMarché pilot also shows the emergent nature of outcomes and impact in a complex ICT4 $\mathrm{D}$ project, that could not have been foreseen at the start of the project. The causal loop scenario in Figure 56 illustrates the RadioMarché project as an alternative, systemic "theory of change", grounded in field-based empirical data and experience.

Despite the promising results of RadioMarché, many problems still remain unsolved in $\mathrm{ICT}_{4} \mathrm{D}$ : problems related e.g. to infrastructure, language, illiteracy and many other issues. One major problem revealed by this pilot is the issue of sustainability of $\mathrm{ICT}_{4} \mathrm{D}$ systems and services. How can this issue be addressed and anticipated upon, at an early stage of $\mathrm{ICT}_{4} \mathrm{D}$ development? In the next chapter, the problem of economic sustainability of $\mathrm{ICT}_{4} \mathrm{D}$ systems and services will be discussed. 
Sustainability is the Achilles heel of ICT4D projects. Many projects do not survive after the period of donor funding. ICT4D still lacks good methods that help understand which factors contribute to sustainability or to the contrary. This chapter examines the key issue of economic sustainability of ICT solutions in development. It is obvious (although not often mentioned in $I_{C} T_{4} D$ studies) that one of the key factors for the sustainability of a new ICT service depends on the value that it brings to all stakeholders involved. Based on this simple premise, the next question is to understand how value will be provided by an ICT service. I propose a methodology that allows assessment of sustainability upfront. This is done by making scenarios and evaluating various possible outcomes, already before deployment. To this end, a novel method is used, based on the $\mathrm{e}^{3}$ value networked business modeling theory and methodology. I illustrate this with an example of a voice-based ICT service, deployed in rural Mali. ${ }^{1}$ Our method supports the fourth Principle for Digital Development: Build for Sustainability. ${ }^{2}$

\subsection{THE BUSINESS MODELING DIMENSION IN ICT4D}

As discussed in Chapter 1 , the high rate of unsuccessful project outcomes of $\mathrm{ICT}_{4} \mathrm{D}$ is of general concern in international development. In previous chapters I have attributed this to approaches that ignore local operational goals and real-world context. Apparently, ICT4 $\mathrm{D}$ projects lack the tools and methods to assess sustainability and feasibility of ICT4D projects before deployment, making deployments often a situation of "hit and miss". There are similarities here with the early days of the Web (in the 1990s). In those days many new ICT and Web services were set up, which soon proved not to be sustainable. This was due to the lack of a realistic business case, and lack of insight in the value proposition of a proposed ICT service [170].

As is the case with all innovations, long-term sustainability of a service is an ultimate measure of success. To achieve this, all stakeholders (end-users and service providers) must obtain something of value from the service, otherwise the service will not survive. As I will show in this chapter, an understanding how this works, starts with the assessment of local users' needs and operational goals. Moreover, a proper assessment of business requirements is necessary to model and evaluate different scenarios, upfront. A methodology to do this is presented in this chapter.

\footnotetext{
I Parts of this chapter have previously been published by Anna Bon, Jaap Gordijn and Hans Akkermans (2017) [45].

2 See: https://digitalprinciples.org/, (accessed o8-10-2020)
} 
8.2 ECONOMIC SUSTAINABILITY AS A REQUIREMENT: A BUSINESS CASE IN RURAL MALI

A farmer e.g. in Tominian, Mali may be interested in a mobile voice-based messaging service that provides her with market information. However, she will only pay for the service, when it creates a real added value for her. A small entrepreneur such as a radio station, e.g. radio Moutian in Tominian, may be interested in participating in the future commercial voice-service delivery. However, the profitability of the service for the radio station is not obvious upfront. In order to help create ICT-service ecosystems in resource-low regions such as rural Mali, a sustainability-oriented approach in $\mathrm{ICT}_{4} \mathrm{D}$ must be taken, based on the idea of value, value exchange and value networks.

In general, ICT services based on network technologies are provided in networked constellations (see e.g.[296]), or as we call them "value webs", in which each enterprise brings in a specific core competency. All these competencies of the participating enterprises in the value web jointly satisfy a customer need, which could not have been satisfied by a single enterprise.

Likewise, innovative mobile/web services in Africa consist of networked constellations. These constellations may look different from the ones in high-tech e-commerce settings. The speed of transactions may be slower than in Internet-based e-commerce, especially due to absence of on-line payment services. They may involve paper-based transactions between "low-tech" actors such as farmers, village reporters, local organizations, rural radio stations etc. Still, as argued in this chapter, the concept of value web is valid in low-tech, constrained rural contexts. This will be illustrated by an example of a voice-based radio service, deployed in rural Mali.

I propose a methodology to assess financial sustainability of an $\mathrm{ICT}_{4} \mathrm{D}$ project upfront (ex ante) and/or after implementation (ex post). Here, it is important to note that - as we want to evaluate the feasibility and long-term sustainability of an ICT service - the entire value web must be evaluated. The $e^{3}$ value methodology was therefore selected [169, 170]. This methodology has the advantage that it allows to make different future scenarios using different conditions, ex ante.

The novelty of this proposed method is in (i) assessing sustainability from multiple perspectives, i.e. for different stakeholders simultaneously, and (ii) the construction of multiple and alternative business scenarios. I will illustrate the method for a use case collected and elaborated in Mali between 2012 and 2018. A sketch of this use case scenario is given in Figure 57.

\subsection{A METhod to ASSESS ECONOMIC SUSTAINABility}

The $e^{3}$ value methodology provides a conceptual modeling tool ${ }^{3}$ for qualitative and quantitative assessment of feasibility and sustainability of a networked business idea. It

3 See: http://e3value.com (accessed o8-10-2020) 


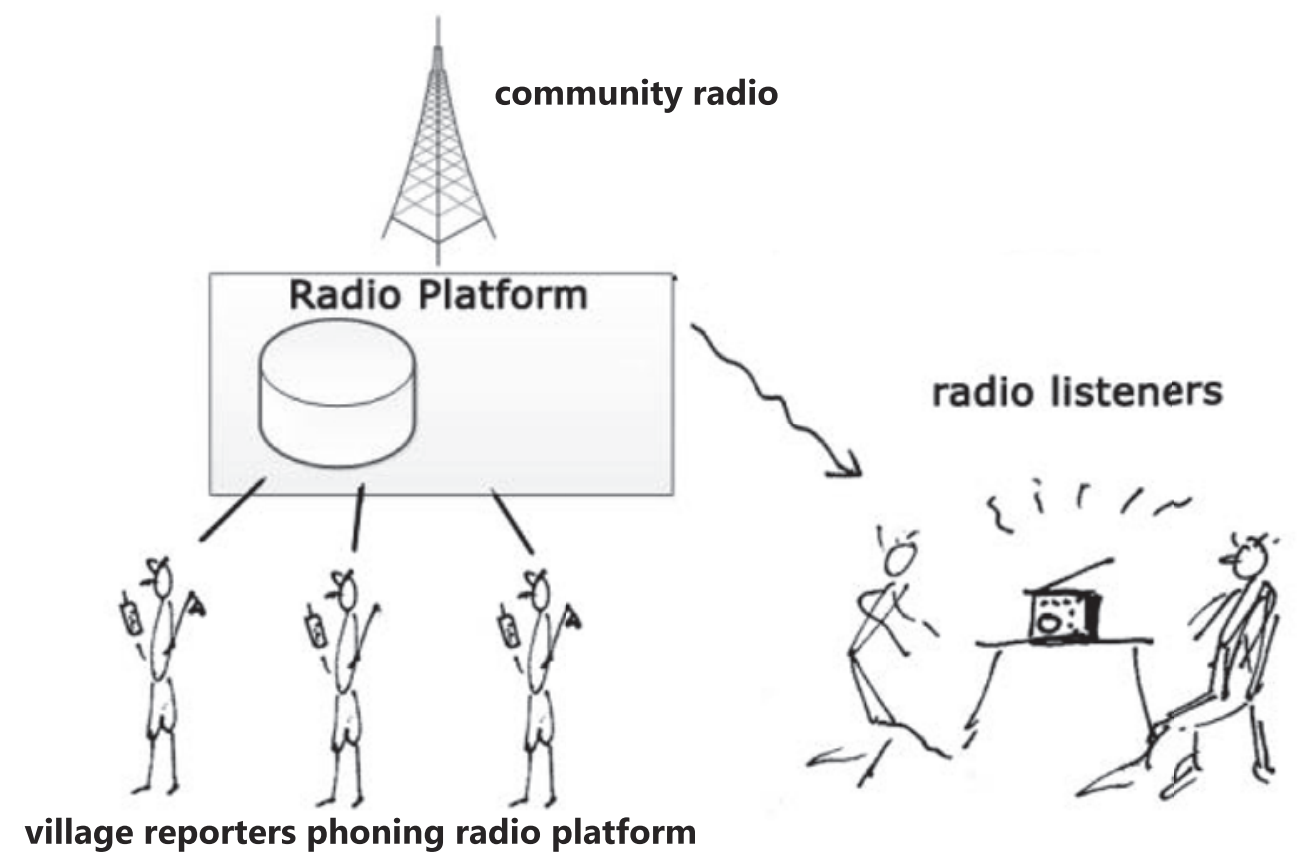

Figure 57: Sketch of the radio platform for people who are out of reach of computers and the Internet, and want to leave a message for broadcasting on the radio. 


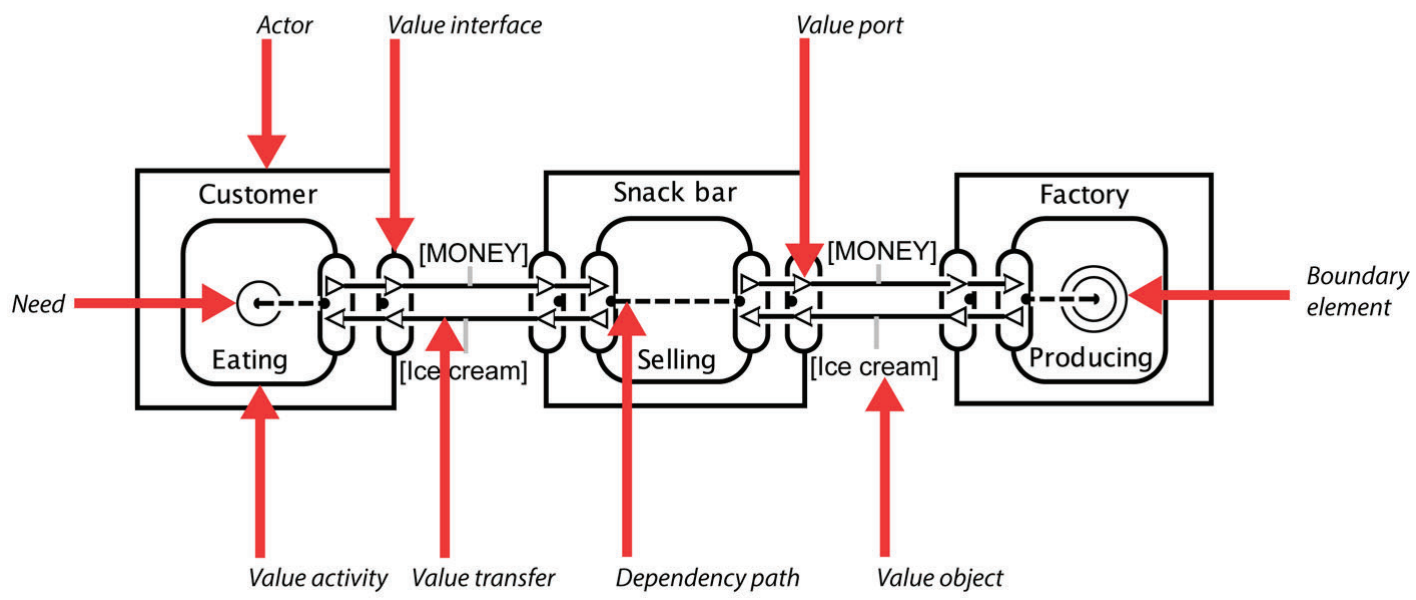

Figure 58: An educational $e^{3}$ value model, adapted after J. Gordijn \& H. Akkermans 2001 "e3value: Design and evaluation of e-business models" IEEE Intelligent Systems, 16(4):1117. Copyright Gordijn \& Akkermans [169].

is supported by a graphical language and software tool to assess the economic sustainability of innovative e-biz network projects. In this chapter I discuss how this methodology can be employed to assess sustainability of $\mathrm{ICT}_{4} \mathrm{D}$ projects.

Figure 58 shows a simple illustrative example of the $e^{3}$ value model, for a customer buying an ice cream from a snack bar. The snack bar, in turn, obtains the ice cream from the ice cream factory and pays for it. The example explains the various concepts underlying the $e^{3}$ value method. (The following text is an excerpt from [169, 170].

The simple $e^{3}$ value model in Figure 58 shows entities exchanging value objects. In this case the entities are single actors - e.g. a customer, an ice cream factory, a business - exchanging value objects in a value network. The value objects (e.g. an ice cream, money) represent economic value for the actors. The actors exchange (provide or require) value objects via value ports. Value ports are grouped into value interfaces. These value interfaces model the economic reciprocity, which exists in every business transaction. Evidently, an actor provides a value object only, if he or she gets something in return, of equal or higher value.

Entities, in $e^{3}$ value, can be single actors or entire market segments. Market segments are represented graphically in the $e^{3}$ value ontology as a stack of actors. (For the sake of simplicity, the market segment is not shown in the example of Figure 58). In a market segment every actor has the same economic utility function for the given model. Any other transactions that may be needed to satisfy the customer's need are not represented in this model. 
In Figure 58 a customer and a snack bar exchange an ice cream for money. This occurs through a value transfer. The actual transfer of the value object is modelled here, meaning that the ownership of the ice cream is transferred from the snack bar to the customer. Given the reciprocity principle, when an ice cream is transferred, money is transferred in the opposite direction.

A customer need is central in the business process: in this very simple case, the customer wants to have an ice cream. To satisfy this need, an exchange of value objects takes place via an interface (in this particular case, ice cream against money). This is modelled by connecting the value interfaces by dependency paths. It becomes clear that the snack bar obtains the value object (ice cream) from the ice cream factory. A boundary element at the ice cream factory indicates where this value transfer actually ends (which demarcates the scope of the model).

\subsubsection{Sustainability assessment in $\mathrm{ICT}_{4} \mathrm{D}$}

The $e^{3}$ value model makes it possible to calculate a net cash flow for each actor in the value network, and can therefore serve as an indicator for feasibility of the value network as a whole. We therefore will analyze the socio-economic network as a whole. Not just individual actors, as usually done in other business modeling methods. Below is explained in five steps how one can assess the sustainability of innovative ICT services in rural African contexts. This is an iterative, collaborative approach which starts during needs assessment, see Chapter 5 .

SteP 1: CONCISEly StATE THE ICT4D idea As described during the use case and requirements analysis, an assessment of stakeholders, their relationships and operational goals is made. The use case is described in terms of business and operational goals and objectives. This ensures that the system is embedded into the local ecosystem. The important point to stress here is that it is essential to analyze the socioeconomic network as a whole - not just individual actors as commonly done in other business modeling methods.

STEP 2: REPRESENT THE ICT4D IDEA AS AN $e^{3}$ value DiAgRAM The concisely stated $\mathrm{ICT}_{4} \mathrm{D}$ idea and the $e^{3}$ value approach are used to construct a graphical representation of the $\mathrm{ICT}_{4} \mathrm{D}$ idea. Typically, workshops with the stakeholders involved in the $\mathrm{ICT}_{4} \mathrm{D}$ idea are necessary to construct an $e^{3}$ value diagram that is agreed upon by all these stakeholders, and that represents the $\mathrm{ICT}_{4} \mathrm{D}$ idea adequately.

STEP 3: ASSESS ECONOMIC SUSTAINABILITY FROM A STRUCTURAL POINT OF VIEW From the $e^{3}$ value model we can assess the economic sustainability of ICT4 $\mathrm{D}$ in a qualitative manner. Depending on the actual case, observations can be done without doing 
calculations at all. As a general rule, each actor in the network should have some benefit, otherwise there is no sustainability.

STEP 4: ASSESS ECONOMIC SUSTAINABILITY FROM A QUANTITATIVE POINT OF VIEW This step involves quantification of the $e^{3}$ value model to assess economic sustainability of the $\mathrm{ICT}_{4} \mathrm{D}$ project. There are various diagram elements that require quantification. First, the number of customer needs per timeframe (e.g. one year) must be stated. Second, in case market segments are used (e.g. to model a number of customers), the number of actors which are part of that market segment must be given. Using the estimated figures, the $e^{3}$ value software is used to conduct a quantitative analysis of the $e^{3}$ value model. If the quantification is done correctly, the $e^{3}$ value software can generate a net value flow sheet for each actor in the network. The flow represents a monetary unit for each value transaction. Clearly, if this flow is a negative value (on the long term), the $\mathrm{ICT}_{4} \mathrm{D}$ project cannot be considered sustainable. In order for the $\mathrm{ICT}_{4} \mathrm{D}$ idea to be sustainable, all the actors in the diagram should have a positive net cash flow.

If the $e^{3}$ value methodology is used to design a new $\mathrm{ICT}_{4} \mathrm{D}$ case, its quantification is always an estimate. If the assessment is done while the ICT4 4 service is already upand-running, the quantification should be based on actual numbers of the case. Before quantification starts, it is necessary to agree upon the timeframe the $e^{3}$ value diagram spans. Typically, a timeframe of one year is used, however, it is equally well possible that the timeframe is a month, week, or day.

STEP 5: IMPROVE THE ICT4D IDEA BY REVISING THE $e^{3}$ value MODEL The proposed sustainability analysis is done iteratively. It is normal that a first version of the $e^{3}$ value model may not produce a final result. In order to improve the model, the quantification can be iteratively improved/optimized. The generated net value flow sheets indicate which actors experience problems. We can modify values and recalculate until we understand under which conditions a positive value flow for all actors will occur. $e^{3}$ value can also be used to build alternative future scenarios for ICT services, as will be shown in the following case from an ICT service in rural Mali.

\subsection{CASE: DEVELOPING AN ICT SERVICE IN RURAL MALI}

This section describes the case of Foroba Blon, an $\mathrm{ICT}_{4} \mathrm{D}$ system designed and built to support citizen journalism, rural radios and farmers in rural Mali. The Foroba Blon system was jointly developed by the $\mathrm{W}_{4} \mathrm{RA}$ team, $\mathrm{SBC}_{4} \mathrm{D}$ and Malian NGO Sahel Eco in collaboration with five rural radios in Mali. One of the radio stations, Radio Moutian in Tominian, is shown on Figure 59. The project was awarded the IPI (International Press 


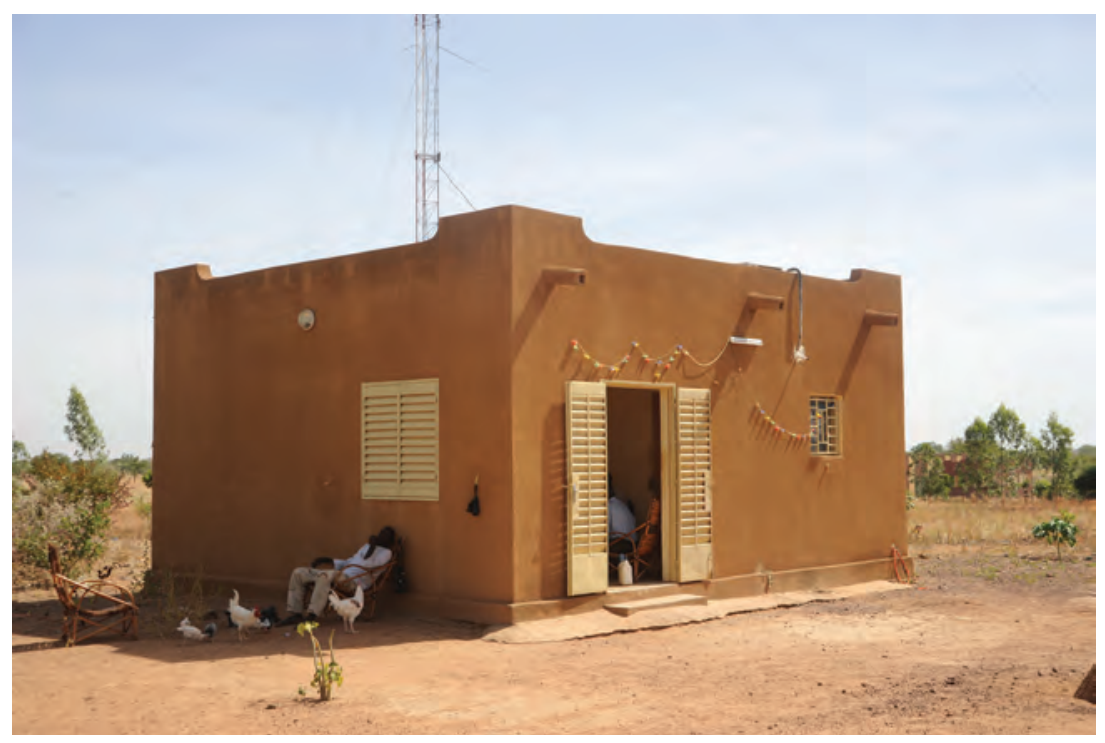

Figure 59: The office of radio Moutian in Tominian, Mali. Photo: Bruno van Moerkerken.

Institute) Innovation Prize 2011 and received a grant of 250.000 US dollar. ${ }^{4}$ A logo for Foroba Blon was designed by Victor de Boer, see Figure 61.

To develop the Foroba Blon service many co-creation workshops and focus group discussions were organized in the period 2011-2012 in Bamako, Ségou, Tominian, San in Mali. These collaborative workshops were aimed at better understanding the local context, at reducing the cultural distance between all stakeholders, and at elicitation of technical and business requirements. User evaluation of the technical architecture and business models was also done iteratively during face to face meetings between developers and users. The Foroba Blon service was built at the request of three Malian radio stations, to facilitate an existing (paper-based) workflow, as shown in Figure 6o. The name of the system/service, Foroba Blon, (some people write "Foroba Blo") in Bambara language refers to a large space, where everyone has the right to speak in front of the village chief; the truth must be told here, but only respectfully, without insulting anyone. The name was given to the service by the radio journalist from Radio ORTM Ségou, Fousseyni Diarra.

The Foroba Blon ICT service consists of a voice-based micro-blogging service. The key idea is as follows. People from rural villages (without having an Internet connection), send a voice message by (simple, GSM) mobile phone to a local radio in their region, because they want to do an announcement on the radio (for example a wedding, a funeral or reporting a missing cow). The radio journalist accesses the incoming (spoken) messages via a web or (mobile/voice) interface on his/her local computer. The radio station charges a fee to the customer/villager, for broadcasting the message.

4 See https://tinyurl.com/forobablon-wins - IPI- contest, (accessed o8-10-2020) 


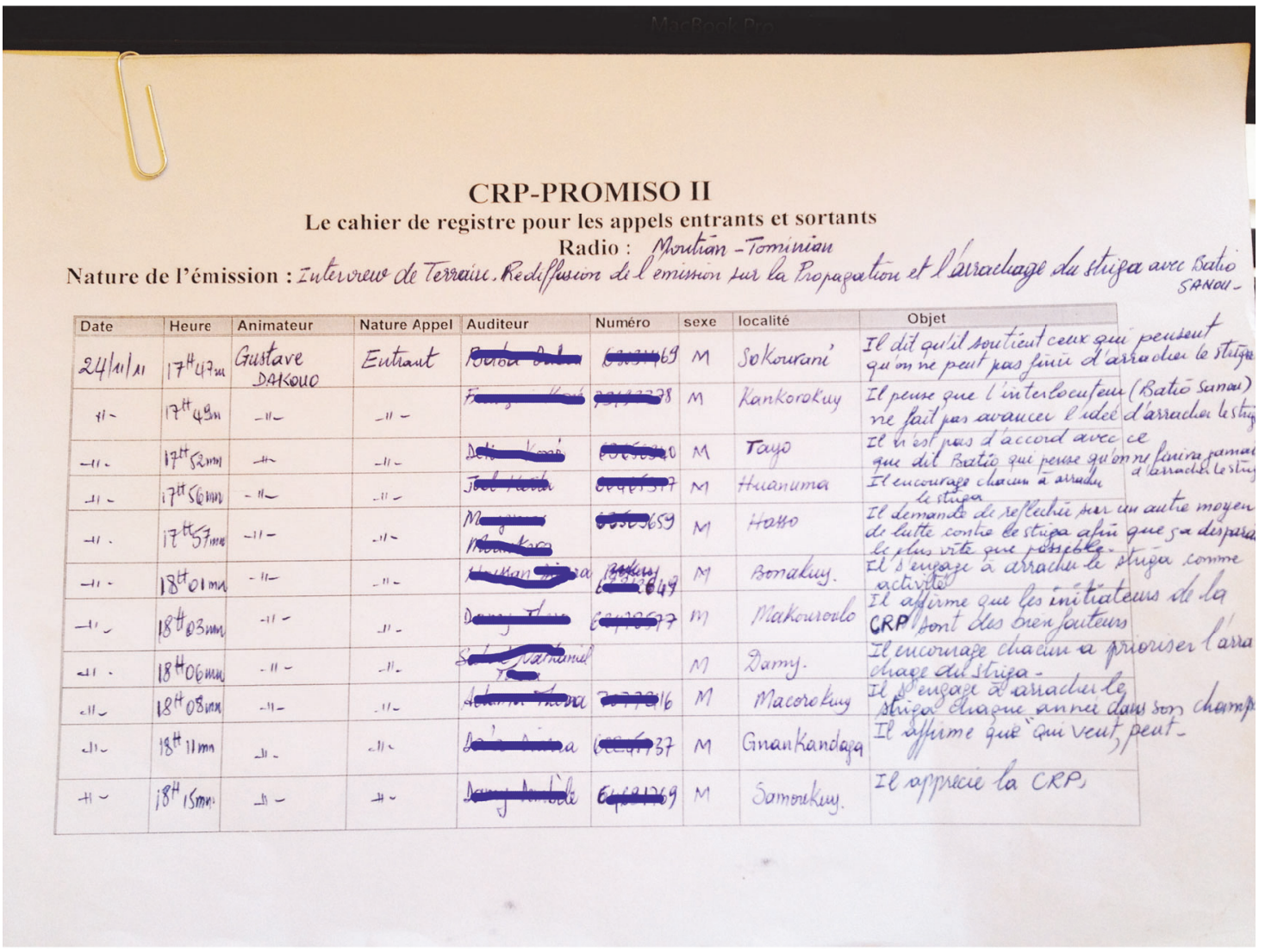

Figure 60: At radio Moutian the incoming messages are registered by hand in a caller log, November 2011. Photo Bruno van Moerkerken.

In the sustainability study of the Foroba Blon system three different scenarios of a voice and radio-based ICT-services are shown, developed and deployed in rural Africa, in close collaboration with the local end-users. During the workshops, different actors were identified, who would make up the value web for ICT-service delivery and consumption. The following information was collected during various focus group discussions with radio journalists, local NGO staff members and farmers. (The full process according to the stepwise approach for the first scenario is described in the next sections. For the second and third scenarios only, the qualitative results of the business analysis are presented.)

\subsubsection{Radios are potential service providers}

As discussed in Chapter 5, rural radios are important local information providers and hubs in rural Africa, in the absence of other mass media (Figure 59). 


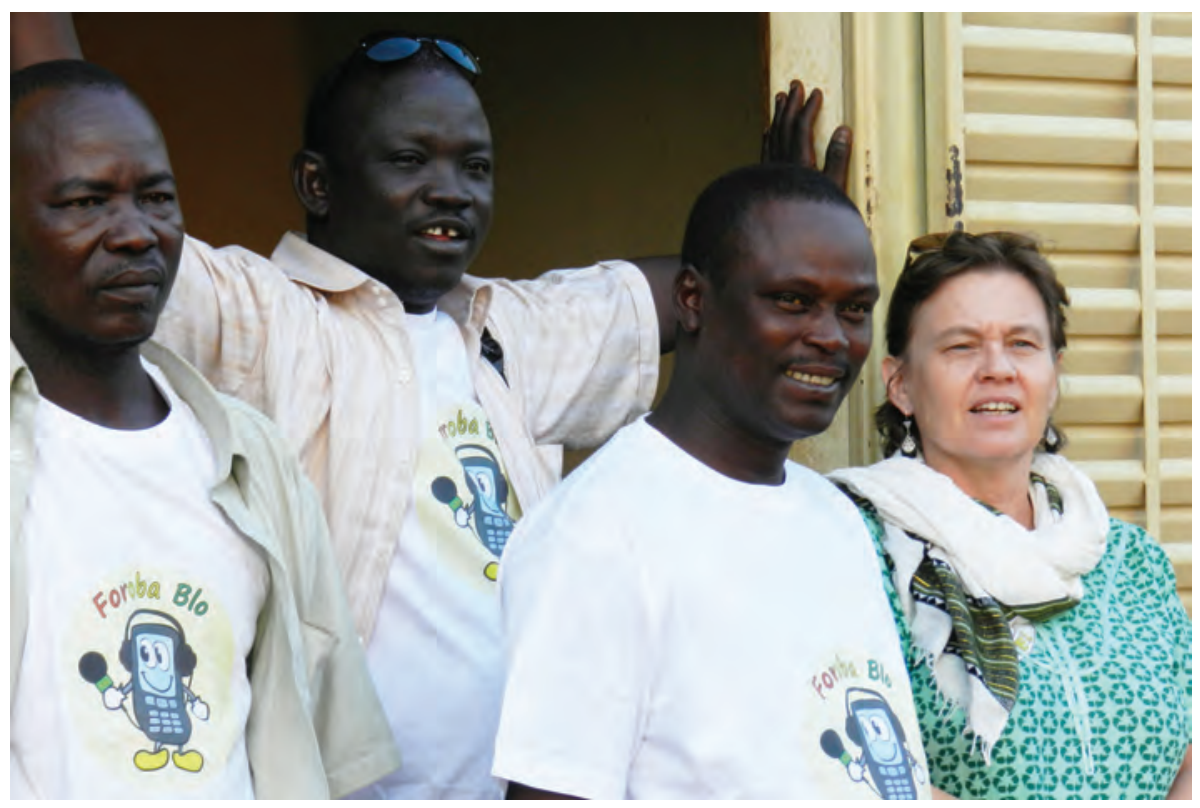

Figure 61: Four members of the Foroba Blon (or "Foroba Blo") co-creation team at Radio Moutian, Tominian, Mali, November 2012, the radio journalists Bakary Dembelé and Gustave Diallo from radio Moutian, Amadou Tangara and Mary Allen from Sahel Eco. (The Foroba Blon logo is visible on their T-shirts.) Photo: Anna Bon.

The same Malian community radios were involved in the Foroba Blon research project as in the RadioMarché project: (i) Radio ORTM Ségou, a state-owned radio that has computers and a fixed Internet connection (DSL). Radio ORTM Ségou broadcasts programs in French and Bambara, the most widely spoken language in Mali; (ii) Radio Moutian (see Figures 61 and 62), in the village Tominian, an independent radio, that generates revenues from selling airtime for announcements and receiving some private gifts from third parties. Radio Moutian has a computer but no Internet connectivity. Programs are mainly broadcast in Bomu, a local language in the Tominian region; (iii) Radio Seno in Bankass. This is an independent radio, with only analogue equipment: no computers, no Internet connection. Still, this radio has many listeners $(80,000)$ in the area around Bankass, in the south-east of Mali. The language spoken here is Dogon. The activities of the three above mentioned radio stations are related to different types of customers and business contacts.

\subsubsection{The village reporters}

Journalists or trusted village reporters work for the radio. They provide them with local news from the villages or interviews with village people, on a regular base. In 


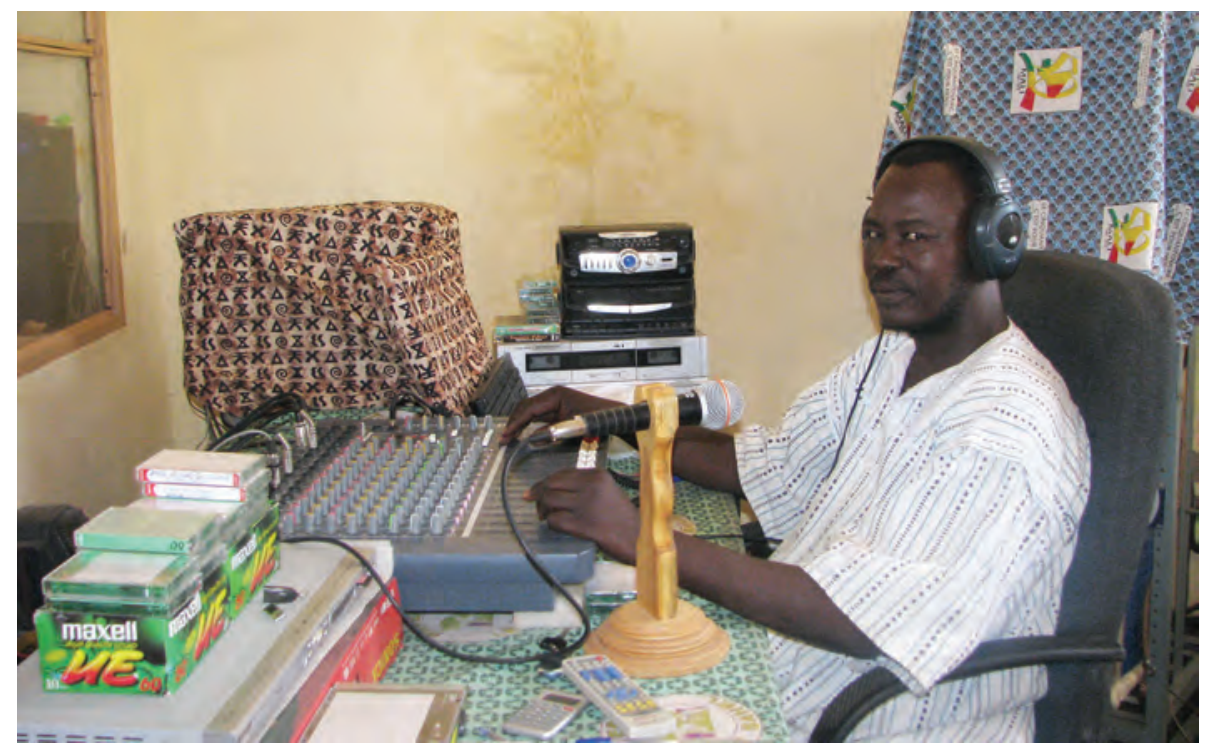

Figure 62: Journalist Bakary Dembelé at work at Radio Moutian in Tominian, Mali. Photo: Bruno van Moerkerken.

the initial (low-tech) situation, all incoming phone calls are attended by a radio staff member and annotated in tabular form on paper (see Figure 60).

Another service provided by village reporters is the provision of mobile phone access for villagers, (e.g. non-commercial radio listeners) who want to send a spoken announcement to the radio, but do not own a mobile phone. The village reporter acts as a service provider between the villager and the radio. Apart from phone access, he/she arranges the payment for the broadcast between the villager and the radio and receives a fee for this service.

\subsubsection{Potential customers}

The proposed service has three types of potential customers (actors as a market segment).

1. Non-commercial radio listeners living in the surrounding rural communities buy a few minutes of airtime and pay a broadcast fee per minute airtime. Their average income is usually between 1 and 2 US\$ a day. The information is usually brought to the radio on paper, or communicated via phone and subsequently written down on paper by the radio staff. These announcements can be e.g. about weddings, funerals or other messages to the public.

2. Non-governmental organizations (NGOs) buy airtime to broadcast public announcements about informative and educational topics, such as agriculture and 
public health information. They pay the radio a fixed monthly subscription fee for recurring broadcasts.

3. Commercial services broadcast advertisements on the radio. These were not considered in the model, but are a potential future source of income for the radios. The fees charged for commercials are 150 percent of the fee for private announcements. 5

\subsubsection{The technical architecture}

The proposed radio service which we coined Foroba Blon (FB) runs on a platform consisting of a data store. This is where recorded voice messages and related metainformation are stored, as shown in Figure 57. The Foroba Blon service will replace the existing legacy system, which is a hand-written, paper-based caller log, see Figure 60. The interface to the service is either mobile (GSM) or web-based. Calls are answered by the system with a pre-recorded welcome message in a local Malian voice inviting the user to leave a message.

The incoming, recorded voice messages are stored as audio files in the data store, with meta-information: date and time of the call, length of phone call in seconds, phone number of the caller. Messages from trusted users are linked to owner, his/her address, and his/her preferred language. For all users of the system, confidentiality and anonymity are ensured, according to broadcast policies used by the radio stations in Mali.

For web users - the radio journalists who have Internet access - the service provides a web-based interface, enabling them to manage the data in the data store. It provides a file list where they can access, listen, broadcast, delete files, and add/update/delete meta-information, see the activity diagram in Figure 63 and a screenshot of the system's interface in Figure 64.

The physical radio platform can be hosted either locally, on a stand-alone computer, even without an Internet connection, or in the cloud. It includes a voice-server, i.e. an open source web server and a local voice browser that handles the voice interaction (this can be e.g. the Kasadaka voice platform as described in Chapter 7, on Figure 52).

\subsubsection{Organizing the radio content}

The next challenge is how to manage the spoken content of un-resourced languages such as Bomu, Bambara and Dogon. Since up to present no interactive voice response (IVR) systems exist for these languages, the voice-based content cannot be indexed by conventional search engines. Therefore, collecting as much meta-information as possible is essential. Very simple ways of indexing the messages are based on owner

5 Source: Personal information by Adama Tessougué, Radio Sikidolo, Mali, May 2016. 


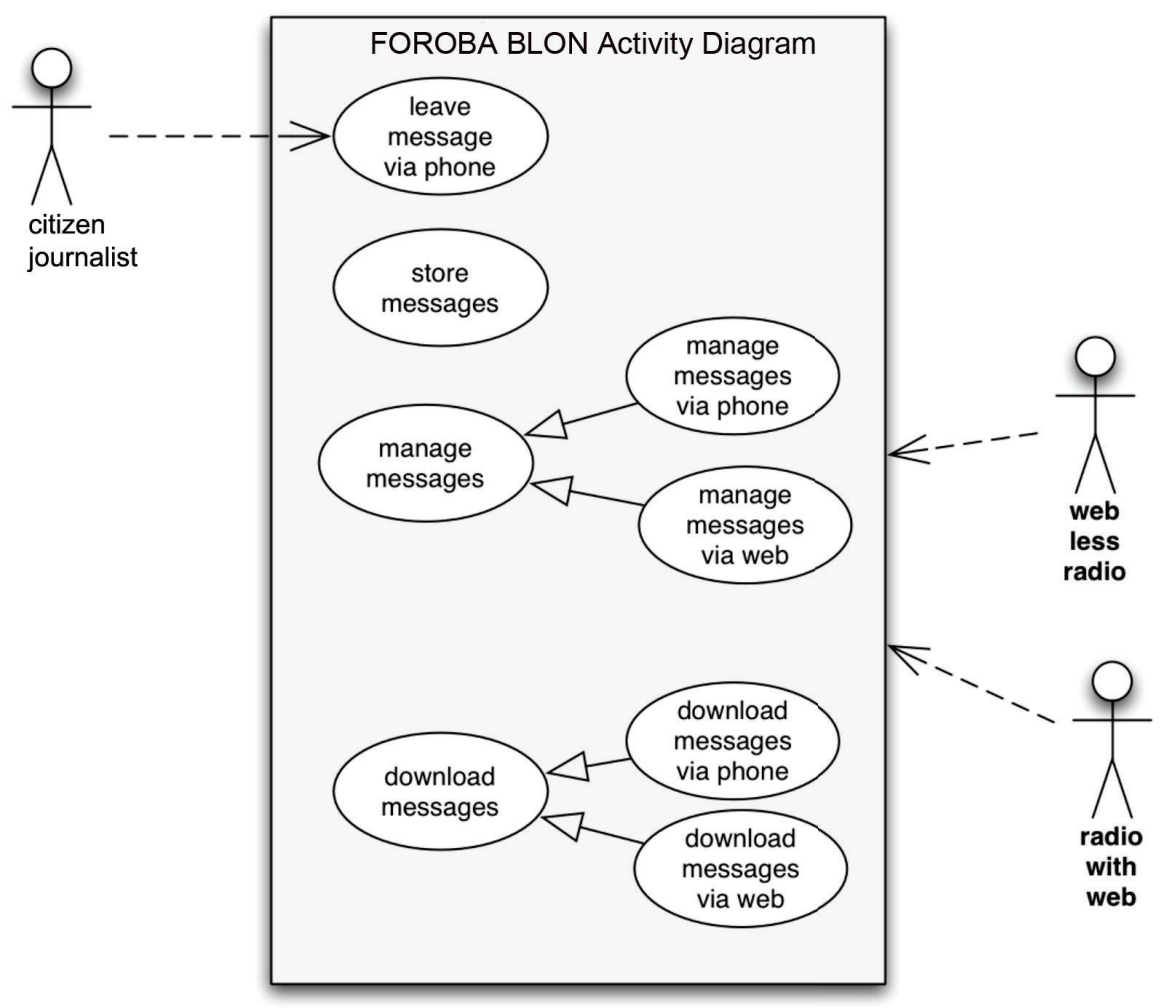

Figure 63: Activity diagram showing the users and the activities of the radio platform. Foroba Blon has been developed between 2012 and 2018 by Stéphane Boyera, Anna Bon, Hans Akkermans, Chris van Aart, Adama Tessougué, Bakary Dembelé and André Baart. 


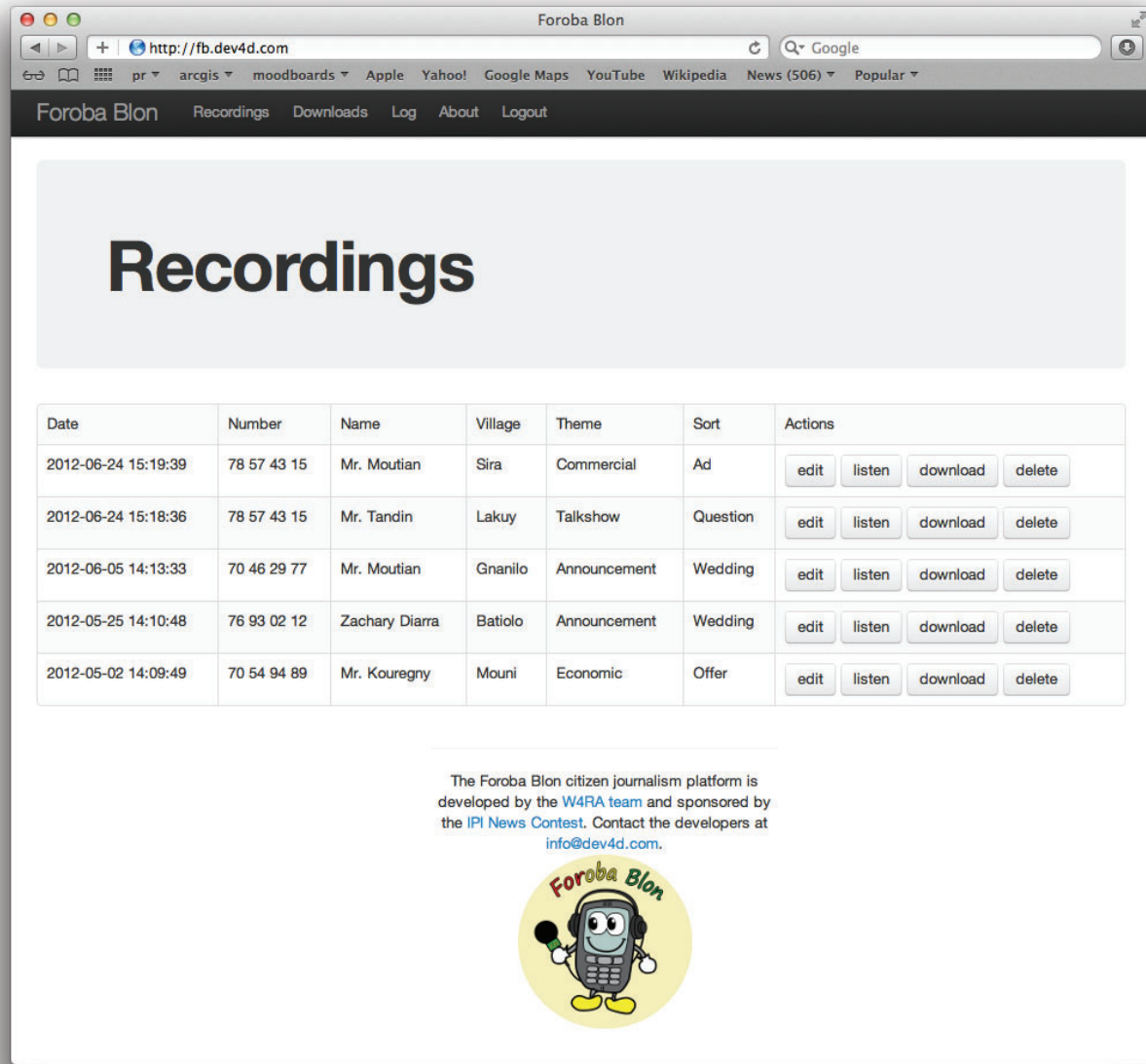

Figure 64: Screenshot of web interface for Foroba Blon, for managing audio content. This first version of the system was developed together with Stéphane Boyera; the logo is by Victor de Boer.

(known through phone number), automatic language recognition, time slot, (e.g. all messages collected on January 13 between 10 and 11 a.m. are related to the radio program on harvesting shea nuts). The radio journalist can manually enter meta-information such as village, region, language, name or any other attribute to an audio file using her radio-web interface.

\subsection{EVALUATION OF DIFFERENT POSSIBLE BUSINESS MODELS}

The first release of the voice-based micro-blogging system, Foroba Blon, based on local business ideas and requirements expressed by the radio journalists, was tested and taken into production by Radio Sikidolo in Konobougou and radio Moutian in 
Tominian, Mali. (The technical architecture of the Foroba Blon platform has been previously published $[184,37])$. This version of the FB system was engineered by Stephane Boyera.

We received extensive feedback from the radio journalists about the assets and the problems they experienced while using the Foroba Blon system. This feedback was used to construct value models, based on real and estimated costs, and used to predict feasibility. Accordingly, scenarios for potential services were designed and analyzed for Foroba Blon. The analysis using the $e^{3}$ value methodology yielded three business models that can be feasible and sustainable; they are associated, however, with different roles and network configurations of involved actors. Each model also has different implications for the technical ICT requirements. Scenario I, was based on a paperbased legacy system that the radio stations are already using. Scenarios II and III, were new in 2012, and not based on a legacy system. They were initially only thought experiments, used to evaluate if alternative services for Foroba Blon would eventually be sustainable.

Scenario I, is about a village reporter who owns a mobile phone and sends messages from people who do not own a mobile phone to the Foroba Blon system. For this service, the village reporter obtains a small fee.

Scenario II, supposes there will be commercial parties such as a local business, who want to broadcast announcements. These commercial users pay a fee for every broadcast.

Scenario III, is about a news provider who wants to obtain news items from the local region. The news provider can be a newspaper or a television station who wants to have content (the news items) to broadcast. For receiving local news, the news provider pays a fee. This last scenario became reality in 2012/2013 and showed the success of the idea of the Foroba Blon service in a totally different context.

\subsubsection{Scenario I: village-reporter based business model}

STEP 1: CONCISELY STATE THE ICT4D IDEA. The radio stations in rural Mali want to have a message system for citizen journalism, accessible through phone. In brief, such a system should allow citizen journalists to deliver voice messages to the radio station via a voice response system. The radio station should be able to retrieve the messages and broadcast the messages. The messages are short news reports from villages.

Before the deployment of the Foroba Blon platform, the rural radios already received voice messages for broadcasting, but these were usually written on paper. The village reporters brought these written messages to the radio station. The messages were broadcast as spoken messages by the journalist. Foroba Blon has improved the workflow by allowing customers (or village reporters) to phone in and record the message that they want to broadcast. The radio journalist can access the voice messages at 
a later time. The message is stored as an audio file. The radio journalist can select from a list of messages, optionally add meta-information and manage the list of received messages and broadcast when needed (as a web-based voice-mailbox).

STEP 2: REPRESENT THE ICT4D IDEA AS AN $e^{3}$ value DiAgram. Figure 65 presents the $e^{3}$ value model for the FB platform. There are six actors involved. The actors are customer (or sender), village reporter, radio station, telco, FB service provider and listener.

The customer is a person living in a remote village in Mali (e.g. Konobougou). The customer usually does not own a mobile phone. This person has a need (annotated $\left.\#_{1}\right)$ to announce a message to other people in the region. For instance, he wants to broadcast a message on the radio, because he is missing one of his cows. By reporting this lost animal on the local community radio, the message will be reached by 80.000 people, the listeners base of the radio station Sikidolo, in Konobougou. The customer pays for broadcasting the announcement on the radio.

The village reporter is a person in the village who owns a mobile phone. On behalf of the customer, he makes the phone call to do the announcement, e.g. concerning the lost cow, or allows the customer to do the announcement. For doing so, the customer pays a fee to the reporter. The AND-fork annotated \#2 represents that the village reporter has to transfer economic value objects with two actors, namely the radio station and the telco. For each announcement broadcast by the radio station, the village reporter pays the radio station an amount of money. Also, the village reporter should pay the telco a fee for the telephone connection. This is just the normal fee to be paid to a telecom operator for a voice call.

At a certain point in time the radio station broadcasts the announcement to the listeners of the radio station. Explosion element annotated with $\#_{3}$ indicates that one received announcement by the radio station is broadcast to 80,00o listeners. A listener receives announcements. In general, announcements are considered as valuable to the listener because they reflect interesting content. In return for the received announcements, they give the radio station audience. As a radio station's primary goal is to serve an audience, this is of value to the radio station. Optionally, the radio station can use the audience to attract other sources of revenue, e.g. advertisements (not shown in the model).

Finally, the radio station obtains the voice platform service (FB) from the FB service provider and pays for this service, including regular maintenance. As this is a monthly service, the radio station pays only once per month. Therefore, there is one need per month for the platform. The costs of products and services, as provided to us by the radio journalists, are listed in Table 6.

STEP 3: ASSESS ECONOMIC SUSTAINABILITY FROM A QUALITATIVE, STRUCTURAL POINT OF VIEW. There are a number of observations that can be done from the 


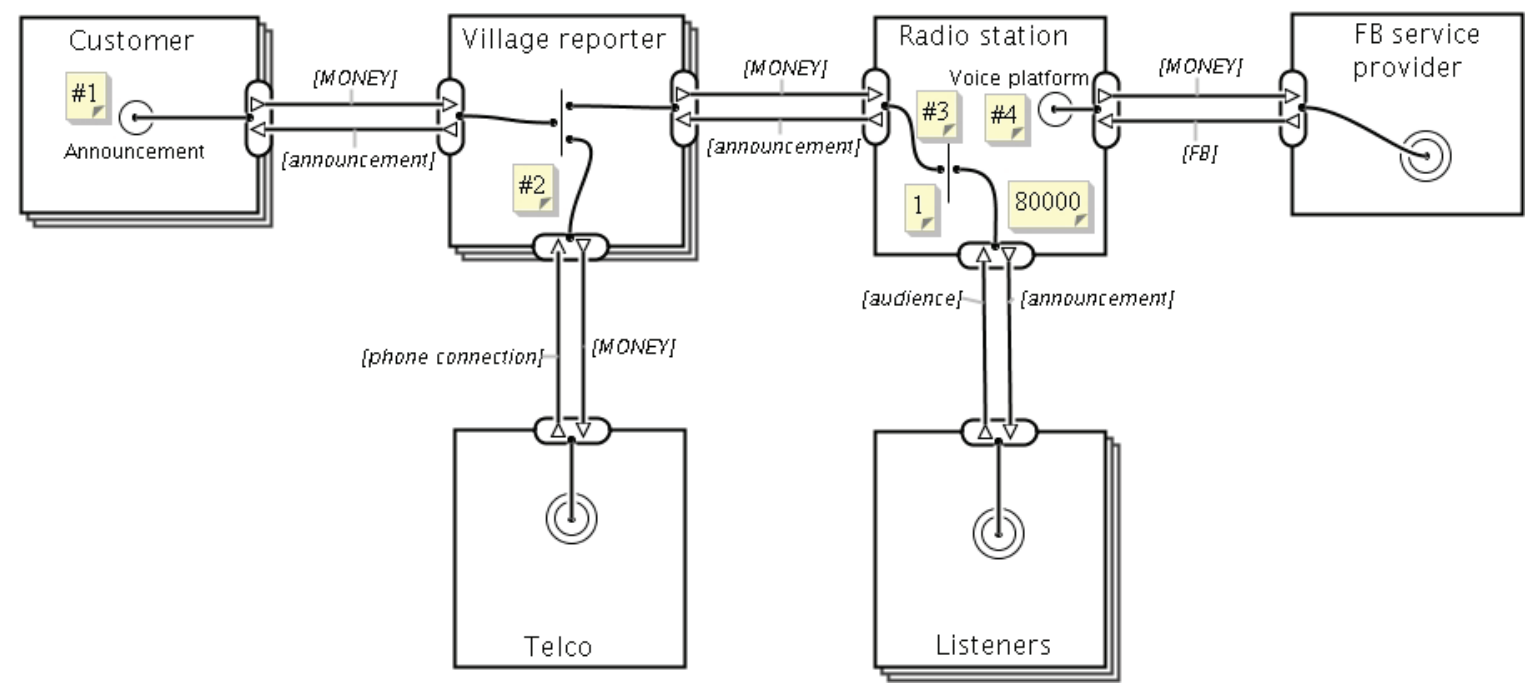

Figure 65: Scenario I: village reporter-based business model. By Anna Bon and Jaap Gordijn.

Table 6: Prices of products and services.

\begin{tabular}{|l|l|}
\hline Value object & Value (fCFA) \\
\hline $\begin{array}{l}\text { Announcement service } \\
\text { (customer) }\end{array}$ & fCFA 1.000 per announcement \\
\hline $\begin{array}{l}\text { Announcement service } \\
\text { (reporter) }\end{array}$ & fCFA 750 per announcement \\
\hline Phone call & fCFA 100 (for one announcement) \\
\hline FB service & fCFA 200.000 \\
\hline
\end{tabular}


graphical model, see e.g. Figure 65. The first observation does not consider something that is in the model, but what is actually missing in the model.

- Observation 1: phone-lines, with corresponding subscription fees are not part of the model.

- Explanation: the proposed platform supposes that radio stations have their own infrastructure for handling phone calls. The platform solves this by a GSM telephony device, which is connected to the Foroba Blon platform. The GSM device uses a pre-paid phone-card, so there are no monthly subscription fees (only a one-time investment in the pre-paid card). Therefore, monthly subscription fees are not part of the model. A possible drawback is that the current platform only supports one GSM device per platform instance. This is fine for a service start up, but once the service is popular, customers may experience that the phone is occupied if they want to make an announcement. This may hinder further growth of the service.

- Recommendation: there are a couple of ways how to deal with a limited number of phone-lines. First, the platform instances of the radio stations, each equipped with a GSM device, may use the devices of other platform instances if they are not occupied. However, this requires that radio stations exchange received messages with each other, which imposes telephone connection costs for the radio stations. Second, the platform may be hosted at a (telecom) provider, along with a number of land telephone-lines. This however would result in expenses for hosting, as well as for telephone-lines (subscription fees), and both are expensive in Mali.

- Observation 2: there is a one-to-one relationship between the radio station and the FB service provider.

- Explanation: as can be seen from the $e^{3}$ value diagram, the FB service provider has only one customer, namely the radio station. The pricing of the FB service provider has been chosen in such a way that the provider at least has a positive cash flow. However, the total revenue is not sufficient for the FB service provider to make a living.

- Recommendation: the FB service provider needs more income. This can be achieved by attracting multiple local radio stations, operating in different geographical regions. On the short term, additional funding for the FB service provider can be arranged by donor funding. Such funding can be used to develop and improve the FB platform. On the long term however, the FB platform should be provisioned by multiple radio stations. 
Table 7: Number of customer needs.

\begin{tabular}{|l|l|}
\hline Customer need & Count /month \\
\hline announcement (per customer per month) & 1 \\
\hline FB platform & 1 \\
\hline
\end{tabular}

STEP 4: ASSESS ECONOMIC SUSTAINABILITY FROM A QUANTITATIVE POINT OF VIEW. In this step we detail the constructs numerically. We make reasonable estimates, as realistic as possible. The data for this model are provided to us by Adama Tessougué from Radio Sikidolo and Amadou Tangara ${ }^{6}$.

1. Quantification of products and services. The customer pays for broadcasting an announcement on the radio and access to the FB platform fCFA 1.ooo. The alternative would be to travel to the radio station to leave the message personally. The travel to reach the radio station would cost him on average 4.00o fCFA. As this is not a viable alternative, we can consider it a sound motivation to use the FB service.

The radio broadcasts the message and receives a payment for each broadcast announcement from the village reporter. The village reporter pays the radio station for each announcement fCFA 750.

Also, the village reporter should pay the Telco for the phone call. We assume the average phone call costs fCFA 100.

The radio station pays for the Foroba Blon service fCFA 200.000 per month.

2. Quantification of the number of actors. Table 8 shows the number of customers and the number of village reporters. We assume 2.550 customers for the total of participating villages. Also, there are 85 village reporters.

3. Quantification of the customer needs. There is, on average, one announcement per customer per month. On a daily basis, the radio station collects the submitted announcements, therefore there are on average 30 needs per month to collect such announcements. Finally, since the subscription on the Foroba Blon platform is on monthly basis, there is one need per month. This is summarized in Table 7.

Similar to the first case, we can use the $e^{3}$ value toolset to generate net value flow sheets, the result is in Table 9. Again, here I summarize a few observations based on the net value flow calculations.

- Observation 3: the telco and radio station are the winners.

6 Amadou Tangara is currently country manager in Mali for Tree Aid in Bamako. 
Table 8: Number of actors in a market segment.

\begin{tabular}{|l|l|}
\hline Actor & Count \\
\hline Customer & 2.550 \\
\hline Village reporter & 85 \\
\hline
\end{tabular}

Table 9: Sustainability analysis using the $e^{3}$ value model.

\begin{tabular}{|l|l|}
\hline Actor & Revenue per actor (fCFA) \\
\hline Village reporter & fCFA 4.500 \\
\hline FB service provider & fCFA 200.000 \\
\hline Telco & fCFA 255.000 \\
\hline Radio station & fCFA 1.712 .500 \\
\hline Customer & fCFA - 1.000 \\
\hline Listener & n.a. \\
\hline
\end{tabular}

- Explanation: considering all actors in Table 9, the radio station and the telco are the parties who earn most of the money in the system. Both the radio station and telco are actors of which there is only one in the model. Naturally, these parties collect most of the money.

- Recommendation: the model may benefit from competition. For the radio station, this would imply addition of radio stations that operate in the same geographical region. This may lead to price competition between those radio stations. The same holds for the telecommunication companies; the world-wide model of mobile telephony allows competition between operators in the same geographical region.

- Observation 4: the village reporter earns a modest amount of money.

- Explanation: the village reporter only earns fCFA 4.500 per month, which is, compared to the price to be paid for a single announcement by the customer, not much.

- Recommendation: the revenue for the village reporter is low, but the service provided (lending the phone for a minute) is rather shallow too. Therefore, the revenue sounds not unreasonable and therefore acceptable. The low revenue is caused by the relative high number of village reporters. There is competition here, and the total amount of money related to the submission of announcements must be divided over a large number of village reporters. 
STEP 5: IMPROVE THE ICT4D IDEA AND $e^{3}$ value DiAgRAM. The model as proposed is useful for a field test. It has to be considered that the FB service provider cannot really make a living by having just one radio station as a customer. This may be solved with donor funding. In the longer run, the value model should evolve:

1. More radio stations should participate. From a modelling perspective, this would imply that the radio station in the current model becomes a market segment (multiple actors) rather than one actor.

2. Having more than one operator available would possibly lower the fees. Also, here, the mobile operator would - from a modelling perspective - change into a market segment.

3. The current technical solution, namely one mobile phone per radio station, does not really scale well, once the service gets popular. There is then an increased chance that customers will not be able to deliver their announcement. There are various ways to solve this. A first option would be to use (multiple) land lines per radio station. This requires that the radio station takes a subscription at those lines, supplied by a telecom operator. This would change the value model. A second option is that the Foroba Blon platform is capable to forward phone calls to other platform instances. In other words, if a customer tries to connect to a particular radio station and that station is occupied, that customer is re-routed to another, not occupied radio station. Also, this option results in a change in the value model. First, radio stations may charge each other for this service; second, radio stations need to obtain messages delivered at other radio stations using some communication mechanism for which costs are involved.

IMPLICATIONS FOR ICT REQUIREMENTS The village reporter-based business model was designed and built following existing practice and workflow at Radio Sikidolo, who came up with the initial idea. The first-cycle deployment was done and radio journalist Adama Tessougué tested the system with a number of village reporters. He was pleased with the system and came up with some technical adjustments and new requirements, which affect the technical design and the business model.

- A notification message must be sent as an SMS text-message to the radio, once a new voice-message has been issued. Since Radio Sikidolo had no Internet at the time of first deployment (2012), he had to phone in to the Foroba Blon system. When testing the system, the radio spent several phone calls to access the Foroba Blon system, while no messages had been issued. Since the cost of a phone call in Mali is relatively expensive, this was an important cost-driven ICT requirement.

- A mobile payment system, so that the broadcast service can be paid to the radio, was one of the requirements to avoid cumbersome cash transactions between the 
radio and the village reporter. Moreover, paying in advance discourages people to phone in to the Foroba Blon service and leave fake messages. During the first cycle, mobile payment systems were not available for mobile operators in Mali (the main ones here are Orange and Malitel). In 2013 mobile operator Orange launched Orange Money as a mobile payment system in Mali. An application programming interface provided by the local mobile operators (Orange, Malitel) allows further development of modules for mobile payment (based on mobile airtime).

\subsubsection{Scenario II: radio-based advertisement business model}

The second value model for Foroba Blon has a different type of customer, for example a commercial business that wants to advertise a product or service, an NGO or governmental department that wants to send information to a broad audience, e.g. on health, agriculture, education. In the value model shown in Figure 66, the customer wants to broadcast a message (such as an ad) to a large audience.

The sender obtains from the Foroba Blon system a delivered message and pays a fee in return. Note that in this model, Foroba Blon is the commercial entity the sender deals with, in contrast to the village reporter-based business model where the radio station is the party the sender deals with. Then the AND fork annotated with \# 1 indicates that two things happen: (1) the message is broadcast via radio stations, and (2) the message is sent via mobile phones to receivers.

In case the message is sent via radio stations, the upper dependency path is followed (inside Foroba Blon). The explosion element marked \#2 indicates that one message can be broadcast via multiple radio stations, thus reaching a larger audience. The local radio station delivers the message to its listeners (the receivers) and gets paid for that by Foroba Blon.

The message is sent via mobile phone connections to subscribers. This is represented by the lower dependency path inside Foroba Blon. The explosion element marked as \#3 shows that one message is sent to multiple receivers. The AND fork annotated with $\#_{4}$ indicates that for the delivery of a message to a receiver, there are value transfers necessary for the mobile connection (with a mobile operator) and for the message delivered to the receiver.

The receiver provides the service of a delivered message to Foroba Blon (or the radio station). Similarly, Foroba Blon offers a delivered message to the sender. As message delivery is of value to the sender, the related transfer points towards the sender. It is supposed here that the content of the message is of value somehow to the receiver. Consequently, there is a value transfer from Foroba Blon and the local radio station to the receiver representing the economic value of the content of a message. 


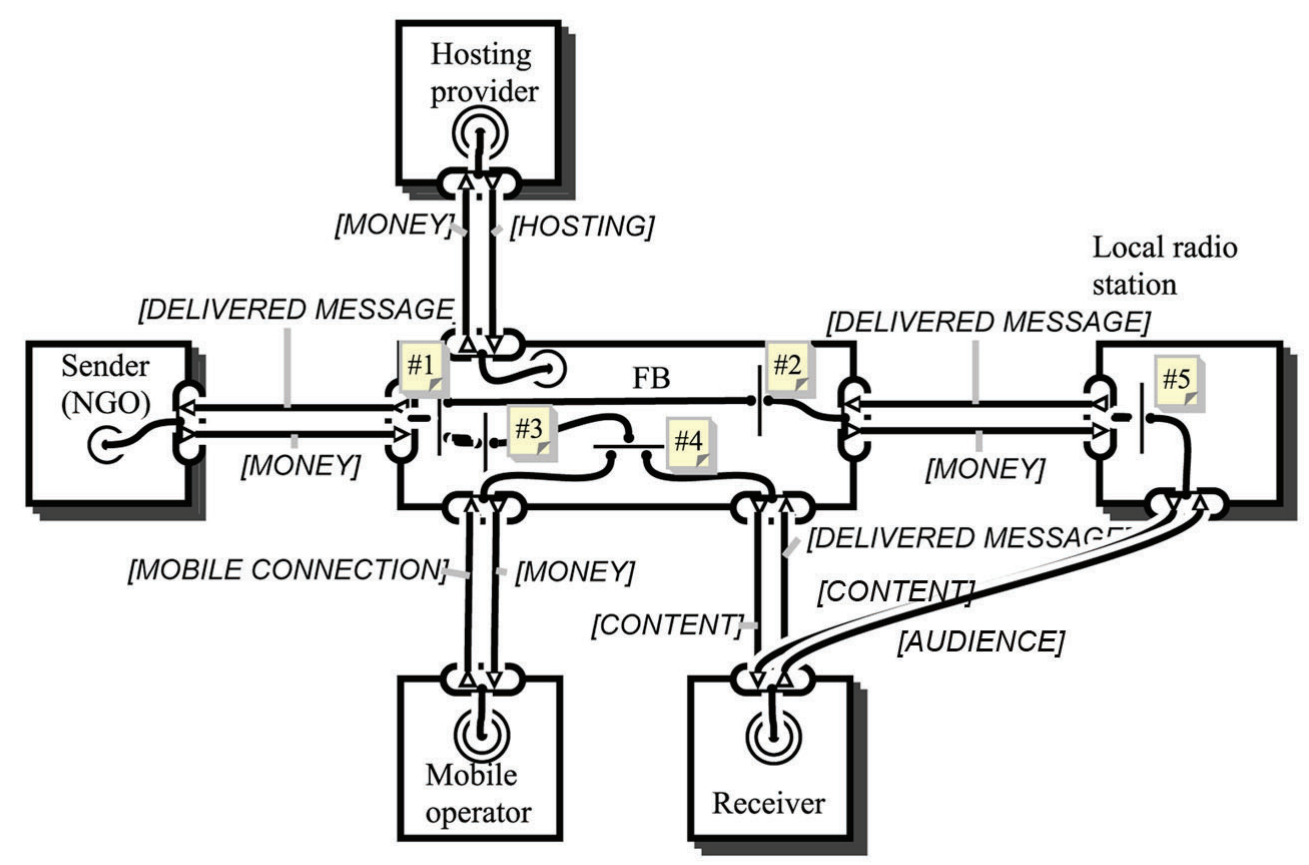

Figure 66: Scenario II: the sender pays directly to the provider of the Foroba Blon service. By Anna Bon and Jaap Gordijn.

IMPLICATIONS FOR ICT REQUIREMENTS Based on feedback and evaluation of the models, the technical architecture is refined and re-adjusted. New requirements that came up after the business model was designed were:

- Since the sender in this case has an Internet connection, a new requirement is a web interface where the sender can enter the message to be broadcast;

- A new requirement by the NGO was to add the possibility to stream the message to a number of phone recipients, instead of sending it to the radio for regional broadcast; with this addition, the message can be optionally sent to a limited number of recipients, if the sender wants to reach a limited number of known contacts (e.g. to invite 50 participants for a meeting or event).

\subsubsection{Scenario III: citizen journalism-based business model}

This business model supports citizen journalism in e.g. rural Mali. It shows an information pull, in which local reports by village reporters and local citizen journalists are requested by the customer, who is, for example, a large media company (a news provider). 
The news provider (e.g. Al Jazeera, CNN, ORTM, BBC, Wereld Omroep) needs news items (context) for their programs. Part of this content is obtained from regional reporters in the field. This is especially interesting regarding the unstable political situation in northern Mali, where incidents may take place, reported by eye-witnesses and village reporters, or during presidential elections, e.g. in Ghana or Kenya, or during e.g. Ebola-outbreaks in the country. News providers pay a fee per news item to Foroba Blon. The FB service obtains voice-based news messages from local radio stations. Local radio stations are paid a fee per delivered news item. In order to facilitate delivery of news items by local reporters via mobile phones, the FB service provider has a contract with a mobile operator. The value model in Figure 67 shows that the FB service provider pays per news item a mobile operator fee for a telephone connection. Note that the FB service provider pays for the phone connection and not the reporter. In reality, this is implemented as a toll-free number that reporters can use for free, while FB pays for this toll-free number.

IMPLICATIONS FOR ICT REQUIREMENTS Based on feedback and evaluation of the models, the technical architecture is refined and re-adjusted.

The technical design of this business model is similar to Foroba Blon model I, only the business case is different, because different values are transferred. The village reporter now sells his voice report to the news provider, instead of buying broadcast airtime from the radio. This requires the following additional technical requirements:

- A payment module must be built into the web interface of the customer; in which the radio and the individual reporters are remunerated for each relevant report they enter into the system;

- The radio station, who operates as the intermediary between the village reporter and the customer, has an Internet connection for management of the content and to do the payments to the village reporter;

- A toll-free number is provided by the telecom operator for the village reporter, who no longer pays for entering a message. He receives a payment for each spoken news item entered into Foroba Blon and accepted by the customer.

Local radio stations in turn obtain news items from freelance reporters. In turn, these reporters are paid a fee per news item. The radio station also organizes and enriches each news item with some meta-data, such that it can easily be accessed online by the customer.

\subsubsection{Discussion of the development process of the business models}

The first scenario we designed and built was based on a business idea by local radios. The service replaces an existing (legacy) work flow, which was an existing, cost- 


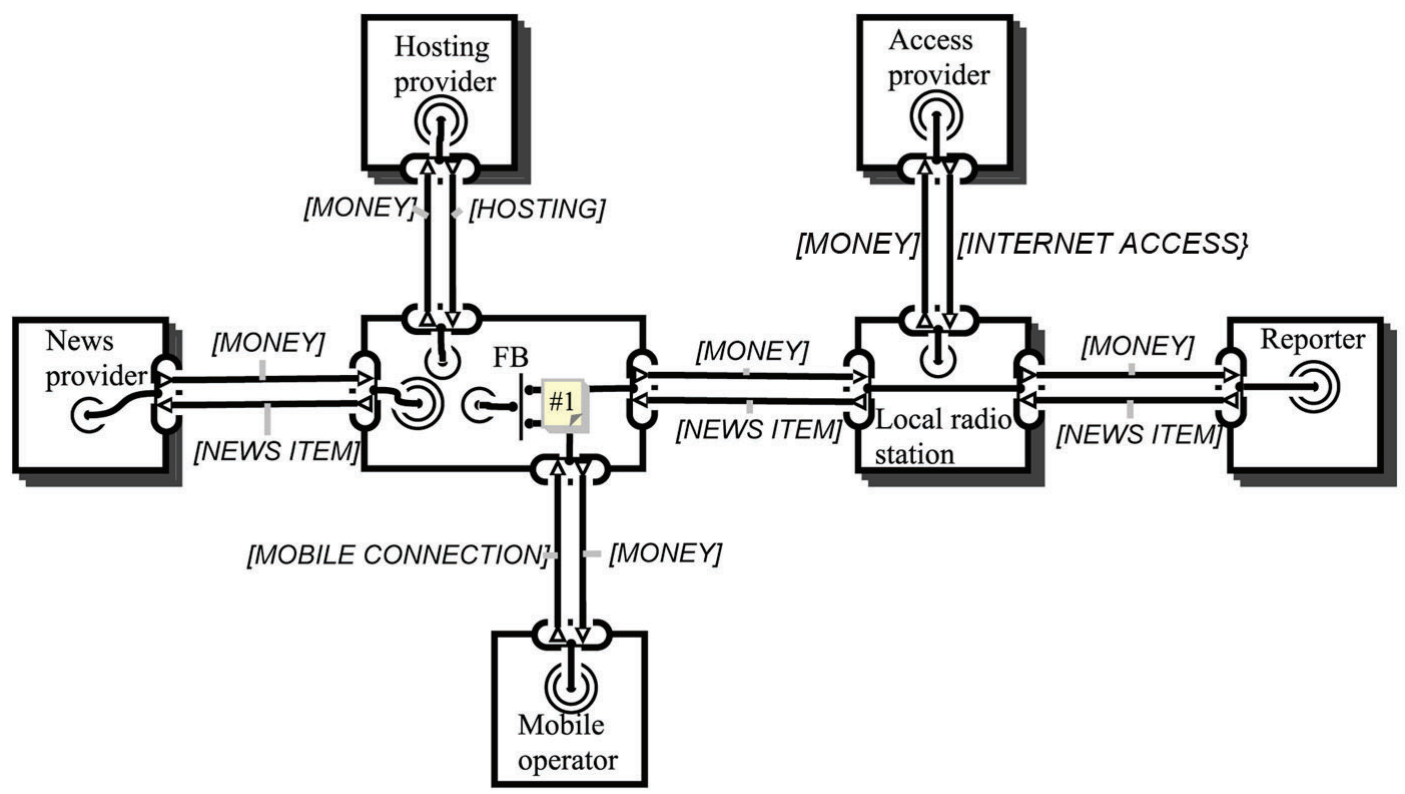

Figure 67: Scenario III: the news provider pays for obtaining regional news items. By Anna Bon and Jaap Gordijn.

effective, legacy broadcasting service from the radio to the rural community. The customer and the radio station experienced improved efficiency once the Foroba Blon service was operational. Radio journalist Adama Tessougué tested the Foroba Blon system with a number of village reporters in Konobougou and surrounding villages.

The second and third value model scenarios are examples of new services that were adaptations of the initial service. Value models II and III, described above, did not exist previous to the Foroba Blon deployment. These models represent a local innovation or rather a local reinvention - as a consequence of the introduction of an innovative technology in this local rural (constrained) environment.

In models II and III the village reporter (or farmer, or rural community member) is no longer the customer or sender in the value model, but a service provider or a targeted market segment. The farmers provide the listeners base, for the customer (NGO or advertiser, etc.) who wants to send information or advertisements. In models II and III the radio no longer pays for the Foroba Blon service, but receives the payment from the Foroba Blon provider to provide a service. The telecom company provides the phone calls to and from the Foroba Blon platform and receives payment from Foroba Blon provider, so that reporters can use toll free numbers e.g. to enter information in model III, or to receive or access information in Foroba Blon model II.

One of the concerns in $\mathrm{ICT}_{4} \mathrm{D}$ has to do with the costs of software. Therefore, all software that the $\mathrm{W}_{4} \mathrm{RA}$ team developed, according to the collaborative approach is 
delivered and made available as free and open-source software, published 7 including documentation for re-use and further development by communities of developers. I strongly encourage all people who work in $\mathrm{ICT}_{4} \mathrm{D}$ to make all software available as open-source. This is a way to support the process of innovation and spread of knowledge.

\subsubsection{Validation}

The validation of the used methodology for sustainability assessment was done by the users who gave us frequent feedback and declared themselves satisfied with the results and improvements. Key user of e.g. the Foroba Blon service, Radio Sikidolo in Konobougou, Mali, has used the Foroba Blon system with 50 village reporters, to make radio programs and produce documentaries from neighboring villages. (In 2020 we are still working with Radio Sikidolo on an improved version of Foroba Blon deployed on Kasadaka.)

An important goal of the presented approach is to produce ICT services through local value webs that are economically sustainable. Consequently, a sign of success (and an external validation) is where other parties (such as commercial entities) consider the ICT service to be useful and viable. We have several indicators for this. The Foroba Blon ICT service was used by Al Jazeera for monitoring the presidential elections in Ghana and Kenya in 2012-2013. The Foroba Blon service was winner of the News Innovation Contest 2011 from the International Press Institute. ${ }^{8}$

\subsection{REFLECTION}

Based on the results of three scenarios and various business models, we reflect how the $e^{3}$ value methodology contributes to a better understanding of the sustainability issue of $\mathrm{ICT}_{4} \mathrm{D}$ services.

HOW DOES BUSINESS INNOVATION WORK IN CONSTRAINED ENVIRONMENTS SUCH AS RURAL AFRICA? From the business models we learn that ICT-service innovation is possible, even in a constrained context such as rural Africa, but only if these conditions are met: (i) there is understanding of the context; (ii) business requirements are developed in concert; (iii) social interaction is taken care of from the grassroots perspective; (iv) potential partners are involved from the start throughout the business analysis process; (v) sustainability for the whole network is evaluated before deployment (see further [41]).

7 E.g. on http://github.com/nanabaahgyan/RadioMarche (accessed o8-10-2020)

8 http://www.ipinewscontest.org/news/congratulations.html (accessed o8-10-2020) 
how does the approach ensure sustainability? From the Foroba Blon pilot we have learned that it is best to start from a legacy system: a work flow that is already in place for an existing (value) network. $e^{3}$ value proved to be a useful method, even in this context where no ICT-services existed prior to this research project. $e^{3}$ value makes it possible to evaluate and predict feasibility and profitability for a complete network of collaborating business actors. It enables to calculate or estimate potential profitability, not only from a single business perspective, but for the whole multi-actor value network. It is also possible to design and evaluate alternative business models, do sensitivity analysis and design and evaluate future scenarios using the $e^{3}$ value methodology. To build realistic scenarios, local business partners and users have to be involved in the process, and real local data have to be obtained.

\subsection{SUMMARY}

This chapter has proposed a structured, formal method to (qualitatively and quantitatively) assess economic sustainability and financial feasibility of networked ICT services in low resource environments. Such an approach or method is still lacking in mainstream interventionist approaches and sustainability studies on $\mathrm{ICT}_{4} \mathrm{D}$. The proposed method is easy to learn and can be used to evaluate networked value constellations in any context.

It is important to note that (i) the exercise of business analysis should be done collaboratively, involving local users and business partners; (ii) the sustainability assessment should go hand in hand with a proper context analysis; (iii) relevant quantitative data are needed to feed the models; the data have to be provided by local stakeholders and business partners.

There are two key points in this chapter. Firstly, economic sustainability assessment covers the whole network of business actors, not just a single business. Secondly, economic sustainability assessment can be and must to be done collaboratively, starting at an early stage of an $\mathrm{ICT}_{4} \mathrm{D}$ project. Having proposed a new approach to assess sustainability of $\mathrm{ICT}_{4} \mathrm{D}$ in a collaborative, adaptive and iterative way, in the next chapter a synthesis of the collaborative methods is presented, as a theoretical framework and methodology for collaborative, adaptive, iterative $\mathrm{ICT}_{4} \mathrm{D}$. 
Part III

\section{REFLECTIONS}

[In which all empirical findings are integrated into one collaborative framework for $\mathrm{ICT}_{4} \mathrm{D}$. The validation of the framework in various contexts is discussed. Next I reflect on innovation, collaboration and context, and argue that a networked approach is the most appropriate way of coping with complexity. Finally, we reflect on the inherently value-laden aspects of poverty, livelihoods and interests and how this could be addressed in ICT4D.] 


$\mathrm{FOR} \mathrm{ICT}_{4} \mathrm{D}$

Having discussed the experiences of the field research in the previous chapters, in this chapter all components (tasks) of the field studies are integrated into one framework that covers the full lifecycle of ICT innovation, starting from context analysis and needs assessment, through use case and requirements analysis and sustainability assessment, towards collaboratively and iteratively developing, deploying and evaluating the outcomes and impact. The framework includes the intentions (purposes, goals), strategies and methodologies for each aspect and illustrates the collaborative, iterative and adaptive nature of the approach. It shows how the concerns, outlined in Chapter 2 are addressed. The framework provides a bridge between the academic/theoretical world of ICT4D research and the practitioners' grassroots perspective, field experiences and approach how to "do" ICT4D. The framework is dubbed ICT4D 3.o. Parts of this chapter have previously been published (see $[36,40])$.

\subsection{CONSIDERING THE FULL INFORMATION SYSTEMS LIFE CYCLE}

This chapter presents a synthesis of the experiences and methods from the previous chapters (in particular from chapters 4 to 8 ) into one single framework for ICT $4 \mathrm{D}$. This is a flexible framework, capable of addressing the general concerns that exist in $\mathrm{ICT}_{4} \mathrm{D}$. Using this framework (according to its collaborative approach), requires an interdisciplinary team and good partnerships. The composition and diversity of the team is important and will therefore be discussed. The ICT4 $\mathrm{D}$ framework itself is presented in two different views: as (i) a synthesis of components and their corresponding methods and techniques, and (ii) a collaborative-adaptive-iterative process model, expressed as an intention-strategy map.

\subsection{TEAMS AND PARTNERSHIPS}

Since our first field visit (to rural regions of in Burkina Faso, 2009, described in Chapter 4)) it became clear that a variety of capabilities and skills is needed for this research project. To this end we have brought together an interdisciplinary, multi-cultural team. Our team includes local users, local partner organizations and ICT developers with a diversity of skills and experience in the team.

LOCAL KEY-USERS. The core team involves key-users, who are representative for a larger community of future users. Some users give information, others brainstorm 
and help design solutions; some users set priorities, evaluate, test and validate results. Text-literacy, computer-literacy or knowledge of French/English are not required for participation in the team. Key-users (men and women) are for example: farmers, village reporters, pastoralists, local entrepreneurs, local experts.

LOCAL PARTNER ORGANIZATIONS. Local organizations act as intermediaries between the ICT team and local communities. They are engaged with communities and their problems. They have expertise in local issues. They maintain contacts, organize venues and field visits, translate between languages, organize transport, field visits, and give introductions. As partnerships matter, it is important to build long-term relationships. The organizations we have as our partners strongly support communitybased social development, and are inspired by value-driven, collaborative, adaptive development approaches. The following local partners have played a key role in the collaborative $\mathrm{ICT}_{4} \mathrm{D}$ projects described in the previous chapters.

- $A O P P$ - Association des Organisations Professionnelles Paysannes is a national Malian association of smallholder farmer organizations. AOPP was established in 1995 and consists of 250 basis organizations, including cooperations, village associations, women groups and local youth groups. In total more than 40.000 people: farmers, fishermen and pastoralists are associated with AOPP. AOPP's aim is to support and improve the livelihoods of its members by representing them in the political dialogue at the national and regional levels and by facilitating knowledge sharing between its members. AOPP bridges the gap between the developers from the $\mathrm{W}_{4} \mathrm{RA}$ team and the real users: farmers (men and women) in Mali, inviting them to participate in the projects/workshops. AOPP is a partner organization of VU since 2011. (AOPP as an organization did not yet have a website in 2017.)

- Réseau MARP is a local NGO in Burkina Faso that aims to promote the participatory action research approach in rural development, in collaboration with local farmers and communities. For several decades Réseau MARP has played an important role in supporting and promoting regreening and farmer-managed natural regeneration in the Sahel. VU has worked with Réseau MARP since it was founded in 1992.

- University for Development Studies - UDS² is a public university in Ghana, established in 1992. The mission of UDS is to blend the academic world with that of the community, to the benefit of the development of Ghana as a whole, and in particular the rural Northern region where UDS is physically located. UDS has a pro-poor focus, which is reflected in its methodology of teaching, research and

I http://reseaumarpbf . org, (accessed o8-10-2020)

2 http://Www. uds. edu.gh (accessed o8-10-2020) 
outreach services. The specific emphasis on (practically-oriented) community service learning has as goal to contribute to poverty reduction and the acceleration of national development. UDS' mission is operationalized in the "Third Trimester Practical Field Programme". In this program, every student of UDS has to do a community-based internship and work in a rural community during a certain period of his/her study. VU has worked with researchers from UDS since the early 2000 in various research and education projects for ICT and (rural) development.

- Sahel Eco is a local Malian NGO with headquarters in Bamako and branch offices in Tominian, Sevare and Mopti. In 201133, Sahel Eco had about 11 employees, two of which were posted in Bamako and the others working in various regions of Mali, to be able to support the rural communities locally. Sahel Eco gives trainings and organizes farmer-to-farmer visits. Sahel Eco helps to disseminate and improve regreening initiatives, and trains farmers how to improve methods to make a living out of tree products. One of the activities is their support to emerging agro-forestry value chains for small-holder farmers.

LOCAL TECHNOLOGY AND BUSiness PARTNERs. Business partners and technical service providers are often future adopters of innovative ICTs, and must participate in the team. Examples are community and rural radio stations. These are information hubs of rural Africa, that have a broad coverage in rural West Africa. Various radio stations in Mali and Burkina Faso became closely involved with the W4RA program.

For example: the following radio stations in Mali and Burkina Faso (and various others as well) have contributed to our $\mathrm{ICT}_{4} \mathrm{D}$ projects (and continue to collaborate with the W4RA team): (i) Radio Sikidolo in Konobougou has been key to the development of various services. Radio journalist and director Adama Tessougué is one of the key users and co-creators of our systems. Other partner radios are: (ii) Radio ORTM Ségou, a national Malian state-owned radio; (iii) Radio Moutian, an independent radio in the village Tominian; its staff members collaborated intensively with the $\mathrm{W}_{4} \mathrm{Ra}$ team in the development of voice services; (iv) Radio Seno in Bankass; (v) Radio La Voix du Paysan in Ouahigouya, Burkina Faso: its staff members have participated since 2010 in our collaborative workshops. Interviews with $\mathrm{W}_{4} \mathrm{RA}$ members have been broadcast several times at this radio. (vi) Radio Notre Dame in Ouahigouya, and (vii) Radio Solidarité, a small radio station in Ouahigouya, are close partners in our workshops. All these radio stations (and others as well) are commonly involved in $\mathrm{W}_{4} \mathrm{RA}$ activities to provide ICT services for farmers in rural regions of the Sahel.

3 At the time of the start of the VOICES project. 


\subsection{COMPOSITION OF THE FULL ICT RESEARCH \& DEVELOPING TEAM}

Our research team consisted of local partners, ICT developers and researchers. Various roles have to be represented. One person can represent more than one role. People can switch between roles.

- A project manager, to manage and organize an international project; this person should be able to take decisions over resources, finances etc;

- A requirements engineer/information manager, for bridging the cultural distance between users/developers, moderate sessions;

- An information analyst to translate the user stories into concepts and processes and build conceptual models of the elicited information/knowledge;

- One or several context experts, preferably from the region, or with extensive local experience;

- One or more ICT developers with hands-on skills, able to build rapid prototypes, apps, interfaces, and able to explain this to non-technical people;

- An ICT-business requirements \& service expert, who can evaluate and model business information and safeguard long-term sustainability issues;

- If the users are low-literate, voice technologies must be considered, and voicetechnology skills are required in the team;

- A filmer/photographer to record all meetings, and able to produce documentaries for further use and dissemination;

- One or several local contact persons who maintain daily contacts with the user communities, translate to and from local languages, explain the local context and chair the meetings;

- A driver, because the project requires long drives, usually by bus, with many people;

- One or more local ICT business partners or service providers, able to learn new skills and help deploy the systems;

- Key users: farmers men and women, extension workers who work in the communities, herders, local sales persons, farmer-innovators. 


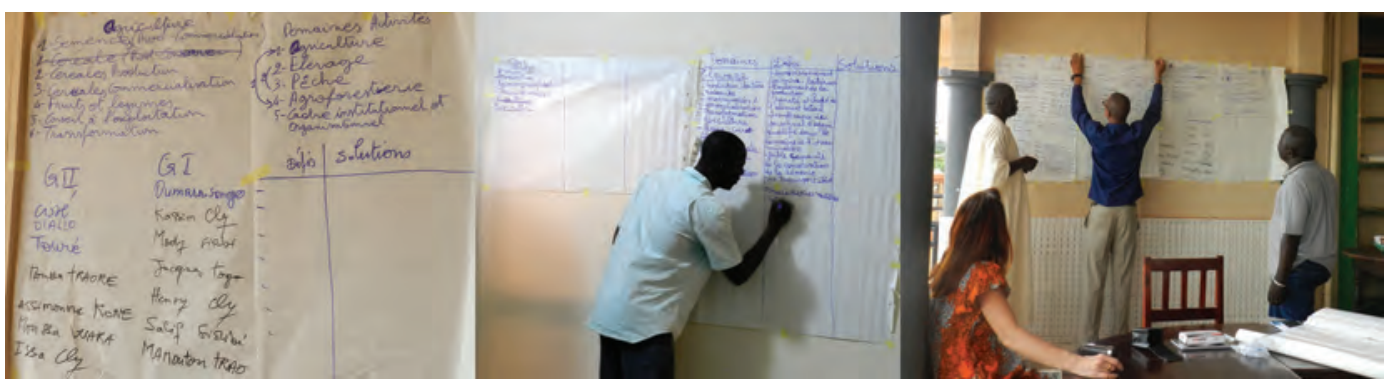

Figure 68: Defining priorities during co-creation workshops with farmer organization AOPP in Mali, October 2015.

\subsection{A CONFIGURABLE FRAMEWORK}

In Chapter 4 concerns are discussed that are characteristic for what I refer to in this thesis as a "low-resource environment". These environments are found e.g. in rural regions of the Sahel in West Africa. To address these concerns in a user-centered way, considering the needs and objectives of local users, I proposed collaboration, adaptation and iteration as an alternative to interventionist approaches that focus on transfer of knowledge and technologies from the Global North without notion of emergent innovation, local agency, and complexity of local contexts.

In Chapter 5 to Chapter 8, the adaptive approach was illustrated by various pilot studies in rural Africa. Based on the field experiences and an iterative learning approach, I will make a synthesis of all methods and techniques into a flexible framework that describes how to develop ICT-enabled services for people in low-resource contexts. The proposed framework consists of five components or aspects as summarized in Figure 70 context analysis (i), needs assessment (ii), use case and requirements analysis (iii), sustainability assessment (iv), engineering, deploying, evaluating (v). Because of its adaptive and iterative nature, I refer to the framework as a configurable list of 'components' or tasks. In practice the framework components heavily interact with each other, instead of being applied in a traditional, top-down waterfall approach or logical framework approach. Reflection and dialogue about ethical aspects should be present in each of the components/tasks. This is added as a sixth, transversal component.

The first version of this framework was published in 2014 under the name "ICT $4 \mathrm{D}$ 3.0" [36]. I proposed this as an inclusive, field-based alternative to another framework, a linear (and quite techno-optimistic) framework named "ICT4D 2.0" [195]. ICT4 2.0 is a theory-driven model of $\mathrm{ICT}_{4} \mathrm{D}$, in which the end-user perspective and the operational aspects are not addressed [194]. As I argue in this thesis, the voice of the end-user must be heard. This can only be achieved by allowing the end-user to participate in the agenda setting and design. In that sense, moving from the "ICT $4 \mathrm{D} 2.0$ " paradigm to " $\mathrm{ICT}_{4} \mathrm{D} 3.0$ " marks the entrance of the "user" in the decision-making process and 
sociotechnical development [36, 198]. How the framework caters for the concerns of $\mathrm{ICT}_{4} \mathrm{D}$ in low-resource environments, is described in the following paragraphs.

- Context analysis, as described in Chapter 4 and illustrated by examples from our research in the Sahel in West Africa, is one of the key aspects of $\mathrm{ICT}_{4} \mathrm{D}$ and one of the components of our framework. This aspect is often overlooked in mainstream ICT4 $\mathrm{D}$ projects, based on an (unwarranted) assumption that technology will work irrespective of context. Context analysis is called for in our framework for two important reasons: (i) to bridge the big gap between technology and developers on the one hand and the world of the end-user on the other hand; (ii) because of the contextual nature of ICT and information systems themselves. Context analysis consists of field visits (see e.g. Figure 69), road shows, focus group discussions, interviews and technology demos. It is based on field-based action research.

- Needs assessment, presented in Chapter 5 and illustrated by examples from collaborative workshops with farmers and rural communities in Mali, Burkina Faso and Ghana, can be described as a method for collaborative goal construction (see e.g. Figure 68). Needs assessment, as an aspect of our $\mathrm{ICT}_{4} \mathrm{D}$ framework is a two-way, iterative process, which consist of several phases (i) jointly exploring the problem space (ii) jointly defining the solution space (iii) selecting the best key ideas, setting priorities, evaluating and jointly deciding which ICTs should be further elaborated. Needs assessment workshops make use of collaborative techniques for knowledge elicitation (living labs, ba, participatory technology development etc.).

- Use case and requirements analysis. Use case and requirements analysis and elaboration constitute an important aspect of the $\mathrm{ICT}_{4} \mathrm{D}$ framework and often overlooked in mainstream $\mathrm{ICT}_{4} \mathrm{D}$ projects. We propose a method to structure the collected data from the field research/workshops, presenting this in different views: (i) in formal technical specifications, that allow the ICT developer to design the architecture and build the system (ii) in a narrative and informal way to make sure the end-user can validate requirements and understand and discuss the technical idea/design. The method here proposed is coined "structured narrative method". This method and its corresponding format are explained in Chapter 6 through an example of a mobile ICT service for farmers in Mali.

- Engineering, deploying, evaluating in a collaborative approach. In Chapter 7 this collaborative process is described and illustrated through an example of an extensive $\mathrm{ICT}_{4} \mathrm{D}$ project in rural Mali. This case shows how such an $\mathrm{ICT}_{4} \mathrm{D}$ project can be carried out and why an adaptive, iterative approach is required when coping with innovation and complexity of the local context. The case shows that 


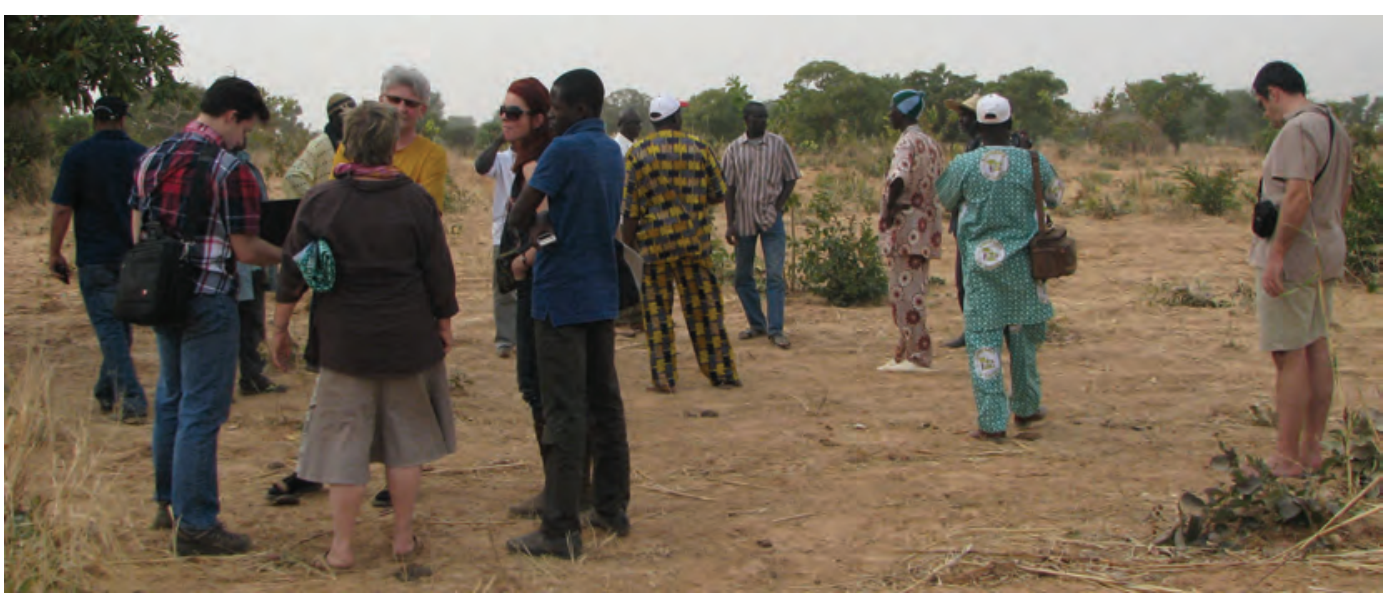

Figure 69: Field visit to farmer and regreening champion Moussa Sangara, during a 12-day roadshow in West Africa, near Bandiagara, Mali, January 2011. Photo: Bruno van Moerkerken.

many questions are still open. More interdisciplinary field research is needed to improve the outcomes of $\mathrm{ICT}_{4} \mathrm{D}$.

- Sustainability analysis. A method to perform economic sustainability analysis in a structured and formal way is presented in Chapter 8. This method uses field research data to build scenarios and calculate business models for all actors in a value network. This analysis, which is based on the $e^{3}$ value methodology, makes it possible to analyze the economic sustainability of an ICT service from the start of the $\mathrm{ICT}_{4} \mathrm{D}$ project, i.e. before its deployment. It allows to anticipate and adjust the $\mathrm{ICT}_{4} \mathrm{D}$ project, during the project period. The collaborative aspect of this sustainability assessment method is that it evaluates sustainability and profitability for all actors in the value network. In this it differs from other business modelling tools that commonly evaluate profitability from one single entity/business perspective. This method of sustainability assessment has not previously been used in $\mathrm{ICT}_{4} \mathrm{D}$.

- Ethical considerations As discussed in Chapter 1, one of the central ideas of this research is to include ethical considerations in $\mathrm{ICT}_{4} \mathrm{D}$ : concerned with people and their problems/situation, taking into account the intricate aspects related to issues of e.g. interests and power (e.g. gender); respectful to local culture and local people/communities. Therefore, this sixth is added as a transversal component to the framework. Its activities consist of reflection and dialogue. 


\subsection{HOW THE FRAMEWORK ADDRESSES THE CONCERNS OF THE CONTEXT}

To be effective, the $\mathrm{ICT}_{4} \mathrm{D}$ framework should be able to address a set of important concerns of people and communities living in so-called low-resource context, which are widely and commonly encountered in developing and emerging countries. Based on field visits and context analysis (described in Chapter 4) (see also: [104, 42, 106, 41, 184, $183,40]$ ) a list of observations and concerns was collected, related to (i) the specific local conditions, which can be encountered in low-resource environments, and (ii) methods to bridge the cultural gap between the ICT developers and users and their local context. The most important ones are listed in Chapter 4, section 4.5. The concerns and how they are addressed in $\mathrm{ICT}_{4} \mathrm{D} 3.0$ framework, is discussed below.

LOCAL NEEDS UNKNOWN. This is, we believe, the core issue for any real-world adequate $\mathrm{ICT}_{4} \mathrm{D}$ framework. Namely, the domain is rife with generic statements on the progress that ICT can (or even will) bring for development and more specifically for 'the poor', in alleviating or even eradicating poverty (see the opening sentences of this paper, the United Nations Millennium Development and Sustainable Development Goals, Jeffrey Sacks' neoliberal Millennium Village Project [36o], or much of the $\mathrm{ICT}_{4} \mathrm{D}$ policy literature - cf. [194] as a typical example). Our point is that such statements have noble intentions, but are scientifically speaking no more than hypotheses about the possible importance of ICT, and so they need to be put at the test as any scientific hypothesis. This is however rarely done, or if so it is done from a big distance through desk research. In our view, this is far from good enough. Therefore, our framework reserves a special place for needs assessment clarified through local field research that takes place on-the-ground and at the grass-roots level in a collaborative fashion akin to action research.

CONTEXT UNKNOWN. Information needs of people do not emerge and exist in isolation. Instead, they are situated within the specific contexts of people's everyday work, practice, life. The more this is different from the mainstream ICT developer context (certainly if the latter is from the Global North, as is often the case), the bigger the need to study it in detail. Hence, our framework includes extensive context analysis that is again in-the-field, on-the-ground at grassroots level. In other words, academic desk research carried out at-a-distance as is often done in a development context is inadequate: again, it usually involves hypotheses that are scientifically untested in the Global South but are uncritically accepted by quite a many in the Global North.

SIGNIFICANT LEVELS OF LOW-LITERACY. This issue impacts heavily (also) on the technical ICT solutions that are entertained in the engineering, deploying and evaluating component of our framework. The Internet, World Wide Web and the use of social media, as well as the use of SMS in mobile phones, are heavily biased towards text, 
and so in fact discriminate against those who cannot read or write. Field research into this typically triggers the correction of such text biases and the prioritization of non-text solutions such as voice services.

LOW PURCHASING POWER OF END-USERS. This is a given that especially impacts the durability of ICT solutions beyond initial project development and piloting. Hence, in our framework it is factored into sustainability assessment, and in particular made explicit through the $e^{3}$ value methodology focused on the value network of stakeholders' balance of benefits and costs, introduced in this paper.

AVAilability of CRUCial technology and infrastructure. Policy statements (and similarly, big-company attempts) make it often seem easy to resolve issues such as affordable Internet for everyone everywhere. In contrast, the reality on-theground is that electricity is already a major issue that is not going away easily, especially in the rural areas where most of the poor live. So, any real $\mathrm{ICT}_{4} \mathrm{D}$ project has to shy away from (vaguely) stating what might be possible in a distant future, and is to start (realistically) from what is there already now. This again underlines the importance of empirical field research in $\mathrm{ICT}_{4} \mathrm{D}$.

LACKING UNDERSTANDING OF ICT POSSIBILITIES. This is a common problem also in the Global North with non-ICT users. Our experience is that this problem can be quite well overcome within field research by properly designed demos and roadshows that are tailored to the specific interests of relevant local audiences. A key criterion is that technical demos and associated explanations are such that people can imagine for themselves how technological possibilities and affordances might work out in their own situation.

SUSTAINABILITY CONCERNS. It goes without saying that anyone would like an ICT development to be successful for many years, also after initial project development and piloting. We have introduced novel methods for sustainability assessment in this paper. Often, in the conventional monitoring and evaluation (M\&E) approaches in development, this is studied after the fact, when it is in fact too late (not only post hoc but even post-mortem). Instead, I propose in this framework to perform sustainability assessments at an early stage, such that the associated what-if scenario analyses can impact ICT development at the early design stages.

MISMATCH BETWEen DONOR gOALS AND 'BENEFICIARY' END-USERs. This is a concern quite specific for $\mathrm{ICT}_{4} \mathrm{D}$. In the Global North it is typically the end-user company that ultimately pays the bill in ICT projects. This is also the assumption in the Agile approach to software engineering. In $\mathrm{ICT}_{4} \mathrm{D}$ this is however typically split: projects are structured according to donor and sponsoring funding agency ideas and 
Low-resource aware framework for development of ICT4D services

Components (tasks) Possible methods

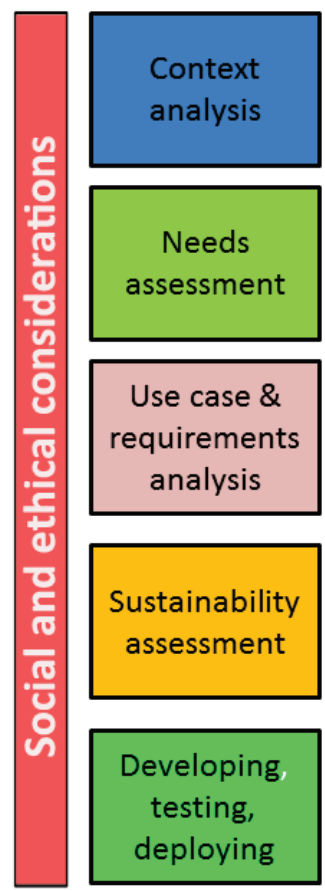

Action research

Roadshow

Literature review

Field research

Collaborative workshops

Participatory rural appraisal

(PRA model suite)

Use case modeling

Requirements elicitation

Agile Development Methods

Functional evaluation

Business case evaluation

Technology assessment

Scenarios

Living Labs

Agile Development methods

User-centered evaluation
Techniques \& tools

Field visits

Focus groups

Demos

Interviews

Field visits

Focus groups

Demos

Interviews

Demos \& focus groups

Rapid prototyping

Conceptual modeling

Interview, focus groups

E3 Value modeling

Dynamic systems conceptual

modeling

Demos \& focus groups

Prototypes

Figure 70: A consistently collaborative framework for $\mathrm{ICT}_{4} \mathrm{D}$ with five tasks or components and the corresponding methods, techniques and tools. Ethical considerations are present in all tasks, and are placed as a sixth, transversal component.

goals about what are assumed to be the (supposed) beneficiaries' ("the poor") goals. Commonly, there is a big difference between the two and, minimally, such donor goals go untested against the reality in the supposed beneficiaries' context. Our framework provides an antidote to these biases by its emphasis on collaborative field research in all the ICT stages.

ETHical CONSIDERATions. The well-being of the people concerned is the first prority of $\mathrm{ICT}_{4} \mathrm{D}$ 3.0. Ethics have to do with all its aspects: how project goals are defined, how systems are designed, tested, evaluated and deployed, how data are collected, processed and stored, how the stakeholders' eco-system is included etc. Since ethical issues are very diverse, there are no strict guidelines how this should be carried out in practice. A reflective attitude, concern for people, their problems and livelihood, and being respectful to local culture and local people and communities, are integral part of the approach. Intended and (potential) unintended consequences must be discussed in an ongoing open dialogue, in which all voices are heard. 


\subsection{A PROCESS MODEL FOR ICT4D SERVICE DEVELOPMENT}

By integrating the various components and aspects of the $\mathrm{ICT}_{4} \mathrm{D}_{3} .0$ framework (cf. Figure 70), and formulating the exposition and case examples of the previous chapters in a generalized fashion, we obtain an overview picture as in Figure 71. It gives a process model of our $\mathrm{ICT}_{4} \mathrm{D}$ service development framework in the form of an intention-strategy map [330, 352], a technique stemming from goal-oriented requirements engineering 4 . Here, ovals denote intentions (goals), and arrows denote strategies to achieve these goals. In a single phrase, the framework for $\mathrm{ICT}_{4} \mathrm{D}$ service development is collaborative, adaptive and iterative throughout.

Some of the above-mentioned concerns and the ways our framework addresses them might seem pretty obvious and straightforward. Indeed, some of the mentioned concerns are also an issue in the Global North (such as the gap between ICT-developers and non-ICT end-users), and many suggested methods are already in existence (although the sustainability assessment methods here proposed are novel). Within the $\mathrm{ICT}_{4} \mathrm{D}$ literature, there is a (limited) number of authors pointing in similar directions as this framework, often from a human-computer interaction (HCI) perspective $[29,109,110,316,317,400]$. Notwithstanding this, this thesis shows that $\mathrm{ICT}_{4} \mathrm{D}$ is not just ICT business-as-usual. There are three reasons for thinking so:

1. There is no denying that the concerns to be resolved in ICT developments are much more severe, critical and constraining in the case of $\mathrm{ICT}_{4} \mathrm{D}$, and this on a very broad front, social and technical. What initially are matters of degree at some point combine and then turn into fundamental qualitative differences.

2. Perhaps surprisingly, many modern developments in software engineering, computer science, and information-systems practices, that are by now taken for granted by scientists and professional specialists, still escape the attention of the development circles that fund and drive (also) ICT projects.

3. More fundamentally, our observation is that a lot of external (mostly western) bias is commonly introduced into $\mathrm{ICT}_{4} \mathrm{D}$ projects. Many of these biases originate from assumptions about stakeholder goals, needs, technologies and their context. The basic problem here is that often these presumptions are not critically tested against developing countries' realities on the ground, in order to see whether they are actually warranted.

4 For a full account on mapping of purposeful systems, see Colette Rolland (2007)“Capturing System Intentionality with Maps" [352]. 


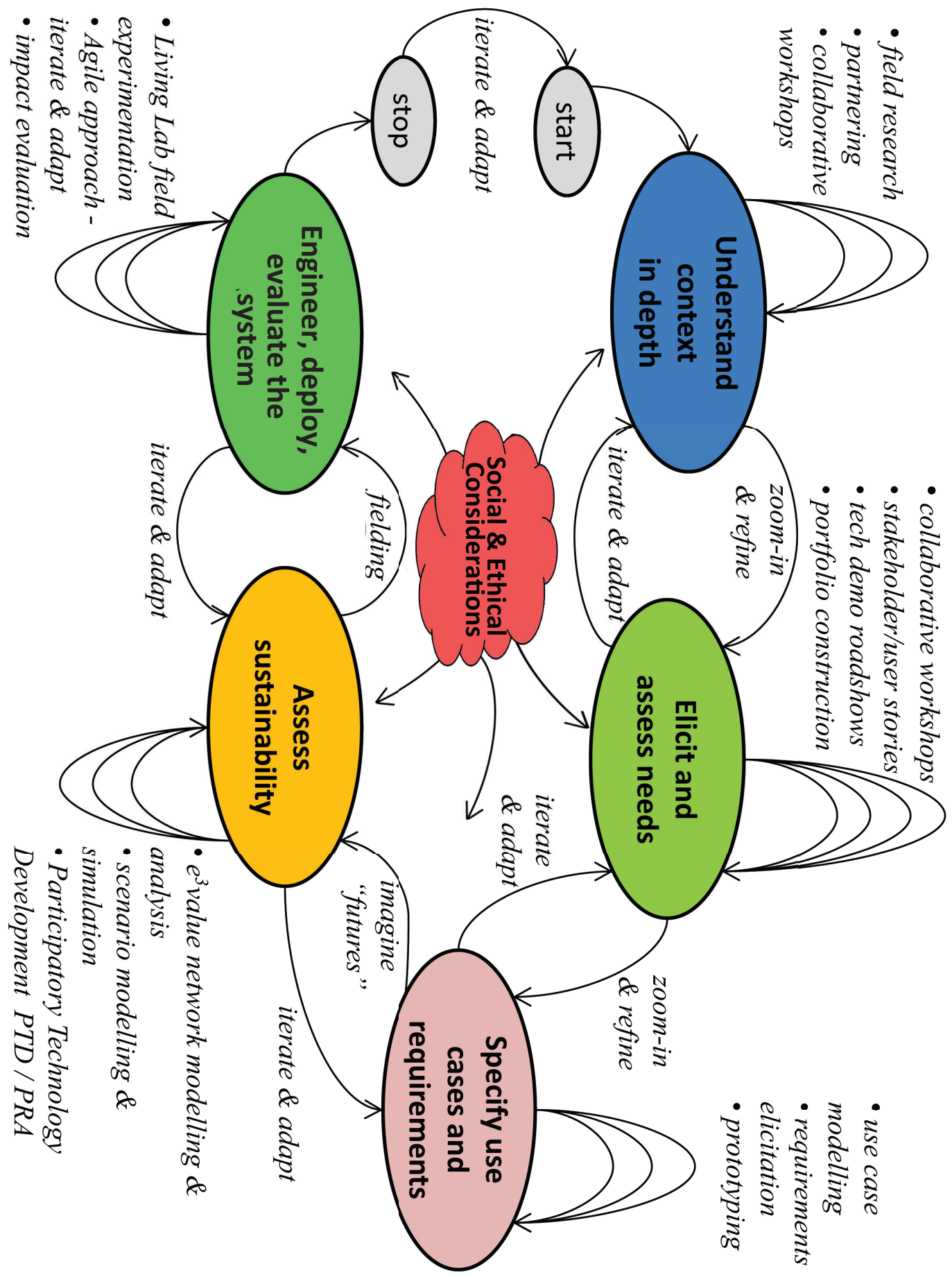

Figure 71: The collaborative-adaptive-iterative process model for our $\mathrm{ICT}_{4} \mathrm{D}$ Service Development framework, expressed in the form of an intention-strategy map. Ethical considerations are present in all tasks. 


\subsection{A CONSISTENTLY COLLABORATIVE FRAMEWORK FOR ICT4D}

In this chapter I have proposed a service development framework and methodology, dubbed $\mathrm{ICT}_{4} \mathrm{D}$ 3.0, which is thoroughly and inherently collaborative, adaptive and iterative, throughout the whole development lifecycle. It puts emphasis on (i) the composition of the interdisciplinary and multicultural team and (ii) the importance of the early upstream stages of ICT systems development. It emphasizes needs analysis, in context 'sur le terrain'/'on the ground' - even before ICT technologies are necessarily being implied. The reason is that inherently sociotechnical systems such as $\mathrm{ICT}_{4} \mathrm{D}$ services have a heavily contextualized nature: the 'known unknown' that requires extensive field-based research. 



\section{VALIDATION OF THE RESEARCH OUTCOMES}

One way to validate the outcomes of praxis-oriented research such as this $I_{C} T_{4} D$ research, is to ask its users or stakeholders how useful the outcomes are for them. We can e.g. (i) ask stakeholders if the artefacts that are designed and built are useful and meaningful for them and contribute to achieving their operational goals, or (ii) ask developers to use the artefact(s) in other, yet comparable contexts. Another criterium for validation is to assess generalizability of the research outcomes in different contexts.

\section{O.I UTILITY AS EXTERNAL VALIDATION}

In Chapter 7, the RadioMarché project is described, including the evaluation of the process of sales of non-timber forest products. The observed impact of increased sales of honey and sheabutter for local communities in the Cercle de Tominian, in Mali, is a proof of utility. In interviews with farmers, which we held in April 2013, they explained us how the RadioMarché project in 2011- 2013 had resulted in a considerable and lasting increase of sales of honey. ${ }^{1}$ This testimony by local stakeholders is an indirect type of validation. It is an endorsement of the approach and framework. Yet, to validate claims of generalizability, we need to assess the present research in other contexts as well.

1O.2 USING THE ICT4D FRAMEWORK IN DIFFERENT CONTEXTS

After its deployment in West Africa's drylands, (for the first time in 2009 - 2013) the present framework, which in 2014 became known as "ICT4D 3.0" $[36,46]$, was used in a variety of contexts:

- In a project-based educational setting, for teaching and learning how to "do" $\mathrm{ICT}_{4} \mathrm{D}$, since 2013.

- In a low resource context in sub-urban and rural communities in Sarawak, Malaysia, in 2018-2019.

- In a wealthy urban context in the Global North, aimed at serving and collaborating to serve vulnerable groups/communities in 2018-2019.

I The interviews with farmers Naomi Dembelé and Zakary Diarra are available online. See also: https : //w4ra.org/naomi-dembele-bianivo- \discretionary $\{-\}\{\}\{\}$ mounkoro- and - anna-bon $\backslash$ - about - agro - forestry-value- chains - in-mali/, (accessed 08-10-2020) 
The projects and their evaluation, are described in the following sections.

\subsection{ICT4D 3.0 AND COMMUNITY SERVICE LEARNING}

Since 2013 "ICT4 D" is lectured at VU, as a (6 ECTS/2 months elective) classroom-based course in the master tracks of Computer Science, Information Science and Artificial Intelligence. The framework ICT4 $\mathrm{D}_{3.0}$ is used by the students in this course, to elaborate existing use cases that have been collected by the lecturers ${ }^{2}$ in West Africa during ongoing field research. In 2018 a new, additional $\mathrm{ICT}_{4} \mathrm{D}$ course was set up at VU, targeting the same student groups. In this follow-up course, the field research component of $\mathrm{ICT}_{4} \mathrm{D} 3.0$ was included.

\subsubsection{Setup of the ICT4D course}

The ICT $4 D$ in the Field course is organized, coordinated and lectured by academic staff from Vrije Universiteit Amsterdam (VUA) and the Universiti Malaysia Sarawak (UNIMAS) in Sarawak, Malaysia. In this project-based course students learn how to design/build information systems for local stakeholders who live in a (low-resource) community. In 2018 and 2019 fieldwork was done by the students in the surroundings of Kuching, Sarawak's capital. The results and evaluation of this course/educational research project have been published [46].

The $\mathrm{ICT}_{4} \mathrm{D}$ in the Field course is set up according to the educational framework of Community Service Learning (CSL). In CSL, students work with local communities in social innovation projects. The goal is to respond to some aspect of their needs, through collaborative design and deployment of a real-world (ICT) solution. In the study guide of the VU the goals for ICT4 $\mathrm{D}$ in the Field are described: ${ }^{3}$

- to make the next generation of information scientists aware of the potential role of ICTs for the developing and emerging world, with appreciation for the highly diverse and complex contexts (in contrast to a one-size-fits-all approach), socialcultural factors and human needs that must be addressed.

- to equip the students with relevant field research \& development methods and skills, to develop technologies in a low resource environment.

- to acquire and reflect on the experience of carrying out a full life-cycle of realworld software development project in the field, thereby learning to deal with unfamiliar and complex contexts and engaging with communities, taking into consideration their specific contextual constraints, needs and goals.

2 The ICT4 $\mathrm{D}$ course is lectured by Victor de Boer, Francis Dittoh and the author.

3 Source: https://studiegids.vu.nl/nl/Master/2018-2019/information-sciences/X_405101, (accessed o8-10-2020) 
10.3.2 ICT 4 D 3.0 as central framework of the course

$\mathrm{ICT}_{4} \mathrm{D}$ in the Field follows the tasks of the framework $\mathrm{ICT}_{4} \mathrm{D}$ 3.o. Students start, the first day of the course, with a general context analysis. This is followed by problem identification/collaborative needs assessment and goal construction, together with local stakeholders. Next, or in parallel, they perform a use case and requirements analysis, make a problem conceptual design, a technical architecture design, followed by engineering a prototype, iterative testing with the users and developing and adjusting the prototype until it is considered acceptable by its users. Evaluation and sustainability analysis/value network design are also part of their tasks. Real-world context constraints are taken into consideration.

The course takes in total four weeks, on location in a low resource environment. It includes lectures and field visits. It is conducted in a way that should meet the community goals. Students do interviews and focus group discussions in the community. There is time for user-tests and feedback sessions. Apart from the five stages (tasks) of the $\mathrm{ICT}_{4} \mathrm{D}$ framework, attention is given to guidelines and protocols for interviews and focus group discussions and cultural aspects. The ethical aspects of doing this type of research are extensively discussed.

Student work in teams of five to seven persons. Teams are established in the first week and stay together until the end of the course. Attention is given to the formation of mixed student groups, which should be balanced in expertise (technical skills, social, communication \& business skills, local context, content), gender and cultural background. The student groups are self-organizing (so-called scrum) teams. Each group takes one relevant use case to elaborate. Group members divide tasks and work closely together. Users are involved to make sure that their needs and (business) requirements are met.

During the course there is plenty of time for reflection and dialogue. At the end of the course period, teams present results to users, local experts, the academic community and other stakeholders. This may include the local government, civil society organizations and local business enterprises. It takes place during an official closing ceremony.

A validation of the usefulness of the framework $\mathrm{ICT}_{4} \mathrm{D}_{3} .0$ was the subject of a master thesis by Tom de Jong, which I supervised in $2018^{4}$

A contribution to the validation of the $e^{3}$ value method for sustainability analysis, described in Chapter 8 was done in a master research project by Jamila Daoudi, in June $2017^{5}$ with field data collected from a local business partner: Radio Sikidolo, in Konobougou, Mali.

4 Thesis by Tom de Jong, see https://w4ra.org/wp-content/uploads/2018/08/Jong_Thesis_final - 1.pdf 5 Thesis by Jamila Daoudi, see https://tinyurl.com/sust-e3-Mali, (accessed o8-10-2020) 


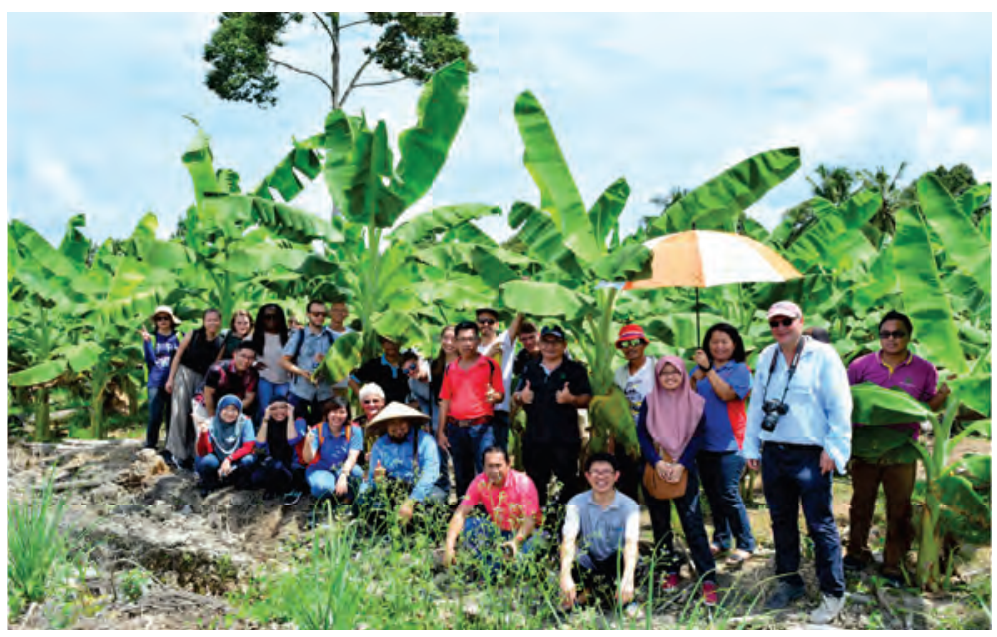

Figure 72: First day in the field with students during the $\mathrm{ICT}_{4} \mathrm{D}$ in the Field course in Sarawak, for students from VU and UNIMAS, June 2018. Context analysis: visiting a banana plantation.

\subsubsection{ICT4D in the Field: projects in Sarawak, June 2018}

During the course in 2018 three $\mathrm{ICT}_{4} \mathrm{D}$ student projects were carried out. In 2019, again three projects were executed. All projects were relevant for the community and technically feasible for a proper $\mathrm{ICT}_{4} \mathrm{D}$ educational project in less than four weeks.

The projects are structured according to $\mathrm{ICT}_{4} \mathrm{D}$ 3.0: evaluating with the users and sustainability analysis using the $e^{3}$ value methodology, use case is structured according to the Structured Narrative Format, see Chapter 6. In the following paragraphs a few highlights are mentioned, for projects from 2018 and 2019.

\subsubsection{Context analysis in Sarawak}

During the first few days of the course the students went to the neighboring kampungs (communities) Pinggan Jaya and Muhibbah. They visited a banana plantation, a mangrove forest and a primary community school. They held various focus group discussions in the kampung. The lecturers from VU and UNIMAS were present during these sessions. The researchers from UNIMAS introduced the VU team to the local communities. From these general context assessments, field trip reports were made. Various discussions led to the formulation of the $\mathrm{ICT}_{4} \mathrm{D}$ student projects. In 2018 the executed projects were dubbed: (i) BannaTree [302], (ii) Appong [213] and (iii) EDUCOMX [50]. In 2019 the projects were labeled: Dengaway [432], Majunet [291] and MonkeyMath [410]. Four of the student projects are briefly described in the following paragraphs. ${ }^{6}$

$6 \overline{\text { More student reports are available at https }: / / w 4 r a . o r g / s t u d e n t-p a p e r s /(a c c e s s e d ~ o 8-10-2020) . ~}$ 


\subsubsection{The BannaTree student project}

During the context analysis (see Figure 72) the students learned about the banana value chain in Sarawak. The contract farmers plant and harvest bananas called pisang sekaki. Crops are transported to small local banana chips factories where they are processed and packed for export (mainly to China). The government of Sarawak aims to increase income and standards of living of banana contract farmers. This is done through support to small food factories and policy measures to improve the working conditions for contract farmers [302].

NEEDS AND GOALs: From interviews with contract farmers and other experts, the students learned that banana crop yields are currently not well planned. Lack of information on timing and amount of expected crop yields leads to planning problems in the industrialization process. This leads to crop loss for the farmers and supply inconsistencies in the factory's chips production [302].

USE CASE \& REQUiREMENTS ANALysis: To improve coordination and logistics, the students designed and proposed an information system with a dual mobile \& web user interface. The system was dubbed BannaTree. Aim of the system was to report on the status and planning of the banana crops, with different views for different users: (i) the farmers, for planning; (ii) the factory for logistics; (iii) the local government for monitoring and evaluation [302].

ITERATIVE BUILDING OF THE APP: The prototype system was discussed with a group of users: banana farmers, representatives of the banana chips factory, a commercial fertilizer supplier and experts, the agricultural department, and key expert from UNIMAS. The discussions led recurrently to changing requirements and two major redesigns of the system in a week time. The first working prototype of the BannaTree application was delivered in the third week of the course [302].

ECONOMIC SUSTAINABILITY: The business processes of the network of stakeholders were also modeled by the students according to business requirements. Special attention was given to stakeholder analysis, to understand the operational goals and elicit the user requirements for every component of the envisaged system. The students modeled the complete work process and information flows. During the whole process two weekly meetings and demonstrations/discussions were held with key experts and users [302].

EVALUATION AND REFLECTION: The students became aware of the complexity of (sometimes conflicting) interests of various stakeholders with respect to this use case. The requirements changed several times, making the time to really finalize and finetune the application a stressful activity, the days before deadline. The team learned 
about the complexity of the use case. They also discussed together their roles as reflective practitioners. The Bannatree project was ready in time but the final delivery test to the banana farmers was unfortunately cancelled due to external reasons [302].

\subsubsection{The Appong student project}

Another use case, dubbed Appong, consisted of a need of independent smallholder sugar palm farmers, who live in kampung Pinggan Jaya and work in the neighboring mangrove forest. Aim of the project was to increase local sales of the artesanal sugar product: Gula Apong [213].

CONTEXT AnAlysis: Our student and staff group visited the Gula Apong production area. The work in the mangroves is challenging for the farmers: there are ants and snakes in the forest. When the tide is high, mangroves are a dangerous place for the farmers, risking crocodile attacks. The government wants to better support these small producers, because Gula Apong producers protect the forests. Mangroves are environmentally protected areas because of their great biodiversity. Moreover, there is a growing consumer market for Gula Apong which needs further exploration [213].

NEEDS ASSESSMENT: From the initial interviews with the community inhabitants, in the first week of the $\mathrm{ICT}_{4} \mathrm{D}$ course, the students learned about the production of Gula Apong which is produced from the flower of the Nipa palm, which grows in the mangrove forests, along the estuaries of the Sarawak river. Nipa juice is collected manually by the farmers. It is transformed into sugar by a manual process of boiling and stirring, in large pans. This is done locally, in the mangrove forest. After being boiled, the caramelized sugar is carried to the community homes, a few yards from the mangrove. There it is packed for sales by the women of the community, in packs of $1 \mathrm{~kg}$. One farmer family in kampung Pinggan Jaya produces on average 20-30 kg per day. The farmers told us that about 300 farmers are actively producing Gula Apong in this neighborhood of Kuching [213].

use CASE \& Requirements analysis: A mobile app, dubbed Appong, was designed by the students to help increase sales of Gula Apong. The app allows producers to enter information about quantities of Gula Apong offered and the locations of sale. This app is aimed at facilitating and improving exposure of the products to potential customers, to make sales of Gula Apong easier and more efficient. It also aims at stimulating cooperation between the producers in this region.

The local government of Sarawak showed interest in the app, when this was presented by the students during a meeting at the Ministry of Industrial \& Entrepreneur Development (MIED). The app could provide interesting and relevant data on the production of Gula Apong for the government, in the light of a pending state policy to 


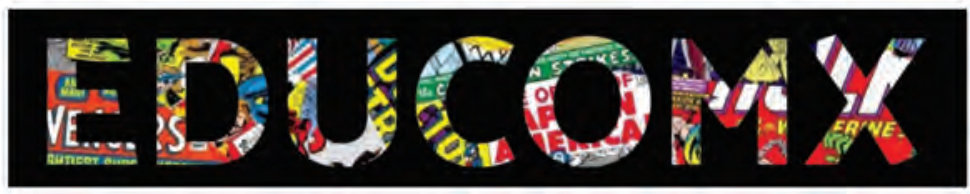

Figure 73: A logo for the game app to teach children in the kampung English. Logo and app designed and built by Anastasios Sidiropoulos, Ludwig Hoon, Guusje Boomgaard, en Nip van Wees.

provide this group of farmers (who do not own the land of the mangroves, which is state-owned) the right to harvest in the public mangrove forests [213].

economic sustainability: The economic feasibility of the Appong application was assessed using the $e^{3}$ value methodology [170]. The $e^{3}$ value method maps the actors (or market segments) in a value network, the value they exchange with each other and calculates for each actor the income it generates. The model allows quantitative evaluation and feasibility study for the complete value network.

\subsubsection{The EDUCOMX student project}

Another student project had as an objective to provide a language learning tool for children. During interviews with parents, school teachers and children in Kampung Pinggan Jaya, one of the student groups learned that, although English is widely spoken in urban areas of Malaysia, the level of English education at primary schools in poor rural areas lags behind, wit hrespect to urban (private) primary schools. Since school subjects such as science and math are taught in English, poor knowledge of English limits the education of rural children even more [46].

NEEDS ASSESSMENT: Learning English is considered of key importance according to the parents and school teachers, who were interviewed by the students. Since educational resources at public schools are not sufficient, alternative learning methods are sought. The students proposed a serious game as a mobile/web app, (as most of the families here in the community own a smartphone, despite a lack of Internet connectivity in the village. The game, built by a mixed group of VU and UNIMAS students, was dubbed EDUCOMX [50]. As it is a web app, it runs on any platform, including SmartPhone (Android) on OLPC XO laptop. UNIMAS deployed a number of XO's for user tests, and made them available for our test session (see Figure 74).

ITERATIVE BUILDing THE APP: The students decided to build EDUCOMX as a pilot app to teach children English. They tried to make the app engaging, while staying in the scope of the English learning methods used at school. For the use case and requirements analysis, the students met a group of children in the kampung and asked 
them to draw their favorite super heroes and write down their hobbies and aspirations. This input was used for the artwork and the reading materials of the app [50]. This process was of great significance in context analysis, (in line with the ICT $4 \mathrm{D}_{3.0}$ framework). The whole exercise showed how user interviews, meaningful objects and narratives can be key to the success of an application deployed in the field.

USE CASE AND REQUIREMENTS: For the design of the application, gamification methods were used. A game can unconsciously help to improve the level of English proficiency. The design is playful and includes animations, sounds, fun colors and images. A scoring system was also implemented. Children could do the assignments through chapters that look and feel like game levels, which they had to complete successfully, in order to continue to the next one. There were status bars that show progress and scores of the user [50]. Two main contextual issues influenced design decisions for the EDUCOMX project: (i) connectivity and (ii) specificity. First, as in rural areas of e.g. Sarawak there was no consistently stable Internet connectivity, online content was not a design option. Second, the now existing digital learning platforms for education in English language were not tailored to the local culture and specific wishes of this group of stakeholders (the children, their parents, their teachers) [50].

TESTiNg THE EDUCOMx APp With CHILdREN: After one week of building and lab testing, the user tests for the prototype were carried out in Kampung Pinggan Jaya with a group of twenty-one children. The age range was ten to twelve years. Testing was done in the community house, which was turned into a Living Lab. The children were allowed to play freely with the EDUCOMX application. Since the application was web-based, the application could be accessed by the children on Android mobile phone, laptop and XO.7

EVALUATION AND REFLECTION: The children liked the concept of the comic books and started to read the English sentences aloud, so it was good to hear their reading skills. The children evaluated the application while playing. By observing the children play with the game, the students could validate the design of the app and collect some new requirements for further improvement. They could see where the strengths and weaknesses were in the prototype design, what should be improved in the system architecture. This test session, which took about 1.5 hour, can be seen as a special adaptation of the $\mathrm{ICT}_{4} \mathrm{D} 3.0$ framework to meet the design of a prototype for serious games for children in a community in Sarawak [50].

\footnotetext{
7 A short video clip of the test session of EDUCOMX with children in the kampung: at https://w4ra.org/ 2018/06/28/a- living- lab- in-kampung- pinggan- jaya-sarawak-short-clip/, (accessed o8-10-2020)
} 


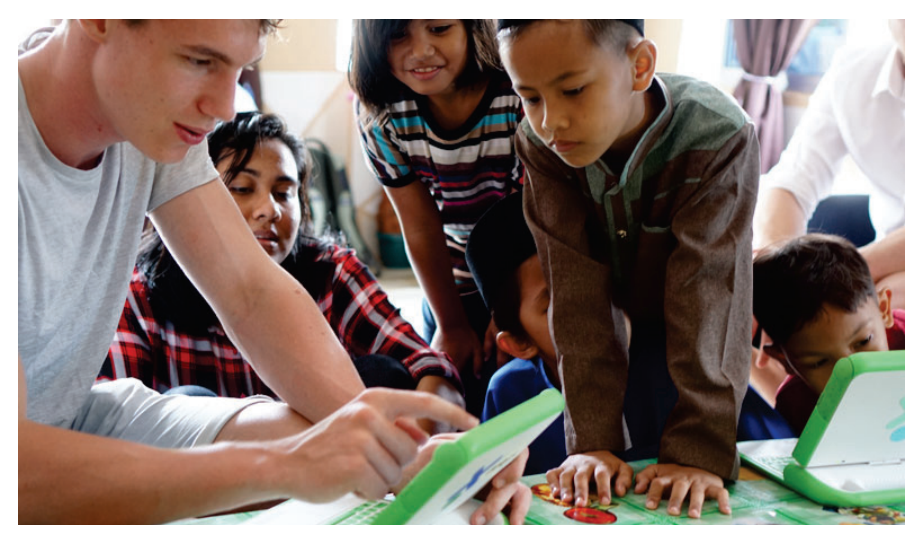

Figure 74: First-cycle testing the "serious game" application with children as users/evaluators, photo by André Baart.

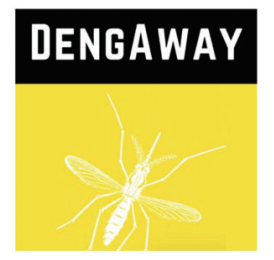

Figure 75: Logo for the Dengaway app. The app, including the logo, was designed by a group of students from UNIMAS and VU: Chong Xing Zi, Lucas Fijen, Marit van Dijk, Michelle Ten LiBin, Nur Asheila Abdul Taib, Shanna Simon. The app was made available as mobile app in the Playstore. This mobile app was built as a student project, based on the $\mathrm{ICT}_{4} \mathrm{D} 3.0$ framework, for self-screening of the Dengue disease, targeting local communities in Sarawak.

\subsubsection{The Dengaway student project}

In June 2019 the Dengaway project [432] was carried out by a mixed student group (VU and UNIMAS) during the $\mathrm{ICT}_{4} \mathrm{D}$ in the Field course. The Dengaway project was also carried out according to the $\mathrm{ICT}_{4} \mathrm{D}_{3} .0$ framework. The project consisted of the design and development of an artificial intelligence/knowledge engineering-based mobile application, after extensive context analysis and needs assessment with local stakeholders, in this case health workers in Sarawak. The function of the mobile application was a self-screening and prevention/early detection system for self- management of Dengue. The targeted users were mainly local communities in Sarawak, who did not have always easy access to medical care. The Dengue virus, which is spread by a mosquito, is endemic in this region. A lot of cases are recorded every year. In 2019 there was a quick and violent outbreak of this disease in the whole of Malaysia, including in Kuching.

The Dengaway student project was carried out according to the $\mathrm{ICT}_{4} \mathrm{D}_{3} .0$ approach and framework, and structured using the structured narrative formal, described in 
Chapter 6 of this thesis. A meaningful logo was designed by the students for this use case, see Figure 75 .

The use case was selected and designed together with local stakeholders in Sarawak. It was tested and re-adjusted based on feedback from community members from kampung Pinggan Jaya. To meet the requirements of language, the system was given a text-based user interface in two languages: English and Malaysian[432]. ${ }^{8}$

In contrast to other use cases, it turned out that a medical/health related use case has commonly more restrictions. Medical information systems distributed in the cloud must comply with regulations of the WHO (World Health Organization), with national health authorities and with European GDPR. In the case of the Dengaway app no patient information/user info was collected or stored digitally, so no problems were faced by the developers. The app was made available in the Android Playstore, where it remained downloadable for several months.

\subsection{EVALUATING ICT4D IN THE FIELD}

In June 2018, parallel with the ICT4D in the Field course in Sarawak, an evaluation/validation study of the $\mathrm{ICT}_{4} \mathrm{D} 3.0$ framework was done by Tom de Jong, for his master research [108]. Evaluation of $\mathrm{ICT}_{4} \mathrm{D} 3.0$ in an educational setting was done along three axes, see also [46]. The evaluation questions are:

1. Is $\mathrm{ICT}_{4} \mathrm{D} 3.0$ a useful framework to learn how to "do" ICT4 $\mathrm{D}$ in the Field?

2. Are the $\mathrm{ICT}_{4} \mathrm{D}$ projects carried out in a community-centered way and do the results meet the needs of the local communities?

3. Is $\mathrm{ICT}_{4} \mathrm{D}$ 3.0 useful in this specific low-resource in Sarawak? (which is different from the African rural context.)

This meta-research showed that the three student projects successfully used all five tasks from the $\mathrm{ICT}_{4} \mathrm{D} 3.0$ framework. The evaluation showed usefulness and adaptivity of the framework, in a rural/suburban context of communities in Sarawak [108]. The evaluation yielded the following observations, as answers to the questions in 10.4:

1. The framework was evaluated in 2018 as useful to train the next generation of $\mathrm{ICT}_{4} \mathrm{D}$ professionals [46]. Based on the produced artefacts (information systems) by the three student projects and the documentation of the process in their final reports, using the "structured narrative framework" (see Chapter 6), the educational goals, as set in the study guide of VU, were largely met. The course was a success for VU and UNIMAS and could therefore be repeated in 2019.

8 The full report is available at https://w4ra.org/wp-content/uploads/2019/08/DengAway_ reduzedsize2019.pdf, (accessed o8-10-2020). 
2. The projects were carried out in a community-centered way. Evaluation shows that all students groups collaborated sufficiently with local users, learned from the context, and worked iteratively, while testing and improving the technological solution according to the users' needs. With respect to the question if the projects meet the requirements of community-orientation and context-sensitivity, one month turned out to be too short for a complete overview of the local context, for an in-depth engagement with the users, and to build a long-term relationship to design, test and deploy a fully sustainable $\mathrm{ICT}_{4} \mathrm{D}$ solution for a real problem they face.

3. The framework was suitable for the projects in Sarawak. In terms of the $\mathrm{ICT}_{4} \mathrm{D}$ 3.o life cycle of information systems development, the course covers only a brief first cycle deployment, with a number of sub-iterations. In terms of serving the community, it is important to foster long-term partnerships and continue to work with the local partner university (UNIMAS) and the local communities.

10.5 YET ANOTHER CONTEXT: ICT4D 3.0 IN AMSTERDAM

Not intended, in the first place, as a validation study of the $\mathrm{ICT}_{4} \mathrm{D} 3.0$ framework, but out of a combination of social engagement and interest in a new context, we formulated a new research question in November 2018:

Is it possible to build information systems for the most vulnerable people in an urban environment in the Global North?

This idea was the result of conversations in 2017 and 2018 with colleagues from the VU Athena Institute, who were doing participatory action research to study the Digital Divide and digital inclusion in Amsterdam. [165].

By that time, we had already built up experience in how to "do" $\mathrm{ICT}_{4} \mathrm{D}$ in rural areas of Africa and Asia. However, the context of the Digital Divide in our own home city was still unknown to our research team. We decided to formulate new projects and launch a call for student projects in Information Science. Fortunately, a group of very motivated students joined the W4RA research team in December 2018.

So, in 2019 the $\mathrm{ICT}_{4} \mathrm{D}_{3}$.o framework was used again by master students. The projects were all in support of disadvantaged citizens in the urban context of Amsterdam people who feel excluded by the digital technologies that do not match their context, needs and skills. At the start of this new project the urban "low-resource" context was terra incognita to us in terms of problems and living conditions of the stakeholders. The results of the student research projects were promising and have been published as a book: Digital Divide, Citizenship and Inclusion in Amsterdam [48]. The case studies by four master students are briefly discussed in the following sections. 


\subsubsection{Four student research projects in $\mathrm{ICT}_{4} \mathrm{D}$}

Four master studies were carried out in the Amsterdam Digital Divide research project, by Derek van den Nieuwenhuijzen, Marc Hegeman, Carlbandro Edoga and Wouter de Boer, describing the process of designing and building information systems and digital services for and together with people who are at risk of digital and social exclusion: (i) homeless people, (ii) people with low literacy skills, (iii) migrants with a low level of education or low levels of proficiency in Dutch language, and (iv) digitally illiterate people [48].

Each of the case studies describes the quest and effort to find and build contextaware user-centered ICT solutions. The approach shows user needs and opportunities and reveals barriers and limitations to the deployment and use of digital solutions by the target groups.

\subsubsection{Exploring the context of homeless people}

Carlbandro Edoga and Marc Hegeman explored information needs of homeless people and examined the obstacles they encounter when in search for information. They investigated the needs and context of homeless people, which are unique and require specific relevant, timely and adapted information. They focused on developing and designing a user-friendly application suite that provides information e.g. where to find shelter, food bank or medical aid [200, 126].

To get familiar with the context of homeless people in Amsterdam, Marc and Carlbandro did voluntary work as context analysis, in a "homeless restaurant" in Amsterdam, where the homeless are offered a free meal. To guide the process the students used the ICT4 $\mathrm{I}_{3}$.o framework.

NEEDS ASSESSMENT: WHERE TO EAT? Based on the focus group discussions and needs assessment, the students found out that the most relevant information requested by homeless people is (i) where to find a free meal today in Amsterdam (ii) where to sleep (iii) where to get a medical treatment or a dentist, without having an insurance [200].

USE CASE AND REQUIREMENTS ANALySis Based on the collected information needs, a design was made by Marc and Carlbandro for a homeless app called straathub.nl. For the real-time search, search optimization was used, to make sure that the information was relevant for the specific users. For this requirement Carlbandro proposed an NLP (Natural Language Processing) method [126].

EVALUATION OF RESUlts In the process of designing and building this system, three test sessions with users took place. The homeless users were very pleased with 
the prototype, as it met their requirements. The weak point of the system was its financial sustainability. Due to the short period available for the student projects (six months), the app was available online as (http://straathub.nl), but it could not further be maintained. This issue is still pending at the moment of writing (March 2020) [200].

\subsubsection{Virtual agents for low literate people}

Derek van den Nieuwenhuijzen focused on how to overcome digital problems of lowliterate and digitally illiterate people in the Netherlands. He applied user-centered design to build a smart solution consisting of a virtual agent. The virtual agent was designed to help users fill in complicated online administrative forms, issued by the Dutch government. Derek tested and adapted the system in three user sessions thoroughly, together with representatives from these target groups [290].

\subsubsection{Language and ICTs for people with a migrant background}

Wouter de Boer used the ICT4 3.0 framework to find out the information needs of migrants with relatively low literacy skills and low proficiency in Dutch. Based on extensive use case and requirements analysis he proposed a method to scan and translate letters from the government into the language of the participating users. He combined existing tools from the web such as online scan tools and language translation web tools to perform the tasks. He provided an "infographic" learning tool to facilitate the users in the use of the proposed online solution. His digital system was tested in three cycles with users and iteratively adapted according to their comments and feedback [32].

10.6 EVALUATING THE RESULTS

Evaluation shows that the four student projects used the $\mathrm{ICT}_{4} \mathrm{D} 3.0$ approach and framework successfully to structure their projects. They worked, socially and technically, in line with the collaborative, iterative, adaptive approach. The work was done in collaboration with local stakeholders (homeless people, migrants, people with low literacy skills, but also the members of the organizations that take care of the vulnerable people). The design and iterative testing led to gradual improvement of the artefacts and learning. The solutions were creative and purpose-oriented. The stakeholders were treated respectfully by the students as co-researchers and experts about their own context and livelihoods [48]. 
The $\mathrm{ICT}_{4} \mathrm{D} 3.0$ framework can be seen as a result of a design question. In design questions - in contrast to knowledge questions, where only one answer to a research question can exist - various different valid and meaningful solutions to a problem can co-exist [419]. The contribution does not claim to be the only solution to the problem at hand. Various other studies have proposed agile methods or participatory action research or a combination of various aspects for $\mathrm{ICT}_{4} \mathrm{D}$, or have proposed frameworks with similar ideas. Some frameworks have been implemented in different contexts.

The following operational frameworks for $\mathrm{ICT}_{4} \mathrm{D}$ are found in literature. They are briefly summarized below. In Table 10 seven different frameworks for $\mathrm{ICT}_{4} \mathrm{D}$ are compared, based on ten characteristics.

- The Nordic model is an inclusive model for ICT4D by Hansson et al. (2009) [188], Projects carried out according to the Nordic model are designed often in close collaboration or even participation with its stakeholders. An agile approach is used. The Nordic model is used in projects in various different countries. Although the model has been deployed in Tanzania and Sri Lanka, the model is only briefly described[188].

- DRAMATICS (DistRibuted Agile Methodology Addressing Technical ICTD in Commercial Settings), proposed by Doerflingen and Dearden (2013) [121] is a model for agile collaborative development in $\mathrm{ICT}_{4} \mathrm{D}$ projects. The authors stress the importance of participation in technology design and propose approaches that are interactive and agile and argue for careful attention to the nature and processes of participation and its human and relational dimensions [120].

- Speedplay is a framework for "social good" projects, described by Ferrario et al. (2014) [145]. It is inspired by agile and spiral software development, Action Research, and Participatory Design. Speedplay consists of four phases (p. 522): (i) Prepare, build trust and search for user requirements (ii) design to gain understanding of user requirements (iii) build collaboratively (iv) sustain: review and consider future development [145]. It uses an interdisciplinary management approach for digital and social innovation research devised to negotiate the challenges of working in partnership with hard-to-reach communities in fast-paced project environments [145].

- The Choice Framework has been proposed by Dorothea Kleine [231] based on field research in Chile. The Choice Framework is not a design-based framework to guide socio-technical development, but a theoretical model to conceptualize how ICTs contribute to a user's individual choice. This model is closely linked to and inspired by Amartya Sen's Capability Approach [376]. The Choice Framework is focused on the user and his/her capabilities. It is not a community- 
centered approach. The user is, according to this model, an individual person with a free choice; and development means freedom of individual choice [376].

- Pitula and Radhakrishnan (2011) [317] have proposed a detailed framework for $\mathrm{ICT}_{4} \mathrm{D}$ which includes various elements that are similar to $\mathrm{ICT}_{4} \mathrm{D} 3.0$ and uses elements from PRA (Participatory Rural Appraisal). It comprises needs assessment based on structured story-telling, and requirements elicitation and modeling using causal-loop diagrams and which has similarities to the networked complexity approach, as described in Chapter 6.

- In South Africa several community-initiatives for digital development have been taken place over the past decade. The Llisa - Living Labs in South Africa is the name of the overall activity. Herselman et al. have analyzed these initiatives, which are community-driven and participatory, iterative and eco-system aware. The focus is less on developing new technologies, and more in applying existing technologies in an adaptive way [203].

- Matt Haikin (2013) [187] explored in the literature the parallels between agile development methods and participatory approaches, and found striking similarities in user-centeredness. He did not implement the model in the field, as this project was desktop research.

\subsection{SUMMARY}

In this chapter we discussed the $\mathrm{ICT}_{4} \mathrm{D} 3.0$ framework with respect to its external validity in different contexts. Student projects carried out in Sarawak Malaysia and Amsterdam have shown that the framework is useful in very different contexts and countries. Moreover, it is also suitable for educational projects, as it provides a step-bystep guidance how to carry out the necessary tasks in a systematic way.

A recurring problem shown in the evaluations of the actual implementations of $\mathrm{ICT}_{4} \mathrm{D}$ 3.0, is the concern about the (lack of) long-term (economic) sustainability of the deployed technologies. Whereas the model provides measures how to make the solutions sustainable on the long run, this has not been effectuated in a real-world case. In the student projects the pilots and student projects of $1-6$ months are too short to achieve a solution that stays alive and running after the end of the project. The student projects are too short in time, and can only deliver of a proof-of-concept. More research is needed to learn where and how this could be improved to provide long-term sustainability. 

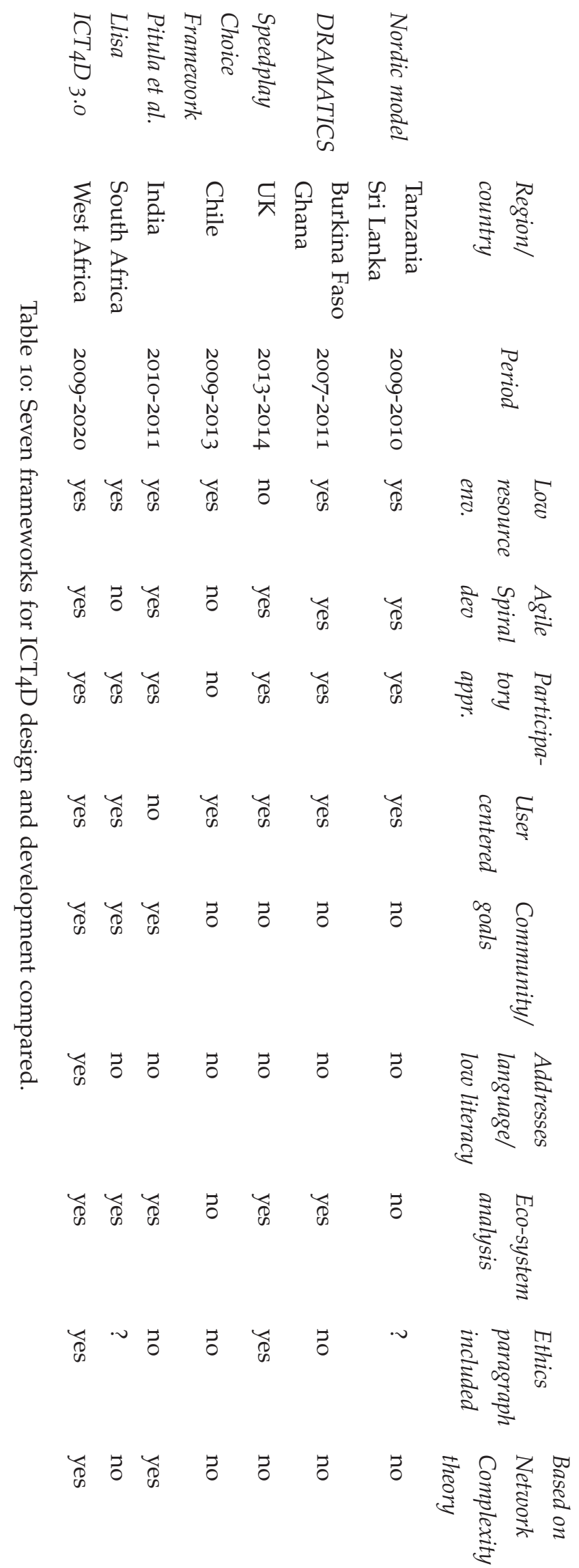


\section{$\mathrm{ICT}_{4} \mathrm{D}=$ INNOVATION COMPLEXITY $\neq$ INTERVENTION}

The field research described in the previous chapters has not only led to the formulation of an operational approach to ICT 4 D, but has also delivered insights for general theory. The ICT $4 D$ field research shows that change is not a linear and direct effect of the introduction of new technology, but a complex, nonlinear process in which knowledge and information propagate through social networks and contextual factors come into play. In this chapter I introduce network complexity as a foundational theory for ICT4D. I discuss what makes an operational, networked approach to ICT 4 D capable of coping with complexity. Network complexity and innovation theories underpin the need for: an adaptive process of socio-technical innovation, to fit the variety of contextual requirements; an iterative process to allow cycles of learning and improvement; a collaborative process (two-way knowledge sharing between various stakeholders) to encompass as many viewpoints and knowledge domains (academic/non-academic) as possible on the subject and context.

\subsection{THE INNOVATION DIMENSION: ITERATIVE, ADAPTIVE, COLLABORATIVE}

In this section, I first return to the linear model of innovation, discussed in Chapter 2, and, illustrated with various examples (e.g. telephony in its early days in the US, the emergence of the Web, the expansion of mobile telephony and mobile money in Africa) I argue that innovation is a dynamic, networked process with many contingencies, that is very different from the abstract linear model of innovation.

In section 11.2, I discuss innovation as two-way communication, and, in section 11.3, I show how traditional views that claim a superiority for western technology and scientific knowledge are reflected in the linear transfer of technology from upstream (high technology) to downstream (end-users seen as passive receivers), and how they tend to overlook the importance of indigenous knowledge, local knowledge networks or networks of innovation.

In section 11.4, I discuss innovation from the perspective of various theories. I link the findings from our $\mathrm{W}_{4} \mathrm{RA}$ research in the field to complexity theory and theories of innovation and its diffusion.

In sections 11.5 and 11.6, with reference to the SECI framework [293], I discuss different aspects of (networked) social learning, illustrated with examples in my field research. I conclude the chapter showing the importance of culture and meaning in the innovation process, in section 11.7 .

To understand complex, networked processes of innovation, this chapter will focus on the characteristics of the actors, their context and their interactions. What drives 


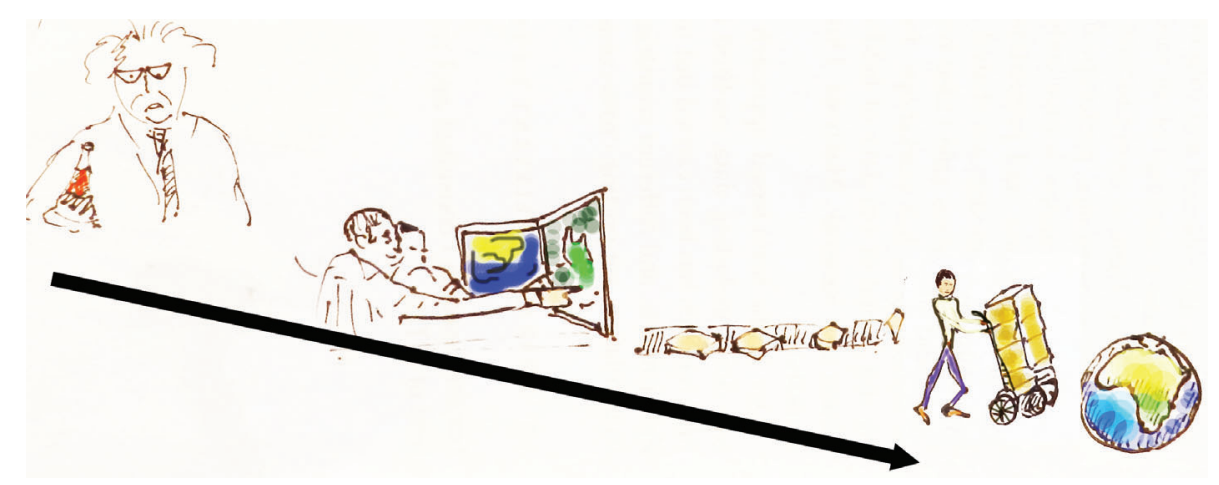

Figure 76: The linear, one-directional model of innovation for development, from inventor and research \& development to production, and roll-out at large-scale in developing regions.

people to innovate? How do they learn? How does communication and exchange of knowledge work? How are resulting artefacts used in practice? How are requirements found, in order to match user needs? ${ }^{1}$

These reflections lead to the construction of a different model for $\mathrm{ICT}_{4} \mathrm{D}$ than the linear, top-down and deterministic model of technology transfer from the intervention paradigm. The theories discussed in this chapter provide a theoretical underpinning for the $\mathrm{ICT}_{4} \mathrm{D} 3.0$ approach, pointing at the following characteristics: collaborative usercentered design, networked two-way communication, respect for culture and (local or indigenous) knowledge, using an iterative, adaptive approach.

\subsubsection{Innovation: top-down or networked?}

In Chapter 2, the linear, top-down model of innovation has been discussed: a model still dominant in international development cooperation. According to this model, innovation starts with an inventor, generating an idea or doing an invention. This is followed by a phase of research and development, located in high-tech laboratories, followed by a phase of large-scale manufacturing. When ready, the roll-out takes place in developing countries. This model, which is conceptually visualized in Figure 76, has been described by Joseph Schumpeter, A.P. Usher, Everett Rogers and others [371, 404, 350]. The way the OLPC (One Laptop per Child) project was designed and deployed is an example of the linear - unidirectional transfer of technologies - innovation model.

Yet, various studies have criticized the linear model of innovation for being incomplete and unrealistic, and for not explaining certain phenomena which are observed in innovations [402, 222, 235]. Alternative theories of innovation show the important role of users, social networks, and communities of practice in innovation processes.

1 A brief outline of the idea of networked complexity as a basic theory for $\mathrm{ICT}_{4} \mathrm{D}$ was published in a conference document in 2019 [38]. 
These theories are based on innovation studies in various different contexts: high-tech environments e.g. [402, 414, 415, 150, 222, 235] as well as low-resource, low-tech environments, in developing regions $[338,99,98,280]$. The networked approach as a more effective way to deal with complex contexts and problems, has been proposed in various studies $[16,57]$. In $\mathrm{ICT}_{4} \mathrm{D}$ for the health sector Braa et al [57] invoke complexity theory to achieve a better understanding of the 'networks of action' involved in health information systems in developing countries. Decolonial author Arturo Escobar refers to complexity theory in his recent work [132] in relation to the struggles of indigenous and Afro-descendant peoples in Colombia and other Latin-American countries. In a (posthumously published) article Rogers et al. [351] discuss the diffusion of innovations (DIM) model in the light of Complex Adaptive Systems (CAS) theory, reaching the conclusion that DIM and CAS can be brought into a co-theoretical model, with a pivotal conceptual role for heterogeneous and differentiated social networks and the associated "strength of weak ties" [174].

User-induced innovation, unanticipated ways in which users re-invent technologies, interaction and two-way communication between developers and users are aspects which are not mentioned in the linear models of innovation $[414,414,415,338]$. Whereas linear models focus mainly on the economic aspects of innovation, they tend to entirely overlook social learning, cultural aspects and e.g. the importance of 'meaning' $^{\prime}[82,232,402]$. In the next sections several cases from literature will point at the (social) networked aspects of innovation.

\subsubsection{ICT4D as innovation}

As discussed in Chapter 2, large similarities exist between complex adaptive systems, social networks $[275,273]$ and diffusion of innovation models [351]. People in social networks interact, exchange knowledge and build social networks with strong and weak links, and feedback loops. This leads to emerging patterns of (decentralized) aggregated behavior, as a complex adaptive system. Diffusion is the process in which innovation is communicated through certain channels over time along the members of a social system. Innovations are technologies, ideas, artefacts, practices which are adapted and reinvented, also in the process of diffusion and adoption [350].

As briefly discussed in Chapter 2, innovation researcher Everett Rogers, in his book "Diffusion of Innovations" gave the characteristics of decentralized diffusion systems: (i) much diffusion is unplanned and uncontrolled, there is a wide sharing of power and control among the members of the social group; (ii) diffusion occurs peer-to-peer through horizontal networks; (iii) innovations come from experimentation by nonexperts, local units decide which innovations should diffuse on the basis of informal evaluations of the innovations; (iv) there is a problem-centered approach, technology pull, created by locally perceived needs and problems; (v) there is a high degree of local adaptation as they diffuse along adopters [350]. 
Rogers compared the processes of decentralized diffusion of innovations with those of highly centralized, top-down interventions. He perceived that decentralized systems are more likely to fit users' needs and problems, as users feel a sense of control when they participate in making key decisions, for example, about which of the perceived problems most need attention, which innovations meet these needs, how to seek information and which information sources to select ([350], p. 398). This is an argument in favor of $\mathrm{ICT}_{4} \mathrm{D}$ 3.0, i.e. collaborative and grassroots instead of a top-down intervention approach.

\subsubsection{Users influencing innovation}

An example how users influence an innovation process in unanticipated ways, creating and giving meaning to a technology within their daily practice, is the introduction of the telephone, before World War II [150]. The telephone, originally introduced in the United States as a top-down broadcast medium to centrally inform customers, has grown out to be the most important tool for social interaction until present day [150]. Claude Fischer describes how users have influenced this new technology:

"... Users are represented in negotiations that reshape innovations and channel their use by interest groups and ultimately by the purchase decisions of individual consumers and the actual use to which those individuals put the technology. By this process, the telephone is transformed in something different. In the case of the telephone we see how ATET leaders, pressed in part by consumers, eventually tried to redefine their product from a totally practical service into a 'comfort' a 'luxury' of the modern lifestyle. Most social constructivism has concentrated on the producers, marketers or experts of a technological system. I intend to go further [...] to the point at which the final consumers choose, employ and experience a technology" [150]

Another example of user-driven innovation and unanticipated use, is the emergence of the World Wide Web, which went viral since the early 1990s. This process is studied by Illka Tuomi as an example of collaborative innovation [402].

The design of the World Wide Web was made by Tim Berners-Lee at the European institute for nuclear research CERN. It was originally set up as an information exchange platform for nuclear scientists. Its design was so simple that Tim Berners-Lee's proposal was rejected several times by the management of CERN before it was recognized as useful [402]. The presumed weaknesses of the design became eventually its strengths. The design's simplicity and flexibility, the lack of a central coordination, the absence of authentication mechanisms or security made the system vulnerable, but also replicable on any computer connected to the Internet. The lack of a central content management system was at first regarded as a weakness. It made it difficult to find documents, due to a lack of directory structures. The problem of finding content was later solved in a much more efficient way by the emergence of powerful search 
engines. The simplicity of the hypertext markup language HTML enabled millions of users around the world to create web pages and publish their own content.

The lack of security in the Web's design has later been solved by others, who introduced encryption to secure data and enable commercial transactions and e-business on the Web. The exponentially increasing computer power, disk capacity and network bandwidth, following Moore's Law [277] of doubling capacity roughly every two years, made it possible to start massive exchange of data-intensive applications such as videos, games and music. The Web was continuously expanded and re-invented through the innovative and creative capacity of millions of users, developers, entrepreneurs. The open structure and flexible design of the Web combined with unanticipated use and re-invention of technologies made the Web become the largest human information network until present day: a platform for online shopping, for social interaction, for the exchange of home-made videos of cute cats.

\subsubsection{Evolution of a high-tech innovation: mobile}

Mobile telephony is the largest and fastest technological innovation ever deployed in developing countries. Currently, in Africa 81 out of 100 people have a cellular subscription, where this was only 4 out of 100 inhabitants in $2002 .^{2}$

Mobile phones can be observed, even in very remote rural areas. During our field trips from 2009 - 2018 in West Africa, we often spoke to mobile phone users in rural villages, where there is no electricity e.g. Zanlerigu, Yameriga, Tongo-Beo (Ghana), Ranawa, Minima Durga, Basi (Burkina Faso), Kokele (Mali). Despite the technical constraints, the majority of people use mobile phones on a daily basis. On the streets a dynamic eco-system of small-scale service providers can be observed: small shops where you can buy phone credits, (sap-sap), charge your phone battery in creative ways: with small solar panels, or car batteries. In Ranawa, Burkina Faso we met a 'mobile mobile' recharger, a person who traveled from village to village to charge phones with his motor cycle battery, which provides him with income. (Figures 77 and 78).

Anthropologist Lotte Pelckmans studied mobile phone usage in Mali. She described innovative ways in which the phone is used in Mali: "... an example of local contextshaping phone use in, for example, West Africa is the practice of 'flashing' (in French: biper). It entails calling someone with the sole purpose of making the phone ring, without expecting the other person to answer" [309].

The mobile revolution generated business in the formal and informal sectors in Africa. According to the GSMA3 Mobile Economy Report 2015, the mobile eco-system in 2014, provided 4.4 million jobs in the whole of Sub-Saharan Africa, of which 2 million were official resellers. This figure is probably a low estimate of the total number of

2 Source: http://www.itu.int/en/ITU-D/Statistics/Documents/facts/ICTFactsFigures2016.pdf, (accessed 08-10-2020)

3 GSMA is the Groupe Spécial Mobile, the world association of mobile operators. 


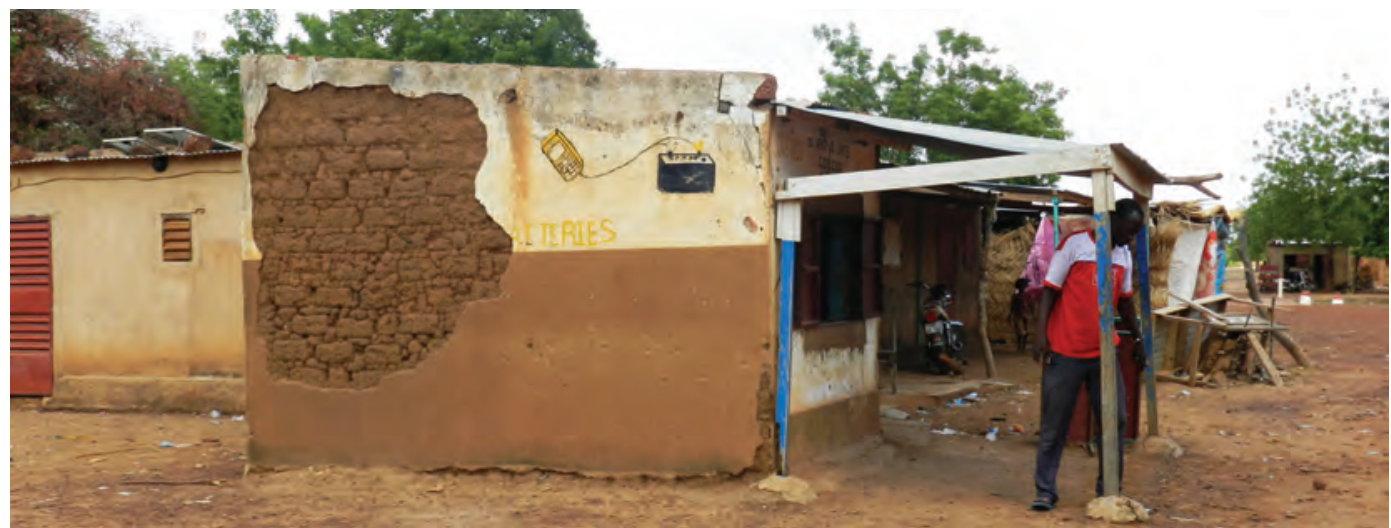

Figure 77: A 'mobile' entrepreneur in front of his shop, near Gourcy, Burkina Faso, June 2016.

jobs, if we consider the large, informal economy in developing regions: battery charging providers, second hand handset vendors and other creative street business that have emerged in the past few years [107].

Mobile telephony in Sub-Saharan Africa is not the same service as in e.g. Western Europe. While in industrialized countries $4 \mathrm{G}$ networks have massively deployed for SmartPhone use, in West Africa first generation - the simple voice-based GSM phone still accounts for $90 \%$ of connections ${ }^{4}$. Mobile service was subject of many adaptations, since it took off, in urban middle-class settings in the early 1990s [260], until it became accessible for low-income users in e.g. rural Africa.

Mobile telephony was initially positioned as a luxury commodity, an expensive complement to the fixed line phone [221]. Prices of phone handsets were high, more than 100 US\$. Subscribing to a mobile service required a contract, a mobile phone purchase, 12 or 24 monthly service obligations, usage charges, and a connection fee, including, often, a credit check to ensure liability of the customer [221]. Adaptations of the service towards low-income groups occurred gradually and iteratively. Once financial and technical barriers had been removed, roll-out took off in developing regions.

The introduction of prepaid SIM cards in 1992 was a remarkable (supplier-side) innovation in the mobile service [60]. Prepaid consists of an inexpensive SIM card (in Mali a SIM card or puce for the Orange or Malitel networks costs less than one euro, and can be purchased on the streets, without name registration, still in 2014). The SIM can be topped up with prepaid phone credits. The top ups can be small: e.g. 50 cents to a few euros. Prepaid allowed people without steady income to own a phone without subscription or contract.

The prepaid system, which consists technically of storage and billing software only, was first launched in Mexico in 1992 during the financial 'peso' crisis. Soon this proved

4 Source: GSMA report Mobile Economy Sub-Saharan Africa 2015, https://www.gsma.com/r/ mobileeconomy/sub-saharan - africa/, (accessed o8-10-2020) 

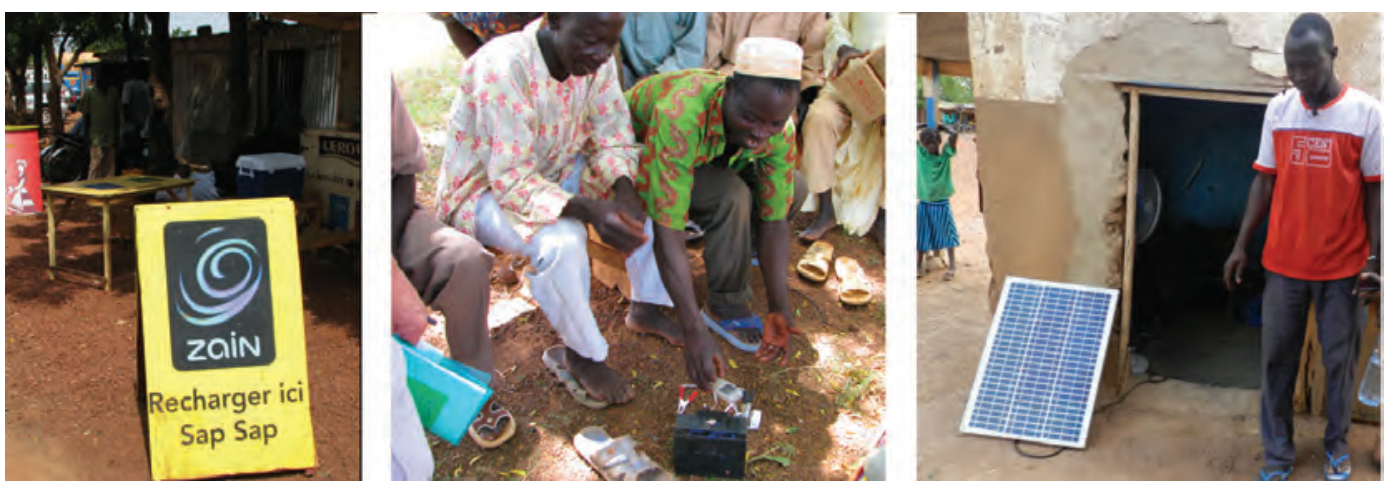

Figure 78: Mobile businesses in Burkina Faso, (left and middle: 2009, right: 2016.)

its value in other parts of the world. Apart from success on the user side, prepaid reduced financial risks for the mobile operators and the time-consuming distribution and billing tasks, leaving this to small local entrepreneurs and street vendors, which created new local (low-income) jobs. By 2006 the prepaid had become a leading mobile business model in the world [260].

Lack of electricity in rural regions was another barrier to mobile roll-out. For network operators it raises the investment costs for deployment of new GSM cells. The problem of charging the users' handsets was solved by local creativity, of mobile rechargers and other informal phone services (see e.g. Figure 78).

While several (technical, financial, organizational) barriers to mobile adoption were step by step removed, mobiles came increasingly in the reach of low-income users, first in urban and gradually in rural regions. The continuous migration between urban and rural areas in Africa may have contributed to the diffusion. Meanwhile, prices of GSM handsets (by Nokia, Ericsson, Motorola, LG, Samsung) went down. Small and large, formal and informal businesses entered the mobile market [221].

As became clear from various interviews we did with low-income users in Ghana, Burkina Faso and Mali, phone brought advantages of remote communication for those who had been hitherto unconnected. The technology was easy to learn and use, and affordable to a certain extent. The phone was used in creative ways, flashing, beeping to save credits. While mobile money was not yet introduced, sap-sap (transferring credit remotely from one phone to another) was used as a sort of payment channel by phone users in Burkina Faso, transferring credit to another phone as a payment ${ }^{5}$.

The number of phone users continued to grow in Africa, in the early and mid-20oos. Mobiles became more valuable when numbers of users started to increase, creating a self-amplifying feedback loops accelerating its diffusion (this network mechanism is discussed by e.g. Rogers (2003) [350], and Monge \& Contractor (2003) [275]). Because of the high cost of rolling out the GSM infrastructure in rural regions of Africa,

5 Personal communication Mathieu Ouedraogo, September 2009. 
while this roll-out depended on investments by the private sector (telecom operators), user adoption and network expansion occurred iteratively. Competition between mobile operators, induced by regulation authorities (which were established in African countries in the late 1990s) $)^{6}$ resulted in a competitive telecom market, with often four, five or more operators. This competition was an incentive to expand networks to rural regions. The forecasts for further expansion of mobile networks in rural regions in SubSaharan Africa are currently less optimistic. According to the GSMA report for Africa 2015:

"The majority of unconnected people in Sub-Saharan Africa live in rural and geographically remote areas. The main challenge to extending mobile broadband coverage to the unconnected is the cost of rolling out and maintaining network infrastructure in thinly populated areas where the majority of consumers are typically on low incomes... A factor limiting subscriber growth is the relatively weak business case for rural network rollout; low average revenue per user (ARPU) for rural consumers makes it hard to justify high costs of network deployment and maintenance in remote communities."

According to the GSMA, in 2014 the direct GDP contribution of the mobile ecosystem in Africa was 43 billion US\$ or 2,4 \% of GDP. This is calculated as the total income generated by the industry to its employees, through payment of wages, government taxes and shareholders (in the form of profits). From this amount $70 \%$ goes to the (multinational, mainly non-African) network operators. The other $30 \%$ goes to content and application providers, retailers, infrastructure providers and handset manufacturers.

As becomes clear from this brief account, the evolution of mobile telephony in Africa was influenced by different players, with different roles and interests. Its unpredictability is illustrated by the late recognition from the international development community $^{7}$. From the mid-2000s on mobile telephony was acknowledged by researchers and policy makers as transformative technology for development [3, 107, 218, 282, 324]. The history of mobile telephony in Africa illustrates innovation as a dynamic process with many contingencies, instead of a linear model.

One of the unforeseen impacts of mobile telephony was the emergence of another innovative service that appeared first in rural Africa: mobile money, which became a huge success for the private sector and therefore rolled out rapidly. These two innovations (mobile and mobile money) in the development setting are somehow connected, as I will discuss this in the next section.

6 Induced by neoliberal policies and the World Bank.

7 In the early 2000s, leading policy papers like UNDP Human Development Report 2001 [94] and the World Summit for the Information Society: http://www.itu.int/wsis/docs2/regional/outcome-accra. pdf, (accessed 08-10-2020), marginally mention mobile telephony as a tool for development, focusing mainly on computers and Internet. The WSIS Plan of Action (2003) and the WSIS documentation (2005) contain few references to mobile telephony. 


\subsubsection{Mobile money}

Another innovation that started in Africa, which illustrates the - often contingent interaction between networks of users and developers is mobile money. The widespread availability of mobile phones made this possible, as a critical mass of users is needed to make this service successful. The first mobile money service was M-Pesa (pesa is the Swahili word for money) a service which allows users to deposit money on a cell phone, and/or transfer it to other users of the service. It allows to cash it back to currency from a network of agents, airtime resellers and retail outlets acting as banking agents. Users are charged a small fee for each transfer. M-Pesa has become a banking service for millions in Africa who never owned a bank account before.

Mobile money was introduced in Kenya in 2007 by the local mobile operator Safaricom. M-pesa registered 1.1 million users in the first eight months after its inception, while an amount of US\$ 87 million was transferred over the system. By September 2009, 8.5 million Kenyans had registered to use the service. In 2013 this was 17 million, two-thirds of Kenya's adult population ${ }^{8}$ [266].

After the success of M-Pesa in Kenya, new mobile payment systems popped up in many other countries in Africa, offered by other mobile operators such as Orange, Vodafone, Airtel, MTN.

The diffusion of mobile payment systems was a spin-off of the mobile revolution. The advantages perceived by users were: the ability to store and transfer money at distance - e.g. remittances [318], the perceived compatibility with existing values and payment habits, its simplicity to learn and operate, its triability and observability using interpersonal communication channels [350].

Mobile money has shown social impacts. According to Mbiti and Weil "only a decade ago, family members in different parts of Kenya had a very limited scope of communicating with relatives from distant parts of the country, and faced difficulties in sending and receiving remittances. Now, in many cases, money can be transferred almost instantaneously". M-Pesa has enabled small businesses to expand and has increased the circulation of money in small communities [318]. The cases describing the emergence of mobile service and web show the role of users and their unanticipated ways of using technologies. It also shows how manufacturers and service providers adjust their marketing strategies according to progressive insights into users' preferences.

The above examples of mobile telephony and mobile money show that high-tech technologies can rapidly spread, also in a very constrained low-tech environment. The success of mobile telephony has often been used as an argument why ICT $4 \mathrm{D}$ should work, and why the Internet should be rolled out by the private sector, as happened with mobile services - and if necessary with financial support from the public sector.

At the customer side, diffusion will only occur when certain conditions are met the new technology brings a relative advantage; its compatibility with local practices such

8 Source: http://tinyurl.com/o59nw6t 
as language, illiteracy; its affordability, etc). At the supplier side the provisioning only occurs when a technology can be easily deployed and scaled up, and when the average revenue per user (ARPU) is sufficient to justify investments for scaling up, against quick profits (at the so-called "fortune at the bottom of the pyramid" [324]) which are in it for the private sector. In case when higher investments are needed to kickstart the innovation process, the international private telecom sector no longer acts as a vector for innovation. In that case public investments and $\mathrm{ICT}_{4} \mathrm{D}$ research are needed.

The two examples of closely related innovations in Africa: mobile phone and mobile money (the widespread availability of mobile phones made this possible, as a large number of users is needed to make mobile money successful) illustrate the - often contingent - evolution and spread of these innovations, in line with the complexity model of innovation diffusion [350, 351].

\subsection{TWO-WAY COMMUNICATION: DEVELOPERS - USERS}

Using the linear model of innovation, one assumes that the source of innovation is 'upstream', at the loci of the inventors, researchers, developers or manufacturers [402, 414, 415]. With this model a physical or conceptual (geographical, cultural) barrier is drawn, between the upstream (inventor/manufacturer) in the wealthy Global North and the downstream (passive customer, user, beneficiary) in the 'receiving' or developing country. This implies that there is only a one-way information flow, downstream. A two-way interaction-interface between developer and user is not considered in this model. As a consequence, the information from communities of users is not used for (re-) design or further development. It does not feed the inventor with new contextualized knowledge.

Also in ICT/software development projects in the western world, a one-direction linear approach, named the waterfall model, was widely used. In the 1960s and 1970s this was the common approach to centrally plan and control software development projects $[117,395,175,343,424])$. The waterfall model is still used in many software development trajectories in large firms and governments.

Over the years, the linear waterfall model - in which the information analysts and software engineers talk mainly to bosses and project managers, but do not have access to the actual users - has been held responsible for high rates of failure in large-scale ICT projects. Failure is attributed to lack of real end-user involvement. This leads to incomplete requirements/specifications, because user requirements tend to change during the development process $[248,254]$.

From the 1990s on, adaptive, iterative methods have been introduced in software development as a response to high failure rates of linear models [175, 343, 424]. Usercentered spaces of innovation have become fashionable, such as living labs [203, 182]. Users are involved in early stages of the design process. They are observed in their own natural environment, performing normal tasks which are difficult to explain in words, 
but easy to demonstrate on the spot. Creative techniques such as rapid prototyping and extreme programming are often used[412]. These are methods for building prototypes or demos in a short time span (e.g. one day), sometimes even in the presence of the end-user, to show them the basic idea and check if the requirements have been well understood by developers and users.

Another improvement in software development is the introduction of self-organizing teams. These teams are usually non-hierarchically organized, team members have high commitment and team spirit and creativity are highly valued. An example of this method are scrum teams (a term borrowed from rugby) [346]. These methods are usually grouped under the large umbrella of agile development methods. [117, 395]. Agile methods are a set of principles how innovation and software development can be done, rather than a suite of cook-book recipes. Adaptation to context and end-user involvement are central to agile methods. Agile methods are widely used in ICT projects in western countries $[259,388,387,236,172]$. However, in the execution of international development programs and projects, including $\mathrm{ICT}_{4} \mathrm{D}$, agile methods are still uncommon.

\subsection{UPSTREAM - DOWNSTREAM}

As previously remarked, in innovation for development - including $\mathrm{ICT}_{4} \mathrm{D}$ - the gap between the upstream development and downstream 'passive adopter or user', has as implication that it tacitly attributes a 'superior' role to 'western' technology and 'scientific' knowledge, in comparison to downstream, indigenous knowledge and innovation capacity of local communities. This attitude is observed in many domains of innovation for development $[79,77,59,350,338,82]$. As a consequence, local knowledge and context are often overlooked by the development experts.

An example of a typical linear innovation project that failed because of overlooking local knowledge systems, occurred in Bali, Indonesia, during the Green Revolution [240]. The Green Revolution was a global-scale intervention program, rolled out in Asian countries in the 1970s [321]. It aimed at increasing food production for growing populations through a rapid introduction of genetically modified seeds, fertilizers and pesticides, at very large scales [240].

In Indonesia and other Asian countries, the Green Revolution was a nation-wide operation supported by the international community and the agro-technology industry [321]. It consisted of large-scale transfer of technology, aimed at speeding up and facilitating the transition from subsistence farming to intensified agriculture. The approach was typical for large-scale interventions without any notion of adaptation to specific local conditions [380, 162]. For example, in Bali, farmers were summoned to abandon traditional farming and use new, subsidized technology packages that were available through extension services [240, 241]. 


\subsubsection{Traditional knowledge in Bali}

Shortly after introduction of the Green Revolution, rice harvests in Bali were plagued by increased pest outbreaks [240]. Rice harvests were seriously threatened and damaged. Balinese farmers complained that new development plans were creating unprecedented problems in water scheduling and pest control [244].

In 1983, two researchers, Stephen Lansing and James Kremer discovered an ancient system of wet-rice farming in Bali, which was coordinated in a distributed way by cooperating rural communities, named 'subaks'[240]. This complex agro-ecological system consisted of an intricate system of canals, rice terraces, and irrigation works linked to a network of water temples and shrines. Through a symbolic system of temple rituals, the cooperating subaks were able to coordinate complex tasks in their production of rice and pest control, including allocation of irrigation water, and scheduling of seeding and cropping [241]. The temples and shrines, dedicated to the Goddess of the Crater Lake and other local agricultural gods, and their religious events and feasts, were pivotal in the effective management of water and the synchronization of cropping and harvesting calendars between the various rice paddies and subaks [240].

The study by Lansing showed how the complete system had been developed over the course of centuries by cooperating farmers who gradually engineered the landscape of their island, cleared the forests, dug irrigation canals and terraced hillsides to grow irrigated rice. Doing so, the subaks succeeded in optimizing production and created resilience in the ever-changing environment, in the absence of a central controlling mechanism [240, 241]. In parallel to the physical labor, they constructed networks of water temples and shrines [242]. The system of ritual technology had remained unnoticed in the scholarly literature about Bali, until the sudden disruption of the whole system, triggered by the rapid introduction of new agricultural systems through the "Green Revolution" [240].

Development agencies, not aware of the role and complexity of the ancient agroecological systems had blamed the resistance of the farmers (to adopt the new agrosystems) on conservative religious ignorance. One statement made on an occasion by an agro-specialist was: 'These people need a hydrologist, not a priest!' [240].

Stephen Lansing used cultural and historical analysis, supported by numerical simulation, to understand the complexity of the interdependent variables and feedback loops of human agency and the natural environment [216, 242]. The coordinating role of the temples in irrigation and harvest planning, was demonstrated in a computer simulation [242].

At last, evidence from the study of Lansing convinced donors and experts, including the Asian Development Bank, of the importance of the local knowledge and the effectivity of the ritual technology of the subaks [240]. The old wisdom, which had not yet been destroyed, could be reactivated. The subaks restored their cropping calendars and coordination schemes through the water temple networks. The rice production 
was restored and pest outbreaks were contained. Unfortunately, not all modern agriculture measures were abolished, and chemical fertilizers, introduced during the Green Revolution, continued to pollute the water systems for a long time [243].

This case of the subaks in Bali illustrates how interventions, based on linear innovation methods, technology transfer, and assumptions about the superiority of 'modern' technology with respect to the 'downstream, traditional, indigenous', often fail to see local agency, community-based, collaborative knowledge production and the embeddedness of culture and meaning in everyday technologies.

\subsubsection{Farmer innovation in the Sahel}

Another example of large-scale local innovation within a social system, is the case of Regreening in the Sahel. The context of regreening is a social/ecological system, in which local actors operate, driven by the need to improve their livelihoods [336]. Without a centrally managed intervention, localized groups communicate with each other, share knowledge, and strive to solve local problems through local innovation (e.g. $[338,377,280]$.) Innovations here are not high-tech, but simple traditional practices, that are reinvented and diffused within the social networks of the communities. The reason for adoption of local innovations such as stone bunds and zaï, are that these innovations solve a real problem, while being easy to implement, manual and inexpensive [219, 339]. The increase of on-farm trees is slow, as it takes a few years to have large trees $[345,344]$, but impacts are visible, and the innovation propagates steadily through the communities [336, 337, 339, 423].

In many rural regions of Africa, farmer-innovations, cross-learning and joint experimentation have been identified, and have been shown to be wide-spread [338, 398]. These examples of indigenous experimentation and knowledge are practiced by young and old, poor and wealthy, men and women farmers [303]. The operational goal of innovators is to improve farming, increase production, and create more resilience for families and communities [156]. Many farmers are open to share innovations. The status of farmer-innovator creates esteem in the community [396]. Innovation is communitybased and emerges from collaboration through social networks and joint learning [289].

The cases described in this section are examples of indigenous knowledge networks. These local social networks are often overlooked in top-down development interventions and mainstream technology transfer projects, as illustrated in the case of the subaks.

\subsection{INNOVATION, KNOWLEDGE, AND SOCIAL NETWORKS}

In a world full of ideas, technologies are seldom the work of one single heroic inventor. Many studies have shown how it is not the scientist or engineer, but the user, who invents a product $[338,415,402,143]$. 
In the example of Regreening in the Sahel, farmer-innovators experiment with certain, indigenous techniques which are further diffused, adapted and adopted by others in his/her local community $[338,186]$. The emergence of innovations depends on resources that are accidentally available, whereas users give meaning to the innovation in their social practice $[268,82,225]$. Tuomi defines innovation as something that generates and facilitates change in social practice ([402], p. 11).

Innovation does not emerge in isolation. It takes place in groups, teams or communities $^{9},[293,370,338,402,350]$, in so-called innovation networks or knowledge networks $[402,275]$. As knowledge networks are a special type of social networks in which actors exchange knowledge, we briefly a look at the definitions of these concepts in literature.

\subsubsection{Knowledge networks}

We define knowledge as the body of data and information that people bring to bear to practical use in action, in order to carry out tasks and create new information [370]. According to this definition knowledge is not universal, but domain-specific, only understandable in relationship to other knowledge concepts [249].

Knowledge networks can be small or big: organizations with only a few agents, up to global size as e.g. the World Wide Web [275, 95]. Knowledge in a network is exchanged or diffused, as to increase the level of knowledge among all agents. In some cases, collective knowledge can remain in certain nodes, while some agents possess relatively unique, non-redundant knowledge. The latter configuration will enable a network to accomplish work collectively, through division of tasks [275]. Knowledge networks are dynamic in terms of actors and links: people join or leave a knowledge network on the basis of interests, resources, and commitments [275].

\subsubsection{Innovation networks}

Tuomi studied a special type of knowledge networks, i.e. innovation networks. These are social networks where knowledge is exchanged amongst its members who are driven by a purpose, a common goal to solve a problem [402]. The innovation networks described by Tuomi are not hierarchically structured, and not confined to a single organization. Knowledge creation in these networks is not a meta-process of obtaining 'information about information' [370], for the sake of curiosity, but purpose-driven, to bring knowledge into practice.

Typical examples of knowledge networks are global communities of ICT developers that organize themselves around an open-source project such as Wikipedia, open source learning environment Moodle, or open-source operating system Linux. What makes these networks interesting examples, is the fact that they exist in cyber-space,

9 We use the term 'community' here for a socially integrated group. 
so they are easy to observe, and they are a new phenomenon, as they use the Web as their communication platform.

The development of Linux as innovation network was subject of a detailed case study by Illka Tuomi. The development of this system was not driven by economic motives and was done by voluntarily participation of developers from all over the world, who devote their free time to it [402]. As can be seen in the Linux community, this knowledge network has a core team or even a core community, which can be described as the locus of innovation. It is here where the idea initiated. The core team acts as the gatekeeper of the core technology, but they do not exert direct control over the innovation process [402]. There is a large periphery of developers who are concerned with the less vital or more peripheral parts of the system. The periphery itself is divided in many smaller sub-communities.

Innovation networks as the Linux community are not hierarchically organized, as in commercial organizations [402]. Yet, there is an (informal) internal social control system, that emerged spontaneously from the communication structures in the network, that prevents development of the system to become unmanageable. To keep this complex socio-technical system alive, despite the great number of collaborators, the system's design has to be modular, so that each sub-community can work on a distinct part, without destabilizing the whole system or disturbing the work of others. Without a predefined masterplan, Linux continues to expand and improve itself by the constant work of developers all over the world, who communicate, experiment and share knowledge in many online forums, gradually increasing the total amount of knowledge about the technology itself and about its development process [402].

Apart from the special characteristics of an open-source online development community (working globally, using the Web as platform, developing at high speed), the overall process of experimentation, knowledge sharing and self-organization is not restricted to high-tech environments only. There are various case studies of community innovation in e.g. low-tech rural Africa, where experimentation takes place, ideas are exchanged, adaptation is done, improvement of the ideas or artefacts, within the communities, and ideas from outside communities are fed-back into the innovations, and social coordination is done $[338,98,280]$. The importance of partnerships, crosslearning and re-invention are shown in many studies [350, 407, 280].

In the adaptive approach people from different backgrounds collaborate to achieve a common goal. The community consists of ICT developers and illiterate farmers, local extension workers, sustainable management experts, requirement engineers, information analysts, local radio journalists. Co-creation workshops are the loci of innovation. Here the generation of ideas, the modelling of information, construction of prototypes, the exchange of knowledge and creation of knowledge take place.

The community is driven by a joint objective to improve a situation or solve a realworld problem, expressed by people, through design and construction of a useful technology. The knowledge to do this is initially not available in the team, and has to 


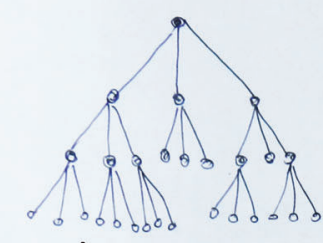

A.

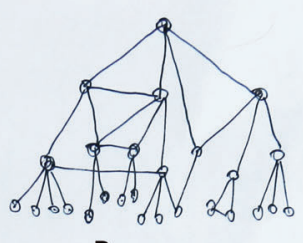

B.

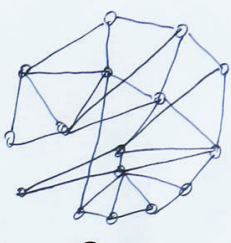

C.

Figure 79: Model of three types of organization: A. hierarchical structure: low complexity B. hierarchical with some cross-links: intermediate complexity C. networks structure: high complexity. Adapted after Yaneer Bar-Yam 2004, Making Things Work: Solving Complex Problems in a Complex World. Knowledge Press, p.66 [16].

emerge from the exchange of knowledge between different team members, from experimentation and social learning during the process. This is an iterative process with many short cycles. Physical proximity is important as this speeds up the innovation process and motivates the participants to find the best solutions. Communication cycles are therefore short. There are different experts and roles in the community. There is a core team who loosely manages and keeps the process alive, as the larger community acts as a self-organizing network, without a hierarchical structure.

\subsubsection{Problem-solving capabilities of innovation networks}

According to complexity researcher Yaneer Bar-Yam, an organization (or a knowledge network) is only able to complete a complex task, if the level of complexity of that organization equals the complexity of the task. To measure a difficult concept as 'complexity', Bar-Yam uses the following heuristic: complexity can be quantified as the number of words which are needed to describe a certain concept. The more words are needed, the more complexity [16].

Using this rule of thumb Yaneer Bar-Yam estimates that one would need an amount of data equivalent with the capacity of 1o DVD's in written text to describe the tasks of a CEO of an organization on one single day [16]. That seems much, but obviously the amount of complexity increases with the size of a knowledge network in which all actors exchange knowledge, with the goal to solve a technological/scientific problem.

In hierarchically organized organizations, see Figure 79 A, the information flows are only vertical. The complexity which can be tackled is theoretically that of one person only. In practice, organizations are not strictly hierarchical, but hybrid like Figure 79 B. In Figure $79 \mathrm{C}$ a fully networked organization is shown. There are many more interactions. This type of organization structure is much more complex, and can tackle a much higher degree of complexity.

This model, shown from a complex system approach, supports the idea that innovation networks, where more people participate and more knowledge is exchanged, 

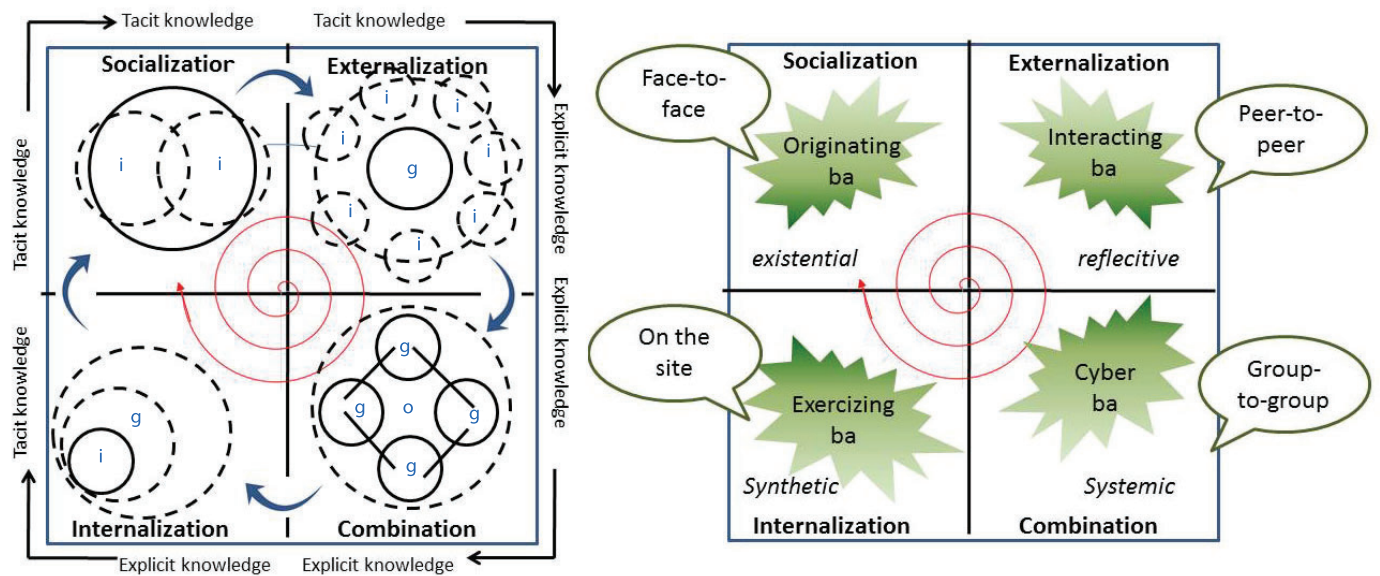

Figure 80: For each type of knowledge exchange, different ways of communication are applied and this occurs in different (physical, virtual) spaces of innovation (left); The four characteristic of Ba (right). Reprinted from: Ikujiro Nonaka and Noboru Konno. "The concept of Ba: Building a foundation for knowledge creation" California Management Review 40(3): 40, p.43 and 46, 1998 [293].

have a higher capacity to innovate and find better solutions than in the case of linear innovation, when knowledge production is considered the task of a small group of developers only. The networked model is used in Open Innovation (e.g.[89, 90]).

\subsection{SOCIAL LEARNING}

As discussed above, knowledge exchange is important for innovation. In the case that innovation teams consist of people with similar backgrounds, expertise, culture and language, knowledge exchange is easier to achieve than in very heterogeneous groups.

But since heterogeneity is the common situation in an 'innovation for development' setting, the process of knowledge exchange has to be well organized, and effort must be put into this aspect. This is the social learning aspect of innovation.

According to theories about knowledge and social learning, knowledge can be either tacit or explicit [293, 15]. Tacit knowledge is informal and intuitive, residing in people's heads, sometimes even without being aware. People may very well know-how to bake a cake, drive a car or play the second horn concerto of Mozart, but they often find it difficult to explain how they actually perform these tasks. Tacit knowledge can be technical - related to skills, know-how and practice experience - or cognitive - related to beliefs, values, intuitions and mental models [293]. Depending on the nature of knowledge exchange (tacit or explicit) there are different modes of doing this. 
Nonaka and Konno proposed a framework ${ }^{10}$ for knowledge exchange: from tacit to tacit, from tacit to explicit, from explicit to explicit, and from explicit to tacit [293]. For each type of knowledge exchange, different ways of communication are applied, as conceptualized in Figure 8o. The (physical, virtual) proximity (space) in which social learning occurs is important for exchange of tacit knowledge. In our case study this is the physical location of the workshop, in the region where the users live. Explicit knowledge (from explicit to explicit) is easier to transfer and can be done via e.g. email, websites, written documentation, film, audio. The space where innovation occurs is very important for knowledge exchange. Nonaka refers to this (physical, virtual) meeting space of innovation as "ba", a concept from the Japanese epistemological tradition, [293].

\subsection{ICT4D AS A KNOWLEDGE-EXCHANGING INNOVATION NETWORK}

During our field work in West Africa, elicitation of information and knowledge of the users was part of the needs assessment and use case and requirements analysis of the $\mathrm{ICT}_{4} \mathrm{D} 3.0$ approach 70. A number of farmers - domain experts in their work, farming or pastoralism in their own environment - who participate in the co-creation workshops are illiterate. Their knowledge has never been written down and can therefore be considered tacit. During a workshop we organized in April 2014 in Ouahigouya, Burkina Faso, Ousséini Zoromé was one of the participants. He said in Mooré language: "The farmer-innovator has the knowledge and the know-how, and he wants to share this with his community".

\subsubsection{Socialization during field visits and workshops}

The first technique used to obtain the tacit knowledge from the farmers is socialization. This is the transfer of tacit knowledge from one person to another, by observing, being together in the same space, working together. This was organized through field visits to rural communities. Walking together in the fields and observing users in their own working context provides tacit information to the developers' team. During roadshows and workshops there are frequent field visits to several farming sites, or to local radio stations or small factories. This gives the developers' team knowledge of the local context. Developers' teams are often 5-8 people. These recurring field experiences create a shared group memory and understanding of the (new, unfamiliar) local context, for the developers' team. This type of social learning (tacit to tacit) is called socialization $[293,370]$. Figure 81 shows how socialization is done during field visits with a group of ICT developers and farmers.

10 The SECI (Socialization, Externalization, Internalization, Combination) conceptual framework of social learning, by Nonaka (1998) [293]. 


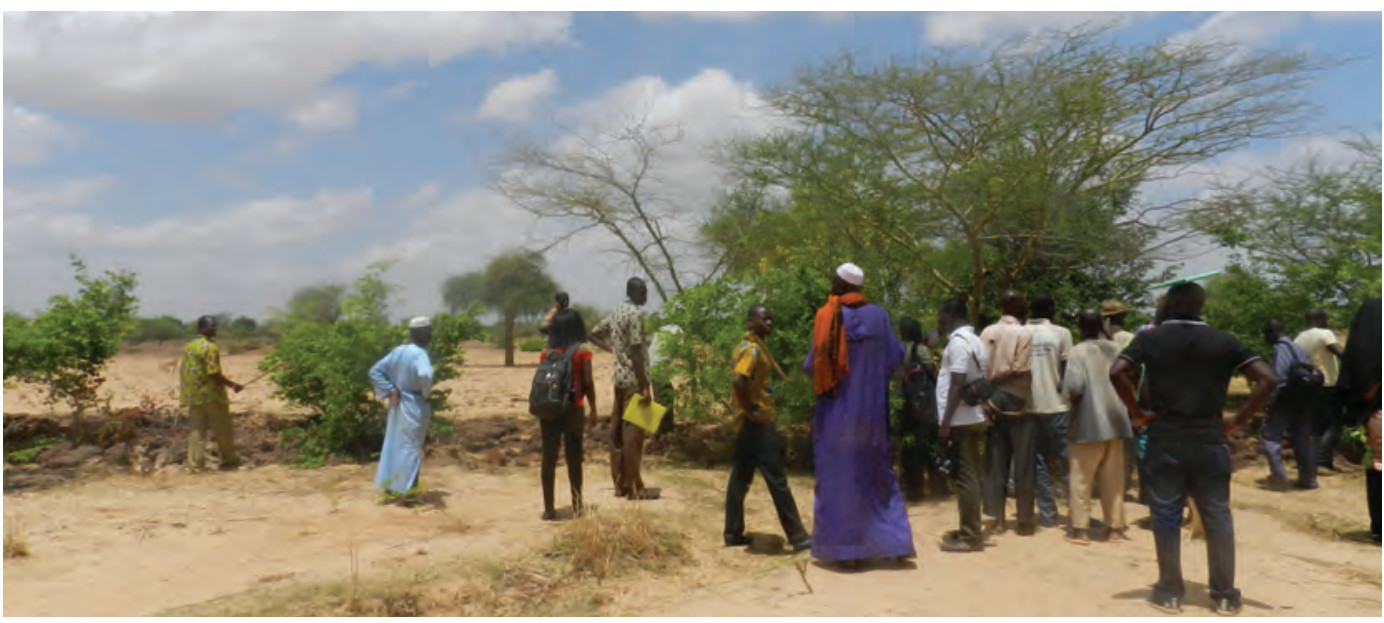

Figure 81: Field visits are organized to exchange knowledge that is difficult to understand without seeing the context.

\subsubsection{Externalization through writing, modeling, structuring the knowledge}

The second step in the elicitation of local knowledge is to capture tacit knowledge from the users and make it explicit. Photos, video images and recorded audio help to capture the information. Use case and requirement analysis techniques provide a structured approach to capture the requirements of a technological solution, and make them explicit [248, 254].

Capturing local knowledge involves focus group discussions, interviews, group assignments, groups presentation, semi-structured questionnaires, and long dialogues. It is done with groups of users and other stakeholders, usually business partners. Since there are different languages, there are always translators, from local language, (Mooré, Bambara, Bomu) depending on the region, to French (in Burkina Faso, Mali) or English (in Ghana), sometimes even to Dutch. An example of this type of knowledge production (a requirements analysis workshop) is shown in Figure 82.

The tacit knowledge obtained by the developers' team can be seen as a form of context knowledge, this is tacit, and difficult to capture in text. However, this knowledge is crucial for the technological development. All core team members who are involved in the co-design, must have this field experience. This is an essential aspect of the approach to $\mathrm{ICT}_{4} \mathrm{D}$.

The next phase consists of needs assessment and the collection of key ideas. This involves mutual learning, as the local users must become familiar with technology and ICT. This is done by demos and users testing certain prototypes, to give them a look and feel of an application. These techniques also involve tacit knowledge and are part of the socialization process of social learning. 


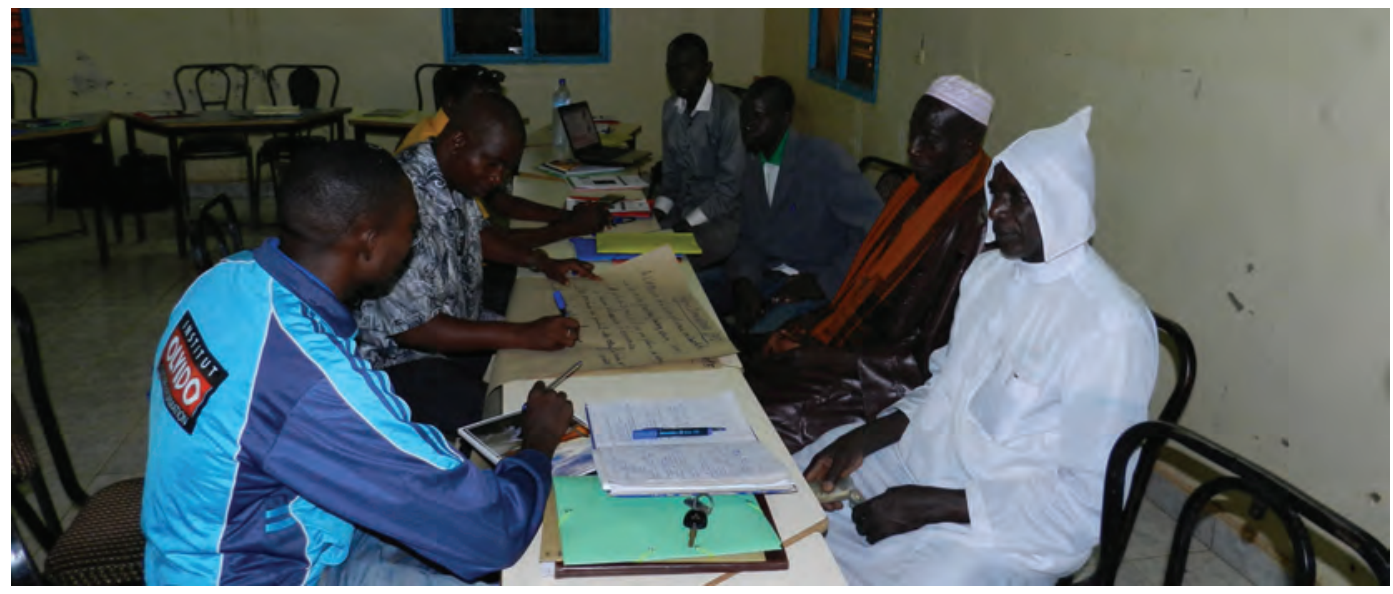

Figure 82: A group of farmers-innovators from the Zondoma and Yatenga regions, Burkina Faso, during a requirements engineering workshop, June 2016, formulating their information needs.

From these social learning sessions, ideas are generated, by the users. "We want a system that gives us information on the weather, accessible on our phones." We would like to have a way to diagnose diseases of our cattle. We would like to have an alert when it will storm." All these ideas are collected and structured formally into a usecase format. This type of capturing and structuring the ideas is referred to, in the SECI model, as "externalizing" (see Figure 82).

Having collected a list of ideas and selected which one to further develop, the exact requirements have to be sought. This is again a process of information elicitation. This is often done using informal scenarios, story boards or conceptual models. There are several iterations, to make sure users and developers understand the design of a technological solution and all its requirements.

All the information collected about the requirements is modeled using formal and informal, conceptual methods. Conceptual modelling stems from the tradition of ontology engineering, requirements engineering, design science [4]. Conceptual modelling comprises the activity of formally defining aspects of the physical and social world around us for the purpose of understanding and communication [283]. Conceptual models, either formal or informal, are powerful communication tools, as they can clarify certain complex processes or information that is difficult to explain in words.

Formal models are designed as UML diagrams, and conceptualize certain aspects of the solution or workflow. Together with questionnaires, they are used to store all information in a structured way. Formal methods are often used for further development or technical specifications for the ICT-developers and software engineers. Informal models such as story boards, scenarios, narratives, films, are useful for communication between developers and users, to make sure that there is a shared understanding of 
the technology and its design and requirements. This form of social learning is called externalizing [293]. It is a form of converting tacit into explicit knowledge.

\subsubsection{Combining various sources of knowledge}

The actual design of a technological solution requires a combination of different types of knowledge. This is also a crucial aspect of ICTD and innovation for development, as it provides the combination of local and non-local knowledge, i.e. technical ICT knowledge and user requirements, which reflect the work, tasks and context of the local users. It entails the act of integrating, analyzing, disseminating, reorganizing explicit knowledge.

The new knowledge is a result of recombination of existing knowledge (e.g. how to design ICT systems, how to analyze and model information, how to plan cropping calendars in rural Mali, how to diagnose chicken disease, how to prototype and build a voice application and deploy it on a voice-based platform).

An example of a form of recombination of knowledge (explicit-explicit) is shown in Figure 83. Master students in the ICT4 $\mathrm{D}$ course at VU, working on use cases that were collected and elaborated by the W4RA team together with farmers in Ghana and Mali.

In the case of RadioMarché the combination of knowledge on speech technologies, knowledge on database and interface programming, knowledge on the seasonal availability of non-timber forest products in Mali and knowledge of Bambara and Bomu languages made it possible to build the system. Since there is no person in this world with this specific combination of expertise, the construction of RadioMarché is a unique example of a combination of local and non-local knowledge, through collaborative innovation. This type of knowledge transfer, explicit to explicit, is called, according to Nonaka's SECI model: "combination" [293].

\subsubsection{Internalizing the new knowledge}

As the last of the four, there is the internalization of knowledge, the act of learning, and embodying explicit knowledge into one's mind through action and practice and through a process of meaning creation. This is another aspect of knowledge exchange in innovation, as it relates to group identity, and provides meaning to the technological innovation. Internalizing can be described as a way of converting explicit knowledge into "tacit". This is the social, non-materialistic aspect of the technological development within an innovation network. This will be discussed in the next section. 


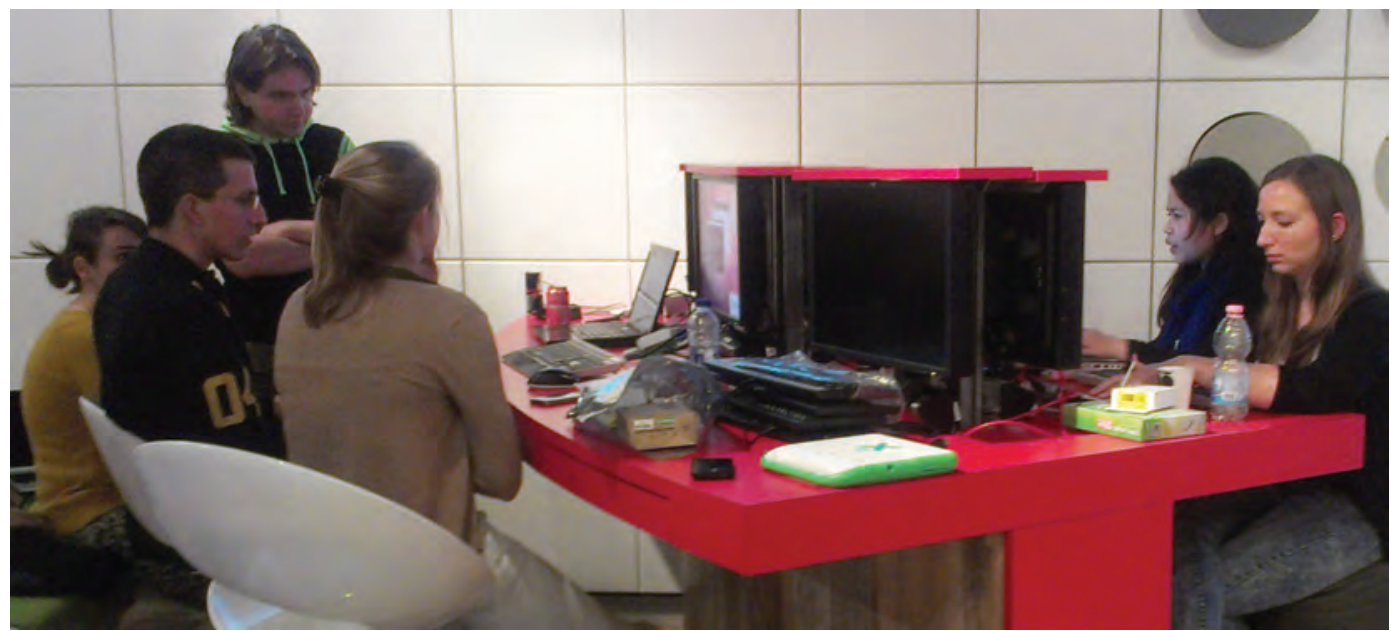

Figure 83: A group of students and supervisor at VU, building systems for farmers in Ghana and Mali, during the $\mathrm{ICT}_{4} \mathrm{D}$ course in May 2014.

\subsection{INNOVATION, MEANING AND CULTURE}

The entanglement of technological innovation with culture and symbolic meaning has been shown in various studies (e.g. [82, 240, 60, 311, 309, 386]).

Communication scientist Anita Chan studied this for popular cultures in Peru. Chan focuses on the rituals, ceremonies and other meaningful expressions that surround communities of techno-innovative youngsters and hackers in Peru who are creating alternative learning and research sites, as they say 'to bridge technology, art, and society' [82].

Chan describes how digital communities of technicians and teachers jointly embraced the OLPC program, which by 2008 was massively rolled out at primary schools by the Peruvian government, without any support or implementation plan. Chan shows how local community-based initiatives took off, created content and translated the existing content of the XO laptop of OLPC into the local indigenous languages Quechua and Aymara. She describes how face to face meetings of local ICT developers' teams took place, and local ceremonies were held, with prayers to local spirits, as meaningful expressions of the uncertainties surrounding the ICT deployments and other technological developments. Chan points at the untapped and unexplored innovation capacity of the peripheries - sites in developing regions - with respect to the incumbent, elite design centers [82]. Quoting Anita Chan:

"... gray markets of digitized local music and pirated films fill multi-story buildings, and street markets of used, recycled, and reassembled computer parts and people meet at local Internet cafés. Such technological hacks and local improvisations are an everyday part of the periphery's technology landscape [82]." 
Through the images of vibrant contemporary Peruvian socio-technical culture, in what Chan describes as networking peripheries, she shows the role of community and their cultural, meaningful expression in the use of technology in daily practice and its embeddedness in local context. Chan also shows how, in these peripheries, technologies are appropriated by local communities and reinvented and embedded into local culture [82].

Inge Brinkman and others studied the social and cultural meaning of mobile phone in the streets of Khartoum, Sudan, and made this observation: "The function of status marker related to the mobile phone has shifted to middle-class residents and even to those on low incomes. They save up to buy the latest model, decorate it with lights and other accessories, equip it with fancy ring tones and wear their phone conspicuously on their belt." [6o].

Another study on mobile phone use in Africa, by Julia Pfaff, also demonstrates 'meaning' which is attributed to a technological device: "It is evident that the mobile phone is much more than just a tool for calling, text messaging, music, photos and phone numbers. It is the device itself as well as its attributes that play a role in processes of individual expression and identification. The relationship of the Zanzibari woman to the phone and the phone as 'imagined adaptability', 'temporary enjoyment' and 'bongo life' point out how the mobile phone works to demonstrate the importance, financial situation, style and 'trendiness' of its user "[311].

Lotte Pelckmans did extensive field research on the use of mobiles in Mali. She describes the variety of cultural codes that have emerged, regarding the use of the mobile phone:

"A Malian phone credit seller explained that flashing [letting the recipients phone ring once or twice without making a call] could be compared to tapping someone's shoulder or winking at them as it is a means of confirming and/or reminding the other person that you are friends (qu'on est ensemble) [...] In Mali when someone flashes someone who is clearly better off, more often than not the flash is no longer a metaphorical 'digital blink' but should be interpreted as a request to phone back. The one considered to have money at his disposal is thus put in the position of the 'credit caretaker'. [..] Some flashers are so persistent that new strategies to avoid them have emerged: taking several numbers with different companies, changing one's phone number regularly or giving a wrong number." [309]

In our case studies in West Africa rituals, social practices and symbols played an important role in the formation of shared experiences in the multi-cultural team. This gave meaning to the partnership and to the technological innovations that were built. This is expressed by the use of logos, the names of ICT services in local language, given by the local partners: Foroba Blon in Bambara language (the space where one can speak out), Tabale (the king's drum in Mali), Raas Kibaya in Mooré language (market information). Visits to village chiefs, opening ceremonies of workshops, group pictures, T-shirts with project logo, are all expressions of a self-created group culture, 
that can be seen as the social, non-materialistic aspect of the technological development within an innovation network.

\subsection{SUMMARY}

In this chapter I have taken networked complexity as a theoretical lens to observe the dynamic processes in a given development context, and to explain how a networked approach to $\mathrm{ICT}_{4} \mathrm{D}$ makes it capable of coping with this complexity. Various examples of innovations show how the adoption of technologies fundamentally deals with innovation and its diffusion. This occurs in complex, nonlinear processes of change, in which knowledge and information propagate through social networks and contextual factors come into play. A networked approach means two-way knowledge sharing = collaboration between various stakeholders, including ICT developers and users. This underpins the need for an adaptive process of socio-technical innovation (to fit the variety of contextual requirements), collaborative (to encompass as many viewpoints and knowledge domains (academic/non-academic) as possible on the subject and context), and iterative (because of learning cycles). 
"Be Collaborative", the ninth Principle for Digital Development [417], is not an issue to be solved at the technocratic level only. It requires a debate at the policy level. In this chapter I want to reflect on what the ICT $4 D$ researcher can do to include a critical, normative element and engage in the Development Debate. We discuss how the ICT 4 D 3.0 framework relates to policy issues and debates, and compare it to other frameworks.

\subsection{THE VALUES AND INTERESTS DIMENSION IN ICT4D}

As discussed in Chapter 1 , "Be Collaborative" is the imperative of the community of international development donors and multilateral organizations to the community of $\mathrm{ICT}_{4} \mathrm{D}$ practitioners [417]. Yet, is this something to be solved at the operational level only?

To clarify this question, we take a look at e-Choupal, a development project in rural India, to "serve the world's poor, profitably" [323, 324]. As one of the largest ICT for rural development projects in India, it seeks to combine poverty alleviation with profit for the private sector. e-Choupal is an initiative of ITC Limited, one of India's leading agriculture firms. The project received international awards for furthering the Millennium Development Goals and contributing to economic development in rural India. $^{1}$

The e-Choupal project is prototypical for the free-market ideology, which, according to the advocates of appropriate market interventions, can help private businesses make profits, while achieving poverty alleviation at the same time: (cf. "as the poor get richer, they buy more of the goods and services that industrialized countries produce, ensuring a benefit to all from poverty reduction" [194]). However, detailed field evaluations in Utter Pradesh, India by independent researchers revealed that poor farmers had been disadvantaged by the intervention. A perceived increase of social and economic inequalities was attributed by local farmers to e-Choupal [413].

e-Choupal shows how $\mathrm{ICT}_{4} \mathrm{D}$ can lead to diverging interests between the private sector and the supposed "beneficiaries". One of the prominent scholars in the academic field of poverty and development, Nobel-prize winner and economist Amartya Sen, (often quoted in $\mathrm{ICT}_{4} \mathrm{D}$ literature e.g. [232, 161]), envisages a world of "reasoned social progress" [376] (p.279), in which well-informed individuals contribute to policies that promote a just and prosperous society in the context of free speech and free markets [364]. A critical question here is whether "the poor" are well informed, whether the

1 Source: http://tinyurl.com/empowering - farmers - echoupal (accessed o8-10-2020) 
information provided to them is relevant and unbiased, whether it can be criticized and verified, and whether it will provide them with capabilities.

Decision-making in $\mathrm{ICT}_{4} \mathrm{D}$, according to democratic values that are loudly claimed by our modern Global North society needs to be inclusive and involve all stakeholders - also the voices of the people who are often referred to as the "bottom of the pyramid" [324].

Considering the fact that there are many projects like e-Choupal, in which information, technologies and actions can - tacitly or explicitly - constitute structures of dominance [130, 176, 391], considering the fact that issues related to poverty, livelihoods, interests and power are influenced by international development policy, the question is, whether there is a role for a critical $\mathrm{ICT}_{4} \mathrm{D}$ researcher/reflective practitioner in addressing these core issues.

\subsection{ALTERNATIVE METHODS OF KNOWLEDGE PRODUCTION}

A point to note is that, in contrast to the interdisciplinary real-world research as the one described in this thesis, in many traditional paradigms of science, e.g. empirical research on innovation and technology or quantitative hypothetico-deductive dependent/independent variable research [6] the researcher is not supposed to take a critical position in value-laden discussions [298, 155]. To do so, the researcher has to resort to different "ways of knowing" [333]. Meanwhile, this position has often to be defended and explained to various research communities. I therefore return to the classic concept of phronesis, one of the knowledge categories and intellectual virtues described by Aristoteles [11], (which I introduced in Chapter 1 as the knowledge category for the present $\mathrm{ICT}_{4} \mathrm{D} /$ action research).

Phronesis includes practical reason and prudence (wisdom) and is therefore very suited for real-world research in $\mathrm{ICT}_{4} \mathrm{D}$. In contrast to the well-known knowledge concepts: episteme (analytical knowledge, universal truth) and techne (art, instrumental skill, technical know-how) [11], it is critical and discursive. Phronesis is encountered in various disciplines, including e.g. web science [6], (participatory) action research [136, $138,333]$, technology and engineering [421], some strands in social sciences [151, 366].

A second point for reflection is the notion of trans-disciplinarity - in the sense of research collaboration between academics and non-academics - which is necessary in $\mathrm{ICT}_{4} \mathrm{D}$, to engage multiple perspectives from various knowledge domains (also local or indigenous knowledge) to tackle complex real-world problems [298, 246]. This can be defended by referring to the concept of agora [297, 6]. Agora can be understood as society or real-world social context, i.e. the space where research activities are situated and debated. Agora reflects the presence of interacting actors and co-creation in the space of knowledge creation: the local context, the field-based collaborative research. In our research, collaboration as a goal-constructing mechanism and as sociotechnical 
innovation, is taking place in the agora, i.e. outside the traditional loci of academic scientific research.

Examples of critical, phronetic or field-oriented, real-world (action) research, that take place in the agora can be found in various disciplines and research communities over the past decades (e.g. [79, 73, 372, 373, 137, 138, 154, 246, 56, 338, 339, 280, 99]). These actionable, practically oriented studies call for value-driven research, inclusiveness, reversed (grassroots, south-north) perspectives, and imagination. I mention two examples of critical research that have inspired my work.

In Chambers' critical studies, starting in 1983, he calls to put the farmer first in rural development [71]. Chambers has kept this idea until his most recent work [74, 77, 76]. Chambers introduced the user-centered "people paradigm", in contrast to the, what he calls "things paradigm", which describes the interventionist approaches to rural development, based on transfer of (agro-) technologies, expert-based knowledge transfer, and outsiders' biases [74]. Chambers' work has had much influence in stirring up the Development Debate and has largely influenced the development discourse [372].

In the book Rethinking Development Studies in Africa ${ }^{2}$ John Victor Mensah, Stephen Kendie and other African scholars show how international development continues to be dominated by western-centered modernization theory (characterized by accumulation, individualism, liberalism and the free market), whereas local traditions and the voice of the people concerned are considered irrelevant [269]. They call for rethinking the "benefits" of envisaged "progress", which are so often proclaimed in international development policy and practice [70]. These African scholars argue for more critical analysis of the principles of scientific research and its relevance and meaning in the African context [269].

What these studies have in common - despite the different traditions from which they emanate and the different approaches they use - is reflection and critical thinking, the idea of society, community, reciprocity between science and society, and the acknowledgement of the importance of context. How are these value-laden aspects of policy and practice addressed in various other $\mathrm{ICT}_{4} \mathrm{D}$ studies?

\subsection{VALUES AND INTERESTS IN ICT4D RESEARCH}

There seems to be a dynamic tension, in the growing field of $\mathrm{ICT}_{4} \mathrm{D}$ policy research, between those who focus on business and economic development and those who focus on empowerment and community development, the two most salient domains in this field [166]. Since business and economic development are part of the incumbent political ideology, while empowerment and community development are desired endpoints only, this tension can be seen as a choice between the objective, value-free, positivist research, and normative research: "as it should be". Many studies that include a nor-

2 Conference proceedings of the conference "Rethinking Development Studies in Africa", organized by the Institute for Development Studies of the University of Cape Coast in Ghana, in November 2008 [269]. 
mative element stay at a rather abstract level. Do these studies include an empirically grounded critical aspect? What values do they espouse and what implications do they have for practice? Moreover, is this debate informed by context-embedded field research or goal-constructing collaboration? In search of an answer, I briefly discuss a number of $\mathrm{ICT}_{4} \mathrm{D}$-related studies for an inclination towards value-driven research and critical engagement.

A review of key $\mathrm{ICT}_{4} \mathrm{D}$ academic research shows that value-driven research in $\mathrm{ICT}_{4} \mathrm{D}$ is often seen as problematic. In disciplines such as computer science the focus has been traditionally on the "advanced" western, connected world. It takes the Global North context for granted (as if it were a universal context), and more strongly, views this as the blueprint for the Global South. Field-based ICT4D research, aimed at downscaling and decentralization under low resource conditions, is not naturally recognized academically as an interesting research direction.

In certain research paradigms, solving real-world problems is considered unscientific (e.g. $[62,207])$. In human computer interaction research for development ( $\left.\mathrm{HCI}_{4} \mathrm{D}\right)$, a discipline related to computer science, and embedded in global development, some researchers complain that they are distracted from their scientific work, as they are asked to engage in tasks that have more to do with helping the poor than in writing scientific papers [207]. Some research communities, especially in the social sciences prefer to speak about ICTD, removing the purposeful "4" (for), to avoid the impression that this research aims at "helping people" [66, 400].

In a study by Roger Harris (2016), titled "How ICT4D fails the poor", is described how $272 \mathrm{ICT}_{4} \mathrm{D}$ researchers were inquired about the impact of their $\mathrm{ICT}_{4} \mathrm{D}$ research (not taking into consideration academic impact i.e. citations, but only real-world impact) [190]. Harris shows in this study how $\mathrm{ICT}_{4} \mathrm{D}$ researchers are more concerned with citation indexes than reaching and influencing policy. Harris argues that $\mathrm{ICT}_{4} \mathrm{D}$ research "fails the poor", because it fails to reach the (evidently Global North) policy makers and practical experts - readers outside the academic community [190].

Harris' study shows how the majority of ICT4D studies are not intrinsically policyoriented. Some are policy oriented but do not acknowledge the reality in the field. Desk studies (often from MIS, the Management Information Systems discipline) lack the necessary field experience to generate a well-informed debate. Apparently, many $\mathrm{ICT}_{4} \mathrm{D}$ researchers do not participate at all in the development debate, and do not display any concern about purpose, interests and values [190].

Surprisingly, Harris' study not only shows the disengagement of the academic community to contribute to the ICT4 $\mathrm{D}$ debate at the policy level, it also shows, indirectly by his own research, how the role of beneficiaries as stakeholders in the $\mathrm{ICT}_{4} \mathrm{D}$ process is absent in $\mathrm{ICT}_{4} \mathrm{D}$ (desk) research. Harris himself does not mention the role of beneficiaries as stakeholders of $\mathrm{ICT}_{4} \mathrm{D}$. The recommendations Harris makes towards the academic $\mathrm{ICT}_{4} \mathrm{D}$ community is that more efforts are needed towards influencing policy. The arguments given by Harris why this is important speak for themselves: (i) to 
continue receiving funding; (ii) to realize their potential for influence on international development policy and practices and (iii) because it is the right thing to do [190].

In another policy-oriented study from 2008 , the concept of "ICT4 2.0 " is introduced [194]. This model is proposed as an alternative to widespread observed failures and lack of sustainability of the large class of $\mathrm{ICT}_{4} \mathrm{D}$ telecentre projects and off-the-shelf solutions. The latter is referred to as the first generation: $\mathrm{ICT}_{4} \mathrm{D}$ 1.0. ICT $4 \mathrm{D} 2.0$ is presented as the new generation of $\mathrm{ICT}_{4} \mathrm{D}$ approaches, characterized by new technologies, new approaches to innovation, new intellectual integration and a "new view of the world's poor" [194]. Despite mentioning "pro-poor, para-poor, per-poor innovation, $\mathrm{ICT}_{4} \mathrm{D} 2.0$ embraces the idea of transfer of technologies. Contextualized methods and user-centered methods and the importance of trans-disciplinary sociotechnical innovation of how to deal with complexity and dynamic contexts - crucial elements in sociotechnical innovation processes - are not mentioned in this article [194]. With respect to values and interests, it writes: "ICT4D offers new opportunities for informatics professionals and new markets for ICT vendors" [194]. The claim that ICT4D 2.0 will benefit "the world's poor, those who suffer from the blot on the global conscience" echoes the underlying assumptions of the interventionist approach. This assertion [194] as a generalized statement ignores the contextual aspects of ICT4 $\mathrm{D}$ development projects. The way to find out whether such statements and claims are warranted, is to investigate them in the field. This illustrates the important contribution of practical case-oriented field-research, because this provides field evidence to inform policy and bridge the (physical, conceptual, cultural) distance to the end-user at the grassroots level. "Intellectual integration in $\mathrm{ICT}_{4} \mathrm{D}$ 2.0", refers to collaboration between three so-called "ICT4 4 champions": researchers from (i) computer science, (ii) information systems and (iii) development studies, to let the champions jointly solve $\mathrm{ICT}_{4} \mathrm{D}$ issues [194]. Here again, the stakeholders from the Global South - the "poor and unconnected people" - are absent in the innovation process and in the debate about issues that concern their livelihoods.

An example of a study that accepts the reality of contemporary development policy "as-is", avoiding to take a position in the Development Debate, is an essay by Burell and Toyama (2009), titled: 'What constitutes good ICTD research?' [66]. This essay consists of a discussion about the tension between qualitative and quantitative research methodologies and their respective communities. About the purpose of development, the authors accept that there are different notions of development: "... there are additional tensions between top-down versus bottom-up approaches, between providing welfare and promoting agency, and between paternalism and partnership. 'For ICTD, what we'd like to propose is an acceptance that all of these viewpoints will and should continue to coexist within the community' [66].

In sum, this analysis supports the view of Harris [190] and of Burell \& Toyama [66], that $\mathrm{ICT}_{4} \mathrm{D}$ academic research is only marginally addressing the core issues in the Development Debate, with respect to interests and values related to $\mathrm{ICT}_{4} \mathrm{D}$. 
As discussed, to bring the voices from the grassroots to the level of policy, $\mathrm{ICT}_{4} \mathrm{D}$ has to include a critical and normative element and raise issues about poverty, livelihoods, interests and power. This can be done, for example, by comparing and debating different (policy) frameworks and their underlying principles.

Policy frameworks are instruments to create a shared understanding, to guide decision-making, communicate purposes and principles. In international development, policy guides the formulation of programs and projects ${ }^{3}$ and frame concepts in the Development discourse [130]. Policy frameworks have a positive (how it is; shared knowledge) and a normative aspect (how it should be; shared vision) [197] expressing political ideology. In this sense, $\mathrm{ICT}_{4} \mathrm{D} 3.0$ can also be interpreted as a policy framework, because it has policy dimension implications. How are other frameworks for $\mathrm{ICT}_{4} \mathrm{D}$ ?

I take as an example the intervention framework, discussed in Chapter 2. This framework follows the conventional development discourse from the international institutions of development and national governments [130, 372]. This discourse is influenced by ideas from colonialism, classical economy, neoliberal thinking, contemporary management practices [131, 193, 138, 372, 74, 331].

In his book "Information and communication technologies for development" (2018) [197] Richard Heeks proposes a foundational framework for ICT4D. See Figure 84. This model shows a value chain which starts upstream with precursors (policy context, regulatory, institutional environment and infrastructure), and (ICT) "readiness" i.e. the systemic prerequisites including hard factors (data, money, technology) and soft factors (knowledge, motivations, political support). This stage is followed by "availability": the making available of technology, for example by bringing telecenters and cybercafés. This is followed by uptake/adoption/use and finally development impact.

In this model technology is transferred linearly along the chain, while users enter the stage after decision-making about adoption has taken place. Contextual factors (called here "exogeneous factors" in Figure 84) come into play in the final stages only. The model implies that innovation is a planned action. Outcomes and impacts occur according to strategy. User needs are not addressed by this model. Issues related to interests and power are not mentioned. Concerns about livelihoods are left out, as shown in Figure 84, in a model representing an abstract, contextless world in which technology must be or is rolled out according to plans.

In contrast to $\mathrm{ICT}_{4} \mathrm{D}$ 2.0, my proposed framework $\mathrm{ICT}_{4} \mathrm{D}$ 3.0, see Figure 85, starts from the opposite (grassroots) direction: not with technology or infrastructure, but from the users' needs and their desired outcomes. It moves backwards, towards defining what is necessary to achieve this. The first concern is to find out what the local

3 See e.g. ADS Chapter 201, USAID Program Cycle Operational Policy https://www.usaid.gov/sites/ default/files/documents/1870/201.pdf, (accessed o8-10-2020). 


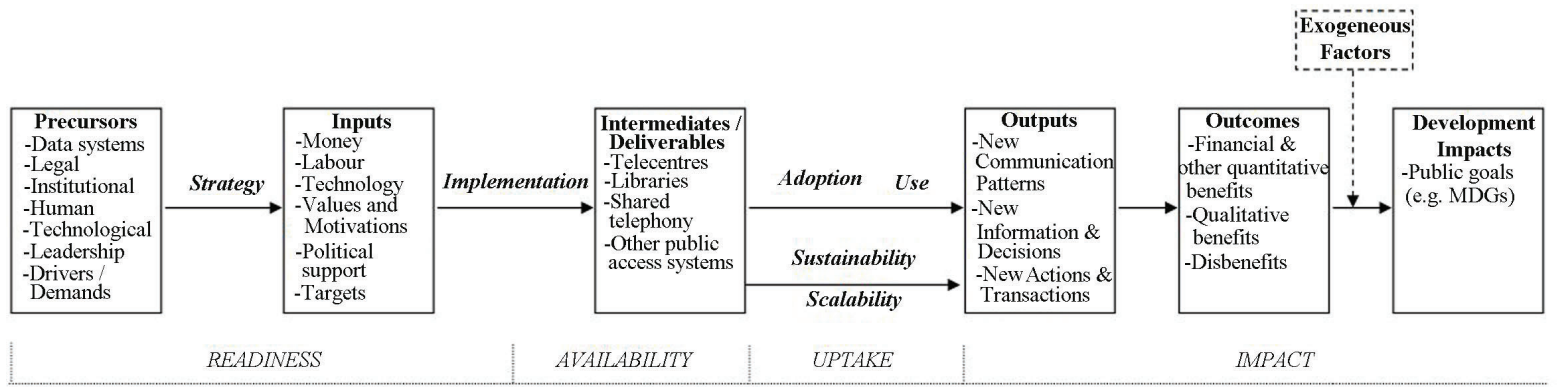

Figure 84: ICT4D Value chain. Reprinted from Richard Heeks, 2018 Information and Communication Technologies for Development London: Routledge, p.38 [197].

operational goals are, and to analyze the context. By putting emphasis on involvement of local knowledge and collaborative decision-making, and by focusing on the broader context of the users (see: Chapter 4 ) the model safeguards the idea of inclusion (as discussed in Chapter 5).

Context in ICT4D 3.0 refers to local "livelihoods".4 or more specifically, the total social, physical, cultural and economic environment(s) that directly or indirectly influence the user and his/her community in relationship to the envisaged technological solution. By involving "context" in this broad definition, the networked, community-based aspect of $\mathrm{ICT}_{4} \mathrm{D}$ is expressed, in contrast to approaches that address the user as an individual, detached from his/her social network(s). Figure 86 is yet another view on $\mathrm{ICT}_{4} \mathrm{D}$ 3.0, that shows how this is made operational in the field.

The $\mathrm{ICT}_{4} \mathrm{D} 3.0$ framework is normative and challenges the conventional thinking about technology in $\mathrm{ICT}_{4} \mathrm{D}$ policy. It informs the Development Debate that there is no need for technological determinism, in which we have to accept technology "as is" (see also $[142,140,425,123,141])$. In this thesis I point out in practice how down-scaled, networked and inexpensive alternatives are possible for ICT development, as discussed in Chapter 11.

While being critical, the framework does not embrace the idea that ICT is only "a grand contemporary strategy for the penetration and control of the Third World" [130]. Its sociotechnical approach acknowledges ICT as flexible, inexpensive and adaptive, not necessarily requiring high investments. Moreover, it bridges the gap between usercentered practical action and policy in $\mathrm{ICT}_{4} \mathrm{D}$.

\subsection{A POSITIVE AND NORMATIVE ARGUMENT FOR COLLABORATION}

Given the (often tacit) general acceptation of interventionist approaches and implicit power, it is important to propose and discuss alternative, collaborative frameworks for

4 For an extensive discussion of the term livelihoods, see e.g. Scoones (2009) [372, 73] 


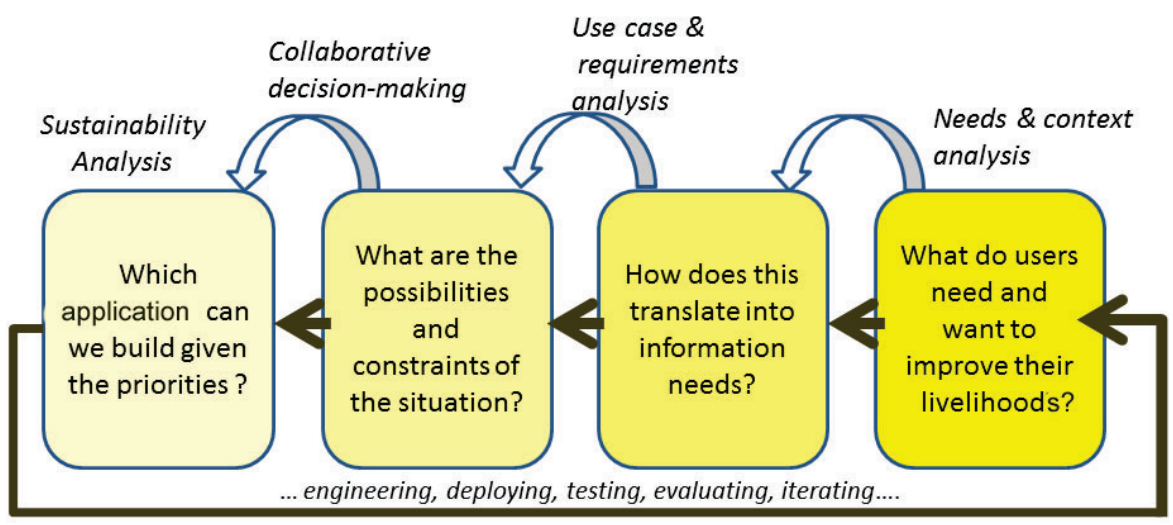

Figure 85: The $\mathrm{ICT}_{4} \mathrm{D}$ framework in four questions. It starts from the user needs and perspective, moving bottom-up. Users and context are guiding the technological design, development and deployment in this model. The five tasks of the operational ICT $4 \mathrm{D}$ 3.o framework (context analysis, needs assessment, use case \& requirements analysis, sustainability analysis, engineering etc.) are shown as arrows, connecting the questions in this model.

$\mathrm{ICT}_{4} \mathrm{D}$. According to a normative argument ("we want $\mathrm{ICT}_{4} \mathrm{D}$ to be in the benefit of the poor and unconnected people") it is the critical researcher's responsibility - however small her contribution - to engage in the Development Debate and help bring the voices of the beneficiaries/users/communities to the level where policy is formulated. 


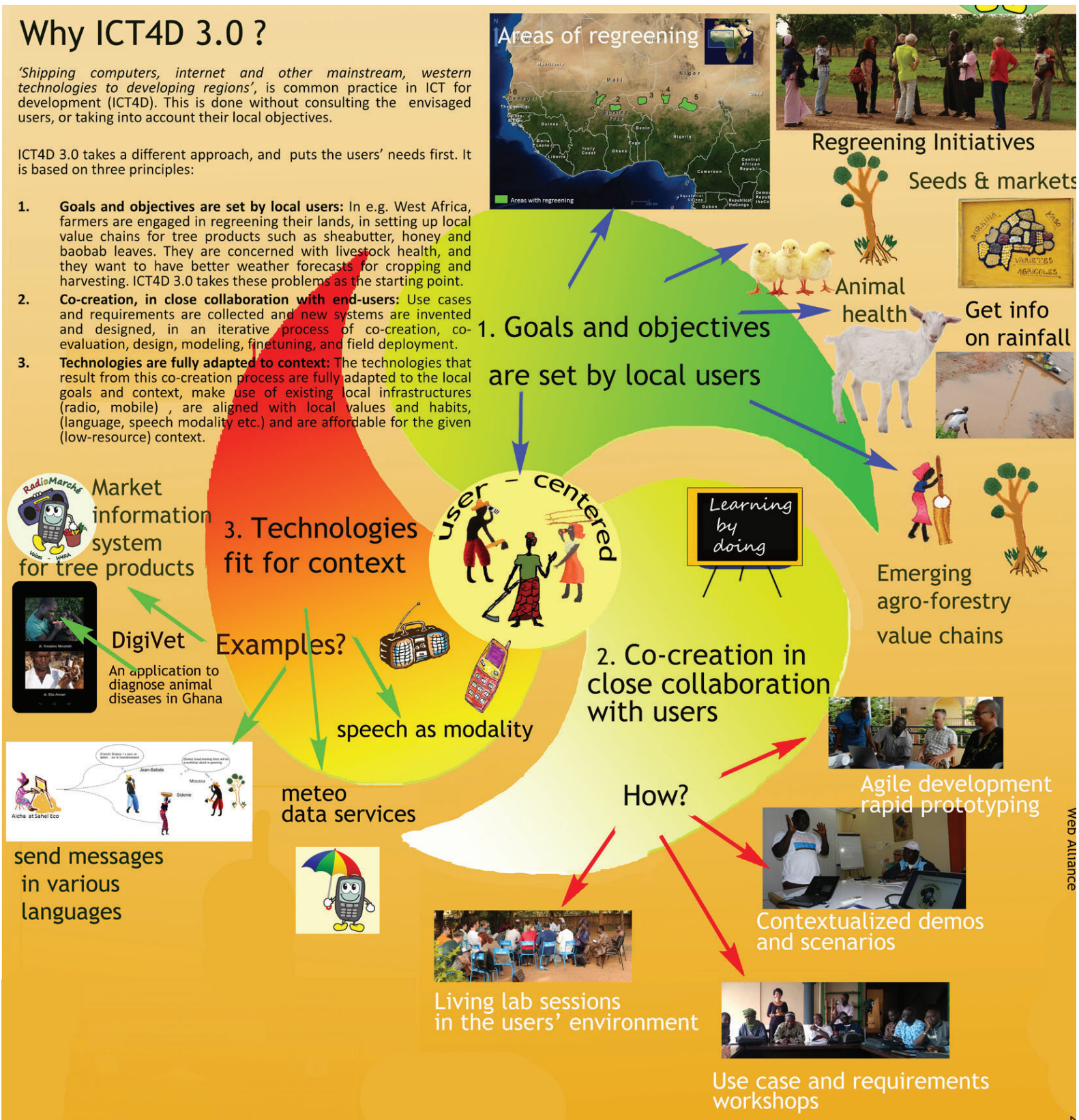

Figure 86: A different view of $\mathrm{ICT}_{4} \mathrm{D}_{3}$ 3.0: a collaborative, user centered approach, that positions the users' needs at the center of the technology development process. 

Part IV

CONCLUSION 


THE LAST FIRST

In this last chapter I will revisit the research questions formulated in Chapter I, "What are the underlying assumptions and ensuing limitations of the mainstream Global North approach to today's ICT 4 D projects, programs and policies?" and "How can we correct for these limitations of ICT $T_{4} D$, so as to come to a new approach that truly incorporates the diverse considerations from the Global South ?" In my research I have addressed this as a design question: "Can we design an operational approach to developing ICT systems and services, such that it takes into consideration the complex realities of local context and involves the envisaged users in decision-making and sociotechnical development?"

\subsection{INTERVENTION OR COLLABORATION?}

In this thesis, I have questioned how $\mathrm{ICT}_{4} \mathrm{D}$ as a top-down, externally defined "intervention" aims to "connect the unconnected" people in the world and bridge the Digital Divide to make the benefits of digital technologies serve the poorest people in the world. I have formulated this as the following research question:

- RQ-1: "What are the underlying assumptions and ensuing limitations of the mainstream approach to today's $\mathrm{ICT}_{4} \mathrm{D}$, as expressed in international development policy and programs?"

To answer this question, I have analyzed conventional $\mathrm{ICT}_{4} \mathrm{D}$ project and programs, asking the following questions: How are goals and objectives for $\mathrm{ICT}_{4} \mathrm{D}$ defined? What is the role of end-users and beneficiaries of $\mathrm{ICT}_{4} \mathrm{D}$ ? How are project evaluations done? Which project management methods are used? How does $\mathrm{ICT}_{4} \mathrm{D}$ cope with the complexity of real-world contexts?

Based on the analysis of several large-scale, donor-funded $\mathrm{ICT}_{4} \mathrm{D}$ projects from literature, I have shown how a "linear", mechanistic notion of "intervention" lies at the root of $\mathrm{ICT}_{4} \mathrm{D}$ in international development, where "change" is thought to be (causally) brought about by an intervention. This is generally conceptualized as some measure, such as a new technology - say ICT, or Internet - or some other "improvement" that is introduced from the outside and as a result, in a deterministic way, is supposed to cause social change. It shows how the practice of $\mathrm{ICT}_{4} \mathrm{D}$ in development projects and programs is tacitly conceptualized as a linear transfer of technologies and knowledge, from wealthy countries to developing regions. It shows how this approach ignores the 
subtle and contextual realities that influence the processes of sociotechnical innovation and social change.

I have pointed out, in this thesis, how, in the linear model of innovation, the source of innovation is situated "upstream", in the space of the inventors, researchers, developers or manufacturers [402, 414, 415]. This draws a physical or conceptual (geographical, cultural) barrier between the upstream (inventor/manufacturer) and the downstream (passive customer, user, beneficiary) in the "receiving" or developing region and implies a one-way information flow, downstream. The linear model does not acknowledge or support a two-way interaction interface between developer and user. The information from communities of users is not used for (re-)design or further development. It does not feed the inventor with new contextualized knowledge.

\subsection{INNOVATION}

The research I describe in this thesis is collaborative, technical action-research. It aims to improve a real world situation. My second research question is therefore formulated as:

- RQ-2: "How can we correct for these limitations of $\mathrm{ICT}_{4} \mathrm{D}$, so as to come to a new approach that truly incorporates the diverse considerations from the Global South - which may significantly differ from those of the Global North?"

A point put forward in this thesis, from the perspective of innovation theory, is the interpretation of $\mathrm{ICT}_{4} \mathrm{D}$ action as a networked process of sociotechnical innovation. Complexity theory offers a theoretical lens to explain why $\mathrm{ICT}_{4} \mathrm{D}$ projects are inherently complex, why they easily fail, why simple recipes (such as linear intervention) do not work in most cases, and why alternative engineering and management methods (dubbed iterative, adaptive, collaborative) are needed to deal with real-world contexts. This is an alternative to the incumbent intervention models that take the introduction of ICTs in developing regions as a regular business-as-usual measure, and therefore overlook the complex nature of change.

The idea of ICT4 $\mathrm{D}$ action as innovation has implications for the operational domain. I therefore propose, as a practical solution, an operational approach that meets the following requirements:

- it takes into consideration the complex realities of local context(s);

- it involves the envisaged users in decision-making and sociotechnical development.

This operational framework and approach, which we dubbed ICT4 $\mathrm{D}_{3.0}$, is the artefact that is produced as a result of a design question: 
RQ-3 How can we design an operational approach to developing ICT systems and services, such that it (i) takes into consideration the complex realities of local context, and (ii) involves the envisaged users in decision-making and sociotechnical development?

The previous chapters 4 to 8 have shown how this approach and framework, dubbed $\mathrm{ICT}_{4} \mathrm{D}$ 3.0, has been iteratively constructed and adapted. In the next section I discuss how the proposed framework meets the two requirements, mentioned above.

\subsection{THE PROPOSED FRAMEWORK: ICT4D 3.0}

As I discussed in this thesis, "being connected" is important for social and economic development, even of poor regions of the world. ICTs can help users to achieve their operational goals. But how can we know what the "unconnected want"? ICT4 3.0 is a framework and methodology for collaborative innovation that takes the users' perspective. It covers the full lifecycle of technical development and deployment and is composed from reconfigurable elements: context analysis, needs assessment, use case \& requirements analysis, designing, building \& evaluating, sustainability assessment.

$\mathrm{ICT}_{4} \mathrm{D} 3.0$ is thoroughly and inherently collaborative, adaptive and iterative, throughout its lifecycle. It puts emphasis on (i) the composition of the interdisciplinary and multicultural team, (ii) the importance of the early upstream stages of ICT systems development, (iii) two-way knowledge exchange between developers and users.

\subsubsection{Context}

In this thesis I propose context analysis as a starting and recurring activity in sociotechnical innovation. My argument here, underpinned by theory from complexity research and diffusion of innovations, is that novel technologies can only become successfully embedded, if there is the ability to cope with the dynamics of real world contexts. To do so, $\mathrm{ICT}_{4} \mathrm{D} 3.0$ provides a context-sensitive, multi-perspective, networked approach. Sociotechnical development takes place within a knowledge network. The iterative and adaptive aspects of $\mathrm{ICT}_{4} \mathrm{D} 3.0$ reflect its agile, user-centered attitude, in which socialization, explicitation, combination and internalization of knowledge in a network of innovation is leveraged, in multiple learning loops.

As an example, this thesis presents a new method for use case and requirements in a context of high complexity: the "structured narrative method". This method captures and structures key ideas and user stories and other forms of complex unstructured information and converts it into a structured format. The method facilitates communication about requirements in a non-formal way, using narratives and storyboards, but also captures technical system specifications and represents the information through formal models. This method is appropriate for $\mathrm{ICT}_{4} \mathrm{D}$ software development projects 
as it bridges the worlds of users and technical developers. It covers more than just the narrow technical system. It includes business requirements and information related to the local context - topics not commonly covered in mainstream use case and requirement analysis methods (see e.g. [173, 236, 248, 388]). The structured narrative method is useful for $\mathrm{ICT}_{4} \mathrm{D}$, but is equally useful in other software development projects, especially in dynamic (complex) contexts or in projects in which communication between various stakeholders is cumbersome, due to e.g. large differences in backgrounds or world views.

The aspect of sustainability assessment in $\mathrm{ICT}_{4} \mathrm{D} 3.0$ is covered through a methodology that is based on yet another networked aspect of $\mathrm{ICT}_{4} \mathrm{D}$, presenting it as a networked constellation of agents or actors exchanging value. This element is a structured, formal method to assess financial sustainability and feasibility of ICT services in low resource environments. Such an approach or method is still lacking in sustainability studies on $\mathrm{ICT}_{4} \mathrm{D}$. The proposed method is easy to learn and can be used to evaluate networked value constellations in any context. It is based on the $e^{3}$ value methodology and allows early qualitative or quantitative assessments and evaluations of potential value of the service for the complete value network. The sustainability assessment method is collaborative, based on locally collected business requirements. It is part of the process of collaborative goal construction, portfolio selection and use case and requirements analysis.

For this sustainability assessment it is important to note that (i) the exercise of business analysis should be done collaboratively, involving local users and business partners; (ii) the sustainability assessment should go hand in hand with a proper context analysis; (iii) relevant quantitative data are needed to feed the models; the data have to be provided by local stakeholders and business partners.

\subsubsection{Collaboration}

Collaboration between developers, end-users and other stakeholders is the key element of $\mathrm{ICT}_{4} \mathrm{D}$ 3.o. Collaboration is a practical methodology, facilitating innovation and knowledge exchange. More fundamentally, $\mathrm{ICT}_{4} \mathrm{D}_{3} .0$ acknowledges collaboration as a core principle of equity, inclusiveness and respect for the end-user. It holds the intention to jointly improve a real-world situation. An important implication of the collaborative approach, is that it allows end-users to define project goals and objectives. This is inherently different from projects that consist of implementations of externally designed solutions according to externally (donor-)defined goals and objectives.

Collaboration implies a multi-actor network approach where diverse viewpoints are confronted and diverse knowledge domains come together. ${ }^{1}$ Yet, collaboration, according to the present research does not equate to the position that local users are the only contributors to this process, or that an $\mathrm{ICT}_{4} \mathrm{D}$ program should necessarily emerge from

1 Participatory action research approaches e.g. Fals Borda \& Rahman (1987) [139] express similar views. 
the grassroots. Collaboration in $\mathrm{ICT}_{4} \mathrm{D}$ means also: bringing in technical judgment and associated ICT knowledge and skills, as ICT professionals can do (and in the case of low-resource environments this is often from outside the community of users).

As an answer to sub-question (ii), $\mathrm{ICT}_{4} \mathrm{D}$ needs to be placed in and confronted with the critical international Development debate. If $\mathrm{ICT}_{4} \mathrm{D}$ wants to declare itself "propoor", "para-poor" or "per-poor" (e.g. [194, 197]), it must be capable of demonstrating how this inclusion and acknowledgement of local agency and context are to be operationalized. Validation by local users and field-based evidence are required to warrant the claims. I do so by placing $\mathrm{ICT}_{4} \mathrm{D}_{3} .0$ in the tradition of various critical studies, that put the farmer first and acknowledge the importance and value of local agency, local knowledge and local innovation capacity: e.g. Chambers (1983, 1994, 2010), Reij (e.g. 2001, 2005, 2009, 2015), Scoones (2009, 2015), Fals Borda (1979, 1987, 2013), Mudhara et al. (2016) and others. [71, 81, 74, 338, 336, 337, 339, 136, 137, 138, 99, 372, 373, 280].

The endeavor to be collaborative by e.g. eliciting the voice and views of supposed beneficiaries (such as rural villagers and smallholder farmers in the Sahel in this case, often lumped into the label of the rural poor) has to take a central place in this type of $\mathrm{ICT}_{4} \mathrm{D}$ research. This is a normative standpoint, but this study in addition shows that its approach makes much more realistic sense in handling the many complexities of ICT-based innovation. Accordingly, collaboration represents not just a moral argument (as it usually is); it shows that there are good reasons to assert a key principle of collaboration as the best rational approach in a reality of complex innovation social networks.

\subsection{FUTURE PERSPECTIVES FOR THIS RESEARCH}

Collaboration can be made operational and hands-on for practitioners and students, as shown in the previous chapters. This is validated by users and underpinned with innovation and complexity theories. Despite the promising results and time plus effort it took to build this framework (more than 1o years), this is only a modest start. $\mathrm{ICT}_{4} \mathrm{D}$ as a process of innovation will require more field research. Since this thesis covers only the initial phases of the innovation process, research is needed to understand the mechanisms that lead to (or hamper) scaling-up and diffusion of technologies. More research is needed in the field of complexity and complex adaptive systems to better understand the nature of interactions between local agents, technologies and their physical and social environment (livelihoods). More field research, analysis and action are needed to understand the complex processes of sociotechnical innovation and its diffusion and preconditions for long-term sustainability of ICTs in low resource environments.

Concerning sustainability, more field research is needed on $\mathrm{ICT}_{4} \mathrm{D}$ business and value constellations to know how business innovation networks operate and evolve over time, in low resource, low tech environments. The $e^{3}$ value model is a user-centered, 
networked approach, validated as a methodology that can be generalized for low resource context. Still, knowledge gaps may exist and contextual conditions have not yet been captured in the current version of this approach (see e.g. [365]).

When starting from the user needs, as shown in Figure 85, this raises new research questions, for example, concerning solutions for lack of (internet, electricity) infrastructure, for issues related to cultural aspects, such as modality and language, or to issues related to (local, distributed, networked, inexpensive, etc.) data services.

As the Internet will take a long time before it reaches poor remote regions ${ }^{2}$, solutions are needed to extend the Web beyond the current Internet. Concerning technical infrastructures for internet-less regions, more research is needed into how to do decentralized service innovation, as infrastructure and affordability of ICT services may continue to be a large bottleneck in the diffusion of ICTs in remote, low resource environments. This will demand innovative solutions to "downscale" towards inexpensive, decentralized solutions and "small" data that fit low resource, low-tech environments 3 , how to provide new ways of accessing and sharing knowledge such as radio and GSM phone etc. (see e.g. [41, 180, 406, 258]).

Concerning context-aware data services for local communities, further research is needed related to speech, e.g. resourcing of small local languages (see e.g. [23o]) and voice technologies (see e.g. [1, 183]), integration of local and global data, how to organize and manage distributed local data, how to integrate different modalities of data (e.g. spoken data, icons, etc.), how to capture, process, link "small" local data $[105,106,257]$, how to capture, represent, and link indigenous knowledge [256], how to tackle issues related to data security, data protection, intellectual property, how to harness the potential of community-based open source software development and crowdsourcing and many other topics.

Currently, Artificial Intelligence and Data Science are making gigantic leaps into our daily lives (e.g.[357, 385]). How will this affect low-resource environments, for example in Africa? Much is still unclear, for example how this will work out for the poorest countries and regions. Will these trends benefit the rich and powerful more than the poor, or is there still hope for a more just society, with less inequality (e.g. [313]) ? The influence of the corporate digital giants Facebook, Google, Microsoft and Amazon who are increasingly in control of data, information and knowledge [433], while largely investing in technologies to reach the market segments "at the bottom of the pyramid", is a reason for concern, debate and action.

2 See e.g. open letter by Tim Berners-Lee 2018: https://webfoundation.org/2018/03/web-birthday-29/, (accessed 08-10-2020)

3 See e.g. research by Christophe Guéret, Victor de Boer, André Baart et al. 2018, https://w4ra.org/ wp-content/uploads/2018/08/WEBIST_2018_6_CR.pdf, (accessed 08-10-2020), master thesis by Fahad Ali 2017, https://w4ra . org/wp - content/uploads/2017/12/machine-machine- communication - 4. pdf, (accessed o8-10-2020) 
The recent Covid-19 outbreak in the first quarter of 2020 placed unprecedented pressure on the networked world and has clearly demonstrated its vulnerability. At the same time, it has become clear how important it is to be digitally connected.

\subsection{THE 1OTH PRINCIPLE FOR DIGITAL DEVELOPMENT: PUTTING THE LAST FIRST}

As discussed in Chapter 1 , in recent years the international community of development donors and multilateral organizations, concerned with poor results of $\mathrm{ICT}_{4} \mathrm{D}$ practice, discussed and formulated nine Principles for Digital Development ${ }^{4}$, the first principle reads: "Design with the User". 5

But who is this "User" ? Is the "User", for example, a doctor in a hospital in a developing country, a local representative of an international NGO, an educated urban person? Or is the "User" an illiterate farmer in a remote village in the Sahel? With other words: whom is $\mathrm{ICT}_{4} \mathrm{D}$ targeting? Those expected to be online in the next five years or does this also include the "last billion"6, the most disadvantaged world citizens, grappling with lack of resources, environmental, political, economic hazards and vulnerable to the effects of climate change?

As pointed out in this thesis, it is possible to make ICTs serve the "last billion", even in the absence of literacy, purchasing power or infrastructure. But this requires inputs, time, (technical, social, organizational) skills, patience, perseverance, team spirit, commitment, and long lasting partnerships.

Whereas linear interventions have shown to be a recipe for failure and alternatives must be sought, I cannot claim that our proposed approach covers all answers. Collaboration holds a promise - but no guarantee - of a just, democratic, inclusive process. But collaborative approaches can also be used for co-optation, for pursue of interests that may harm the users ([136]). Still, collaboration is to be preferred over interventionist approaches, based on positive, normative and phronetic grounds. Prudent judgement is always necessary, especially when the reflective practitioner is confronted with conflicting, messy real world situations in which aspects of poverty, livelihoods, interests and power often come into play.

More efforts, research and practical action are needed to tackle the problems and needs of the least connected people. Therefore, I propose, for $\mathrm{ICT}_{4} \mathrm{D}$ 3.0, a 1oth Principle for Digital Development: "Putting the Last First" [77]. In this thesis I have given some directions how this additional Principle for Digital Development could be put into practice.

4 https://digitalprinciples.org/, (accessed o8-10-2020)

5 I note that these principles tacitly express universalistic, context-independent assumptions and pretentions.

6 According to Tim Berners-Lee the last billion will not be connected until 2042, https://webfoundation . org/2018/03/web- birthday-29/, (accessed 08-10-2020) 



\section{Part V}

APPENDIX 

What is the impact of this research for science and society? At the end of this research journey, this confronting question is still open. Did my research matter? Did it contribute to achieving goals of people in low-resource environments? Did it lead to uptake of innovation by businesses? Did it provide new insights to inform policy? Did it contribute positively to the Development Debate? And did I inspire others to bring this research further? I will try to answer these questions, starting with a personal reflection.

\section{A.I DigitAL INEQUALITIES}

Early 2020, Hans Akkermans and I submitted a proposal for a workshop, titled Digital (In)Equalities, Digital Inclusion, Digital Humanism (DigDivDigHum), to a call from the 12th ACM Conference on Web Science. This event, which would take place in Southampton, UK, was transformed, due to the worldwide Corona crisis in March 2020, into an online conference. This was unfortunate, but had also advantages, as, due to reduced participation costs, it opened opportunities for researchers from the Global South to present their papers. We launched a call for workshop papers and invited researchers from our wide international network. It led to an interesting workshop with rich discussions and a variety of perspectives from four different continents. It also resulted in fourteen papers published in the WebSci'20 12th ACM Conference on Web Science Companion 2020 [378]. We consider this a success, as, to present date, research from and about the Global South is underrepresented in prestigious academic conferences. What motivated me in organizing this workshop, was not only addressing this important issue of digital inequality, and putting it on the academic agenda, but also having the opportunity to give the floor to researchers whose voices are not often heard. My inclination to this theme may be a consequence of my origin, born in the northeast of Brazil, where inequality is still a harsh reality.

\section{A.2 GIVING A VOICE TO THE UNCONNECTED}

The design challenge of my research is to build solutions according to what the unconnected want. To make this happen, developers have to talk with users, listen to their personal stories and respect their personal goals. Co-creation gives a voice to people whose voices are absent in most project plans and strategic papers.

This also holds for indigenous knowledge. Regreening, the indigenous knowledge that became the context of my research in West Africa, was initiated by farmers- 
innovators like Yacouba Sawadogo, Ousseini Zoromé and Ousseini Kindo. Regreening is an important local innovation that can feed many people, but indigenous knowledge and local agency are commonly overlooked in international development and scientific research, and set away as unscientific or are simply ignored. Listening to the voices of poor farmer communities in Africa, puts sustainable solutions in a very different perspective.

Sometimes, voices are picked up. The efforts of researcher Chris Reij brought farmermanaged regreening under the attention of the World Resources Institute in Washington, US, one of the world's influential institutes on environmental policy and research. Our $\mathrm{W}_{4} \mathrm{RA}$ research was mentioned in one of its publications, titled Scaling up Regreening, Six Steps to Success ${ }^{1}$. This has further inspired several international NGOs, including Oxfam Novib, Care and Both Ends, who work in the Sahel ${ }^{2}$, to include our $\mathrm{ICT}_{4} \mathrm{D}$ approach in their projects for international development.

Our research has also led to various development projects on Food Security in Mali, Burkina Faso and Ghana in the period 2014 - 2020, financed by the Dutch development agency Nuffic. Our work with the Malian farmer organization AOPP has also drawn attention of policymakers. In October 2016, I invited representatives from the Dutch, Swedish and Norwegian embassies and staff members from the European Commission for a workshop that I organized together with the AOPP in Bamako, Mali. For the embassy representatives - more familiar with conferences in fancy venues - this meeting, situated at the modest headquarters of AOPP, must have given them the local flavor of low-resource environments in rural Africa. This event has given the floor to the farmers of AOPP, who not often talk to these policy makers from the Global North.

\section{A.2.1 This research, regreening, rural radio and the voice of citizens}

To support the goals of people in low-resources environments with innovative voicebased information systems, was the objective of the VOICES research project in West Africa, in the period 2011-2013. ${ }^{3}$ The field pilot in Mali, which we executed with the local organization Sahel Eco and four local radios, was situated in 19 small villages in the neighborhood of Tominian, Mali. For farmers who were previously unable to sell their products, a communication channel for commercialization was realized through the RadioMarché system, reaching 800.000 listeners.

Zakary Diarra was one of the honey producers (honey is a forest product of regreening) who was heavily involved in our project. Zakary Diarra always visits us in Bamako, when we give our $\mathrm{W}_{4} \mathrm{RA} / \mathrm{ICT}_{4} \mathrm{D} 3.0$ use case and analysis workshops. He told me in an interview how much he had personally benefited from the increased sales through the RadioMarché project. Even after the project was finished, Zakary Diarra continued

1 This is a policy \& practice paper published by the WRI [339], page 47 .

2 See e.g. https://w4ra.org/2020/04/13/how-to-enhance-the-seed-value-chain- in-rural-mali/

3 See the EU-FP7 VOICES research project website: https://mvoices.eu, (accessed o8-10-2020) 
to have a good business - better than before - because he had established contacts with new clients through this system.

In 2012 we started the Foroba Blon project to design a system that gives a voice to citizen journalists in rural Africa, through "interactive radio". This project won the News Innovation Contest (worth 250,000 US\$) from the International Press Institute.4 This radio system for Citizen Journalism in Africa was the work of our W4RA team, in collaboration with the French company $\mathrm{SBC}_{4} \mathrm{D}$, the Malian NGO Sahel Eco, and the radio stations in Mali: Radio Sikidolo, Radio Moutian5 ${ }^{5}$ Radio ORTM Ségou, Radio Bankass. Foroba Blon was considered a great success. Later, $\mathrm{SBC}_{4} \mathrm{D}$ delivered a version of Foroba Blon to the media concern Al Jazeera in 2013 to monitor the presidential elections in Ghana and Kenya by citizen journalists in the field. Meanwhile, at VU my colleagues continued to work in parallel on the further development of Foroba Blon on small hardware ${ }^{6}$ at the request of one of the radio stations in Mali. For this project W4RA colleague André Baart won the High Potential Award in 2018 in the Amsterdam Innovation Contest for his master thesis work.7

\section{A.2.2 Our research in the news}

Our research was often mentioned in the news for its innovative character in combination with a societal mission. On behalf of the $\mathrm{W}_{4} \mathrm{RA}$ team, I gave various interviews, lectures and presentations. In April 2013, I was interviewed by Hal Hodson about our research, which resulted in an article in the New Scientist ${ }^{8}$, titled: "Voice-based web access helps illiterate get online".

In January 2014, our key-user from Mali, Amadou Tangara and I were interviewed about the RadioMarché project. The whole interview was broadcast by SciDevNet Radio. ${ }^{9}$ I was interviewed various times about our research, on the radio in Africa: in 2011 by Radio La Voix du Paysan, in Ouahigouya, Burkina Faso and again in 2017, for the same radio, this time together with two farmers-innovators, Yacouba Sawadogo and Ousseini Zoromé, who were with us in a W4RA workshop. ${ }^{10}$

In November 2013, together with our partner Mathieu Ouedraogo from Burkina Faso, and our business partner, the telecom provider Orange, Hans Akkermans and I presented the $W_{4} R A$ research at the European Development Days in Brussels, Belgium,

4 The winning project Foroba Blon: https://tinyurl. com/IPI - prize2012, (accessed o8-10-2020)

5 Documentary of our research in Mali https://w4ra.org/films/the-web-of-voices-documentary/, (accessed 08-10-2020)

6 This is the Kasadaka small hardware project, initiated by Christophe Guéret and Victor de Boer.

7 See the pitch by André Baart: https://tinyurl.com/kasadaka-highpotential-award, (accessed o8-102020)

8 Interview in the New Scientist https://tinyurl.com/newscientist-w4ra

9 Radio interview for SciDevNet: https: //tinyurl.com/scidev-w4ra, (accessed o8-10-2020)

10 We gave this historical radio interview together with two iconic farmer innovators https://tinyurl. com/ lavoixdupaysan, (accessed o8-10-2020) 
in front of a large audience of international development policymakers from the EU and representatives of governments from various African countries. ${ }^{11}$

In March 2016, I was invited to give a keynote speech titled "Connecting the Unconnected", to which I was introduced by the Dutch politician Sylvana Simons at the VU lustrum symposium ${ }^{12}$ "Guide to the Network Society". In 2018, I was interviewed again, together with my colleagues Francis Dittoh and André Baart, by the BBC, about our W4RA research in Ghana and Burkina Faso. ${ }^{13}$

In 2019, I was interviewed about our project for citizen journalism in Africa, Foroba Blon, by journalist Anna Pujol Mazzini, for the Los Angeles Times. A small section was written about this project in a larger article in the Los Angeles Times about mobile services in Mali. ${ }^{14}$ In May 2020, the online journal Ad Valvas interviewed me and published an article about our $\mathrm{ICT}_{4} \mathrm{D}$ research to the benefit of seed value chains and food security in Mali. ${ }^{15}$

All these activities have led, not only to dissemination of our work, but also to the general idea that collaborative research, where academics and non-academics work in a trans-disciplinary setting, is key to addressing societal challenges. The importance of giving the floor to people whose voices are not often heard, is the central message.

\section{A.3 IMPACT OF THIS RESEARCH ON EDUCATION}

This research has directly contributed to education at VU. Due to our $\mathrm{W}_{4} R A$ research in West Africa, $\mathrm{ICT}_{4} \mathrm{D}$ has become the subject of two courses in the master tracks Computer Science, Information Science and Artificial Intelligence. In the two $\mathrm{ICT}_{4} \mathrm{D}$ courses, students design and build information systems for people in low-resource environments, for which they use the framework "ICT4 $\mathrm{D}_{3.0 "}$ ".

\section{A.3.1 ICT4D as a master course at $V U$}

The first $\mathrm{ICT}_{4} \mathrm{D}$ course, which we ${ }^{16}$ started in April 2013 as an educational pilot with only twelve students, is now (in 2020) one of the elective courses ${ }^{17}$ given at the Com-

11 See: https://w4ra.org/web-of-voices - at - european- development - days - brussels - 26 - november - 2013/ anna_edd/

12 See the keynote on video https://www. youtube.com/watch?v=WQEK3uAIlno, (accessed o8-10-2020)

13 Our research at the BBC https://www. bbc.com/news/business - 43409952, (accessed o8-10-2020)

14 The Los Angeles Times mentioning our Foroba Blon project https ://tinyurl . com/latimes - fb, (accessed 08-10-2020)

15 Article in Ad Valvas: https://tinyurl.com/ai-afrika-w4ra, (accessed o8-10-2020)

16 This course was set up by Stefan Schlobach, Christophe Guéret, Victor de Boer and myself. André Baart and Francis Dittoh have also greatly contributed to its success.

17 See in VU study guide: https://studiegids.vu.nl/en/2020-2021/courses/X_405101, (accessed o8-102020) 
puter Science Department of VU. This project-based course has about fifty students every year.

\section{A.3.2 ICT4D in the Field: education in a real world context}

In 2017, together with Jaap Gordijn and Hans Akkermans, I initiated and designed a second course at VU, in this same curriculum - this time with an extensive field research component. This course is carried out in a period of four weeks, as a community service learning course in a resource-constrained environment in Asia or Africa. This project-based course ${ }^{18}$, which also consists of designing and engineering information systems, puts emphasis on context analysis in complex, resource-constrained environments, and user-centered design with "real" users. The course is named "ICT4D in the Field".

I organized and coordinated this course at the request (and with funds) of VU International Office in the framework of a new educational concept called "a broader mind". The course was given in Sarawak in 2018 and 2019. A mixed team of lecturers from VU and UNIMAS ${ }^{19}$ taught a mixed classroom of twenty students from UNIMAS and VU how to design and build information systems in co-creation with local communities in the suburbs of Kuching, Sarawak. These field-based student projects ${ }^{20}$ cover the $^{2}$ full life-cycle of software development. We learned a lot from the community-oriented approach of UNIMAS in ICT4 $\mathrm{D}$ and community service learning. Conversely, UNIMAS has officially included the $e^{3}$ value methodology and sustainability analysis in their education in the software engineering track. This course led to a Memorandum of Understanding between UNIMAS and VU, which I prepared. This document was officially signed by the executive boards of both universities, on June 8 2018, the first day of the course, during a ceremonial event at UNIMAS.

In January 2020 our W4RA team visited the University for Development Studies in Tamale Ghana, where we concretized plans to give the ICT4 $\mathrm{D}$ in the Field course in Ghana in 2020. Apart from that plans were made to set up a project for African Artificial Intelligence. This collaboration also led to a signed Memorandum of Understanding (MoU) between UDS and VU.

In February 2020 I selected a motivated team of ten students from VU, doing their master in Computer Science, Information Science or Artificial Intelligence, to follow this course in Ghana in June 2020. Unfortunately, due to the Corona crisis we had to cancel the course of June 2020.

18 See in VU study guide: https://studiegids.vu.nl/en/2020-2021/courses/XM_0008, (accessed o8-102020)

19 The Faculty of Computer Science and Information Technology of the University of Malaysia Sarawak.

20 See the student projects: https://tinyurl.com/BannaTree, https://tinyurl.com/GulaApp and https:// tinyurl. com/EDUCOMX, (accessed o8-10-2020) 
Also, with Amrita University, India, a collaboration in $\mathrm{ICT}_{4} \mathrm{D}$ education and research was set up after a brainstorm meeting I organized in 2015 for researchers from Amrita University and the $\mathrm{W}_{4} \mathrm{RA}$ team. In 2018 and 2019 we wrote plans for joint $\mathrm{ICT}_{4} \mathrm{D}$ and Living Labs projects, which have still to be implemented.

\section{A.3.3 Master research projects in $\mathrm{ICT}_{4} \mathrm{D}$}

In the period 2015-2020, the $\mathrm{W}_{4} \mathrm{RA}$ program has inspired a number of students at VU to do their master research project in $\mathrm{ICT}_{4} \mathrm{D}$. This has led to about thirty interesting master theses. ${ }^{21}$ These are titled for example: "Economic Sustainability of ICT Services for the Rural Poor in sub-Sahara Africa" [102] or "An Intelligent System to Track Tree Loss in Rural Africa using Satellite Image Data" [122] or "Local currency networks in rural communities in Africa: A feasibility study of block chain payment network" [431] and many others. The students were invited to meet the weekly meetings at the $\mathrm{W}_{4} \mathrm{RA}$ office and discuss with us their research. Some students became core members of our team and did field research with us in Africa, even after their graduation. ${ }^{22}$

\section{A.3.4 The Digital Divide in Amsterdam}

Student research projects far from home - for example in Africa or Asia - are expensive and often difficult to organize. So, we looked for alternatives. A meeting with colleagues from the VU Athena Institute, Nicole Goedhart and Christine Dedding, who investigate the Amsterdam Digital Divide [165], led to plans to expand our $\mathrm{ICT}_{4} \mathrm{D}$ research to the Global North. In October 2018, I launched a call for student projects in Information Science. The research question was: Is it possible to co-create information systems with vulnerable or unconnected people in an urban environment in the Global North?

This resulted in five master research projects, all in support of disadvantaged citizens in Amsterdam - people who feel excluded by the digital technologies that do not match their context, needs and skills. A news item about the student projects appeared in Ad Valvas. ${ }^{23}$

At the start, the urban "low-resource" context was still terra incognita for the team, in terms of problems and living conditions of the stakeholders: who were these homeless people, low literates and people with a migration background?

The five resulting master theses have been published in a book: Digital Divide, Citizenship and Inclusion in Amsterdam [48]. The book was offered to a delegation of the Dutch government and representative of the Municipality of Amsterdam during a workshop that I organized to make ICT researchers from VU meet policymakers in Digital Devel-

21 All student theses are at: https://w4ra.org/student-papers/, (accessed o8-10-2020)

22 This has been the case for Gossa Lô and André Baart, who have become great ICT4D professionals, and are working for innovative AI B-corp Bolesian, often in "AI for Good projects".

23 Ad Valvas news item, June 2019: https://tinyurl.com/AdValvas - daklozenapp, (accessed o8-10-2020) 
opment and vice-versa. The book is available at the website of the Amsterdam municipality. ${ }^{24}$ The Amsterdam Digital Divide project has been endorsed by various charity organizations, including Sant' Egidio in Amsterdam and Stichting Vooruit. Unfortunately, due to the Corona crisis this research project is now temporarily on hold, but it will hopefully soon be continued.

\section{A.4 ORGANIZING THE SCIENTIFIC AND PROFESSIONAL COMMUNITY}

Since 2014 I have taken the initiative to organize a series of international scientific events. Together with colleague Victor de Boer I co-chair the annual symposium "Perspectives on $\mathrm{ICT}_{4} \mathrm{D}^{25}$ with presentations by international guests and panel discussions with the audience. Key questions at the symposium are: What are successful or promising approaches to $\mathrm{ICT}_{4} \mathrm{D}$ ? What is the role of ICT in the broader context of development? What has scientific research to offer? What is the contribution and role of different disciplines, such as computer science and social sciences? Sixty up to one hundred participants participate at the symposium every year. In 2018 and 2020 this symposium was collocated with the ACM Web Science Conference. We also organized some other events, and were invited to participate in larger conferences. The main activities as listed below:

- Workshop: Digital (In)Equality, Digital Inclusion, Digital Humanism, collocated with the ACM Web Science Conference - on 7 July 2020, co-organized and cochaired with Hans Akkermans [378, 39, 118, 47].

- Sixth Symposium Perspectives on $\mathrm{ICT}_{4} \mathrm{D}$ - Tackling Global Challenges, Collaboratively, 23 May 2019 - co-chaired with Victor de Boer.

- Fifth Symposium Perspectives on $\mathrm{ICT}_{4} \mathrm{D}$ - The Web and the Digital Divide, cochaired with Victor de Boer. It was collocated with the ACM Web Science 2018, 27 May 2018 [43]. I was member of the core organizing team of the ACM Web Science Conference 2018, held in Amsterdam, 27-30 May 2018.

- Turing Lecture by Sir Tim Berners-Lee, inventor of the World Wide Web, for the occasion of his ACM Turing Award, also known as "Nobel Prize for Informatics". The public lecture was held at VU Amsterdam on 29 May 2018, as part of the ACM WebSci'18, with 900 attendants ${ }^{26}$. Hans Akkermans, Wendelien Tuyp, and I were the organizers of this event at VU.

- Fourth Symposium Perspectives on $\mathrm{ICT}_{4} \mathrm{D}$ - Sustainability and $\mathrm{ICT}_{4} \mathrm{D}$ - 18 May 2017 - co-chaired with Victor de Boer.

24 https://tinyurl. com/Amsterdam-DigDiv, (accessed o8-10-2020)

25 See: https://perspectives - on-ict4d.org/, (accessed 08-10-2020)

26 A report: https://tinyurl.com/TBL-Turinglecture, (accessed o8-10-2020) 
- W4RA at the National Day for Sustainability - 25 May 2017 - Workshop as part of a conference - co-chaired with Victor de Boer ${ }^{27}$

- Third Symposium Perspectives on $\mathrm{ICT}_{4} \mathrm{D}$ - Community Service \& Education - 6 April 2016 - co-chaired with Victor de Boer.

- Keynote which I gave, titled "A World Wide Web for Everyone" at the "VU 130" Lustrum Conference ${ }^{28}$ "Guide to the Network Society" - 18 March 2016.

- Second Symposium Perspectives on $\mathrm{ICT}_{4} \mathrm{D}$ - Data for Development - 22 May 2015 - co-chaired with Victor de Boer.

- First Symposium Perspectives on $\mathrm{ICT}_{4} \mathrm{D}$ - Exploring this Interdisciplinary Field 16 May 2014 - co-chaired with Victor de Boer.

- Symposium The Web and Social Development - chaired by Hans Akkermans with a keynote from Sir Tim Berners-Lee, and talks by Chris Reij, Mathieu Ouedraogo and Stéphane Boyera in the presence of Yacouba Sawadogo, The Man who Stopped the Desert - 20 October 2009. I was member of the core organizing team, with Hans Akkermans and Wendelien Tuyp.

With these symposia and other events, we try to organize the scientific and professional community and to set the agenda for a more inclusive and collaborative $\mathrm{ICT}_{4} \mathrm{D}$. In this effort we have found a partnership with the TU Wien, Austria. This university has launched in 2019 the Vienna Manifesto for Digital Humanism, of which the W4RA is an official partner. ${ }^{29}$

These activities have also received some international attention. In March 2020 I was invited to become a senior editor of EJISDC, the International Journal of Information Systems in Developing Countries, published by Wiley Online Library. This was on the invitation of the chief editors Robert Davison and Roger Harris. ${ }^{30}$

\section{A.5 SOCIAL ENTERPRENEURSHIP AND INCLUSIVE INNOVATION}

The research of $W_{4} R A$ has inspired - directly and indirectly - several businesses in Europe and Africa to engage in social enterpreneurship and inclusive innovation. One example is the Dutch innovative enterprise Bolesian ${ }^{31}$, that has become a partner of $\mathrm{W}_{4} \mathrm{RA}$ and has taken up our work for further commercialization. On their website

27 See: https://w4ra.org/2017/05/26/w4ra-at-national-day-for-sustainability/, (accessed o8-102020)

28 The video of the lecture: https://Www. youtube. com/watch?v=WQEK3uAIlno, (accessed o8-10-2020)

29 Vienna Manifesto on Digital Humanism https://www. informatik. tuwien.ac.at/dighum/index.php, (accessed 08-10-2020)

30 See the EJISDC website" https://onlinelibrary.wiley.com/journal/16814835, (accessed o8-10-2020)

31 See https://bolesian.ai, (accessed o8-10-2020) 
is written: Bolesian is a partner of $W_{4} R A$, the Web-alliance for Regreening in Africa. With Bolesian's expertise in artificial intelligence we contribute to the W4RA's mission to support farmer-managed regreening activities specifically by enhancing information, communication and knowledge sharing for rural development. Bolesian is considered to be one of the Top-3 most innovative tech companies in the Netherlands.

Another business partner of $\mathrm{W}_{4} \mathrm{RA}$ is the innovative firm The Value Engineers. Our work is also mentioned on their website. ${ }^{32}$

$\mathrm{SBC}_{4} \mathrm{D}$ is a French innovative firm, based in Toulouse, led by one of our international partners, Stéphane Boyera, who built the voice services RadioMarché and Foroba Blon with us in 2011 and 2012. Later SBC4D managed to build commercial services from these projects. Foroba Blon was delivered by $\mathrm{SBC}_{4} \mathrm{D}$ to the media concern $\mathrm{Al}$ Jazeera, who used it to collect voices from the field and monitor the presidential elections in Ghana and Kenya in 2013.

In the past five years $\mathrm{SBC}_{4} \mathrm{D}$ did a project in Senegal and helped to set up a social enterprise, run by a Senegalese team that offers voice services to rural communities. This firm, named Jokalante, has recently become a partner of $\mathrm{W}_{4} \mathrm{RA}$. Jokalante's existence can be seen as an impact from the $\mathrm{W}_{4}$ RA-VOICES project in Mali in 2011-2013. Even the logo of Jokalante is familiar to us (it is inspired by a design by colleague Victor de Boer).

Early 2020 the W4RA team joined a network of digital innovation hubs or "tech hubs" in Africa and Europe, including tech hubs in Ghana (Mobile Web Ghana), Tanzania (dLab Tanzania), the Netherlands (Waag Society) and Austria (I2C at the TU Wien in Vienna). Together with business partners like telecom operator Orange, tech innovation companies $\mathrm{SBC}_{4} \mathrm{D}$ in France and Jokalante in Senegal, and knowledge institutes CSIR in South Africa, UDS in Ghana and TU Wien in Austria, a project was designed for Artificial Intelligence for Sustainable Development in Africa. The collaborative design of this project plan, which I coordinated, has been completed but the actual implementation has not yet started.

\section{A.6 THIS RESEARCH AND THE SUSTAINABLE DEVELOPMENT GOALS}

The United Nations Sustainable Development Goals 33 have become the guiding principles for a sustainable and equitable world. The $\mathrm{W}_{4} \mathrm{RA}$ research contributes to SDGI no poverty, SDG2 - zero hunger, SDG15 - life on land, in support of farmer-managed regreening. I consider the central theme in my work to be SDGio - reduce inequalities. This can be done by giving a voice to people who are not often heard.

This goal, which is expressed in the co-creation aspect of framework "ICT4D 3.o", with its critical approach to decolonializing and de-imperializing conventional $\mathrm{ICT}_{4} \mathrm{D}$,

32 See https://www.thevalueengineers.nl/stakeholder-driven-ecosystem-development/, (accessed o810-2020)

33 https://sdgs.un.org, (accessed o8-10-2020) 
has led to some opposition by those who want to safeguard the supposedly a-political neutrality and objectivity of science. Yet, given the grand challenges humanity is facing, value-laden discussions can no longer be avoided, also in science. Reflection about ethical aspects of future technical developments and innovations are becoming more frequent in disciplines as Computer Science, Information Systems, Web Science and most importantly - Artificial Intelligence and Data Science. I hope this research will contribute to drawing attention, also in these disciplines, to the challenges of people in low-resource environments and poor regions of the world. In this turbulent year 2020 there have been worldwide calls for justice, against racism and hidden power structures, also in science. It is time for a shift. We have only just started. 


\section{B.I DATA COLLECTION AND FIELD WORK}

In the past eleven years of field research our research team has collected and produced a large base of research data (over 1,2 Terabyte on disk). I have included a list of collected data and produced information, from the period 2009 - 2020 in Appendix $C$, as these materials have all been used in the preparation of this thesis. All data have been systematically collected and are carefully (digitally, safely and redundantly) stored.

In this appendix I have included a list of field activities, participants and collected materials. An overview of the most important research outcomes from the period 2013 - 2020 is available at https://w4ra.org. From the period 2009 - 2010 there are trip reports. The period $2011-2013$ is documented through trip reports and the VOICES project deliverables of work package $\mathrm{WP}_{5}$ (m-agro knowledge sharing pilot) and $\mathrm{WP}_{7}$ (dissemination and exploitation of the research outcomes). From 2014-2020 this includes audio recordings, video, field notes and photos. There is also a collection of semi-processed information such as field trip reports, use cases, prototypes, scenarios, portfolios of software, conceptual models. There are dissemination materials such as short films, articles, lecture notes, presentations, conference papers and full journal articles. Each output targets a different target group or community.

I have decided not to place this research data fully online, as suggested by FAIR ${ }^{1}$ (Findable-accessible-inter-operational-reusable) principles for research data. The collection of data is too large to be put online in an integral form. Moreover, some resources include sensitive information. Other resources are online, but not as raw materials. All data are accessible, at a special request.

\section{B.2 List of ACTivities, PARTicipants, MATERials}

\section{B.2.1 Context analysis, 26-29 September 2009, Burkina Faso}

First fact finding mission to Burkina Faso: field visit to Ranawa, field visit to innovative farmers in the Yatenga region, farmers-innovators who started the regreening initiatives in this region: Ousseini Kindo, Yacouba Sawadogo in Ouahigouya, Burkina Faso.

1 https://Www.go-fair.org/fair-principles/, (accessed o8-10-2020). 
COllected MAterials: Field trip report, September 2009 by Anna Bon.

\section{B.2.2 Context analysis, 2-5 February 2010, Burkina Faso}

Second fact finding mission and field excursion to farmers fields in the northeast of Burkina Faso; workshop in Bamako with various stakeholders: national and international NGOs, local ICT entrepreneurs, telecom operators, local radio journalists, academia, Web Foundation.

COllected materials: Participants list, workshop materials and a trip report by Anna Bon \& Wendelien Tuyp.

\section{B.2.3 Roadshow Mali, Burkina Faso, Ghana 14-26 January 2011}

First VOICES-W4 RA field trip for the VOICES m-Agro Knowledge Sharing Pilot. The trip consisted of field visits, focus group discussions, workshops, technology demos and presentations in rural regions of Mali, Burkina Faso and Ghana.

COLLeCtED MATERials A full trip report is part of EU-FP7 VOICES project deliverable 1.1. Use case descriptions also included.

Editors of D1.1: Anna Bon \& Hans Akkermans, authors: Hans Akkermans, Anna Bon, Nana Baah Gyan, Victor de Boer, Chris van Aart, Wendelien Tuyp, Stéphane Boyera, Aman Grewal, Mary Allen, Ralph Ankri, Emmanuelle Boyer, Moustafa Zouinar, JeanMarie Preira, Christophe Longuet, Jenny de Boer, Nienke Akkermans, Onno Wassenaar.

Document available at: https ://w4ra.org/wp - content/uploads/2014/08/V0ICES_D1. 1-v1.0-VUA_FT-28Sep2011-final . pdf Raw data: audio files and photography of complete workshop.

\section{B.2.4 Roadshow Ségou, San, Tominian, Mali 12-19 November 2011}

Second VOICES-W4RA Field Trip -m-Agro Knowledge Sharing Pilot; First iteration cycle deployment of Radio Marché Voice System. The terms of reference for this field trip are summarized below:

- Install Radio Marché Voice System in Mali;

- Test and validate the system under field conditions;

- Show and teach the local end-users how the system works;

- Get as much feed-back as possible on usability and new requirements; 
- Deploy it in Mali during six months until May 2012;

- Collect as much information as possible from stakeholders to ensure sustainable business models beyond the lifespan of the project.

COllected materials: The trip report and all VOICES deliverables, related to the field work and development in this Mali pilot available at: https://w4ra.org/ publications/voices/ Two documentaries about this project, produced by Victor de Boer, Anna Bon, Bruno van Moerkerken and others is available at: https://w4ra.org/ films/the - web - of - voices - documentary/

\section{B.2.5 Foroba Blon use case E requirements collection 12-16 February 2012 Mali}

Field trip for the selection of a use case, and to collect end-user feedback about the already implemented Radio Marché system (for VOICES). Radio ORTM Ségou and Radio Moutian were visited during this trip, organized by Sahel Eco.

COLLECTED MATERials: All audio files and photography of the workshop systematically collected and stored.

\section{B.2.6 Field tests 10-19 November 2012 in Mali}

The objective of this field trip was to do user evaluations for the second cycle iterative development. The following activities were carried out by the full team.

- Discuss with Amadou Tangara (Sahel Eco) his recent evaluation visit to 7 radio stations in Oct 2012, the evaluation forms he received during this trip; sales info on Radio Marché;

- Testing and validation and verification of the Radio Marché and Foroba Blon systems under field conditions;

- Show and teach the local end-users how the Tabale (m-event) system works;

- Get as much feed-back as possible on usability and validate and verify functional and non-functional requirements;

- Recording prompts for Foroba Blon in French and Bambara (Tangara's voice) and Bomu (Bakery's voice)

- Recording name of new producer for RM: Emile Keita in Bambara and Bomu

- Evaluation of TTS in Bambara and Bomu by native speakers 
- Record names of new producers;

- Collect as information, as possible, from all stakeholders to understand and work towards sustainable business models beyond the lifespan of the VOICES project.

COLLECTED MATERIAls A trip report, technical documentation, recordings, photography, films, translation, audio files for voice application Foroba Blon.

\section{B.2.7 Evaluation and dissemination workshop 21-28 April 2013 workshop Mali}

Objective of this conference was to present, discuss and evaluate the results of the magro knowledge sharing pilot of the VOICES project and discuss this with end-users and stakeholders in Mali.

COLlected MATERials All workshop materials and a trip report are available. Includes an (unstructured) evaluation interview with Malian farmers Zakary Diarra, Naomi Dembel é by Anna Bon and Bianivo Mounkoro. Field trip by Wendelien Tuyp \& Anna Bon.

B.2.8 13-18 January 2014 Needs assessment $\mathcal{E}$ use case and requirements workshop with NGO, Farmers and radio journalists in Ségou, Mali

- 14 January (Tuesday) visit to Malian ICT company Yeleman, in Bamako; trip to Ségou by car

- 14-18 January workshop with Sahel Eco staff and partners in hotel Esplanade;

- 18 January (Saturday) road trip back to Bamako; meeting Chris Reij at Hotel Résidence Bouna;

- 19 January (Sunday) Workshop and demos (tree app Mr. Jiri) with Mady Sidibe and others at farmer organization AOPP office in Bamako.

B.2.9 19-22 January 2014 Needs assessment and use case and requirements workshops in Burkina Faso

- 20 January (Monday) Travel to Gourcy and Ouahigouya; meeting farmer Ousseini Zoromé; visit four radios;

- 21 January (Tuesday) Meeting Ousseini Kindo, four farmer innovators in Gourcy; Meeting officials of the ministry of agriculture in Yako; 
- 22 January (Wednesday) Meeting at local telecom operator Airtel in Ouagadougou; debriefing at Réseau MARP;

Collected materials Trip report by Anna Bon. All meetings of this trip are audio taped, filmed; photos are available upon request.

B.2.10 30 April-2 May 2014

Continuation of needs assessment and use case and requirements workshop Burkina Faso.

- 30 April 2014 First workshop meeting with Sahel Eco in Gourcy; Stay in Ouahigouya;

- I May 2014 (Thursday) seminar with Sahel Eco staff Réseau MARP and Radio Stations in Ouahigouya;

- 2 May 2014 (Friday) seminar with Sahel Eco staff, Réseau Marp and 5 farmer innovators from Yatenga. Arrival late night in Ouagadougou by car.

COllected materials A trip report is available; and all meetings of this trip are systematically audio taped, filmed, photos are available

\section{B.2.11 Burkina Faso workshop 18-28 July 2014}

Continuation of needs assessment and use case and requirements workshop in Burkina Faso

- 19 July Arrival of CARE Niger team at hotel Ricardo:

- 20 July Sunday Visit to young ICT network organization Ouagalab in Ouagadougou;

- 21 July Monday Visit to Réseau Marp; visit to the Meteo service of Burkina Faso;

- 22/7 Tuesday workshop in Gourcy with group of farmers-innovators;

- 23/7 Wednesday Meeting four radio stations at La Voix du Paysan; recordings of voices in Mooré;

- 24/7 Thursday workshop at Radio; lunch chez Francine; back to hotel Ricardo;

- 25/7 Friday debriefing with Mathieu and CARE Niger at Réseau MARP; meeting Ouagalab;

COLLECTED MATERIALs A trip report is available; all meetings of this trip are systematically audio taped, filmed, photographed. 
B.2.12 29 July-1 August 2014

Continuation of needs assessment and use case and requirements workshop in Mali

- 29 July Workshop Ségou hotel Esplanade with Sahel Eco and partners;

- 30 July Workshop Ségou;

- 31 July Meeting local ICT SME Yeleman and AOPP at their office;

- I August Debriefing at Sahel Eco office in Bamako.

A TRIP REPORT BY ANNA BON IS AVAILABLE; ALL MEETINGS OF THIS TRIP ARE SYSTEMATICALLY AUDiO TAPED, FILMED, PHOTOGRAPHED.

\section{B.2.13 ICT workshops in Walewale Ghana, 9-12 December 2014}

Needs assessment Use case and requirements workshop in Walewale Ghana with researchers from UDS; field visit and focus groups with Guabuliga community on 11 December.

All meetings of this trip are systematically audio taped, filmed, photos are available. Written materials from the workshop are available. A short film is produced of this workshop.

https : //w4ra. org/2015/01/05/new-w4ra-documentary-living-labs - in - rural - africa/

\section{B.2.14 ICT workshops in Walewale Ghana 27 April-1 May 2015}

Needs assessment and use case and requirements workshop in Walewale, Ghana with researchers from UDS; field visit and focus groups to Guabuliga community on 30 April.

COLlected MATERials All meetings of this trip are systematically audio taped, filmed, photos are retrievable upon request.

\section{B.2.15 Farmers needs assessment workshop in Mali 8-12 October 2015}

AOPP farmers needs assessment use case and requirements workshop in Bamako including field visit to farmers field and urban farmer women cooperation.

collected materials A trip report by Anna Bon \& Wendelien Tuyp. All meetings of this trip are systematically audio taped, filmed, photos are available. 
B.2.16 Ghana field trip 12-19 December 2015

Field trip to Tacoradi, and Tamale Ghana. Context analysis, visiting a shea butter cooperation, interview a local veterinary.

COLLECTED MATERIALS Trip report; all meetings of this trip are systematically audio taped, filmed, photos are available.

B.2.17 Interview with Mary Allen, 15 February 2016

Skype interview Anna with Mary Allen about history of Regreening in Mali. Audio and text available.

B.2.18 Goal constructing workshops with farmer organization AOPP - 12 May 2016 Mali

Workshop at AOPP office with group of AOPP members (participants list available).

COLLECTED MATERIALS Trip report; all meetings of this trip are systematically audio taped, filmed, photos are available.

\section{B.2.19 Meteo trip 20-25 June 2016 Burkina Faso}

Needs assessment and use case and requirements workshop with farmers and radio journalists about meteo - Gourcy and Ouahigouya

COLLECTED MATERIALS Trip report; all meetings of this trip are systematically audio taped, filmed, photos are available.

B.2.20 Goal constructing with AOPP farmers 26-27 June 2016 Mali

Use case and requirements workshop at AOPP.

Collected materials Trip report by Anna Bon and Wendelien Tuyp; all meetings of this trip are systematically audio recorded, filmed, photos are available.

B.2.21 Prototype testing and dissemination activities, 12-15 October 2016 Bamako, Mali

- Prototype tests of Kasadaka platform and Foroba Blon with Tangara, Adama Tessougué at AOPP office, 12 October 2018. 
- Green Climate Fund workshop at AOPP office, 13 October 2016.

- Visit and dialogue with Yeleman, Malian SME in ICT, 14 October.

- Interviews with Amadou Tangara, 15 October.

COLLECTED MATERials Trip report, technical documentation, new use cases and all meetings and interviews of this trip are systematically audio taped, filmed, photos are available.

\section{B.2.22 Meteo needs and requirements, 6-12 February 2017, Burkina Faso}

Continuation of use case and requirements workshop, including user tests with farmers and radio journalists. Field visits to farmers who collect rain data in the environment of Bassi, near Gourcy, Burkina Faso.

COLLECTED MATERIALS Trip report and all meetings of this trip are systematically audio taped, filmed, photos are available.

\section{B.2.23 Green Sahel trip to Burkina Faso, 4-7 July 2017}

Participants: Hans Akkermans, Anna Bon, Wendelien Tuyp (VU), Seydou Tangara, Souleymane Diarra (AOPP Mali), Amadou Tangara (Radio Rural Mali), Mathieu Ouedraogo, Julien Ouedraogo (Réseau MARP).

Ouagadougou, workshop at the office of Réseau MARP, 4-6 July.

Ouahigouya, 7 July: Field trip and visit to innovative farmers of the Yatenga region 7 July 2017. All meetings of this trip are systematically audio recorded; photos are available. Participants:: Anna Bon, Wendelien Tuyp, Hans Akkermans.

\section{B.2.24 Malivert workshop, 10, 11 July 2017, Bamako, Mali}

Workshop at AOPP office, Bamako. Topic: how to support farmer innovation with ICTs and effective local communication.

COLLECTED MATERIAls The meetings of this trip are systematically audio taped. Materials are available.

\section{B.2.25 User tests of Foroba Blon, 12 to 16 February 2018, Mali}

Bamako User tests of Foroba Blon system with end-users from Radio Sikidolo. 
Needs assessment with AOPP about seeds; user testing with Adama Tessougué in Konobougou. Testing of Foroba Blon new version.

B.2.26 Workshop and field visit in Sarawak, Malaysia 28 August - 1 September 2017

Collected materials A trip report by Anna Bon and Victor de Boer is available and all meetings of this trip are systematically audio recorded, photos are available. A film about regreening by Chris van Aart and Wendelien Tuyp is available.

COLLECTED MATERIALS The trip report and all meetings of this trip are systematically audio recorded, photos are available.

B.2.27 Explorative discussions about ICTs for seeds and meteo: 19, 20 February 2018 Tamale, Ghana

Visit to Savanna Institute, visit to a sheabutter cooperative. Discussions about development of seed system value networks, and serving rural communities using ICT.

collected materials A trip report by Anna Bon and Victor de Boer is available and all meetings of this trip are systematically audio recorded, photos are available. A film about regreening by Chris van Aart and Wendelien Tuyp is available.

B.2.28 ICT 4 D in the Field, Sarawak Malaysia 7 June - 2 July 2018

A 6-ECTS course for a mixed group of students from VU and UNIMAS. Three student projects for the community of Kampung Pinggan Jaya: BannaTree, Appong, EDUCOMX.

COllected materials Three student reports, audio, video, notes, three short clips by Leeuw, prototypes, reflection reports of students, presentation slides.

B.2.29 Seed value chain in Mali, AOPP preparation trip Bamako 16 - 25 February 2019

Visit to Bamako and one field trip to the field of AOPP, south of Bamako. Discussions and interviews.

COLLECTED MATERIALS Trip report, notes, photos.

B.2.30 Seed value chain in Mali, AOPP workshop with farmers Bamako 23 - 29 April 2019

Workshop with farmers from AOPP, Bamako, including fieldtrip to Sibi. 
COLLECTED MATERIALS Trip report, notes, photos, field notes, presentations, use cases by students, video, audio recordings.

B.2.31 ICT4D in the Field, Sarawak Malaysia 5 June - 2 July 2019

A 6-ECTS course for a mixed group of students from VU and UNIMAS. Two student group projects: Majunet and Dengaway and three individual master research projects in $\mathrm{ICT}_{4} \mathrm{D}$ (ICT4"E" is education).

B.2.32 Seed value chain in Mali, AOPP workshop with farmers Bamako, 12-21 January 2020

Workshop with farmers from AOPP, Bamako.

COLLECTED MATERials Trip report, notes, photos, field notes, presentations, use cases by students, video, audio recordings. 
Table 11: List of use cases which we collected in West Africa during the research period 20092020, and which are described in this thesis. The use cases collected by my students during the $\mathrm{ICT}_{4} \mathrm{D}$ in the Field course in Sarawak, Malaysia in 2018-2019, which are briefly described in Chapter 10, are not included in this list.

\begin{tabular}{|c|c|c|c|c|c|}
\hline Use case & Country & Period & In thesis & Technology & Project \\
\hline RadioMarché & Mali & $2011-2013$ & $\mathrm{Ch}_{7}$ & $\begin{array}{l}\text { GSM \& } \\
\text { radio } \\
\text { web }\end{array}$ & $\begin{array}{l}\text { VOICES/ } \\
\text { W4 }_{4} \text { A }\end{array}$ \\
\hline Tabalé & Mali & 2011-2014 & Ch 6 & GSM, web & $\begin{array}{l}\text { VOICES/ } \\
\text { W4RA }\end{array}$ \\
\hline Foroba Blon & Mali & $2011-2020$ & Ch 8 & $\begin{array}{l}\text { GSM, } \\
\text { radio }\end{array}$ & $\begin{array}{l}\text { Foroba } \\
\text { Blon/W4RA }\end{array}$ \\
\hline Semences & Mali & $2015-2020$ & $\mathrm{Ch}_{5}$ & GSM, web & $\begin{array}{l}\text { W4RA/ } \\
\text { TMT-AOPP }\end{array}$ \\
\hline Mali Milk & Mali & $2017-2020$ & $\mathrm{Ch}_{5}$ & GSM, web & $\begin{array}{l}\text { W4RA/ } \\
\text { TMT-AOPP }\end{array}$ \\
\hline Mr. Meteo & $\begin{array}{l}\text { Ghana, } \\
\text { Burkina } \\
\text { Faso }\end{array}$ & $2016-2020$ & $\mathrm{Ch}_{5}$ & $\begin{array}{l}\text { GSM, radio, } \\
\text { web }\end{array}$ & $\begin{array}{l}\text { UDS W4RA } \\
\text { TMT R-MARP }\end{array}$ \\
\hline Mr. Jiri & Mali & 2014 & - & $\begin{array}{l}\text { Smartphone, } \\
\text { GPS }\end{array}$ & $\begin{array}{l}\text { TMT } \\
\text { Sahel Eco/ } \\
\text { W4RA }\end{array}$ \\
\hline DigiVet & Ghana & $2015-2016$ & $\mathrm{Ch}_{5}$ & $\begin{array}{l}\text { Smartphone, } \\
\text { GSM, } \\
\text { expert system }\end{array}$ & $\begin{array}{l}\text { UDS/NIAA/ } \\
\text { W4RA }_{4}\end{array}$ \\
\hline $\begin{array}{l}\text { Vaccination } \\
\text { des poules }\end{array}$ & Mali & 2016 & - & GSM, web & $\begin{array}{l}\text { AOPP/ } \\
\mathrm{W}_{4} \mathrm{RA}\end{array}$ \\
\hline Bip Vote & Mali & 2016-2018 & - & $\begin{array}{l}\text { GSM, web, } \\
\text { radio }\end{array}$ & $\begin{array}{l}\text { Radio } \\
\text { Sikidolo/ } \\
\mathrm{ICT}_{4} \mathrm{D} \\
\text { course }\end{array}$ \\
\hline Kasadaka & Ghana & 2015-2019 & $\mathrm{Ch}_{7}$ & $\begin{array}{l}\text { Small } \\
\text { hardware, } \\
\text { GSM, web }\end{array}$ & $\mathrm{W}_{4} \mathrm{RA}$ \\
\hline
\end{tabular}



LIST OF DATA 2009-2020

C.I TRIP REPORTS

2009 Trip_BF_W4RA_Fieldvisit

2010 Trip_BF_Workshop W4RA_WebFoundation_2010

2011 Trip_Mali_Nov_2011_W4RA_VOICES

2011 Trip_W4RA_VOICESRoadshow _Jan 2011

2012 Trip_Mali Feb 2012-W4RA ForobaBlon

2012 Trip_Mali Nov2012_W4RA VOICES_ForobaBlon

2013 Final_Mali_W4RA_VOICES trip and Conference 23Apr2013

2014 Trip_Mali_BF_January

2015 Trip_Ghana UDS Dec 2015

2015_2016_TMT AOPP Trip reports

2015 Trip_Mali TMT_AOPP_Bamako-October

2016 Trip_Mali_0ct 2016_GCF

2016 Trip_Mali_TMT_AOPP-May

2016 Trip _BF_TMT_RM__Juni

2017 Trip_BF_TMT-RM_Febr

2018 Trip_Mali_BF_GHana_Febr

2019 Trip Mali_RC_February_AOPP_Bamako

2019 Trip Mali RC_April_Workshop_AOPP_Bamako_Sibi

2019 Trip Sarawak ICT4D_in the Field

2020 Trip Mali RC_January_AOPP_Workshop

C.2 FOLDER STRUCTURE OF ALL DATA 2009 - 2020

W4RA_2009_09 Trip Burkina Faso Sep2009

W4RA_2010_02workshop _Burkina feb 2010

W4RA_2011_1-VOICES Req_Use_Cases Roadshow West Africa 14-26Jan2011

W4RA_2011_11Nov_VOICES Recordings_etc_trip_Mali_12-20Nov2011

W4RA_2011_1_Jan_Roadshow

W4RA_2012_2 Videos and Photos Mali Field Trip Feb2012

W4RA_2012_Nov-FB_Fieldtrip_Mali_11-18

W4RA_2012_Trip to Mali Nov_2012_collected_data

W4RA_2013-VOICES videos of Final Conference Bamako 23Apr2013

W4RA_2013-VOICES videos post-Conference Bamako 24-26Apr2013 
W4RA_2014_1-TMT-Fieldtrip-Mali_Burkina-13_23Jan2014

W4RA_2014_12 TMT-Ghana Walewale Workshop 06_16Dec2014

W4RA_2014_4_DGIS Field Trip 30Apr2014 Gourcy farmers video

W4RA_2014_5 DGISBurkina R_MARP_ownworkshops_video_photo

W4RA_2014_5_DGIS Field Trip Burkina Mali 29Apr-07May2014

W4RA_2014_8 DGIS trip Burkina Mali 19Jul-02Aug2014

W4RA_2015_10 TMT-Mali_A0PP_08-150ct2015

W4RA_2015_12 trip Ghana_Tacoradi_Tamale_BF 12-19Dec2015

W4RA_2015_4TMT Trip Ghana Walewale 25Apr-02May2015

W4RA_2016_05_TMT-Mali_A0PP_02 - 12May2016

W4RA_2016_06_MT-BF et Mali 19-27Jun2016

W4RA_2016_06_TMT_BF_Demo docs TMT-BF_Mali 19-26Jun2016

W4RA_2016_10_Mali_GCF_AOPP_Trip_10-170ct2016

W4RA_2017_02_Abidjan_BF_Gourcy_TMT_Mali_Bamako_AOPP_4_17feb2017

W4RA_2017_07_Droomfonds_Malivert_workshops_2-11July2017

W4RA_2017_08_Malaysia_SARAWAK_trip 24-31Aug2017

W4RA_2017_1_ TMT Burkina GCF Mali 04-17Feb2017

W4RA_2018_02_Mali-BF-Gh_trip_10-27Febr2018

W4RA_2019_02_Mali-OKP_RC_AOPP_Preparation_Seeds

W4RA_2019_04_Mali-OKP_RC_AOPP_Workshop-Seeds_and_Sibi_fieldvisit

W4RA_2019_06_Sarawak_ICT4D_in_the_Field_UNIMAS

W4RA_2020_01-Ghana_Erasmus_UDS_ICT4D - prep

W4RA_2020_01-Mali_OKP_RC_AOPP_Seeds_workshop

C.3 DATA FROM FIELD RESEARCH 2009 - 2020

C.3.1 2009 - Trip Burkina Faso, September

Handout W4RA 0ct 09.pdf

Mathieu Ouedrago en Yacouba Sawadogo.doc

Mathieu Ouedrago, Yacouba Sawadogo,Chris Reij.doc

Photos Anna Bon Burkina Faso 27-29Sep2009

Photos Anna Bon Dies 200ct2009

SRI activity report no.7.doc

SRI two page overview.doc

Sahel_Regreening_Initiative-presentation-CIS-VU-Jun2009.ppt

Semantic_Web_Revisited-IEEE_IS-May2006.pdf

Stories - Mobile Web in Developing Countries Wiki.mht

TheManWhoStoppedThe Desert-1.jpg

Uitnodiging Dies symposium 200ct2009 A4.pdf

VU Connected Closing Remarks Rene Smit Dies Symposium 200ct2009 v23Sep2009.doc 
VUA WebSci edu and research and Web Foundation-HansA- 29Sep2009.doc Yacouba Mathieu and Hans.jpg

Yacouba_1-hres.jpg

WWW-vu-nl_en_news-agenda_news_2009_juli-september_Inventor-of-the-WWW-g.pdf

C.3.2 2010 - Trip Burkina Faso, field visit and workshop

Atelier 4 fevrier.doc

Economist-Special-Report-Mobile-Marvels-26Sep2009.pdf

Final report French.doc

Final report Workshop Mobile Web for Rural Development.doc

ICTs and Rural Dev review of literature.pdf

Participant list 4 feb 2010.xls

Proposal W4RA kick-off project application NLnet 30Jan2010.pdf

Rapport besoins information vfinal 271009.doc

Report Workshop 3 feb.doc

Two page for proposal.doc

User discussion last day workshop groups_information needs update_Mary Allen

SahelEco-Poster-Fiche technique Karite en Francais.ppt

SahelEco_Reverdir-le-Sahel-photo reportage+videotexts-2010

SahelEco_Reverdir-le-Sahel-promo-videos-DVD-2010

\section{C.3.3 2011 - VOICES Roadshows}

DATA VOICES ROADSHOW WEST AFRICA 14-26 JANUARY 2011

01a W4RA Roadshow video Workshop Bamako Sat 15Jan2011 morning

01b W4RA Roadshow audio Workshop Bamako Sat 15Jan2011 morning

02a W4RA Roadshow video Radio ORTM Segou Sat 15Jan2011 evening

02b W4RA Roadshow audio Radio ORTM Segou Sat 15Jan2011 evening

03a W4RA Roadshow video Radio Moutian Mopti Sun 16Jan2011

03b W4RA Roadshow audio Radio Moutian Tominian Sun 16Jan2011

04a W4RA Roadshow video farmerinterview ORTM Mopti_RadioBaguineMon17012011morning

04b W4RA Roadshow audio famerinterview ORTM Mopti_RadioBaguineMon17012011morning

05a W4RA Roadshow video Workshop Bandiagara Mon 17Jan2011 afternoon

05b W4RA Roadshow audio Workshop Bandiagara Mon 17Jan2011 afternoon

06a W4RA Roadshow video Bankass Tue 18Jan2011

06b W4RA Roadshow audio Radio Seno Bankass Tue 18Jan2011 morning

07a W4RA Roadshow video Ousseni Yacouba Wed 19Jan2011 morning

07b W4RA Roadshow audio Ousseni Yacouba Wed 19Jan2011 morning

08a W4RA Roadshow video Interview La Voix du Paysan Ouahigouya Wed 19Jan2011 midday 
08b W4RA Roadshow audio Interview La Voix du Paysan Ouahigouya Wed 19Jan2011 midday 09a W4RA Roadshow video Workshop Gourcy Wed 19Jan2011 afternoon 09b W4RA Roadshow audio Workshop Gourcy Wed 19Jan2011 afternoon 10a W4RA Roadshow video Workshop Ouagadougou Thu 20Jan2011 10b W4RA Roadshow audio Workshop Ouagadougou Thu 20Jan2011 11a W4RA Roadshow video Workshop Tamale Sat 22Jan2011 morning 11b W4RA Roadshow audio Workshop Tamale Sat 22Jan2011 morning 12 W4RA Roadshow audio GBC Radio Savannah Tamale Sat 22Jan2011 afternoon 13 W4RA Roadshow visit Upper East World Vision Sun 23Jan2011 14a W4RA Roadshow video Workshop Bolgatanga Mon 24Jan2011 14b W4RA Roadshow audio Workshop Bolgatanga Mon 24Jan2011 15 W4RA Roadshow radio capture

DATA ROADSHOW MALI, NOVEMBER 2011

W4RA_2011_11Nov_VOICES Recordings_etc_trip_Mali_12-20Nov2011 01b_W4RA-V0ICES_trip_Mali_Nov2011_Bamako_Sun13 Nov2011-video 02a_W4RA-VOICES_trip_Mali_Nov2011_Bamako_Mon14 Nov2011-audio 02b_W4RA-V0ICES_trip_Mali_Nov2011_Bamako_Mon14 Nov2011-video 03a_W4RA-VOICES_trip_Mali_Nov2011_Segou_ORTM_Tue15 Nov2011-audio 03b_W4RA-VOICES_trip_Mali_Nov2011_Segou_ORTM_Tue_15 Nov2011-video 04a_W4RA-V0ICES_trip_Mali_Nov2011_Segou_TreeAid_FocusGroup_Tue15 Nov2011-audio 04b_W4RA-VOICES_trip_Mali_Nov2011_Segou_TreeAid_FocusGroup_Tue15 Nov2011-video 05b_W4RA-VOICES_trip_Mali_Nov2011_San_Wed16 Nov2011-video 06a_W4RA-VOICES_trip_Mali_Nov2011_San_SahelEco_Project0verview_Thu17 Nov2011-audio 07a_W4RA-VOICES_trip_Mali_Nov2011_San_SahelEco_FocusGroup_Thu17Nov2011-audio 07b_W4RA-VOICES_trip_Mali_Nov2011_San_SahelEco_FocusGroup_Thu17 Nov2011-video 08b_W4RA-VOICES_trip_Mali_Nov2011_Tominian_Radio-Moutian_Thu17 Nov2011-video 09b_W4RA-VOICES_trip_Mali_Nov2011_Tominian_Karite-tree-field_Thu17 Nov2011-video 10a_W4RA-VOICES_trip_Mali_Nov2011_Bamako_Sat19 Nov2011-audio 10c_W4RA-VOICES trip_Mali_13-18Nov2011-photos

\section{OTHER DOCUMENTS 2011}

Deliverable documents VOICES-D1.1 and VOICES-D5.1

Voices-W4RA_Public_Report_V2.1.pdf

Fiche technique Karite en Francais.pdf

Fiche technique Karite en Francais.ppt

ISWC - Gueret - awardwinning - out rageous - idea -W4RA - 270ct2011. pptx

Out rageous - Ideas - Award - 1stPrize-ISWC - Bonn-270ct2011.jpg

Out rageous - Ideas - Award-3rdPrize-ISWC-Bonn-270ct2011.jpg

REFSQ - v020ct2011. tex 
RM_Mode_d-emploie_0NG_comstore.ppt

Refsqv28Sep2011.pdf

W4RA-VOICES-WP5pilot-UMFarmer_comstore.ppt

WorldBank-SahelprogrWB0001-27Sep2011.pdf

Final_outrageous_ideas_ISWC_VOICES-Aart.pdf

Final_outrageous_ideas_ISWC_VOICES-Gueret.pdf

Radio_programme_mali_nov2011.docx

Communiques RadioMarche

C.3.4 2012, W4RA Foroba Blon Mali

W4RA 2012 FEBRUARY FIELDTRIP MALI:

W4RA Mali field trip videos Feb2012

W4RA Mali field trip photo Feb 2012

W4RA Mali field trip audio Feb 2012

Takes for RadioMarche demo Jan2012

W4RA 2012 NOV-FB FIELDTRIP MALI II-18:

W4RA Mali Fieldtrip 12Nov2012 video Sikidolo en ORTM

W4RA Mali Fieldtrip 12Nov2012 audio Sikidolo en ORTM

W4RA Mali Fieldtrip 12Nov2012 photo Sikidolo en ORTM

W4RA Mali Fieldtrip 13Nov2012 video Segou en San

W4RA Mali Fieldtrip 13Nov2012 audio Segou en San

W4RA Mali Fieldtrip 13Nov2012 photo Segou en San

W4RA Mali Fieldtrip 14Nov2012 audio Tominian

W4RA Mali Fieldtrip 14Nov2012 video Tominian

W4RA Mali Fieldtrip 14Nov2012 photo Tominian

W4RA Mali Fieldtrip 15Nov2012 video

Recordings Segou Fousseyni et Tangara

Recordings Tominian_15nov2012

Recordings_Tangara M-event Bomu \& other records

W4RA_2012_Trip to Mali Nov_2012_collected_data:

Interview_forms 2012 survey RadioMarche

Notes on honey producers in Tominian nov 2012.docx

C.3.5 2013, VOICES trip and final conference Bamako, Mali

W4RA_fieldtrip-Mali_Bamako_22_26April_2013_video

Entretien_et_etude_de_cas_Zakary_Diarra_avril 2013.doc

Interview_Zakary_Diarra_april 2013.doc 
Invitation_conference-VOICES_Senegal20_6_2013_en.pdf

List of participants_23_april

Presentations_conference_Mali_23_4_2013

Flipovers_workshop_23 April_VOICES

Notes_Conference_HansA.JPG

Originals

Handouts

Program_VOICES-FInal_Conference-Bamako-Mali-23Apr2013-program.pdf

Questions and answers conference 23 april.doc

SE_Termes de Reference_conference-VOICES_avril_final.docx

VOICES brochure

Voices-W4RA_Mali_trip_report_Apr_2013

W4RA photos Anna Dakar VOICES conference 18-20Jun2013

ALL DELIVERABLES W4RA-VOICES 2011-2013 M-AGRO PILOT MALI

VOICES_Deliverable 1.1 Use cases and requirements analysis

VOICES_Deliverable $5.1 \mathrm{~m}$-Agro Regreening pilot Specifications and Content

VOICES_Deliverable 5.2 Pilot roll out cycle 1 RadioMarche

VOICES_Deliverable 5.3 Pilot roll out cycle 2 Tabale

VOICES_Deliverable 5.4 Pilot evaluation

VOICES_Deliverable 7.1 Dessimination of the VOICES project

VOICES_Deliverable 7.2 Dessimination and Use Plan

VOICES_Deliverable 7.3 Technical Deployment Plan

C.3.6 2014, New field trips and workshops in Mali, Burkina Faso and Ghana

W4RA TMT MALI, BURKINA FASO, 13 - 23 JANUARY 2014

HansA-Notes_FieldTrip-W4RA-recordings-13_23Jan2014.pdf

W4RA-fieldtrip-14Jan2014-Bamako-presentations_docs

W4RA- fieldtrip-14Jan2014-Bamako-video

W4RA- fieldtrip-15Jan2014-Segou_WS_day1-audio

W4RA-fieldtrip-15Jan2014-Segou_WS_day1-photo

W4RA- fieldtrip - 15Jan2014-Segou_WS_day1-video

W4RA - fieldtrip-16Jan2014-Segou_WS_day2-photo

W4RA - fieldtrip-16Jan2014-Segou_WS_day2-video

W4RA-fieldtrip-17Jan2014-Segou_WS_day3-photo

W4RA-fieldtrip-17Jan2014-Segou_WS_day3-presentations_docs

W4RA-fieldtrip-17Jan2014-Segou_WS_day3-video

W4RA- fieldtrip-Mon20Jan2014-Ouahigouya-audio

W4RA- fieldtrip-Mon20Jan2014-0uahigouya-photo 


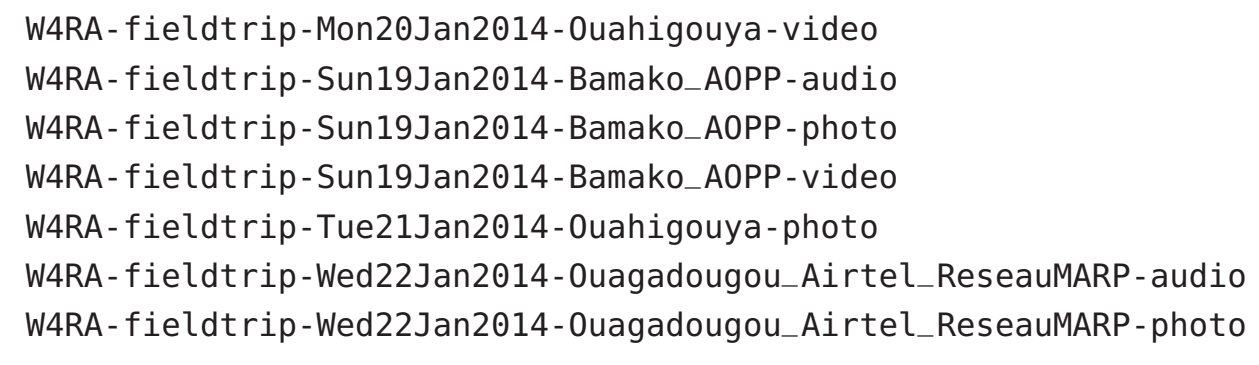

2014 JANUARY: OTHER DOCUMENTS

W4RA Trip report_jan2014_v02_WTP.docx

W4RA_rapportage_de voyage_jan2014_v02.docx

W4RA TMT FIELDTRIP BURKINA FASO, APRIL-MAY 2014

W4RA DGIS Field Trip May2014 Burkina Reseau MARP workshops footage video W4RA DGIS Field Trip O1May2014 0uahigouya radiostations video W4RA DGIS Field Trip O1May2014 Ouahigouya radiostations audio W4RA DGIS Field Trip O1May2014 0uahigouya radiostations photo W4RA DGIS Field Trip 02May2014 Ouahigouya farmers video W4RA DGIS Field Trip 02May2014 Ouahigouya farmers audio W4RA DGIS Field Trip 02May2014 0uahigouya farmers photo W4RA DGIS Field Trip 05May2014 Bamako DGIS partners audio W4RA DGIS Field Trip 05May2014 Bamako Ouaga DGIS partners photo W4RA DGIS Field Trip 30Apr2014 Gourcy farmers audio W4RA DGIS Field Trip 30Apr2014 Gourcy farmers photo W4RA DGIS Field Trip May2014 Burkina Reseau MARP workshops footage photo

2014 APRIL -JUNE: OTHER DOCUMENTS

Burkina Faso_june2014_converted

W4RA_2014_5 DGISBurkina R_MARP_ownworkshops_video_photo: 00229. MTS to 00406 .MTS

Photo formation meteo_Reseau MARP-METE0-delic 2013.docx

W4RA DGIS Field Trip May2014 Burkina Reseau MARP workshops footage photo W4RA-2014-5-DGIS Field Trip Burkina Mali 29Apr-07May2014:

DGIS W4RA Burkina Reseau MARP May2014

Scaling-up re-greening successes Reij_Winterbottom revised draft 09Apr2014.doc TMT - Proposal - UDS - VUA-2014-v1.0.pdf W4RA DGIS trip 29 avril - 7 mai 2014 notes Wendelien.docx W4RA DGIS trip 29Apr-07May2014 notes HansA ateliers and audio.pdf

W4RA 2014 8 DGIS TRIP BURKINA MALI 19JUL-O2AUG 2014: 
20140719 Ouagadougou Anna Sat 19Jul2014 photo

20140720 - FabLab Ouagadougou Sun 20Jul2014 audio

20140720 - FabLab Ouagadougou Sun 20Jul2014 photo

20140720 - FabLab Ouagadougou Sun 20Jul2014 video

20140721 - ReseauMARP Ouagadougou Mon 21Jul2014 audio

20140721 - ReseauMARP Ouagadougou Mon 21Jul2014 photo

20140721 - ReseauMARP Ouagadougou Mon 21Jul2014 video

20140722 - ReseauMARP Farmer-Innovators Gourcy Tue 22Jul2014 audio

20140722 - ReseauMARP Farmer-Innovators Gourcy Tue 22Jul2014 photo

20140722 - ReseauMARP Farmer-Innovators Gourcy Tue 22Jul2014 video

20140723 - ReseauMARP Radio-Stations Ouahigouya Wed 23Jul2014 audio

20140723 - ReseauMARP Radio-Stations Ouahigouya Wed 23Jul2014 photo

20140723 - ReseauMARP Radio-Stations Ouahigouya Wed 23Jul2014 video

20140724 - ReseauMARP Radio-Stations Ouahigouya Thu 24Jul2014 audio

20140724 - ReseauMARP Radio-Stations Ouahigouya Thu 24Jul2014 photo

20140724 - ReseauMARP Radio-Stations Ouahigouya Thu 24Jul2014 video

20140725 - ReseauMARP CARE_Niger Ouagadougou Fri 25Jul2014 music audio

20140725 - ReseauMARP CARE_Niger Ouagadougou Fri 25Jul2014 photo

20140725 - ReseauMARP CARE_Niger Ouagadougou Fri 25Jul2014 video

20140726 - FabLab Yam-Pukri Ouagadougou Sat 26Jul2014 audio

20140726 - FabLab Yam-Pukri Ouagadougou Sat 26Jul2014 photo

2014 JULY: OTHER DOCS

DGIS Project Presentation Mali- BMounkoro-30Jul2014.ppt

DGIS-Burkina Cadre_Logique_DGIS_BF_Consolide.pdf

DGIS-Burkina Cadre_Logique_DGIS_BF_Consolide.xls

DGIS-Burkina-Convention parteanaires terrain.doc

DGIS-Burkina-ReseauMARP-ICRAF_contract_and_log frame-2014 . pdf

DGIS-SahelEco-Besoin en TIC-Segou_Workshop-30Jul2014.xls

W4RA-Chris -20140720-RainApp - LeMeteoImpression . ppt

W4RA-Chris-20140721-Voices_TreeApp-MrTiiga2.ppt

W4RA-FrenchGov-VOICES-Mali-promo_movie-Dec2013.mp4

W4RA-HansA-Architecture-RaasKibaya-pictures-Segou-30Jul2014.pptx

W4RA-Raas_Kibaya-application_modules-30Jul2014.pptx

W4RA-Raas_Kibaya-application_modules.jpg

W4RA-Raas_Kibaya-architecture.jpg

W4RA-Raas_Kibaya-infra_platform.jpg

W4RA-Tangara-Ce que on peut faire tout de suite-30Jul2014.pptx

W4RA-Tangara-Cluster_Formation-30Jul2014.ppt

W4RA-Tangara-VOICES_presentation- DGIS-Segou- 29Jul2014.ppt

W4RA_Atelier_Sahel_Eco_DGIS_Anna-30juillet2014.pptx 
W4RA_Logframe_budget_DGISproject-2014_2015-v28Jul2014.xlsx W4RA_Raas_Kibaya-Ouhahigouya-24Jul2014.pptx Anna-W4RA_team_caricatures-10Jul2014.JPG

W4RA 2014 TMT-GHANA WALEWALE WORKSHOP O6-16DEC 2014:

20141207 W4RA TMT-Ghana Ouagadougou 07Dec2014 photo Anna

20141209 W4RA TMT-Ghana Walewale Workshop 09Dec2014 audio 20141209 W4RA TMT-Ghana Walewale Workshop 09Dec2014 photo Anna 20141209 W4RA TMT-Ghana Walewale Workshop 09Dec2014 video 20141210 W4RA TMT-Ghana Walewale Workshop 10Dec2014 audio 20141210 W4RA TMT-Ghana Walewale Workshop 10Dec2014 photo Anna 20141210 W4RA TMT-Ghana Walewale Workshop 10Dec2014 video 20141211 W4RA TMT-Ghana Guabuliga FieldTrip 11Dec2014 morning audio 20141211 W4RA TMT-Ghana Guabuliga FieldTrip 11Dec2014 morning photo 20141211 W4RA TMT-Ghana Guabuliga FieldTrip 11Dec2014 morning video 20141211 W4RA TMT-Ghana Guabuliga FieldTrip Debriefing 11Dec2014 afternoon audio 20141211 W4RA TMT-Ghana Walewale FieldTrip Debriefing 11Dec2014 afternoon photo 20141211 W4RA TMT-Ghana Walewale FieldTrip Debriefing 11Dec2014 afternoon video 20141212 W4RA TMT-Ghana Walewale Workshop 12Dec2014 audio 20141212 W4RA TMT-Ghana Walewale Workshop 12Dec2014 photo 20141212 W4RA TMT-Ghana Walewale Workshop 12Dec2014 video 20141213 W4RA TMT-Ghana Tiehisuma Shea Butter Women Coop Tamale 13Dec2014 photo 20141213 W4RA TMT-Ghana Tiehisuma Shea Butter Women Coop Tamale 13Dec2014 video

2014, DECEMBER: OTHER DOCS

Programme ICT4 food and water security in Ghana.pdf

Theses_0nur_Serdar-02Dec2014.zip

W4RA TMT Ghana Ouaga trip 06_16Dec2014

W4RA Walewale Workshop presentations 09_12Dec2014

W4RA Walewale film materials 11Dec2014

Walewale W4RA Workshop Field Visit Guabuliga and Debriefing 11Dec2014

W4RA_2014_4_DGIS Field Trip 30Apr2014 Gourcy farmers video:

00005.MTS to 00017 .MTS

\section{C.3.7 2015 Workshops and field trips}

W4RA 2015 1O TMT-MALI AOPP O8-15OCT2015:

01 - W4RA TMT Mali Fri 090ct2015 - Bamako Ambassade - FarmRadio

$02 a$ - W4RA TMT Mali Sat 100ct2015 AOPP - audio 


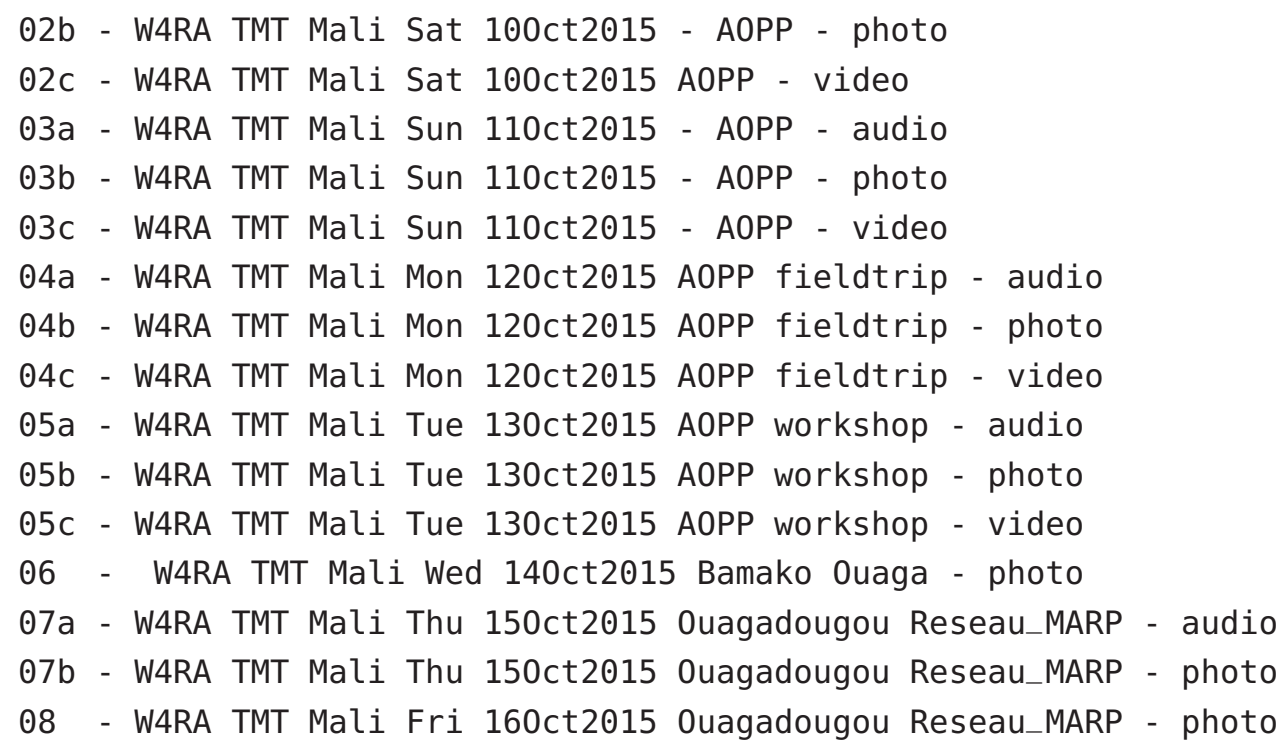

2O15 OCTOBER: OTHER DOCS

Programme Atelier VUA-AOPP 0ctobre 2015.pdf

WRI_Working Paper ISWM in Burkina Faso_FINAL_03Feb2014.pdf

WRI_Working Paper ISWM in Burkina Faso_FINAL_03Feb2014_V2.pdf

WRI_Working Paper ISWM in Burkina Faso_FINAL_January2014.pdf

aopp_8mai.pptx

W4RA 2015 4TMT TRIP GHANA WALEWALE 25APR-O2MAY2O15:

2015 - 04 - 27_W4RA_TMT_Walewale - photo

2015-04-28_W4RA_TMT_Walewale-audio

2015 - 04-28_W4RA_TMT_Walewale - photo

2015-04-28_W4RA_TMT_Walewale-video

2015-04-29_W4RA_TMT_Walewale-audio

2015 - 04 - 29_W4RA_TMT_Walewale - photo

2015-04-29_W4RA_TMT_Walewale-video

2015-04-30_W4RA_TMT_Walewale - audio-Guabuliga

2015-04-30_W4RA_TMT_Walewale - photo-Guabuliga

2015-04-30_W4RA_TMT_Walewale - video-Guabuliga

2015-05-01_W4RA_TMT_Walewale-audio

2015-05-01_W4RA_TMT_Walewale - photo

2015-05-01_W4RA_TMT_Walewale-video

2015 APRIL: OTHER DOCS

W4RA-TMT-Walewale-Apr2015-presentations_reports 
W4RA 2015 TRIP GHANA TACORADI TAMALE BF 12-19 DEC 2015

20151213 W4RA Accra-Takoradi-Santia Sun13Dec2015 - photos

20151214 W4RA Takoradi-Elmina-Cape Coast Mon 14Dec2015 - photos

20151215 W4RA Accra-Tamale Tue15Dec2015 - photo

20151216 W4RA Tamale Wed16Dec2015 - photo

20151217 W4RA Tamale Thu17Dec2015 interview Vet - audio

20151217 W4RA Tamale Thu17Dec2015 - photo

20151218 W4RA Tamale-Bolgatanga-Ouaga Fri18Dec2015 - photo

20151219 W4RA Ouagadougou Sat19Dec2015 - photo

Chris VR_APP

2015 DECEMBER OTHER DOCS

\item Panorama foto's Burkina_ChrisvA

\item W4RA Gossa Digivet Questionnaires

\item W4RA\_Trip-UDSGhana_Dec2015

\item photos Chris (1)

\item photos Chris (2)

C.3.8 2016: Workshops and field trips

W4RA 2016 TMT-MALI AOPP O2-12MAY2016:

00a W4RA TMT-Mali Ouagadougou 01-02May2016 photo

○०b W4RA TMT-Mali Ouagadougou 01-02May2016 video

01a W4RA TMT-Mali Ouagadougou RM Tue 03May2016 audio

01b W4RA TMT-Mali Ouagadougou RM Tue 03May2016 photo

01c W4RA TMT-Mali Ouagadougou RM Tue 03May2016 video

02a W4RA TMT-Mali Bamako AOPP NL-ambassade Wed 04 May2016 audio

02b W4RA TMT-Mali Bamako A0PP Wed 04May2016 photo

02c W4RA TMT-Mali Bamako A0PP Wed 04 May2016 video

03a W4RA TMT-Mali Bamako Farm Radio Int'l Thu 05May2016 audio

03b W4RA TMT-Mali Bamako Thu 05May2016 photo

03c W4RA TMT-Mali Bamako Thu 05May2016 video

04a W4RA TMT-Mali Bamako interview Diakite Fri 06May2016 audio

04b W4RA TMT-Mali Bamako Fri 06May2016 photo

04c W4RA TMT-Mali Bamako SahelEco Fri 06May2016 video

05a W4RA TMT-Mali Bamako-Kokele Sat 07May2016 audio

05b W4RA TMT-Mali Bamako-Kokele Sat 07May2016 photo Anna-Leeuw

05b W4RA TMT-Mali Bamako-Kokele Sat 07May2016 photo HansA

05b W4RA TMT-Mali Bamako-Kokele Sat 07May2016 photo Wendelien 
05c W4RA TMT-Mali Bamako-Kokele Sat 07May2016 video

06a W4RA TMT-Mali Bamako-AOPP_field_trip Sun 08May2016 audio

06b W4RA TMT-Mali Bamako-AOPP_field_trip Sun 08May2016 photo HansA

06b W4RA TMT-Mali Bamako-AOPP_field_trip Sun 08May2016 photo Wendelien

06c W4RA TMT-Mali Bamako-AOPP_field_trip Sun 08May2016 video

07a W4RA TMT-Mali Bamako-AOPP Mon 09May2016 audio

07b W4RA TMT-Mali Bamako-AOPP Mon 09May2016 photo Anna

07b W4RA TMT-Mali Bamako-AOPP Mon 09May2016 photo HansA

07b W4RA TMT-Mali Bamako-AOPP Mon 09May2016 photo Wendelien

07c W4RA TMT-Mali Bamako-AOPP Mon 09May2016 video

08a W4RA TMT-Mali Bamako-AOPP Tue 10 May2016 audio

08b W4RA TMT-Mali Bamako-AOPP Tue 10 May2016 photo Chris

08b W4RA TMT-Mali Bamako-AOPP Tue 10 May2016 photo HansA

08b W4RA TMT-Mali Bamako-AOPP Tue 10May2016 photo Victor

08b W4RA TMT-Mali Bamako-AOPP Tue 10 May2016 photo Wendelien

08c W4RA TMT-Mali Bamako-AOPP Tue 10 May2016 video

09a W4RA TMT-Mali Bamako-Farm_Radio_Int'l Wed 11May2016 audio

09b W4RA TMT-Mali Bamako-Farm_Radio_Int'l Wed 11May2016 photo

2016 MAY: OTHER DOCS

Le \_web\_par\_la\_voix.mov

TMT Mali trip AOPP 02-12May2016

W4RA presentations at AOPP 8-10May2016

W4RA_Fotos_MaliA0PP2016_Anna'sPhone

rmdemo3.wmv

W4RA 2016 BF ET MALI 19-27 JUNE 2016

20160620 TMT-BF Ouaga Gourcy Mon 20Jun2016 photo Anna

20160621 TMT-BF Atelier Gourcy Tue 21Jun2016 audio

20160621 TMT-BF Atelier Gourcy Tue 21 Jun2016 photo

20160621 TMT-BF Atelier Gourcy Tue 21Jun2016 video

20160622 TMT-BF Atelier Gourcy Wed 22Jun2016 audio

20160622 TMT-BF Atelier Gourcy Wed 22Jun2016 photo

20160622 TMT-BF Atelier Gourcy Wed 22Jun2016 video

20160623 TMT-BF Field Visits Wed 23Jun2016 audio

20160623 TMT-BF Field Visits Wed 23 Jun2016 photo

20160623 TMT-BF Field Visits Wed 23 Jun2016 video

20160624 TMT-BF Atelier Gourcy Fri 24Jun2016 audio

20160624 TMT-BF Atelier Gourcy Fri 24Jun2016 photo

20160624 TMT-BF Atelier Gourcy Fri 24Jun2016 video 
20160624 TMT-BF Foroba_Blon_demo-Messages_Atelier_Gourcy

20160626 TMT-BF Mali Bamako Tangara demos Sun 26Jun2016 photo

20160626 TMT-BF Mali Bamako Tangara demos Sun 26Jun2016 video

20160627 TMT-BF Mali Bamako AOPP demos Mon 27Jun2016 audio

20160627 TMT-BF Mali Bamako AOPP demos Mon 27Jun2016 photo

2016 JUNE: OTHER DOCS

BF Trip reportJune 2016

ChickenVaccination_document_june_2016.pdf

ForobaBlonMessagesGourcy24Juin

ForobaBlon_Kasadaka_WebInterface.png

Guide Foroba-blon VU 25Jun2016 3.0_Fr\&Eng.docx

TMT-AOPP mai 2016_rapportage

TMT-BF group results flipovers summary 23 Jun 2016.docx

W4RA_Fotos_Mali-AOPP-May2016_Anna'sPhone

foroba-blon guide VU 25Jun2016 2.0.docx

old presentations related to ateliers $\mathrm{BF}$

presentations at TMT-BF atelier 21-24Jun2016

snapshots Foroba_Blon_Kasadaka demo Gourcy 23Jun2016

W4RA 2016 GCF VISIT BAMAKO, RRI, GCF, AOPP, YELEMAN, TANGARA

W4RA_2016_10_Mali_GCF_AOPP_Trip_10-170ct2016:

20161012 RRI Tangara Adama_FB AOPP Wed 120ct2016 audio

20161012 RRI Tangara Adama_FB AOPP Wed 120ct2016 photo

20161012 RRI Tangara Adama_FB AOPP Wed 120ct2016 video

20161013 GCF Workshop AOPP Thu 130ct2016 audio

20161013 GCF Workshop AOPP Thu 130ct2016 photo

20161013 GCF Workshop AOPP Thu 130ct2016 video

20161014 Yeleman 140 ct2016 photo

20161014 Yeleman Fri 140ct2016 audio

20161015 Tangara Sat 150ct2016 audio

20161015 Tangara Sat 150ct2016 photo

2016 OCTOBER: OTHER DOCS

AOPP-coordinates - P1010753.JPG

Chris - Bamako - 0ct2016

Mali GCF Atelier Liste des Participants AOPP_130ct2016.doc

Mali Selectie Gossa Lo

Participants_GCF_Workshop-130ct2016-HansA-audio_notes_Mali-10-160ct2016.pdf

Plan d'Action Climate Change Mali CPDN_MALI_VFsegal-Sep2016.pdf 
Tangara - Emissions CRP1 SIKIDOLO

Tangara -Emissions CRP1 KAFOKAN

ForobaBlonMessagesGourcy24Juin

TMT-BF flipovers groups I-II-III results Day 121 Jun2016

TMT-BF flipovers groups I-II-III results Day 2 22Jun2016

W4RA_demos_BF_june2016

\section{C.3.9 2017: Field trips and workshops}

W4RA 2017 TMT BURKINA FASO MALI O4-17 FEB 2017

20160626 W4RA TMT Burkina Faso Jun2016 materials

20170206 RESEAU MARP meteo docs 06Feb2017

20170206 W4RA TMT Burkina GCF Mali Mon 06Feb2017 audio

20170206 W4RA TMT Burkina GCF Mali Mon 06Feb2017 photo HansA Wen

20170206 W4RA TMT Burkina GCF Mali Mon 06Feb2017 video HansA

20170206 W4RA TMT Burkina GCF Mali Mon 06Feb2017 video photo Andre

20170207 Meteo data files Chris van Aart 07Feb2017

20170207 W4RA TMT Burkina GCF Mali Tue 07Feb2017 audio

20170207 W4RA TMT Burkina GCF Mali Tue 07Feb2017 document scans Andre

20170207 W4RA TMT Burkina GCF Mali Tue 07Feb2017 photo HansA Wen

20170207 W4RA TMT Burkina GCF Mali Tue 07Feb2017 video HansA

20170207 W4RA TMT Burkina GCF Mali Tue 07Feb2017 video photo Andre

20170207 W4RA TMT Burkina Pieces Comptables Reseau MARP Tue 07 Feb2017 photo HansA

20170208 W4RA TMT Burkina GCF Mali Wed 08Feb2017 audio

20170208 W4RA TMT Burkina GCF Mali Wed 08Feb2017 photo

20170208 W4RA TMT Burkina GCF Mali Wed 08 Feb2017 slot-filler audio Andre

20170208 W4RA TMT Burkina GCF Mali Wed 08Feb2017 video HansA

20170209 W4RA TMT Burkina GCF Mali Thu 09Feb2017 FB More files Andre

20170209 W4RA TMT Burkina GCF Mali Thu 09Feb2017 audio

20170209 W4RA TMT Burkina GCF Mali Thu 09Feb2017 photo

20170209 W4RA TMT Burkina GCF Mali Thu 09Feb2017 photo Anna

20170209 W4RA TMT Burkina GCF Mali Thu 09Feb2017 video

20170209 W4RA TMT Burkina GCF Mali Thu $99 \mathrm{Feb2017}$ video photo Andre

20170210 W4RA TMT Burkina GCF Mali Fri 10Feb2017 audio

20170210 W4RA TMT Burkina GCF Mali Fri 10Feb2017 interviews Radio Voix du Paysan

20170210 W4RA TMT Burkina GCF Mali Fri 10Feb2017 photo Anna

20170210 W4RA TMT Burkina GCF Mali Fri 10Feb2017 photo HansA

20170210 W4RA TMT Burkina GCF Mali Fri 10Feb2017 photo Wendelien 
20170210 W4RA TMT Burkina GCF Mali Fri 10Feb2017 video HansA

20170210 W4RA TMT Burkina GCF Mali Fri 10Feb2017 video photo Andre

20170211 W4RA TMT Burkina GCF Mali Sat 11Feb2017 audio

20170211 W4RA TMT Burkina GCF Mali Sat 11Feb2017 photo Anna

20170211 W4RA TMT Burkina GCF Mali Sat 11Feb2017 photo HansA

20170211 W4RA TMT Burkina GCF Mali Sat 11Feb2017 photo Wendelien

20170211 W4RA TMT Burkina GCF Mali Sat 11Feb2017 video HansA

20170211 W4RA TMT Burkina GCF Mali Sat 11Feb2017 video photo Andre

20170212 W4RA TMT Burkina GCF Mali Sun 12Feb2017 photo

20170212 W4RA User Manual Andre to change the Foroba Blon language Jan2017

20170213 W4RA AOPP docs on 4th West Africa AEB Conference 2017

20170213 W4RA TMT Burkina GCF Mali Mon 13Feb2017 AOPP audio

20170214 AOPP project docs Seydou 14Feb2017.zip

20170215 TMT UDS Ghana final proposalTMT-GHA-2017 subm 15Feb2017

20170215 W4RA TMT Burkina GCF Mali Wed 15Feb2017 photo FB Adama Radio Sikidolo

20170215 W4RA TMT Burkina GCF Mali Wed 15Feb2017 video FB Adama Radio Sikidolo

20170215 W4RATMT Mali Wed 15Feb2017 audioAdama Sikidolo

20170216 W4RA WASH Mali Docs for GCF Fonds Climat Mali project proposal 16Feb2017

2017 FEBRUARY: OTHER DOCS

Anna - 4 apps use cases Anna - v18Jan2017.pdf

Anna-4apps-usecases-docs-18Jan2017 . zip

Anna_Use case Meteo Services for farmers in West Africa_Jan2017.docx

Foroba Blon fr to bambara guide Jan2017. docx

RM-meteo-info-table.pdf

W4RA TMT-BF Andre More FB translation demo slide 09Feb2017 slot filler techniek.pptx W4RA TMT-BF Andre slides 08Feb2017 slot filler techniek.odp

W4RA TMT-BF Andre slides 08Feb2017 slot filler techniek.pptx

W4RA-Atelier_TMT-BurkinaFaso-meteo-08_09Feb2017-complete.pptx

2017 WORKSHOP NPL - W4RA BURKINA FASO

20170704 NPL workshop Ouagadougou Tue 04July2017 photo

20170704 NPL workshop Ouagadougou Tue 04July2017 video

20170705 NPL workshop Ouagadougou Wed05July2017 photo

20170706 NPL workshop Ouagadougou Thu06July2017 photo

20170707 NPL Green Sahel Field Trip Gourcy-Ouahigouya Fri07July2017 audio

20170707 NPL Green Sahel Field Trip Gourcy-Ouahigouya Fri07July2017 photo

20170707 NPL Green Sahel Field Trip Gourcy-Ouahigouya Fri07July2017 video 
c.3.10 2018 Field trip Mali and Ghana, February

20180219 W4RA Bamako AOPP Seydou TreeAid Tangara - audio

20180219 W4RA Bamako AOPP Seydou TreeAid Tangara - photo

20180221 W4RA Konobougou Adama Radio Sikidolo - audio

20180221 W4RA Konobougou Adama Radio Sikidolo - photo

20180221 W4RA Konobougou Adama Radio Sikidolo - video

20180222 W4RA Bamako AOPP Seydou - audio

20180222 W4RA Bamako AOPP Seydou - photo

20180223_26 W4RA Tamale UDS - photo

20180226_28 W4RA Tamale-Bolga-Ouaga - photo

C.3.11 $2018 \mathrm{ICT}_{4} \mathrm{D}$ in the Field course, Sarawak Malaysia

ICT4DInthefield2018.jpg

ICT4D_In_The_Field-UNIMAS-Malaysia-Sarawak-notes - HansA-Jun2018- l res .pdf

ICT4D_in the field2018_preparation

ICT4D_in_the_Field_HansA_en_Jaap2018

Judiths blog

Kasadaka_new_image Sarawak_Andree

Logos

Mid-term reports students

Pictures MoU signing

Pictures user test children

Sarawak Kampung Pinggan Jaya - use case Tom_de_Jong 08May2018.pdf

Sarawak Use Case - Banana - Tom_de_Jong 25Apr2018.pdf

Sarawak_ICT4D_20180607

Sarawak_ICT4D_20180612

Sarawak_ICT4D_20180613

Sarawak_ICT4D_20180614

Sarawak_ICT4D_20180615

Sarawak_ICT4D_20180616

Sarawak_ICT4D_20180617

Sarawak_ICT4D_20180618

Sarawak_ICT4D_20180619

Sarawak_ICT4D_20180620

Sarawak_ICT4D_20180621

Sarawak_ICT4D_20180622

Sarawak_ICT4D_20180623

Sarawak_ICT4D_20180624

Sarawak_ICT4D_20180625 
Sarawak_ICT4D_20180626

Sarawak_ICT4D_20180627

Sarawak_ICT4D_20180628

Sarawak_ICT4D_20180629

Sarawak_ICT4D_20180630

Sarawak_ICT4D_20180701

Sarawak_ICT4D_20180702

Sarawak_trip2017

Short clips 3 projects

Storytelling_School_Kuching (2).pptx

Three short clips by Leeuw

Trip report ICT4D in the Field course 2018 Sarawak_Anna.docx

Video Leeuw 21 en 23

C.3.12 2019 February Preparation Seed Value Chain project in Mali

Notes Anna meetings AOPP

Photo:video Andre Mali feb 2019

Pictures Anna Mali feb 2019

Trip Mali Februari 2019_v01..docx

Trip Mali Februari 2019_v02..docx

Trip Mali Februari 2019_v02..pdf

W4RA_2019_2_16_Arrival_Bamako_Andre

W4RA_2019_2_17_Bamako_Sunday

W4RA_2019_2_18_Bamako_Monday_AOPP

W4RA_2019_2_19_Bamako_Tuesday_TreeAid

W4RA_2019_2_20_Bamako_Wednesday_Carpa

W4RA_2019_2_21_Bamako_Thursday_Yeleman_AOPP

W4RA_2019_2_22_Field_trip_AOPP_champs_agro_eco

W4RA_2019_2_23_Boite_Tangara_Lamine

W4RA_2019_2_25_Bamako

C.3.13 2019 April Workshop Seed Value Chain project in Mali

20190425_Atelier AOPP.pptx

20190425_Thu

20190426_Fr

20190427_Sa_Fieldtrip

20190428_Su

20190429_Mo

Groupwork_AOPP 
InvitationLetterSeydouTangara.docx

Notes_Sibi_and interview

Photo Nikon Monday group work

Presentations_TMT_AOPP

Seeds Mali Information

Student ICT4D presentations_for AOPP

The team pictures

Trip report and additional resources

Victor_Feedback from_AOPP_for ICT4D_course 2019.pdf

W4RA_AOPPApril2019_Trip_report_v2.0-reducedsize.pdf

W4RA_AOPPApril2019_Trip_report_v2.0.pdf

video_Leeuw

C.3.14 2019 June ICT4D in the Field, Sarawak Malaysia

20190607 Kampung Muhibah Fri07Jun2019 - audio HansA

20190607 Kampung Muhibah Fri07Jun2019 - photo HansA

20190607 visit Kampung Muhibah Fri07Jun2019 - video HansA

20190607 07-12Jun2019-group project course docs and photos

20190609 visit Kampung Pinggan Jaya Sun09Jun2019 - photo HansA

20190609 visit Kampung Pinggan Jaya Sun09Jun2019 - video HansA

20190610 ICT4DInTheField Course UNIMAS Labwork Mon10Jun2019 - photo HansA

20190610 ICT4DInTheField Course UNIMAS Labwork Mon10Jun2019 - video HansA

20190610_13 ICT4DInTheField UNIMAS invited lectures 10-13Jun2019 - slides

20190611 UNIMAS Labwork Use Cases Tue11Jun2019 - photo HansA

20190612UNIMAS Lab Work Wed12Jun2019 - videoreport HansA

20190612-13 ICT4DInTheField 12-13Jun2019 - photo Jaap

20190613 ICT4D-In-The-Field Thu13Jun2019-group project course docs and photos

20190613 ICT4D-In-The-Field Thu13Jun2019-photo Anna

ICT4D in the Field 2019

ICT4D2019_Materials_classroom_course

Lecture_ICT4DintheField 2019_24June.pptx

Sarawak student reports 2019

C.3.15 2020 January workshop AOPP Seed Value Chain project in Mali

AOPP Jan2020 Andre

AOPP Semences audio files.xlsx

Atelier 13 Janvier 2020

Atelier 14 Janvier 2020

Atelier 15 Janvier 2020 
Atelier 16 Janvier 2020

Atelier 17 Janvier 2020

Bamako 18 Janvier

Barke_interview.png

Barke_interview.psd

Group3 Taart.jpg

Photo Anna_Mal_13_18 jan 2020

Presentatie AOPP 16012020.pptx

Presentatie AOPP 16012020_Gossa_Andre.pdf

Presentielijsten_WorkshopAOPP_jan2020.pdf

Solutions.jpg

Video Leeuw_13-17_January2020

Recordings_gerant_demo.mp3

Recordings_haricots.mp3 

[1] Chris van Aart, Anna Bon, Hans Akkermans, Victor de Boer, Stéphane Boyera, Wendelien Tuyp, and Nana Gyan. The Web of Voices: How to connect 4.5 billion internet-less people to the Web. Outrageous Ideas Track, The 1oth International Semantic Web Conference, 2011. Public Award Winning Paper. http://iswc2011.semanticweb.org/fileadmin/iswc/Papers/ outrageous/iswc2011outrageousid_submission_18.pdf, (accessed o8-10-2020). (Cited on pages 6 and 264.)

[2] Corey M. Abramson and Neil Gong. Beyond the Case: The Logics and Practices of Comparative Ethnography. Oxford University Press, USA, 2020. (Cited on page 25.)

[3] Jenny C. Aker. Does Digital Divide or Provide? The Impact of Cell Phones on Grain Markets in Niger. Working Paper 154, Center for Global Development, 2008. http://dx.doi.org/10.2139/ssrn.1093374, (accessed o8-10-2020). (Cited on page 230.)

[4] Hans Akkermans and Jaap Gordijn. Ontology engineering, scientific method and the research agenda. In Managing Knowledge in a World of Networks, 15th International Conference, EKAW 2006, Poděbrady, Czech Republic, October 2-6, 2006. Proceedings, pages 112-125. Springer, 2006. (Cited on pages 25, 28, and 242.)

[5] Hans Akkermans and Jaap Gordijn. What is this Science called Requirements Engineering? In Requirements Engineering, 14th IEEE International Conference, pages 273-278. IEEE, 2006. (Cited on pages 7, 23, 25, and 28.)

[6] Hans Akkermans, Nana Baah Gyan, Anna Bon, Wendelien Tuyp, Aman Grewal, Stéphane Boyera, and Mary Allen. Is (Web) Science Ready for Empowerment? In Proceedings of the 3rd International Web Science Conference, page 27. ACM, 2011. (Cited on pages 6, 7, and 248.)

[7] Maryam Ali and Savita Bailur. The Challenge of 'Sustainability' in $\mathrm{ICT}_{4} \mathrm{D}$ - is Bricolage the Answer? In Proceedings of the 9th International Conference on Social Implications of Computers in Developing Countries, São Paulo, Brazil, 2007. https: //tinyurl. com/ali-bricolage- ICT4D, (accessed 08-10-2020). (Cited on page 40.)

[8] Esteve Almirall, Melissa Lee, and Jonathan Wareham. Mapping living labs in the landscape of innovation methodologies. Technology Innovation Management Review, 2(9), 2012. (Cited on pages 25, 58, and 90.) 
[9] Morgan G. Ames. 1o Translating Magic: The Charisma of One Laptop per Child's XO Laptop in Paraguay. In Beyond Imported Magic: Essays on Science, Technology, and Society in Latin America, page 207. MIT Press, 2014. (Cited on page 36.)

[10] E.S. Andersen and Svein Arne Jessen. Project Evaluation Scheme: a Tool for Evaluating Project Status and Predicting Project Results. Project Management Journal, 6(1):61-69, 2000. (Cited on pages 33 and 45.)

[11] Aristoteles. Ethica Nicomachea, Book VI. Translated by E.L.H. Poortman and C.A.M. Hupperts. Damon, The Netherlands, 2004. (Cited on pages 7 and 248.)

[12] Rajindra Ariyabandu. Role of Telecentres as Knowledge Networks: Successes and Challenges. Working paper, ESCAP, 2009. https://tinyurl.com/ ariyabandu-telecentres, (accessed o8-10-2020). (Cited on page 38.)

[13] David Baccarini. The logical framework method for defining project success. Project Management Journal, 30(4):25-32, 1999. (Cited on pages 44 and 45.)

[14] Philip Ball. Critical mass. Random House, 2014. (Cited on page 51.)

[15] Albert Bandura. Social Learning Theory. Oxford, England: Prentice-Hall, 1977. (Cited on page 239.)

[16] Yaneer Bar-Yam. Making Things Work: Solving Complex Problems in a Complex World. Knowledge Press, 2004. (Cited on pages 20, 26, 47, 49, 50, 225, and 238.)

[17] Etienne Barnard, Marelie H. Davel, and Gerhard B. Van Huyssteen. Speech Technology for Information Access: a South African Case Study. In AAAI Spring Symposium: Artificial Intelligence for Development, pages 13-15, 2010. (Cited on page 150.$)$

[18] Richard Baskerville. What design science is not, 2008. (Cited on pages 16, 17, and 59.)

[19] Richard Baskerville, Jan Pries-Heje, and John Venable. Soft Design Science

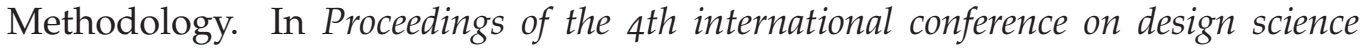
research in information systems and technology, pages 1-11, 2009. (Cited on page 17.)

[20] Richard Baskerville and A. Trevor Wood-Harper. Diversity in information systems action research methods. European Journal of Information Systems, 7(2):90-107, 1998. (Cited on pages 16 and 17.)

[21] Tor A. Benjaminsen. Conservation in the Sahel: Policies and People in Mali, 1900-1998. Producing Nature and Poverty in Africa. Elanders Gotab, Stockholm, 2000. (Cited on page 78.) 
[22] Tor Arve Benjaminsen and Christian Lund. Politics, Property and Production in the West African Sahel: Understanding Natural Resources Management. Nordiska Afrikainstitutet, Uppsala, 2001. (Cited on pages 72, 74, and 78.)

[23] Birgitta Bergvall-Kåreborn, Carina Ihlström Eriksson, Anna Ståhlbröst, and Jesper Svensson. A Milieu for Innovation - Defining Living Labs. In 2nd ISPIM Innovation Symposium, New York, pages 6-9, 2009. https://tinyurl.com/ bergvall - innov-livinglabs, (accessed o8-10-2020). (Cited on pages 25, 26, 57, 58,60 , and 90.)

[24] Tim Berners-Lee. Looking Back, Looking Forward: The Process of Designing Things in a Very Large Space, inaugural lecture. Technical report, University of Southampton, 2007. http://www.w3.org/2007/Talks/0314-soton-tbl, (accessed 08-10-2020). (Cited on page 25.)

[25] Tim Berners-Lee, Robert Cailliau, Jean-François Groff, and Bernd Pollermann. World Wide Web: the Information Universe. Internet Research, 1992. (Cited on page 5.)

[26] Tim Berners-Lee, Wendy Hall, James A. Hendler, Kieron O'Hara, Nigel Shadbolt, and J. Daniel Weitzner. A Framework for Web Science, Foundations and Trends in Web Science. Now Publishers Inc., Boston-Delft, 2006. (Cited on page 6.)

[27] Michael L. Best and Rajendra Kumar. Sustainability Failures of Rural Telecenters: Challenges from the Sustainable Access in Rural India (Sari) Project. Information Technologies and International Development, 4(4):31-45, 2008. (Cited on page 40.)

[28] Hugh Beyer and Karen Holtzblatt. Contextual Design. Interactions, 6(1):32-42, 1999. (Cited on page 59.)

[29] Edwin H. Blake and William David Tucker. Socially aware software engineering for the developing world. In IST-Africa 2006 Proceedings, Paul Cunningham and Mirjam Cunningham Eds. IIMC International Information Management Corporation, 2006. (Cited on pages 22 and 203.)

[30] Barry W. Boehm. Software Engineering Economics. Prantice- Hall Englewood Cliffs NJ, 1981. (Cited on page 10.)

[31] Barry W. Boehm. A Spiral Model of Software Development and Enhancement. Computer, 21(5):61-72, 1988. (Cited on page 123.)

[32] Wouter de Boer. Reduce the Digital Divide in the Netherlands: A Smartphone-based Method to support Low Literate People. W4RA student papers, 2019. https://w4ra.org/wp-content/uploads/2019/07/Low_res_7_July_ 2019Final_Master_Thesis_Wouter_de_Boer.pdf, (accessed 08-10-2020). (Cited on page 219.) 
[33] Anna Bon. Can the Internet in Tertiary Education in Africa contribute to social and economic development? International Journal of Education and Development using ICT, 3(3), 2007. (Cited on page 5.)

[34] Anna Bon. ICTs in Tertiary Education, a Case Study from Ghana. In Wanjira Kinuthia and Stewart Marshall, editors, Educational Technology in Practice: Research and Practical Case Studies from the Field, pages 57-66. IAP, 2010. (Cited on page 5.)

[35] Anna Bon. Les TIC dans l'enseignement supérieur en Afrique subsaharienne. In Enseignement supérieur et mondialisation: Défis, menaces et opportunités pour l'Afrique. Edité par Damtew Teferra et Heinz Greijn, pages 67-84. Maastricht University MUNDO, 2010. (Cited on page 5.)

[36] Anna Bon and Hans Akkermans. Rethinking technology, ICTs and development: Why it is time to consider ICT4D 3.0. W4RA Working Papers, 2014. (Cited on pages $23,193,197,198$, and 207.)

[37] Anna Bon and Hans Akkermans. Rethinking Technology, ICTs and Development: Why it is Time to Consider $\mathrm{ICT}_{4} \mathrm{D}$ 3.o. W4RA working papers, Network Institute, Vrije Universiteit Amsterdam, 2015. https://w4ra.org/wp-content/ uploads/2015/01/ICT4D3. pdf, (accessed 08-10-2020). (Cited on page 178.)

[38] Anna Bon and Hans Akkermans. Digital development: Elements of a Critical $\mathrm{ICT}_{4} \mathrm{D}$ Theory and Praxis. In International Conference on Social Implications of Computers in Developing Countries, pages 26-38. Springer, 2019. (Cited on pages 16, $17,19,20,23$, and 224.)

[39] Anna Bon and Hans Akkermans. Digital (in)equality, Digital Inclusion, Digital Humanism: Summary of the Web Science Workshop DigDivDigHum-20. In 12th ACM Conference on Web Science (WebSci '20 Companion), July 6-10, 2020, Southampton, United Kingdom, WebSci '20, pages 3-5, New York, NY, USA, 2020. Association for Computing Machinery. (Cited on page 275.)

[40] Anna Bon, Hans Akkermans, and Jaap Gordijn. Developing ICT Services in a Low-Resource Development Context. Complex Systems Informatics and Modeling Quarterly, pages 84-109, 2016. (Cited on pages 86, 193, and 200.)

[41] Anna Bon, Victor De Boer, Pieter De Leenheer, Chris Van Aart, Nana Baah Gyan, Max Froumentin, Stephane Boyera, Mary Allen, and Hans Akkermans. The Web of Radios: Introducing African Community Radio as an Interface to the Web of Data. In Elena Simperl et al., editors, ESWC 2012 Satellite Events, Heraklion, Crete, Greece, May 27-31, 2012. Revised Selected Papers, pages 219-232. Springer Berlin Heidelberg, 2012. https://doi . org/10.1007/978-3-662-46641-4_16, (accessed 08-10-2020). (Cited on pages 6, 86, 189, 200, and 264.) 
[42] Anna Bon, Victor De Boer, Pieter De Leenheer, Chris Van Aart, Nana Baah Gyan, Wendelien Tuyp, Stephane Boyera, Max Froumentin, Aman Grewal, Mary Allen, Amadou Tangara, and Hans Akkermans. Use Case and Requirements Analysis in a Remote Rural Context in Mali. In Requirements Engineering: Foundation for Software Quality, pages 331-346. Springer, 2013. (Cited on pages 6, 86, and 200.)

[43] Anna Bon, Victor de Boer, Christophe Guéret, Gallo Diallo, and Jaap Gordijn, editors. Frontmatter. CEUR Workshop Proceedings, 2018. Co-located with 1oth ACM Web Science Conference - WebSci'18. (Cited on page 275.)

[44] Anna Bon, Tom De Schryver, Hossana Twinomurinzi, and Dolf Jordaan. Less (in context) is more (creativity): m-Learning as a Short Lived Traveling Idea at the University of Pretoria. International Journal of Business Anthropology, 3(2), 2012. (Cited on page 5.)

[45] Anna Bon, Jaap Gordijn, and Hans Akkermans. E-Service Innovation in Rural Africa Through Value Co-Creation. In Handbook of Research on Strategic Alliances and Value Co-Creation in the Service Industry, pages 355-373. IGI Global, 2017. (Cited on page 165.)

[46] Anna Bon, Jaap Gordijn, Hans Akkermans, Victor de Boer, André Baart, Cheah Wai Shiang, and Sze San Nah. Community-centered, Project-based ICT4D Education in the Field. In International Conference on Social Implications of Computers in Developing Countries, pages 386-397. Springer, 2019. (Cited on pages 207, 208, 213, and 216.)

[47] Anna Bon, Jaap Gordijn, and Cheah Wai Shiang. Digital Inclusion Requires a Business Model Too: Sustainability Analysis of Value Webs in Rural Sarawak. In 12th ACM Conference on Web Science Companion, WebSci '20, pages 64-69, New York, NY, USA, 2020. Association for Computing Machinery. (Cited on page 275.)

[48] Anna Bon, Derek van den Nieuwenhuijzen, and Hans Akkermans, editors. Digital Divide, Citizenship and Inclusion in Amsterdam. Pangea, Amsterdam, 2020. (Cited on pages 217, 218, 219, and 274.)

[49] Grady Booch, James Rumbaugh, and Ivar Jacobson. The Unified Modeling Language User Guide. Reading, UK: Addison Wesley, 1999. (Cited on page 25.)

[50] Guusje Boomgaard, Anastasios Sidiropoulos, Ludwig Hoon, and Nip van Wees. EDUCOMX, An educational game for children to learn English. W4RA Working Papers, pages 1-22, 2018. https://w4ra.org/wp-content/uploads/ 2018/07/EDUCOMX_Documentation_English-for-Children-1.pdf, (accessed o810-2020). (Cited on pages 210, 213, and 214.) 
[51] Kim Bosman and Jari Ferguson. The Kasadaka Weather Forecast Service. In Proceedings of the 4th International Workshop on Downscaling the Semantic Web-2016, 2016. http://w4ra.org/wp-content/uploads/2016/07/Downscale2016_paper_1. pdf (accessed 08-10-2020). (Cited on page 121.)

[52] Rosemary Bosu and Anna Bon. Improving teaching and learning in polytechnics with ICT. In G. Wim Kouwenhoven, G.K.T. Oduro, and Kwasi Nsiah Gyabaah, editors, Trends in Polytechnic Education in Ghana. Centre for International Cooperation, VU Amsterdam, 2009. (Cited on page 5.)

[53] Patricia Botero. Investigación y acción colectiva "IAC". Una experiencia de investigación militante. Utopía y praxis latinoamericana, 17(57), 2012. (Cited on pages 16 and 24.)

[54] Adele Botha, Karen Calteaux, Marlien Herselman, Aditi Sharma Grover, and Etienne Barnard. Mobile User Experience for Voice Services: A theoretical framework. Proceedings of M4D2012, 28-29 February 2012 New Delhi, India, Vikas Kumar and Jakob Svensson (eds.), 2012. (Cited on pages 22 and 150.)

[55] Pierre Bourque, François Robert, Jean-Marc Lavoie, Ansik Lee, Sylvie Trudel, and Timothy C. Lethbridge. Guide to the Software Engineering Body of Knowledge (SWEBOK) and the Software Engineering Education Knowledge (Seek) - a Preliminary Mapping. In Proceedings of the 1oth International Workshop on Software Technology and Engineering Practice, pages 8-23. IEEE, 2002. (Cited on pages 123 and 129.)

[56] Jørn Braa, Ole Hanseth, Arthur Heywood, Woinshet Mohammed, and Vincent Shaw. Developing Health Information Systems in Developing Countries: the Flexible Standards Strategy. MIS Quarterly, pages 381-402, 2007. (Cited on pages 22 and 249.)

[57] Jorn Braa, Sundeep Sahay, John Lewis, and Wilfred Senyoni. Health Information Systems in Indonesia: Understanding and Addressing Complexity. In International Conference on Social Implications of Computers in Developing Countries, pages 59-70. Springer, 2017. (Cited on page 225.)

[58] Hilary Bradbury. The Sage Handbook of Action Research. Sage, 2015. (Cited on page 16.)

[59] John Briggs and Joanne Sharp. Indigenous Knowledges and Development: a Postcolonial Caution. Third World Quarterly, 25(4):661-676, 2004. (Cited on pages 23, 24, and 233.)

[6o] Inge Brinkman, Mirjam de Bruijn, and Hisham Bilal. The Mobile Phone, 'Modernity' and Change in Khartoum, Sudan. In Mirjam de Bruijn, Francis Nyamnjoh, 
and Inge Brinkman, editors, Mobile Phones: The New Talking Drums of Everyday Africa, pages 69-91. LANGAA and African Studies Centre, Leiden, 2009. (Cited on pages 228,244 , and 245 .)

[61] Frederick P. Brooks. The Mythical Man-Month. Datamation, 20(12):44-52, 1974. (Cited on page 10.)

[62] Allen E. Brown and Gerald G. Grant. Highlighting the duality of the ICT and development research agenda. Information Technology for Development, 16(2):96111, 2010. (Cited on page 250.)

[63] Suzanne Fox Buchele and Romeo Owusu-Aning. The One Laptop per Child (OLPC) Project and its Applicability to Ghana. In Proceedings of the 2007 International Conference on Adaptive Science and Technology, pages 113-118, 2007. https : / / people.southwestern.edu/ bucheles/ICAST_0LPC_Paper.pdf, (accessed o8-102020). (Cited on page 36.)

[64] Seth Buhigiro. The Role of Telecentres in Promoting Socio-economic Development in Rwanda. PhD thesis, Faculty of Commerce, Law and Management, University of the Witwatersrand, South-Africa, 2013. https://tinyurl.com/ seth-buhigiro-phd-thesis, (accessed o8-10-2020). (Cited on page 39.)

[65] Roland Bunch. Two Ears of Corn. World Neighbors, 1985. http:// marriottschool.net/emp/WPW_bak/Two_Ears_of_Corn_lg.pdf, (accessed 08-102020). (Cited on pages 26 and 61.)

[66] Jenna Burrell and Kentaro Toyama. What Constitutes Good ICTD Research? Information Technologies E International Development, 5(3):82-94, 2009. (Cited on pages 250 and 251.)

[67] Rebecca Butterfield. Prosopis in Sahelian Forestry Projects: A Case Study from Niger. Building Consensus for the Disenfranchised, 1996. http: //www. udep. edu . pe/ upadi, (accessed o8-10-2020). (Cited on pages 73 and 74.)

[68] Ronel Callaghan and Marlien Herselman. Applying a living lab methodology to support innovation in education at a university in South Africa. TD: The Journal for Transdisciplinary Research in Southern Africa, 11(1):21-38, 2015. (Cited on page 22.)

[69] Carlos Canal, Juan Manuel Murillo, Pascal Poizat, et al. Software Adaptation. L'objet, 12(1):9-31, 2006. (Cited on page 40.)

[70] Dennis C. Canterbury. Rethinking Development and Change in Africa: Towards an Alternative Vision. In Re-thinking Development Studies in Africa. Institute for Development Studies (IDS), 2009. (Cited on pages 25 and 249.) 
[71] R. Chambers. Rural Development: Putting the Last First. Pearson Education Limited, 1983. (Cited on pages 11, 18, 22, 26, 61, 74, 249, and 263.)

[72] Robert Chambers. The Origins and Practice of Participatory Rural Appraisal. World Development, 22(7):953-969, 1994. (Cited on pages 61 and 62.)

[73] Robert Chambers. Poverty and Livelihoods: Whose Reality Counts? Environment and Urbanization, 7(1):173-204, 1995. (Cited on pages 22, 249, and 253.)

[74] Robert Chambers. Paradigms, poverty and adaptive pluralism. IDS Working Paper 2, 2010(344):01-57, 2010. https://opendocs.ids.ac.uk/opendocs/handle/ 123456789/3712, (accessed 08-10-2020). (Cited on pages 10, 18, 22, 49, 61, 62, 249, 252 , and 263.)

[75] Robert Chambers. Ideas for development. Routledge, 2013. (Cited on page 10.)

[76] Robert Chambers. Knowing in development: A radical agenda for the TwentyFirst Century. Forum for Development Studies, 41(3):525-537, 2014. (Cited on pages 18,22 , and 249.)

[77] Robert Chambers. Knowing in Development: A Radical Agenda for the Twenty-First Century, volume 41-3. Routledge, 2014. (Cited on pages 22, 233, 249, and 265.)

[78] Robert Chambers. Inclusive rigour for complexity. Journal of Development Effectiveness, $7(3): 327-335,2015$. (Cited on pages 18,46 , and 47 .)

[79] Robert Chambers and B.P. Ghildyal. Agricultural research for resource-poor farmers: the farmer-first-and-last model. Agricultural administration, 20(1):1-30, 1985. (Cited on pages 22, 233, and 249.)

[8o] Robert Chambers and Janice Jiggins. Agricultural research for resource-poor farmers part II: A parsimonious paradigm. Agricultural Administration and Extension, 27(2):109-128, 1987. (Cited on page 74.)

[81] Robert Chambers, Arnold Pacey, and Lori Ann Thrupp. Farmer First: Farmer Innovation and Agricultural Research. Intermediate Technology Publications, 1989. (Cited on page 263.)

[82] Anita Say Chan. Networking Peripheries: Technological Futures and the Myth of Digital Universalism. MIT Press, 2014. (Cited on pages 46, 225, 233, 236, 244, and 245.)

[83] Robert Chapman and Tom Slaymaker. ICTs and rural development: review of the literature, current interventions and opportunities for action. Overseas Development Institute, 2002. (Cited on page 54.) 
[84] Marc Chapon and Isabella Tourette Diop. Local Milk Sector in West Africa. Technical report, AVSF, VSFB, AOPP, 2011. http://www.inter-reseaux.org/IMG/ pdf_2a2_FILLA0-SMALL-UK.pdf, (accessed o8-10-2020). (Cited on page 111.)

[85] Peter Checkland. Systems Thinking, Systems Practice. John Wiley \& Sons, 1999. (Cited on page 17.)

[86] Peter Checkland. Soft Systems Methodology: a 30-year Retrospective. Systems Research and Behavioral Science, 17:S11-S58, 2000. (Cited on pages 17 and 90.)

[87] Peter Checkland and Sue Holwell. Information, Systems and Information Systems: Making Sense of the Field. John Wiley \& Sons, 1997. (Cited on page 25.)

[88] Peter Checkland and Sue Holwell. Action research: Its nature and validity. Systemic Practice and Action Research, 11:9-21, 1998. (Cited on pages 18, 19, and 28.)

[89] Henry Chesbrough. Open services innovation: Rethinking your business to grow and compete in a new era. John Wiley \& Sons, 2011. (Cited on page 239.)

[90] Henry Chesbrough and Marcel Bogers. Explicating open innovation: Clarifying an emerging paradigm for understanding innovation. New Frontiers in Open Innovation. Oxford: Oxford University Press, Forthcoming, pages 3-28, 2014. (Cited on page 239.)

[91] Dai Clegg and Richard Barker. Case method fast-track: a RAD approach. AddisonWesley Longman Publishing Co., Inc., 1994. (Cited on pages 139 and 149.)

[92] Michael A. Clemens and Gabriel Demombynes. The New Transparency in Development Economics: Lessons from the Millennium Villages Controversy. Working paper, Center for Global Development, 2013. https://ssrn. com/abstract= 2366970, (accessed 08-10-2020). (Cited on pages 46 and 47.)

[93] Royal D. Colle and Raul Roman. Editorial: The Telecenter Environment in 2002. The Journal of Development Communication, 12(2):15, 2001. (Cited on page 38.)

[94] Planning Commission. National Human Development Report 2001. Technical report, Government of India, 2007. https://ideas.repec.org/p/ess/wpaper/ id1284.html, (accessed 08-10-2020). (Cited on page 230.)

[95] Noshir S. Contractor and David R. Seibold. Theoretical frameworks for the study of structuring processes in group decision support systems. Human Communication Research, 19(4):528-563, 1993. (Cited on pages 20 and 236.)

[96] Philip Cooke. Complex adaptive innovation systems, 2012. (Cited on page 50.) 
[97] Julian Cristia, Pablo Ibarrarán, Santiago Cueto, Ana Santiago, and Eugenio Severín. Technology and child development: Evidence from the one laptop per child program. Working papers, idb-wp-304, Inter-American Development Bank, 2012. https://tinyurl.com/IDB-OLPC-evidence, (accessed 08-10-2020). (Cited on page 36.$)$

[98] Will Critchley and John W. Gowing. Water Harvesting in Sub-Saharan Africa. Routledge, 2012. (Cited on pages $62,71,73,76,85,225$, and 237.)

[99] Will Critchley and Verity Nyagah. Promoting Farmer Innovation. United Nations Development Programme, 1999. (Cited on pages 22, 62, 225, 249, and 263.)

[10o] Abel Pires da Silva and Walter D. Fernández. Significance of 'Contexts' in $\mathrm{ICT}_{4} \mathrm{D}$ projects: Alignment and Misalignment of Stakeholders' interests. In Proceedings of the 49th Hawaii International Conference on System Sciences 2016 (HICSS), pages 2708-2717. IEEE, 2016. (Cited on pages 4, 26, and 40.)

[101] Abel Pires da Silva and Walter D. Fernández. Sustainability of ICTD Projects and its Influencing Factors: A Comprehensive Literature Review. In Proceedings of the 49th Hawaii International Conference on System Sciences 2016 (HICSS), pages 2718-2727. IEEE, 2016. (Cited on pages 4, 26, and 46.)

[102] Jamila Daoudi. Economic Sustainability of ICT Services for the rural Poor in sub-Sahara Africa. Technical report, VU Amsterdam, Master thesis, Information Science, 2017. https://w4ra.org/wp-content/uploads/2017/06/Thesis_ Jamila_Daoudi_25_May2017.pdf, (accessed 08-10-2020). (Cited on page 274.)

[103] Rahul De, Abhipsa Pal, Rupal Sethi, Sunil K Reddy, and Chetan Chitre. ICT4D research: a call for a strong critical approach. Information Technology for Development, 24(1):63-94, 2018. (Cited on pages 19 and 23.)

[104] Victor de Boer, Pieter De Leenheer, Anna Bon, Nana Baah Gyan, Chris van Aart, Christophe Guéret, Wendelien Tuyp, Stéphane Boyera, Mary Allen, and Hans Akkermans. Radiomarché: Distributed Voice-and Web-interfaced Market Information Systems under Rural Conditions. In J. Ralyté, X. Franch, S. Brinkkemper, and S. Wrycza, editors, Advanced Information Systems Engineering, Proceedings CAiSE '12 Conference, pages 518-532. Springer, 2012. (Cited on pages 6, 86, and 200.)

[105] Victor De Boer, Nana Baah Gyan, Anna Bon, Pieter De Leenheer, Chris Van Aart, and Hans Akkermans. Voice-based access to linked market data in the Sahel. In DownScale2012, page 16, 2012. (Cited on pages 6 and 264.)

[106] Victor de Boer, Nana Baah Gyan, Anna Bon, Wendelien Tuyp, Chris van Aart, and Hans Akkermans. A Dialogue with Linked Data: Voice-based Access to Mar- 
ket Data in the Sahel. Semantic Web, 6(1):23-33, 2015. DOI:10.3233/SW-130132. (Cited on pages 86, 200, and 264.)

[107] Mirjam de Bruijn, Francis B. Nyamnjoh, and Inge Brinkman. Mobile Phones: The New Talking Drums of Everyday Africa. Langaa and African Studies Centre, Leiden, 2009. (Cited on pages 46,228 , and 230.)

[108] Tom de Jong. A field validation of the $\mathrm{ICT}_{4} \mathrm{D} 3.0$ framework in rural Sarawak Malaysia. Master Thesis - Information Sciences, 2018. https://w4ra.org/ wp - content/uploads/2018/08/Jong_Thesis_final - 1.pdf, (accessed o8-10-2020). (Cited on page 216.)

[109] Andy Dearden and Haider Rizvi. Adapting participatory and agile software methods to participatory rural development. In Proceedings of the Tenth Anniversary Conference on Participatory Design 2008, pages 221-225. Indiana University, 2008. (Cited on pages 22 and 203.)

[110] Andy Dearden, Haider Rizvi, Rogerio DePaula, Cecilia Oyugi, and Heike Winschiers-Theophilus. Participatory Design and International Development. In Proceedings of the Tenth Anniversary Conference on Participatory Design 2008, pages 293-294. Indiana University, 2008. (Cited on pages 22 and 203.)

[111] Philippe Lavigne Delville, Emmanuel Grégoire, Pierre Janin, Jean Koechlin, and Claude Raynaut. Societies and Nature in the Sahel. Routledge, 2002. (Cited on page 50.)

[112] Norman K. Denzin. Critical qualitative inquiry. Qualitative Inquiry, 23(1):8-16, 2017. (Cited on page 27.)

[113] Norman K. Denzin and Yvonna S. Lincoln. Handbook of qualitative research. Sage publications, inc, 1994. (Cited on page 27.)

[114] Norman K. Denzin and Yvonna S. Lincoln. The landscape of qualitative research, volume 1. Sage, 2008. (Cited on page 27.)

[115] Anind K. Dey. Understanding and using context. Personal and ubiquitous computing, 5(1):4-7, 2001. (Cited on page 23.)

[116] Sabina Di Prima, Abdou Hassane, and Chris Reij. Small-scale and Simple for Sustainability. In Water Harvesting in Sub-Saharan Africa, pages 99-117. Earthscan, 2012. (Cited on page 84.)

[117] Torgeir Dingsøyr, Sridhar Nerur, VenuGopal Balijepally, and Nils Brede Moe. A decade of agile methodologies: Towards explaining agile software development. Journal of Systems and Software, 85(6):1213-1221, 2012. (Cited on pages 18, 25, 58, $59,60,127,232$, and 233.) 
[118] Francis Dittoh, Victor de Boer, Anna Bon, Wendelien Tuyp, and André Baart. Mr. Meteo: Providing Climate Information for the Unconnected. In 12th ACM Conference on Web Science (WebSci '20 Companion), July 6-10, 2020, Southampton, United Kingdom, page 6. ACM, New York, NY, USA, 2020. DOI=https://doi. org/10.1145/3394332.3402824. (Cited on page 275.)

[119] Annabel Z. Dodd. The Essential Guide to Telecommunications. Prentice Hall Professional, 2002. (Cited on page 155.)

[120] Joerg Doerflinger and Andy Dearden. Evolving a software development methodology for commercial ICTD projects. Information Technology and International Development, 9(3):43-60, 2013. (Cited on pages 22 and 220.)

[121] Joerg Doerflinger, Andy Dearden, and Tom Gross. A software development methodology for sustainable ICTD solutions. In $\mathrm{CHI}^{\prime} 13$ Extended Abstracts on Human Factors in Computing Systems, pages 2371-2374. ACM, 2013. (Cited on page 220.)

[122] Jan Drábek. An Intelligent System to Track Tree Loss in Rural Africa using Satellite Image Data. Technical report, Vrije Universiteit Amsterdam, 2019. (Cited on page 274.)

[123] Delia Dumitrica and Sally Wyatt. Digital Technologies and Social Transformations: What Role for Critical Theory? Canadian Journal of Communication, 40(4), 2015. (Cited on pages 21 and 253.)

[124] Tore Dyba. Improvisation in small software organizations. IEEE Software, 17(5):82-87, 2000. (Cited on pages 26, 49, and 58.)

[125] Dave Ebbelaar, Falko Lavitt, and Pieter Geurts. Further Expanding Marcedi. W4RA student papers, 2018. https://w4ra.org/wp-content/uploads/2018/08/ Marcedi.pdf, (accessed 08-10-2020). (Cited on page 140.)

[126] Carlbandro Edoga. Digital Divide: How to find up to date and dynamic information for homeless people in Amsterdam. W4RA student papers, 2019. https://w4ra.org/wp-content/uploads/2019/07/Lowres_Final_Thesis_ Bandro_ACM_9July2019.pdf, (accessed 08-10-2020). (Cited on page 218.)

[127] Pelle Ehn. Work-oriented design of computer artifacts. PhD thesis, Arbetslivscentrum, 1988. (Cited on page 59.)

[128] Olav Eikeland. Action research: applied research, intervention research, collaborative research, practitioner research, or praxis research? International Journal of Action Research, 8(I):9-44, 2012. (Cited on page 16.) 
[129] Mats Eriksson, Veli-Pekka Niitamo, and Seija Kulkki. State-of-the-art in utilizing Living Labs approach to user-centric ICT innovation - a European approach. Lulea: Center for Distance-spanning Technology. Lulea University of Technology Sweden: Lulea, 2005. https://tinyurl .com/eriksson-state-ot-art-livlab, (accessed 08-10-2020). (Cited on pages 25, 26, and 57.)

[130] Arturo Escobar. Discourse and power in development: Michel Foucault and the relevance of his work to the Third World. Alternatives, 10(3):377-400, 1984. (Cited on pages $4,248,252$, and 253.)

[131] Arturo Escobar. Encountering development: The making and unmaking of the Third World. Princeton University Press, 2011. (Cited on pages 24 and 252.)

[132] Arturo Escobar. Designs for the pluriverse: radical interdependence, autonomy, and the making of worlds. Duke University Press, 2018. (Cited on pages 11, 16, and 225.)

[133] Virginia Eubanks. Popular technology: Exploring inequality in the information economy. Science and Public Policy, 34(2):127-138, 2007. (Cited on page 22.)

[134] Virginia Eubanks. 11 feminist phronesis and technologies of citizenship. Real social science: applied phronesis, page 228, 2012. (Cited on page 22.)

[135] Virginia Eubanks. Automating inequality: How high-tech tools profile, police, and punish the poor. St. Martin's Press, 2018. (Cited on page 22.)

[136] Orlando Fals Borda. Investigating Reality in Order to Transform it: The Colombian Experience. Dialectical Anthropology, 4(1):33-55, 1979. (Cited on pages 16, 24, $26,53,248,263$, and 265.)

[137] Orlando Fals Borda. The Application of Participatory Action-Research in Latin America. International Sociology, 2(4):329-347, 1987. http://journals. sagepub. com/doi/abs/10.1177/026858098700200401, (accessed 08-10-2020). (Cited on pages $16,18,22,249$, and 263.)

[138] Orlando Fals Borda. Action research in the convergence of disciplines. International Journal of Action Research, 9(2):155, 2013. (Cited on pages 7, 22, 26, 248, 249, 252, and 263.)

[139] Orlando Fals Borda and Muhammad Anisur Rahman. Action and knowledge: Breaking the monopoly with participatory action-research. Apex Press New York, 1991. (Cited on pages 18 and 262.)

[140] Andrew Feenberg. Questioning Technology. Routledge, 2012. (Cited on pages 21 and 253.) 
[141] Andrew Feenberg. Critical Theory of Technology. In Ulrike Felt, Rayvon Fouché, Clark A Miller, and Laurel Smith-Doerr, editors, Handbook of Science and Technology Studies, pages 635-663. MIT Press, 2017. (Cited on pages 21 and 253.)

[142] Andrew Feenberg et al. Critical theory of technology, volume 5. Oxford University Press New York, 1991. (Cited on pages 21 and 253.)

[143] Ulrike Felt, Rayvon Fouché, Clark A Miller, and Laurel Smith-Doerr. The handbook of science and technology studies. MIT Press, Cambridge, Massachusetts, 2017. (Cited on pages 21 and 235.)

[144] Natalie Fenton. Digital, political, radical. John Wiley \& Sons, 2016. (Cited on page 22.)

[145] Maria Angela Ferrario, Will Simm, Peter Newman, Stephen Forshaw, and Jon Whittle. Software engineering for 'social good': integrating action research, participatory design, and agile development. In Companion Proceedings of the 36 th International Conference on Software Engineering, pages 520-523. ACM, 2014. (Cited on pages 22, 25, and 220.)

[146] Edgar Ferrer. ICT policy and perspectives of human development in Latin America: The Peruvian experience. Journal of technology management \& innovation, 4(4):161-170, 2009. (Cited on page 36.)

[147] Abbe Fessenden, Duval LeRoy, and Allassane Kanoute. Forestry and the Environment, Mali Case Study. USAID working paper, USAID, 1994. http://pdf. usaid.gov/pdf_docs/PNABU997.pdf, (accessed o8-10-2020). (Cited on page 74.)

[148] Karin Feurstein, Alexander Hesmer, Karl A. Hribernik, K.D. Thoben, and J. Schumacher. Living Labs: a New Development Strategy. European Living Labs - a new approach for human centric regional innovation, pages 1-14, 2008. https://tinyurl . com/feurstein-living - labs, (accessed 08-10-2020). (Cited on page 58.)

[149] Paul Feyerabend. Against Method. Verso, 1993. (Cited on page 28.)

[150] Claude S. Fischer. America Calling: A Social History of the Telephone to 1940. University of California Press, 1994. (Cited on pages 37, 225, and 226.)

[151] Bent Flyvbjerg. Making Social Science Matter: Why Social Inquiry Fails and How It Can Succeed Again. Cambridge University Press, 2001. (Cited on pages 7 and 248.)

[152] Bent Flyvbjerg, Todd Landman, and Sanford Schram. Real social science: Applied phronesis. Cambridge University Press, 2012. (Cited on pages 7 and 22.)

[153] Paulo Freire. Pedagogy of freedom: Ethics, democracy, and civic courage. Rowman \& Littlefield, 1998. (Cited on pages 17 and 24.) 
[154] Paulo Freire. Pedagogía de la autonomía: saberes necesarios para la práctica educativa. Siglo XXI, 2006. (Cited on pages 17, 22, and 249.)

[155] John Gaventa and Andrea Cornwall. Power and knowledge. The Sage handbook of action research: Participative inquiry and practice, 2:172-189, 2008. (Cited on page 248.)

[156] Yohannes Gebremichael. Community Assessment of Local Innovators in Northern Ethiopia. In Chris Reij and Ann Waters-Bayer, editors, Farmer Innovation in Africa: A Source of Inspiration for Agricultural Development, pages 171-177. Earthscan Publications, London, UK, 2001. (Cited on page 235.)

[157] Murray Gell-Mann. Complex adaptive systems. Complexity: Metaphors, models and reality, pages $17-45,1994$. (Cited on page 26.)

[158] Murray Gell-Mann. What is complexity? In Complexity and industrial clusters, pages $13-24$. Springer, 2002. (Cited on page 49.)

[159] Paul J. Gertler, Sebastian Martinez, Patrick Premand, Laura B. Rawlings, and Christel M.J. Vermeersch. Impact evaluation in practice. World Bank Publications, 2016. (Cited on pages 45,46 , and 47 .)

[160] Michael Gibbons. Mode-2 society and the emergence of context-sensitive science. Science and public policy, 27(3):159-163, 2000. (Cited on page 18.)

[161] Björn Sören Gigler. Development as Freedom in a Digital Age: Experiences from the Rural Poor in Bolivia. World Bank Publications, 2015. (Cited on pages 24, 38, 46, and 247.)

[162] Bernhard Glaeser. The Green Revolution revisited: critique and alternatives. Taylor \& Francis, 2010. (Cited on page 233.)

[163] Benoît Godin. The linear model of innovation: The historical construction of an analytical framework. Science, Technology, E Human Values, 31(6):639-667, 2006. (Cited on page 37.)

[164] Benoit Godin. In the shadow of Schumpeter: W. Rupert Maclaurin and the study of technological innovation. Minerva, 46(3):343-360, 2008. (Cited on page 37.)

[165] Nicole S. Goedhart, Christine Dedding, and Rolinka Kattouw. Digitale ongelijkheid: Een participatieve verkenning in Amsterdam. Technical report, Vrije Universiteit Amsterdam, 2017. (Cited on pages 217 and 274.)

[166] Ricardo Gomez, Luis F. Baron, and Brittany Fiore-Silfvast. The changing field of ICTD: Content analysis of research published in selected journals and conferences, 2000-2010. In Proceedings of the Fifth International Conference on Information 
and Communication Technologies and Development, pages 65-74. ACM, 2012. (Cited on page 249.)

[167] Ricardo Gomez and Shaun Pather. ICT evaluation: are we asking the right questions? The Electronic Journal of Information Systems in Developing Countries, 50, 2011. (Cited on pages 19 and 46.)

[168] Dena Goodman. Enlightenment salons: The convergence of female and philosophic ambitions. Eighteenth-Century Studies, 22(3):329-350, 1989. (Cited on page 9.)

[169] J. Gordijn and H. Akkermans. e3-value: Design and Evaluation of e-Business Models. IEEE Intelligent Systems, 16(4):11-17, 2001. (Cited on pages 13, 25, 166, and 168.)

[170] Jaap Gordijn and Hans Akkermans. Value based requirements engineering: Exploring innovative e-commerce ideas. Requirements Engineering Journal, 8(2):114134, 2003. (Cited on pages 13, 25, 165, 166, 168, and 213.)

[171] Amith Gotamey, Abhinav Shankar, and Taavi Toomasson. Rain Forecasting Service for Rural Ghana. W4RA student papers, 2018. https://w4ra.org/ wp-content/uploads/2018/08/Gotamey_et_al_Rainforecasting.pdf, (accessed 08-10-2020). (Cited on page 140.)

[172] Ellen Gottesdiener. Requirements by collaboration: getting it right the first time. IEEE Software, 20(2):52-55, 2003. (Cited on pages 25, 26, 60, and 233.)

[173] Ellen Gottesdiener. Use cases: Best Practices. Rational Software White Paper, 2003. https://Www.ebgconsulting.com/Pubs/Articles/ UseCaseBestPractices-Gottesdiener.pdf, (accessed 08-10-2020). (Cited on pages 13,60 , 140, and 262.)

[174] Mark Granovetter. The Strength of Weak Ties: A Network Theory Revisited. Sociological Theory, I(1):201-233, 1983. (Cited on pages 50 and 225.)

[175] Joan M. Greenbaum and Morten Kyng. Design at work: Cooperative design of computer systems. L. Erlbaum Associates Inc., 1991. (Cited on pages 58 and 232.)

[176] David Singh Grewal. Network Power: The Social Dynamics of Globalization. Yale University Press, 2008. (Cited on page 248.)

[177] Independent Evaluation Group. Capturing Technology for Development. An evaluation of World Bank Group activities in Information and Communication Technologies, volume 1. The World Bank Group, 2011. https://openknowledge.worldbank. org/handle/10986/2370, (accessed 08-10-2020). (Cited on pages 3, 4, 26, 34, 36, and 40.) 
[178] The Boston Consulting Group. Internet for All: A Framework for Accelerating Internet Access and Adoption. Technical report, World Economic Forum, 2016. http://Www3. weforum.org/docs/WEF_Internet_for_All_Framework Accelerating_Internet_Access_Adoption_report_2016.pdf. (Cited on page 4.)

[179] The World Bank Group. Digital Dividents, World Bank Development Report. The World Bank, Washington, US, 2016. DOI: 10.1596/978-1-4648-0728-2; https:// tinyurl.com/WB-digital-dividents, (accessed 08-10-2020). (Cited on pages 4 and 26.)

[180] Christophe Guéret, Victor de Boer, and Stefan Schlobach. Let's Downscale" Linked Data. IEEE Internet Computing, 18(2):70-73, 2014. (Cited on page 264.)

[181] Christophe Guéret, Stefan Schlobach, Victor De Boer, Anna Bon, and Hans Akkermans. Is Data Sharing the Privilege of a Few? Bringing Linked Data to Those without the Web. Proceedings of ISWC2011-Outrageous Ideas Track, Best paper award, pages 1-4, 2011. (Cited on page 6.)

[182] Sibukele Gumbo, Hannah Thinyane, Mamello Thinyane, Alfredo Terzoli, and Susan Hansen. Living Lab Methodology as an Approach to Innovation in ICT4D: The Siyakhula Living Lab experience. In Proceedings of the IST-Africa 2012 Conference, volume 24, pages 29-74, 2012. (Cited on pages 22 and 232.)

[183] Nana Baah Gyan. The Web, Speech Technologies and Rural Development in West Africa, An ICT4D Approach. PhD thesis, Faculteit der Exacte Wetenschappen, Vrije Universiteit Amsterdam, 2016. (Cited on pages 86, 96, 142, 146, 149, 200, and 264.)

[184] Nana Baah Gyan, Victor de Boer, Anna Bon, Chris van Aart, Hans Akkermans, Stephane Boyera, Max Froumentin, Aman Grewal, and Mary Allen. Voice-based Web access in rural Africa. In Proceedings of the 5 th Annual ACM Web Science Conference in Paris, pages 122-131. ACM, 2013. (Cited on pages 6, 86, 142, 178, and 200.)

[185] Edward J. Hackett, Olga Amsterdamska, Michael Lynch, and Judy Wajcman. The Handbook of Science and Technology Studies. MIT Press, 2008. (Cited on page 21.)

[186] Steven Haggblade, Gelson Tembo, Daniel Kaboré, Chris Reij, Oluyede C. Ajayi, Steven Franzel, Paramu Mafongoya, and Frank Place. Sustainable soil fertility management systems. Successes in African Agriculture. Lessons for the future, pages 262-319, 2010. (Cited on pages 23, 72, and 236.)

[187] Matt Haikin and Richard Duncombe. A Framework to Assess Participation and Empowerment Impacts of ICT4DProjects. Development Informatics Group, Institute for Development Policy and Management, University of Manchester, 2013. (Cited on pages 22 and 221.) 
[188] Henrik Hansson, Peter Mozelius, Jarkko Suhonen, Erkki Sutinen, Mikko Vesisenaho, and Gunnar Wettegren. ICT4D with a Nordic flavor-A Stepwise and Multithreaded Approach. In IST-Africa 2009 conference proceedings. IIMC International Information Management Corporation, pages 1-9, 2009. (Cited on page 220.)

[189] Roger Harris. Telecentres in rural Asia: Towards a success model. Europe, 40(23.4):13-7, 2001. (Cited on page 38.)

[190] Roger W. Harris. How ICT4D Research Fails the Poor. Information Technology for Development, 22(1):177-192, 2016. (Cited on pages 10, 250, and 251.)

[191] R.J. Harrison Church. West Africa, a Study of the Environment and of Man's Use of it. Longmans London, 1957. (Cited on page 72.)

[192] Amir Hartman, John G. Sifonis, and John Kador. Net Ready: Strategies for Success in the E-conomy. McGraw-Hill New York, 2000. (Cited on pages 95 and 96.)

[193] David Harvey. Neoliberalism as Creative Destruction. The Annals of the American Academy of Political and Social Science, 610(1):21-44, 2007. (Cited on page 252.)

[194] Richard Heeks. ICT4D 2.0: The Next Phase of Applying ICT for International Development. Computer, 41(6):26-33, 2008. (Cited on pages 10, 23, 38, 46, 47, 48, $197,200,247,251$, and 263.)

[195] Richard Heeks. The ICT4D 2.o Manifesto: Where Next for ICTs and International Development? Technical report, University of Manchester. Institute for development policy and management (IDPM). Development informatics group, 2009. (Cited on pages 23 and 197.)

[196] Richard Heeks. Do Information and Communication Technologies (ICTs) Contribute to Development? Journal of International Development, 22(5):625-640, 2010. (Cited on page 46.)

[197] Richard Heeks. Information and Communication Technology for Development (ICT4D). Routledge, 2017. (Cited on pages 3, 8, 38, 48, 252, 253, and 263.)

[198] Richard Heeks. From the Digital Divide to Digital Justice in the Global South: Keynote Web Science Workshop DigDivDigHum-20. In 12th ACM Conference on Web Science (WebSci '20 Companion), July 6-10 2020, Southampton, United Kingdom, page 2. ACM, New York, NY, USA, 2020. DOI=https://doi.org/10.1145/ 3394332.3402821. (Cited on pages 23 and 198.)

[199] Richard Heeks and Alemayehu Molla. Compendium on Impact Assessment of ICT-for-Development Projects. Technical report, IDRC, 2009. https://tinyurl . com/heeks - molla-compendium-ict4d, (accessed o8-10-2020). (Cited on pages 46 and 48.) 
[200] Marc Hegeman. Mobile Apps for Homeless People: Co-creation of Information Solutions for Digital Inclusion. $W_{4} R A$ student papers, 2019. https://w4ra.org/wp-content/uploads/2019/07/Low_res_3July2019_Final_ Thesis_Master_Marc_Hegeman.pdf, (accessed 08-10-2020). (Cited on pages 218 and 219.)

[201] James Hendler, Nigel Shadbolt, Wendy Hall, Tim Berners-Lee, and Daniel Weitzner. Web science: an interdisciplinary approach to understanding the web. Communications of the ACM, 51(7):60-69, 2008. (Cited on pages 6 and 25.)

[202] Marlien Herselman and Adele Botha. Designing and Implementing an Information Communication Technology for Rural Education Development (ICT4RED) Initiative in a Resource Constraint Environment: Nciba School District, Eastern Cape, South Africa. CSIR, 2014. (Cited on pages 3 and 22.)

[203] Marlien Herselman, Mario Marais, and M. Pitse-Boshoman. Applying Living Lab Methodology to Enhance Skills in Innovation. In Proceedings of the eSkills Summit, Cape Town, 2010, 2010. https://researchspace.csir.co.za/dspace/handle/ 10204/4628, (accessed 08-10-2020). (Cited on pages 22, 221, and 232.)

[204] Alan Hevner and Samir Chatterjee. Design Science Research in Information Systems. In Design Research in Information Systems, pages 9-22. Springer, 2010. (Cited on page 15.)

[205] Alan R. Hevner, Salvatore T. March, Jinsoo Park, and Sudha Ram. Design science in information systems research. MIS quarterly, pages 75-105, 2004. (Cited on page 15.)

[206] Hans-Dieter Hiep, Roy Overbeek, and Paweł Ulita. BipVote: rural Mali voting system. W4RA student papers, 2018. https://w4ra.org/wp-content/uploads/ 2018/08/Bipvote.pdf, (accessed 08-10-2020). (Cited on page 140.)

[207] Melissa R. Ho, Thomas N. Smyth, Matthew Kam, and Andy Dearden. HumanComputer Interaction for Development: the Past, Present, and Future. Information Technologies E International Development, 5(4):pp-1, 2009. (Cited on pages 22 and 250.)

[208] Bjørn Hofmann. Medicine as Techne - A Perspective from Antiquity. The Journal of medicine and philosophy, 28(4):403-425, 2003. (Cited on page 7.)

[209] Alexandra Hofmänner. Science \& Technology Studies Elsewhere - A Postcolonial Programme. Schwabe Verlag, Switzerland, 2020. (Cited on pages 21 and 24.)

[210] John H. Holland. Complex Adaptive Systems. Daedalus, pages 17-30, 1992. (Cited on pages 26, 49, and 50.) 
[211] John H. Holland. Complexity: A very short introduction. OUP Oxford, 2014. (Cited on pages 49 and 50 .)

[212] Monica Horten. The Closing of the Net. Polity Press: Cambridge, England, 2016. (Cited on page 22.)

[213] Kuan Huiggy, Giorgi Kikolashvili, Judith Schermer, and Chris Valladares. APPong, an application that provides an overview of the Gula Apong production in Sarawak. W4RA Student Papers, pages 1- 62, 2018. https://w4ra.org/wpcontent/uploads/2018/o7/Report-Gula-Apong-Use-Case.pdf. (Cited on pages 210,212 , and 213 .)

[214] Bill Jackson. Designing Projects and Project Evaluations Using The Logical Framework Approach. UCN Monitoring and Evaluation Inatiative, 1997. (Cited on page 44.)

[215] Ivar Jacobson, Pan-Wei Ng, Paul E. McMahon, Michael Goedicke, et al. The Essentials of Modern Software Engineering: Free the Practices from the Method Prisons! Morgan \& Claypool, 2019. (Cited on pages 18, 25, and 47.)

[216] Marco A. Janssen. Coordination in Irrigation Systems: an Analysis of the Lansing-Kremer Model of Bali. Agricultural Systems, 93(1):170-190, 2007. (Cited on page 234.)

[217] Pertti Järvinen. Action Research is Similar to Design Science. Quality \& Quantity, 4I(1):37-54, 2007. (Cited on page 17.)

[218] Robert Jensen. The Digital Provide: Information (Technology), Market Performance, and Welfare in the South Indian Fisheries Sector. The Quarterly Journal of Economics, 122(3):879-924, 2007. https://doi.org/10.1162/qjec.122.3.879, (accessed o8-10-2020). (Cited on page 230.)

[219] Daniel Kaboré and Chris Reij. The Emergence and Spreading of an Improved Traditional Soil and Water Conservation Practice in Burkina Faso. International Food Policy Research Institute, 2004. (Cited on pages 76, 83, 84, and 235.)

[220] Daniel Kahneman. Thinking, Fast and Slow. Macmillan, 2011. (Cited on page 46.)

[221] Kas Kalba. The Adoption of Mobile Phones in Emerging Markets: Global Diffusion and the Rural Challenge. International Journal of Communication, 2:31, 2008. (Cited on pages 228 and 229.)

[222] Patrick Kelly and Melvin Kranzberg. Technological Innovation: A Critical Review of Current Knowledge. San Francisco Press, 1978. (Cited on pages 224 and 225.) 
[223] Stephen Kemmis. Exploring the relevance of critical theory for action research: Emancipatory action research in the footsteps of Jurgen Habermas. Handbook of action research, 4:94-105, 2006. (Cited on page 16.)

[224] Stephen Kemmis and Robin McTaggart. Participatory action research: Communicative action and the public sphere. Sage Publications Ltd, 2005. (Cited on pages 7 and 18.)

[225] Aalok Khandekar, Koen Beumer, Annapurna Mamidipudi, Pankaj Sekhsaria, and Wiebe E. Bijker. STS for Development. In Ulrike Felt, Rayvon Fouché, Clark A Miller, and Laurel Smith-Doerr, editors, Handbook of Science and Technology Studies, pages 665-693. MIT Press, 2017. (Cited on pages 21 and 236.)

[226] Do Ba Khang and Tun Lin Moe. Success criteria and factors for international development projects: A life-cycle-based framework. Project Management Journal, 39(1):72-84, 2008. (Cited on pages 33, 44, and 45.)

[227] L. Douglas Kiel. Chaos theory and disaster response management: lessons for managing periods of extreme instability. What Disaster Management Can Learn From Chaos Theory, pages 18-19, 1995. (Cited on page 50.)

[228] Leslie A. King. Traditions, Traps and Trends: Transfer of Knowledge in Arctic Regions, jarich oosten and barbara helen miller (eds.), 2019. (Cited on page 23.)

[229] Wadkar Sagar Kisan, Argade Shivaji Dadabhau, Khajan Singh, et al. Factors affecting the sustainability of ICT intervention for agricultural development-A review. Agricultural Reviews, 34(3):198-206, 2013. (Cited on pages 40 and 54.)

[230] Justyna Kleczar. General purpose methodology and tooling for Text-to-Speech support in voice services for under-resourced languages. Technical report, Master Thesis Computer Science, Vrije Universiteit Amsterdam, 2017. (Cited on pages 150 and 264.)

[231] Dorothea Kleine. ICT4WHAT? Using the choice framework to operationalise the capability approach to development. Journal of International Development, 22(5):674-692, 2010. (Cited on page 220.)

[232] Dorothea Kleine. Technologies of Choice? ICTs, Development, and the Capabilities Approach. MIT Press, Cambridge, MA, USA, 2013. (Cited on pages 24, 46, 225, and 247.)

[233] Ronald Kline. Construing "Technology" as "Applied Science": Public Rhetoric of Scientists and Engineers in the United States, 1880-1945. Isis, 86(2):194-221, 1995. (Cited on page 37.) 
[234] Stephen J. Kline. Innovation is not a linear process. Research management, 28(4):3645, 1985. (Cited on page 37.)

[235] Stephen J. Kline and Nathan Rosenberg. An overview of innovation. In The Positive Sum Strategy: Harnessing Technology for Economic Growth, volume 14, page 640. World Scientific, 1986. (Cited on pages 37, 224, and 225.)

[236] Gerald Kotonya and Ian Sommerville. Requirements Engineering: Processes and Techniques. John Wiley and Sons, Chichester, UK, 1998. (Cited on pages 13, 25, 140, 233, and 262.)

[237] Kirstin E.M. Krauss. Practice-driven theory: Using Bourdieu's critical lineage in $\mathrm{ICT}_{4} \mathrm{D}$ work. In Paper submitted for the 7 th International IDIA Development Informatics Conference, Bangkok, Thailand, pages 1-3, 2013. (Cited on pages 19 and 23.)

[238] Rajendra Kumar and Michael L. Best. Impact and Sustainability of EGovernment Services in Developing Countries: Lessons learned from Tamil Nadu, India. The Information Society, 22(1):1-12, 2006. https : //doi . org/10 . 1080/ 01972240500388149, (accessed o8-10-2020). (Cited on page 46.)

[239] J. Stephen Lansing. Complex adaptive systems. Annual Review of Anthropology, pages $183-204,2003$. (Cited on pages 49 and 50.)

[240] J. Stephen Lansing. Priests and Programmers: Technologies of Power in the Engineered Landscape of Bali. Princeton University Press, 2007. (Cited on pages 23, 24, 26, 49, 233, 234, and 244.)

[241] J. Stephen Lansing. Perfect order: Recognizing complexity in Bali, volume 22. Princeton University Press, 2012. (Cited on pages 49, 233, and 234.)

[242] J. Stephen Lansing and James N. Kremer. Emergent Properties of Balinese Water Temple Networks: Coadaptation on a Rugged Fitness Landscape. American Anthropologist, pages 97-114, 1993. (Cited on pages 24, 49, and 234.)

[243] J. Stephen Lansing, James N. Kremer, Vanda Gerhart, Patricia Kremer, Alit Arthawiguna, Sang Kaler Putu Surata, Ida Bagus Suryawan, I. Gusti Arsana, Vernon L. Scarborough, John Schoenfelder, et al. Volcanic Fertilization of Balinese Rice Paddies. Ecological Economics, 38(3):383-390, 2001. (Cited on page 235.)

[244] J. Stephen Lansing, James N. Kremer, D.M. Warren, D. Slikkerveer, L.J.and Brokensha, et al. A Sociological Analysis of Balinese Water Temples. The Cultural Dimension of Development: Indigenous Knowledge Systems, pages 258-268, 1995. (Cited on pages 24 and 234.)

[245] Phillip A. Laplante and Colin J. Neill. The Demise of the Waterfall Model is Imminent. Queue, $1(10): 10,2004$. (Cited on page 48.) 
[246] Melissa Leach, John Gaventa, and Katy Oswald. Engaged Excellence-Full issue. IDS Bulletin, 47(6):1-179, 2016. (Cited on pages 22, 248, and 249.)

[247] Dean Leffingwell. Agile Software Requirements: Lean Requirements Practices for Teams, Programs, and the Enterprise. Addison-Wesley Professional, 2010. (Cited on pages 25 and 48 .)

[248] Dean Leffingwell and Don Widrig. Managing software requirements: a use case approach. Pearson Education, 2003. (Cited on pages 13, 25, 26, 48, 49, 58, 60, 140, 232, 241, and 262.)

[249] Yves Lesperance. A Formal Theory of Indexical Knowledge and Action. University of Toronto, 1992. (Cited on page 236.)

[250] Simon Levin. Fragile Dominion. Basic Books, 2007. (Cited on page 49.)

[251] Simon A. Levin. Ecosystems and the Biosphere as Complex Adaptive Systems. Ecosystems, 1(5):431-436, 1998. (Cited on page 49.)

[252] Kurt Lewin. Action research and minority problems. Journal of social issues, 2(4):34-46, 1946. (Cited on page 16.)

[253] Cecilia I.C. Lin and Michael D. Myers. Extending ICT4D Studies: The Value of Critical Research. MIS Quarterly, 39(3), 2015. (Cited on pages 19 and 23.)

[254] Kurt R. Linberg. Software Developer Perceptions About Software Project Failure: a Case Study. Journal of Systems and Software, 49(2):177-192, 1999. (Cited on pages 48,232 , and 241.)

[255] Yvonna S. Lincoln and Egon G. Guba. The constructivist credo. Left Coast Press, 2013. (Cited on page 27.)

[256] Awa Gossa Lô and Stefan Schlobach. The power of knowledge sharing: innovative ICTs for the rural poor in the Sahel. Technical report, $\mathrm{W}_{4}$ RA Student Papers 2016-1, Bachelor thesis, Lifestyle Informatics, VU Amsterdam 2016, 2016. http : // w4ra.org/wp-content/uploads/2016/07/Gossa-Lo-Bachelor-Project.pdf, (accessed o8-10-2020). (Cited on page 264.)

[257] Gossa Lô and Romy Blankendaal. Digivet: a knowledge-based veterinary system for rural farmers in North Ghana. Technical report, W4RA Student papers 2016-3, VU Amsterdam, Artificial Intelligence - student research, 2016. http:// w4ra.org/wp-content/uploads/2016/07/DigiVet_Gossa_Romy.pdf (accessed o810-2020). (Cited on page 264.)

[258] Gossa Lô, Gayo Diallo, Victor de Boer, and Stefan Schlobach. Linking African Traditional Medicine Knowledge. In Proceedings of the 1oth Conference on Semantic Web Applications and Tools for Life Sciences, 2017. (Cited on page 264.) 
[259] Pericles Loucopoulos and Vassilios Karakostas. System Requirements Engineering. McGraw-Hill, Inc., 1995. (Cited on pages 60 and 233.)

[26o] Gary Madden, Grant Coble-Neal, and Brian Dalzell. A dynamic model of mobile telephony subscription incorporating a network effect. Telecommunications Policy, 28(2):133-144, 2004. (Cited on pages 228 and 229.)

[261] Annapurna Mamidipudi and Wiebe Bijker. Mobilising Discourses: Handloom as Sustainable Socio-Technology. Economic and Political Weekly, pages 41-51, 2012. (Cited on page 24.)

[262] Annapurna Mamidipudi and Wiebe E. Bijker. Innovation in Indian handloom weaving. Technology and Culture, 59(3):509-545, 2018. (Cited on page 24.)

[263] Mario Marais. Analysis of the factors affecting the sustainability of ICT4D initiatives. In Proceedings 5 th IDIA Conference: ICT for Development: People, Policy and Practice, Lima, Peru, 26 - 28 October 2011, 2011. https://researchspace.csir.co. za/dspace/handle/10204/5374, (accessed 11-11-2017). (Cited on pages 3, 4, 26, 40, and 46.)

[264] Salvatore T. March and Gerald F. Smith. Design and natural science research on information technology. Decision support systems, 15(4):251-266, 1995. (Cited on page 16.)

[265] Jean-Yves Marchal. Vingt ans de lutte antiérosive au nord du Burkina Faso. Cahiers ORSTOM, Série Pédologie, 22(2):173-180, 1986. (Cited on pages 72 and 73.)

[266] Isaac Mbiti and David N. Weil. Mobile Banking: The Impact of M-Pesa in Kenya. Working Paper 2011-13, Brown University, Department of Economics, 2011. http: //hdl . handle. net/10419/62662, (accessed 08-10-2020). (Cited on page 231.)

[267] Cheryl McEwan. Postcolonialism, decoloniality and development. Routledge, 2018. (Cited on page 24.)

[268] John Robert McNeill and William H. McNeill. The Human Web: A Bird's-Eye View of Human History. New York: WW Norton \& Co, 2003. (Cited on page 236.)

[269] John Victor Mensah, Stephen Bugu Kendie, and Francis Enu-Kwesi. Preface. In Re-thinking Development Studies in Africa, pages vi-xiii. Institute for Development Studies (IDS), 2009. (Cited on pages 5, 10, 26, and 249.)

[270] Robert King Merton. On Sociological Theories of the MiddleRange. New York, Simon \& Schuster, The Free Press, 1949. (Cited on page 25.) 
[271] Isabel Meyer and Mario Alphonso Marais. Design for Sustainability: Countering the Drivers of Unsustainability in Development Projects. The Journal of Community Informatics, 11(3), 2015. http://www.ci-journal.net/index.php/ciej/ article/view/1169/1161, (accessed o8-10-2020). (Cited on pages 4, 26, and 46.)

[272] Walter D. Mignolo. Introduction: Coloniality of power and de-colonial thinking. Cultural studies, 21(2-3):155-167, 2007. (Cited on page 24.)

[273] John H. Miller and Scott E. Page. Complex Adaptive Systems: An Introduction to Computational Models of Social Life. Princeton University Press, 2002. ISBN: 9781400835522. (Cited on pages 49, 50, and 225.)

[274] Cyrus C.M. Mody. New Editor-in-Chief Editorial. Engineering Studies, 10-I:1-11, 2018. (Cited on page 22.)

[275] Peter R. Monge and Noshir S. Contractor. Theories of Communication Networks. Oxford University Press, 2003. (Cited on pages 20, 26, 50, 225, 229, and 236.)

[276] Marie Monimart. Femmes du Sahel: La désertification au quotidien. Karthala, 1989. (Cited on page 83.)

[277] Gordon E. Moore. Cramming More Components onto Integrated Circuits. Proceedings of the IEEE, 86(1):33-35, 1998. Reprinted from Electronics, volume 38, number 8, April 19, 1965, pp. 114 ff. (Cited on page 227.)

[278] Gareth Morgan and Rafael Ramírez. Action Learning: A Holographic Metaphor for Guiding Social Change. Human Relations, 37(1):1-27, 1984. (Cited on pages 49 and 58.)

[279] Evgeny Morozov. To save everything, click here: The folly of technological solutionism. PublicAffairs, 2014. (Cited on page 22.)

[280] Maxwell Mudhara, Critchley William, Sabina Di Prima, Saa Dittoh, and Mohamed Sessay. Community Innovations in Sustainable Land Management. Earthscan, 2016. (Cited on pages 22, 37, 62, 225, 235, 237, 249, and 263.)

[281] M. Mulard and D. Groene. Les méthodes de lutte contre l'érosion du sol en Haute - Volta. Revue Bois et Forêts des Tropiques, 9(79):7-16, 1961. (Cited on pages 72 and 73.$)$

[282] Megumi Muto and Takashi Yamano. The Impact of Mobile Phone Coverage Expansion on Market Participation: Panel Data Evidence from Uganda. World Development, 37(12):1887-1896, 2009. (Cited on page 230.)

[283] John Mylopoulos. Conceptual Modelling and Telos. Conceptual Modelling, Databases and CASE: An Integrated View of Information Systems Development, pages 49-68, 1992. (Cited on page 242.) 
[284] Emma Näslund-Hadley, Scott Kipp, Jessica Cruz, Pablo Ibarrarán, and Gita Steiner-Khamsi. OLPC Pre-pilot Evaluation Report (Haïti). Technical report, Inter-American Development Bank, 2009. https://publications.iadb.org/ handle/11319/2816, (accessed 11-11-2017). (Cited on page 36.)

[285] Haslinda Sutan Ahmad Nawi, Nur Syufiza Ahmad Shukor, Suzana Basaruddin, Siti Fatimah Omar, Azizah Abdul, Rohaya Abu Hassan Rahman, Mohammad Ashri Abu Hassan, and Bestari Jaya. Sustainability Criteria Model: A Field Study of $\mathrm{ICT}_{4} \mathrm{D}$ Project. International Journal of Computer Science Issues, 10(1), 2013. (Cited on page 46.)

[286] Nicholas Negroponte, Walter Bender, Antonio Battro, and David Cavallo. One Laptop per Child. Technical report, OLPC, 2006. http://www.olpcnews.com/ presentations/olpc-nov-2006t.pdf, (accessed 11-11-2017). (Cited on page 35.)

[287] Sridhar Nerur, Alan Cannon, VenuGopal Balijepally, and Philip Bond. Towards an understanding of the conceptual underpinnings of agile development methodologies. In Agile Software Development, pages 15-29. Springer, 2010. (Cited on page 6o.)

[288] Sridhar Nerur, RadhaKanta Mahapatra, and George Mangalaraj. Challenges of migrating to agile methodologies. Communications of the ACM, 48(5):72-78, 2005. (Cited on page 58.)

[289] Flemming Nielsen. Why do Farmers Innovate and Why Don't They Innovate More? Insights from a Study in East Africa. In Chris Reij and Ann WatersBayer, editors, Farmer Innovation in Africa: A Source of Inspiration for Agricultural Development, pages 92-103. Earthscan Publications, London, UK, 2001. (Cited on page 235.)

[290] Derek van den Nieuwenhuijzen. Using Virtual Agents to Bridge the Dutch Illiteracy Gap. $W_{4} R A$ student papers, 2019. https: //w4ra.org/wp - content/uploads/2019/07/18_july_2019_Final_ - Master-Thesis-ACM-style-Derek-van-den-Nieuwenhuijzen.pdf(accessed o8-10-2020). (Cited on page 219.)

[291] Kishan Jayant Nirghin, Alex Zhiluen Fong, Mun Lok Tang, Derek van den Nieuwenhuijzen, and Roz Sabir. ICT4D Project: Information Management System for Repackaging Business. W4RA Working Papers, pages 120, 2019. https://w4ra.org/wp-content/uploads/2019/08/MajuNet_paper reducedsize2019. pdf, (accessed o8-10-2020). (Cited on page 210.)

[292] Kitaro Nishida. An Inquiry Into the Good. Yale University Press, 1992. (Cited on page 6o.) 
[293] Ikujiro Nonaka and Noboru Konno. The concept of 'ba': Building a foundation for knowledge creation. California Management Review, 40(3):40, 1998. (Cited on pages $60,90,223,236,239,240$, and 243.)

[294] Ikujiro Nonaka and Ryoko Toyama. Strategic management as distributed practical wisdom (phronesis). Industrial and corporate change, 16(3):371-394, 2007. (Cited on page 18.)

[295] Ikujiro Nonaka, Ryoko Toyama, and Noboru Konno. SECI, ba and leadership: a unified model of dynamic knowledge creation. Knowledge Management: Critical Perspectives on Business and Management, 2:317, 2005. (Cited on pages 16 and 90.)

[296] R. Normann and R. Ramírez. Designing Interactive Strategy - From Value Chain to Value Constellation. John Wiley \& Sons Inc., 1994. (Cited on page 166.)

[297] Helga Nowotny, Peter Scott, and Michael Gibbons. Rethinking Science, Knowledge and the Public in an Age of Uncertainty. Polity Press Cambridge, UK, 2001. (Cited on pages 18 and 248.)

[298] Helga Nowotny, Peter Scott, and Michael Gibbons. Re-thinking science: mode 2 in societal context. Knowledge creation, diffusion, and use in innovation networks and knowledge clusters. A comparative systems approach across the United States, Europe and Asia, pages 39-51, 2006. (Cited on pages 18 and 248.)

[299] Patricia Noxolo. Introduction: Decolonising geographical knowledge in a colonised and re-colonising postcolonial world. Area, 49(3):317-319, 2017. (Cited on page 24.)

[300] A Nsengiyumva and A.B. Baingana. Rwanda Telecommunications Sector Performance Review-a Supply Side Analysis of Policy Outcomes. Rwanda Education and Research Network, Hosted by KIST, 2007. https://tinyurl.com/ rwanda-telco-sector-review, (accessed 08-10-2020). (Cited on page 38.)

[301] Dita Nugroho and M. Londsale. Evaluation of OLPC Programs Globally: A Literature Review. Mimeographed document, Australian Council of Educational Research, Melbourne, Australia, 2010. https://research.acer.edu.au/digital_ learning/8/, (accessed 11-11-2017). (Cited on page 36.)

[302] Allard Oelen, Aron Van Groningen, Amir Azizi Musa, Deva Ramakrishnan, Hameedat Omoine, and Linh Tran. BannaTree: an Information Management System for Banana Contract Farming. W4RA Working $\mathrm{Pa}$ pers, pages 1- 32, 2018. https://w4ra.org/wp-content/uploads/2018/07/ ICT4D-Field-Banana-case- use-V2 . pdf, (accessed 08-10-2020). (Cited on pages 210,211 , and 212.) 
[303] Milcah Ong'ayo, Janet Njoroge, and Will Critchley. Women and Innovation: Experiences from Promoting Farmer Innovation in East Africa. In Chris Reij and Ann Waters-Bayer, editors, Farmer Innovation in Africa: A Source of Inspiration for Agricultural Development, pages 110-121. Earthscan Publications, London, UK, 2001. (Cited on page 235.)

[304] Vidushi Pandey and Sumeet Gupta. A comprehensive four-stage framework for evaluation of Information Communication Technologies for Development interventions. Information Technology for Development, pages 1-21, 2017. (Cited on page 54.)

[305] Seymour Papert and Idit Harel. Situating constructionism. Constructionism, 36(2):1-11, 1991. (Cited on page 35.)

[306] Tapan S. Parikh and Edward D. Lazowska. Designing an Architecture for Delivering Mobile Information Services to the Rural Developing World. In Proceedings of the 15th International Conference on World Wide Web, pages 791-80o. ACM, 2006. (Cited on page 22.)

[307] Richard T. Pascale, Jerry Sternin, and Monique Sternin. The power of positive deviance: How unlikely innovators solve the world's toughest problems, volume 1. Harvard Business Press, 2010. (Cited on page 63.)

[308] Ray Pawson. Evidence-based policy: A realist perspective. Sage Publications, 2006. (Cited on pages 46 and 47. )

[309] Lotte Pelckmans. Phoning Anthropologists: The Mobile Phone's (re-) Shaping of Anthropological Research. In Mirjam de Bruijn, Francis Nyamnjoh, and Inge Brinkman, editors, Mobile phones: The New Talking Drums of Everyday Africa, pages 23-49. Langaa and African Studies Centre Leiden, 2009. (Cited on pages 24, 227, 244, and 245.)

[310] Kai Petersen, Claes Wohlin, and Dejan Baca. The Waterfall Model in Large-Scale Development. In PROFES, pages 386-400. Springer, 2009. (Cited on page 48.)

[311] Julia Pfaff. Mobile Phone Geographies. Geography Compass, 10(4):1433-1447, 2010. (Cited on pages 24, 244, and 245.)

[312] Rosalind W. Picard, Seymour Papert, Walter Bender, Bruce Blumberg, Cynthia Breazeal, David Cavallo, Tod Machover, Mitchel Resnick, Deb Roy, and Carol Strohecker. Affective learning - a manifesto. BT technology journal, 22(4):253-269, 2004. (Cited on page 35.)

[313] Thomas Piketty. Capital and Ideology. Harvard University Press, 2020. (Cited on page 264.) 
[314] Mónica Pini. Digital technologies: public funds and private policies in Argentina. In Anna Bon, Mónica Pini, and Hans Akkermans, editors, Culture, citizenship, participation - Comparative perspectives from Latin America on inclusive education, pages 177-191. Pangea, Amsterdam, 2019. (Cited on pages 22 and 24.)

[315] Mmamakanye M. Pitse-Boshomane, Mario A. Marais, C.F. Morris, Kobus Roux, Rensie Van Rensburg, M.E. Herselman, A.K. Makan, and Ingrid Mulder. Catalysing innovation: the promise of the Living Lab Approach in South Africa. Prato CIRN 2008 Community Informatics Conference, 2008. (Cited on page 22.)

[316] Kristina Pitula, Deborah Dysart-Gale, and Thiruvengadam Radhakrishnan. Expanding theories of HCI: A case study in requirements engineering for $\mathrm{ICT}_{4} \mathrm{D}$. Information Technologies E International Development, 6(1):pp-78, 2010. (Cited on pages 22 and 203.)

[317] Kristina Pitula and Thiruvengadam Radhakrishnan. On Eliciting Requirements from End-users in the ICT4D Domain. Requirements Engineering, 16(4):323-351, 2011. (Cited on pages 203 and 221.)

[318] Megan Plyler, Sherri Haas, and G. Ngarajan. Community-Level Economic Effects of M-PESA in Kenya: Initial Findings. Assessing the Impact of Innovation Grants in Financial Services Project, 2010. http://Www. fsassessment. umd. edu/publications/pdfs/Community-Effects - MPESA-Kenya.pdf, (accessed o8-102020). (Cited on page 231.)

[319] Karl Popper. Conjectures and refutations: The growth of scientific knowledge. routledge, 2014. (Cited on page 28.)

[320] Robert Potter, Tony Binns, Jennifer A Elliott, Etienne Nel, and David W Smith. Geographies of development: An introduction to development studies. Routledge, 2017. (Cited on page 4.)

[321] Robert B. Potter. Geographies of Development. Pearson Education, 2004. (Cited on page 233.)

[322] Sammia Poveda and Tony Roberts. Critical agency and development: Applying Freire and Sen to $\mathrm{ICT}_{4} \mathrm{D}$ in Zambia and Brazil. Information Technology for Development, 24(1):119-137, 2018. (Cited on page 23.)

[323] Coimbatore K. Prahalad and Allen Hammond. Serving the World's Poor, Profitably. Harvard Business Review, 8o(9):48-59, 2002. (Cited on page 247.)

[324] Coimbatore Krishna Prahalad. The Fortune at the Bottom of the Pyramid. Pearson Education India, 2006. (Cited on pages 230, 232, 247, and 248.) 
[325] Peter Wallace Preston. Development Theory: An Introduction. Siglo XXI, 1999. (Cited on pages 4,33 , and 43.)

[326] Peter Wallace Preston. Theories of Development. Routledge, 2012. (Cited on page 4.)

[327] Ilya Prigogine and Isabelle Stengers. La nouvelle alliance: métamorphose de la science. Gallimard, 1979. (Cited on pages 26, 49, and 50.)

[328] Ilya Prigogine, Isabelle Stengers, and Jacqueline Raoul-Duval. Entre le temps et l'éternité. Fayard Paris, 1988. (Cited on pages 26, 49, and 50.)

[329] Paul M. Pronyk, Maria Muniz, Ben Nemser, Marie-Andrée Somers, Lucy McClellan, Cheryl A. Palm, Uyen Kim Huynh, Yanis Ben Amor, Belay Begashaw, John W. McArthur, et al. The effect of an integrated multisector model for achieving the Millennium Development Goals and improving child survival in rural sub-Saharan Africa: a non-randomised controlled assessment. The Lancet, 379(9832):2179-2188, 2012. (Cited on page 42.)

[330] Jolita Ralyté, Neil A.M. Maiden, Colette Rolland, and Rébecca Deneckère. Mapdriven modular method re-engineering: Improving the RESCUE requirements process. In CAiSE Short Paper Proceedings, 2005. (Cited on page 203.)

[331] Ben Ramalingam. Aid on the Edge of Chaos. Oxford University Press, 2013. (Cited on pages $10,18,26,46,47,49$, and 252.)

[332] Claude Raynaut. Sahels: diversité et dynamiques des relations sociétés-nature. KARTHALA Editions, 1997. (Cited on page 50.)

[333] Peter Reason and Hilary Bradbury. Handbook of Action Research: Participative Inquiry and Practice. Sage, 2001. (Cited on pages 16, 18, and 248.)

[334] C. Reij and T. Thombiano. Développement rural et environnement au Burkina Faso: la réhabilitation de la capacité productive des terroirs sur la partie nord du plateau central entre 1980 et 2001. Rapport de synthèse, Ambassade des Pays-Bas à Ouagadougou, 2003. (Cited on page 83.)

[335] Chris Reij, Ian Scoones, and Camilla Toulmin. Techniques traditionnelles de conservation de l'eau et des sols en Afrique. Karthala, Paris, France, 1996. (Cited on pages $62,72,73$, and 74. )

[336] Chris Reij, Gray Tappan, and Adama Belemvire. Changing land management practices and vegetation on the Central Plateau of Burkina Faso (1968-2002). Journal of Arid Environments, 63(3):642-659, 2005. (Cited on pages 62, 73, 75, 76, 79, $83,84,85,235$, and 263.) 
[337] Chris Reij, Gray Tappan, and Melinda Smale. Agroenvironmental Transformation in the Sahel: Another kind of "Green Revolution", volume 914. International Food Policy Research Institute - IFPRI, 2009. (Cited on pages 23, 71, 72, 73, 76, 77, 83, $84,85,235$, and 263.)

[338] Chris Reij and Ann Waters-Bayer. Farmer Innovation in Africa: A Source of Inspiration for Agricultural Development. Earthscan, 2001. (Cited on pages 22, 23, 26, 37, $61,62,75,76,84,85,91,225,233,235,236,237,249$, and 263.)

[339] Chris Reij and Robert Winterbottom. Scaling up Regreening: Six Steps to Success, A Practical Approach to Forest and Landscape Restoration. World Resources Institute, 2015. (Cited on pages 22, 23, 75, 76, 77, 85, 235, 249, 263, and 270.)

[340] C.P. Reij and E.M.A. Smaling. Analyzing Successes in Agriculture and Land Management in Sub-Saharan Africa: Is Macro-level Gloom Obscuring Positive Micro-level Change? Land Use Policy, 25(3):410-420, 2008. (Cited on pages 76, 77, and 84.)

[341] Paul Richards. Coping with Hunger: Hazard and Experiment in an African Ricefarming System. Allen and Unwin, London, 1986. (Cited on pages 26 and 61.)

[342] J. Barry Riddell. Things fall apart again: structural adjustment programmes in sub-Saharan Africa. The Journal of Modern African Studies, 30(1):53-68, 1992. (Cited on page 78.$)$

[343] Cynthia K. Riemenschneider, Bill C. Hardgrave, and Fred D. Davis. Explaining Software Developer Acceptance of Methodologies: a Comparison of Five Theoretical Models. Software Engineering, IEEE Transactions on, 28(12):1135-1145, 2002. (Cited on pages 58 and 232.)

[344] Anthony Rinaudo. Uncovering the hidden forest. World Vision, pages 1-7, 2004. (Cited on pages $23,73,76,83,85$, and 235.)

[345] Tony Rinaudo. Utilizing the Underground Forest. In Combating Desertification with Plants, pages 325-336. Springer, 2001. (Cited on pages 72, 74, and 235.)

[346] Linda Rising and Norman S. Janoff. The Scrum software development process for small teams. IEEE Software, 17(4):26-32, 2000. (Cited on pages 59 and 233.)

[347] Aske Robenhagen and Bart Aubers. Mali Milk 3.o. a voice-based milk selling and farmer networking platform for Tominian Mali. In Proceedings of the $4^{\text {th }}$ International Workshop on Downscaling the Semantic Web, 2016. https://tinyurl. com/robenhagen-mali-milk, (accessed o8-10-2020). (Cited on page 113.)

[348] Colin Robson. Real World Research: A Resource for Users of Social Research Methods in Applied Settings. Wiley Chichester, 2011. (Cited on page 16.) 
[349] Colin Robson. Small-scale evaluation: Principles and practice. Sage, 2017. (Cited on pages 46 and 47.$)$

[350] Everett Rogers. Diffusion of Innovations. New York: Free Press, 2003. (Cited on pages $26,47,50,51,52,161,224,225,226,229,231,232,233,236$, and 237.)

[351] Everett M. Rogers, Una E. Medina, Mario A. Rivera, and Cody J. Wiley. Complex Adaptive Systems and the Diffusion of Innovations. The Public Sector Innovation Journal, 10(3):1-26, 2005. (Cited on pages 26, 50, 51, 225, and 232.)

[352] Colette Rolland. Capturing System Intentionality with Maps. In Conceptual Modelling in Information Systems Engineering, pages 141-158. Springer, 2007. (Cited on page 203.)

[353] Paul R. Rosenbaum and Donald B. Rubin. The central role of the propensity score in observational studies for causal effects. Biometrika, 70(1):41-55, 1983. (Cited on page 46.)

[354] Leon Rosenberg and Larry Posner. The logical framework: A manager's guide to a scientific approach to design and evaluation. Practical Concepts Incorporated, Washington, DC, 1979. (Cited on pages 26 and 44.)

[355] Walker Royce. Software Project Management. Pearson Education India, 1998. (Cited on page 47.)

[356] James Rumbaugh, Ivar Jacobson, and Grady Booch. The Unified Modeling Language Reference Manual. Pearson Higher Education, 2004. (Cited on page 127.)

[357] Stuart Russell. Human compatible: Artificial intelligence and the problem of control. Penguin, 2019. (Cited on page 264.)

[358] Bryce Ryan and Neal Gross. Acceptance and Diffusion of Hybrid Corn Seed in Two Iowa Communities. Research Bulletin (Iowa Agriculture and Home Economics Experiment Station), 29(372):1, 1950. (Cited on pages 37 and 51.)

[359] Bryce Ryan and Neal C. Gross. The Diffusion of Hybrid Seed Corn in Two Iowa Communities. Rural Sociology, 8(1):15, 1943. (Cited on pages 37 and 51.)

[360] Jeffrey D. Sachs and John W. McArthur. The Millennium Project: a plan for meeting the Millennium Development Goals. The Lancet, 365(9456):347-353, 2005. http://image. thelancet. com/extras/04art12121web.pdf, (accessed o810-2020). (Cited on pages 41, 42, and 200.)

[361] George Sadowsky. Accelerating Development Using the Web: Empowering Poor and Marginalized Populations. World Wide Web Foundation, 2012. (Cited on pages 10 and 38.) 
[362] Beth Lewis Samuelson and Sarah Warshauer Freedman. Language Policy, Multilingual Education, and Power in Rwanda. Language Policy, 9(3):191-215, 2010. (Cited on page 38.)

[363] Pedro Sanchez, Cheryl Palm, Jeffrey Sachs, Glenn Denning, Rafael Flor, Rebbie Harawa, Bashir Jama, Tsegazeab Kiflemariam, Bronwen Konecky, Raffaela Kozar, et al. The African Millennium Villages. Proceedings of the National Academy of Sciences, 104(43):16775-16780, 2007. (Cited on pages 41, 42, and 43.)

[364] Richard Sandbrook. Globalization and the Limits of Neoliberal Development Doctrine. Third World Quarterly, 21(6):1071-1080, 2000. (Cited on page 247.)

[365] Reshmi Sarkar and Jaap Gordijn. Modeling Communities in $e^{3}$ value. Technical report, 12th International Workshop Value Modeling Business Ontologies, Amsterdam, February 2018, 2018. W4RA Working Papers https:// w4ra.org/wp-content/uploads/2018/01/vmbo-Reshmi-Jaap.pdf, (accessed o810-2020). (Cited on page 264.)

[366] Andrew Sayer. Why Things Matter to People: Social Science, Values and Ethical Life. Cambridge University Press, 2011. (Cited on page 248.)

[367] Steve Schmida, James Bernard, Tess Zakaras, Caitlin Lovegrove, and Claire Swingle. Connecting the Next Four Billion: Strengthening the Global Response for Universal Internet Access. USAID, Dial, SSG Advisors, 2017. https://tinyurl. com/connectingthenext4b, (accessed 11-11-2017). (Cited on pages 4 and 26.)

[368] Donald A. Schon. Beyond the stable state: Public and private learning in a changing society. Maurice Temple Smith Ltd., 1971. (Cited on page 37.)

[369] Sanford Schram. Phronetic social science: An idea whose time has come. Real social science: Applied phronesis, pages 15-26, 2012. (Cited on pages 7 and 22.)

[370] A.Th. Schreiber, J.M. Akkermans, A.A. Anjewierden, R. de Hoog, N.R. Shadbolt, W. Van de Velde, and B.J. Wielinga. Knowledge Engineering and Management: the CommonKADS Methodology. MIT Press, 2000. (Cited on pages 25, 236, and 240.)

[371] A. Schumpeter, Joseph. Capitalismo, socialismo e democracia. Editora Fundo de Cultura, Rio de Janeiro, 1961. (Cited on pages 37 and 224.)

[372] Ian Scoones. Livelihoods Perspectives and Rural Development. The Journal of Peasant Studies, 36(1):171-196, 2009. (Cited on pages 22, 61, 249, 252, 253, and 263.)

[373] Ian Scoones. Sustainable Livelihoods and Rural Development. Practical Action Publishing Rugby, UK, 2015. http://Www. developmentbookshelf. com/doi/book/10. 3362/9781780448749, (accessed 08-10-2020). (Cited on pages 18, 22, 61, 69, 249, and 263.) 
[374] Michael Scriven. Key Evaluation Checklist (KEC), volume 15. Claremont Graduate University \& The Evaluation Center, Western Michigan University, 2007. http:// michaelscriven.info/images/KEC_7 .25.2013.pdf, (accessed o8-10-2020). (Cited on page 46.)

[375] Maung K. Sein, Ola Henfridsson, Sandeep Purao, Matti Rossi, and Rikard Lindgren. Action design research. MIS quarterly, pages 37-56, 2011. (Cited on page 17.)

[376] Amartya Sen. Development as Freedom. Oxford University Press, 1999. (Cited on pages 220, 221, and 247.)

[377] Jan Sendzimir, Chris P. Reij, and Piotr Magnuszewski. Rebuilding resilience in the Sahel: regreening in the Maradi and Zinder regions of Niger. Ecology and Society, 16(3):1, 2011. http://dx.doi.org/10.5751/ES-04198-160301, (accessed o8-10-2020). (Cited on pages 23, 50, 53, 72, 73, 75, 76, 77, 78, 79, 85, and 235.)

[378] Oshani Seneviratne and Silke Roth. Introduction to Websci'2o Workshops. In WebSci '20: 12th ACM Conference on Web Science Companion, New York, NY, USA, 2020. Association for Computing Machinery. (Cited on pages 269 and 275.)

[379] Helen Sharp and Hugh Robinson. Three 'C's of Agile Practice: Collaboration, Co-ordination and Communication. In T. Dingsøyr, T. Dybå, and N. Moe, editors, Agile Software Development, pages 61-85. Springer, 2010. (Cited on pages 58 and 6o.)

[380] Vandana Shiva. The Violence of the Green Revolution: Third World Agriculture, Ecology, and Politics. University Press of Kentucky, 2016. (Cited on page 233.)

[381] Paul B. Siegel, Justine Gatsinzi, and Andrew Kettlewell. Adaptive Social Protection in Rwanda: Climate-proofing the Vision 2020 Umurenge Programme. IDS Bulletin, 42(6):71-78, 2011. (Cited on page 38.)

[382] Herbert A. Simon. The Sciences of the Artificial. MIT Press, 1996. (Cited on page 15.$)$

[383] Harminder Singh, Antonio D.íaz Andrade, and Angsana A. Techatassanasoontorn. The practice of ICT-enabled development. Information Technology for Development, 24(1):37-62, 2018. (Cited on pages 19 and 23.)

[384] Sergio Sismondo. Science and technology studies and an engaged program. The handbook of science and technology studies, 3:13-32, 2008. (Cited on page 21.)

[385] Brian Cantwell Smith. The Promise of Artificial Intelligence: Reckoning and Judgment. MIT Press, 2019. (Cited on page 264.) 
[386] Karen Smits and Alfons van Marrewijk. Chaperoning: Practices of collaboration in the Panama canal expansion program. International Journal of Managing Projects in Business, 5(3):440-456, 2012. (Cited on page 244.)

[387] Ian Sommerville and Gerald Kotonya. Requirements Engineering: Processes and Techniques. John Wiley \& Sons, Inc., 1998. (Cited on page 233.)

[388] Ian Sommerville and Pete Sawyer. Requirements Engineering: a Good Practice Guide. John Wiley \& Sons, Inc., 1997. (Cited on pages 13, 60, 140, 233, and 262.)

[389] H. Leslie Steeves and Janet Kwami. Interrogating gender divides in technology for education and development: the case of the One Laptop per Child project in Ghana. Studies in Comparative International Development, 52(2):174-192, 2017. (Cited on page 36.)

[390] Danielle Stein and Craig Valters. Understanding Theory of Change in International Development. Working Paper, Justice and Security Research Programme, International Development Department, London School of Economics and Political Science, 2012. http://eprints. lse.ac.uk/id/eprint/56359, (accessed o8-102020). (Cited on pages 45 and 163.)

[391] Susan Strange. The Retreat of the State: The Dffusion of Power in the World Economy. Cambridge university press, 1996. (Cited on page 248.)

[392] Banu Subramaniam, Laura Foster, Sandra Harding, Roy Deboleena, and Kim TallBear. Feminism, Postcolonialism, Technoscience. In Ulrike Felt, Rayvon Fouché, Clark A Miller, and Laurel Smith-Doerr, editors, Handbook of Science and Technology Studies, pages 407-434. MIT Press, Massachusetts, Cambridge, 2017. (Cited on pages 21 and 24.)

[393] J.E. Sumberg. NGOs and agriculture at the margin: research, participation and sustainability in West Africa. Network Paper-Agricultural Administration (Research and Extension) Network, 1991. (Cited on pages 71, 72, 73, and 74.)

[394] Daniel Svoboda, Kristina Ruśarová, Chaloupkovà Petra, and Jan Banout. Handbook on Project Cycle Management of Development Projects. Faculty of Tropical AgriSciences, Czech University of Life Sciences, Prague, 2018. http://www. dww.cz/ docs/pcm_handbook_2018.pdf, (accessed o8-10-2020). (Cited on page 34.)

[395] Damian Andrew Tamburri and Patricia Lago. Supporting communication and cooperation in global software development with agile service networks. In Software Architecture, pages 236-243. Springer, 2011. (Cited on pages 232 and 233.)

[396] J.B. Taonda, F. Hien, and C. Zango. Namwaya Sawadogo: The Ecologist of Touroum, Burkina Faso. In Chris Reij and Ann Waters-Bayer, editors, Farmer 
Innovation in Africa, pages 137-142. Earthscan Publications, London, UK, 2001. (Cited on page 235.)

[397] Gray Tappan and Michael McGahuey. Tracking environmental dynamics and agricultural intensification in southern Mali. Agricultural Systems, 94(1):38-51, 2007. (Cited on pages 72, 77, and 78.)

[398] Paul Tchawa, Pierre Kamga, Christopher Ndi, S.T. Vitsuh, and A.M. Ze. Participatory Technology Development on Soil Fertility Improvement in Cameroon. In Chris Reij and Ann Waters-Bayer, editors, Farmer Innovation in Africa: A Source of Inspiration for Agricultural Development, pages 221-233. Earthscan Publications, London, UK, 2001. (Cited on page 235.)

[399] Stephen Edelston Toulmin, Richard D. Rieke, and Allan Janik. An introduction to reasoning. Pearson Education (US), 1984. (Cited on page 28.)

[40o] Kentaro Toyama. Human-Computer Interaction and Global Development. Foundations and Trends in Human-Computer Interaction, 4(1):1-79, 2010. (Cited on pages 22, 26, 40, 203, and 250.)

[401] Kentaro Toyama. Design, needs, and aspirations in international development. In International Conference on Social Implications of Computers in Developing Countries, pages 24-32. Springer, 2017. (Cited on page 23.)

[402] Ilkka Tuomi. Networks of Innovation. Oxford University Press, 2002. (Cited on pages 20, 26, 37, 224, 225, 226, 232, 235, 236, 237, and 260.)

[403] USAID. Closing the Access Gap: Innovation to Accelerate Universal Internet Adoption. USAID, 2017. https://tinyurl. com/USAIDclosing-gap, (accessed 11-11-2017). (Cited on pages 4 and 26.)

[404] Abbott Payson Usher. A History of Mechanical Innovation. Oxford University Press, 1954. (Cited on pages 37 and 224.)

[405] Govert Valkenburg, Annapurna Mamidipudi, Poonam Pandey, and Wiebe E. Bijker. Responsible innovation as empowering ways of knowing. Journal of Responsible Innovation, 7(1):6-25, 2020. (Cited on page 24.)

[406] Onno Valkering, Victor de Boer, Gossa Lô, Romy Blankendaal, and Stefan Schlobach. The Semantic Web in an SMS. In European Knowledge Acquisition Workshop, pages 697-712. Springer, 2016. (Cited on page 264.)

[407] Eric Vall, Eduardo Chia, Mélanie Blanchard, Mahamoudou Koutou, Kalifa Coulibaly, and Nadine Andrieu. La co-conception en partenariat de systèmes agricoles innovants. Cahiers Agricultures, 25(1):15001, 2016. (Cited on page 237.) 
[408] Wilbert van der Klaauw. Estimating the Effect of Financial Aid Offers on College Enrollment: A Regression-Discontinuity Approach. International Economic Review, 43(4):1249-1287, 2002. (Cited on page 46.)

[409] Jacobus S. Van Der Walt, Albertus A.K. Buitendag, Jan J. Zaaiman, and Joey Jansen Van Vuuren. Community living lab as a collaborative innovation environment. Issues in Informing Science and Information Technology, 6(1):421-436, 2009. (Cited on page 22.)

[410] Aron van Groningen. Serious games for children in rural Sarawak: The co-creation of a digital tool to support mathematical education at community schools in Sarawak, Malaysia. W4RA student papers, 2019. https:// w4ra.org/wp-content/uploads/2019/08/Thes is - Aron-van-Groningen- 2595737. pdf,(accessed o8-10-2020). (Cited on page 210.)

[411] Gertjan Van Stam. Power Inequities: Observations on the Development of Information and Communication Technologies, from an African Place. In 12th ACM Conference on Web Science (WebSci '20 Companion), July 6-10, 2020, Southampton, United Kingdom, page 6. ACM, New York, NY, USA, 2020. DOI=https: //doi.org/10.1145/3394332.3402830. (Cited on page 24.)

[412] Hans van Vliet. Software Engineering: Principles and Practice. Wiley, New York, NY, 1993. (Cited on pages 59, 131, and 233.)

[413] Rohit Varman, Per Skålén, and Russell W. Belk. Conflicts at the Bottom of the Pyramid: Profitability, Poverty Alleviation, and Neoliberal Governmentality. Journal of Public Policy \& Marketing, 31(1):19-35, 2012. (Cited on pages 40 and 247.)

[414] Eric Von Hippel. The Dominant Role of Users in the Scientific Instrument Innovation Process. Research Policy, 5(3):212-239, 1976. (Cited on pages 26, 225, 232, and 260.)

[415] Eric Von Hippel. Democratizing Innovation: The Evolving Phenomenon of User Innovation. Journal für Betriebswirtschaft, 55(1):63-78, 2005. (Cited on pages 18, $26,37,57,58,225,232,235$, and 260.)

[416] Mark Warschauer and Morgan Ames. Can One Laptop per Child Save the World's Poor? Journal of International Affairs, 64(1):33-51, 2010. http: //www. j stor . org/stable/24385184, (accessed o8-10-2020). (Cited on page 36.)

[417] Adele Waugaman. From Principle to Practice: Implementing the Principles for Digital Development. Proceedings of the Principles for Digital Development Working Group, 2016. (Cited on pages 3, 4, and 247.) 
[418] Roel Wieringa. Design Science as Nested Problem Solving. In Proceedings of the 4th International Conference on Design Science Research in Information Systems and Technology, pages 1-12, 2009. (Cited on page 16.)

[419] Roel Wieringa. Design Science Methodology for Information Systems and Software Engineering. Springer, London, UK, 2014. http://doc.utwente.nl/93356/, (accessed 08-10-2020). (Cited on pages $11,15,16,25,28$, and 220.)

[420] Roel J. Wieringa. Technical Action Research. In Design science methodology for information systems and software engineering, pages 269-293. Springer, 2014. (Cited on page 17.)

[421] Bill Williams, José Figueiredo, and James Trevelyan. Engineering practice in a global context: Understanding the technical and the social. CRC Press, 2013. (Cited on pages 7,25 , and 248.)

[422] Terry Winograd, Fernando Flores, and Fernando F Flores. Understanding computers and cognition: A new foundation for design. Intellect Books, 1986. (Cited on pages 15 and 25.)

[423] Robert Winterbottom, Chris Reij, Dennis Garrity, Jerry Glover, Debbie Hellums, Mike McGahuey, and Sara Scherr. Improving Land and Water Management. Working paper, World Resources Institute, 2013. (Cited on pages 23, 75, 76, and 235.)

[424] P.M. Wognum, J.J. Krabbendam, Henrik Buhl, Xiaofeng Ma, and Ron Kenett. Improving enterprise system support - A case-based approach. Advanced Engineering Informatics, 18(4):241-253, 2004. (Cited on pages 25, 58, and 232.)

[425] Sally Wyatt. Technological Determinism is Dead; Long Live Technological Determinism. In Edward J. Hackett, Olga Amsterdamska, Michael Lynch, and Judy Wajcman, editors, The Handbook of Science and Technology Studies, pages 165-180. MIT Press Cambridge, Massachusetts, 2008. (Cited on pages 21, 22, and 253.)

[426] Sally Wyatt. A Computational Turn in the Humanities? A perspective from Science and Technology Studies. Journal of the Siberian Federal University, 9(2), 2016. (Cited on page 21.)

[427] Sally Wyatt and Brian Balmer. Home on the Range: What and where is the Middle in Science and Technology Studies? Science, Technology, \& Human Values, 32(6):619-626, 2007. (Cited on page 25.)

[428] Sally Wyatt, Flis Henwood, Nod Miller, and Peter Senker. On Technologies, In/Equalities - Questioning the Information society. Technology and in/equality: Questioning the Information Society, pages 1-235, 2000. (Cited on page 22.) 
[429] Robert Youker. Managing International Development Projects: Lessons Learned. Project Management World Journal, IV, 2015. https://tinyurl.com/ youker-man-int-dev-projects, (accessed 11-11-2017). (Cited on pages 26 and 33.)

[430] A.F.M. Zaal, Mineke Laman, Cheikh M. Sourang, et al. Resource conservation or short term food needs? Designing incentives for natural resource management. Technical report, International Institute for Environment and Development, United Kingdom, 1998. https://tinyurl.com/zaal-laman-sourang, (accessed 08-10-2020). (Cited on page 74.)

[431] Yifan Zhan. Local currency networks in rural communities in Africa: A feasibility study of blockchain based community currency. Technical report, Vrije Universiteit Amsterdam, 2019. (Cited on page 274.)

[432] Chong Xing Zi, Lucas Fijen, Marit van Dijk, Michelle Ten LiBin, Nur Asheila Abdul Taib, and Shanna Simon. Dengaway, a self-screening application for prevention and early detection of Dengue. Technical report, Network Institute of VU Amsterdam, 2019. https://w4ra.org/wp-content/uploads/2019/08/DengAway reduzedsize2019.pdf, (accessed 08-10-2020). (Cited on pages 210, 215, and 216.)

[433] Shoshana Zuboff. The Age of Surveillance Capitalism: The Fight for a Human Future at the New Frontier of Power. Profile Books, 2019. (Cited on pages 22 and 264.) 

Hoe kunnen we digitale technologieën ontwerpen en bouwen, voor en met mensen in arme gebieden van de wereld, voor doelen die door henzelf gekozen zijn? En hoe kunnen we dit doen op een manier die verbindend en ethisch is, en past binnen de complexiteit van hun leef- en werkomgeving?

Digitale technologie beschikbaar maken voor sociale en economische ontwikkeling van arme gebieden is een van de ambities van internationale ontwikkelingssamenwerking. Om dit te bewerkstelligen, wordt kennis en technologie uit technologisch geavanceerde landen naar arme gebieden van de wereld gebracht. Ontwikkelingsprojecten waarin dit plaatsvindt - zogenaamde $\mathrm{ICT}_{4} \mathrm{D}$ projecten - eindigen in de praktijk vaak onsuccesvol, of blijken niet duurzaam te zijn.

Het ontbreken van inbedding van de digitale technologie in de beoogde, lokale omgeving, is een veelvoorkomend probleem van $\mathrm{ICT}_{4} \mathrm{D}$ projecten. Dit probleem wordt door de grote internationale ontwikkelingsorganisaties onderkend. Projectresultaten zouden verbeterd kunnen worden, bijvoorbeeld door eindgebruikers in het ontwerpproces te betrekken. "Co-creatie", "participatie" en "gebruikersgericht ontwerp" zijn dan ook termen die tegenwoordig veelvuldig voorkomen in het discours van internationale ontwikkelingssamenwerking. Echter, aangezien $\mathrm{ICT}_{4} \mathrm{D}$ projecten opgezet worden om digitale technologie in arme gebieden uit te rollen conform extern geformuleerde ontwikkelingsdoelen (zo is de conventionele internationale ontwikkelingssamenwerking immers georganiseerd), stelt co-creatie in de praktijk weinig voor, en houdt de term "participatie" weinig in.

Dit proefschrift beschrijft de zoektocht naar, en het ontwerpen van, een alternatieve aanpak voor $\mathrm{ICT}_{4} \mathrm{D}$ : een aanpak die recht doet aan de wensen van de beoogde gebruikers en hun leefomgeving. Hiervoor is echte samenwerking tussen gebruikers en ICTontwikkelaars noodzakelijk. Het resultaat van mijn onderzoek is een methode en aanpak die ik "ICT4D 3.o" genoemd heb. Deze aanpak/methode is ontwikkeld gedurende tien jaar veld- en actieonderzoek in diverse landen, met name Mali, Burkina Faso en Ghana. Waarin onderscheidt deze methode zich?

Allereerst is $\mathrm{ICT}_{4} \mathrm{D} 3.0$ een praktische methode voor onderzoek en actie. Het gebruikt een configureerbaar, "socio-technisch" raamwerk voor het ontwerpen en bouwen van informatiesystemen, waarbij kennisuitwisseling tussen ontwikkelaars en gebruikers voorop staat. Hiertoe komen mensen met verschillende achtergronden en perspectieven bijeen in trans-disciplinaire en multiculturele teams en worden verschillende kennisdomeinen (globale, lokale, inheemse, academische, niet-academische) met elkaar geïntegreerd. De doelstellingen van de gebruikers en hun leef- en werkomgeving zijn leidend in deze resultaatgerichte aanpak. ICT4 3 3.o is de afgelopen jaren in 
verschillende landen en omgevingen gebruikt en gevalideerd, door gebruikers, ICTontwikkelaars, praktijkmensen en studenten.

Ten tweede: $\mathrm{ICT}_{4} \mathrm{D} 3.0$ draagt bij aan theorievorming, waarin digitale ontwikkeling als een proces van innovatie gezien wordt, binnen een complex (adaptief) systeem. De achterliggende gedachte is dat kennisdeling en verspreiding van innovaties complexe (niet-lineaire) dynamische processen zijn, die zich op onvoorspelbare wijze via sociale netwerken ontwikkelen en verspreiden, en ingebed worden in hun omgeving. Contextuele (sociale, culturele, politieke, omgevings-) factoren spelen in dit proces een belangrijke rol. Met al deze aspecten moet rekening gehouden worden bij het ontwerpen, bouwen en uitrollen van technologie voor mensen in arme gebieden. Samenwerking en flexibiliteit zijn hiervoor een vereiste.

Ten derde: $\mathrm{ICT}_{4} \mathrm{D} 3.0$ is gebaseerd op ethische principes. Bij het reflecteren over betekenis en doelen van digitale ontwikkeling wordt gauw duidelijk dat $\mathrm{ICT}_{4} \mathrm{D}$ niet alleen over technologie en praktijk gaat, en dat samenwerking meer is dan alleen een voorwaarde voor succesvolle technologische innovatie en duurzaamheid - samenwerking is ook een fundamentele menselijke, ethische waarde. De reflectieve ICTontwikkelaar moet zich afvragen wiens belangen hij/zij eigenlijk behartigt, welke ontwikkelingsdoelen hij/zij probeert te bereiken, waar deze vandaan komen, hoe macht en politieke kwesties een rol spelen en welke kernwaarden er op het spel staan. Deze overwegingen vragen ook om een democratisch proces van dialoog en overleg, waarin alle stemmen worden gehoord, en de lokale context en complexiteit centraal staan, waarin ontwikkelingsdoelen door de gebruikers zelf worden bepaald, in plaats van opgelegd, van buitenaf.

Uiteindelijk leert de praktijkervaring ons dat $\mathrm{ICT}_{4} \mathrm{D}$, gedreven door lokale initiatieven, een betekenisvol, collaboratief proces van kennisdeling en innovatie kan zijn, dat een positieve bijdrage kan leveren aan het oplossen van complexe problemen in een complexe wereld. 
Collaboration is the theme of my research. This thesis tells a story of people working together in the pursuit of a common goal. I am profoundly thankful to my colleagues and friends, who worked with me in this research odyssey that took many encounters and travels, over a period of ten years.

First of all, I want to thank my research supervisor Professor Dr. Sally Wyatt. We met only recently, but soon, I was captured by her research interests and approach. I discovered many parallels in how we both work and see the world. Sally gave me the wonderful opportunity to bring my research to Maastricht University. This was an unexpected surprise for which I am deeply grateful. I hope this will remain as a long-lasting partnership with many joint research activities.

I am profoundly thankful to my colleagues of the $W_{4} R A$ team who are very dear to me. I will express my gratefulness to them in chronological order of their appearance in this research story.

Hans Akkermans, chair and founding father of $\mathrm{W}_{4} \mathrm{RA}$, you have invited me to join this research adventure more than ten years ago. Thank you for your inexhaustible inspiration and ideas, thanks also for all the activities and interesting discussions. Wendelien Tuyp, team member and buddy from the first day, always cheerful, full of exciting ideas and enthusiasm - thanks Wendelien for your friendship and for having, maybe accidently, introduced me to the extraordinary idea of Complexity Research and complex adaptive systems, which became the central theory of this thesis. Chris Reij, thank you for having introduced me to African Regreening Initiatives, which has become the societal goal and the real-world context of my work. Nana Baah Gyan, I met you in 2009 at the Institute for Advanced ICT Studies in Kumasi, Ghana. We worked closely together from 2010 to 2016, until you concluded your PhD thesis, titled The Web, Speech Technologies and Rural Development in West Africa, and returned to your family in Accra. Francis Dittoh, you investigate and build data services for African farmers. Meanwhile you are the bridge between the University for Development Studies in Tamale and VU Amsterdam. Thank you, Nana and Francis for the collaboration and friendship throughout these years, during courses, workshops and field trips in Africa and long discussions and work in Amsterdam. Dia Eek, I am profoundly thankful for all your kindness and support during all those years. As a guarding angel Dia always showed me how to travel safely, guiding me remotely through insecure regions of the world, making sure everything was more than perfectly organized. And I want to thank Victor de Boer and Chris van Aart, computer scientists and experts in Web Science and Artificial Intelligence. Victor, talented and creative designer and filmmaker and Chris, apart from being a gifted app developer and an extreme programmer (I 
remember how Chris built the tree monitoring application Mr. Jiri in only one afternoon in Ségou) also a business innovator and virtuous horn player. Also, Christophe Guéret who brought many novel ideas, including Semantic XO and the innovative idea of "Downscaling the Web" to make the advantages of the Web more accessible to people in low-resource environments. Thank you, Victor, Chris and Christophe for the interesting and exciting projects we started and carried out together.

In the early years (2009 - 2013), the W4RA group teamed up with Tim Berners-Lee's Web Foundation. This brought new creative minds in the team: Stéphane Boyera, Aman Grewal, and Max Froumentin. We jointly acquired a European research project in the EU-FP7 framework: VOICES, and the Foroba Blon project, that won the International Press Institute Innovation Prize 2011. In these two projects we worked closely with Mary Allen and Etienne Barnard. As a huge joint effort involving many people and organizations, we learned how to successfully design, build and implement voice-based ICT services in rural Mali. We spent many interesting hours discussing the use case and requirements of the envisaged systems. I am thankful to you all for the ideas and experience you brought to me and to our team.

During our field research we made many new friends. Very special thanks to Amadou Tangara, now country manager of Tree Aid in Mali, for your creativity, cheerfulness and for being a source of innovative ideas. I have learned so much from you about so many aspects of life in rural Mali. Merci, grand frère, pour notre travail ensemble, pour la création des idées innovantes, ta dédication infatigable à la cause du développement rural.

I am very grateful to Mathieu Ouedraogo, president of Réseau MARP, the innovative, networked non-governmental organization in Burkina Faso that connects and supports farmer organizations all over the country. Mathieu presented a story of innovation and regreening at VU, the day the $\mathrm{W}_{4} \mathrm{RA}$ was launched. In 2019, Mathieu was awarded the prestigious Land for Life Award, issued by the United Nations Convention to Combat Desertification. We have worked together for many years. In January 2020 Mathieu was part again of our research team, working for at AOPP, in Bamako merci, Mathieu pour ton soutien à nos efforts, au service des paysans innovateurs, pour le reverdissement. Je remercie les paysans innovateurs Ousseini Zoromé, Yacouba Sawadogo et Ousseini Kindo, merci infiniment pour votre participation dans nos ateliers, pour tester nos prototypes et évaluer notre travail. Merci, barka, en votre langue mooré. Merci Julien Ouedraogo pour ton appui et notre bonne coopération. Merci aussi Ismael Ouedraogo. Merci, Radio La Voix du Paysan, pour plusieurs interviews avec nous, diffusés sur la radio, merci, Radio Notre Dame, Radio Savanne, Radio Solidarité, et Radio Wend-Panga au Burkina Faso et Radio Sikidolo, Radio Moutian et Radio ORTM Ségou au Mali, pour votre présence et participation active dans nos rencontres et ateliers.

Je suis profondément reconnaissante à Seydou Tangara, le coordinateur de l'AOPP au Mali, à Barke Ousmane Diallo, à Souleymane Diarra et vos autres collègues, pour notre fructueuse coopération. Je remercie Adama Tessougué, journaliste et directeur de Radio Sikidolo. Merci grand frère pour ton appui et pour notre coopération depuis si longtemps. Je remercie les paysans 
Zakary Diarra, producteur de miel, Naomi Dembelé, et Madeleine Dembelé, productrices de beurre de karité au Mali, qui nous ont aidés dans le développement des systèmes, et qui nous ont encouragés à poursuivre ce travail. Merci aussi Lamine Togola, Alou Dolo et Renaud Gaudin.

After the end of the EU-funded VOICES research project in 2013, and despite its promising results and impact at the level of the communautés, the international VOICES consortium fell apart, (as often happens in donor-funded projects). Our team decided to continue the work, which had only just begun. Based on the idea that long-term sustainability can only be achieved, working together for an extended period, tackling the complexities of the context and the difficulties that arise, I tried to find alternative funding opportunities. We managed to keep the $\mathrm{W}_{4}$ RA research alive, working in Mali, Ghana and Burkina Faso since 2014 until present day, with support from internal VU funds, and with funding from the Dutch Ministry of Foreign Affairs, through the Dutch development agency Nuffic and its NFP program and through a funding from the EU Erasmus+ program. I am very thankful for this support to our work.

In 2015, new enthusiastic young team members joined the $W_{4} R A$ team: André Baart, and Gossa Lô. André gave new life to the idea of Kasadaka (once started by Christophe and Victor) and built a Voice Software Development Kit (VSDK) for which he received the High Potential Innovation Award in 2018. André also rebuilt Foroba Blon version 2.0, which was tested in several occasions by Adama Tessougué at Radio Sikidolo in Konobougou, Mali. André, together with our partners from the local radios, built a meteo voice application in Mooré language, in only one night during a workshop in Gourcy, Burkina Faso, without even speaking a word of Mooré! Gossa spent a few months of research in the Ghanaian rural village of Zanlerigu, together with her colleague and friend Myrthe van der Wekken. Gossa developed DigiVet, a decisionsupport system for diagnosis of animal diseases in rural Ghana. Currently, Gossa is pioneering in artificial intelligence for development, analyzing African narratives and generating automated stories to understand how context-aware story-telling can be used for knowledge sharing. Thank you, André and Gossa for your enthusiasm, for your creativity and great work.

In 2015, I started to work with Jaap Gordijn on sustainability models for development, using the e3-value approach. Soon, also Jaap became a dear colleague and friend. Jaap encouraged me to formulate the framework that became known as $\mathrm{ICT}_{4} \mathrm{D}$ 3.o. I am grateful that you have joined me in this exciting field of $\mathrm{ICT}_{4} \mathrm{D}$. Thank you, Jaap for your inspiration and encouragement, also in some of the darkest moments of this research journey.

In 2015, I met Cheah Wai Shiang, postdoctoral researcher from the Universiti Malaysia Sarawak (UNIMAS), who was working in the Netherlands for a period. I invited Cheah and soon he joined the W4RA team. Cheah invited us back, and in 2017 Hans, Jaap and I made a visit to UNIMAS in Sarawak, Malaysia. This encounter led to an interinstitutional cooperation between VU and UNIMAS, which was formalized with a Memorandum of Understanding and executed through a faculty-led program in Com- 
munity Service Education in $\mathrm{ICT}_{4} \mathrm{D}$, carried out by our $\mathrm{W}_{4} \mathrm{RA}$ team. In 2018 we traveled to Sarawak with eleven VU students Information Science, Computer Science and Artificial Intelligence. I organized the trip and coordinated this four-week course in Sarawak, entitled "ICT4 $\mathrm{D}$ in the Field". This was the first field-based socio-technical Information System Engineering ICT4D master course. In 2019 the course was organized again, successfully. Thank you, Cheah for your great support to this educational $\mathrm{ICT}_{4} \mathrm{D}$ project in Sarawak.

In the period 2017-2019 I supervised a number of master student research projects. This work of students resulted in very interesting master theses on various (interdisciplinary) aspects of ICT4D. I want to thank especially Jamila Daoudi, Jan Drábek, Mickaela Wedervoort, Yifan Zhan, Derek van den Nieuwenhuijzen, Carlbandro Edoga, Marc Hegeman, Wouter de Boer, Aron van Groningen, Natasja Mooij, David Huser, Hella Schaefers, Sophie Vos, Sying Zhang and Shuqi Yan for your commitment and great work.

I am very thankful to my colleagues from the Centre for International Cooperation (CIS) of VU Amsterdam, where I have been working since 2006 until present day. CIS made it possible to do the acquisition and carry out the projects in West Africa during all these years. Thank you, Henk van den Heuvel for your support to the $\mathrm{W}_{4} \mathrm{RA}$ research program. Thanks also, my supportive CIS-colleagues, Marise van Amersfoort, Colette Gerards, Mekky Zaidi, Jorn Dormans, Denyse Snelder, Esther den Hartog, Sabina di Prima, Prosper Maguchu and Bert Haans. Many thanks also to Frans Snijders, director of the International Office of VU. Frans supported and encouraged me and gave me the opportunity to set up an innovative international course between VU and universities in the global South: "ICT4D in the Field". I am also profoundly thankful to Professor Vinod Subramaniam, rector magnificus of VU Amsterdam, for his enduring support to our research, for so many years.

I am also profoundly grateful to the support given to me and my research by Professor Ed Tan, Professor Saa Dittoh and Professor Mirjam de Bruijn. I hope this will result in new, maybe unexpected interdisciplinary collaborations, in exciting new fields.

The writing of this thesis has taken evenings, weekends, holidays and years of my life. I could not participate in many family activities, as I was staring at my screen every evening. This made me wonder if this was worth the effort and what is the purpose of (my?) life. I want to thank my whole family for their support and patience, their presence and care. My father, Ewoud Bon, my brothers Adri (always open to discuss some geopolitical issue) and Arthur (bridging the digital divide in his own creative way), my dear Catarina, Ignácio, Maria and Laura, and Gerry who read my manuscript and brought up many interesting questions. But first and foremost, I am grateful for the patience and care given to me by my love ones, to whom I dedicate this book: Bruno, Paloma and Leeuw.

An important lesson I learned during the past ten years, is that achievement is more than the sum of individual efforts and that there is no better way of learning and 
innovating than through collaboration, commitment and friendship in a non-formal, non-hierarchical, self-organizing and forward looking team. This is the best way to tackle complex problems and cope with unexpected events. It is how I wish to work. It is the central message of this thesis. 

Anna Bon is a researcher in the field of Information and Communication Technologies for Development at Maastricht University and Vrije Universiteit Amsterdam. She also works as an international project manager and senior advisor at the Centre for International Cooperation and as a lecturer at the Computer Science Department of Vrije Universiteit Amsterdam. In 1987 Anna obtained her master degree in Structural Geology and Hydrogeology at the University of Amsterdam and worked a few years at the Institute for Earth Sciences in Amsterdam. Between 1989 and 2006 Anna worked as an ICT professional at the Academic High Performance Computing and Networking Centre (SARA) and for IBM. In the early days of the Web, Anna initiated various ICT innovation projects and participated in ICT projects in the field of education, e-science, healthcare, virtual reality and telecommunication. From 2006 to 2020 she coordinated large-scale international development projects in higher education and advised universities in Africa, Asia and Latin America on their ICT strategy and on ICT for (inclusive) higher education. From 2015 to 2020 she coordinated action research projects on ICTs for food security in the Sahel. In 2018 Anna initiated the first international community service learning course in $\mathrm{ICT}_{4} \mathrm{D}$. Anna signed the Vienna Manifesto on Digital Humanism. She is senior editor of the International Journal for Information Systems in Developing Countries and a member of the interdisciplinary research program $\mathrm{W}_{4} \mathrm{RA}$ (Web alliance for Regreening in Africa). 

2020

o1 Armon Toubman (UL), Calculated Moves: Generating Air Combat Behaviour.

o2 Marcos de Paula Bueno (UL), Unraveling Temporal Processes using Probabilistic Graphical Models.

o3 Mostafa Deghani (UvA), Learning with Imperfect Supervision for Language Understanding.

o4 Maarten van Gompel (RUN), Context as Linguistic Bridges.

o5 Yulong Pei (TUE), On local and global structure mining.

o6 Preethu Rose Anish (UT), Stimulation Architectural Thinking during Requirements Elicitation - An Approach and Tool Support.

o7 Wim van der Vegt (OUN), Towards a software architecture for reusable game components.

o8 Ali Mirsoleimani (UL), Structured Parallel Programming for Monte Carlo Tree Search.

o9 Myriam Traub (UU), Measuring Tool Bias and Improving Data Quality for Digital Humanities Research.

10 Alifah Syamsiyah (TUE), In-database Preprocessing for Process Mining.

11 Sepideh Mesbah (TUD), Semantic-Enhanced Training Data Augmentation Methods for Long-Tail Entity Recognition Models.

12 Ward van Breda (VU), Predictive Modeling in E-Mental Health: Exploring Applicability in Personalised Depression Treatment.

13 Marco Virgolin (CWI), Design and Application of Gene-pool Optimal Mixing Evolutionary Algorithms for Genetic Programming.

14 Mark Raasveldt (CWI/UL), Integrating Analytics with Relational Databases.

15 Konstantinos Georgiadis (OUN), Smart CAT: Machine Learning for Configurable Assessments in Serious Games.

16 Ilona Wilmont (RUN), Cognitive Aspects of Conceptual Modelling.

17 Daniele Di Mitri (OUN), The Multimodal Tutor: Adaptive Feedback from Multimodal Experiences. 
2020

18 Georgios Methenitis (TUD), Agent Interactions Mechanisms in Markets with Uncertainties: Electricity Markets in Renewable Energy Systems.

19 Guido van Capelleveen (UT), Industrial Symbiosis Recommender Systems.

20 Albert Hankel (VU), Embedding Green ICT Maturity in Organ.

21 Karine da Silva Miras de Araujo (VU), Where is the robot?: Life as it could be.

22 Maryam Masoud Khamis (RUN), Understanding complex systems implementation through a modeling approach: the case of e-government in Zanzibar.

23 Rianne Conijn (UT), The Keys to Writing: A writing analytics approach to studying writing processes using keystroke logging.

24 Lenin da Nobrega Medeiros (VUA/RUN), How are you feeling, human? Towards emotionally supportive chatbots.

25 Xin Du (TUE), The Uncertainty in Exceptional Model Mining.

26 Krzysztof Leszek Sadowski (UU), GAMBIT: Genetic Algorithm for Model-Based mixed-Integer opTimization.

27 Ekaterina Muravyeva (TUD), Personal data and informed consent in an educational context.

28 Bibeg Limbu (TUD), Multimodal interaction for deliberate practice: Training complex skills with augmented reality.

29 Ioan Gabriel Bucur (RUN), Being Bayesian about Causal Inference.

30 Bob Zadok Blok (UL), Creatief, Creatieve, Creatiefst.

31 Gongjin Lan (VU), Learning better - From Baby to Better.

32 Jason Rhuggenaath (TUE), Revenue management in online markets: pricing and online advertising.

33 Rick Gilsing (TUE), Supporting service-dominant business model evaluation in the context of business model innovation. 

Be Collaborative is one of the key principles for digital development, formulated by influential multilateral development organizations, targeting people in poor and unconnected parts of the world. When reflecting on the meaning and purpose of this principle, the question comes up: how can one come to know what "the unconnected people" actually want, need or have interest in? This question is central for those who design and build information and communication technologies for development. The answer can only be obtained through dialogue and deliberation.

This thesis describes the search for and the design of a field-based approach to ICT4D. Ten years of field and action research in Mali, Burkina Faso and Ghana have led to a practical approach that guides design and development of information systems. It fosters knowledge exchange between people from different (global, local, indigenous, academic, non-academic) knowledge domains. It brings users, local stakeholders, developers, researchers together to solve complex problems, according to the users' own objectives.

Field experience shows that digital development can be a meaningful, collaborative, networked process of knowledge sharing, driven by local initiatives, realizing change for the better in a complex world. 